\title{
Finite element modeling of dowel -jointed plain concrete pavement response to thermal and moving traffic loads
}

\author{
Michel Ramsis Fahmy \\ West Virginia University
}

Follow this and additional works at: https://researchrepository.wvu.edu/etd

\section{Recommended Citation}

Fahmy, Michel Ramsis, "Finite element modeling of dowel -jointed plain concrete pavement response to thermal and moving traffic loads" (2000). Graduate Theses, Dissertations, and Problem Reports. 2379.

https://researchrepository.wvu.edu/etd/2379

This Dissertation is protected by copyright and/or related rights. It has been brought to you by the The Research Repository @ WVU with permission from the rights-holder(s). You are free to use this Dissertation in any way that is permitted by the copyright and related rights legislation that applies to your use. For other uses you must obtain permission from the rights-holder(s) directly, unless additional rights are indicated by a Creative Commons license in the record and/ or on the work itself. This Dissertation has been accepted for inclusion in WVU Graduate Theses, Dissertations, and Problem Reports collection by an authorized administrator of The Research Repository @ WVU.

For more information, please contact researchrepository@mail.wvu.edu. 
Finite Element Modeling of Dowel Jointed Plain Concrete Pavement Response to Thermal and Moving Traffic Loads

Michel Ramsis Fahmy

\author{
Dissertation Submitted to the \\ College of Engineering and Mineral Resources \\ At West Virginia University \\ in partial fulfillment of the requirements \\ for the degree of
}
Doctor of Philosophy
in
Civil Engineering

Samir N. Shoukry, Ph.D., Chair

David R. Martinelli, Ph.D.

Ron Eck, Ph.D.

John Zaniewski, Ph.D.

Julio Davalos, Ph.D.

Ken Means, Ph.D.

Department of Civil and Environmental Engineering

Morgantown, West Virginia
2000

Keywords: Finite Element Modeling, Concrete Pavement, Moving Traffic Loads, Thermal Gradient, Dowel Bars

Copyright 2000 Michel Ramsis Fahmy 


\title{
ABSTRACT \\ Finite Element Modeling of Dowel Jointed Plain Concrete Pavement Response to Thermal and Moving Traffic Loads
}

\author{
Michel Ramsis Fahmy
}

The objective of this study was to develop Three Dimensional Finite Element Models (3D-FEM) that can be used to investigate the separate or combined effect of moving axle loads and thermal gradient on the response of dowel Jointed Portland Cement Concrete Pavement (JPCCP) structures. The availability of a mechanistic tool that can be used for an accurate prediction of rigid pavement response to such loads would enable designing longer lasting pavements and understanding some of its modes of distress. In this respect, finite element modeling offers a powerful tool for the simulation of the structural behavior of pavements under the effect of combined moving axle loads and thermal gradient. The literature review shows that many pavement computer response models based on the FE method were developed for the analysis of jointed pavement slabs, however, important considerations were overlooked. In this study, a 3DFEM is developed to provide a comprehensive view of the dynamic response of a JPCCP section subjected to moving tire loads. The developed model overcomes the shortcomings of previous studies. The accuracy of the results obtained from this model is verified by a comparison with field measurements. A parametric study is performed to investigate the effect of several variables on the response of the concrete slab and the underlying layers. The variables studied include the effect of model, material, and design parameters on the predicted response, as well as the effect of nonlinear thermal gradient on JPCCP subjected to moving loads. The results indicate that the peak stresses developed in rigid pavement slabs result from combined positive thermal gradient and tandem or tridem axle loads and are located at the middle of the slab. Results also show that the combined negative gradient and axle loads located at the transverse joint subject the mid-slab top to high tensile stress that may explain the initiation of top-down cracks. These stresses increase under corner loading and when the slab length is increased. In general, the results show that the developed 3D-FEM is suitable for identifying the effect of different design features on the structural response of rigid pavements. 


\section{ACKNOWLEDGMENTS}

I wish to express my gratitude and sincere appreciation to Dr. Samir N. Shoukry my research advisor, for his unlimited help, advice, guidance, encouragement, and for the time he spent to improve, evaluate, and correct my work. His support and persistence have been indispensable in the completion of this study. The words are not enough to show my real feelings. Thank you for your patience, your advice, and your great care about me. Appreciation also is extended to other members of the committee including Dr. David R. Martinelli, Dr. Ron Eck, Dr. John Zaniewski, Dr. Julio Davalos, and Dr. Ken Means for serving on the examining committee.

I would like to take this opportunity to express my deepest gratitude to my mother who passed away, my beloved wife, my father, my brother, my father in law, my mother in law, my brother in law, and my lovely daughter for their love, support, and patience during all the stages of study at West Virginia University. I would like also to thank my uncle Father Bishoy Fahmy and my grand mother for their love, emotional support, and encouragement to make this effort possible. Thanks are also due to the author's friends for their encouragement and help.

The work presented in this thesis was performed under research contract with West Virginia Division of Highways. The author gratefully acknowledges the financial support received for this research from West Virginia Department of Transportation. 


\section{TABLE OF CONTENTS}

$\begin{array}{ll}\text { ABSTRACT } & \text { ii }\end{array}$

ACKNOWLEDGMENTS

TABLE OF CONTENTS IV

LIST OF TABLES viii

LIST OF FIGURES ix

LIST OF SYMBOLS AND ABBREVIATIONS X Xvi

$\begin{array}{lll}\text { CHAPTER ONE INTRODUCTION } & 1\end{array}$

1.1 Problem Statement 1

1.2 Research Objective 2

1.3 Research Methodology 2

1.4 Research Scope 3

1.5 Organization of this Dissertation 3

1.5.1 Chapter One: Introduction and Literature Review 3

1.5.2 Chapter Two: Pavement Structural Model 3

1.5.3 Chapter Three: Effect of Some Model Parameters on the Finite Element Predicted Response $\quad 4$

1.5.4 Chapter Four: Effect of Some Material Parameters on the Finite Element Predicted Response 4

1.5.5 Chapter Five: Effect of Some Design Parameters on the Finite Element Predicted Response

1.5.6 Chapter Six: Effect of Nonlinear Thermal Gradient on Jointed Portland Cement Concrete Pavement Subjected to Moving Load 4

1.5.7 Chapter Seven: Conclusions and Future Research Needs 5

1.6 Assumptions and Applications of Westergaard Theory 5

1.6.1 Applications of Westergaard Theory in current design methods 6

1.6.2 Response Charts 6 
$\begin{array}{lll}1.7 & \text { Stresses and Deflections Due to Loading } & 7\end{array}$

$\begin{array}{lll}1.8 & \text { Rigid Pavement Joints } & 7\end{array}$

1.8.1 Joint spacing $\quad 8$

1.8.2 Joint layout 9

1.9 Finite Element Modeling 10

1.9.1 Explicit versus Implicit Dynamic Analysis 10

1.9.2 Linear versus Nonlinear Finite Element Analysis 11

1.9.3 Some Features of the Finite Element Code Used in this Study 12

1.9.4 Review of Two-Dimensional Finite Element Modeling 14

1.9.5 Review of Three-Dimensional Finite Element Modeling Subjected to Traffic Loads $\quad 15$

1.9.6 Review of Previous Studies Performed to Study the Effect of $\begin{array}{ll}\text { Thermal Induced Stresses } & 18\end{array}$

1.9.7 Review of Verification Procedures Followed by Previous Studies 21

1.10 Summary and Conclusions 22

CHAPTER TWO PAVEMENT STRUCTURAL MODEL $\quad 27$

$\begin{array}{lll}2.1 & \text { Introduction } & 27\end{array}$

2.2 Modeling of Interfaces 28

2.3 Model Loading 28

2.4 Boundary Conditions 30

$\begin{array}{lll}2.5 & \text { Material Models } & 30\end{array}$

2.6 Model Results 31

2.6.1 Method of presenting the history result 32

2.7 Verification of the Finite Element Model 34

2.7.1 Comparison with Ohio Test Road Results 34

2.7.2 Comparison with Falling Weight Deflectometer Results 35

$\begin{array}{lll}2.8 & \text { Conclusions } & 36\end{array}$ 
3.1 Introduction $\quad 52$

3.2 Effect of Tie Bars $\quad 52$

3.3 Effect of Concrete-Base Bond 53

$3.4 \quad$ Effect of Joint Opening $\quad 54$

3.5 Effect of Symmetry Plan 55

3.6 Effect of Finite Element Mesh Size 56

$\begin{array}{lll}3.7 & \text { Conclusions } & 57\end{array}$

CHAPTER FOUR EFFECT OF SOME MATERIAL PARAMETERS ON THE FINITE ELEMENT PREDICTED RESPONSE 80

$\begin{array}{lll}4.1 & \text { Introduction } & 80\end{array}$

4.2 Effect of Concrete Slab Modulus of Elasticity 81

4.3 Effect of Base Course Modulus $\quad 82$

4.4 Effect of Friction Coefficient at Concrete Slab / Base Course Interface 83

4.5 Effect of Dowel Bars $\quad 84$

$\begin{array}{lll}4.6 & \text { Conclusions } & 85\end{array}$

CHAPTER FIVE EFFECT OF SOME DESIGN PARAMETERS ON THE FINITE ELEMENT PREDICTED RESPONSE 104

$\begin{array}{lll}5.1 & \text { Introduction } & 104\end{array}$

5.2 Effect of Concrete Slab Length 104

$\begin{array}{lll}5.3 & \text { Effect of Concrete Slab Thickness } & 107\end{array}$

$\begin{array}{lll}5.4 & \text { Effect of Axle Load Magnitude } & 108\end{array}$

$\begin{array}{lll}5.5 & \text { Effect of Axle Load Configuration } & 109\end{array}$

$\begin{array}{ll}5.6 & \text { Effect of Loading Position } \\ \end{array}$ 
5.6.1 3D Distribution of Stresses and Strains Induced Under Different Loading Positions

5.7 Effect of Traffic Speed

5.8 Conclusions

\section{CHAPTER SIX EFFECT OF NONLINEAR THERMAL GRADIENT ON JOINTED PLAIN CONCRETE PAVEMENT SUBJECTED TO MOVING AXLE LOADS}

$\begin{array}{lll}6.1 & \text { Introduction } & 162\end{array}$

6.2 Method of Presenting the Results in this Chapter 164

6.3 Pavement Response Due to Combined Thermal Gradient and Moving Load 165

$\begin{array}{lll}6.4 & \text { Parametric Study } & 167\end{array}$

6.4.1 Effect of Varying the Thermal Gradient 167

6.4.1.1 Stress and strain histories in the concrete slab 167

6.4.1.2 Thermal stresses induced in the concrete slab 168

6.4.1.3 Comparison between combined, thermal, and axle stresses $\quad 169$

6.4.2 Effect of Axle Configuration 170

6.4.3 Effect of Loading Position 172

6.4.4 Effect of Slab Length 173

6.4.5 Effect of Slab Thickness 176

$\begin{array}{lll}6.5 & \text { Conclusions } & 177\end{array}$

CHAPTER SEVEN CONCLUSIONS AND FUTURE RESEARCH NEEDS 212

$\begin{array}{ll}\text { 7.1 Conclusions } & 212\end{array}$

7.2 Future Research Needs 216

REFERENCES 217

$\begin{array}{ll}\text { CURRICULUM VITAE } & 228\end{array}$ 


\section{LIST OF TABLES}

1.1 Model Features of Previous Three-Dimensional Finite Element Studies 25

2.1 Material Properties Used for the Finite Element Model 31

2.2 Material Properties Used to Simulate Ohio Test Road 35

5.1 Effect of Slab Length on Peak Stresses and Strains Induced in the Slab 105

5.2 Variation of Peak Tensile Stresses and Strains at the Bottom of the Slab and the Base Course for Different Loading Positions

6.1 Cases of Study Performed Under Combined Nonlinear Thermal Gradient and Moving Axle Load 164

6.2 Effect of Thermal Gradient on Differential Displacement in the Slab 166

6.3 Effect of Varying the Thermal Gradient on Thermal and Maximum Combined Stresses in the Slab

6.4 Effect of Slab Length on Rigid Pavement Fatigue Damage 


\section{LIST OF FIGURES}

$1.1 \quad$ Typical Skewed Transverse Joint 26

2.1 Finite Element Mesh of the Full Model 37

2.2 Model Boundary Conditions 38

2.3 Cross Section of Transverse Joint 39

2.4 Tandem Axle Configuration 39

2.5 Distribution of Maximum Principal Stress in the Middle Slab Under the Effect of Tandem Axle Load $\quad 40$

2.6 Stresses Around Dowel Bars Under a Tandem Axle Configuration 41

2.7 Deformed Finite Element Mesh for Different Loading Positions 42

2.8 Variation of Vertical Deformation Distribution as the Tandem Axle Load Traverses the Model 43

2.9 Position of Surface Elements along the Center Line of Inner Tire Motion 44

2.10 Illustration Results Demonstrating the Concrete Slab Response to Tandem Axle Load at the Middle of the Slab

2.11 Illustration Results Demonstrating the Concrete Slab Response to Tandem Axle Load Along the Transverse Joint

2.12 (a) Tire Loads and Axle Spacing for Truck used in the Experimental Section and the Finite Element Model 47

2.12 (b) Location of Sensors in PCC Section 47

2.13 Finite Element Mesh Used in Simulate Ohio Test Road 48

2.14 Measured Longitudinal Strain at Elements C, D, and E from Ohio Section versus 3D-FEM Results $\quad 49$

2.15 Measured Longitudinal Strain at Elements F, G, and H from Ohio Section versus 3D-FEM Results $\quad 50$

2.16 Finite Element Mesh of the Verification Model 51

2.17 Comparison Between Experimental and FE Deflection Basins 51

3.1 Plan View of the Two Models Developed for Investigating the Effect of Tie Bars 58 
3.2 Effect of Tie Bars on Distribution of Maximum Principal Stress in the Concrete Slab

3.3 Effect of Tie Bars on Distribution of Longitudinal Strain in the Concrete Slab 60

3.4 Effect of Tie Bars on Distribution of Transverse Strain in the Concrete Slab 61

3.5 Effect of Tie Bars on Distribution of Vertical Strain in the Concrete Slab 62

3.6 Effect of Concrete-Base Bond on Distribution of Maximum Principal Stress in the Concrete Slab

3.7 Effect of Concrete-Base Bond on Distribution of Longitudinal Strain in the Concrete Slab

3.8 Effect of Joint Opening on Distribution of Maximum Principal Stress in the Concrete Slab

3.9 Effect of Joint Opening on Distribution of Longitudinal Strain in the Concrete Slab

3.10 Effect of Joint Opening on Distribution of Transverse Strain in the Concrete Slab

3.11 Effect of Joint Opening on Distribution of Vertical Displacement 68

3.12 Effect of Moving Tandem Axle Loads on Concrete Slab Deflection 69

3.13 Effect of Symmetry Plan on Distribution of Maximum Principal Stress in the Slab

3.14 Effect of Symmetry Plan on Distribution of Longitudinal Strain in the Slab 71

3.15 Effect of Symmetry Plan on Distribution of Transverse Strain in the Slab 72

3.16 Effect of Symmetry Plan on Distribution of Vertical Strain in the Slab 73

3.17 Effect of Symmetry Plan on Distribution of Maximum Principal Stress at Points C \& F $0.69 \mathrm{~m}$ from Transverse Joint

3.18 Effect of Symmetry Plan on Distribution of Longitudinal Strain at Points C \& F $0.69 \mathrm{~m}$ from Transverse Joint

3.19 Effect of Symmetry Plan on Distribution of Transverse Strain at Points

C \& F 0.69 m from Transverse Joint

3.20 Effect of Symmetry Plan on Distribution of Vertical Strain at Points C \& F $0.69 \mathrm{~m}$ from Transverse Joint

3.21 Different Finite Element Meshes Used To Model the Rigid Pavement Structure 78 
4.1 Location of Longitudinal Line of Maximum Stresses

4.2 Effect of Concrete Modulus on Distribution of Maximum Principal Stress at the Transverse Joint

4.3 Effect of Concrete Modulus on Distribution of Maximum Principal Stress at at the Middle of the Slab

4.4 Effect of Concrete Modulus on Distribution of Longitudinal Strain at the Transverse Joint

4.5 Effect of Concrete Modulus on Distribution of Longitudinal Strain at the Middle of the Slab

4.6 Effect of Concrete Modulus on Peak Principal Stress and Peak Longitudinal Strain in the Concrete Slab

4.7 Effect of Base Course Modulus on Maximum Principal Stress in the Concrete Slab

4.8 Effect of Base Course Modulus on Longitudinal Strain in the Concrete Slab

4.9 Effect of Base Course Modulus on the Distribution of Peak Principal and Longitudinal Stresses in the Concrete Slab

4.10 Effect of Base Course Modulus on the Distribution of Peak Transverse and Vertical Stresses in the Concrete Slab

4.11 Effect of Base Course Modulus on Maximum Shear Stress in the Concrete Slab

4.12 Effect of Friction Coefficient on Distribution of Maximum Principal Stress in the Concrete Slab

4.13 Effect of Friction Coefficient on Distribution of Longitudinal Strain in the Concrete Slab

4.14 Effect of Dowel Bars on Distribution of Maximum Principal Stress in the Concrete Slab

4.15 Effect of Dowel Bars on Distribution of Longitudinal Strain in the Slab 101

4.16 Effect of Dowel Bars on Distribution of Transverse Strain in the Slab 102

4.17 Effect of Dowel Bars on Distribution of Vertical Displacement in the Slab 103 
5.1 Dimensions and Boundary Conditions of the Concrete Slabs Studied

5.2 Effect of Slab Length on Maximum Principal Stress Induced in the Concrete Slab 117

5.3 Effect of Slab Length on Longitudinal Strain Induced in the Concrete Slab 118

5.4 Effect of Slab Length on Transverse Strain Induced in the Concrete Slab 119

5.5 Effect of Slab Length on Vertical Displacement Induced in the Concrete Slab 120

5.6 Effect of Slab Length on Distribution of Peak Principal and Longitudinal Stresses in the Concrete Slab

5.7 Effect of Slab Length on Distribution of Peak Transverse and Vertical Stresses in the Concrete Slab

5.8 Effect of Slab Length on Maximum Shear Stress in the Concrete Slab

5.9 Effect of Slab Length on Rigid Pavement Fatigue Damage Using Four Fatigue Models

5.10 Effect of Slab Thickness on Distribution of Maximum Principal Stress at the Middle of the Concrete Slab

5.11 Effect of Slab Thickness on Distribution of Maximum Principal Stress in the Concrete Slab at the Transverse Joint

5.12 Effect of Slab Thickness on Distribution of Longitudinal Strain at the Middle of the Concrete Slab

5.13 Effect of Slab Thickness on Distribution of Longitudinal Strain in the Concrete Slab Along the Transverse Joint

5.14 Effect of Slab Thickness on Distribution of Peak Principal and Longitudinal Stresses in the Concrete Slab

5.15 Effect of Slab Thickness on Distribution of Peak Transverse and Vertical Stresses in the Concrete Slab

5.16 Effect of Slab Thickness on Maximum Shear Stress Induced in the Concrete Slab 131

5.17 Effect of Axle Load Magnitude on Distribution of Maximum Principal Stress in the Concrete Slab

5.18 Effect of Axle Load Magnitude on Distribution of Longitudinal Strain in the Concrete Slab

5.19 Effect of Axle Load Magnitude on Distribution of Transverse Strain in the Concrete Slab 
5.20 Effect of Axle Load Magnitude on the Distribution of Peak Principal and Longitudinal Stresses in the Concrete Slab

5.21 Effect of Axle Load Magnitude on the Distribution of Peak Transverse and Vertical Stresses in the Concrete Slab

5.22 Effect of Tandem axle Load Magnitude on Maximum Shear Stress Induced in the Concrete Slab

5.23 Single and Tridem Axle Configurations and Wheel Loads

5.24 Effect of Axle Configuration on Distribution of Maximum Principal Stress in Concrete Slab

5.25 Effect of Axle Configuration on Distribution of Longitudinal Strain in Concrete Slab

5.26 Effect of Axle Configuration on Distribution of Transverse Strain in Concrete Slab

5.27 Effect of Number of Axles on Maximum Traffic Induced Longitudinal Strains in in the Slab

5.28 Effect of Axle Configuration on Distribution of Peak Principal and Longitudinal Stresses Along Traffic Direction

5.29 Effect of Axle Configuration on Distribution of Peak Transverse and Vertical Stresses Along Traffic Direction

5.30 Effect of Axle Configuration on Maximum Shear Stress in Concrete Slab

5.31 Locations of the Points of Study for the Three Models Used to Study the Effect of Loading Position

5.32 Finite Element Models used in the Loading Position Study

5.33 Effect of Loading Position on Distribution of Maximum Principal Stress in the Concrete Slab

5.34 Effect of Loading Position on Distribution of Longitudinal Strain in the Concrete Slab

5.35 Effect of Loading Position on Distribution of Transverse Strain in the Concrete Slab

5.36 Effect of Loading Position on Distribution of Maximum Principal Stress in the Base Course 
5.37 Effect of Loading Position on Distribution of Longitudinal Strain in the Base Course

5.38 Effect of Loading Position on Distribution of Transverse Strain in the Base Course

5.39 Locations of the Elements Used to Plot the 3D Stress and Strain Distributions 154

5.40 Effect of Load Position on Distribution of Longitudinal Stress and Strain in Slab 155

5.41 Multiplication Factors Used to Calculate Longitudinal Stress and Strain for any Loading Position

5.42 Effect of Traffic Speed on Distribution of Maximum Principal Stress in the Concrete Slab at the Transverse Joint

5.43 Effect of Traffic Speed on Distribution of Maximum Principal Stress at the Middle of the Slab

5.44 Effect of Traffic Speed on Distribution of Longitudinal Strain at the Middle of the Concrete Slab

5.45 Effect of Traffic Speed on Distribution of $\varepsilon_{\mathrm{x}}$ in the Concrete Slab at the Transverse Joint

5.46 Effect of Traffic Speed on Maximum Traffic Induced Longitudinal Strains in the Slab

6.1 (a) Finite Element Mesh Used to Model the Rigid Pavement Structure

6.1 (b) Deformed Mesh Due to a Nonlinear Gradient of $-12^{\circ} \mathrm{F}$

6.1 (c) Deformed Mesh Due to a Nonlinear Gradient of $+13^{\circ} \mathrm{F}$

6.2 Nonlinear Thermal Gradient Profiles

6.3 Loading Positions Studied

6.4 Variation of Vertical Displacement Distribution Due to Combined Thermal Gradient of $-12^{\circ} \mathrm{F}$ and Tandem Axle Load

6.5 Variation of Vertical Displacement Distribution Due to Combined Thermal Gradient of $+18^{\circ} \mathrm{F}$ and Tandem Axle Load

6.6 Effect of Negative Thermal Gradient on Vertical Displacement Profiles 184

6.7 Effect of Positive Thermal Gradient on Vertical Displacement Profiles 185

6.8 Vertical Displacement Profiles Along Traffic Direction 
6.9 Maximum Principal Stress Distribution at $27 \& 60$ in. from the Transverse Joint 187

6.10 Maximum Principal Stress Distribution at $90 \& 170$ in. from the Transverse Joint 188

6.11 Longitudinal Stress Distribution at $27 \& 60$ in. from the Transverse Joint 189

6.12 Longitudinal Stress Distribution at $90 \& 170$ in. from the Transverse Joint 190

6.13 Transverse Stress Distribution at $27 \& 60$ in. from the Transverse Joint 191

6.14 Transverse Stress Distribution at 90 \& 170 in. from the Transverse Joint 192

6.15 Longitudinal Strain Distribution at $27 \& 60$ in. from the Transverse Joint 193

6.16 Longitudinal Strain Distribution at $90 \& 170$ in. from the Transverse Joint 194

6.17 Transverse Strain Distribution at $27 \& 60$ in. from the Transverse Joint 195

6.18 Transverse Strain Distribution at 90 \& 170 in. from the Transverse Joint 196

6.19 Variation of Thermal Stresses Induced in the Slab with Different Thermal $\begin{array}{ll}\text { Gradient } & 197\end{array}$

6.20 (a) Comparison Between Combined and Thermal Stresses 198

6.20 (b) Computed Stresses Correction Factors 198

6.21 Effect of Axle Configuration on the Maximum Principal Stress Profile along Wheel Path

6.22 Effect of Axle Configuration on the Longitudinal Stress Profile along Wheel Path 200

6.23 Effect of Axle Configuration on Transverse Stress Profile along Wheel Path 201

6.24 Effect of Loading Position on the Maximum Principal Stress Profile along

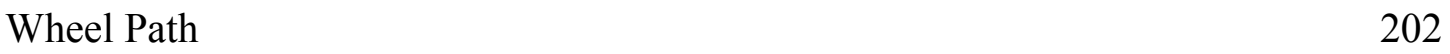

6.25 Effect of Loading Position on Longitudinal Stress Profile along Wheel Path 203

6.26 Effect of Loading Position on Transverse Stress Profile along Wheel Path 204

6.27 Effect of Slab Length on the Maximum Principal Stress Profile along Wheel Path 205

6.28 Effect of Slab Length on Longitudinal Stress Profile along Wheel Path 206

6.29 Effect of Slab Length on Transverse Stress Profile along Wheel Path 207

6.30 Effect of Slab Length on the Stress Profile along Wheel-Path 208

6.31 Effect of Slab Thickness on the Maximum Principal Stress Profile along $\begin{array}{ll}\text { Wheel Path } & 209\end{array}$

6.32 Effect of Slab Thickness on Longitudinal Stress Profile along Wheel-Path 210

6.33 Effect of Slab Thickness on Transverse Stress Profile along Wheel-Path 211 


\section{LIST OF SYMBOLS AND ABBREVIATIONS}

\begin{tabular}{|c|c|c|}
\hline $2 \mathrm{D}$ & $=$ & Two-Dimensional \\
\hline 3D-FEM & $=$ & Three Dimensional Finite Element Modeling \\
\hline ESAL & $=$ & Equivalent Single Axle Load \\
\hline $\mathrm{FE}$ & $=$ & Finite Element \\
\hline FEM & $=$ & Finite Element Model \\
\hline FWD & $=$ & Falling Weight Deflectometer \\
\hline JPCP & $=$ & Jointed Plain Concrete Pavement \\
\hline JPCC & $=$ & Jointed Portland Cement Concrete \\
\hline LTPP & $=$ & Long-Term Pavement Performance \\
\hline MPS & $=$ & Maximum Principal Stress \\
\hline MSS & $=$ & Maximum Shear Stress \\
\hline MR & $=$ & Concrete Modulus of Rupture \\
\hline $\mathrm{PCC}$ & $=$ & Portland Cement Concrete \\
\hline$\sigma_{\mathrm{x}}$ & $=$ & Longitudinal Stress \\
\hline$\sigma_{\mathrm{y}}$ & $=$ & Transverse Stress \\
\hline$\sigma_{\mathrm{z}}$ & $=$ & Vertical Stress \\
\hline$\epsilon_{\mathrm{x}}$ & $=$ & Longitudinal Strain \\
\hline$\epsilon_{\mathrm{y}}$ & $=$ & Transverse Strain \\
\hline$\epsilon_{\mathrm{z}}$ & $=$ & Vertical Strain \\
\hline$\mu$ & $=$ & Coefficient of Friction at Slab/Base Interface \\
\hline$\Delta$ & $=$ & Differential Displacement \\
\hline
\end{tabular}




\section{CHAPTER ONE}

\section{INTRODUCTION}

\subsection{Problem Statement}

Rigid pavements suffer from different types of distress such as longitudinal, transverse, and joint cracks as a consequence of dynamic traffic loading and thermal stresses. Understanding the response of rigid pavement structures under axle loads and thermal gradients is important for the design of new pavements, as well as the implementation of remedial measures for existing pavements. Three Dimensional Finite Element (3D-FE) modeling is a powerful tool that can be used to investigate the combined effect of concrete slab geometry, dowel bars at joints, moving axle loads, thermal gradient through the slab thickness, and stiffness of foundation layers on the stresses induced in rigid pavements. In the past, many pavement computer response models based on the FE method were developed for the analysis of jointed pavement slabs, however, important consideration were overlooked. These include neglecting the combined effect of dynamic traffic loads and thermal temperature gradient, as well as neglecting the modeling of dowel bars or the modeling of their effect using beam or spring elements. Although, the sliding characteristics between dowel bars and the surrounding concrete, as well as the friction at the interface between the concrete slab and base course, influence the response of rigid pavements to dynamic loads, they were also neglected. In this study, a 3D-FE model is developed to overcome the shortcomings of previous studies in terms of handling the different types of loads affecting the pavement such as moving loads, temperature loads, contact loads, and impact loads. The model also handles interfaces with gaps and friction between pavement layers and permits modeling complex geometries, dowel bars and aggregate interlock at joints. The developed model provide a comprehensive view of the variation in pavement response as the axle loads cross the transverse joint and traverse the concrete slab under several aspects related to pavement geometry, material properties, thermal gradients, and axle load and configuration. 


\subsection{Research Objective}

The objective of this study was to develop a 3D-FE model in order to investigate the separate or combined effect of moving axle loads and thermal gradient on the response of jointed plain concrete pavement structures. This approach permitted the identification of the effect of concrete pavement slab geometry, material, traffic speed, axle magnitude, axle configuration, thermal gradient, and several other factors on pavement response.

\subsection{Research Methodology}

A brief review of the assumptions of Westergaard theory is presented. Some aspects related to rigid pavement design are reviewed; these are the design features that are evaluated when designing rigid pavement joints.

The FE method is reviewed with emphasis on its theoretical basis. A brief review of the explicit FE code (LS-DYNA) used to develop the pavement model is presented. The implementation of the FE method in pavement analysis and design originated from Two-Dimensional (2D) models. A review of the available 2D-FE programs is presented. Although these programs represent a significant improvement over the traditional design methods, they have certain limitations. To overcome these limitations and to better understand some pavement failure modes, the 3D-FE modeling approach was adopted by many researchers and is in the process of being implemented in the design procedures of some organizations such as the Federal Aviation Administration (FAA). A comprehensive review of 3D-FE rigid pavement modeling is conducted. The review includes a summary of model features utilized in previous 3D-FE studies and the verification approaches that were adopted by these studies. The presented review reveals the growing use of 3D-FE in pavement analysis and design. However, the review shows some shortcomings and important aspects of the Jointed Portland Cement Concrete Pavement (JPCCP) problems that were neglected by some researchers. To overcome these shortcomings, a 3D-FE model is developed. A detailed description of this model is then presented. To verify the accuracy of the Finite Element Model (FEM), its results are compared to those from Ohio Test Road and to 
experimental Falling Weight Deflectometer (FWD) test results. A parametric study is performed to investigate the effects of some model, material, and design parameters on the FE predicted response of the rigid pavement structure due to the combined or separate effect of moving axle loads and/or thermal loads caused by positive or negative temperature gradients through the rigid pavement slab thickness.

\subsection{Research Scope}

The scope of this study is limited to studying the response of dowel JPCCP under moving axle loads and thermal gradient. The effects of concrete shrinkage during curing and moisture were not taken into consideration. The 3D-FE code used in this study is LS-DYNA.

\subsection{Organization of this Dissertation}

\subsubsection{Chapter One: Introduction and Literature Review}

In this chapter, the problem statement, research objective, research methodology, and organization of the report are presented. This chapter also contains a brief overview of Westergaard theory and its assumptions as well as Picket and Ray response charts. It also discusses the types of transverse joints and the design features evaluated when designing a rigid pavement joint. These two design features are joint spacing and its general layout. In addition, this chapter also includes a review of previous studies based on 2D and 3D-FE modeling of rigid pavement structures.

\subsubsection{Chapter Two: Pavement Structural Model}

This chapter contains a description of the FEM developed in this study including the types of interfaces used between pavement layers, the applied loads and boundary conditions, and the material models. Some examples are presented to show the variety and quality of the results obtained from the model. To investigate the accuracy of the theoretical model, its results are 
compared to two different field measurement results obtained from instrumented rigid pavement section in Ohio and FWD tests performed in West Virginia.

\subsubsection{Chapter Three: Effect of Some Model Parameters on the Finite Element Predicted}

\section{Response}

This chapter contains preliminary studies to investigate pavement response under the effect of some model parameters these are: 1) Constraining the slab edge at tie bar locations. 2) Using a bonded or unbonded interface between the concrete slab and the base course. 3) Modeling the transverse joint with or without joint opening. 4) Utilizing the symmetry of geometry and loading along traffic direction to reduce model size and solution time. 5) Changing the FE mesh size.

\subsubsection{Chapter Four: Effect of Some Material Parameters on the Finite Element Predicted}

\section{Response}

In this chapter, we examine the effects of some material-related parameters such as the effect of concrete slab modulus of elasticity, base course modulus of elasticity, friction coefficient applied at the slab/base interface, and dowel bars.

\subsubsection{Chapter Five: Effect of Some Design Parameters on the Finite Element Predicted Response}

This chapter contains a detailed study to investigate the response of rigid pavement structure under some selected design parameters these are concrete slab length and thickness, axle load magnitude and configuration, loading position, and traffic speed.

\subsubsection{Chapter Six: Effect of Nonlinear Thermal Gradient on Jointed Portland Cement Concrete Pavement Subjected to Moving Load}

In this chapter, the response of a rigid pavement subjected to combined thermal gradient and moving axle loads is studied under some parameters including the effect of varying the thermal gradient applied through the slab thickness, loading position, slab length and thickness, and axle configuration. 


\subsubsection{Chapter Seven Conclusions and Future Research Needs}

This chapter contains the main conclusions of this study and the areas of future research needs.

\subsection{Assumptions and Applications of Westergaard Theory}

Westergaard (1926) developed a theoretical solution for the computation of stresses in concrete pavements based on the theory of elasticity. Westergaard assumed the concrete slab as a plate resting on elastic Winkler foundation. In a Winkler foundation, the layers below the concrete slab are represented by an infinite number of linear springs characterized by a single parameter, the modulus of subgrade reaction. The stiffness of a Winkler foundation (or the subgrade reaction) is expressed by the product of the subgrade stiffness (or modulus of subgrade reaction, $\mathrm{k}$ ) times the deflection, $\Delta$. The modulus, $\mathrm{k}$, is assumed constant at each point independent of the deflections. Such an assumption means that the subgrade reaction on the slab is constant and that the subgrade cannot transfer shear stress.

Westergaard considered three loading cases that produce critical stresses in the concrete slab. These are wheel load close to the corner of a semi-infinite slab, wheel load at the interior of an infinite slab, and wheel load at the edge of a semi-infinite slab. Westergaard made the following assumptions when he developed his solution:

1) The concrete slab acts as homogeneous, isotropic, elastic solid in equilibrium.

2) The reactions of the subgrade are only vertical and proportional to the deflections of the concrete slab.

3) Full contact is assumed between the slab and subgrade.

4) The concrete slabs are infinite during interior loading; (i.e., discontinuities such as joints or cracks have no effect on the solution).

5) The layers underneath the slab respond in a linear elastic manner.

6) Normal stresses in the direction transverse to the plane of the slab are ignored. 
Westergaard (1927) extended the work presented in 1926 to study the stresses induced on concrete pavements as a result of variations in temperature. He developed a solution for a slab in continuous contact with the subgrade and subjected to static load.

\subsubsection{Applications of Westergaard theory in current design methods}

Currently several organizations base their design procedures on Westergaard theory. Current American Association of State Highway and Transportation Officials (AASHTO) procedures for designing rigid pavements are based on Westergaard's equations for infinite and semi-infinite slabs (AASHTO, 1993). The Federal Aviation Administration (FAA) (1995) has developed an alternative design procedure based on Westergaard stress equation for joint edge stress (FAA, 1996 and Lee, 1998). However, the FAA method has many limitations. For example, it does not consider the finite slab size, shear load transfer at joints, and the interaction between the slab and base layer. In addition, this method does not provide information about any other part in the structure other than the slab. To develop a mechanistic design procedure that can overcome the limitations of previous design methods, the FAA is developing computer-based design models. The development of a 3D-FEM comprises a major part of the new design procedures, (Lee, et al., 1998).

\subsubsection{Response Charts}

Picket and Ray (1951) developed influence charts based on Westergaard theory to calculate deflections, moments, and reactive pressure in concrete slabs due to wheel loads. The charts developed include three different loading cases: interior, edge, and near the center, on concrete slabs resting on three different types of foundations springs, elastic solid, and elastic layer subgrade. During the 1960 and 70's, the Portland Cement Association used those charts in the design of rigid pavement. The same charts were adopted by the FAA, U.S. Army, and U.S. Air Force to compute the maximum tensile stress for edge loading (Hutchinson, 1966). 


\subsection{Stresses and Deflections Due to Loading}

Stresses and deflections in concrete pavements can be calculated using three methods: closedform formulas developed by Westergaard, influence charts developed by Picket and Ray, and FE computer programs (Huang, 1993). The closed-form formulas and the influence charts are applicable only for infinite slabs on Winkler foundation. In more complicated cases, such as, loads applied on Jointed Portland Cement Concrete slabs lying on liquid, solid, or layer foundation, the first two methods cannot be used and the FE method should be used.

\subsection{Rigid Pavement Joints}

Joints are mainly constructed in concrete pavements to relieve the stresses resulting from friction and environmental changes (i.e. temperature and moisture). Joints act as the structure by which the load is transmitted between loaded and unloaded slabs (Kawmura, et al., 1993). Their load transfer capabilities are critical for pavement performance since several rigid pavement slabs failed because of joint deterioration (Kuo, 1997). Three types of joints exist: contraction, expansion, and construction. The functions of each type are as follow:

1. Contraction joints are intended to relieve the tensile and bending stresses due to traffic loading, cement hydration process, temperature, moisture, and friction. Transverse contraction joints regulate the location of the cracking caused by dimensional changes in the slab (FHWA, 1990). For this type of joint, load is transferred between slabs either by grain interlock or by dowel bars.

2. Expansion joints provide space for the pavement expansion, a $19 \mathrm{~mm}(3 / 4 \mathrm{in}$.) space is usually maintained, such a space overcome compressive stresses and prevent blowups. The load is transferred through dowel bars since this type of joint has no aggregate interlock. Expansion joints are difficult to maintain, susceptible to pumping (Huang, 1993), and permit adjoining contraction joints to open too wide resulting in a loss of aggregate interlock and sealant damage (American Concrete Pavement Association, 1991). 
3. Construction joints are used to facilitate construction. They are installed at the point where the paving operation is stopped for any reason. They are formed either as contraction or expansion joints, or as simple doweled butt joints (McGhee, 1995).

Two design considerations are evaluated when designing a rigid pavement joint: the spacing and general layout.

\subsubsection{Joint spacing}

From an economic point of view, slabs should be as long as possible to minimize the number of load transfer assemblies required but short enough to prevent transverse cracking (Kelleher, 1989). Shorter slab lengths require larger number of joints and therefore higher construction costs. The lower the number of joints the fewer the number of joint-related pavement problems. Shorter slabs have several advantages including (Kelleher and Larson, 1989) less joint faulting, improved aggregate interlock, lower curling and warping stresses compared to longer slabs, reduced slab movement which means lower friction forces at the slab/base interface and reduced shear stress, and fewer joint problems compared to longer slabs which also means less maintenance. A survey conducted in 1995 of current state highway agency concrete pavement design practices (Jiang, et al., 1997) demonstrates that the mean joint spacing for JPCCP across the nation is $4.6 \mathrm{~m}(15 \mathrm{ft})$ and ranges from 4 to $6 \mathrm{~m}$ (13 to $20 \mathrm{ft})$. An FHWA technical advisory (FHWA, 1990) recommends a maximum joint spacing of $4.6 \mathrm{~m}$ (15 ft) for PCC slabs since longer slabs frequently develop transverse cracks. If slab width exceeds slab length, undesirable longitudinal slab cracks may occur (Kelleher and Larson, 1989). A research study by (Smith, et al., 1990) showed that the amount of transverse cracking is related to the slab length (L) and to the radius of relative stiffness $(l)$, which is computed using the following equations:

$$
l=\sqrt[4]{\frac{E h^{3}}{12\left(1-v^{2}\right) k}}
$$

Where: $\mathrm{h}$ is the thickness of the concrete slab (in inches), $\mathrm{k}$ is modulus of subgrade reaction (in pci), and $\mathrm{E},<$ are the modulus of elasticity (in psi) and Poisson ratio of concrete, respectively. Transverse cracking increases as the ratio $\mathrm{L} / \mathrm{l}$ exceeds five. For a maximum $\mathrm{L} / \mathrm{l}$ ratio of five, the 
allowable joint spacing increases with increased slab thickness, and decreases with increasing the stiffness of the foundation.

\subsubsection{Joint layout}

Transverse joints are placed either at a right angle to pavement centerline (straight joint case), or skewed at the typical angle and orientation with respect to traffic direction. Skewed joints have the following advantages (AASHTO, 1993):

1) Reduced deflection and stress at joints, thereby increasing the load-carrying capacity of the slab, hence, extending pavement life.

2) Less impact reaction in vehicles as they cross the joints, hence, a smoother ride.

A skew arrangement of $0.6 \mathrm{~m}(2 \mathrm{ft})$ in $3.7 \mathrm{~m}(12 \mathrm{ft})$ is recommended (FHWA, 1990 and AASHTO, 1993). Figure 1.1 shows a typical skewed transverse joint. The skewed joint should be placed in a way that the inside wheel crosses the joint before the outside wheel, as shown in Figure 1.1. Therefore, only one wheel crosses the joint at a time. This decreases the stresses in the slab (FHWA, 1990). The obtuse angle between the transverse joint and the outside pavement edge should be ahead of the joint in the direction of traffic. Such an arrangement is required to reduce the impact on the slab corner resulting from sudden application of wheel loads (AASHTO, 1993). Dowels in transverse joints must be placed parallel to the roadway, not perpendicular to the joints $(F H W A, 1990)$. Typical skewed joints may not have dowel bars, whereas on heavily trafficked roads they should be provided with dowels (McGhee, 1995). Some agencies require that highway pavement joints be skewed and doweled (American Concrete Pavement Association Technical Bulletin, 1991). Such a design assumes that, in addition to dowel bars, skewing the transverse joint will improve the load transfer efficiency.

Randomly spaced joints are used to avoid the resonant response in vehicles that can happen with jointed PCC pavements (McGhee, 1995 and AASHTO, 1993). Joint spacing multiple of $2.3 \mathrm{~m}$ (7.5 ft) should be avoided. Randomized spacing patterns of 3.7, 4.0, 4.6, and $4.3 \mathrm{~m}(12,13,15$, and $14 \mathrm{ft}$ ) have been applied in California for several years (FHWA, 1986). The same pattern is adopted by several other states (McGhee, 1995). 


\subsection{Finite Element Modeling}

The FE method is a numerical technique for solving problems with complicated geometries, loading, and material properties. It provides a solution for pavement problems, which are too complicated to solve by analytical approaches. The FE method has two general solution forms displacement (or stiffness method); and force (or flexible method). The former is the most popular form of the FE method. The basic FE process dictates that the complete structure is idealized as an assembly of individual 2D or 3D elements. The element stiffness matrices corresponding to the global degrees of freedom of the structural idealization are calculated and the total stiffness matrix is formed by the addition of element stiffness matrices. The solution of the equilibrium equations of the assembly of elements yields nodes displacements, which are then used to calculate nodes stresses. Element displacements and stresses are then interpreted as an estimate of the actual structural behavior (Bathe, 1982). The higher the number of nodes in a structure the greater the number of equations to be solved during the FE process, hence, the longer it takes to obtain a solution. Generally, the finer the mesh, the more accurate is the FE solution for a particular problem. Therefore, a compromise is needed between mesh refinement, model size, and solution time.

\subsubsection{Explicit versus Implicit Dynamic Analysis}

To perform a dynamic analysis, the equations of equilibrium governing the dynamic response of a FE system under dynamic loads should be integrated using numerical integration. The FE equilibrium equation is (Bathe, 1982):

$$
M \ddot{U}+C \dot{U}+K U=R
$$

Where $\mathrm{M}, \mathrm{C}$, and $\mathrm{K}$ are the mass, damping, and stiffness matrices; $\mathrm{R}$ is the external load vector; and $U, \wedge$, and $\ddot{U}$ are the displacement, velocity, and acceleration vectors of the FE assembly. Two numerical integration algorithms are used to solve dynamic problems these are the explicit and implicit integration algorithms. 
1) In explicit integration, the equilibrium equations of the $\mathrm{FE}$ system are solved at time $t$ in order to calculate the displacements at time $t^{+} \Delta t$ based entirely on available values at time $t$. The main advantage of this method is that the mass matrix (M) in the equilibrium equation is diagonal, which reduces the equations solution time. The shortcoming in the use of this method lies in the severe integration time step restriction: for stability, the time step size $\Delta t$ must be smaller than a critical time step, $\Delta t_{\mathrm{cr}}$, which is approximately equal to the time for the stress wave to cross the smallest element dimension in the FE model. This method can be applied for problems with a short loading duration such as impact problems.

2) Using implicit time integration, the dynamic equilibrium equations are solved at time $t^{+} \Delta t$, the displacement at time $t^{+} \Delta t$ is evaluated as a function of the velocity and the acceleration at time $t+\Delta t$. This method is stable and allows a large integration time step size $\Delta t$. However, the equilibrium equations solution time in this case is very lengthy. This method is useful for problems with minor dynamic effects.

The explicit dynamic analysis procedure in the FE code LS-DYNA used in this study is based upon the implementation of an explicit integration rule together with the use of diagonal element mass matrices (Hallquist, 1998). The equations of motion for the system modeled are integrated using the explicit central difference integration rule.

\subsubsection{Linear versus Nonlinear Finite Element Analysis}

During linear FE analysis of structural problems it is assumed that the displacements of the FE assembly are infinitesimally small and that the material is linear elastic. In addition, it is also assumed that the nature of the boundary conditions remains unchanged during the application of the loads on the FE assembly. In this case, the displacement response is a linear function of the applied loads (Bathe, 1982).

On the other hand, during nonlinear FE analysis, material linearity or nonlinearity depends on the amount of displacement and strain the material is subjected to. If the material is subjected to large displacements and large strains, then the stress-strain relation of the material is usually 
nonlinear. For the case of materials subjected to large displacements but small strain conditions, the stress-strain relation in this case can be either linear or nonlinear. Nonlinearity can also arise in contact problems in which the boundary conditions change during the motion of the body under consideration (Bathe, 1982). The change in boundary conditions can be encountered in the problem of a moving load on a multilayered pavement system.

\subsubsection{Some Features of the Finite Element Code Used in this Study}

The FE code used in this study is LS-DYNA. It is a public domain, general purpose, explicit 3D-FE code for analyzing the large deformation dynamic response of inelastic solids (Hallquist, 1996). The dynamic equilibrium equations and constitutive relations used in the formulation of LS-DYNA are integrated as a function of time using a time increment. That increment is governed by the speed with which the wave propagates through the material. LS-DYNA can handle dynamic loading in which the critical loading time will be several milliseconds such as impact loads, moving loads, temperature loads, and contact loads. LS-DYNA accepts a wide range of material models, equation of state models and user specified models. These models can simulate many material responses such as elastic, isotropic elastoplastic with failure, linear viscoelastic, and temperature and strain-rate dependent plasticity. These material models also include nonlinear and anisotropic material models.

LS-DYNA has built-in material interface capabilities, i.e. contact-impact algorithm, that permits modeling of sliding and impact along interfaces of multilayered structures. Three methods are implemented in LS-DYNA to handle that algorithm including: kinematic constraint method, penalty method, and the distributed parameter method (Hallquist, 1996). The kinematic constraint method uses the impact and release conditions of Hughes et al. (1976). The penalty method consists of placing normal interface force between all penetrating nodes and the contact surface. The magnitude of this force is proportional to the amount of penetration.

In three dimensions, interfaces are characterized by triangular or quadrilateral segments, that comprise each side of the interface. The two sides of the interface are designated as slave and master segments, respectively. The nodes lying in those surfaces are called slave and master 
nodes. After impact, the slave nodes are constrained to slide on the master surface and must remain on the master surface until a tensile force develops between the node and the surface. Twenty types of interfaces can be defined in LS-DYNA, such as sliding only, tied, sliding with impact and friction, single surface contact, and tiebreak interface. The sliding with closure and separation interface is based on the penalty method. Tied interfaces permits sudden mesh transitions without the need of transition regions. The implementation of tied interface constraints includes two steps. Each constraint through the tied interfaces is looped and updated independently at each time step. First, nodal forces and nodal mass of each slave node are distributed to the master nodes, which defines the segment containing the contact point. The following equations illustrate the mass and force increments for each slave node along a tied interface.

) $\mathrm{m}_{\mathrm{m}}^{\mathrm{i}}=\mathrm{N}_{\mathrm{i}}\left(>_{\mathrm{c}}, 0_{\mathrm{c}}\right) \mathrm{M}_{\mathrm{s}} \quad \mathrm{I}=1, \ldots, 4$

) $\mathrm{f}_{\mathrm{m}}^{\mathrm{i}}=\mathrm{N}_{\mathrm{i}}\left(>_{\mathrm{c}}, 0_{\mathrm{c}}\right) \mathrm{f}_{\mathrm{s}}$

Where: )m, and )f are the increments in mass, and forces for each slave node

$>_{\mathrm{c}}, 0_{\mathrm{c}}$, are contact point coordinates, and

$\mathrm{f}_{\mathrm{s}}, \mathrm{M}_{\mathrm{s}}$ are the interface force and mass, respectively

The acceleration of each master surface is calculated after the summation of increments over all slave nodes. The acceleration of each slave node, $\mathrm{a}_{\mathrm{s}}^{\mathrm{i}}$, is then interpolated from the master segment containing its contact points using the following equation: $a_{s}^{i}=3_{j=1}^{4} N_{j}\left(>_{c}, 0_{c}\right) a_{i}^{j}$

The velocities and displacements are normally updated.

LS-DYNA is provided with a preprocessor called LS-INGRID, which is a screen based, menu derived, automatic mesh generator, interactive interface. The interactive post-processor LSTAURUS reads binary plot files generated by LS-DYNA. LS-TAURUS provides a variety of choices of standardized outputs inclusive of XY plots, time histories, contours, meshed and deformed shapes such capabilities permit better results evaluation. LS-TAURUS has the ability of making cross sections through the FE mesh and results animation, it can also display the results as they are generated. 


\subsubsection{A Review of Two-Dimensional Finite Element Modeling}

The enhanced computational capabilities of computers in the recent years with the availability of the FE method resulted in an innovation in the design and analysis of rigid pavements. Cheung and Zienkiewicz (1965) developed the first algorithm for the analysis of rigid pavements. They solved the problem of isotropic and orthotropic slabs on both semi-infinite elastic continuum and Winkler foundation using the FE method. Huang and Wang (1973) followed the procedure of Cheung and Zienkiewicz to develop a FE method to calculate the response of concrete slabs with load transfer at the joints. However, the developed model was incapable of handling multilayer systems. Chou (1981 and 1984) developed a computer program called WESLIQID for rigid pavement analysis. The program was a modification of the model developed by Huang and Wang (1973).

Tabatabaie (1978) developed a computer program ILLISLAB. This program is based on the classical theory of a medium-thick plate on a Winkler foundation. Aggregate interlock and keyway joints were modeled using spring elements which transfer the load between adjacent slabs by means of shear; while bar elements were used to model doweled joints which transfer moment as well as shear across the joint. The slab weight is neglected during load transfer calculations but is included in temperature calculations (Nasim, 1992). Additional capabilities were added to ILLISLAB including a variety of foundation models (Ioannides, 1984 and Khazanovich and Ioannides, 1993) and temperature loading (Korovesis, 1990). ILLISLAB has certain limitations (Nasim, 1992): 1) No more than two layers above the subgrade can be modeled. 2) During temperature analysis, only one single slab laying on top of a Winkler foundation may be considered. 3) Only one load transfer mechanism may be used for all joints and cracks in a certain model.

Nasim developed a method to study rigid pavement damage under moving dynamic loading by combining dynamic truck tire forces with pavement response (Nasim, 1992). Computer models of trucks were used to generate truck tire forces of various trucks. Influence functions were obtained from ILLISLAB for different pavement designs. Truck wheel load histories were 
combined with those from pavement response to calculate time histories of the response of a rigid pavement to moving dynamic truck loads and therefore predict pavement damage.

Other elastic solid and elastic layer 2D-FE programs like KENELS (Huang, 1974) and WESLAYER (Chou, 1981) also exist. These two programs either model a single slab or use an iterative process to transfer forces across joints. Several other 2D-FE programs also exist such as J-SLAB (Tayabji, 1984), KENSLABS (Huang, 1985), and ILSL97 (Roesler and Khazanovich, 1997).

Generally, 2D-FE programs demonstrate the potential capabilities of the modeling approach and represent significant improvement over traditional design methods. Most of these programs rely on plate elements to discretize concrete slabs and foundation layers (Davids, 1998), they allow the analysis of JPCCP with or without dowel bars and incorporate aggregate interlock shear transfer at the joint with linear spring elements. However, they are capable only of performing static analysis, and have limited applications. They cannot accurately model the following (Davids, 1998 and Kuo, 1994):

1) Dynamic loading.

2) Detailed local response, such as stresses at dowel bar/concrete interfaces.

3) Realistic horizontal friction force at the interface between different pavement layers.

4) Vertical separation or voids between the concrete slab and the base.

5) A nonlinear temperature gradient through the slab that can represent either the warping or the curling of the slab.

6) The stress patterns in the subgrade. Modeling the subgrade as a Winkler foundation does not permit the investigation of distress patterns in the subgrade.

\subsubsection{A Review of Three-Dimensional Finite Element Modeling Subjected to Traffic Loads}

With the increased affordability of computer time and memory, and the need for better understanding of the reasons for some modes of pavement failure, 3D-FEM approach was adopted by many researchers. Ioannides, and Donelly (1988) examined the effect of subgrade support conditions on rigid pavement slabs. In this study, the 3D-FE program GEOSYS was 
used to develop a model consisting of a single concrete slab and subgrade. The study examined the effect of mesh refinement, vertical and lateral subgrade extent, and boundary conditions on pavement response. Chatti (1992) developed the 3D-FEM called DYNA-SLAB to examine the effect of load transfer mechanisms and vehicle speed on rigid pavement response to moving loads. The model is an extension of the static 2D-FE model called ILLI-SLAB. He showed that the maximum tensile stress occurs at the mid point of the slab along the free edge, and observed stress reversal at the transverse joint.

Many researchers opted to use general purpose 3D-FE software packages because of the availability of interface algorithms, thermal modules, and material models that make them most suitable for analyzing pavement structures. General purpose software such as ABAQUS, DYNA3D, and NIKE3D have been in the process of development by private and public domain organizations since the 1970s, and were used in design problems ranging from bridges to underground shelters that withstand nuclear explosions (United States General Accounting Office, 1997). Shoukry, et al. (1996 and 1997) examined the dynamic response of composite and rigid pavements to FWD impact using LS-DYNA. The results indicated the reliability of LSDYNA in predicting the dynamic surface deflections measured during FWD test. These results also demonstrated that pavement layer interface properties are very important considerations when modeling pavement structures.

Purdue University and Ohio DOT examined the effect of overloaded trucks on rigid pavements (Zaghloul, 1994). They used the FE code ABAQUS to develop a 3D-FE model of a multilayered pavement structure. An $80 \mathrm{KN}$ (18-kip) Single Axle Load (SAL) was simulated by a tire print. The principal of superposition was used to model the SAL along the pavement. Results from this study showed that, when compared to interior loading, edge loading increased the vertical displacement and corresponding tensile stress by 45 and 40 percent, respectively. Increasing the load speed from 2.8 to $16 \mathrm{~km} / \mathrm{hr}(1.75$ to $10 \mathrm{mph})$ decreased the maximum surface deflection by 60 percent.

Darter, et al. (1995) investigated the mechanisms and effect of loss of support under concrete slabs using ABAQUS. He studied pavement performance under the effect of a static $80 \mathrm{KN}$ (18 
kip) SAL. The effect of a widened base on the stress level was studied under the SAL and a linear temperature gradient. It was concluded that, slab stresses were not reduced by bonding the slab and base course for a curled situation. Results from this study also showed that, the critical stress for a loss of support was found to occur under edge loading.

Hammons developed a 3D-FE model of a rigid pavement slab-joint-foundation system to investigate the load transfer efficiency at doweled joints (Hammons, 1997). This model was implemented in the advanced pavement design concepts currently under development by the FAA. The model was developed using the FE code ABAQUS and aimed at investigating the influence of a stabilized base course on the response of the transverse joint. Several analytical results were extracted from the comparison between results of the FE model to those from experiments, among them was a study of gap formulation across the slab/base interface for a range of static friction coefficient $(\mu)$ from 0.1 to 100 . The study showed that the largest gaps occurred for the lowest value of $\mu$. The magnitude of gap opening depended on the degree of shear transfer between the slab and the base. The largest differential movement between the slab and the base occurred for the lowest value of $\mu$.

Seaman, et al. (1992) attempted the development of mechanistic design procedures for airport pavements based on 3D-FE modeling. He used LS-DYNA to simulate a tandem aircraft landing gear rolling at $161 \mathrm{~km} / \mathrm{hr}(100 \mathrm{mph})$ over a layered PCC airfield pavement. The tires were simulated by rectangular footprints and the runway was modeled as a single PCC slab lying over a subgrade. Model results showed that the maximum horizontal stress in the direction of travel occurred on the lower surface of the slab directly below the load. The value of that stress was high enough to cause cracking damage in the vertical planes. Examination of the horizontal stress normal to the direction of travel, showed higher tensile stress compared to the horizontal stress in traffic direction. Such a high stress illustrated that crack growth is larger at the base of the slab on vertical planes along the direction of motion.

A 3D-FEM interface for modeling pavements structures (Kennedy, et al., 1994) gained the support of the Federal Highway Administration (FHWA) who funded its development (Kennedy and Everhart, 1995 and 1997). This is basically a pavement-meshing algorithm, which relies on 
public domain FE equation solvers DYNA3D and NIKE3D that were developed at Livermore National Laboratories starting in the mid 1970s. The FHWA-funded computer program was experimentally verified using the results from a test section constructed in Ohio (Kennedy and Everhart, 1997). In this model, the bottom surface of the soil layer is supported by dynamic compliant boundaries (springs and dampers). The model was loaded with a test vehicle. Each tire was simulated by a rectangular tire-footprint loaded with a uniform tire pressure. The model was used to study the effect of varying the PCC slab and the base moduli on the peak response of lateral and longitudinal strains.

In 1994, the FAA initiated a 10-year research project aiming at the development of advanced computer-based design procedure for airport pavements (Lee, et al., 1998). As a part of this project, the FAA developed a 3D-FE structural model for PCC airport pavements under aircraft loads using NIKE3D.

\subsubsection{A Review of Previous Studies Performed to Study the Effect of Thermal Induced Stresses}

All rigid pavement designs developed over the years, that take into account the effect of temperature fluctuations through the slab, are based on the assumption that this variation is linear, even though many studies reported the nonlinearity of temperature distribution through the slab. The temperature distribution through concrete slab thickness was first shown to be nonlinear during the Arlington Road tests in the early 1930's (Teller and Southerland, 1943). In spite of this finding, the same study concluded that a uniform temperature gradient would result in the most critical temperature condition.

Faragi, et al. (1987) studied the simultaneous action of traffic and thermal gradient on concrete pavements in Spain. A 2D-FE program was employed to calculate stresses induced in a single slab under combined static single axle load placed at either the transverse joint or mid-slab and linear thermal gradient through the slab thickness. Load transfer through the joints was not taken into consideration. The study concluded that: 
1) Current pavement design procedures are inadequate since the combined effect of traffic loads and thermal gradients do not correspond to the sum of traffic stresses and thermal stresses when each is computed separately.

2) The maximum stresses and the greatest fatigue damage are due to the simultaneous action of a positive thermal gradient and a single axle load.

Earlier 2D-FE models were based on the plate theory, which limits temperature gradient to a linear distribution through the concrete slab thickness (Ioannidies and Salsilli-Murua, 1989, Korovesis, 1990, and Taheri, 1992). Harik et al. (1994) proposed an analysis technique that superimposes the effect of the nonlinear temperature distribution on the 2D-FE solution. The study demonstrated that the disregarding of temperature stresses in rigid pavement design is not conservative and that nonlinearity in the temperature distribution should be considered.

An experimental and analytical study was conducted to determine the thermal-load induced stresses in concrete pavements (Choubane and Tia, 1995). Temperature distributions throughout the test slabs for various times of the day at different periods of the year indicated nonlinear distributions. Based on the field-measured temperature distributions, an analytical study was performed using the 2D-FE program FEACONS IV (Tia, et al., 1987). The concrete slab was modeled by plate elements while the subgrade was modeled as a Winkler foundation. Load transfer across the joints was modeled by linear and rotational springs. The model was subjected to the combined effect of a static single axle load and a linear uniform temperature gradient throughout the concrete depth. Two traffic-loading positions were studied: edge and corner loading for the conditions of positive and negative temperature differentials. The FEM in conjunction with a quadratic equation representing the nonlinear temperature gradient were used to compute the maximum thermal loading stresses. The study concluded that the maximum tensile stress computed in case of linear temperature distribution tends to be higher (overestimates the stresses) for the daytime condition and lower (underestimates the stresses) for the nighttime condition compared to the computed stresses with the consideration of effect of nonlinear temperature distribution. 
Channakeshava and Barzegar (1993) developed a nonlinear static 3D-FEM of a JPCCP. The response of JPCCP was studied under a linear temperature gradient and a static wheel load with different extent of loss of subgrade support and different dowel-concrete interface characteristics. The study concluded the following:

1) The repeated traffic loading reduces the strength of the concrete by fatigue and therefore, increases joint stiffness loss, which reduces shear transfer efficiency.

2) Nighttime curling is a critical loading case since truck traffic is heaviest at night, in addition, nighttime curling causes the loss of support near the joints.

3) Daytime curling condition is not critical to the transverse joint since in this case concrete slab lift-off occurs at its center.

4) The corner load position due to edge load leads to structural corner cracks.

Masad et al. (1996) used ABAQUS to study the effect of curling and thermal-expansion stresses on plain-jointed concrete pavements. The study concluded that:

1) Nonlinear temperature distribution caused higher tensile stresses than linear distribution.

2) Curling stresses increased with an increase in slab thickness.

3) Maximum thermal-expansion stresses increased as a result of an increase in slab length.

4) The friction factor at the interface between the slab and the subgrade has a minimal effect on tensile curling stress in the slab.

Zaman, et al. (1995) developed a FE algorithm for analyzing the dynamic response of rigid airport pavements subjected to temperature gradient and aircraft axle loads. The pavement was modeled as a thin plate supported on uniformly distributed springs and dashpots representing the viscoelastic foundation. Dowel bars at the transverse joint were idealized using grid elements. Results from the study indicated that:

1) Increasing the temperature gradient of the slab increases both the tensile stress and the deflection of the pavement.

2) The presence of dowel bars at transverse joints reduces the discontinuities in the displacement at these joints. 
Uddin, et al. (1997) examined the effect of pavement discontinuities on the surface deflection of a JPCCP subjected to a linear temperature gradient and statically applied loads. ABAQUS was used to develop a 3D pavement-subgrade model. A static analysis was performed by placing 80 KN (18-kip) dual-wheel SAL at the middle of the slab. Analysis of the FE model results indicated that the thermal gradients and truck loading caused significant fatigue cracking and premature deterioration in the outside wheel-path. The results presented in this study were very limited and did not show a good agreement with Westergaard and the 2D-FE program KENSLAB (Huang, 1985) results.

\subsubsection{A Review of the Verification Procedures Followed by Previous Studies}

Validating the results of a theoretical model is one of the main key issues in the formulation of that model. Verifying the results provides confidence in any analysis or conclusions reached from that model. A review of the previous studies showed that researchers followed a variety of approaches to verify their models. One way of investigating the accuracy of a theoretical model is to compare its results with field measurements for the same structure under identical loading conditions. Among other approaches of validating FE models is to compare their results to closed form solutions, or in some cases to match model results with the results obtained from other FE programs that are already verified. The summary presented in Table 2.1 demonstrates that most of the previous studies verified their models by comparing their results to field experiments. Although comparing theoretical results to experimentally measured results is considered the optimum verification criteria, the validity of this method is a function of the quality of the measured data. A comparison to well established earlier road tests or design theories such as AASHO Road Test, Westergaard theory, influence charts, or Portland Cement Association test results is highly favorable since these approaches are considered the basis on which pavement analysis and design were established. On the other hand, matching model results with the results obtained from other already verified FE programs, depends on the quality of these programs and the obtained matching level. In all cases, building a realistic model that can simulate the actual pavement behavior is a key issue that highly affects the matching level obtained from any verification approach. 


\subsection{Summary and Conclusions}

The work done in FE modeling of rigid pavements from the beginning of the 1970's until present is truly rich and lead to a breakthrough in pavement analysis and design. 2D-FE programs demonstrated the potential capabilities of the modeling approach and represented significant improvement over traditional design methods. However, they are capable only of performing static analysis and have limited applications. Many complicated problems are beyond their capabilities. The review presented in this chapter reveals the growing use of 3D-FE modeling in pavement analysis and design. Table 1.1 summarizes the model features of previous 3D-FE studies. Despite the notable improvement that 3D-FE modeling has offered over 2D models, it can be observed from Table 1.1 that some important aspects of the JPCCP problems have been neglected:

1) The 3D-FE models developed so far for rigid pavements have either neglected modeling dowel bars or modeled their effect using beam or spring elements. When dowel bars are modeled using spring elements, the embedded length of the dowel bar cannot be modeled and therefore the dowel/concrete interface is not represented. Such approximation may affect the results obtained at the joint and cause it to be unrealistic. None of the previous studies modeled dowel bars with hexahedron solid brick elements. This type of elements can be integrated over one-point Gaussian quadrature using the volume integration concept. The biggest advantage of one-point integration is the substantial savings in computer time (Hallquist, 1998). For higher level of accuracy the number of integration points (sampling points) can be up to 14 points, however, the higher the number of integration points the longer the solution time.

2) Load transfer across the transverse joints through aggregate interlock has been modeled either by shear spring elements or through the classical frictional behavior. These approximations do not simulate the true behavior of aggregate interlock. Previous studies showed that joint (spring) stiffness can be backcalculated from joint deflection in conjunction with the subgrade modulus and radius of relative stiffness or from load transfer efficiency (Ioannides, 1990). This means that, the spring stiffness changes with 
geometric configuration, material properties, and loading condition (Davids, 1998). Therefore, there is a need for a modeling technique that can model the variability of aggregate interlock with geometry, material properties, and loading.

3) Previous 3D-FE studies investigating the dynamic effect of moving loads on pavements followed several concepts such as:

a. Super-position of a static load (Zaghloul, et al., 1994).

b. Direct shape function method that varies with time as the horizontal position of the load changes with time, or treating the load as a series of impulses spaced at a constant interval and traveling at a constant velocity (Chatti, 1992).

c. Combining pavement response due to a unit static load with truck wheel load histories to calculate the time histories of the response of a rigid pavement to moving dynamic loads (Nasim, 1992).

Although these methods represented pavement response due to dynamic loads, they could not capture some significant details in analyzing the modes of failure of concrete pavements such as the effect of dowel bar vibration on the stiffness of the surrounding concrete. Therefore, a very small integration time step will ensure that the load motion intervals are extremely short and maintain a smooth transition of the load to capture these details.

4) None of the previous studies investigated the combined effect of a moving dynamic load and a nonlinear temperature gradient on the response of rigid pavement slabs.

5) Most of the previous studies modeled multiple pavement slabs. However, the larger the number of slabs, the coarser is the mesh and therefore the lower the accuracy of the obtained results. Thus a compromise needs to be reached between the number of slabs modeled, the accuracy of the results, and solution time and computer memory required. 
The FEM developed in this study addresses all the shortcomings previously discussed in terms of:

1) Modeling the dowel bars using eight-node hexahedron solid brick elements instead of the beam and spring elements previously used.

2) Using a sliding interface with voids and friction to model aggregate interlock.

3) Using an extremely small integration time step, which resulted in a pavement response that matches the response obtained from field studies.

4) Studying the combined effect of both temperature gradient and moving dynamic loads on rigid pavement slabs.

5) Providing a model that simulates multiple slabs with a fine mesh and at the same time does not require a long solution time or large computer memory. 


\section{Table 1.1 Model Features of Previous Three-Dimensional Finite Element Studies}

\begin{tabular}{|c|c|c|c|c|c|c|c|c|c|c|c|c|c|c|c|c|c|c|c|c|c|c|c|c|c|}
\hline \multirow[b]{2}{*}{ Author } & \multirow[b]{2}{*}{ Year } & \multicolumn{7}{|c|}{ Loading } & \multicolumn{3}{|c|}{$\begin{array}{l}\text { Dowel } \\
\text { Bars }\end{array}$} & \multicolumn{3}{|c|}{$\begin{array}{l}\text { Dowel } \\
\text { Interface }\end{array}$} & \multicolumn{3}{|c|}{$\begin{array}{l}\text { Layer } \\
\text { Interface }\end{array}$} & \multicolumn{2}{|c|}{ Subgrade } & \multirow{2}{*}{ 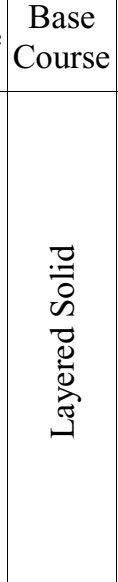 } & \multicolumn{2}{|c|}{$\begin{array}{l}\text { Aggregate } \\
\text { Interlock }\end{array}$} & \multicolumn{2}{|c|}{$\begin{array}{c}\text { Slabs } \\
\text { Modeled }\end{array}$} & \multirow[b]{2}{*}{$\begin{array}{c}\text { Verification } \\
\text { (FEM results are compared with) }\end{array}$} \\
\hline & & : & 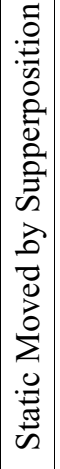 & $\sum_{I}^{2}$ & $\mid \begin{array}{l}0,0 \\
. J \\
0 \\
0 \\
\Sigma\end{array}$ & 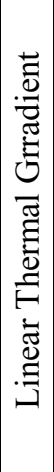 & 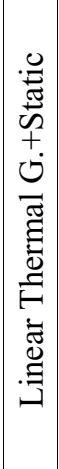 & 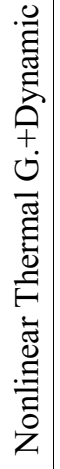 & 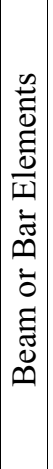 & 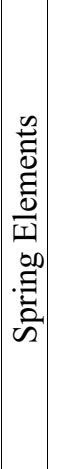 & $\begin{array}{l}\stackrel{\mathscr{Z}}{0} \\
\stackrel{\Xi}{0} \\
\frac{0}{\square} \\
\frac{y}{0} \\
\stackrel{0}{0}\end{array}$ & 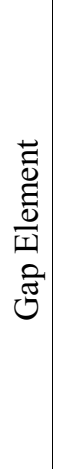 & 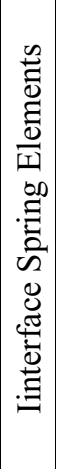 & 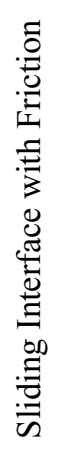 & 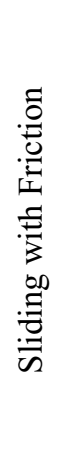 & 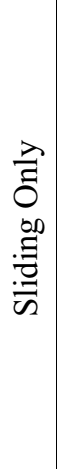 & 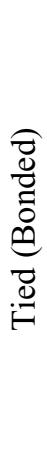 & $\frac{\frac{\dot{d}}{\Delta}}{\frac{\pi}{3}}$ & 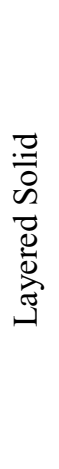 & & 窇 & 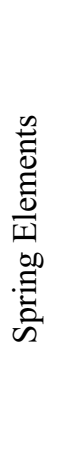 & $\frac{\stackrel{0}{a}}{\stackrel{\Xi}{\Xi}}$ & $\begin{array}{l}\frac{0}{00} \\
\stackrel{\Xi}{\infty}\end{array}$ & \\
\hline Shoukry & 2000 & & & $\mathrm{x}$ & & & & $\mathrm{x}$ & & & $\mathrm{x}$ & & & $\mathrm{x}$ & $\mathrm{x}$ & & $\mathrm{x}$ & & $\mathrm{x}$ & $\mathrm{x}$ & $\mathrm{x}$ & & $\mathrm{x}$ & & $\begin{array}{c}\text { Comparison with Ohio Test Road } \\
\text { results }\end{array}$ \\
\hline Lee, et al. & 1998 & $\mathrm{x}$ & & & & & & & & & & & & & $\mathrm{x}$ & & $\mathrm{x}$ & & $\mathrm{x}$ & $\mathrm{x}$ & & & $\mathrm{x}$ & & $\begin{array}{l}\text { Instrumented PCC runway in } \\
\text { Denver International Airport }\end{array}$ \\
\hline Davids & 1998 & $\mathrm{x}$ & & & & & $\mathrm{x}$ & & $\mathrm{x}$ & & & $\mathrm{x}$ & & & & $\mathrm{x}$ & $\mathrm{x}$ & $\mathrm{x}$ & $\mathrm{x}$ & $\mathrm{x}$ & $\mathrm{x}$ & & $\mathrm{x}$ & $\mathrm{x}$ & $\begin{array}{l}\text { Laboratory-scale JPCCP models } \\
\text { performed by Hammons (1997) }\end{array}$ \\
\hline $\begin{array}{l}\text { Sargand and } \\
\text { Beegle }\end{array}$ & 1998 & & & & & & & & $\mathrm{x}$ & & & & & & $\mathrm{x}$ & & & & $\mathrm{x}$ & $\mathrm{x}$ & $\mathrm{x}$ & & $\mathrm{x}$ & & Measurements from Ohio Test Road \\
\hline Uddin, et al. & 1997 & $\mathrm{x}$ & & $x$ & & & & & $\mathrm{x}$ & & & $\mathrm{X}$ & & & & $\mathrm{x}$ & $\mathrm{x}$ & & $\mathrm{x}$ & $\mathrm{x}$ & $\mathrm{x}$ & & $x$ & & FWD tests performed on US 78 \\
\hline $\begin{array}{l}\text { Kennedy and } \\
\text { Everhart }\end{array}$ & 1997 & $\mathrm{x}$ & & & $\mathrm{x}$ & $\mathrm{x}$ & & & & & & & & & & $\mathrm{x}$ & & $\mathrm{x}$ & $\mathrm{x}$ & $\mathrm{x}$ & & & & $\mathrm{x}$ & Measurements from Ohio Test Road \\
\hline Hammons & 1997 & $\mathrm{x}$ & & & & & & & & $\mathrm{x}$ & & & & & $\mathrm{x}$ & & & $\mathrm{x}$ & & $\mathrm{x}$ & & $\mathrm{x}$ & $\mathrm{x}$ & & Laboratory-scale JPCCP models \\
\hline Masad, et al. & 1996 & $\mathrm{x}$ & & & & $\mathrm{x}$ & & & & & & & & & $\mathrm{x}$ & & & & $\mathrm{x}$ & & $\mathrm{X}$ & & $\mathrm{x}$ & & $\begin{array}{c}\text { 2D-FE programs results and } \\
\text { Bradbury solution (Bradbury, 1938) }\end{array}$ \\
\hline Zaghloul, et al. & 1994 & & $\mathrm{x}$ & & & & & & $\mathrm{x}$ & & & & & & $\mathrm{X}$ & & & & $\mathrm{x}$ & & $\mathrm{x}$ & & $\mathrm{x}$ & & Westergaard and field results \\
\hline Darter, et al. & 1995 & $\mathrm{x}$ & & & & $\mathrm{x}$ & & & $\mathrm{x}$ & & & $\mathrm{X}$ & & & $\mathrm{X}$ & & & $\mathrm{x}$ & $\mathrm{x}$ & $\mathrm{x}$ & & $\mathrm{x}$ & $\mathrm{x}$ & & $\begin{array}{c}\text { ASSHO, PCA, and Arlington Road } \\
\text { Tests. }\end{array}$ \\
\hline $\begin{array}{c}\text { Channakeshava } \\
\text { and Barzegar }\end{array}$ & 1993 & $\mathrm{x}$ & & & & & $\mathrm{x}$ & & $\mathrm{X}$ & & & & $\mathrm{X}$ & & & & & $\mathrm{x}$ & & & & & $\mathrm{x}$ & & \\
\hline Chatti & 1992 & & & & $\mathrm{X}$ & & & & $*$ & & & & & & $\mathrm{X}$ & & & $\mathrm{X}$ & $\mathrm{x}$ & $\mathrm{x}$ & & $\mathrm{x}$ & $\mathrm{x}$ & & Theoretical solutions \\
\hline $\begin{array}{l}\text { Ioannides and } \\
\text { Donelly }\end{array}$ & 1988 & $\mathrm{x}$ & & & & & & & & & & & & & & & & & $\mathrm{x}$ & & & & & $\mathrm{X}$ & Theoretical solutions \\
\hline
\end{tabular}




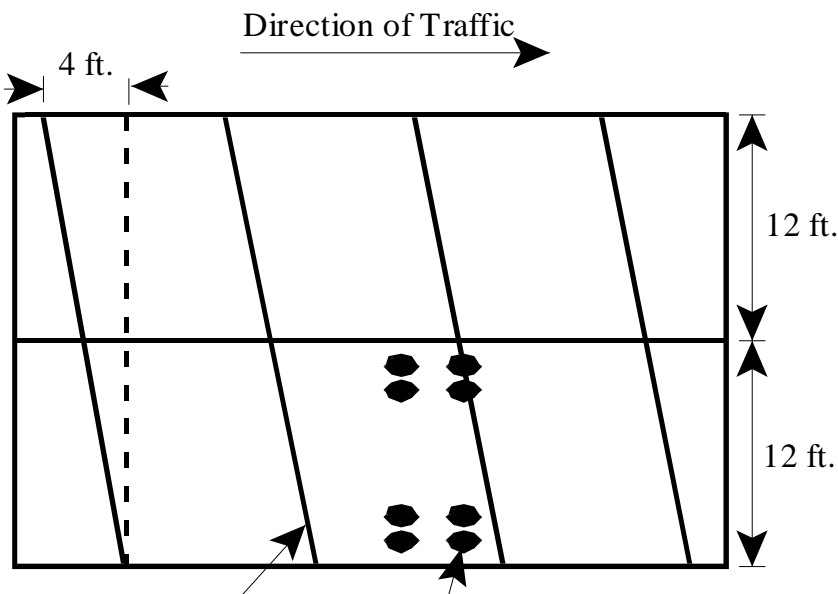

Skewed Contraction Joint Tire Prints

FIGURE 1.1 Typical Skewed Transverse Joint 


\section{CHAPTER TWO}

\section{PAVEMENT STRUCTURAL MODEL}

\subsection{Introduction}

This chapter contains a description of the FEM developed in this study including the types of interfaces used between pavement layers, the applied loads and boundary conditions, and the material models used. Some examples are presented to show the variety and quality of the results obtained from the model. To investigate the accuracy of the theoretical model, its results are compared with two different field measurement results obtained from: 1) Instrumented rigid pavement section in Ohio. 2) Falling Weight Deflectometer (FWD) tests performed in West Virginia.

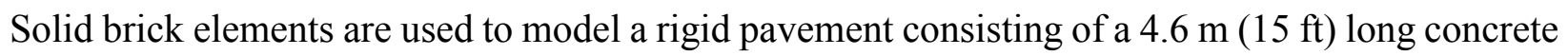
slab supported by a base course and a subgrade. The FE mesh and model layout are illustrated in Figures 2.1 and 2.2. To eliminate the effect of boundary conditions and to ensure a realistic and accurate modeling of the concrete slab, the middle slab is transversely joined at both ends with two half slabs using steel dowels. Regions of high stress intensity such as the transverse joint require a precise mesh refinement. Therefore, a refined mesh is developed in the vicinity of the transverse joint. Such a representation permits the studying of the behavior of transverse joints under moving loads. Eight node square solid brick elements are used to model the dowel bars. Figures 2.3 shows a cross section of the transverse joint modeled. A $9 \mathrm{~mm}$ (0.375 in.) opening is modeled representing the sawcut joint sealant groove, as shown in Figure 2.3. To reduce the computational time, use is made of the symmetry of loading and geometrical features along the traffic direction. Thus, only half the model needs to be solved as illustrated in Figure 2.2, which also illustrates the boundary conditions. 


\subsection{Modeling of Interfaces}

In previous FEM studies of jointed rigid pavements, dowel bars were modeled using either spring or beam elements. This approximation does not allow a realistic representation of the forces generated at the interfaces between dowel bars and the concrete slab. The directions of forces exerted by dowel bars on the slab vary from one dowel bar to another depending on the loading position on the slab. Modeling the dowel bars using solid brick elements accurately simulates the interaction between dowel bars and concrete. Moreover, this also takes into consideration the friction between each bar and concrete on the sliding (unbonded) side as well as the simulation of the bond characteristics between the bar and concrete on the tied side. In absence of experimental data for the coefficient of friction at the bar-concrete interface, a value of 0.02 is assumed on the sliding side. The side interface between the two adjacent slabs (along the transverse joint) is assumed to have zero spacing and a friction coefficient of 1.5 simulating limited aggregate interlocking.

The 1993 AASHTO Pavement Design Guide specifies a range for the coefficient of friction at the slab/base interface that falls between 0.9 and 2.2 depending on the base course type. Based on a parametric study, a sliding interface with voids and friction coefficient of 1.5 is assumed at the concrete/base course interface. The sliding interface allows the interface material to separate upon the development of tensile forces, which exceed the compressive force due to slab weight and applied traffic load. The separating tensile forces can be initiated due to the dynamic nature of the moving load (inertia effects) and thermal warping or curling of the slab. On the other hand, the interface between the base course and subgrade soil is assumed tied since it is unlikely that a granular base will behave as a rigid body layer that separates from the subgrade soil.

\subsection{Model Loading}

In order to accurately simulate the effect of moving load and account for the nonlinear variation in stiffness as the load approaches the transverse joint, explicit FE integration is used. The tire loads 
are applied on a set of contact patches that are moved on the slab at a speed of $105 \mathrm{~km} / \mathrm{hr}(65$ $\mathrm{mph})$. LS-DYNA integration time step is $1.22 \mathrm{e}-6$ second, therefore for a speed of $105 \mathrm{~km} / \mathrm{hr}(65$ $\mathrm{mph}$ ) or $29058 \mathrm{~mm} / \mathrm{sec}(1144 \mathrm{in} . / \mathrm{sec})$ the load will translate $0.036 \mathrm{~mm}$ (1.4e-3 in.) each new time step. Such a small time step permits capturing the small changes in pavement response. This method of representation allows for extremely smooth transition of the load from one nodal point to another along the wheel-path. The use of tire contact patches permits accounting for the rolling friction at the tire/pavement interface, which is assumed to be 0.02 .

The FEM is loaded with a tandem axle configuration. The review of previous studies shows that the maximum tandem axle load ranges between 125 and $178 \mathrm{KN}$ (28,000 and 40,000 lb). Tandem spacings range between 1.0 and $1.35 \mathrm{~m}$ (40 and 53 in.). Spacing centerline to centerline between dual wheels is approximately $0.35 \mathrm{~m}$ (14 in.) (Byung-Wan, 1988). Tire inflation pressure and wheel loads for radial 11R22.5 tires range from 5.6 to $9.1 \mathrm{~kg} / \mathrm{cm}^{2}$ ( 80 to $130 \mathrm{psi}$ ) and 11 to $24 \mathrm{KN}$ (2,500 to 5,500 lb) respectively (Sebaaly and Tabatabaee, 1989). Based on the previous overview, a 16.3-tons $(36000 \mathrm{lb})$ load was selected in this study for the tandem axle with an average tire inflation pressure of $7.35 \mathrm{~kg} / \mathrm{cm}^{2}$ (105 psi). This tire pressure was uniformly applied on each tire patch. Figure 2.4 shows a layout of the tandem axle configuration assumed. The contact area used in this study was calculated according to the Portland Cement Association method (Huang, 1993). This method simplifies the tire-pavement contact area to a rectangular shape whose dimensions are $0.8712 \mathrm{~L}$ length and $0.6 \mathrm{~L}$ width. The length of the actual contact area $(\mathrm{L})$ is calculated using the following equation:

$$
L=\sqrt{\frac{A_{c}}{0.5227}}
$$

Where $A_{c}$ is the contact area, which can be obtained by dividing the load on each tire by the tire pressure. 


\subsection{Boundary Conditions}

Free edge boundaries are assumed for the lateral edges of the concrete slab. This selection resulted from a study performed to select the appropriate boundary conditions as will be described in section 3.2. A non-reflective boundary is applied at the bottom of the model, as shown in Figure 2.2, simulating a semi-infinite extension for the subgrade layer. The non-reflective boundaries feature allows radiating stress waves to be absorbed when they reach this boundary, giving the effect of a continuous layer. The continuity of the model along the traffic direction is also simulated using nonreflective boundaries. On the shoulder side of the concrete slab, an asphalt concrete shoulder is assumed. Thus, the concrete slab edge is reflective while both base and subgrade sides are given non-reflective boundaries.

\subsection{Material Models}

Linear elastic material models are used to represent all pavement layers. Several previous studies showed that pavement layers behave elastically under dynamic loads (Nazarian and Boddapti, 1995 and Mallela and George, 1994). Previous studies (Kennedy, 1996, Hammons, 1997, and Lee, et al., 1998) showed that linear elastic material assumption produced acceptable agreement between FE predicted and field measured pavement responses.A study performed to investigate the performance of backcalculation algorithms through 3D-FE modeling of pavements (Shoukry and William, 1999) demonstrated that the surface deflections measured at various FWD sensor locations when plotted versus different FWD loads follow a linear load-deflection relations at all sensor locations. This linearity is taken as an identification of the validity of linear elastic material behavior in most backcalculation algorithms. The study also showed that the stresses induced in base and subgrade layers are very small which confirm the assumption of linear elastic material models. Moreover, experiments performed in Ohio (Sargand and Beegle, 1998) showed that strains induced by traffic loads in PCC pavement did not exceed 40 microstrains, which is the range within which the results obtained from the FEM in this study fell. Thus, in this study each layer material is characterized by 
its modulus of elasticity, density, and Poisson=s ratio. However, the 3D-FEM software used in this study, can easily accommodate nonlinear viscoelastic or nonlinear viscoplastic material models for the base and subgrade layers, provided that the material constants are well quantified.

The material properties used in this study are obtained from an experimental section tested with a FWD, a listing of those material is shown in Table 2.1. The tested section is a rigid pavement site located on WV Route 857 near Morgantown, West Virginia (Shoukry, et al., 1997). Young's moduli are backcalculated while Poisson's ratios and the densities are assumed.

TABLE 2.1 Material Properties Used for the Finite Element Model

\begin{tabular}{|c|c|c|c|}
\hline Material & $\begin{array}{c}\text { Young=s } \\
\text { Modulus (psi) }\end{array}$ & $\begin{array}{c}\text { Poisson=s } \\
\text { Ratio }\end{array}$ & $\begin{array}{l}\text { Density } \\
\left(\mathbf{l b} / \mathbf{i n}^{3}\right)\end{array}$ \\
\hline Concrete & $2.25 \mathrm{E}+06$ & 0.18 & $2.26 \mathrm{E}-04$ \\
\hline Base Course & $45 \mathrm{E}+03$ & 0.4 & $2.11 \mathrm{E}-04$ \\
\hline Subgrade & $4.4 \mathrm{E}+03$ & 0.45 & $1.96 \mathrm{E}-04$ \\
\hline Steel & $29 \mathrm{E}+06$ & 0.3 & 7.324E-04 \\
\hline
\end{tabular}

\subsection{Model Results}

Figure 2.5 shows the variation of Maximum Principal Stress (MPS) fringes on the top and bottom of the middle slab at different tandem axle positions. The main observation from the results shown in Figure 2.5, is the development of tensile stresses on the slab top along the symmetry plane (slab centerline) as shown in Figure 2.5 ( $a, b$, and c). Those tensile stresses may be responsible for the development of longitudinal cracks along the slab centerline. The tensile stress observed at slab bottom is more severe than that developed at slab top, as shown in Figure 2.5 (d, e, and f), indicating the possibility for a longitudinal crack to initiate from either the top or the bottom of the slab.

Areas of stress concentrations can also be studied, as shown in Figure 2.6. This figure shows the 
MPS and vertical stress $\left(\sigma_{z}\right)$ induced around the dowel bars when one of the tandem axles is located over the transverse joint. The same figure also shows how the concrete surrounding the dowel bars is subjected to compressive and tensile stresses at its top and bottom, respectively. Another observation is that the dowel bars located along the wheel-path are subjected to the highest stresses. The model also displays the deformation pattern of the concrete slab under truck tire-patches and fringes of compressive stresses at the location of these patches. Since the model is composed of several parts, each part can be displayed separately as shown in Figure 2.7 (a, c, and e). The deformed mesh for different loading position is shown in this figure. The figure also shows how it is possible to add or remove any part of the pavement model, as shown in Figure 2.7 (e), where the two half slabs have been removed. Figure 2.7 also shows a cross section along the transverse joint illustrating the MPS distribution for two loading conditions: joint and mid-slab, Figure 2.7 (b and d) respectively. During joint loading, a gap is formed at the vertical interface along the transverse joint at slab bottom, which in turn subject the bottom of the slabs to tensile stresses and their tops to compressive stresses, Figure 2.7 (b). However, during mid-slab loading the opposite is true, the slabs bottom is compressed while the top is tensioned with high tensile stresses along the joint interface and a gap is formulated along the joint interface at slabs top, Figure 2.7 (d). In addition, the cross section shows the deformation pattern of the joint as the load moves along the slab.

To illustrate the load transfer capability along the transverse joint, the fringe distribution of vertical displacement is captured for different tandem axle positions along the slab, as shown in Figure 2.8. The continuity of the fringes along the transverse joint indicates that the dowel bars performed their intended function in transferring the load across the joint. It also shows that the maximum displacement occurs under the tires and decreases as we move away from the loaded area. In addition, this figure demonstrates the continuity of the displacement fringes through pavement layers, indicating that the vertical load applied to the slab is transmitted through the layer interfaces.

\subsubsection{Method of presenting the history results}

In this study, the history of a certain variable, e.g. stress, strain, or deflection, versus the distance of 
the front axle of any axle configuration from a certain point of study will be called Athe variable history @, e.g. stress history or strain history. To describe the history of a certain variable at selected points on the pavement structure, the data are plotted versus model loading position. The horizontal distance of the contact patch from the element under study is plotted on the abscissa. The zero loading position is located at the center of the element under consideration. Thus, a negative sign of the distance on the abscissa means that the moving load is approaching the element and a positive distance means that the load is moving away from the element.

The histories developed in four elements, which fall along the inner wheel-path are examined. Figure 2.9 shows a schematic representation of the location of the four elements selected for any history studies of any variable. Two of these elements are located on the slab top and bottom at mid slab length, elements MT and MB. The other two elements are located on the slab top and bottom at the edge of the second transverse joint, elements JT and JB. The history plotted for the second joint represents the average of the first five elements in traffic direction located along the edge of the approach slab. Since, the vibration of the dowel bars will affect the first element along the slab edge. Therefore, this element will not represent the actual behavior of the transverse joint under moving load. For that reason, the history average of the first five elements along the slab edge is calculated and plotted.

A wide range of response variables can be obtained from the model such as: stresses, strains, and displacement. For example, Figures 2.10 and 2.11 show the MPS, longitudinal strain $\left(\varepsilon_{\mathrm{x}}\right)$, transverse strain $\left(\varepsilon_{y}\right)$, and vertical displacement developed in the same four elements shown in Figure 2.9. A schematic representation is plotted next to each variable $=\mathrm{s}$ distribution illustrated in Figures 2.10 and 2.11 showing the location of the element of study on a minimized model layout. The ordinate on each history plot represents the dependent variable of interest. The stress or strain condition at any element can be either positive or negative. When positive, the element is subjected to tensile stress or strain and when negative the element undergoes compression. Similarly a positive displacement means an upward deflection and a negative displacement means a downward deflection. The stress and strain peaks observed in Figures 2.10 and 2.11, take place each time an axle is loading the 
element of study. Therefore, the two peaks observed at either the top or the bottom of the slab, indicate that a tandem axle is loading the element of study. The distance between the two peaks of a similar curve is equal to the spacing between the two axles of the tandem assembly. These peaks decay as the load moves away from the element of study.

\subsection{Verification of the Finite Element Model}

The most reliable method of investigating the accuracy of the theoretical model is to compare its results with field measurements for the same structure under identical loading conditions. Two verification approaches are used to verify the validity of the FEM through the comparison of its results with: 1) Ohio Test Road results. 2) FWD test results performed in Morgantown, West Virginia.

\subsubsection{Comparison with Ohio Test Road Results}

The FEM results are compared to a field study performed by Ohio University (Sargand and Beegle, 1998). The Ohio Department of Transportation constructed a $5.5 \mathrm{~km}$ (3.4 miles) test road to undertake the Specific Pavement Studies (SPS) defined by the Strategic Highway Research Program (SHRP) and the Long Term Pavement Performance (LTPP) program. The SPS experiments are designed to study the long-term response of various pavements to environmental conditions and traffic loading. Part of that study is performed on instrumented PCC pavement sections. To simulate one of those sections, the dimensions and material properties of the FEM developed in this study are modified. Model loading simulates Ohio DOT dump truck that was used in Ohio Test Road. The tire loads and axle spacing of that truck are shown in Figure 2.12 (a). The longitudinal strain $\left(\varepsilon_{\mathrm{x}}\right)$ history obtained from the FEM is compared to that measured from Ohio Test Road. The histories developed in six elements located along the wheel-path and six other elements located

along the slab centerline are examined. Six of those elements are located at the slab top, the other six elements are vertically aligned with them at slab bottom. Figure 2.12 (b) shows the locations of 
the six elements at slab top. Figure 2.13 shows the FEM used to simulate Ohio Test Road, while Table 2.2 shows the material properties used in the model, which were obtained from (Sargand and Beegle, 1998). Figure 2.14 and 2.15 show a comparison between $\varepsilon_{\mathrm{x}}$ history measured from Ohio Test Road and that computed from the FEM for the six elements along the wheel-path and the other six elements along the slab centerline, respectively. Examination of the two figures show that $\varepsilon_{\mathrm{x}}$ history peak at three points corresponding to the three axles of the dump truck used. The distance between the peaks corresponds to the actual distances between the axles in the truck. The FE results agree qualitatively and quantitatively with the experimentally measured strain. This comparison was published in (Shoukry, 2000). This agreement demonstrates the ability of the FEM to predict the exact pavement response to moving truck loads and therefore increase the confidence in any results obtained from this model.

Table 2.2 Material Properties Used to Simulate Ohio Test Road

\begin{tabular}{|c|c|c|c|}
\hline Material & $\begin{array}{c}\text { Young's } \\
\text { Modulus (psi) }\end{array}$ & $\begin{array}{c}\text { Poisson's } \\
\text { Ratio }\end{array}$ & $\begin{array}{c}\text { Density } \\
\text { (lb/in }^{\mathbf{3}} \text { ) }\end{array}$ \\
\hline Concrete & $4.9 \mathrm{E}+06$ & 0.18 & $2.26 \mathrm{E}-04$ \\
Base & $25 \mathrm{E}+03$ & 0.4 & $2.11 \mathrm{E}-04$ \\
Subgrade & $9 \mathrm{E}+03$ & 0.45 & $1.96 \mathrm{E}-04$ \\
Steel & $29 \mathrm{E}+06$ & 0.3 & $7.324 \mathrm{E}-04$ \\
\hline
\end{tabular}

\subsubsection{Comparison with Falling Weight Deflectometer Results}

The 3D-FE approach is used to simulate the response of a rigid pavement site tested under FWD impact load. The site is located on WV Route 857 near Morgantown, West Virginia (Shoukry, et al., 1997). The pavement structure is modeled as a multilayered system consisting of a PCC slab, base, and subgrade as shown in Figure 2.16. A $25.4 \mathrm{~mm}$ (1 in.) thick and $305 \mathrm{~mm}$ (12 in.) diameter steel loading plate is added to the pavement model to simulate the FWD impact loading setup. The center 
of the loading plate is located at the center of the concrete slab. Due to the geometrical symmetry around the longitudinal plane passing through the center of the loading plate, only one half lane width of $1.85 \mathrm{~m}$ (6 ft.) is meshed as shown in Figure 2.16. Surface deflections are measured at the locations of the nine FWD geophone sensors located at distances of 0, 203, 305, 457, 610, 914, 1219, 1524 , and $1829 \mathrm{~mm}(0,8,12,18,24,36,48,60$, and $72 \mathrm{in}$.) away from the center of the loading

plate. The impact load used in this model is obtained from the measured FWD load applied during the test. The impact loading-time relations recorded by the FWD load cell are digitized over onemillisecond time intervals and the pressure-time history is calculated by dividing the load by the area of the loading plate. Figure 2.16 illustrates the digitized pressure-time curves used for the FE model. The deflection basins obtained from that model are compared to those experimentally measured, and plotted in Figure 2.17. It can be observed that the slopes of the theoretical and experimental deflection basins are in close agreement. A maximum deviation of $0.127 \mathrm{~mm}$ (5 mils) is observed between the two curves. This can be due to the age difference between the pavement section and the FE model, which represents a newly constructed pavement. Dowel bar looseness or loss of partial aggregate interlock at the joints can also reduce the stiffness of the concrete slab and increase the surface deflection.

\subsection{Conclusions}

The work presented in this chapter included the development of an explicit FEM capable of capturing the response of rigid pavement with a unique level of accuracy that was never obtained by any of the previous research studies in the area of pavement modeling. The verification presented illustrates that the theoretical model is capable of producing typically the same results obtained from field studies and therefore increase the confidence in its results. When compared to field measurements, the theoretical model will become more economic, faster in terms of gathering any data, easier to modify, and is more capable of producing detailed local responses at any point in the pavement structure. 


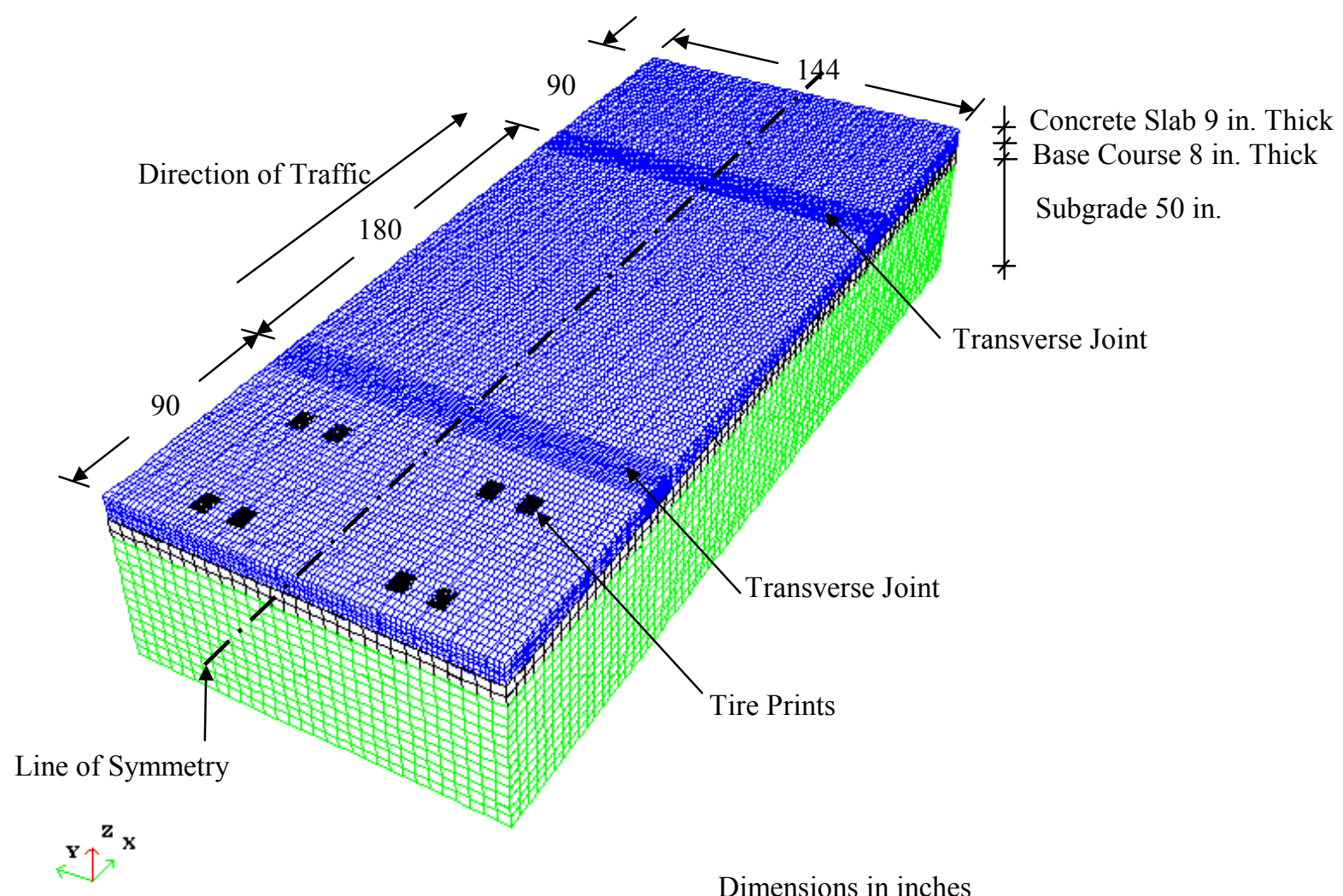

Dimensions in inches

FIGURE 2.1 Finite Element Mesh of the Full Model 


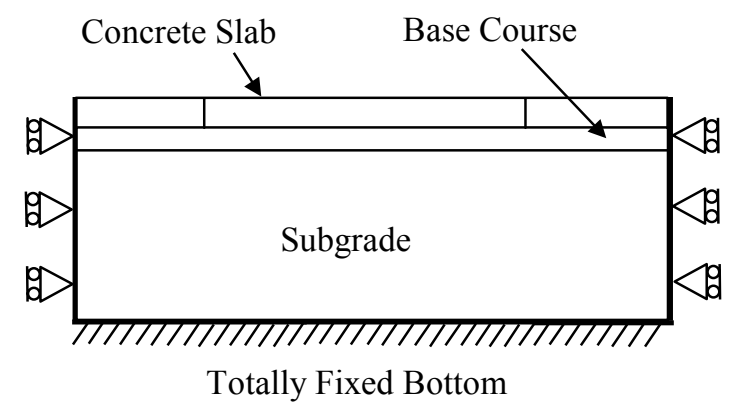

Elevation

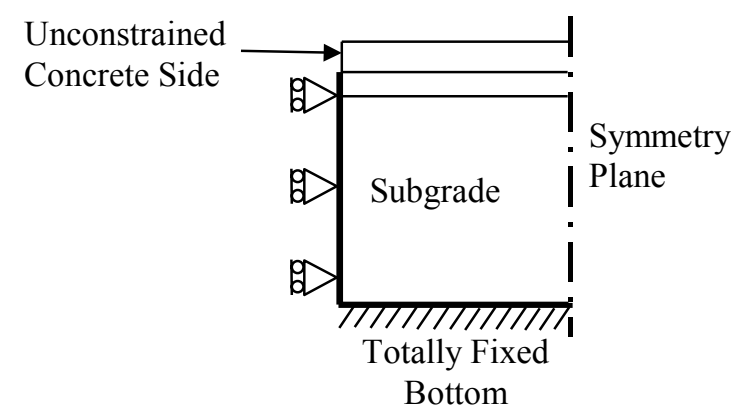

Side View

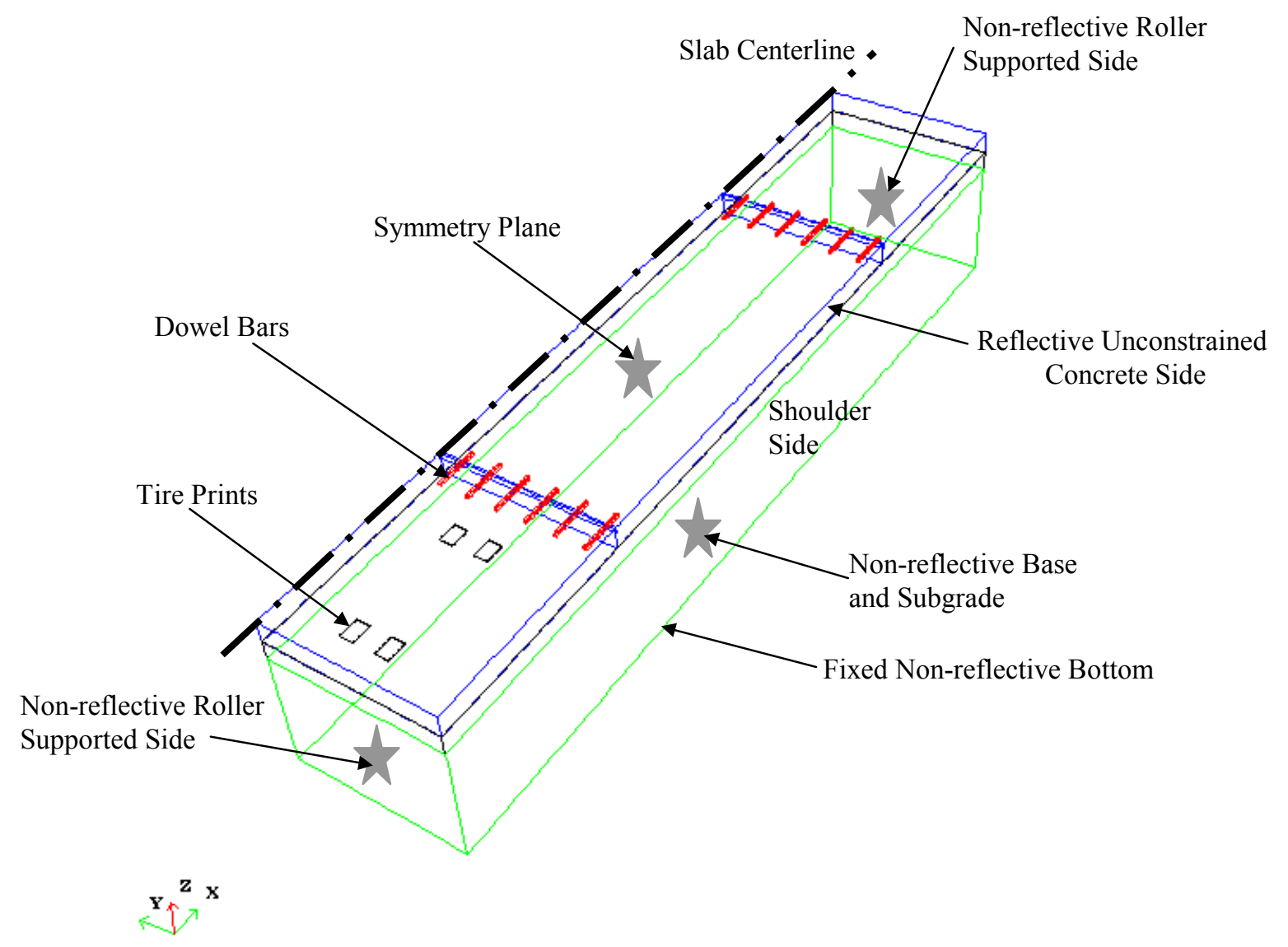

FIGURE 2.2 Model Boundary Conditions 


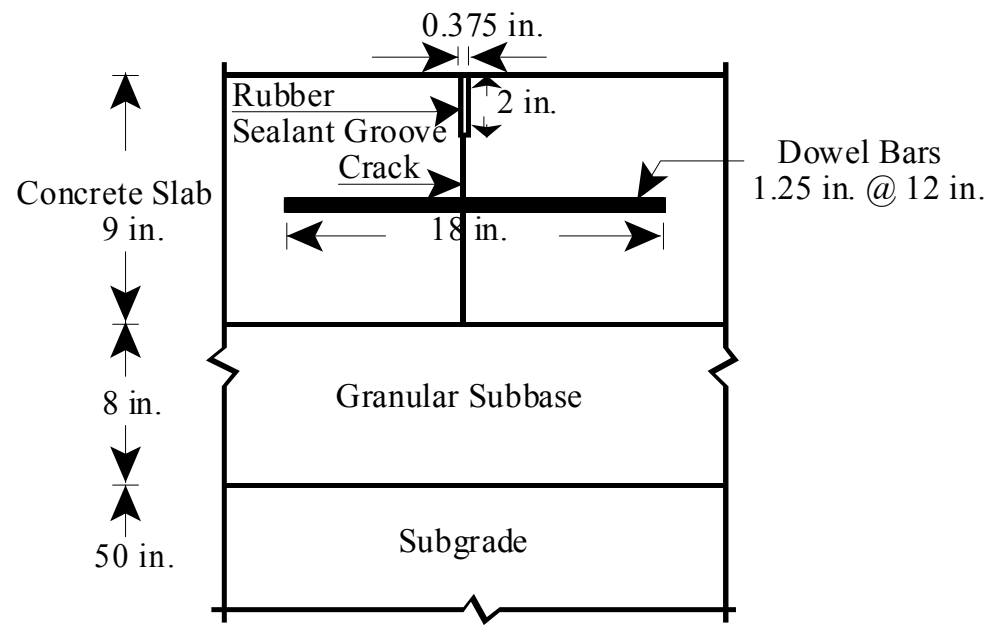

FIGURE 2.3 Cross Section of the Transverse Joint

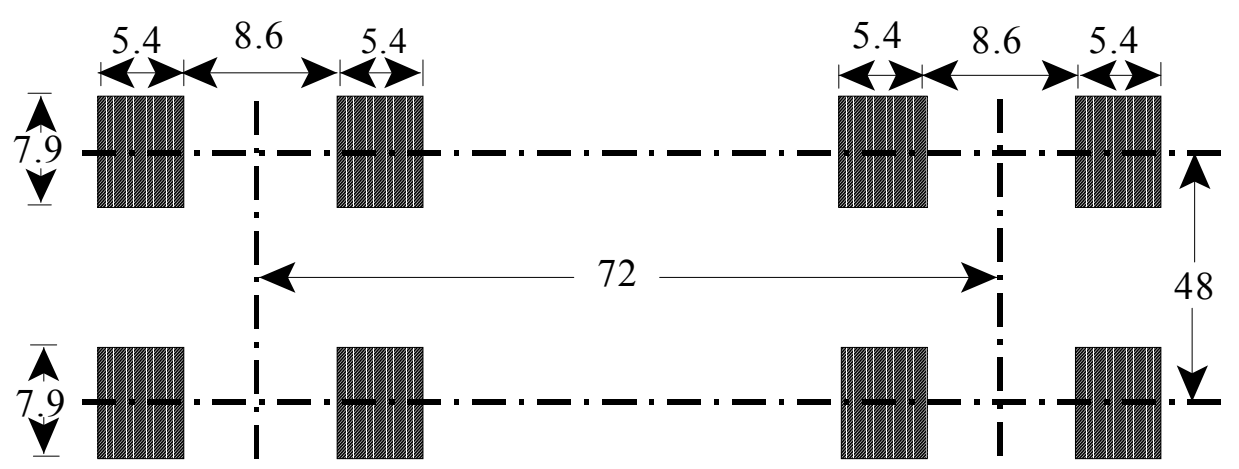

(Dimensions in inches)

Axle Load $=36,000 \mathrm{lb}$

Tire Pressure $=105$ psi

FIGURE 2.4 Tandem Axle Configuration

(Assumed for this Model) 


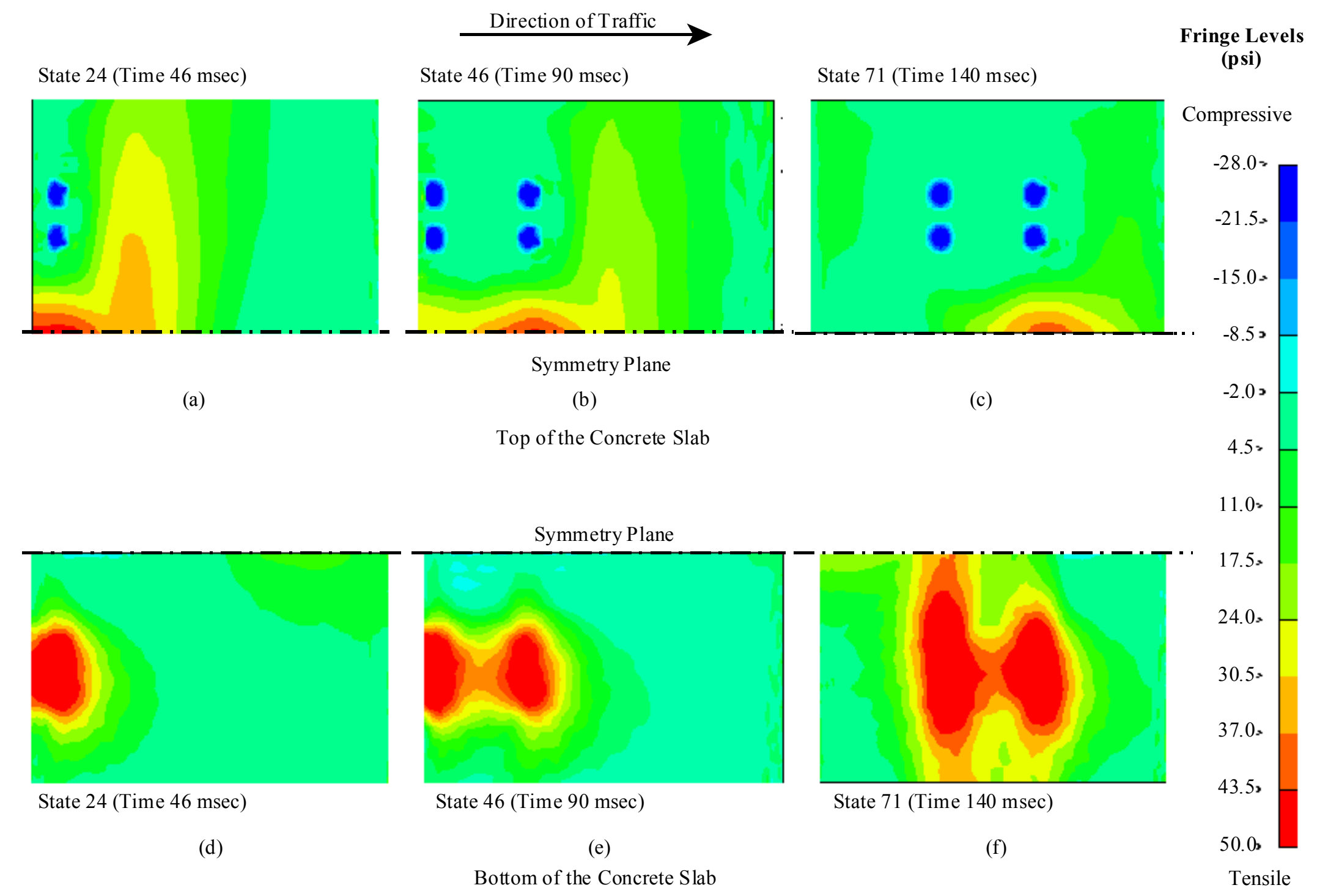

FIGURE 2.5 Distribution of Maximum Principal Stress in the Middle of the Slab Under the Effect of a Tandem Axle Load 


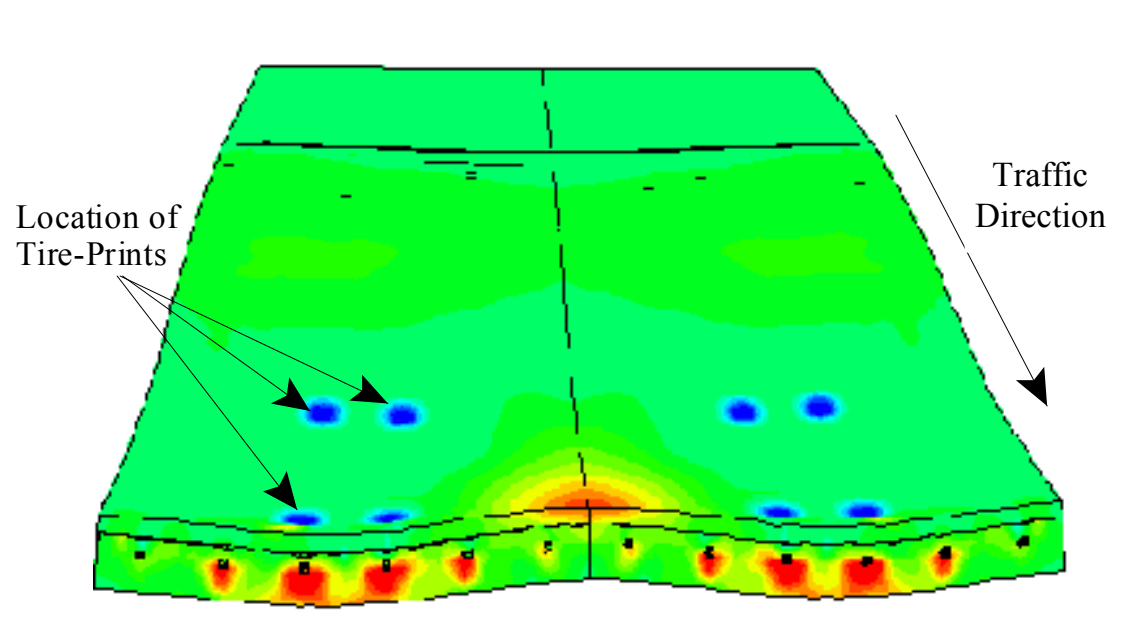

Fringe Level (psi)

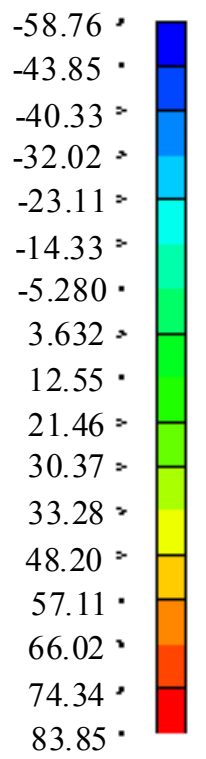

(a) Maximum Principal Stress

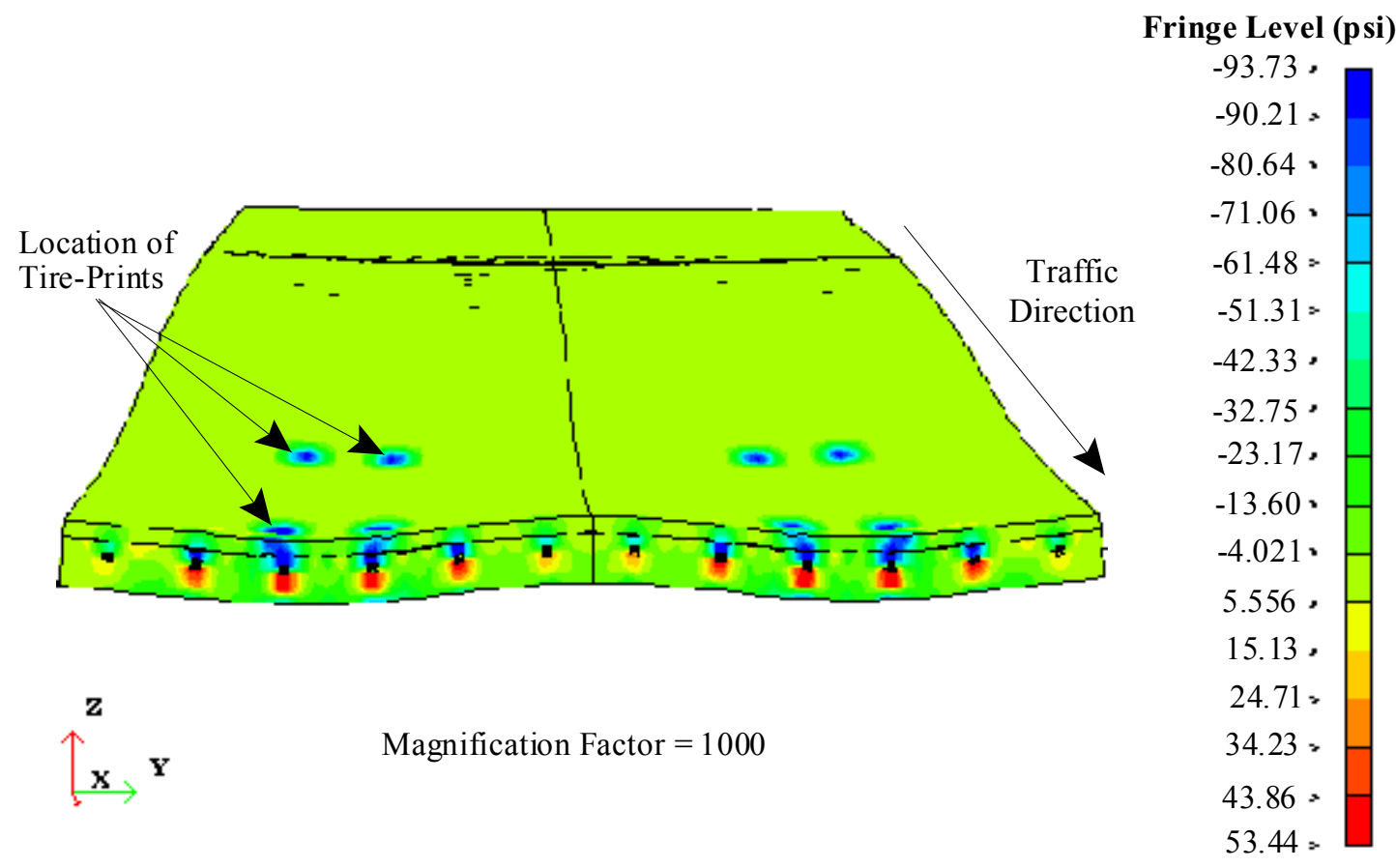

(b) Vertical Stress

FIGURE 2.6 Stresses Around Dowel Bars Under a Tandem Axle Configuration 


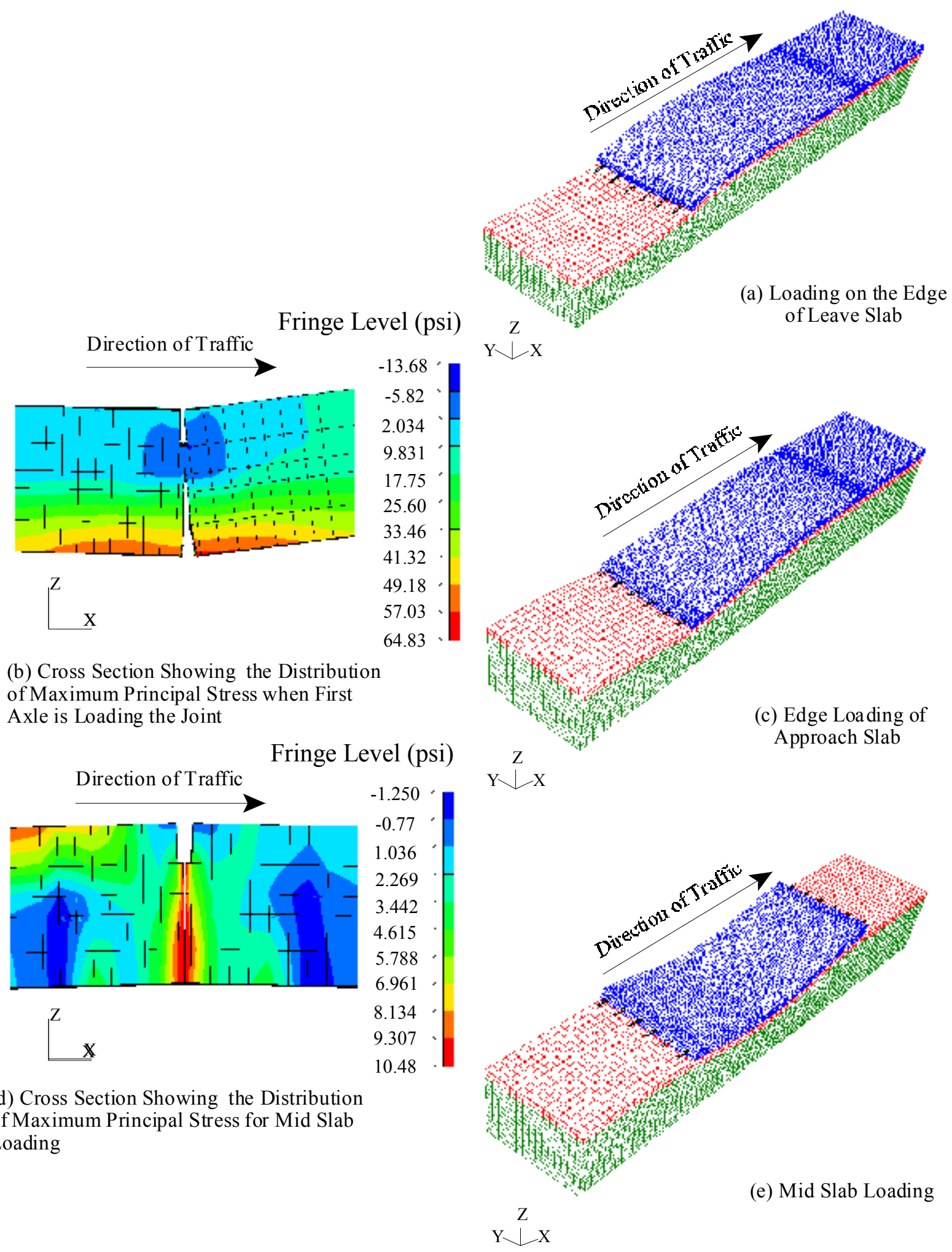

FIGURE 2.7 Deformed Finite Element Mesh for Different Loading Positions 

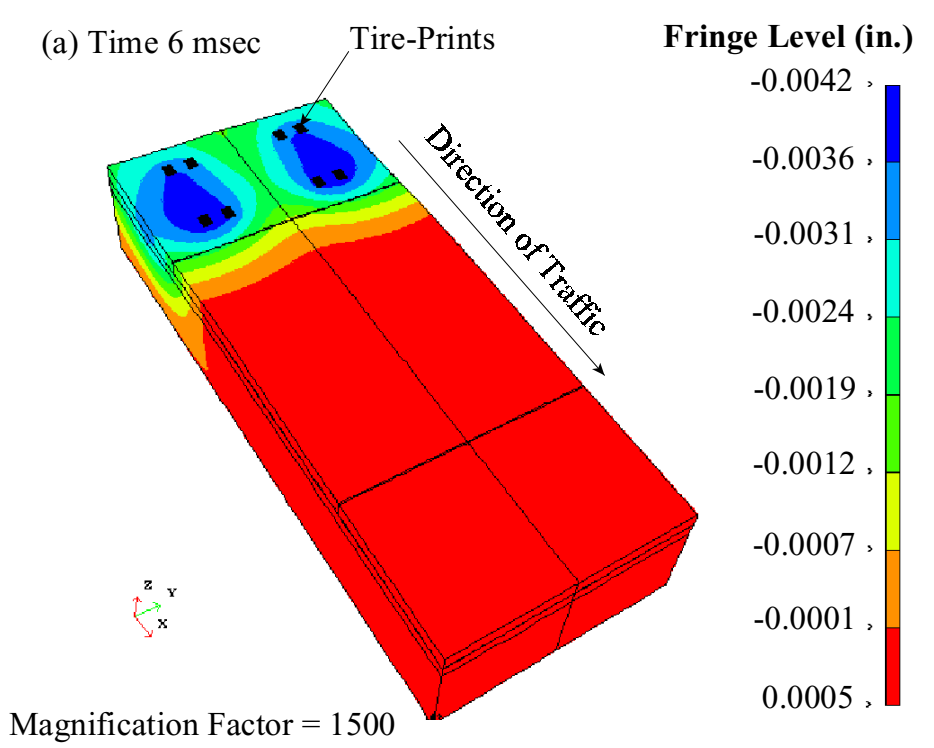

(c) Time $122 \mathrm{msec}$

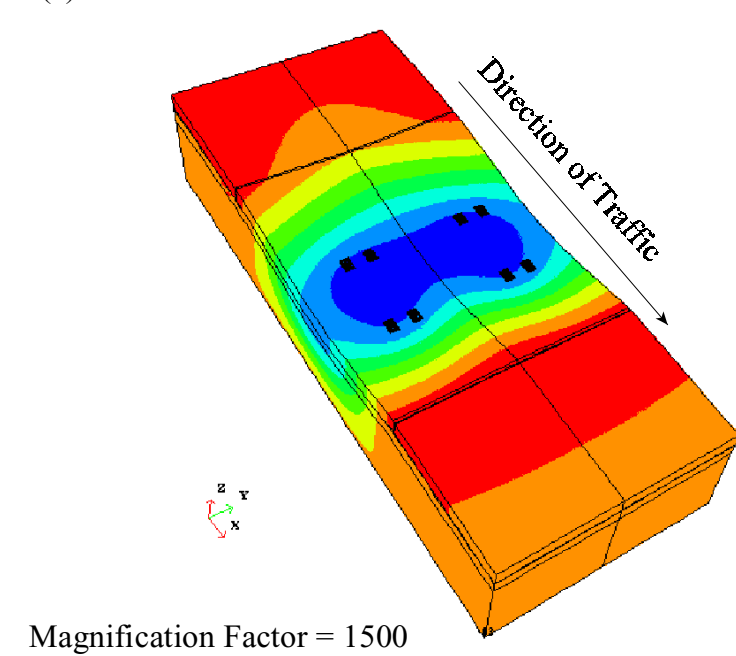

Fringe Level (in.)

$$
\begin{gathered}
-0.0113= \\
-0.0094 \\
-0.0076, \\
-0.0058 \\
-0.0034 \\
-0.0022 \\
-0.0004 \\
0.0015 \\
0.0033
\end{gathered}
$$

(b) Time $26 \mathrm{msec}$

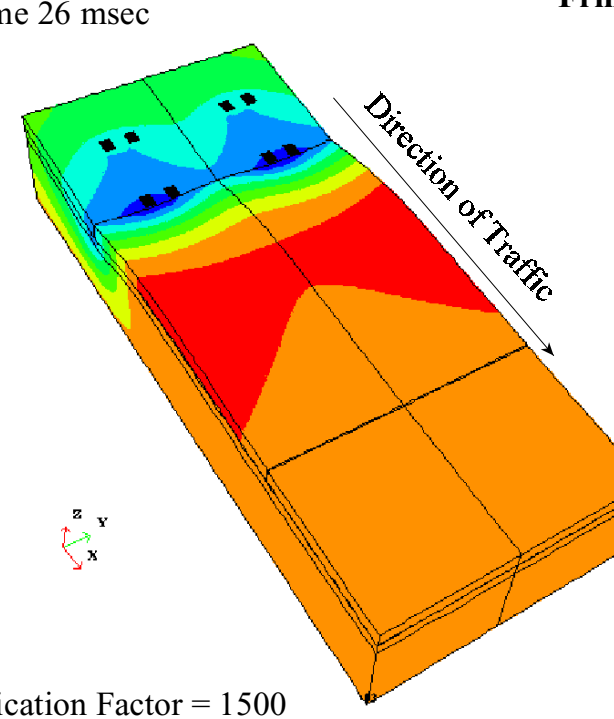

Fringe Level (in.)

$-0.0122$

-0.0103 ,

-0.0082 >

$-0.0063$

-0.0044 ,

-0.0024 ,

-0.0004 ,

0.0016 ,

0.0035 ,

Magnification Factor $=1500$

(d) Time $186 \mathrm{msec}$

Fringe Level (in.)

$-0.0034$

$-0.0078$

-0.0062 ,

$-0.0045$

-0.0023 ,

-0.0013 ,

0.0004 ,

0.0021 ,

0.0036 ,

\section{FIGURE 2.8 Variation of Vertical Displacement Distribution as the Tandem Axle Load Traverses the Model}




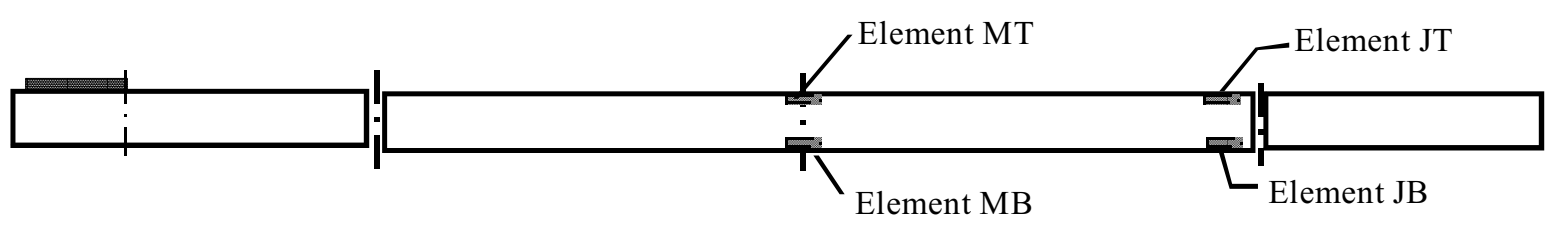

Side View
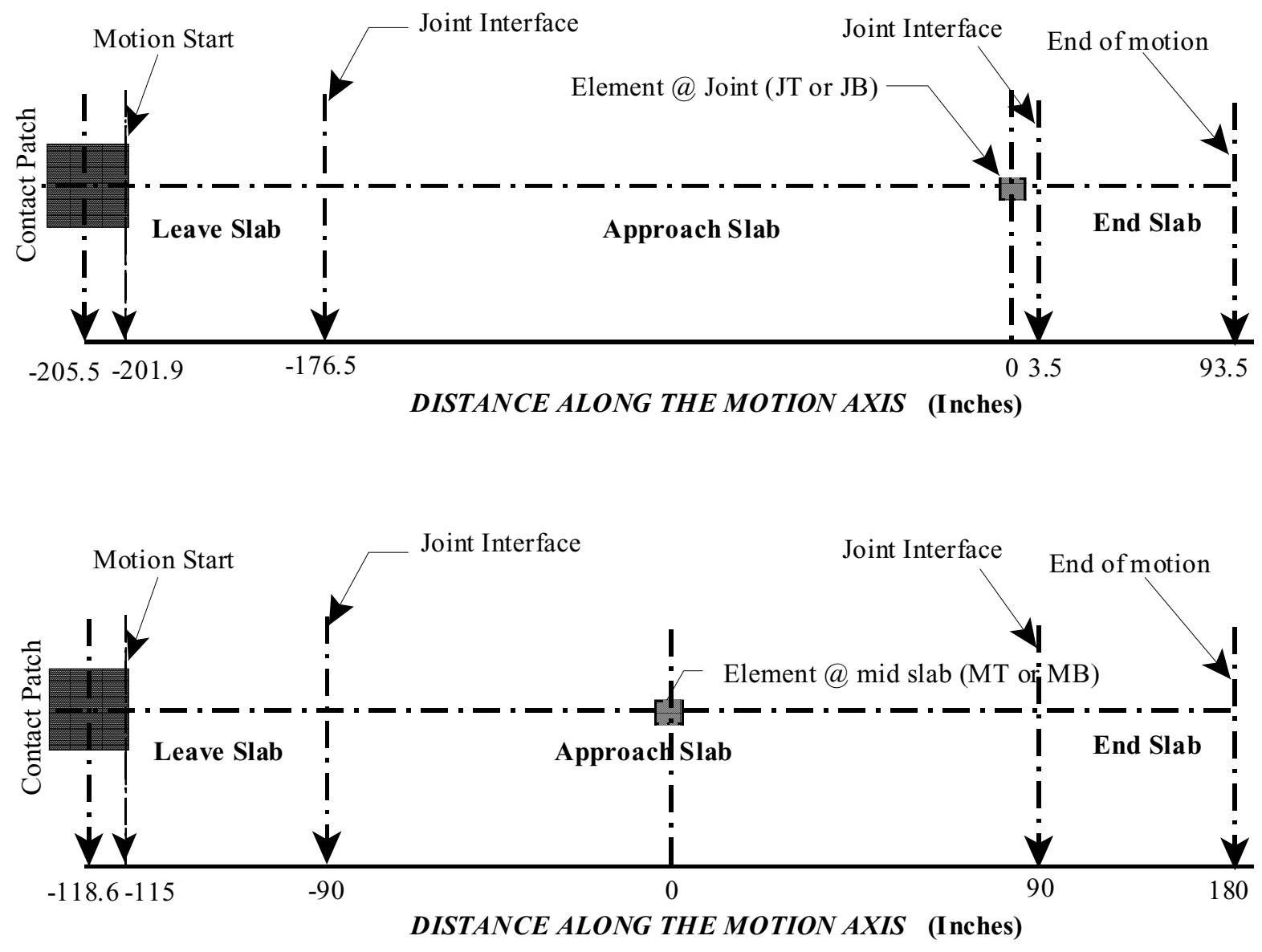

\section{Plan View}

FIGURE 2.9 Position of Surface Elements Along the Center Line of Inner Tire Motion 


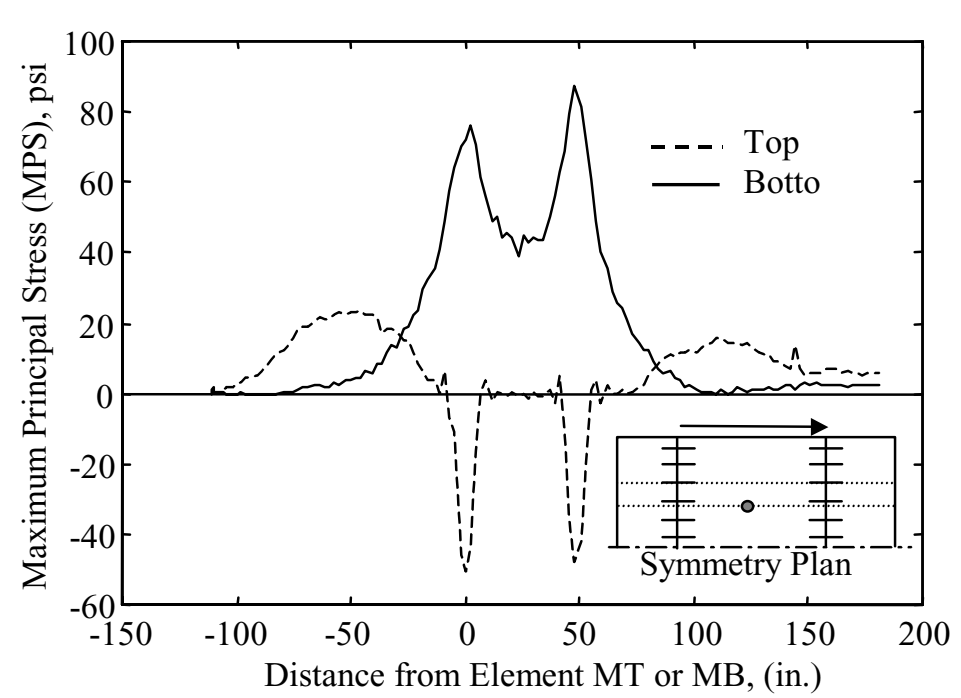

(a)

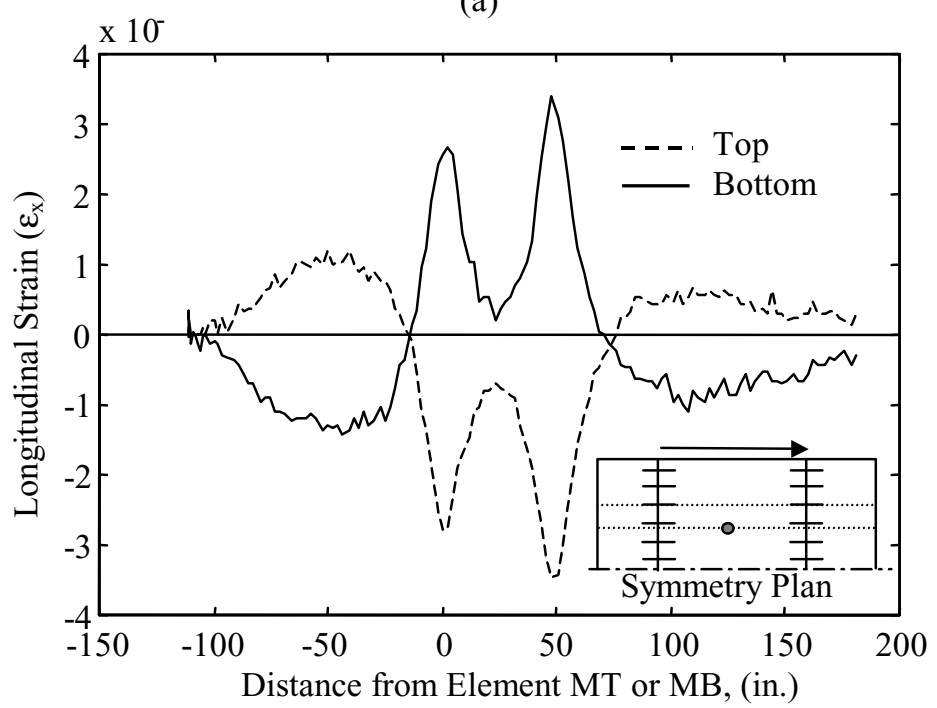

(c)

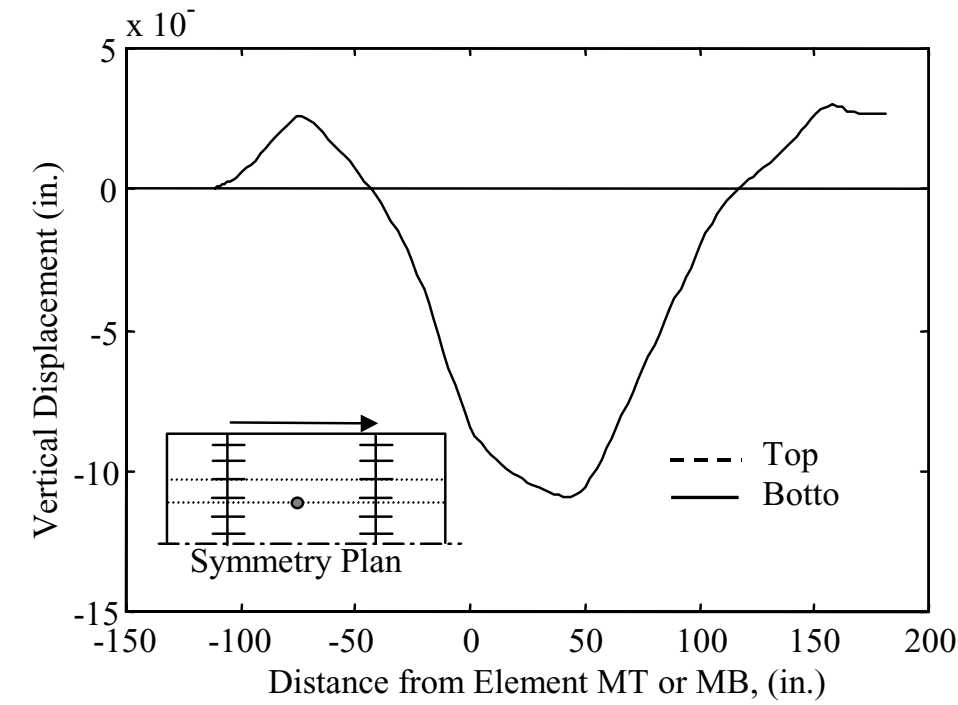

(b)

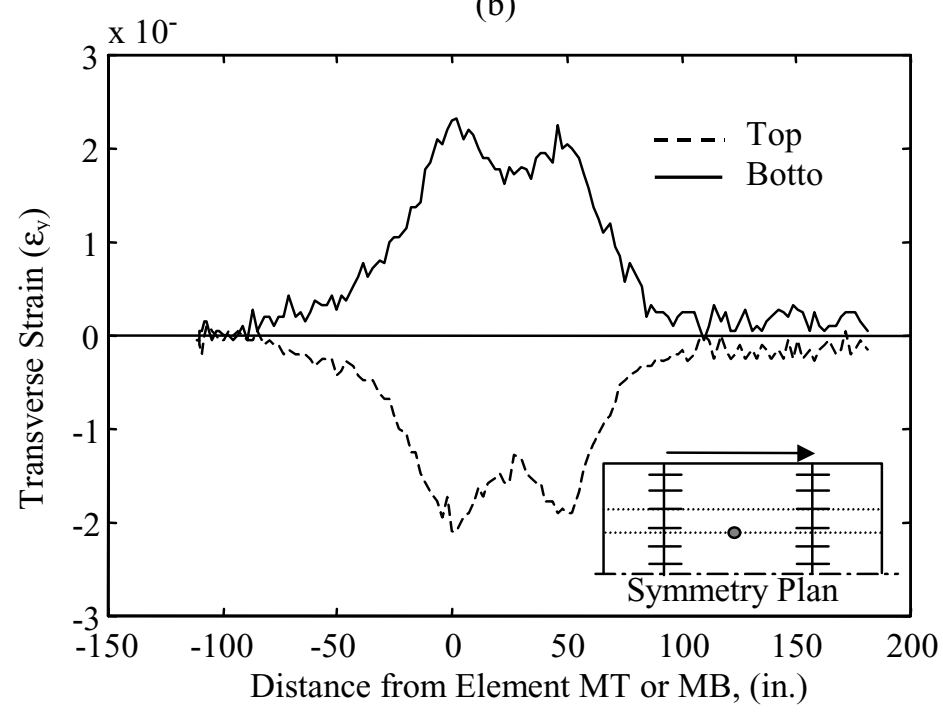

(d)

Figure 2.10 Illustration Results Demonstrating the Concrete Slab Response to Tandem Axle Load at the Middle of the Slab 

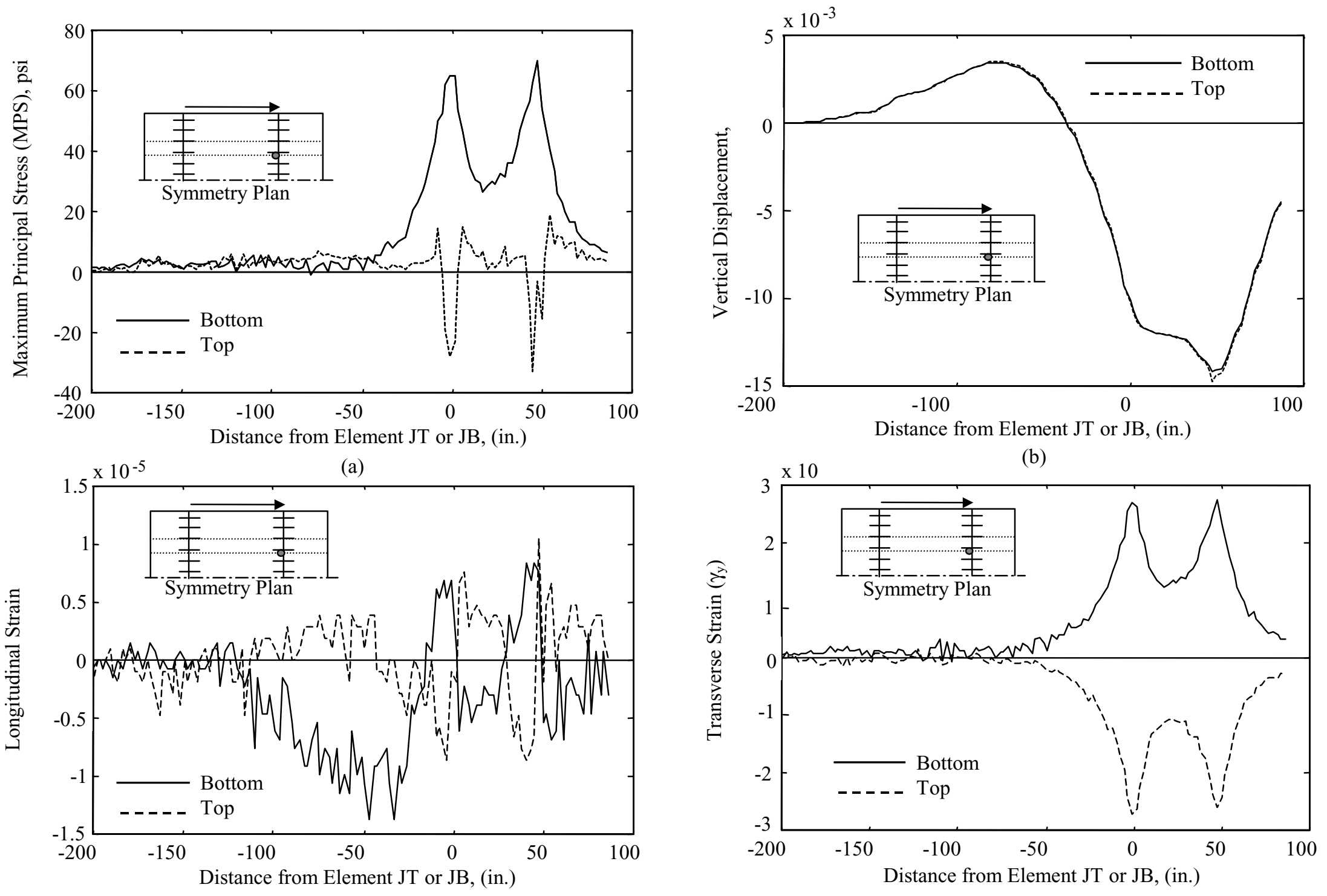

(c)

(d)

Figure 2.11 Illustration Results Demonstrating the Concrete Slab Response to Tandem Axle Load Along the Transverse Joint 


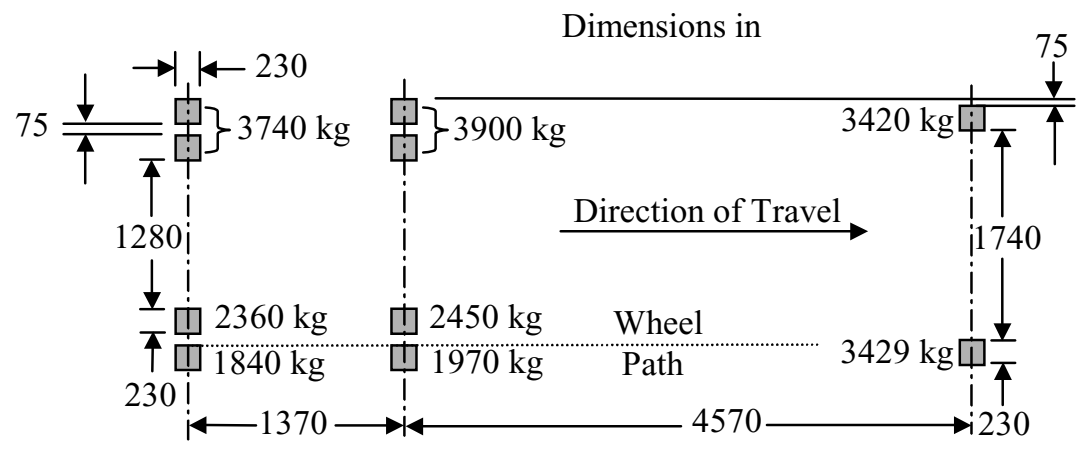

FIGURE 2.12 (a) Tire Loads and Axle Spacing for Truck used in the Experimental Section and the Finite Element Model (Sargand, 1998)

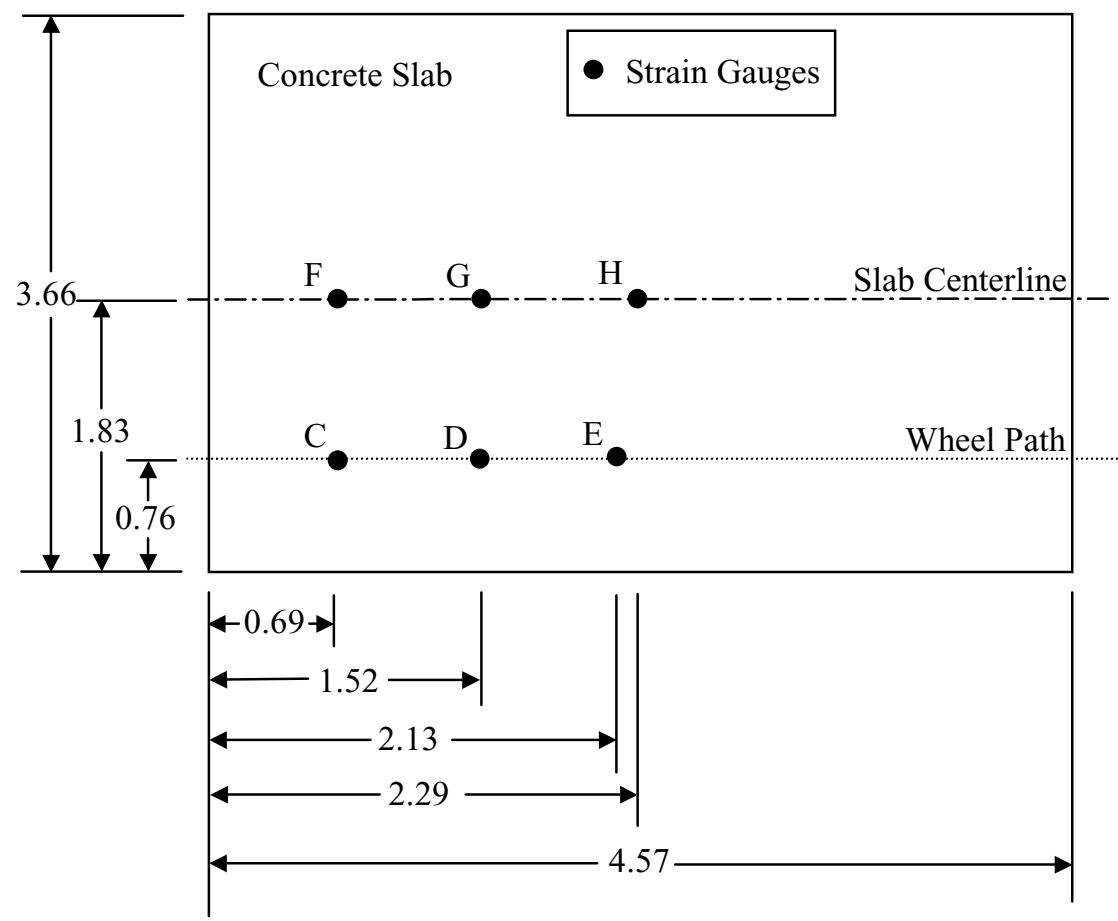

Dimensions in meters

FIGURE 2.12 (b) Location of Sensors in PCC Section (Sargand, 1998) 


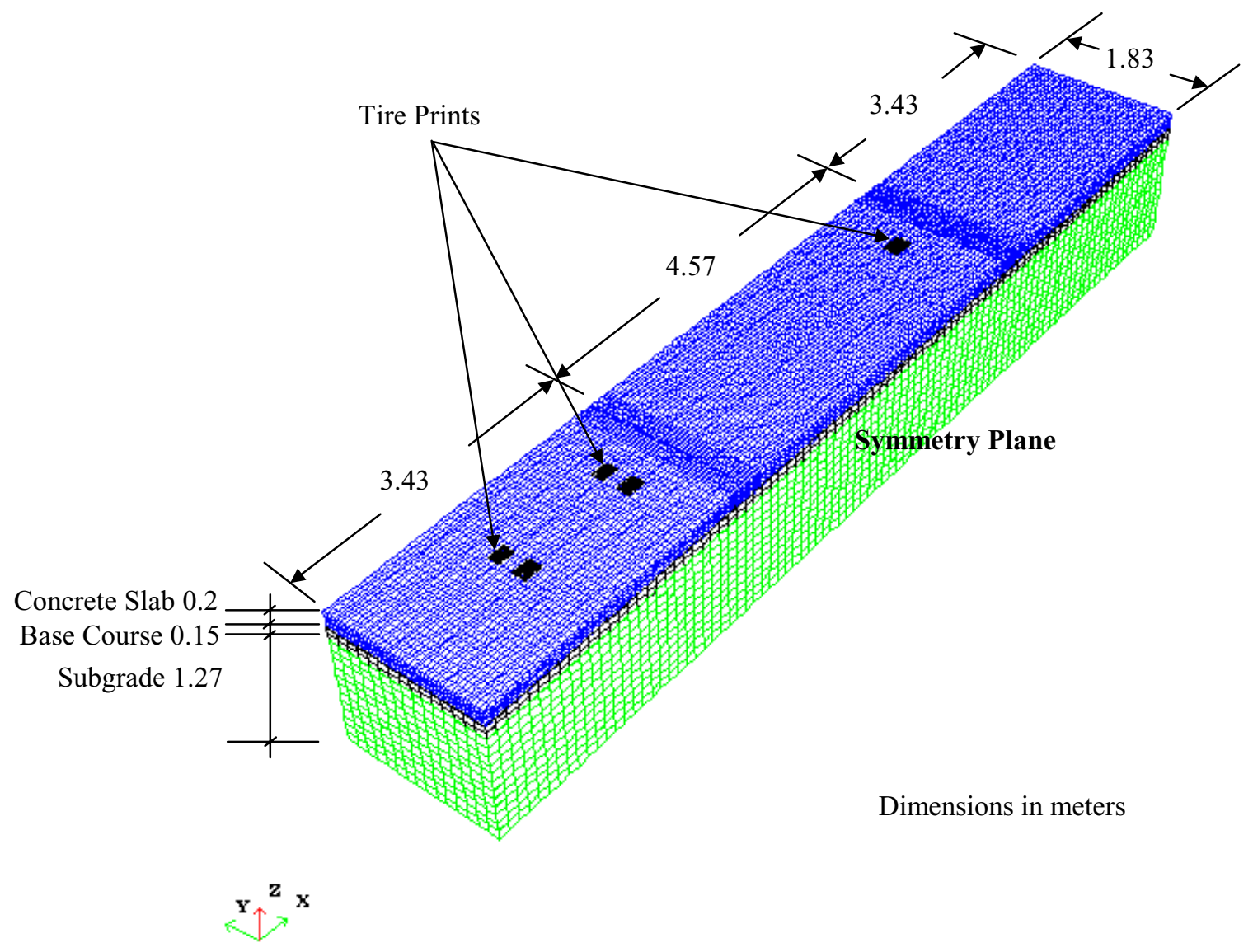

FIGURE 2.13 Finite Element Mesh Used to Simulate Ohio Test Road 

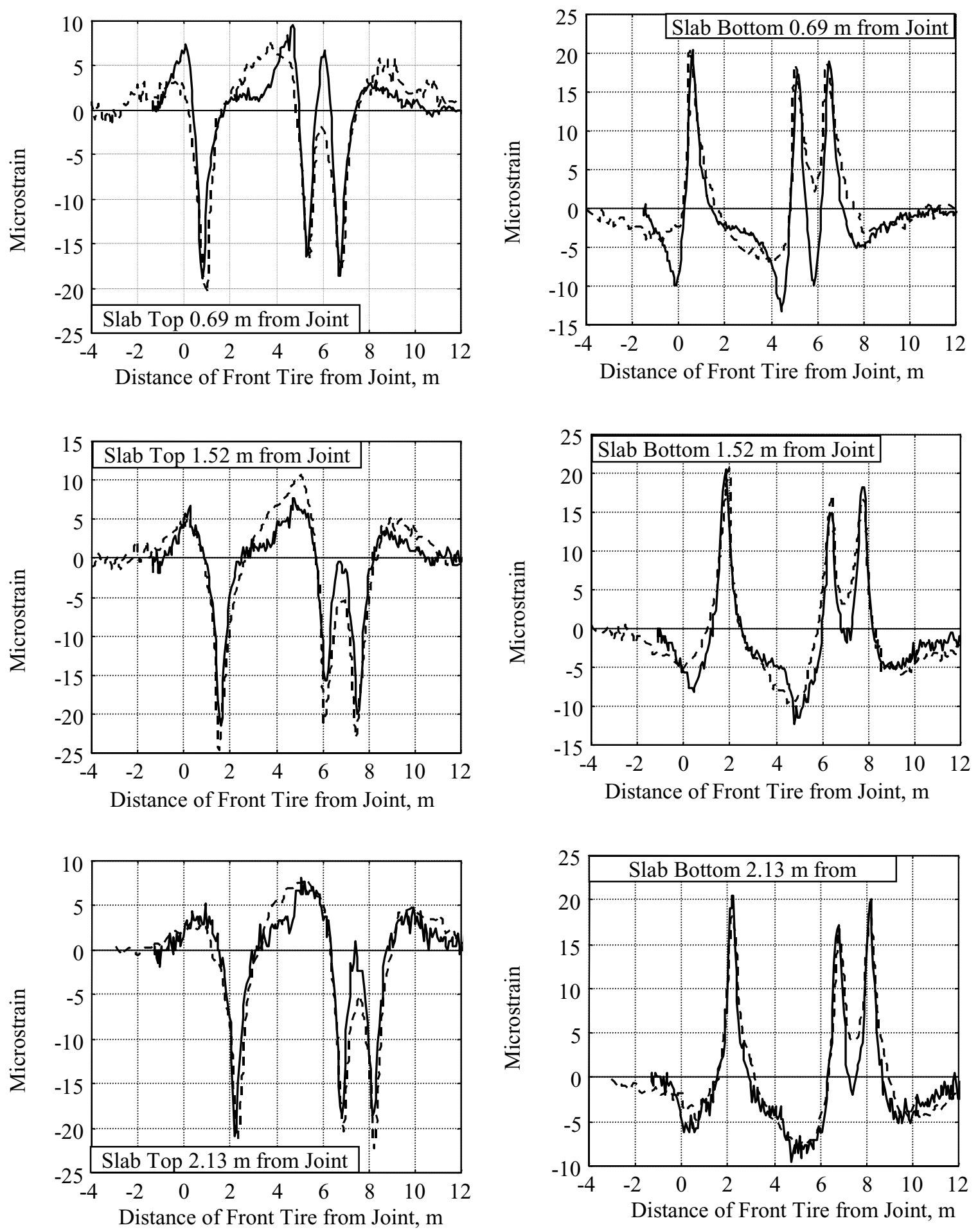

\section{- FEM
- Experimental}

FIGURE 2.14 Measured Longitudinal Strain at Elements C, D, and E from Ohio Section versus 3D-FEM Results 

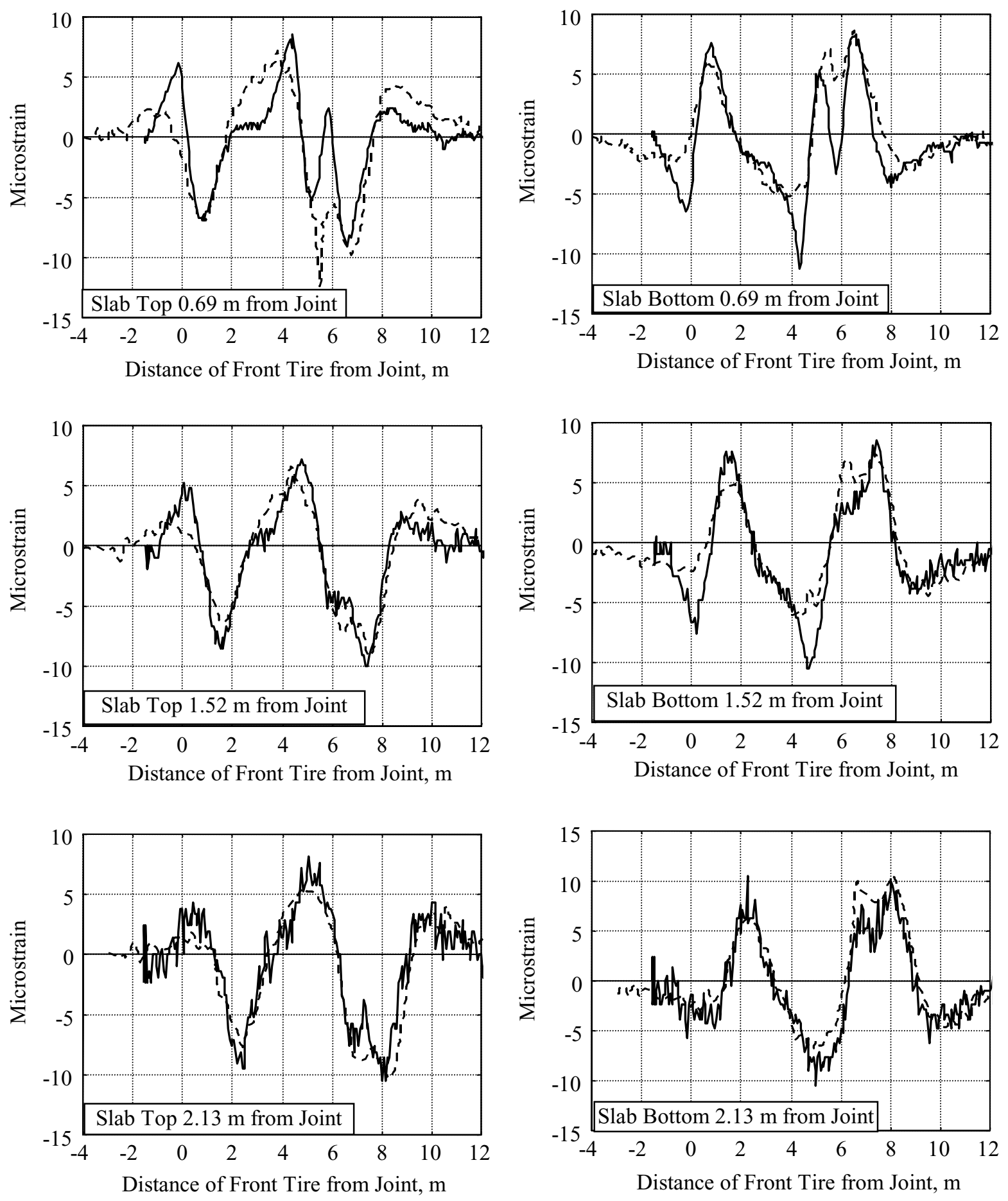

\section{- FEM}

FIGURE 2.15 Measured Longitudinal Strain at Elements F, G, and H from Ohio Section versus 3D-FEM Results 


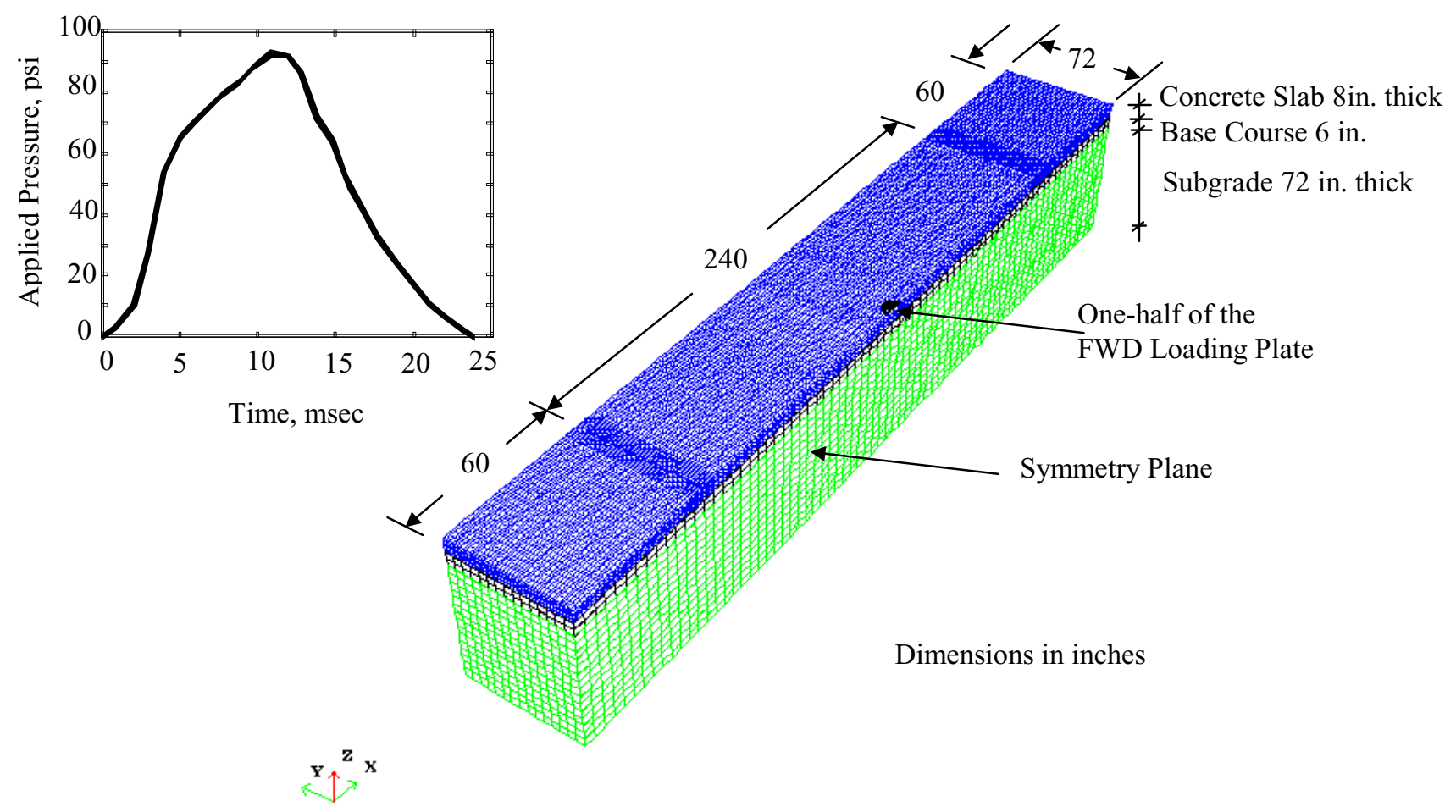

FIGURE 2.16 Finite Element Mesh of the Verification Model

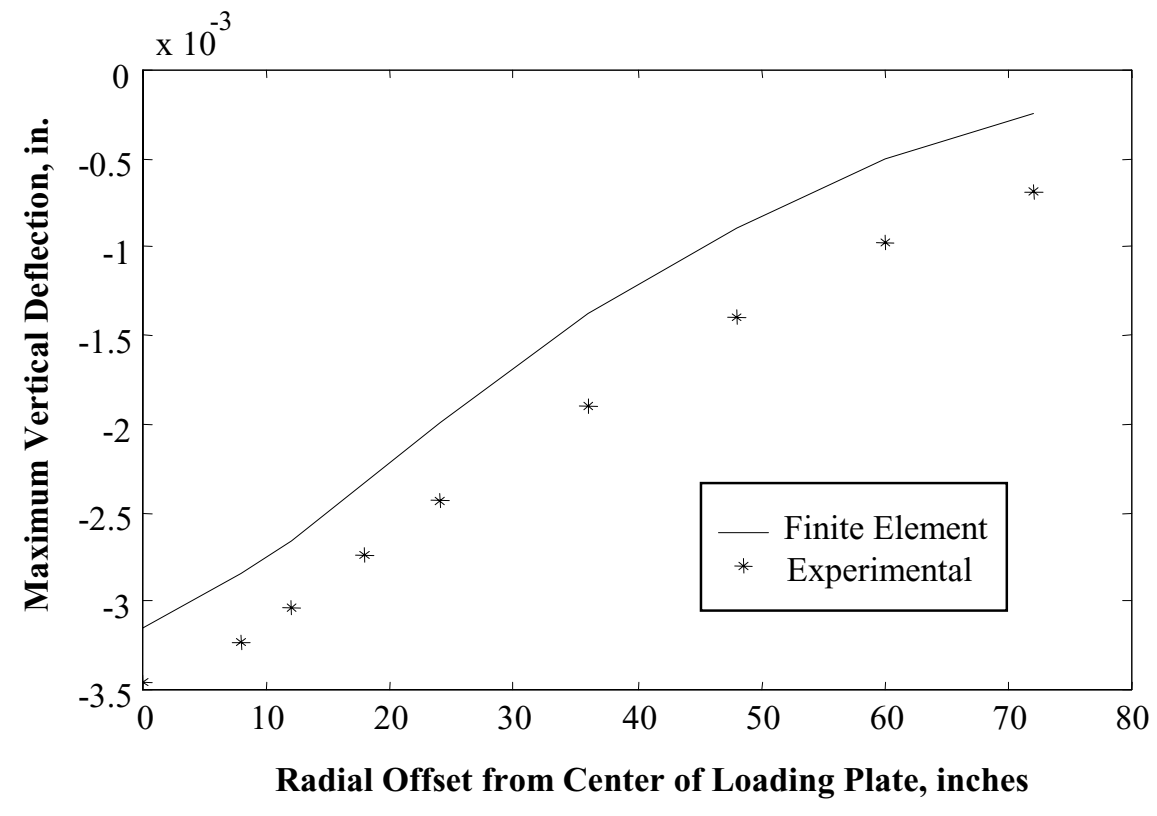

FIGURE 2.17 Comparison Between Experimental and FE Deflection Basins 


\section{CHAPTER THREE}

\section{EFFECT OF SOME MODEL PARAMETERS \\ ON PAVEMENT RESPONSE}

\subsection{Introduction}

This chapter contains preliminary studies to investigate pavement response under the effect of some model parameters these are:

1) Constraining the slab edge at tie bar locations.

2) Using a bonded or unbonded interface between the concrete slab and the base course.

3) Modeling the transverse joint with or without joint opening.

4) Using a symmetry plane to reduce model size and solution time.

5) Changing the mesh size.

\subsection{Effect of Tie Bars}

To select the type of boundary condition applied at the lateral side of the slab adjacent to a tied concrete shoulder or to another slab, a study is conducted to investigate the effect of tie bars on the structural response of the concrete slab. Two sets of boundary conditions are applied along the lateral slab edge parallel to traffic direction as follows: a) unconstrained side, and b) side constrained at the locations of tie bars as shown in Figure 3.1. The first case represents an untied asphalt concrete shoulder while the second case simulates a tied connection with a concrete shoulder or with another slab using tie bars.

Figures 3.2 to 3.5 show the history of four variables: the MPS, $\varepsilon_{\mathrm{x}}$, $\varepsilon_{\mathrm{y}}$, and vertical strain $\varepsilon_{\mathrm{z}}$ at the same four elements of study shown in Figure 2.9. The results show that, constraining the lateral sides of the concrete slab at the tie bars locations has a negligible effect on the stresses and 
strains measured along the wheel-path. The only variation in the results is observed in $\varepsilon_{\mathrm{z}}$ where an average deviation of 7 percent is calculated. This deviation is considered negligible and therefore the free edge boundaries are selected for the lateral edges of the concrete slab.

\subsection{Effect of Concrete-Base Bond}

The purpose of this study is to investigate the effect of concrete/base interface type on concrete pavement response. Only one of two types of interfaces can be assumed at the slab/base interface: a) fully bonded (tied), and b) fully unbonded (sliding with voids and friction). These two conditions represent the two extreme interface conditions that can be found in practice. Guided by the AASHTO Guide for Design of Pavement Structures (1993), the friction coefficient at the slab/base sliding interface is chosen to be 1.5 for the unbonded case representing river gravel base course.

As shown in Figures 3.6 and 3.7, changing the interface type mostly affects the tensile stresses and strains that are induced at the bottom of the concrete slab. That effect is more significant at the transverse joint as shown in Figures 3.6 (c) and 3.7 (c). In case of bonded interface, when the load is located at the edge of the approach slab, and due to the dowel bars constraining effect, the slab top is compressed and the slab bottom is tensioned. However, tying the slabs with the base, forces the two slabs together with the dowel bars to deflect as one unit. Therefore, when the approach slab is loaded, it will tend to move downward, but will be constrained by both the dowel bars and the leave slab/base course assembly. This constrainment adds up an additional tensile stress and strain at the slab bottom which increases when the first axle is located on the approach slab and the second axle loads the leave slab edge. In this case, the approach slab will tend to move upward which would develop an additional tensile stress to that induced by the first axle already located at the approach slab edge. This explains the increase observed in the second peak of both stress and strain profiles at the joint, Figure 3.6 (c) and 3.7 (c). The difference between the two interfaces is higher in $\varepsilon_{\mathrm{x}}$ because the dowel bar's constraining effect is more effective in the longitudinal direction, Figure 3.7 (c and d). On the other hand, at the middle of 
the slab, bonding the concrete slab with the base reduces the tensile stress induced at the slab bottom. Bonding the two layers at the middle of the slab increases the stiffness of the concrete slab and therefore reduces the tensile stresses and strains induced, Figure 3.6 ( $a$ and $b$ ) and 3.7 (a and b). These results agree with the findings reported (Shoukry, et al., 1997) for composite pavements.

\subsection{Effect of Joint Opening}

The model response to moving tandem axle is compared for two cases: no joint opening and aggregate interlock simulated by sliding interface with a coefficient of friction of 1.5 and joint opening of $19 \mathrm{~mm}$ (3/4 in.). The two models have the same boundary conditions and same mesh. The history of the MPS, $\varepsilon_{\mathrm{x}}, \varepsilon_{\mathrm{y}}$, and vertical displacement is plotted for the same elements illustrated in Figure 2.9. Comparison of the plots presented in Figures 3.8 to 3.11 reveals the following:

1) In general, the effect of joint opening appears only at the joint but does not have any effect at the middle of the slab, Figures 3.8 and 3.9.

2) Aggregate interlock (no joint opening) eliminates the stress and strain reversals observed in both MPS and $\varepsilon_{\mathrm{x}}$ at the concrete slab top when the first axle is located at the approach slab edge, Figures 3.8 (c) and 3.9 (c).

3) Aggregate interlock reduces the tensile stress at the bottom of the slab along the joint but only by 15 percent, Figure 3.8 ( $\mathrm{c}$ and d).

4) Aggregate interlock increases $\varepsilon_{x}$ induced at the bottom of the slab along the transverse joint, Figures 3.9 (d). When the joint is doweled without opening, the load is transferred from one slab to the other by both dowel bars and aggregate interlock. In this case, when the load approaches the joint, the bottom of the slab at the joint is constrained by both dowel bars and aggregate interlock. This constrainment prohibits the slab from moving upward and subjects its bottom to compressive strain, Figure 3.9 (d). During joint loading, the joint is subjected to tensile strain, which appears in the form of two 
oscillations in Figure 3.9 (d). The presence of joint opening (absence of aggregate interlock) reduces both compressive and tensile strain observed at the slab bottom by 500 and 22 percent respectively, Figure 3.9 (c).

5) The joint with opening increases the peak transverse strain $\left(\varepsilon_{y}\right)$ induced at the joint by 20 percent when compared to the joint without opening, as shown in Figure 3.10 (c and d).

6) Examination of the vertical displacement at the joint shows an increase in the positive (upward) displacement as the load approaches the joint, Figure 3.11 (c and d). Which means that the slab is separating from the base course and a gap is developed beneath the joint. The presence of dowel bars and joint opening reduced the positive displacement. The percentage of increase in the maximum positive displacement of the joint with opening when compared to that without opening is 40 percent. A doweled joint without opening is more effective in reducing the gap at the slab/base interface and therefore reduces the possibilities of water entrapped underneath the joint, which may lead to the loss of support. On the other hand, joint opening has a negligible effect on the vertical displacement induced at the middle of the slab, Figure 3.11 ( $a$ and b). A visual illustration of the deformation pattern along the centerline of the inner wheel path is provided in Figure 3.12 for different loading positions at a magnification of 3000 . The figure illustrates that the passage of the load over the transverse joint subjects the slab to double bending, which under repetitive traffic loading conditions might initiate cracks around the joint.

\subsection{Effect of Symmetry Plane}

To investigate the effect of symmetry plane on the structural response of concrete slab, the width

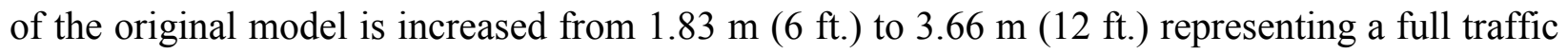
lane width without a symmetry plane. The modified model is compared to the original model. The two models are loaded with the moving tandem axle. Figures 3.13 to 3.16 show the comparison between the two models at the elements shown in Figure 2.9. To illustrate how the transverse distance between the point of study and the symmetry plane affects the results, two 
additional points of study, $\mathrm{C}$ and $\mathrm{F}$ are selected. These two points are located at $0.69 \mathrm{~m}(27.16$ in.) from the first transverse joint along the outer wheel path and the symmetry plane respectively. The results obtained at points $\mathrm{C}$ and $\mathrm{F}$ are shown in Figures 3.17 to 3.20.

In general, negligible differences are observed between the results of the two models. The closer the point of study from the symmetry plane the higher the deviation, as shown in Figures 3.17 to 3.20. All the deviations are within 10 to 15 percent, except for the point located along the symmetry plane where the deviation is greater, especially for the transverse strain. However, considering the 100 percent reduction in program running time (CPU time) and computer memory, the results will be to a great extent effective and economic.

\subsection{Effect of Element Mesh Size}

To study the effect of FE mesh size on the response of the rigid pavement, four models with different mesh sizes are compared as shown in Figure 3.21. Three of those models are developed using a symmetry plane simulating one half of traffic lane, whereas the fourth is a full model representing a full traffic lane. All models are loaded with the moving tandem axle. Figure 3.22 shows the comparison between the four models at points $\mathrm{C}$ and $\mathrm{E}$ located along the outer wheel path at 0.69 and $2.13 \mathrm{~m}$ (27.16 and 83.9 in.) from the first transverse joint. Figure 3.22 also includes a table showing the number of elements and nodes for each FEM. The longitudinal strain history captured at points $\mathrm{C}$ and $\mathrm{E}$ shows a perfect matching for the four models as shown in Figure 3.22. Some deviations are observed in the history obtained from the full model due to the effect of the symmetry plane as was discussed in section 3.5. The matching level in the strain histories shown in Figure 3.22 shows the convergence of the four meshes and that doubling the mesh size did not affect the accuracy of the results. 


\subsection{Conclusions}

The study performed in this chapter showed the following:

1) Constraining the lateral sides of the slab at tie bars locations does not have any effect on slab response along the wheel-path, therefore, unconstrained boundaries are selected to be applied at the slab lateral sides.

2) Results from the FEM shows that, applying an unbonded interface at the slab/base course interface significantly reduces the tensile stresses and strains developed at the slab bottom along the transverse joint. Because most of rigid pavement distresses are mainly due to joint problems, applying an unbonded interface with friction at the slab/base interface may reduce the extent of stresses and strains induced at the joint and accordingly can diminish rigid pavement distresses caused by joint problems.

3) The FEM results obtained along the wheel-path shows that a transverse joint where the load is transferred by both dowel bars and aggregate interlock eliminates the sharp MPS reversals observed at slab top along the joint. It also reduces the tensile MPS induced at slab bottom. In addition, the same joint layout reduces the separation developed at the slab/base interface and therefore reduces the potential of pumping or loss of support, which may occur due to entrapped water. For these reasons the doweled joint without opening was selected for the study.

4) Using a symmetry plane boundary condition along the traffic direction has a minor effect on the structural response of the rigid pavement and results in great savings in model size, computer memory, and CPU time. Hence, symmetry plane boundary conditions are applied and only one half of a traffic lane is modeled.

5) The comparison between several FE models with different mesh refinement shows that the change in FE mesh size within the studied meshes did not affect the accuracy of the results obtained from FE modeling. 


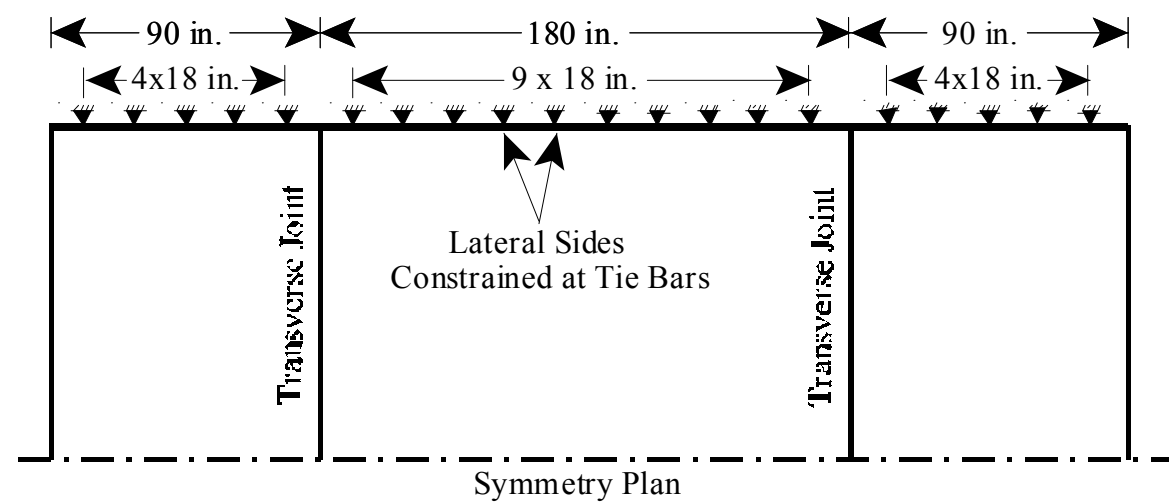

(a) Finite Element Model with Lateral Sides Constrained at Tie Bars Locations

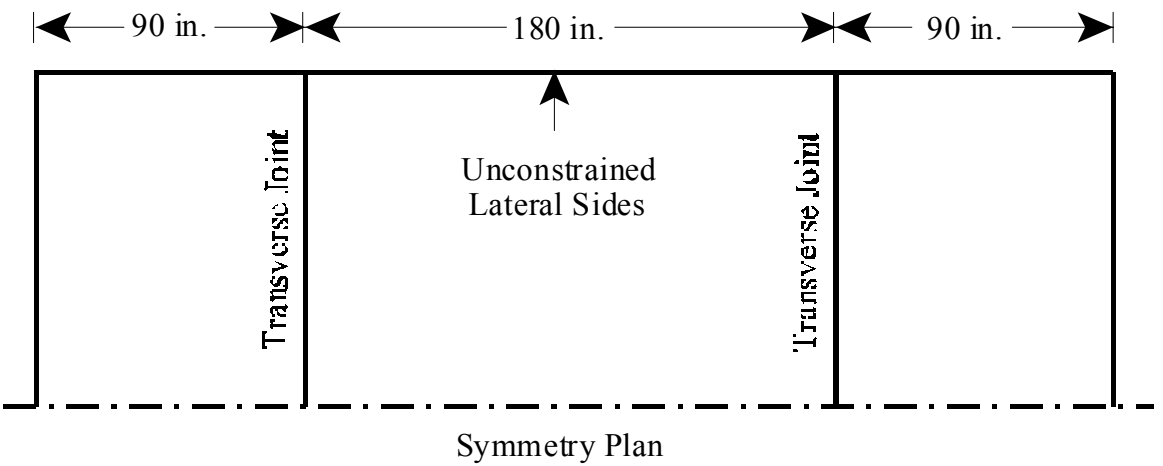

(b) Finite Element Model with Unconstrained Lateral Sides

FIGURE 3.1 Plane View of the Two Models Developed for Investigating the Effect of Tie Bars 


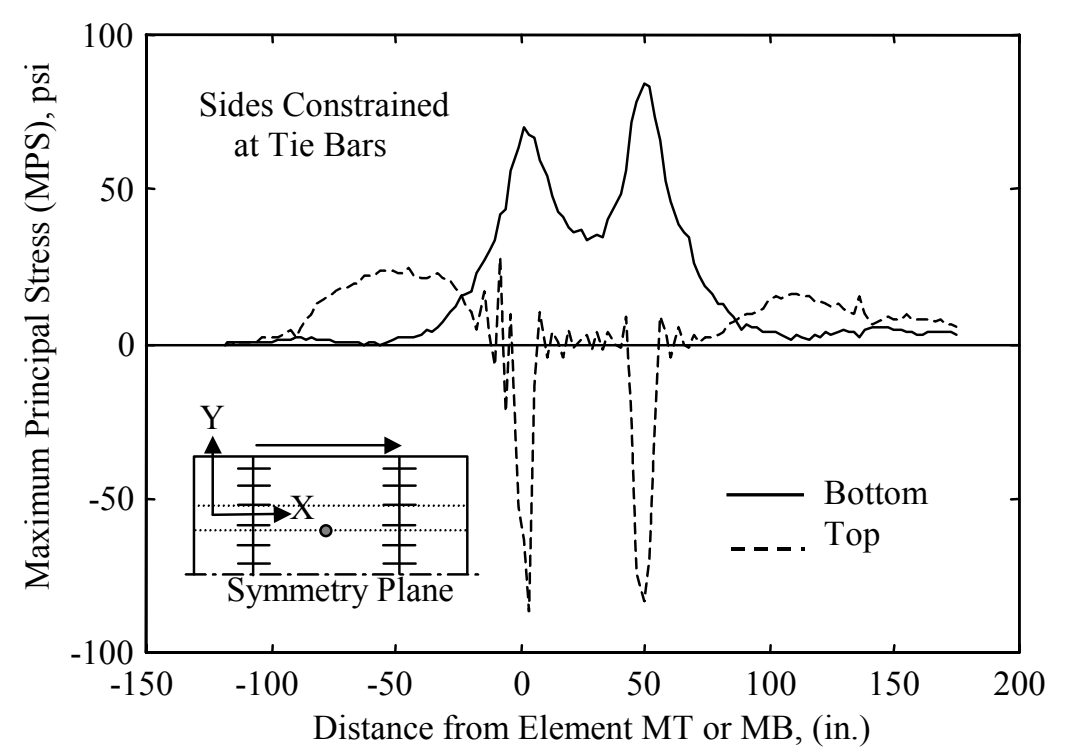

(a)

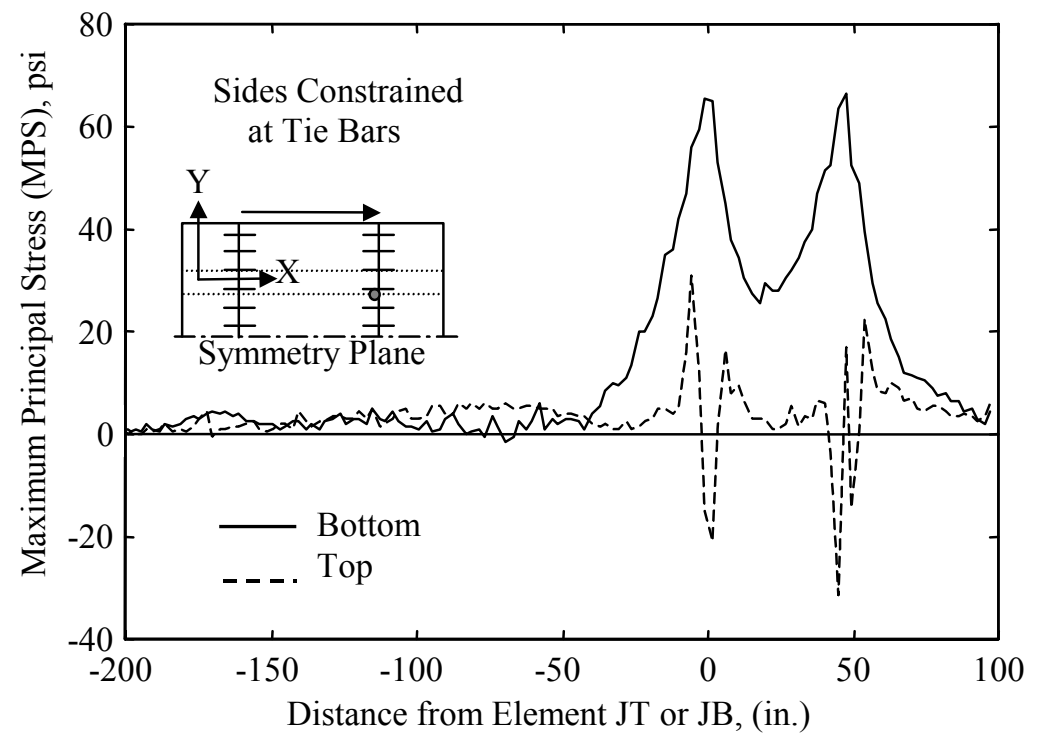

(c)

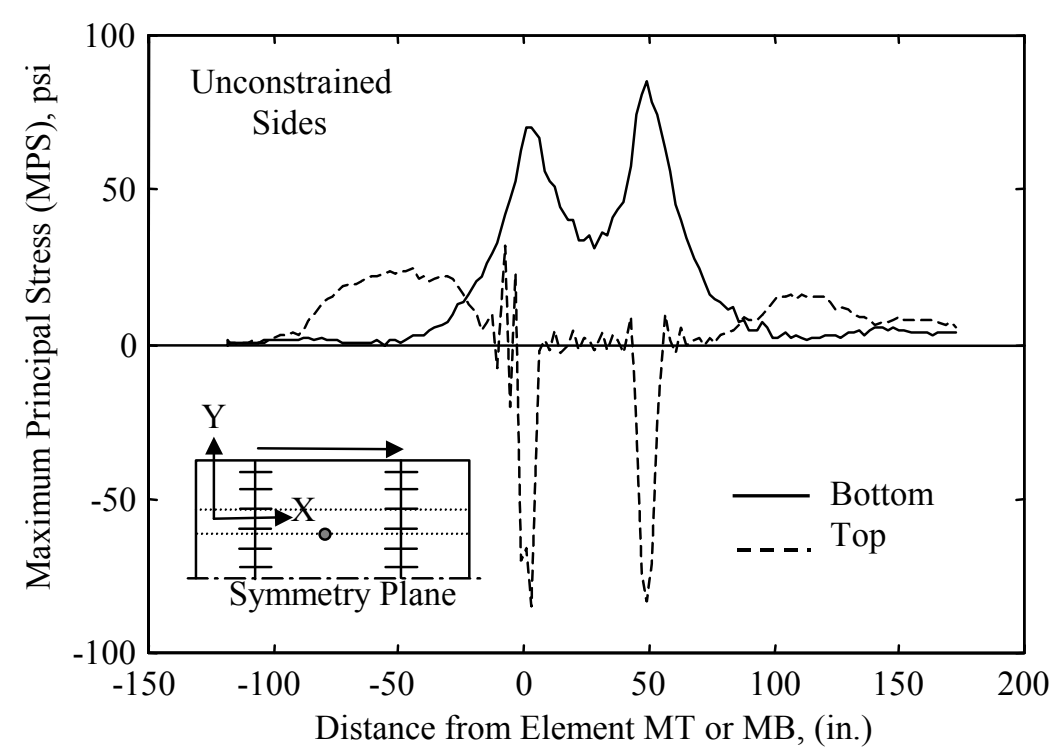

(b)

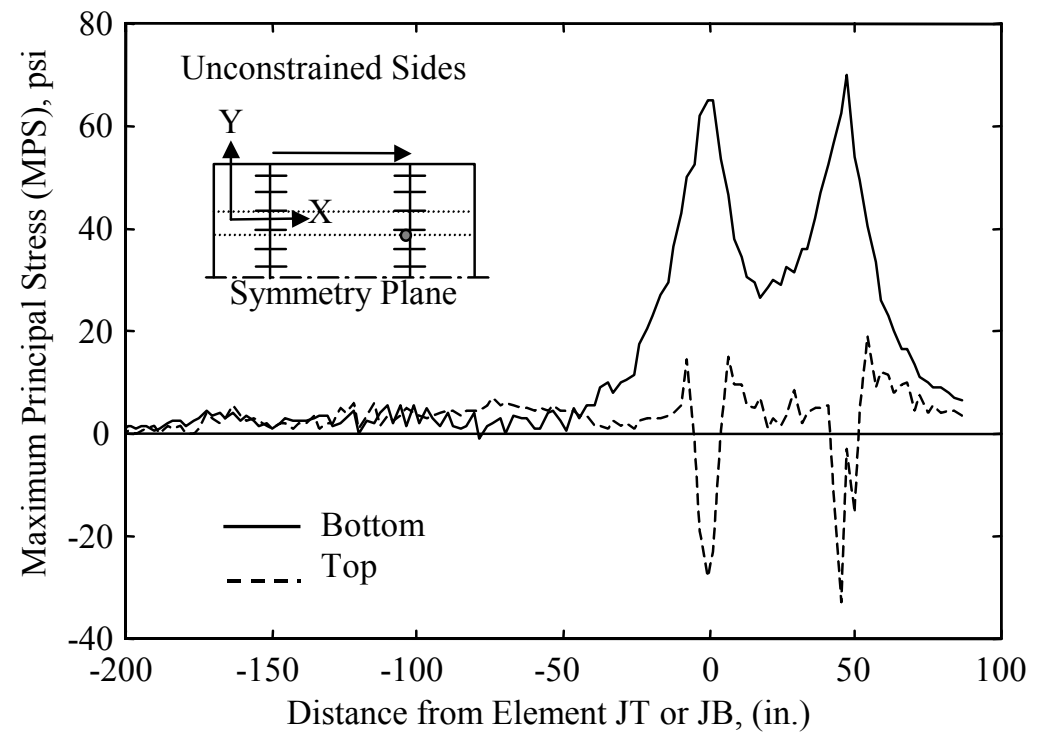

(d)

FIGURE 3.2 Effect of Tie Bars on Distribution of Maximum Principal Stress in the Concrete Slab 

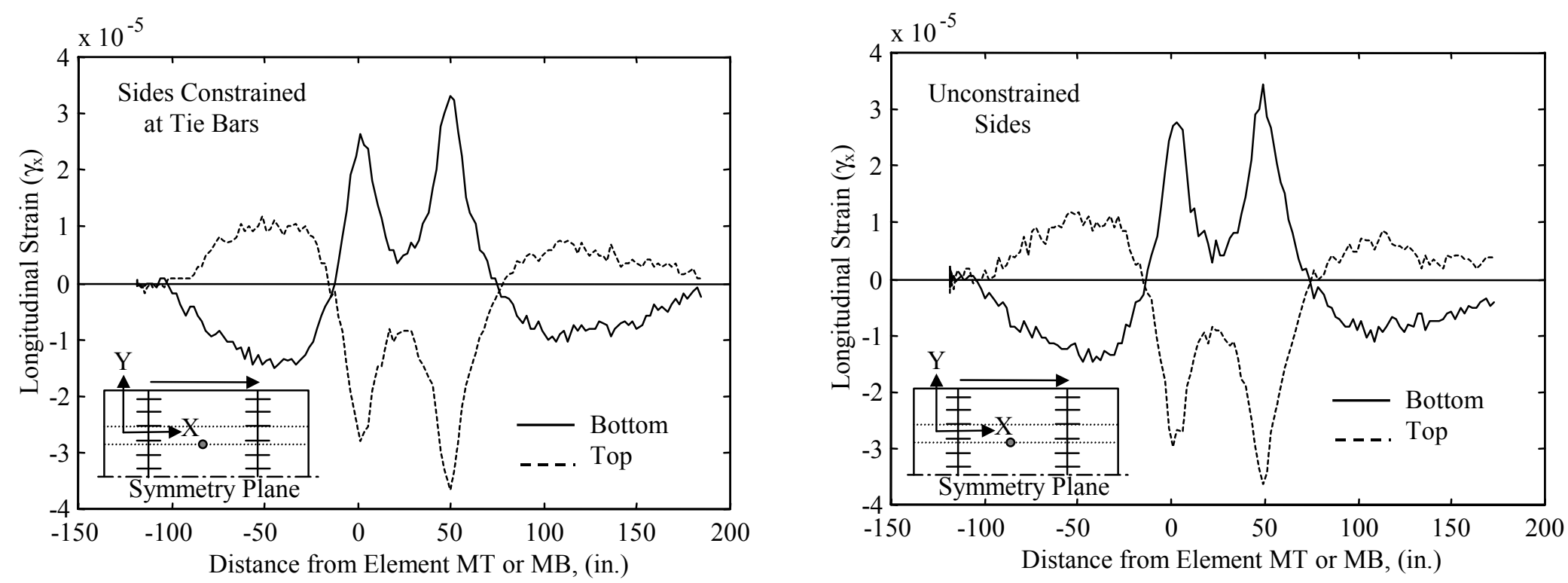

(a)
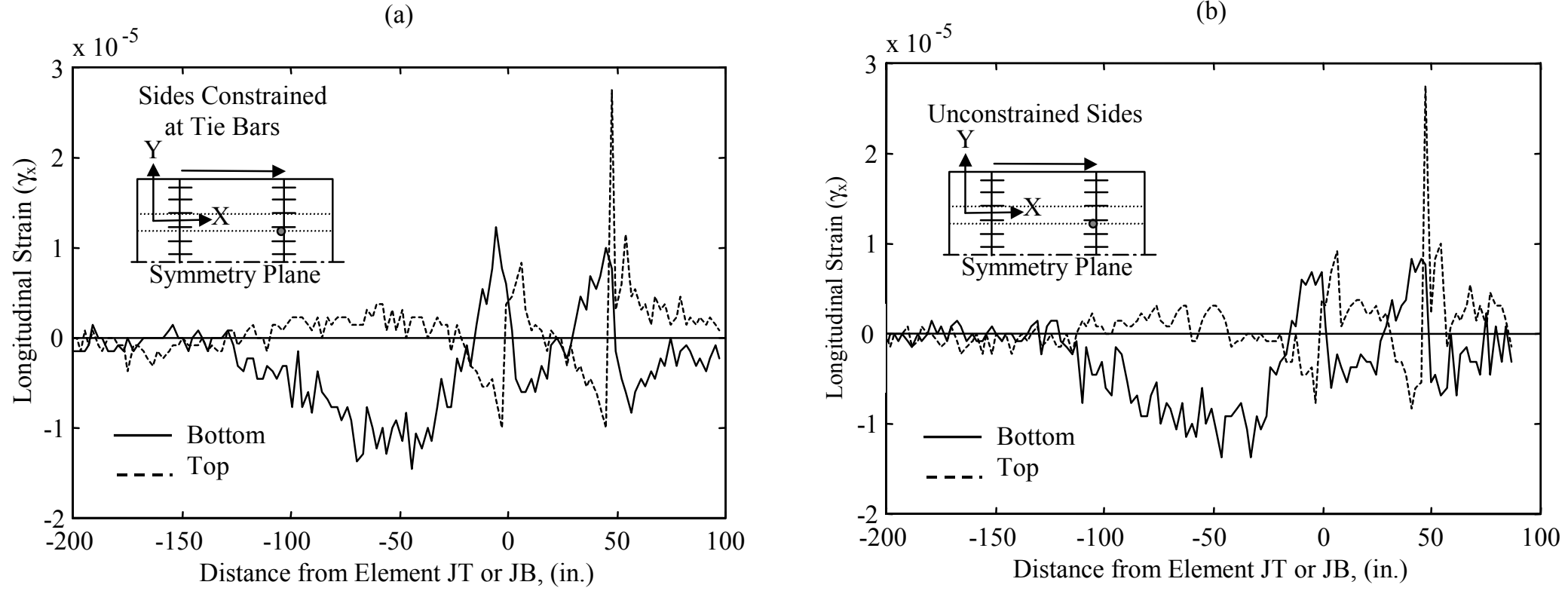

(c)

(d)

FIGURE 3.3 Effect of Tie Bars on Distribution of Longitudinal Strain in the Concrete Slab 

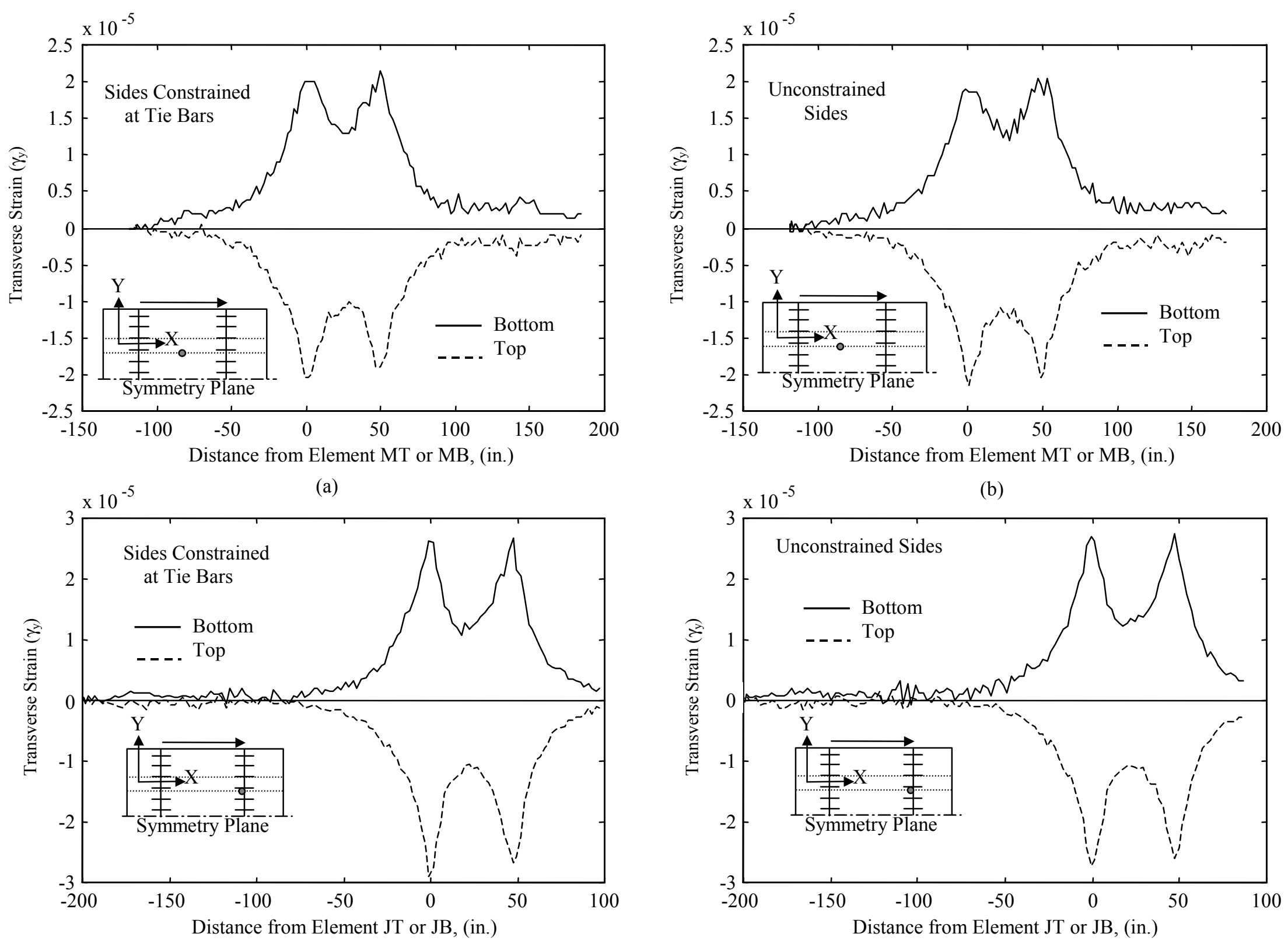

(c)

(d)

FIGURE 3.4 Effect of Tie Bars on Distribution of Transverse Strain in the Concrete Slab 


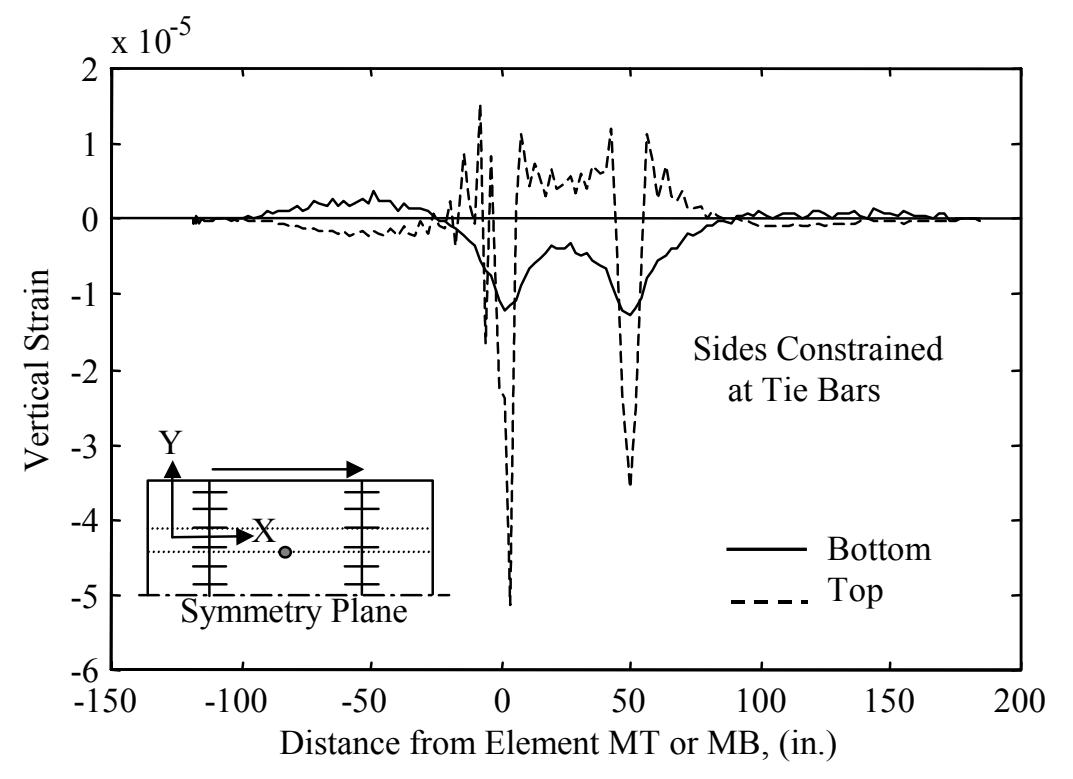

(a)

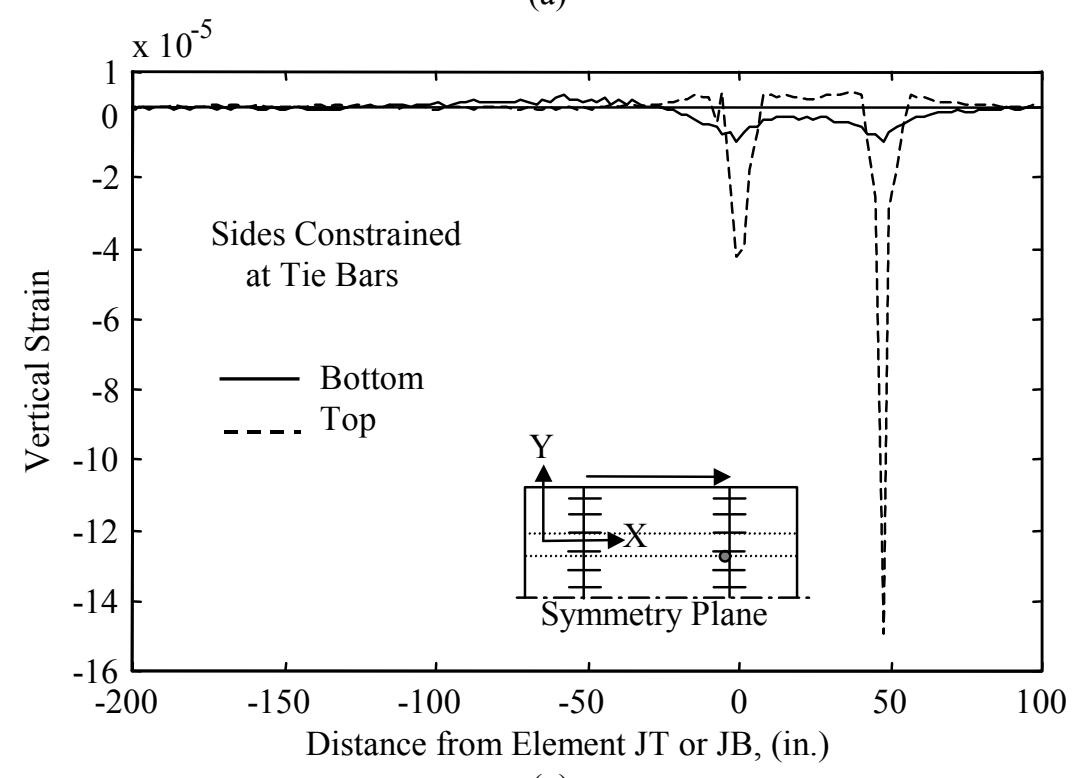

(c)

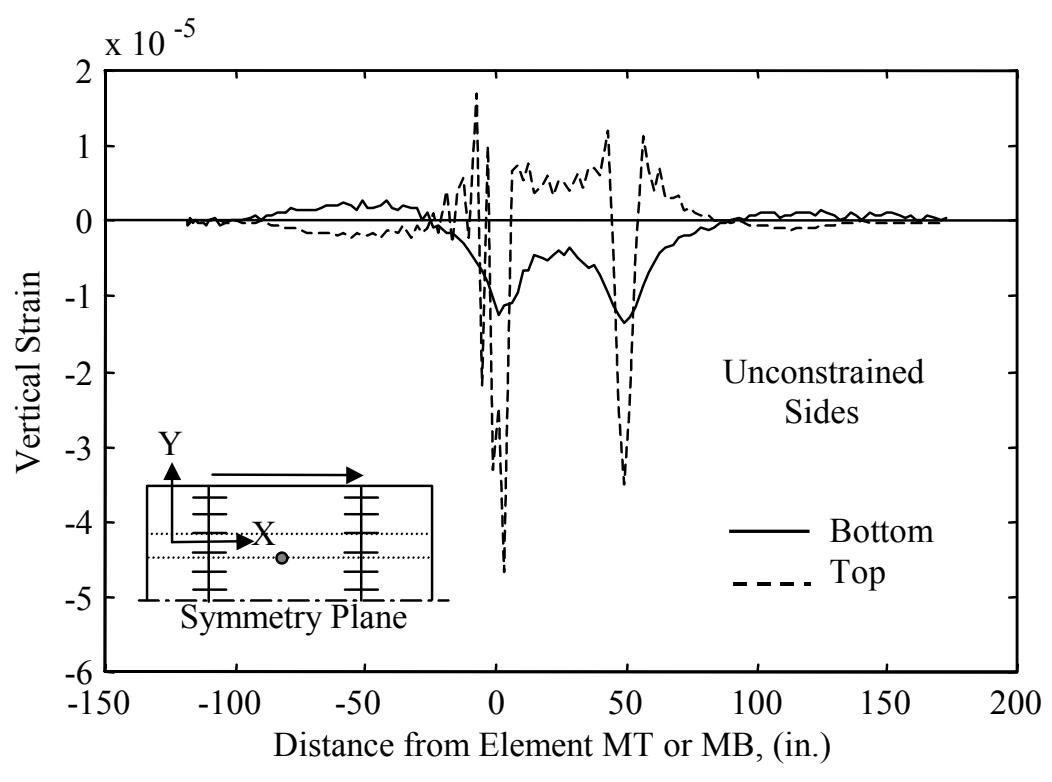

(b)

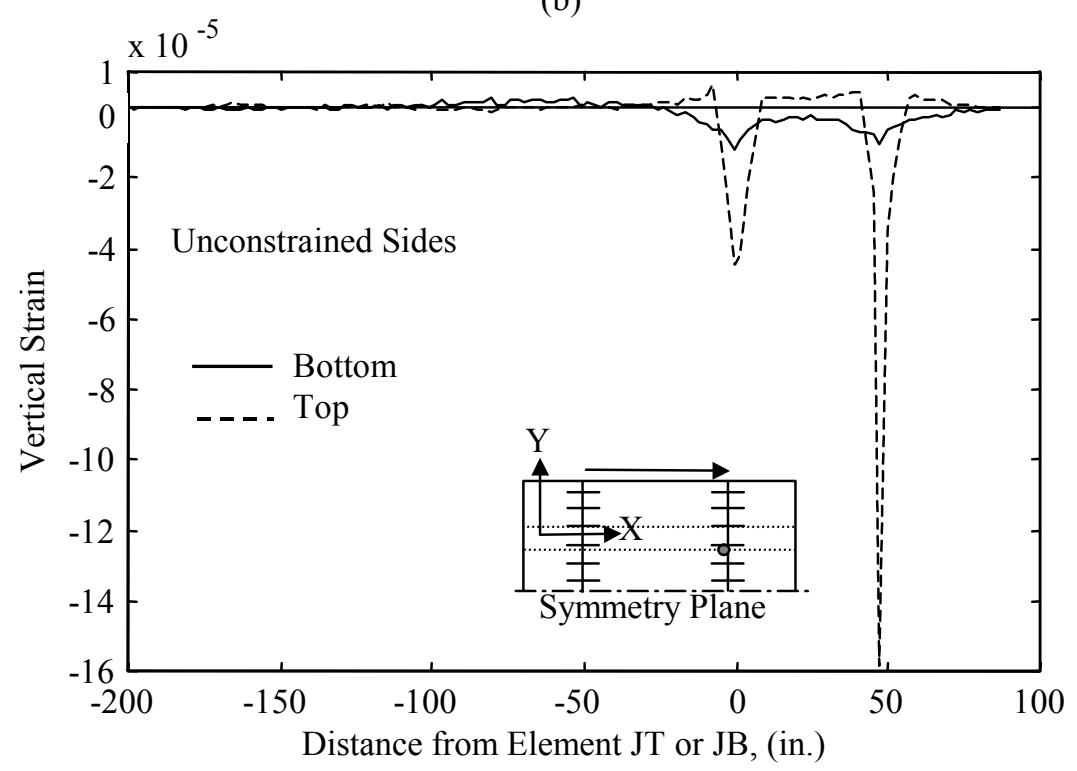

(d)

FIGURE 3.5 Effect of Tie Bars on Distribution of Vertical Strain in the Concrete Slab 


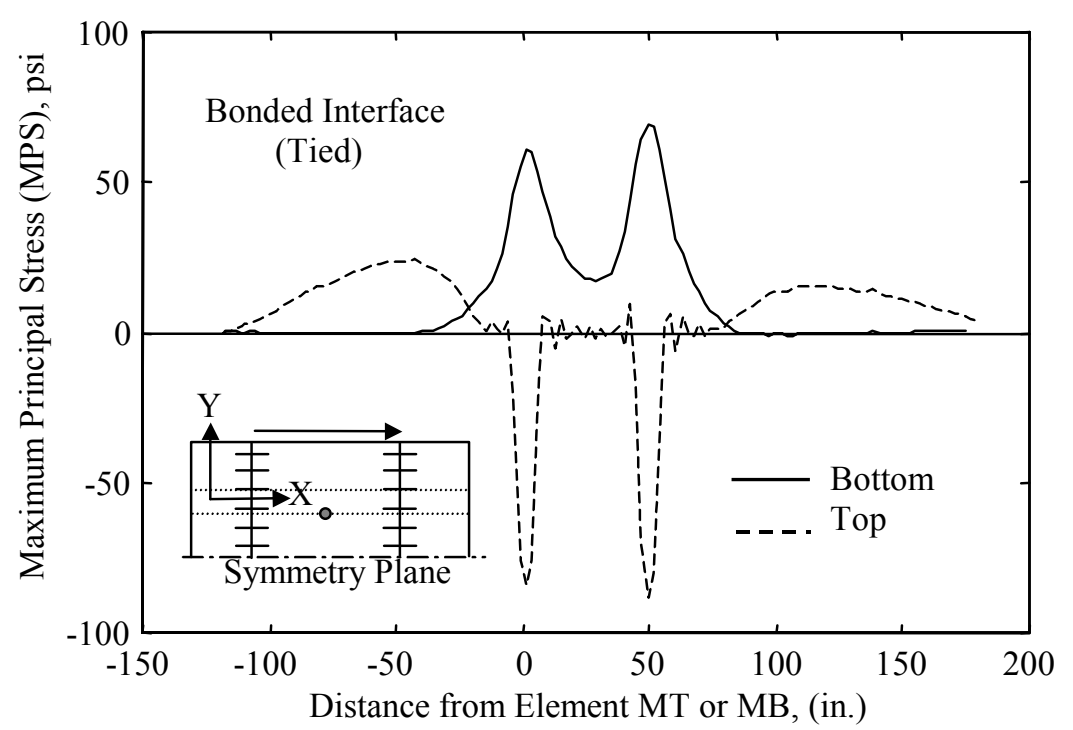

(a)

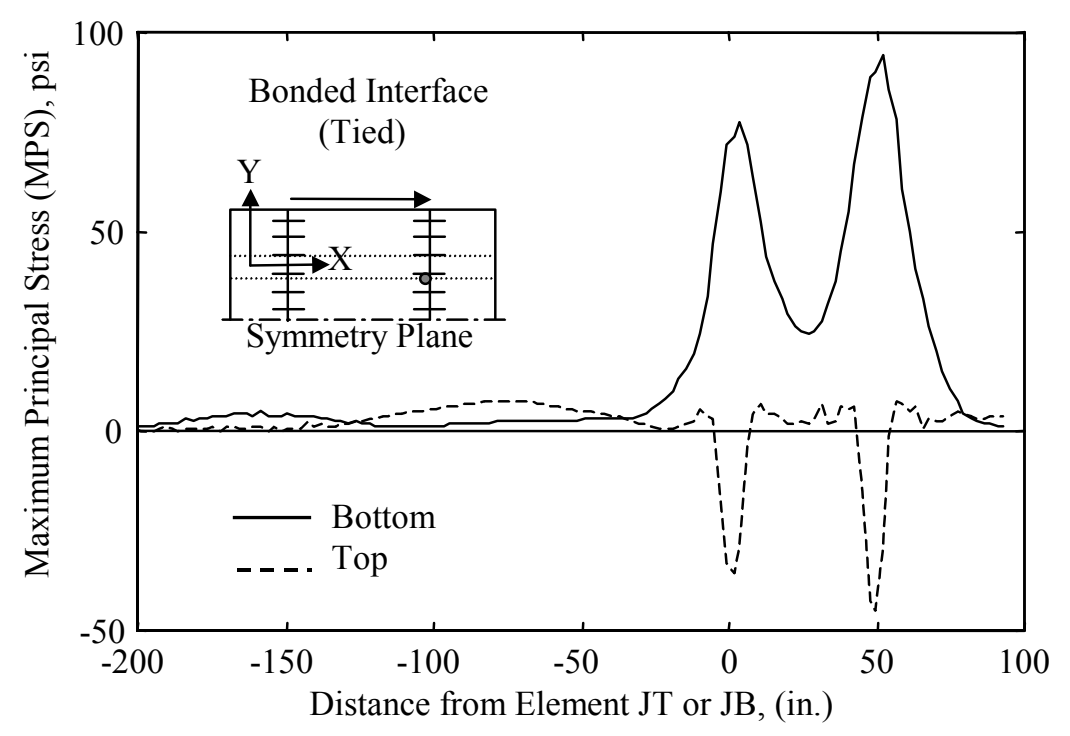

(c)

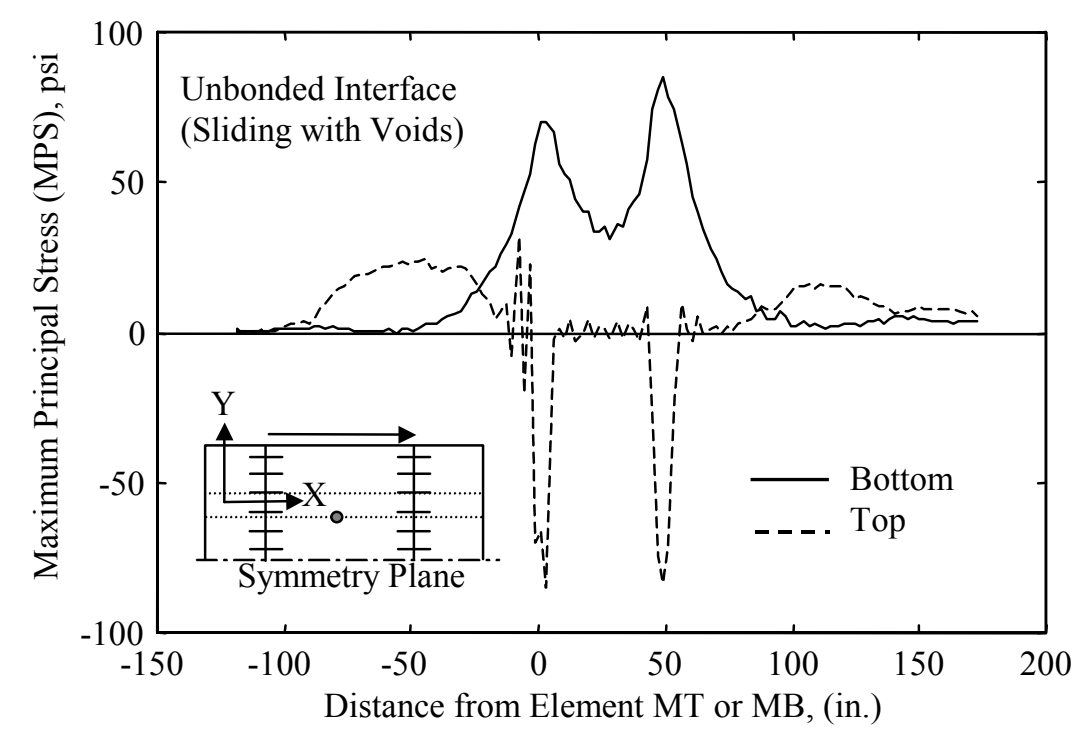

(b)

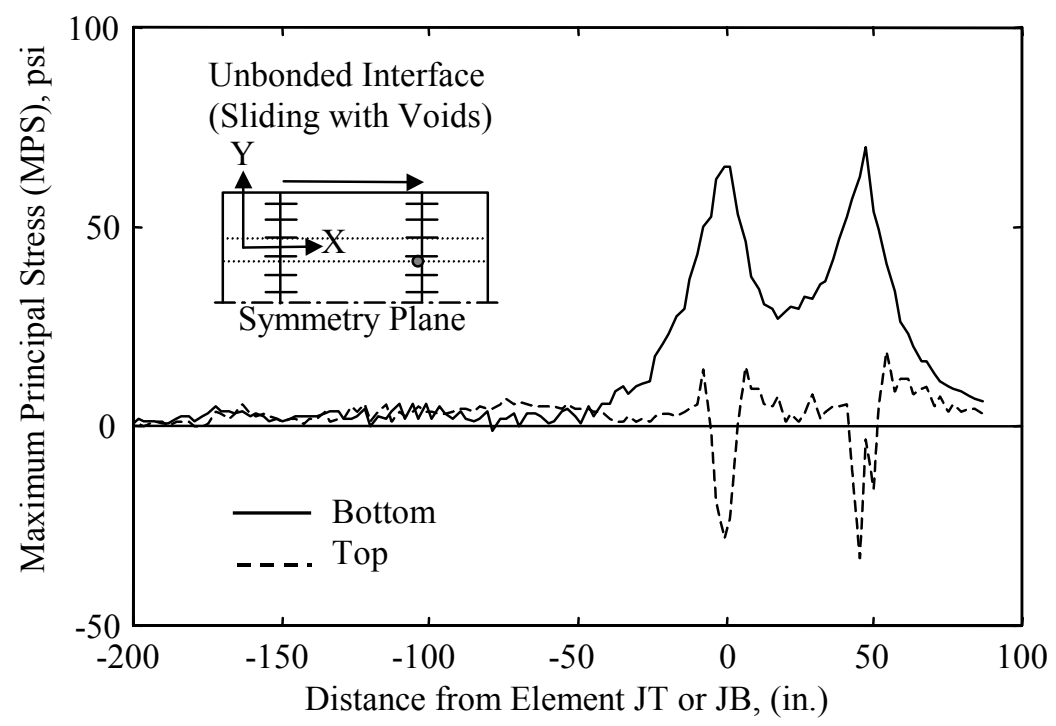

(d)

FIGURE 3.6 Effect of Concrete-Base Bond on Distribution of Maximum Principal Stress in the Concrete Slab 


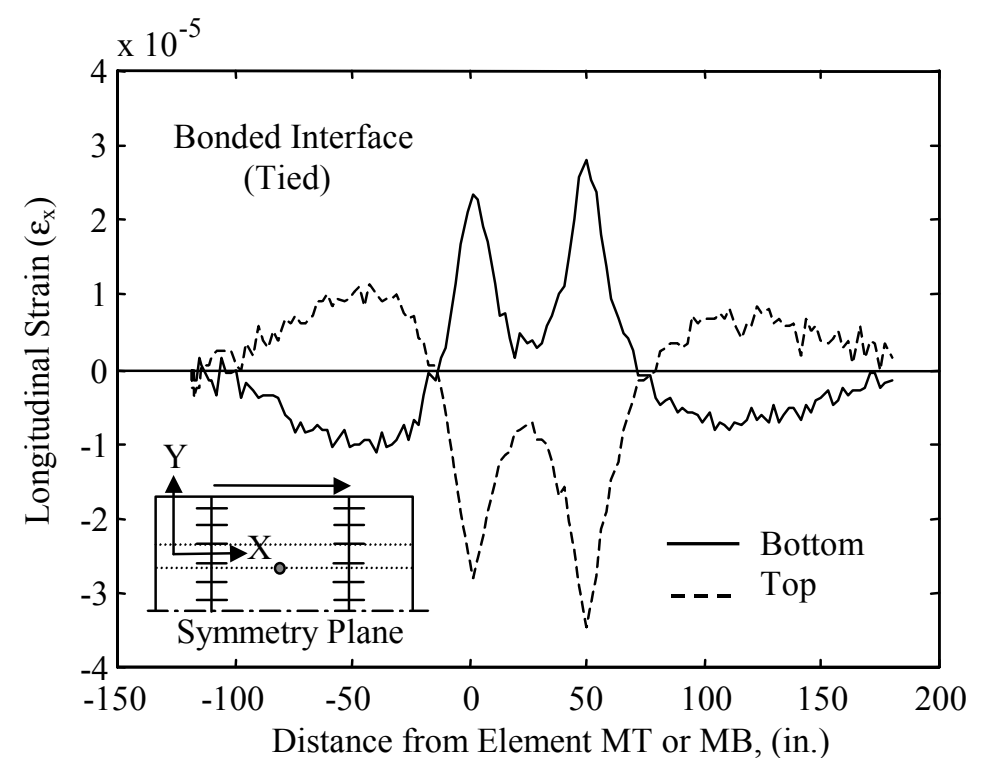

(a)

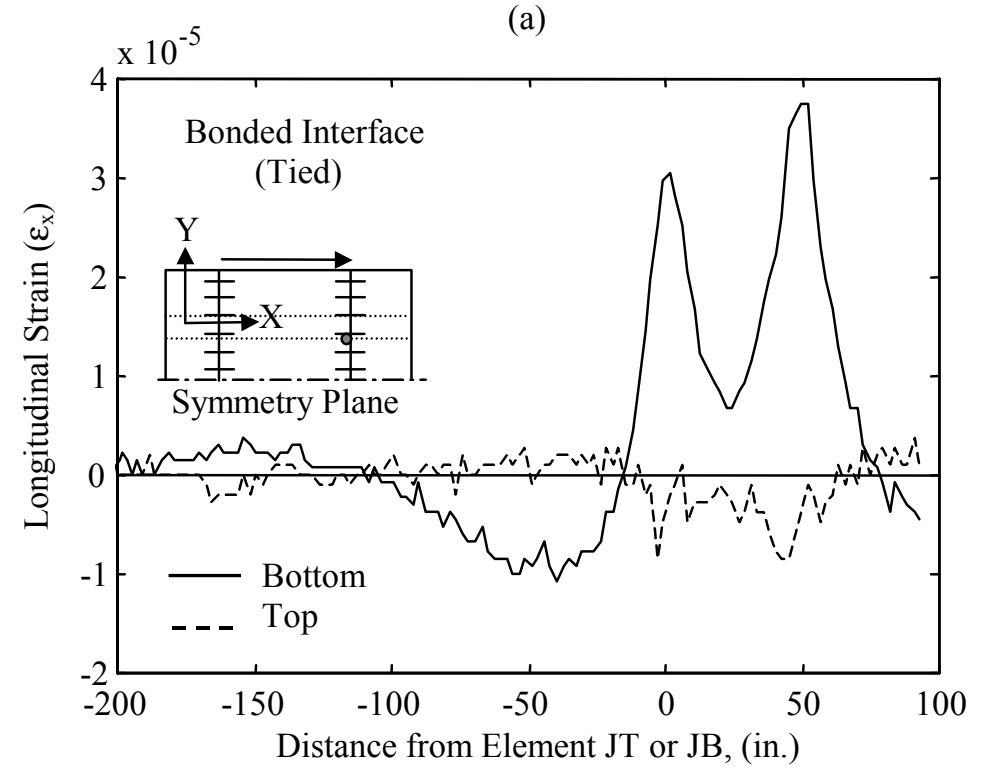

(c)

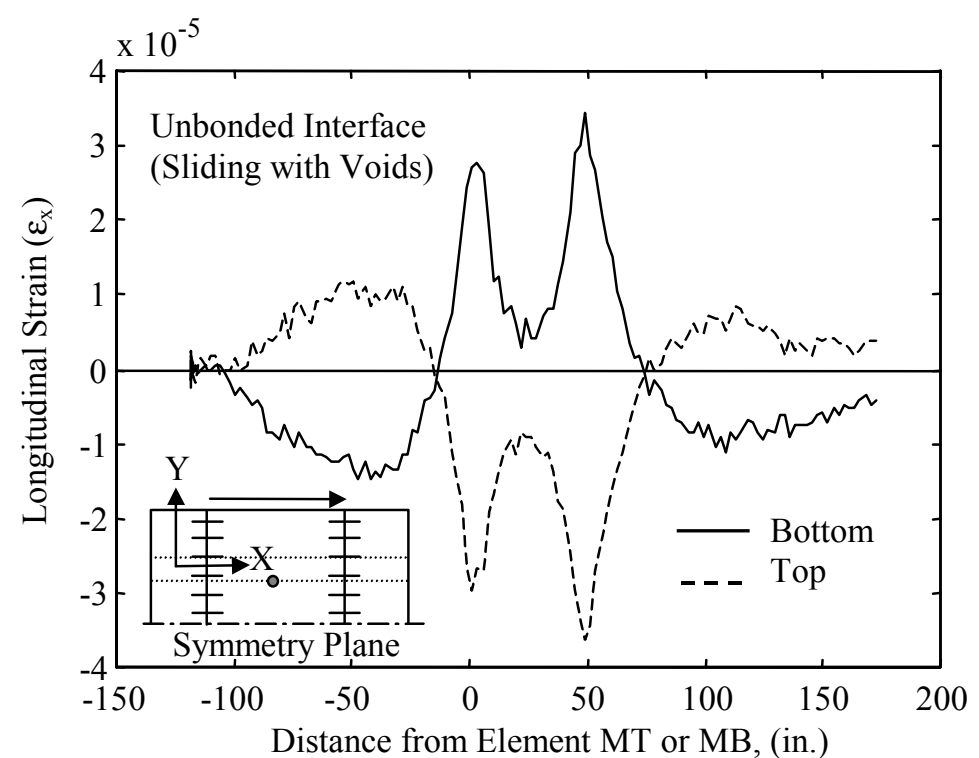

(b)

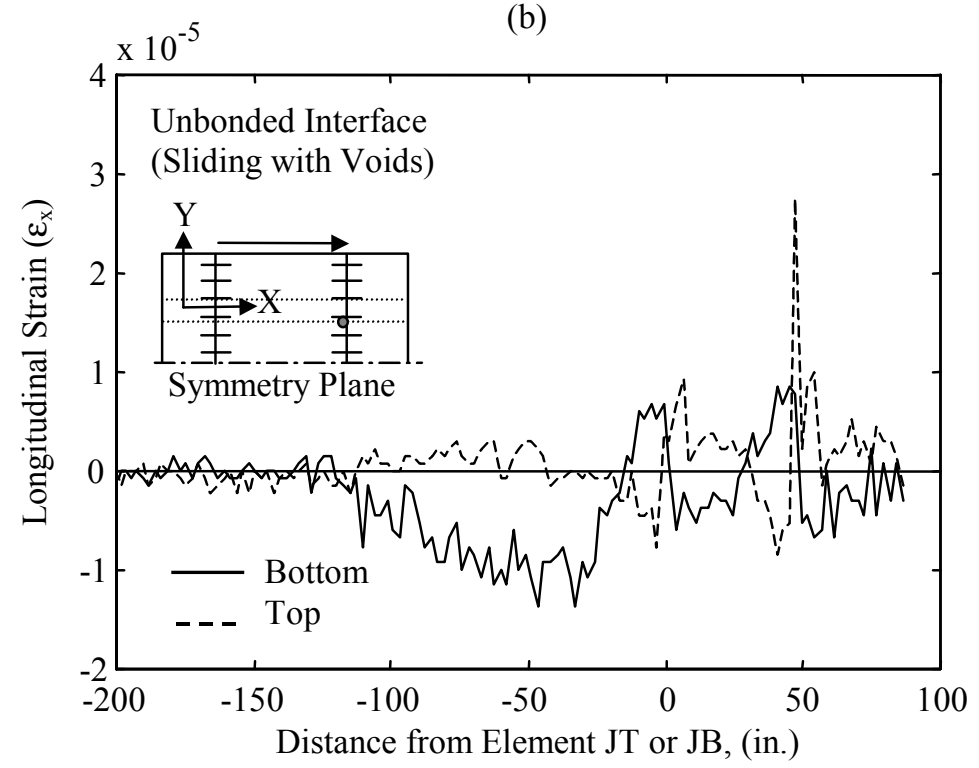

(d)

FIGURE 3.7 Effect of Concrete-Base Bond on Distribution of Longitudinal Strain in the Concrete Slab 


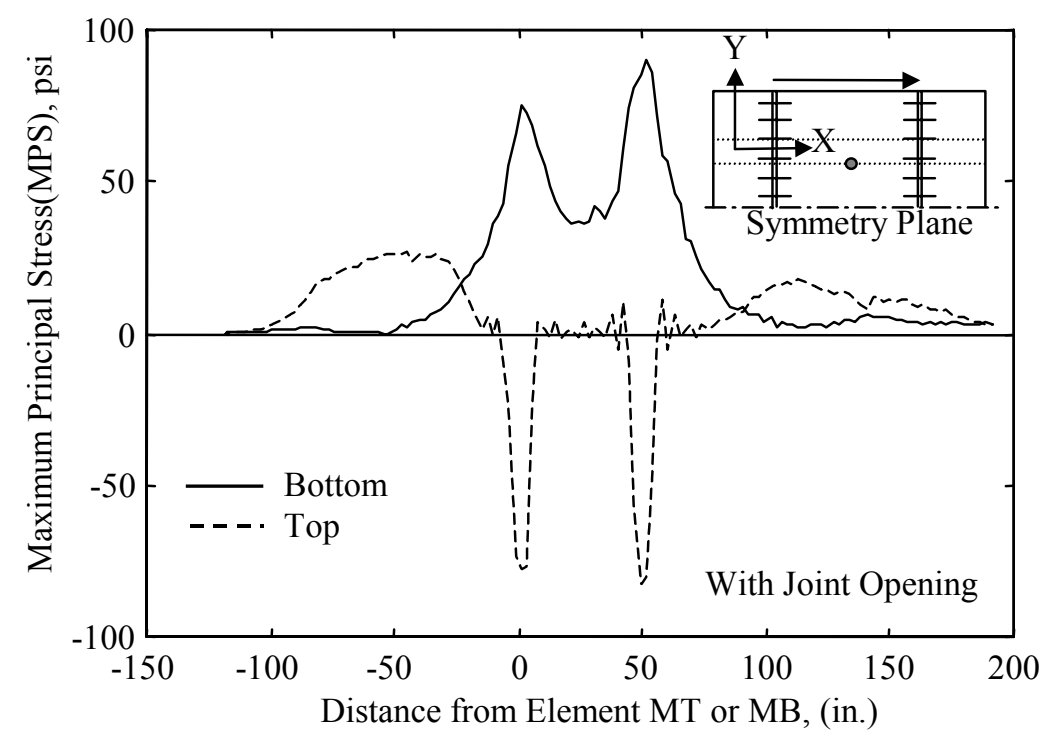

(a)

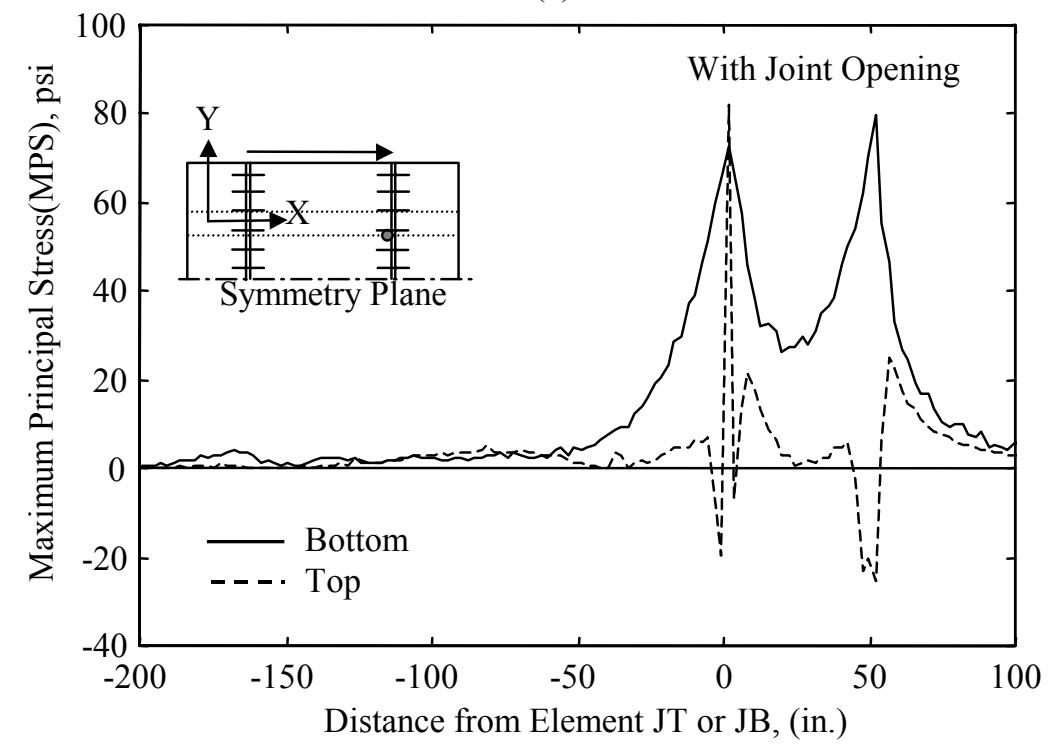

(c)

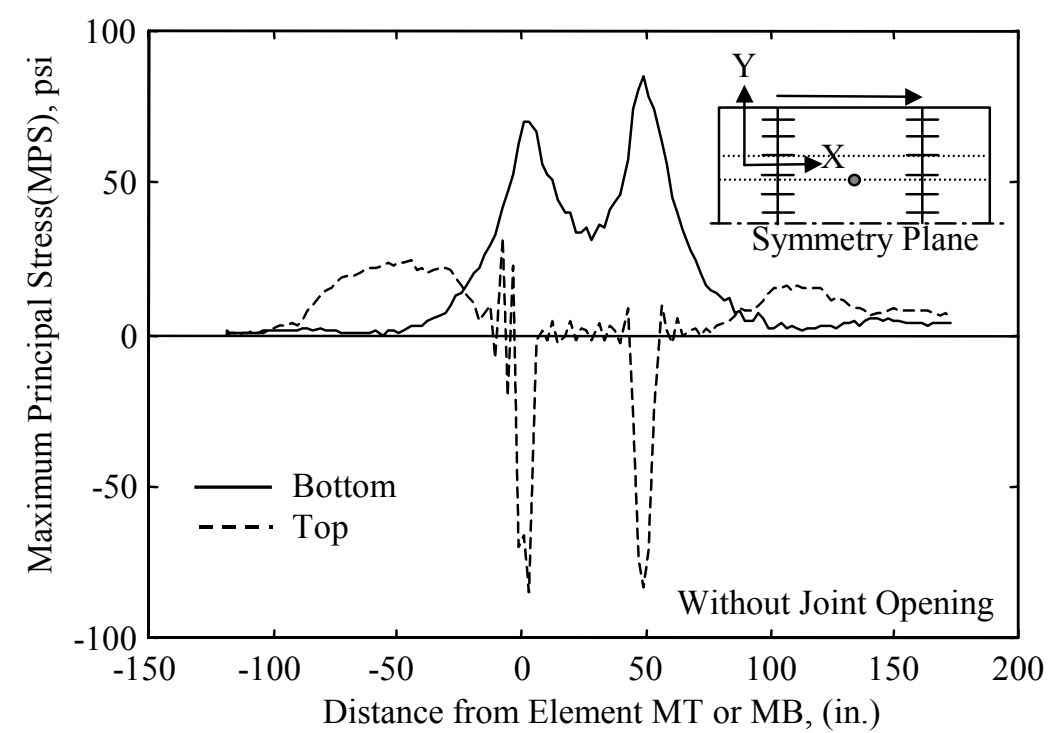

(b)

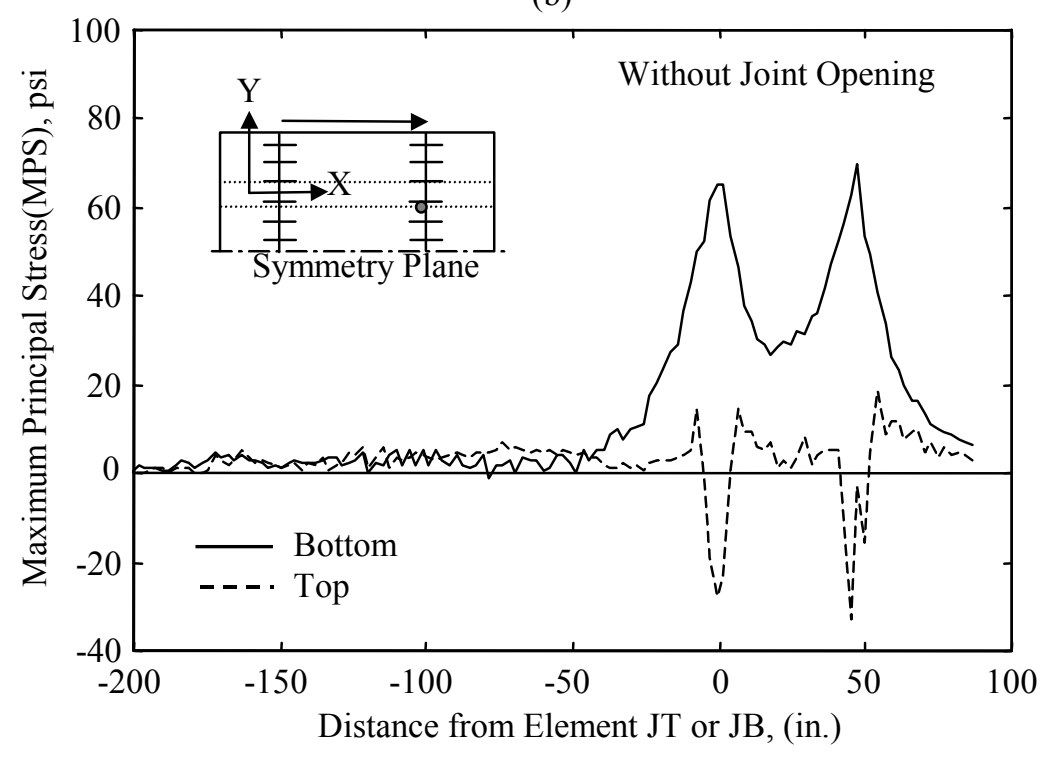

(d)

FIGURE 3.8 Effect of Joint Opening on Distribution of Maximum Principal Stress in the Concrete Slab 

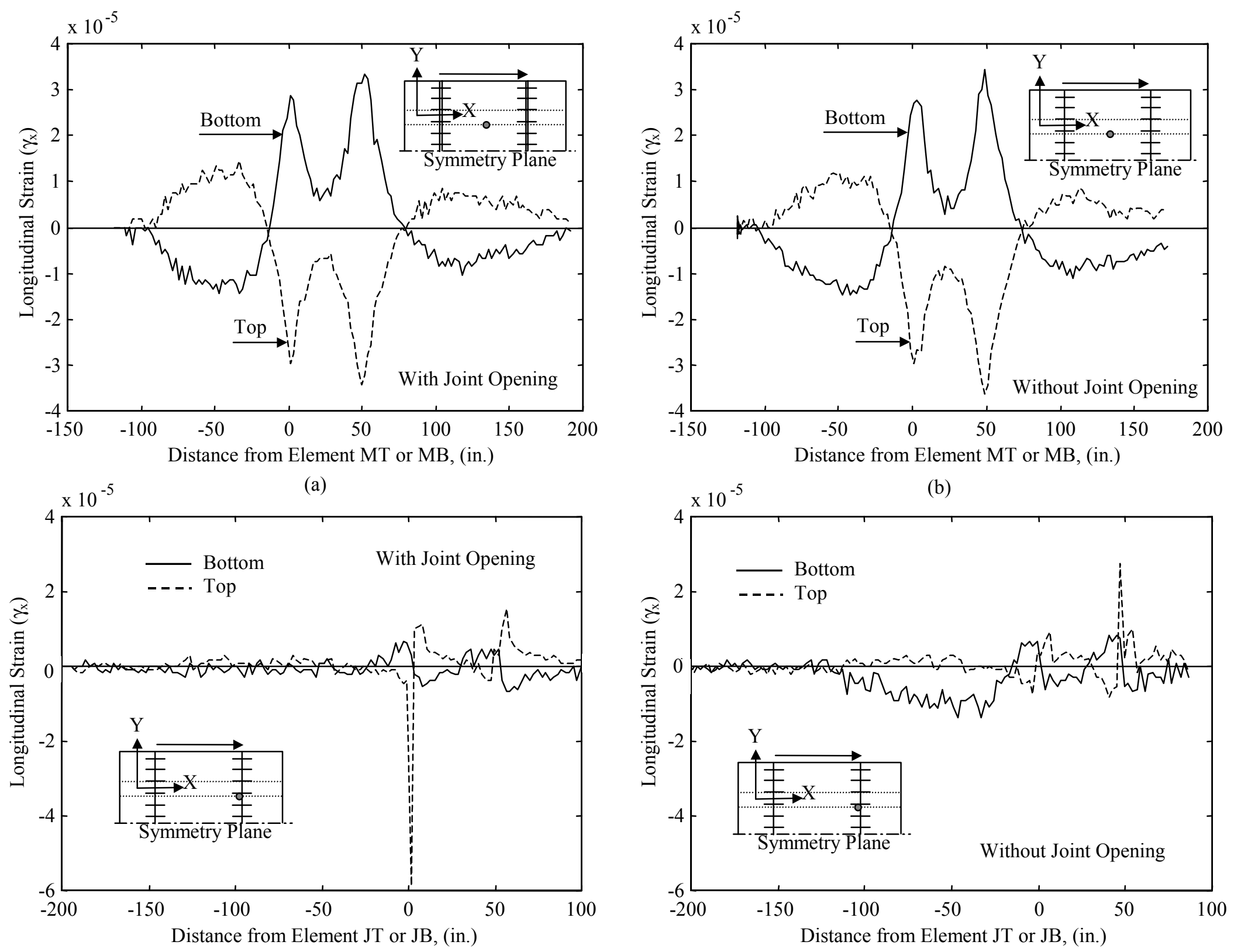

(c)

(d)

FIGURE 3.9 Effect of Joint Opening on Distribution of Longitudinal Strain in the Concrete Slab 

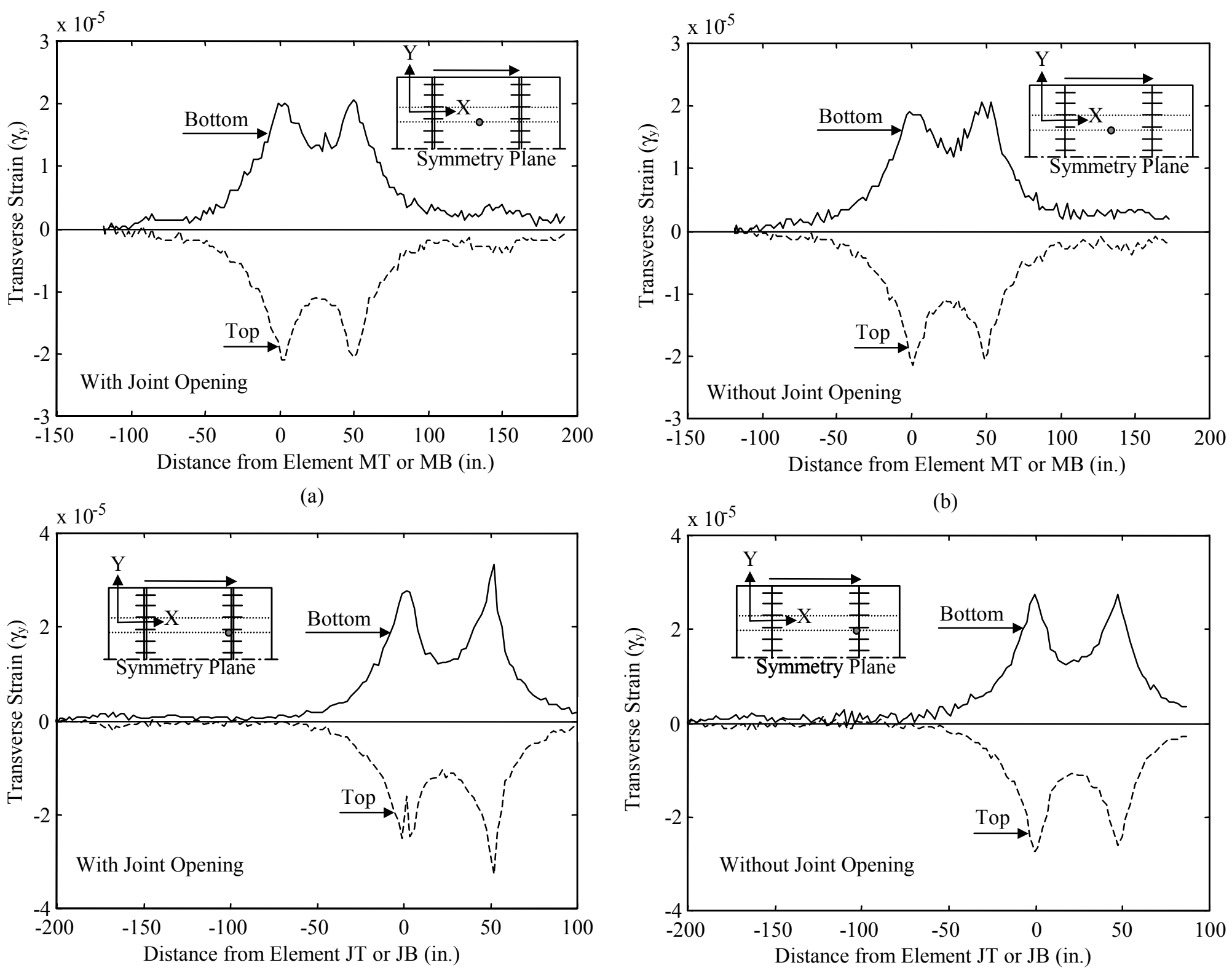

(c)

(d)

FIGURE 3.10 Effect of Joint Opening on Distribution of Transverse Strain in the Concrete Slab 

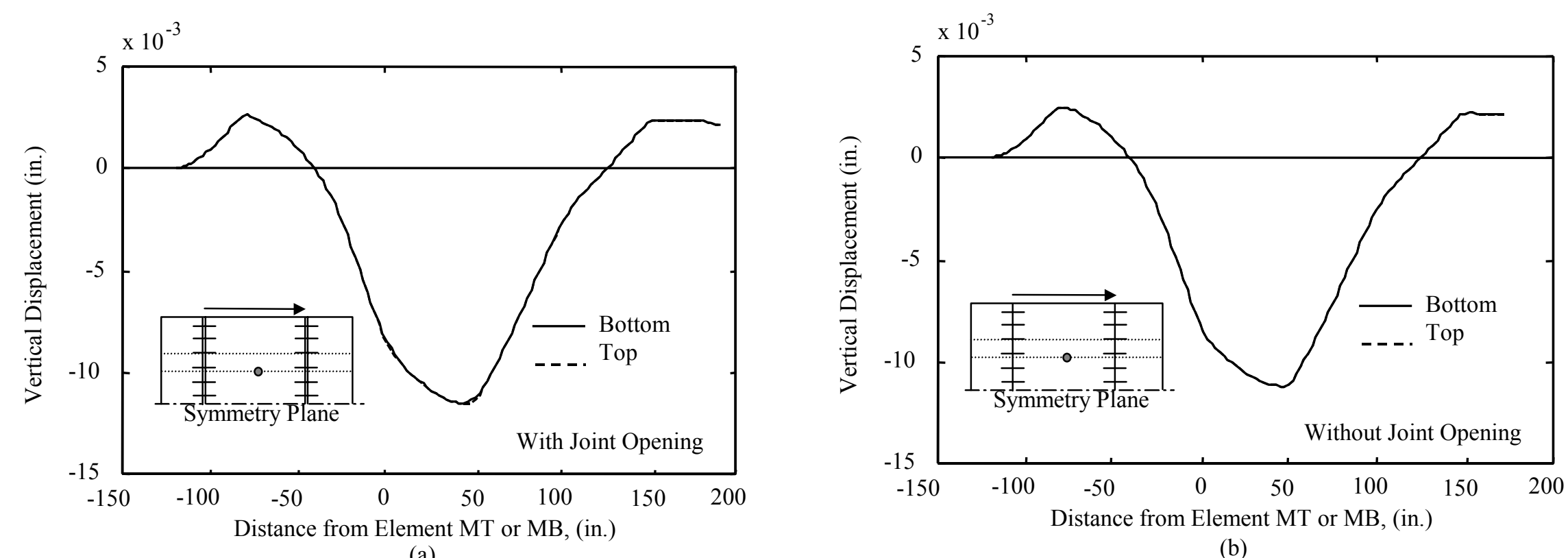

(a)

(b)

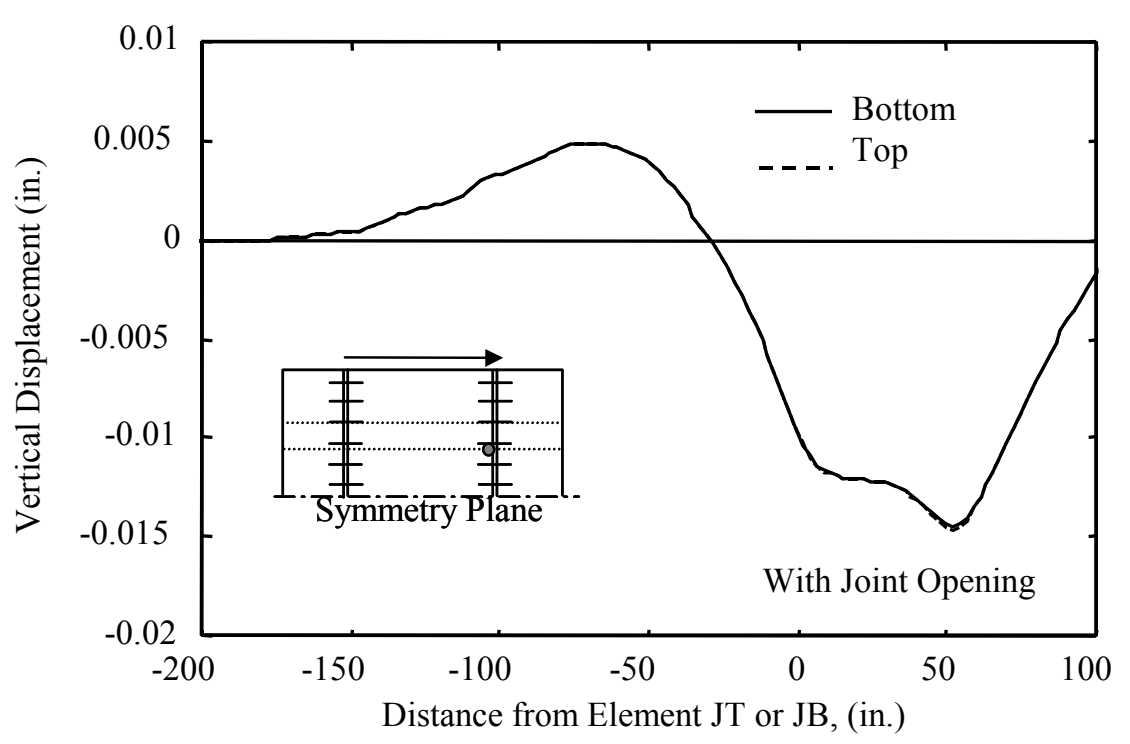

(c)

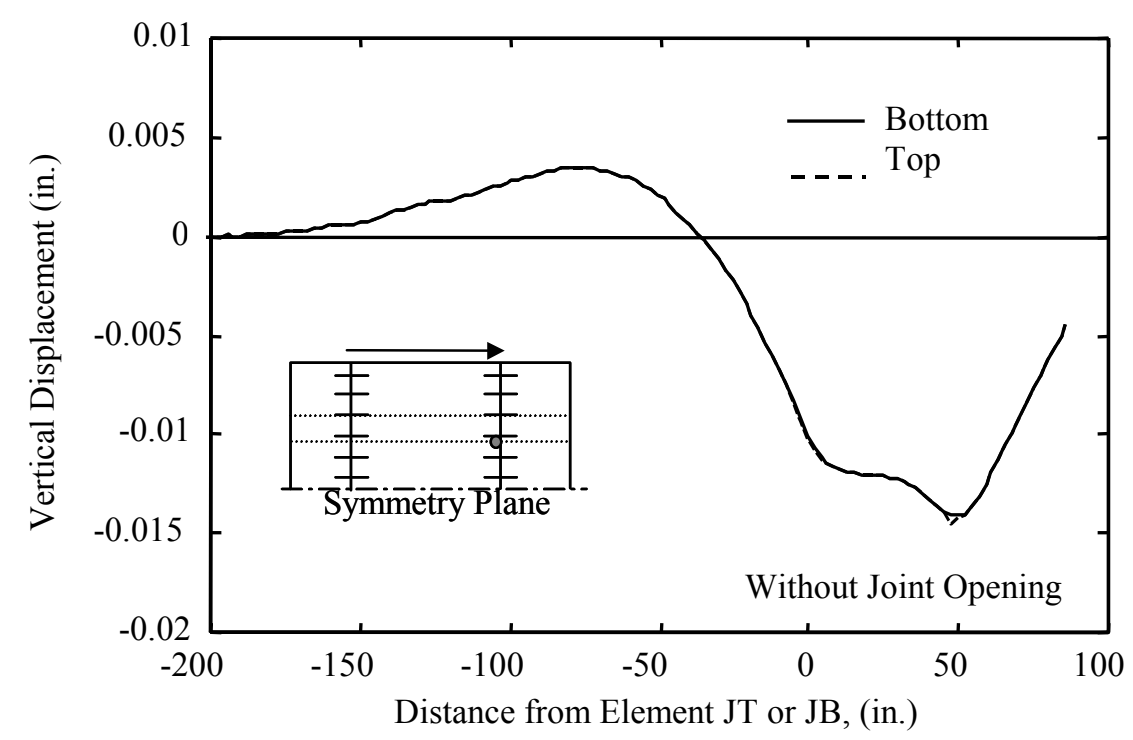

(d)

FIGURE 3.11 Effect of Joint Opening on Distribution of Vertical Displacement 

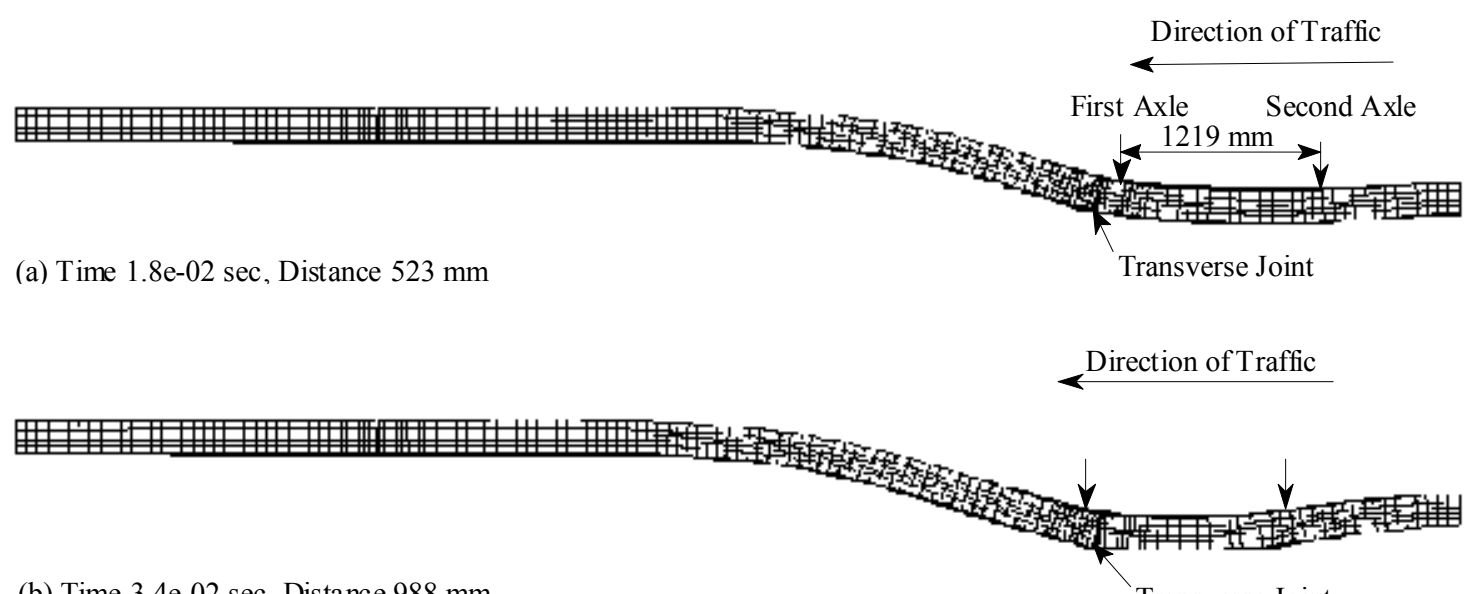

(b) Time 3.4e-02 sec, Distance $988 \mathrm{~mm}$

Transverse Joint

Direction of Traffic

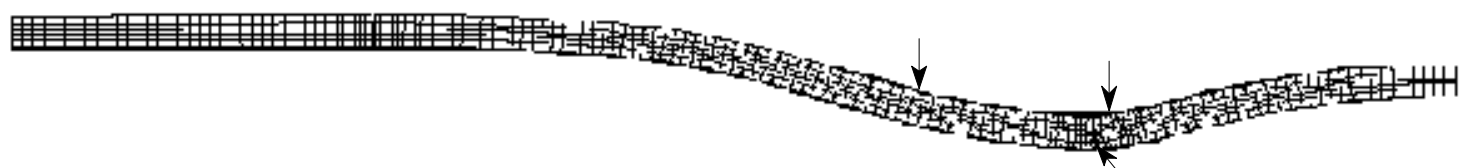

(c) Time $6.2 \mathrm{e}-02 \mathrm{sec}$, Distance $1801 \mathrm{~mm}$

Transverse Joint

$\longleftarrow$ Direction of Traffic

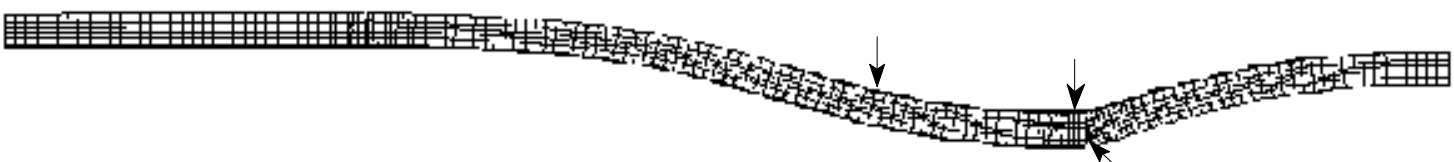

(d) Time 7.2e-02 sec, Distance $2093 \mathrm{~mm} \quad$ Transverse Joint

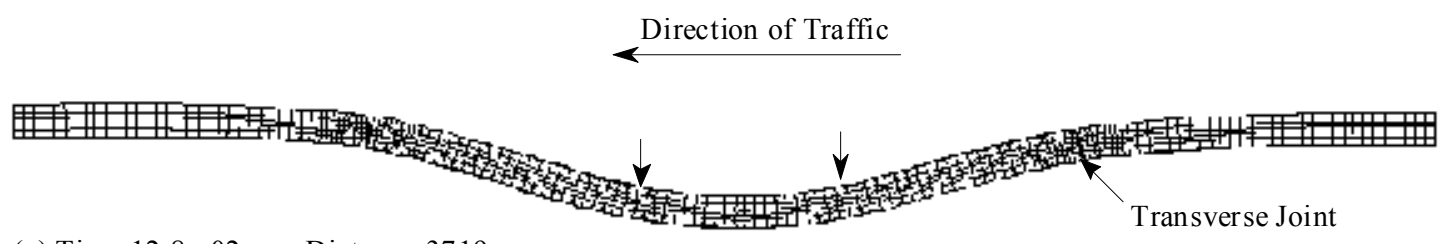

(e) Time $12.8 \mathrm{e}-02 \mathrm{sec}$, Distance $3719 \mathrm{~mm}$

FIGURE 3.12 Effect of Moving Tandem Axle Loads on Concrete Slab Deflection 


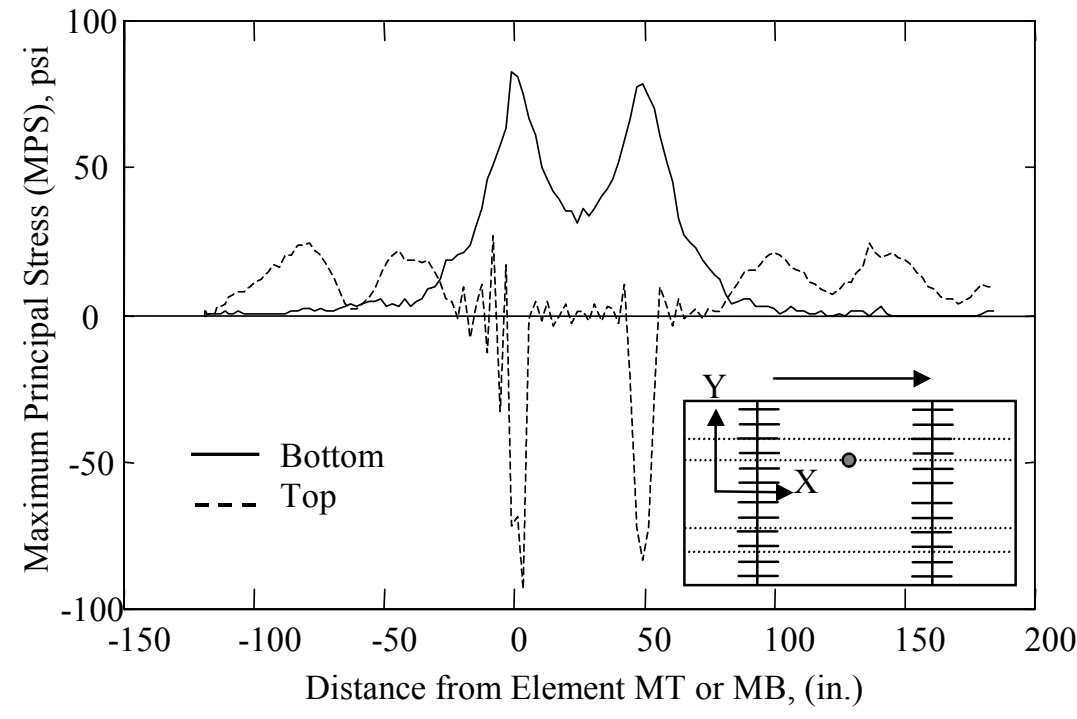

(a)

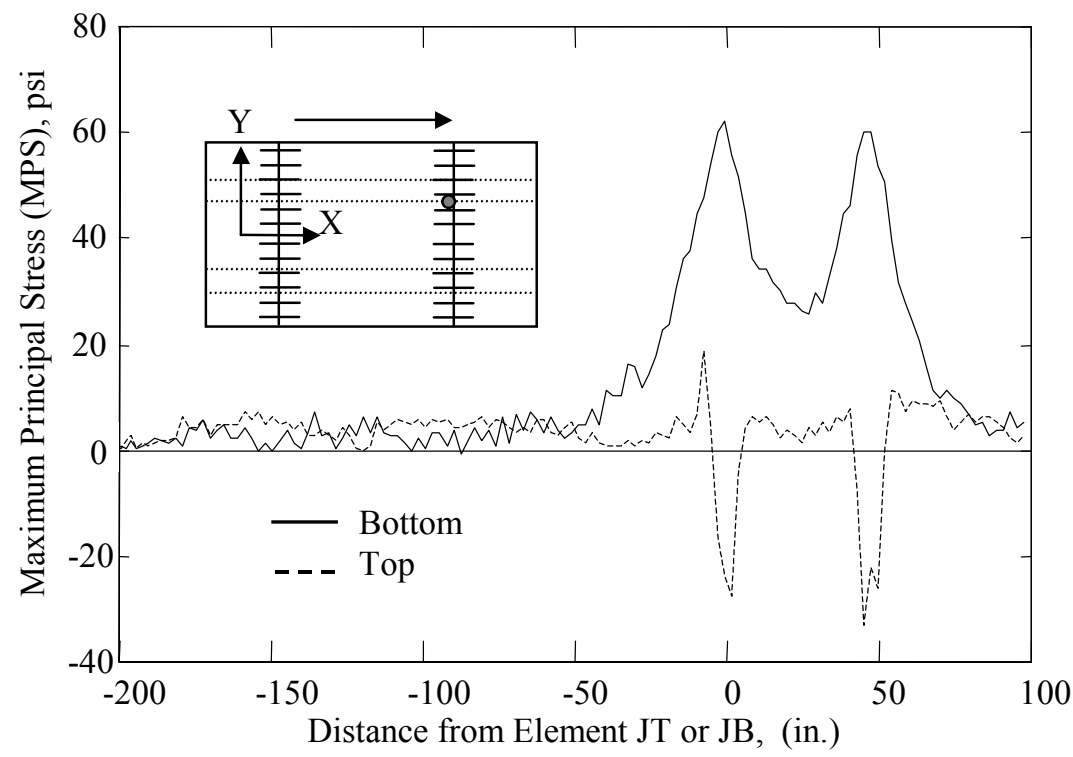

(c)

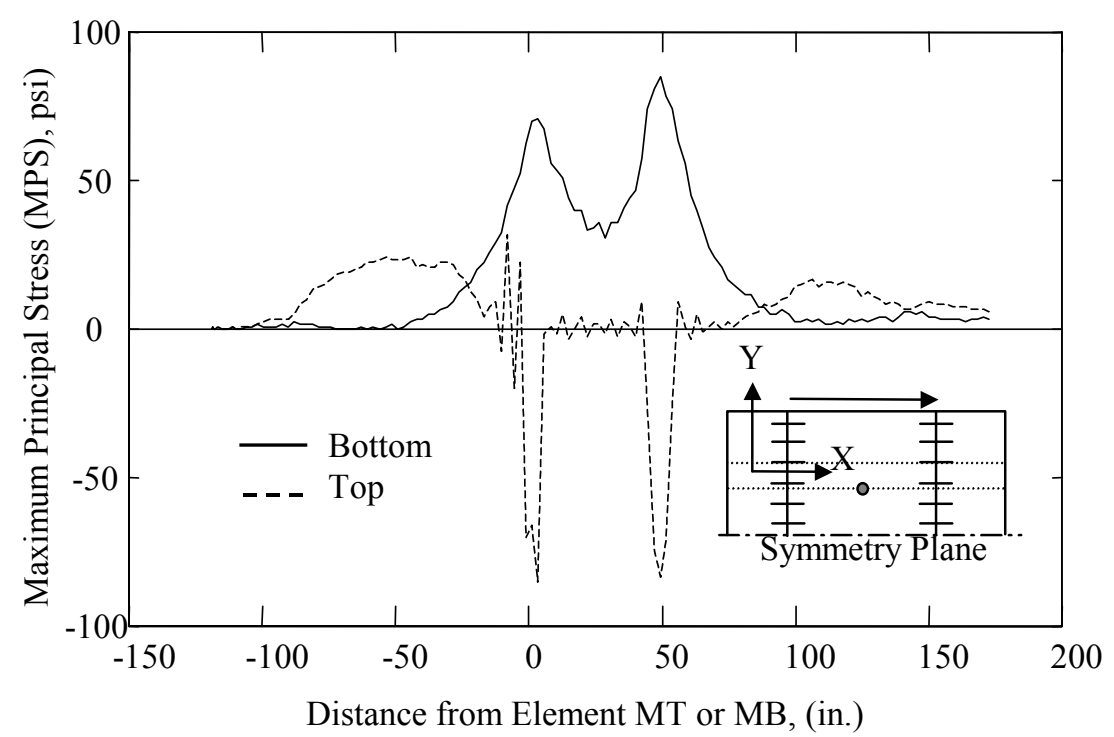

(b)

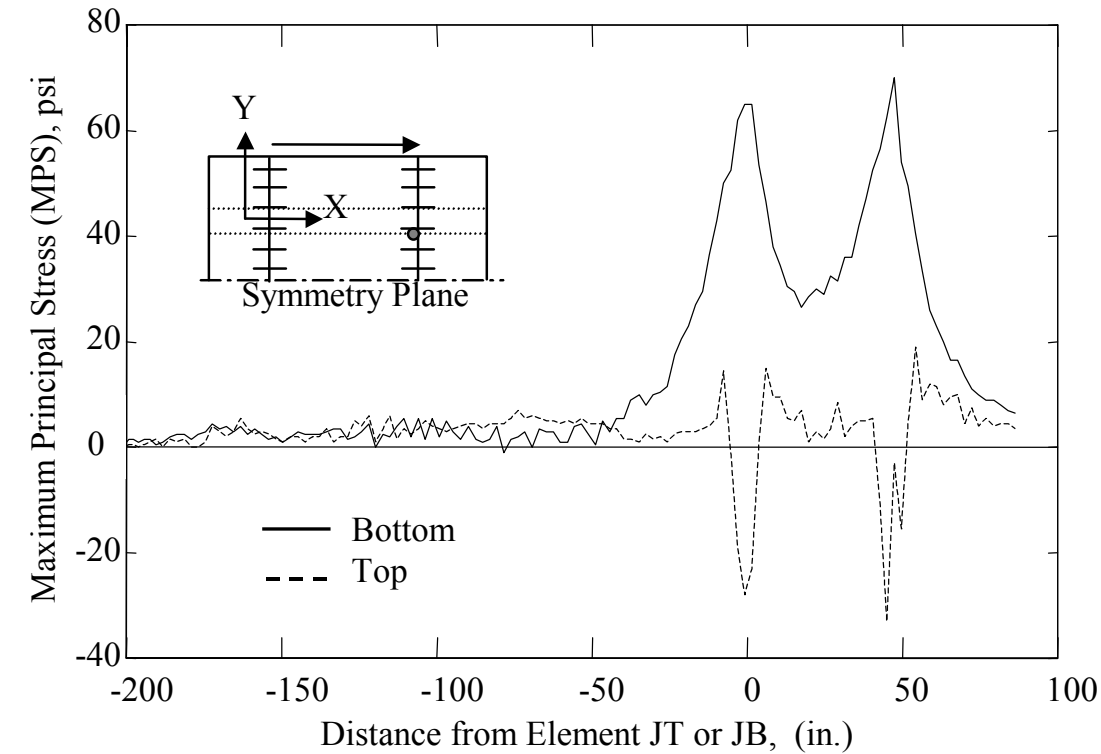

(d)

FIGURE 3.13 Effect of Symmetry Plane on Distribution of Maximum Principal Stress in the Slab 

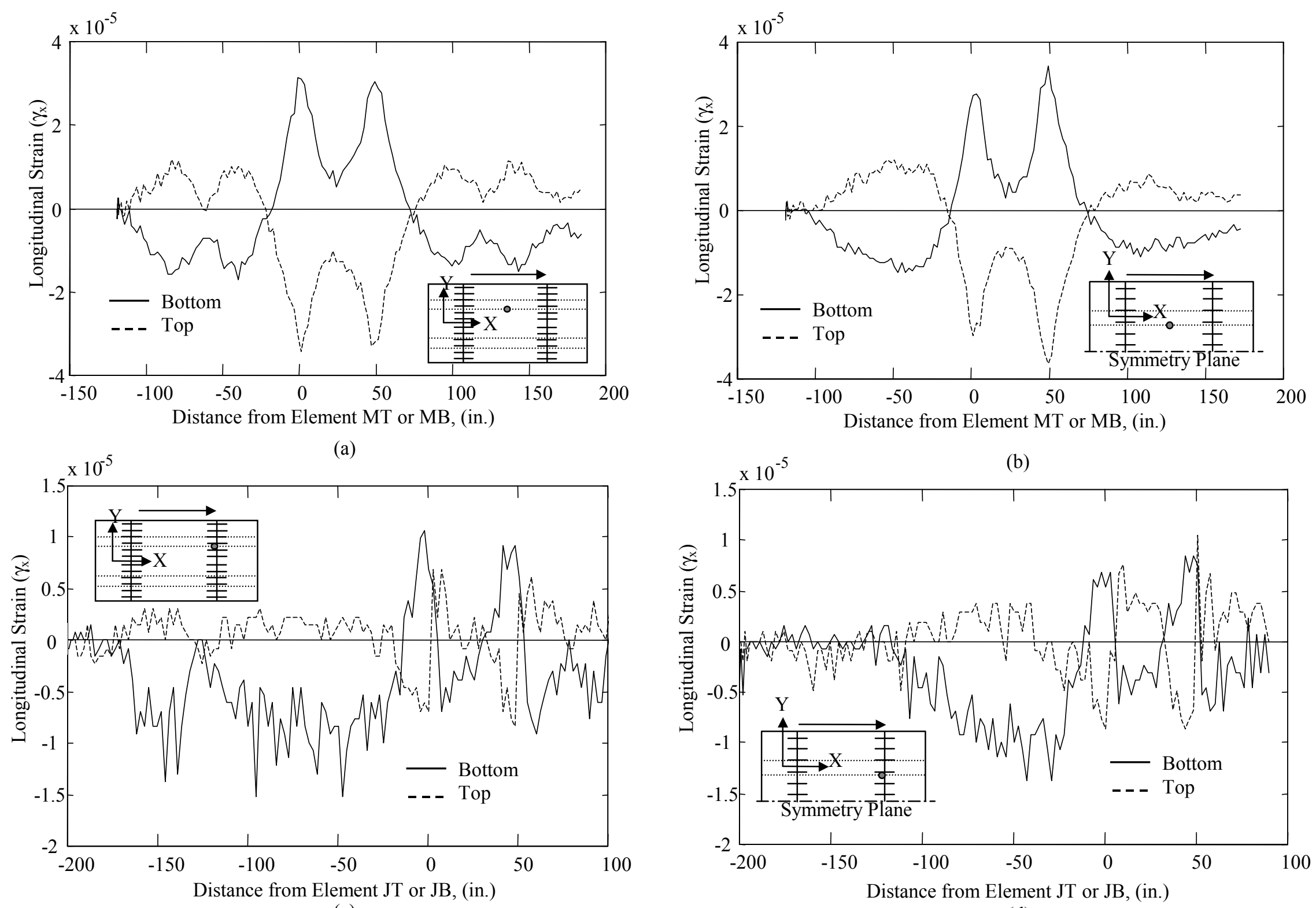

(c)

(d)

FIGURE 3.14 Effect of Symmetry Plane on Distribution of Longitudinal Strain in the Slab 

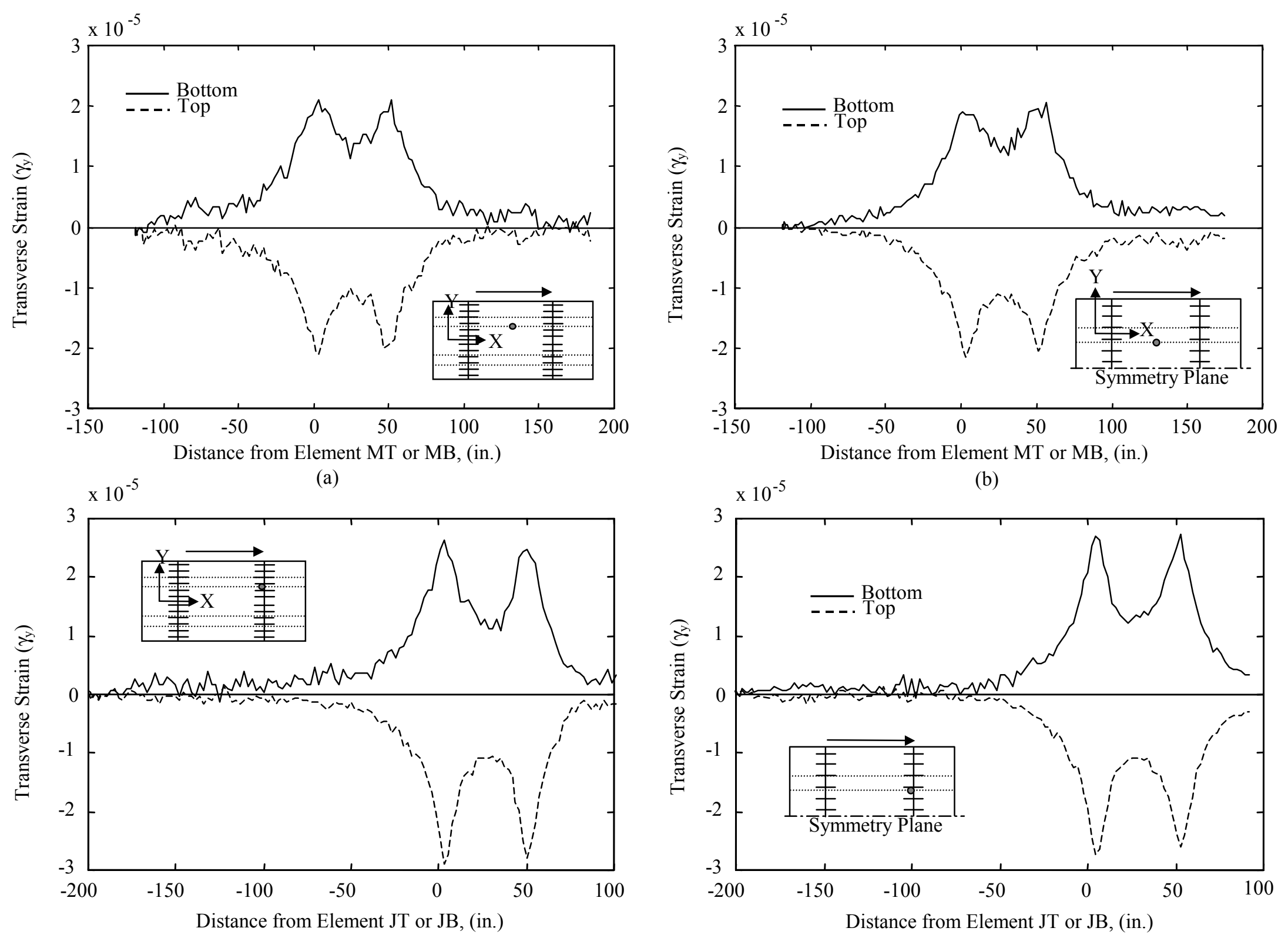

(c)

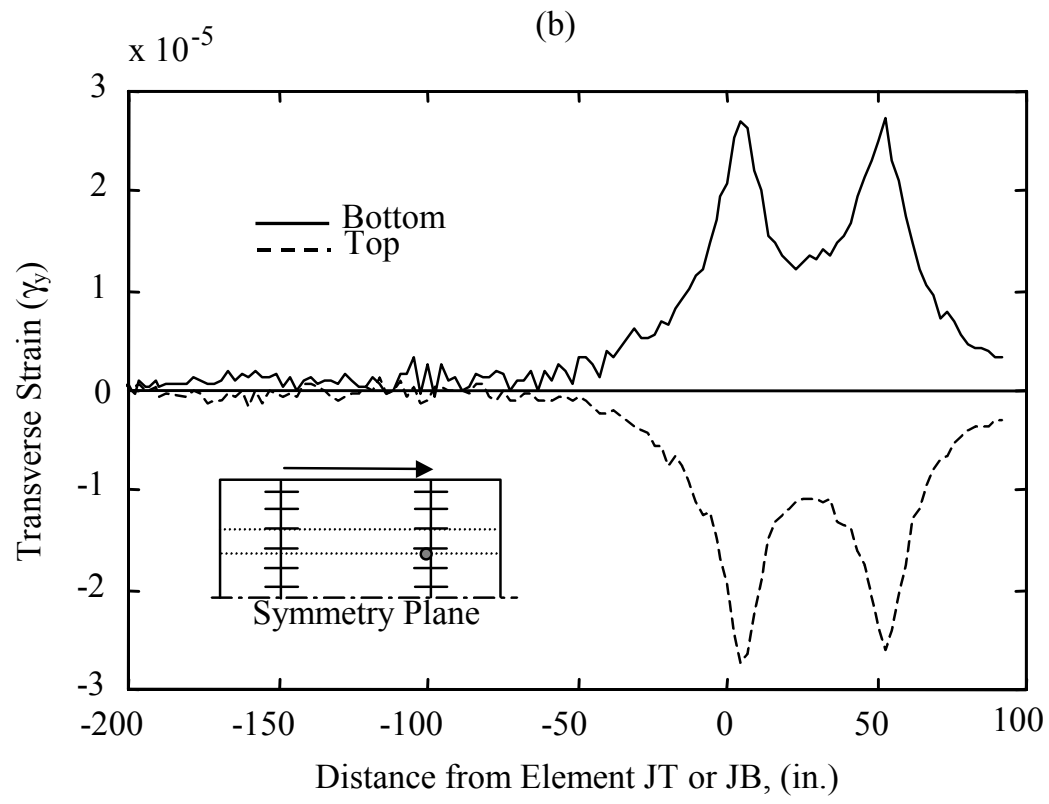

(d)

Figure 3.15 Effect of Symmetry Plane on Distribution of Transverse Strain in the Slab 

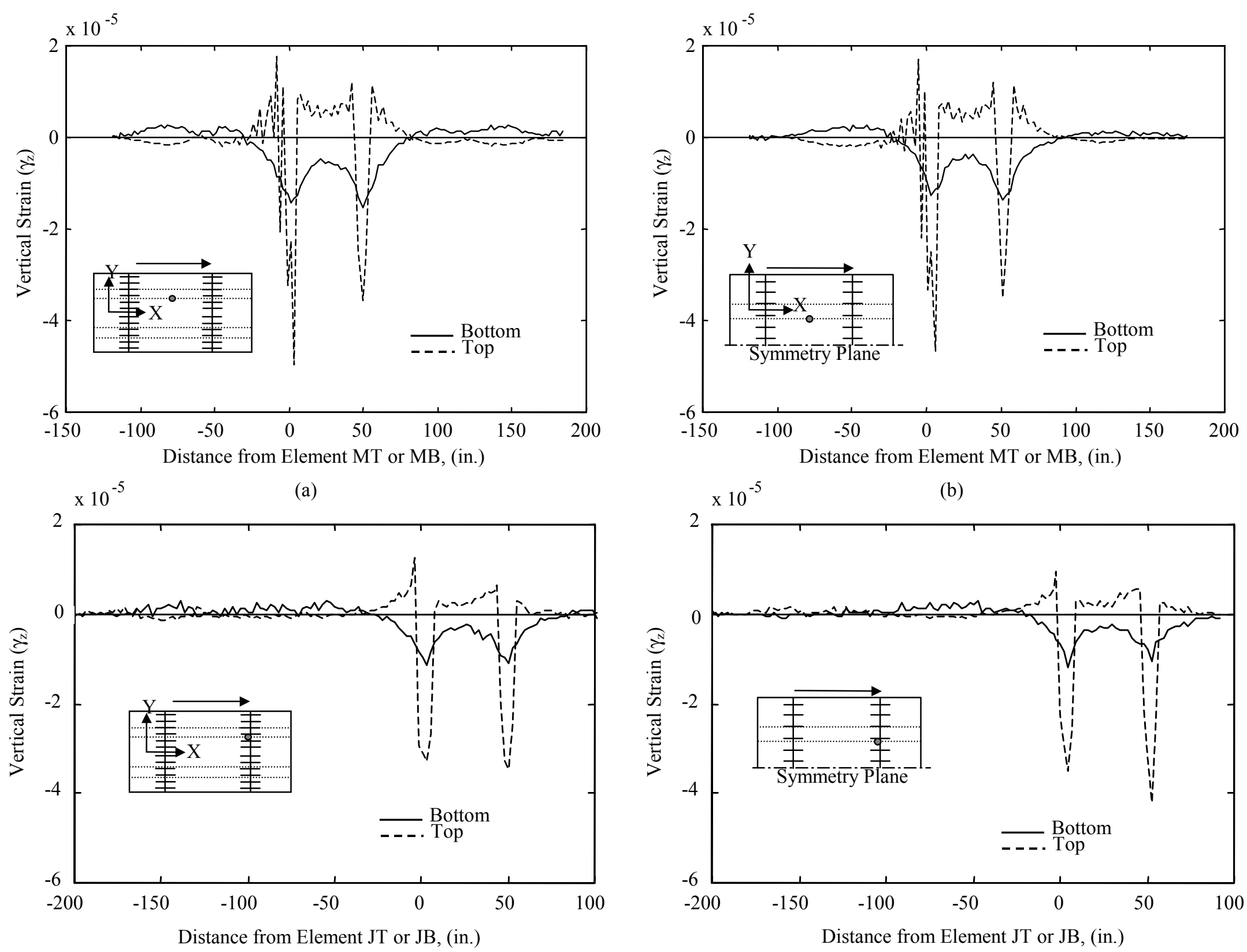

(c)

(d)

Figure 3.16 Effect of Symmetry Plane on Distribution of Vertical Strain in the Slab 


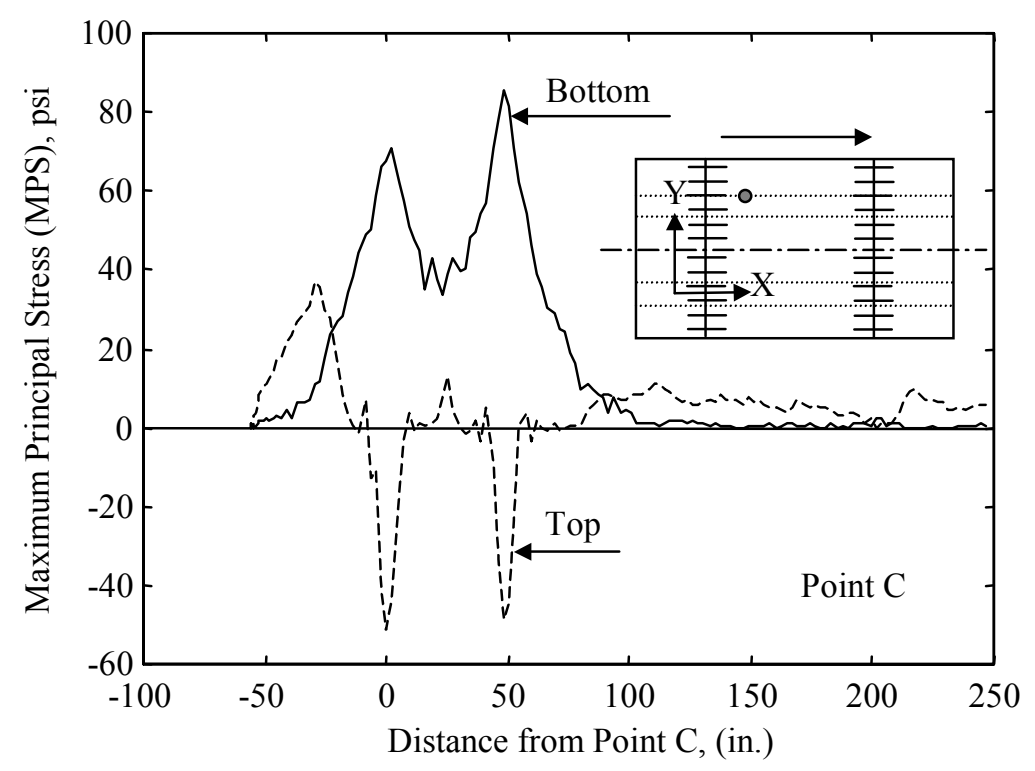

(a)

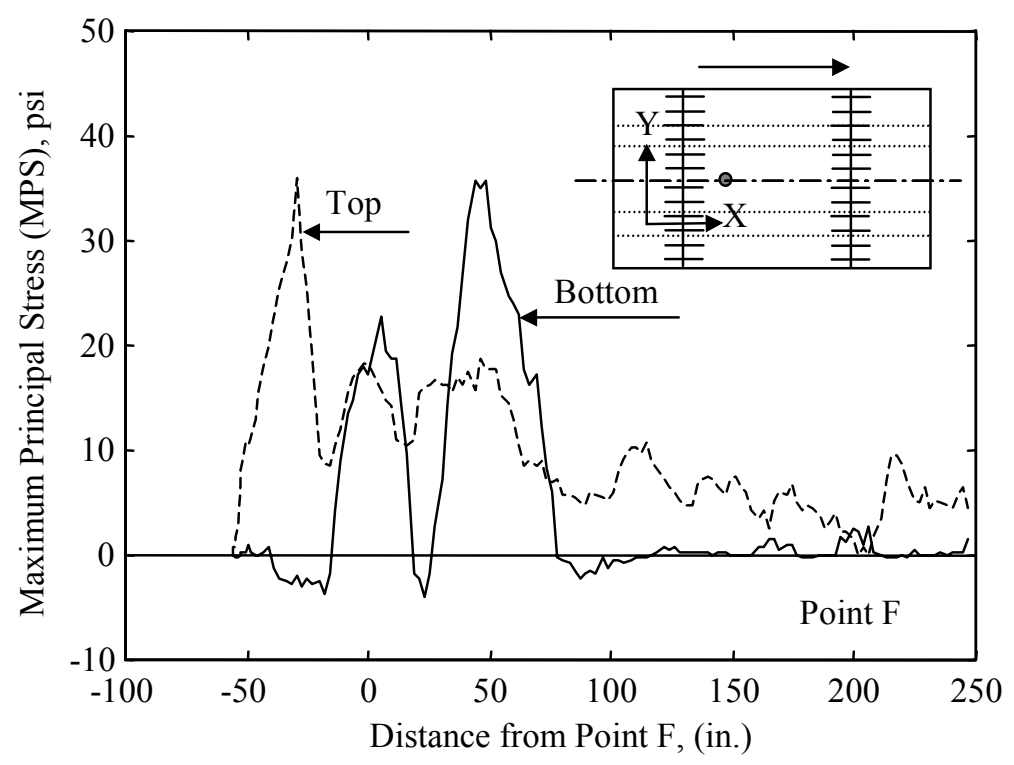

(c)

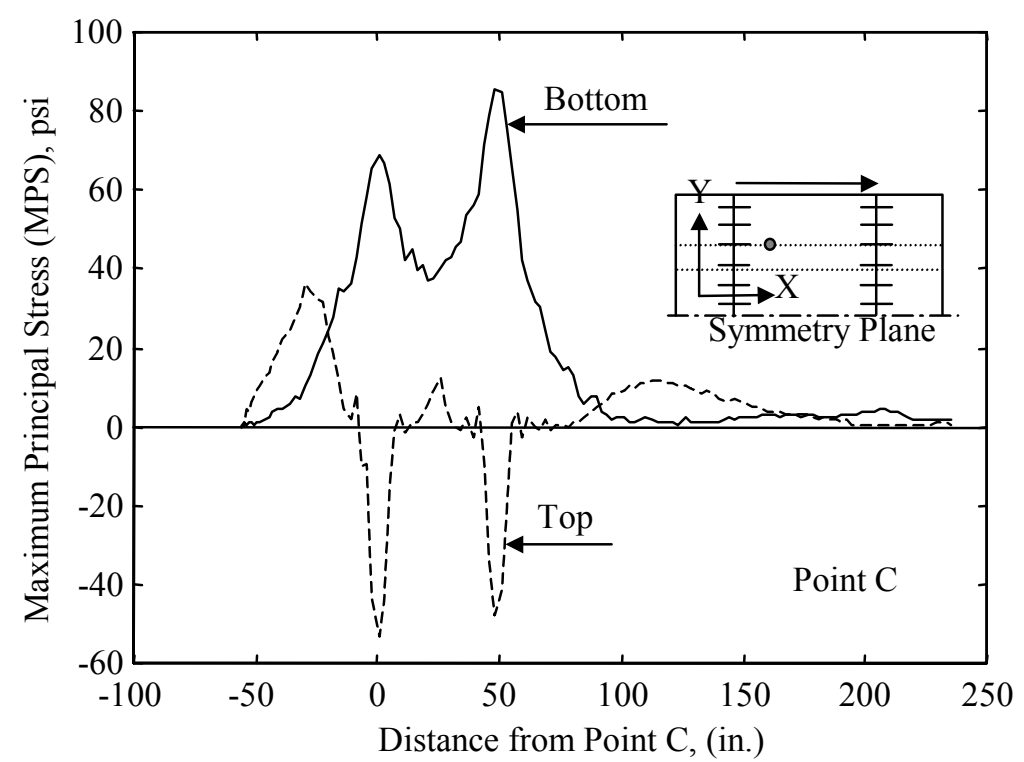

(b)

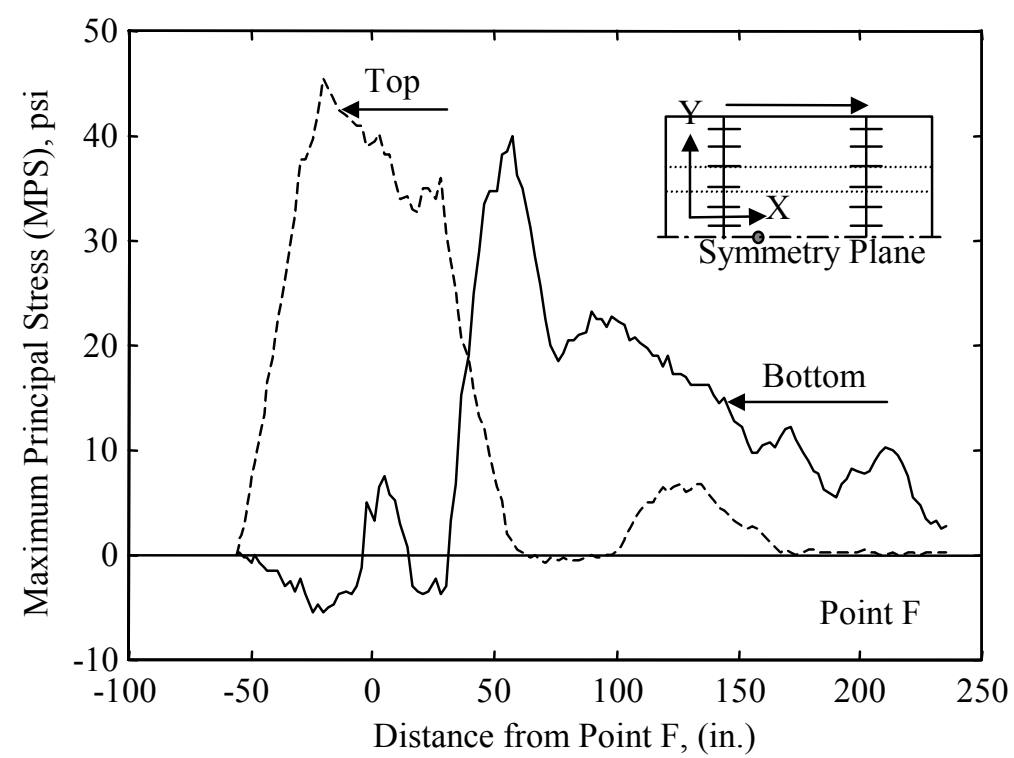

(d)

FIGURE 3.17 Effect of Symmetry Plane on Distribution of MPS at Points C \& F 0.69 m from Transverse Joint 


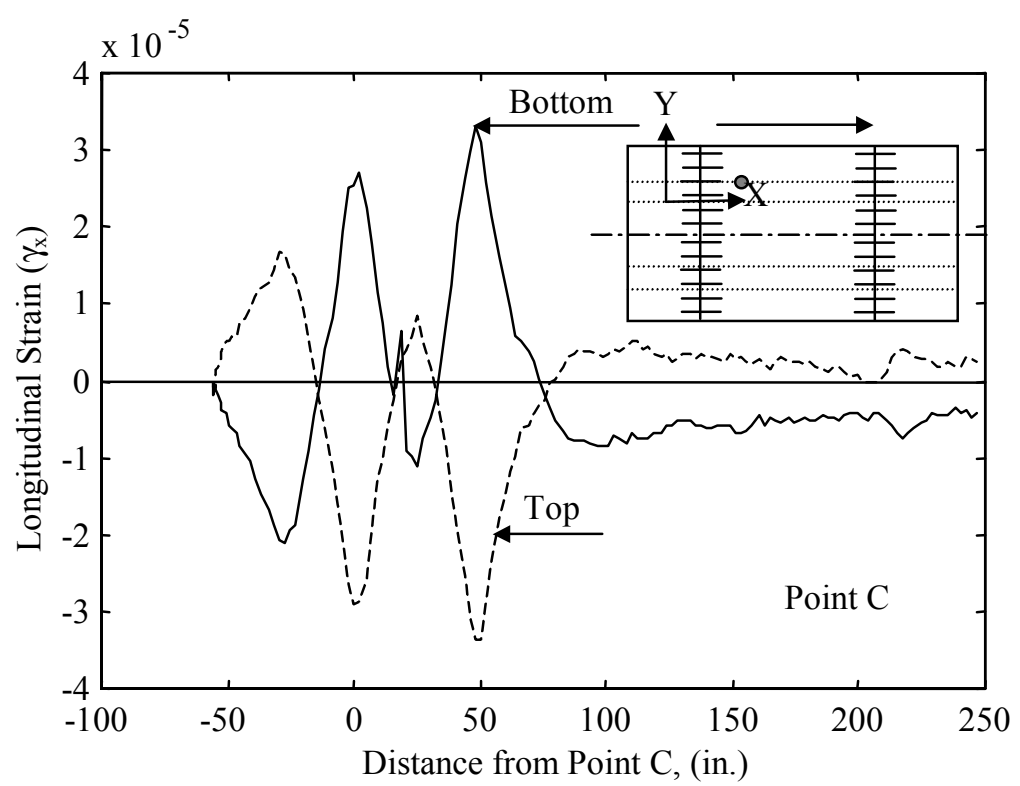

(a)

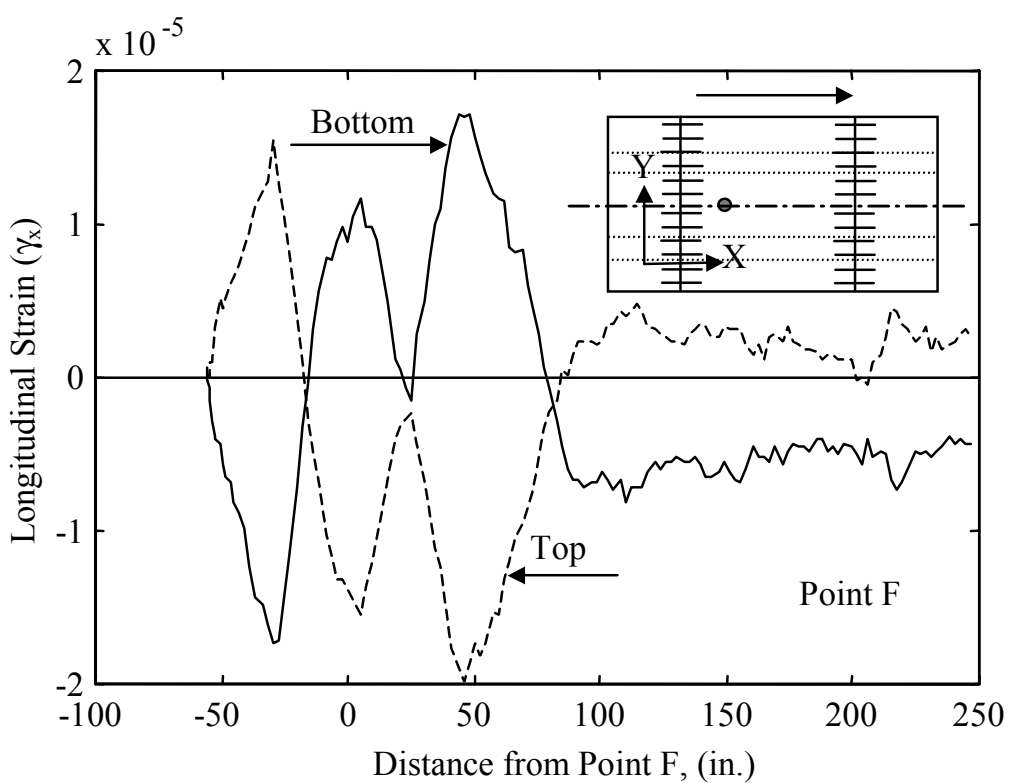

(c)

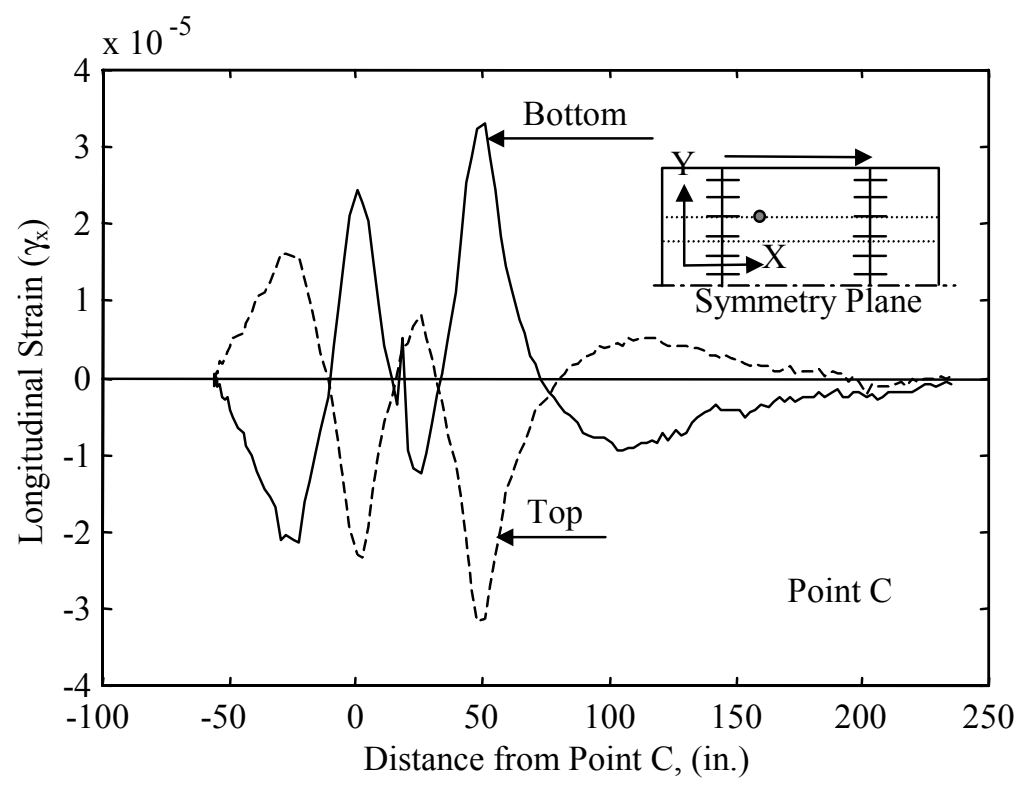

(b)

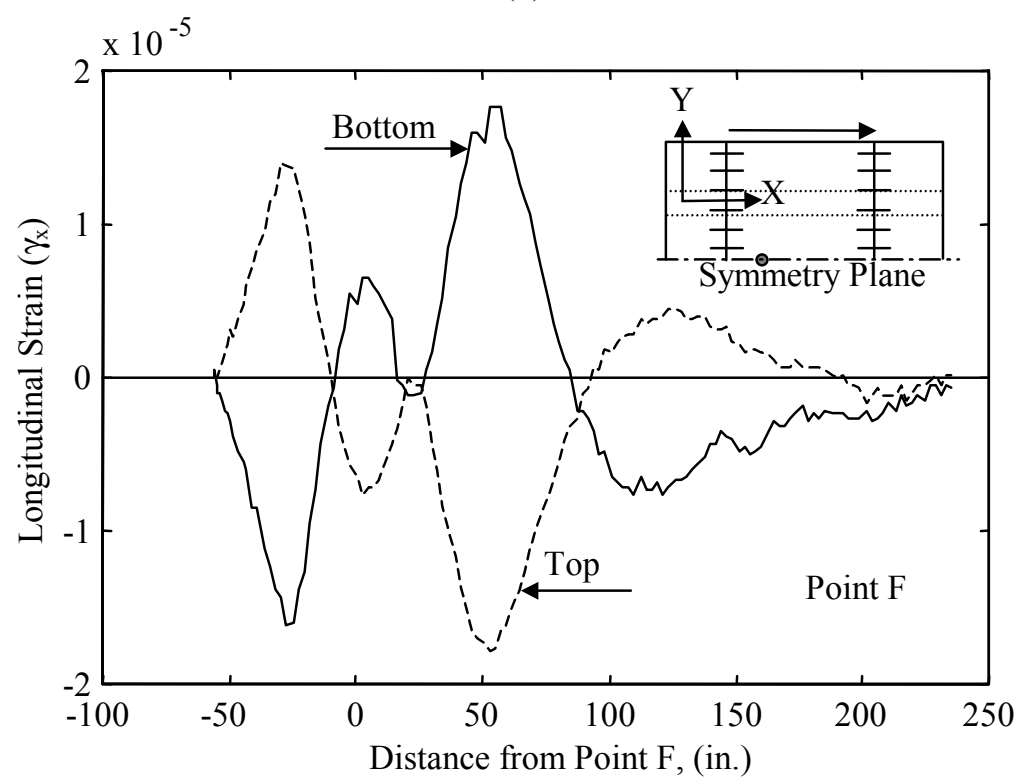

(d)

FIGURE 3.18 Effect of Symmetry Plane on Distribution of $\varepsilon_{\mathrm{x}}$ at Points C \& F $0.69 \mathrm{~m}$ from Transverse Joint 

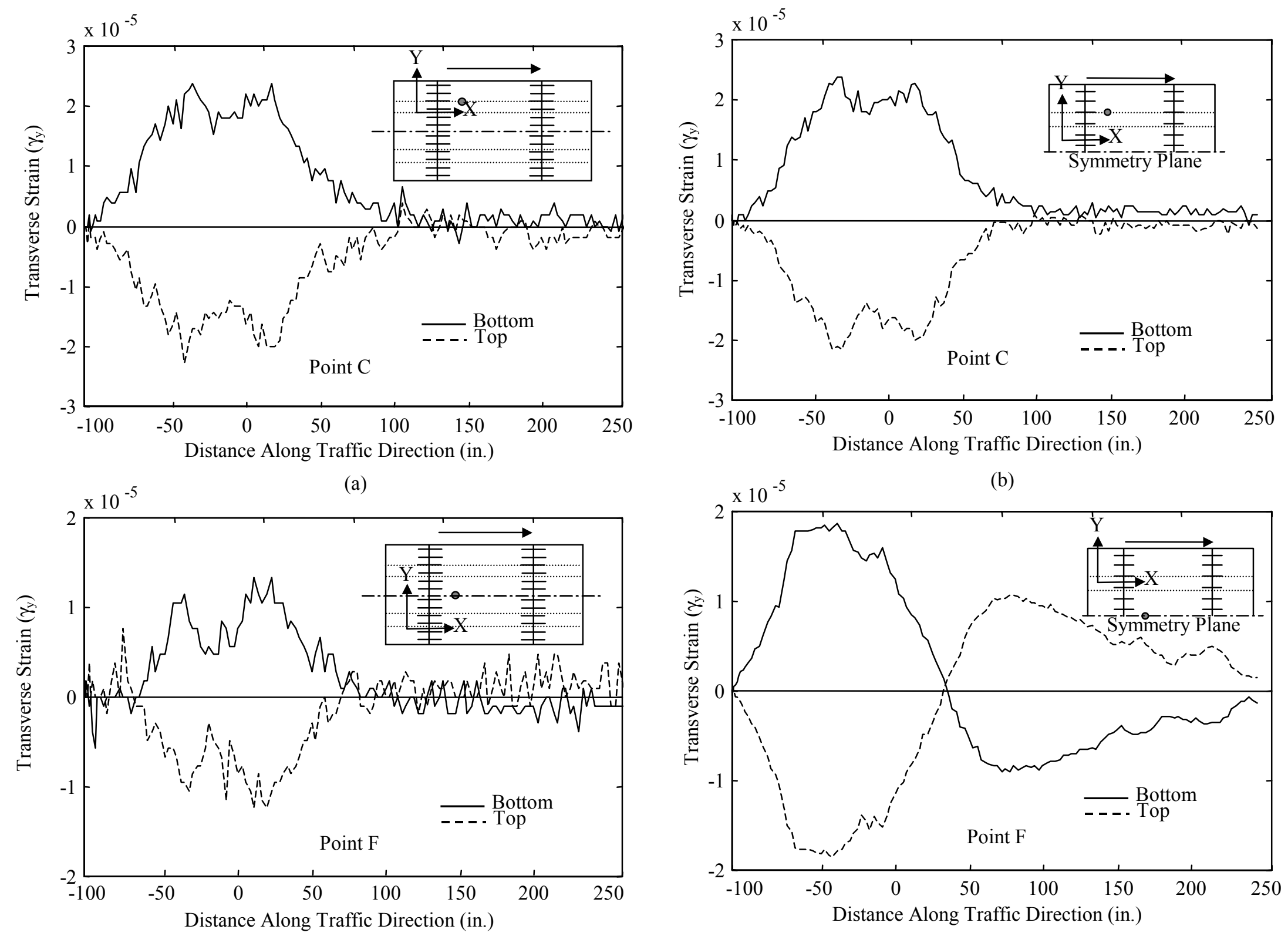

(c)

(d)

FIGURE 3.19 Effect of Symmetry Plane on Distribution of $\varepsilon_{\mathrm{y}}$ at Points $C \&$ F $0.69 \mathrm{~m}$ from Transverse 

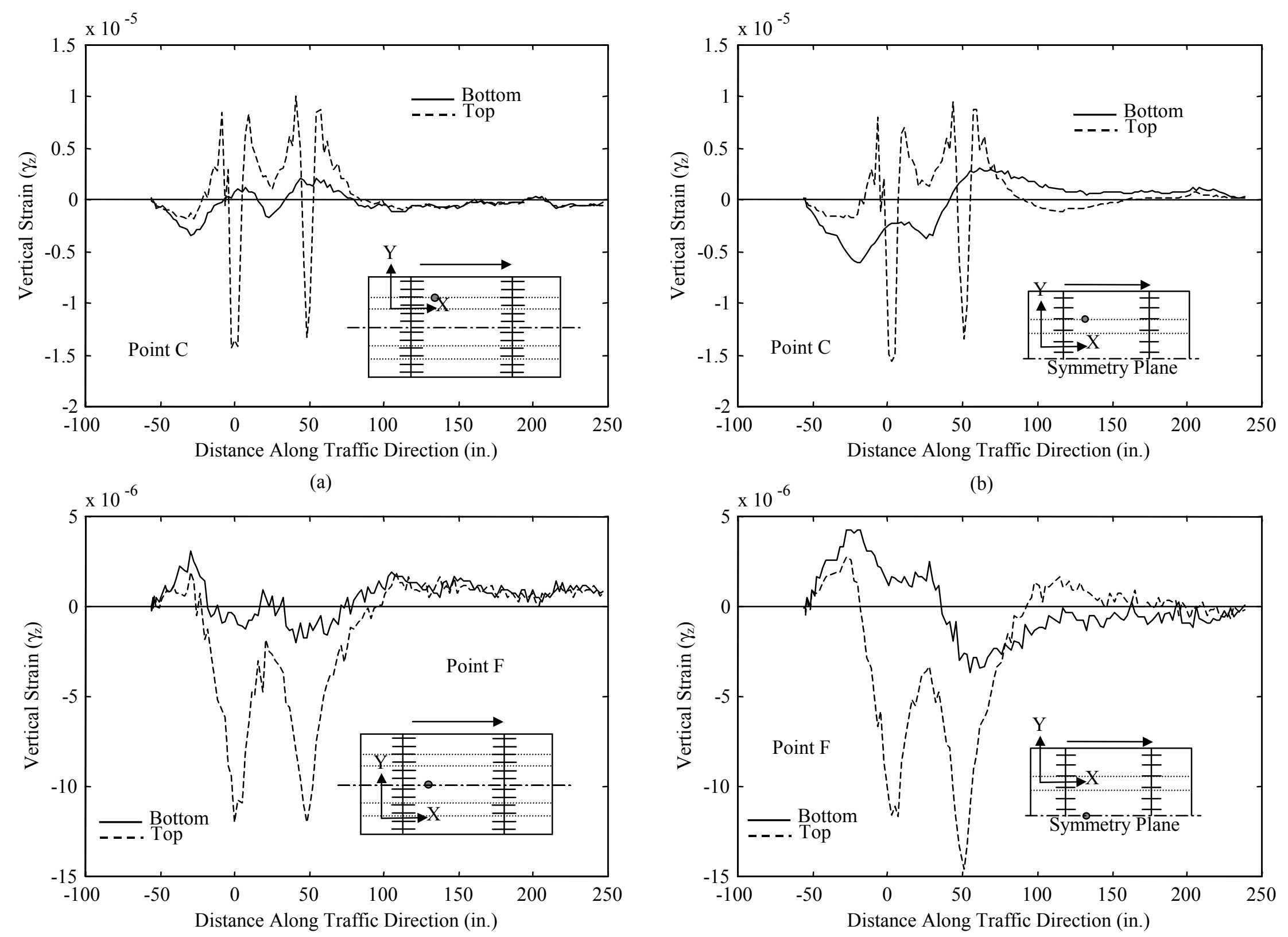

(c)

(d)

FIGURE 3.20 Effect of Symmetry Plane on Distribution of $\varepsilon_{\mathrm{z}}$ at Points $C \& \mathrm{~F} 0.69 \mathrm{~m}$ from Transverse 


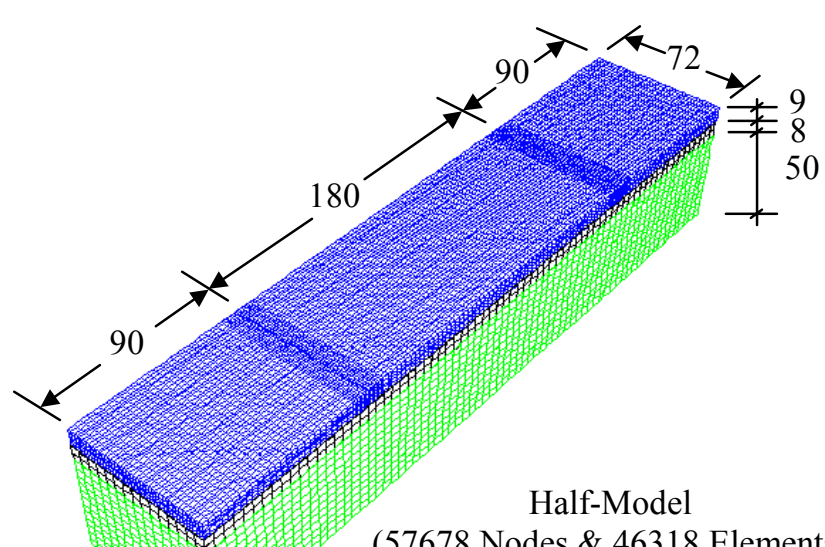

(57678 Nodes \& 46318 Elements)

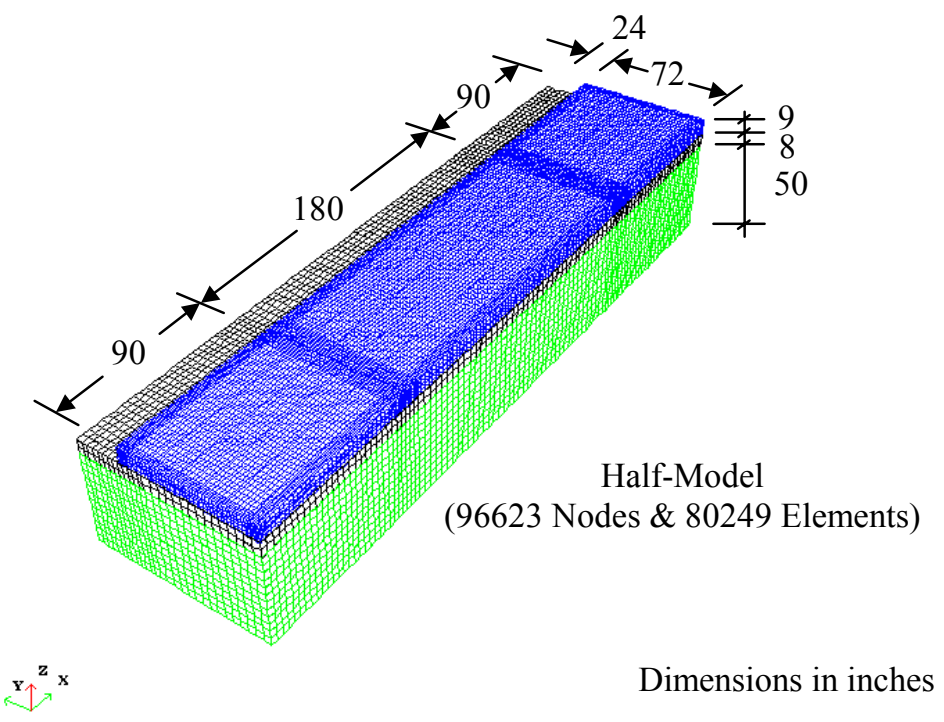

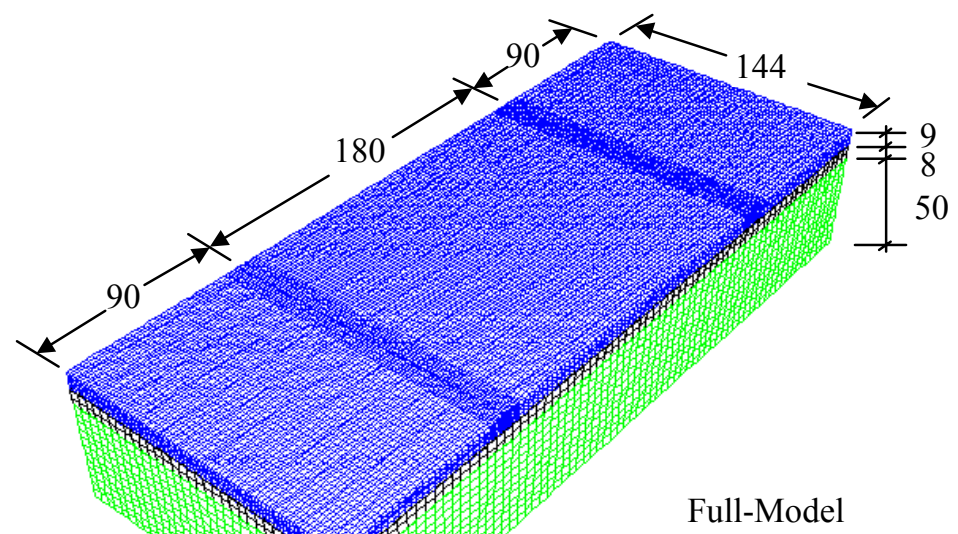

(114043 Nodes \& 93392 Elements)

$\mathbf{x}^{2}{ }^{x}$

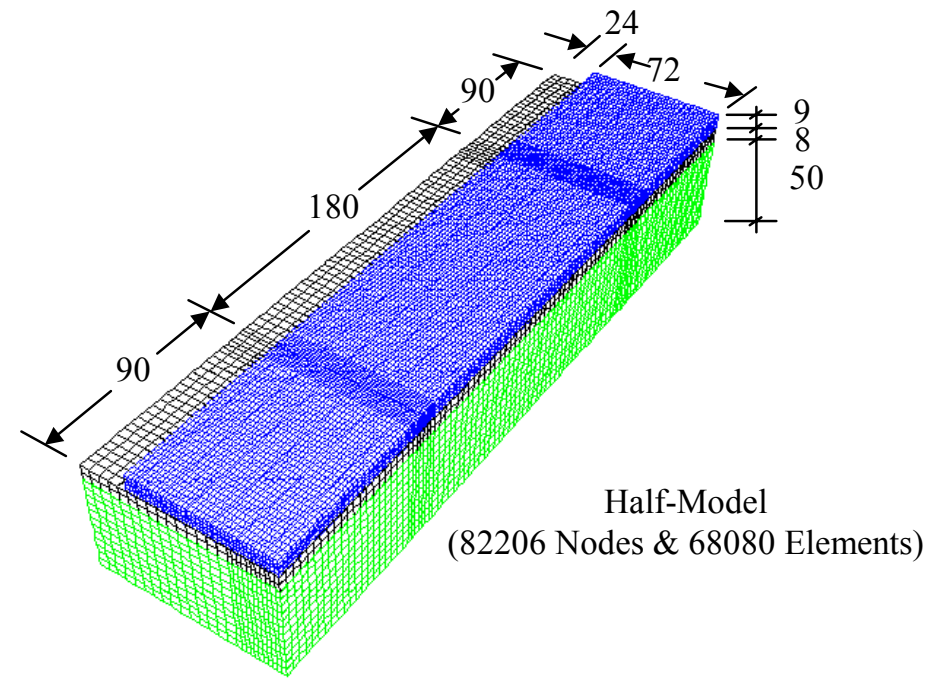

$\mathbf{x}^{z}{ }^{x}$

FIGURE 3.21 Different Finite Element Meshes Used to Model the Rigid Pavement Structure 

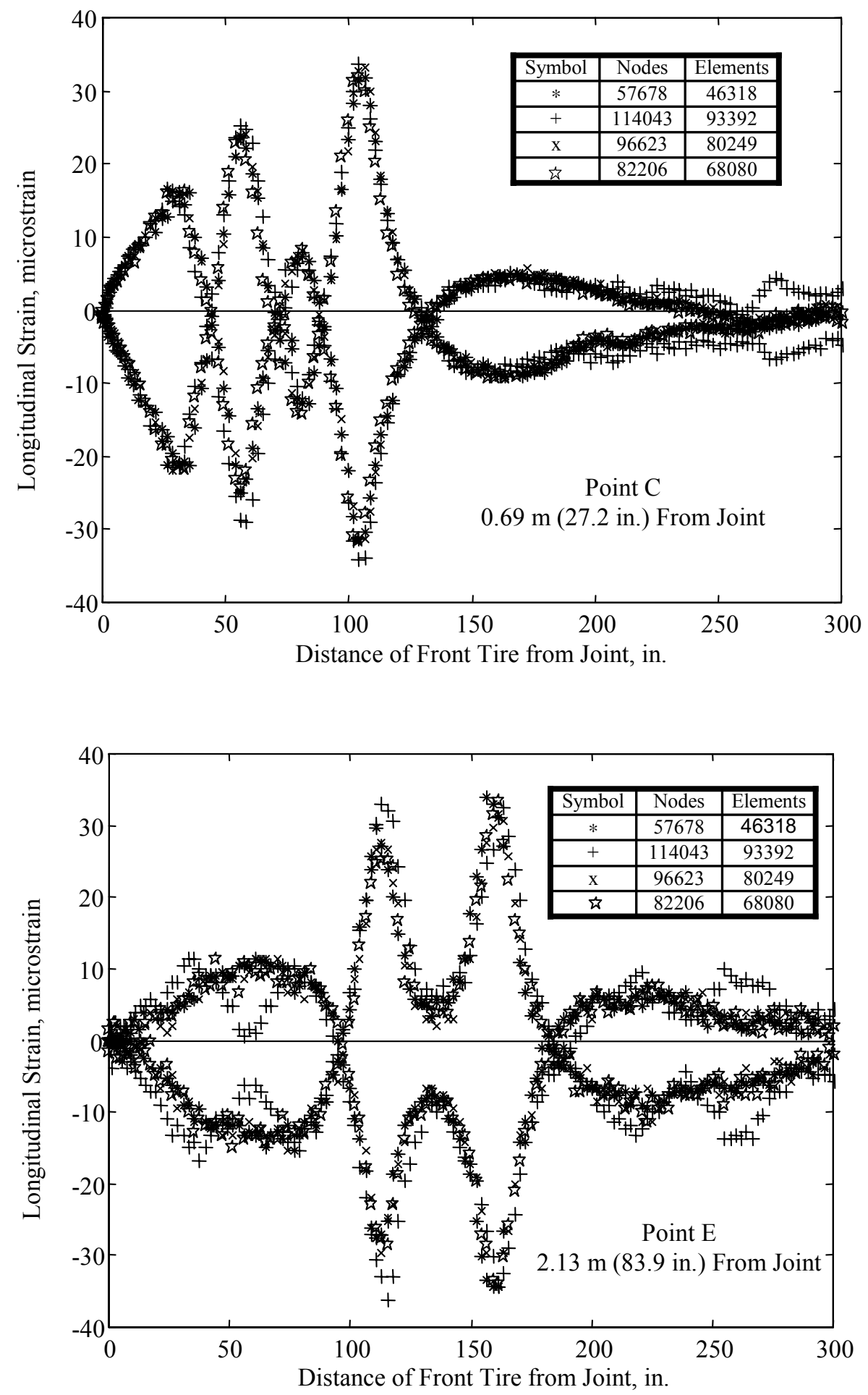

FIGURE 3.22 Variation of Longitudinal Strain Distribution with Finite Element Mesh Size 


\section{CHAPTER FOUR}

\section{EFFECT OF MATERIAL PARAMETERS \\ ON PAVEMENT RESPONSE}

\subsection{Introduction}

Pavements represent a composition of some basic materials conforming to certain specifications to minimize distress resulting from distortion or disintegration (AASHTO Guide for Design of Pavement Structures, 1993). Material properties have a vital effect on the structural response of the slab and therefore its service life. This chapter describes the effect of some material related parameters, those are: a) concrete slab modulus of elasticity, b) base course modulus of elasticity, c) friction coefficient applied at the slab/base interface, and d) dowel bars.

Two illustration methods are used to describe the results: variable (i.e. stress or strain) history and peak stress distribution. The first is described in Chapter Two. To examine the variation of peak stresses along traffic direction, the longitudinal line along which the peak stresses take place, is identified, this is line A-A in Figure 4.1. The peak value of a variable history is collected for each element along that line and plotted versus the distance of the element from the transverse joint. For the Maximum Shear Stress (MSS) along traffic direction, the elements located at mid-slab thickness along line A-A are examined. In all figures showing the distribution of peak stresses, two vertical dotted lines are plotted, showing the locations of dowel bar edges along traffic direction. In addition, a solid vertical line is plotted in all figures showing the right slab edge. Therefore, the distance between the solid and dotted lines on both sides of each graph represents the dowel bar length embedded in the middle slab. In this study, that length is $229 \mathrm{~mm}$ (9 in.). 


\subsection{Effect of Concrete Slab Modulus of Elasticity}

In this section, the slab response is examined for concrete moduli values of 7756,15513 , 31026, and $41369 \mathrm{MPa}(1.125 \mathrm{e} 06,2.25 \mathrm{e} 06,4.5 \mathrm{e} 06$, and $6 \mathrm{e} 06 \mathrm{psi})$. Examination of the results in Figures 4.2 to 4.5 shows that increasing the slab modulus from 7756 to 41369 $\mathrm{MPa}(1.125 \mathrm{e} 06$ to $6 \mathrm{e} 06 \mathrm{psi})$, which represents an increase of 433 percent, increases the stress but significantly reduces the strain, which follows Hooke=s law:

$$
\mathrm{E}=\sigma / \varepsilon \text {. }
$$

Where $\mathrm{E}$ is the modulus of elasticity, $\sigma$ is the stress, and $\varepsilon$ is the strain. Plotting the peak stresses and strains in Figures 4.2 to 4.5 versus the concrete modulus, as shown in Figure 4.6, summarizes the behavior observed in these figures. At the bottom of the slab, the tensile MPS increases as the modulus is increased. As the modulus is increased from 7756 to $41369 \mathrm{MPa}(1.125 \mathrm{e} 06$ to $6 \mathrm{e} 06 \mathrm{psi})$, the MPS increases by 34 and 51 percent for the joint and mid-slab respectively, Figure 4.6 ( $\mathrm{a}$ and $\mathrm{b}$ ). At the slab top, the compressive MPS decreases as the modulus is increased. The percentages of decrease are 35 and 18 percent for the joint and mid-slab respectively, Figure 4.6 ( $a$ and $b$ ). The stress is not significantly affected by the modulus change because it is a function of the applied load and the cross-sectional area and both remains constant in all cases.

The longitudinal strain $\left(\varepsilon_{\mathrm{x}}\right)$ trend at mid-slab is opposite to the MPS trend observed in Figure 4.6 ( $\mathrm{a}$ and $\mathrm{b}$ ). As the modulus is increased, $\varepsilon_{\mathrm{x}}$ is reduced 240 percent at slab bottom and is increased 200 percent at slab top, Figure 4.6 (d). However, at the transverse joint, due to the oscillatory strain history caused by the dowel bars, each $\varepsilon_{\mathrm{x}}$ history curve has two peaks one positive and the other negative. Therefore, two curves exist for either slab top or bottom as shown in Figure 4.6 (c). In this case, the percentages of change in the tensile strain are significantly high compared to these for compressive strain. This observation shows that, increasing the concrete slab modulus effectively reduces the tensile $\varepsilon_{\mathrm{x}}$ induced in the concrete slab under moving loads. 


\subsection{Effect of Base Course Modulus}

A major factor that affects the supporting capabilities of the base course is its stiffness (its modulus of elasticity). The effect of base course modulus is examined for three moduli values of $620.7,310.3$, and 155.2 $\mathrm{MPa}(90,45$, and $22.5 \mathrm{ksi})$ the results are shown in Figures 4.7 to 4.11. The following observations are noticed:

1) Examination of the MPS and $\varepsilon_{\mathrm{x}}$ histories at the transverse joint and the middle of the slab shows that changing the base course modulus has insignificant effect on either the profiles or the magnitudes of the distributions shown in Figures 4.7 and 4.8 .

2) Examination of the effect of base course modulus on the peak MPS, $\sigma_{x}, \sigma_{y}$, and $\sigma_{z}$ induced in the slab along traffic direction, shows that peak stresses are constant at mid-slab and are not affected by changing the modulus. In the vicinity of the transverse joint, changing the base course modulus has a minimal effect on the stresses induced in the slab. For the three moduli values, all stresses start to increase until they reach their peak value in the distance between the dowel bar edge and the slab edge as shown in Figures 4.9 and 4.10.

3) Similar peak stress distributions are plotted for the base and subgrade (results are not reported) and the same trends observed in the concrete slab are still observed in the foundation layers.

4) The significant difference between mid-slab and joint stresses can be explained by examination of the peak MPS and $\sigma_{\mathrm{x}}$ induced in the concrete slabs shown in Figure 4.9. When the load is located at the transverse joint, the slab acts as a cantilever beam. Therefore, the slab edge along the joint (tip of cantilever beam) is subjected to tensile stress at the top and compressive stress at its bottom, Figure 4.9 (f). While under joint loading the slab acts as a cantilever beam, under midslab loading it acts as a simply supported beam. It can be observed that mid-slab is compressed at slab top and tensioned at slab bottom, Figure 4.9.

5) The distribution of peak stresses along traffic direction shows that the variation of base modulus has an insignificant effect on the peak stresses induced at the 
middle of the slab, Figures 4.9 and 4.10. The only effect observed due to changing the base modulus appears in $\sigma_{\mathrm{x}}$ distribution at transverse joints locations.

6) The distribution of Maximum Shear Stress (MSS) along traffic direction shows that increasing the base modulus has no effect on the peak MSS along the whole slab length. Yet, as the axles approach the transverse joints, variations between the MSS, which is induced by the three moduli can be observed, Figure 4.11.

7) The difference in the magnitude of the peak MSS at the two joints may be due to the initialization effects of the tire-prints load and speed at the first joint. The load and speed curves reach their maximum as the load reaches the first joint. Therefore, the behavior of the second joint, will more accurately, represents the transverse joints response under moving loads.

8) The peak MSS distribution at the second joint shows that changing the base modulus has an insignificant effect on peak MSS distributions, Figure 4.11.

\subsection{Effect of Friction Coefficient at Concrete Slab / Base Course Interface}

Friction between rigid pavement slabs and the underlying layers was the subject of several experimental studies (Goldbeck, 1924, Timms, 1964, Ioannides, 1988, and Kuo, 1994). To investigate the effect of varying the friction coefficient $(\mu)$ at the concrete slab/base course interface on the concrete slab response, three different $\mu$ values are applied: $0.9,1.5$ and 1.8. The selection of these values is based on the AASHTO Guide for Design of Pavement Structures recommended values for $\mu$. The assumed values of $0.9,1.5$, and 1.8 represent $\mu$ between the slab bottom and the top of: a natural subgrade, a crushed stone or river gravel base course, and a stabilized base course, respectively.

At mid-slab, changing $\mu$ did not affect either the shape or the magnitude of the MPS or $\varepsilon_{\mathrm{x}}$ as shown in Figures 4.12 (a, b, and c) and 4.13 (a, b, and c). On the other hand, at the transverse joint top, and for a $\mu$ value of 1.5 , the MPS is reduced by 30 percent compared to that induced in case of $\mu$ values of 0.9 or 1.8 , Figure $4.12(\mathrm{~d}, \mathrm{e}$, and $\mathrm{f}$ ). At the joint 
bottom, in case of $\mu$ value of $1.5, \varepsilon_{\mathrm{x}}$ is 64 and 81 percent lower than that induced in case of $\mu$ values of 1.8 and 0.9 respectively, Figure 4.13 (d, e, and f). No changes are observed in MPS at joint bottom and $\varepsilon_{\mathrm{x}}$ at joint top and bottom, Figure 4.12 (d, e, and f) and 4.13 ( $d$, e, and f). The changes observed in slab response due to the variation of coefficient of friction from 0.9 to 1.8 demonstrate that changing the friction coefficient does not affect the stresses or strains induced in the concrete slab. More significant changes in slab response can take place if temperature gradient is considered. Therefore, the recommended value by AASHTO (1993) of 1.5 is used in this study.

\subsection{Effect of Dowel Bars}

To investigate the effect of dowel bars on the structural response of concrete slab, the response of the original model shown in Figure 2.1 is compared to its response after eliminating the dowel bars while keeping all other conditions constant. The comparison shown in Figures 4.14 to 4.17 demonstrates the following:

1) In general, the dowel bars affect only the slab response at the joint, but do not have any effect at the middle of the slab, as shown in Figures 4.14 to 4.17.

2) Doweled joints eliminate the stress and strain reversals observed at the joint top when the first axle is located at the approach slab edge, as shown in Figures 4.14 (c and d) and 4.15 (c and d).

3) Along the transverse joint and at the bottom of the slab, the absence of dowel bars resulted in a significant stress drop in the first stress peak generated from the passage of the first axle of the tandem assembly across the joint, Figure 4.14 (d). While the peak tensile stress at slab bottom resulting from the passage of the first axle dropped from $690 \mathrm{kPa}(100 \mathrm{psi})$ to about $69 \mathrm{kPa}(10 \mathrm{psi})$ for undoweled joints representing a 900 percent drop, the same stress dropped from about 483 to $186 \mathrm{kPa}$ ( 70 to $27 \mathrm{psi}$ ) for doweled joints representing a 160 percent drop, as shown in Figure 4.14 ( $\mathrm{c}$ and d) respectively. The same observations apply to $\varepsilon_{\mathrm{y}}$ measured at the top and bottom of the slab, Figures 4.16 ( $\mathrm{c}$ and d). Under cyclic 
traffic loading, the large tensile stress drop, which took place in non-doweled joints may develop cracks at the bottom of the slab and proceed to develop joint faulting. This observation demonstrates the effectiveness of dowel bars in controlling joint cracks, which may progress to develop joint faulting. The same conclusion was reached by a study performed by the FHWA (1997) to analyze the Long-Term Pavement Performance (LTPP) program data.

4) Similar $\varepsilon_{x}$ trends are observed for both doweled and non-doweled joints, Figure 4.15 ( $\mathrm{c}$ and $\mathrm{d}$ ). However, it appears that the presence of both dowel bars and aggregate interlock, to some extent reduced the oscillatory behavior observed at the joint.

5) Examination of the vertical displacement at the joint shows a significant increase in the positive (upward) displacement as the load approaches the joint, Figure 4.17 ( $\mathrm{c}$ and $\mathrm{d}$ ). This will separate the slab from the base course and a gap is developed beneath the joint. The presence of dowel bars and joint opening (aggregate interlock) reduced the positive displacement, Figure 4.17 (c). For the case of undoweled joint, the percentage of increase in the maximum positive displacement when compared to doweled joint is 117 percent, Figure 4.17 (d).

6) In case of non-doweled joints, a notable reduction in the negative (downward) displacement is observed when the first axle crosses the joint, Figure 4.17 (d). On the other hand, the presence of dowel bars does not affect the vertical displacement at mid-slab, Figure 4.17 ( $a$ and $b$ ).

\subsection{Conclusions}

The effect of varying some pavement material properties is investigated and the following is concluded:

1) To reduce the strains induced in concrete slabs along the wheel-path, it is more effective to increase the concrete slab modulus of elasticity than to increase the base course modulus. 
2) Increasing either the concrete slab or the base course moduli has an insignificant effect on the MPS induced in the concrete slab along the wheel-path.

3) The distributions of peak MPS, $\sigma_{x}, \sigma_{y}$ and MSS show sharp stress changes at transverse joints. This agrees with the common believe that transverse joints are the main source of rigid pavement distresses.

4) Changing the friction coefficient at the slab/base interface has a negligible effect on slab response along the wheel-path. This conclusion might change if thermal gradient through the slab thickness is considered.

5) The presence of both dowel bars and aggregate interlock at the joint reduces the tensile stresses induced at the bottom of the slabs each time an axle traverses the joint. 


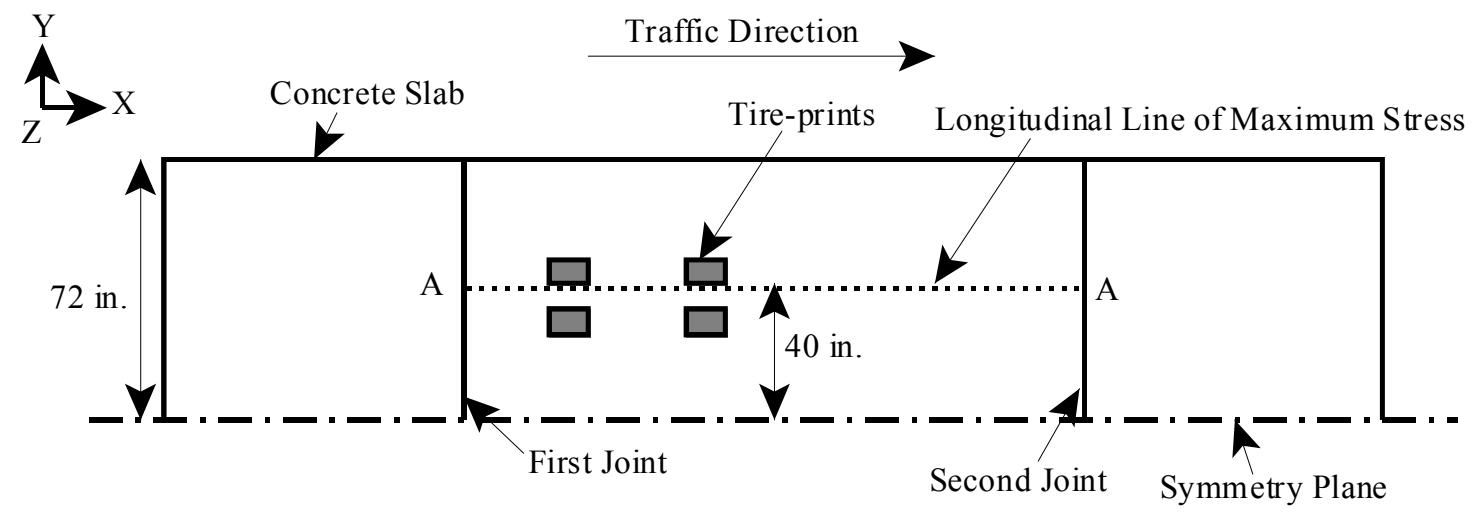

FIGURE 4.1 Location of Longitudinal Line of Maximum Stresses 


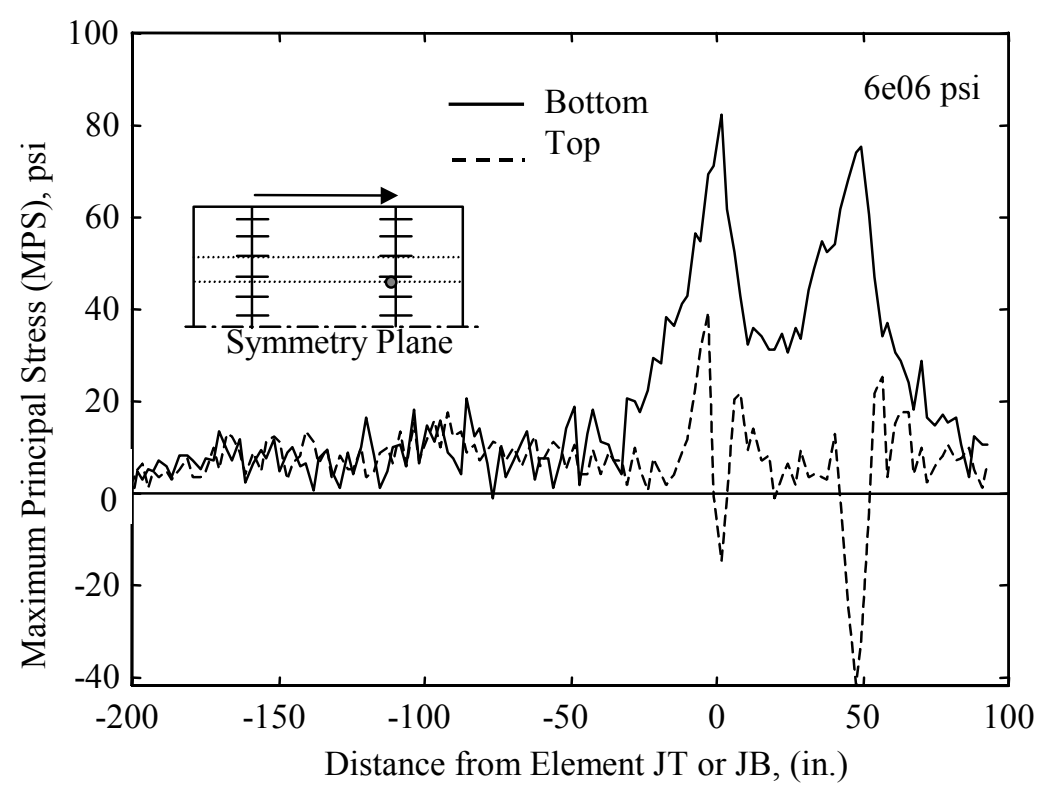

(a)

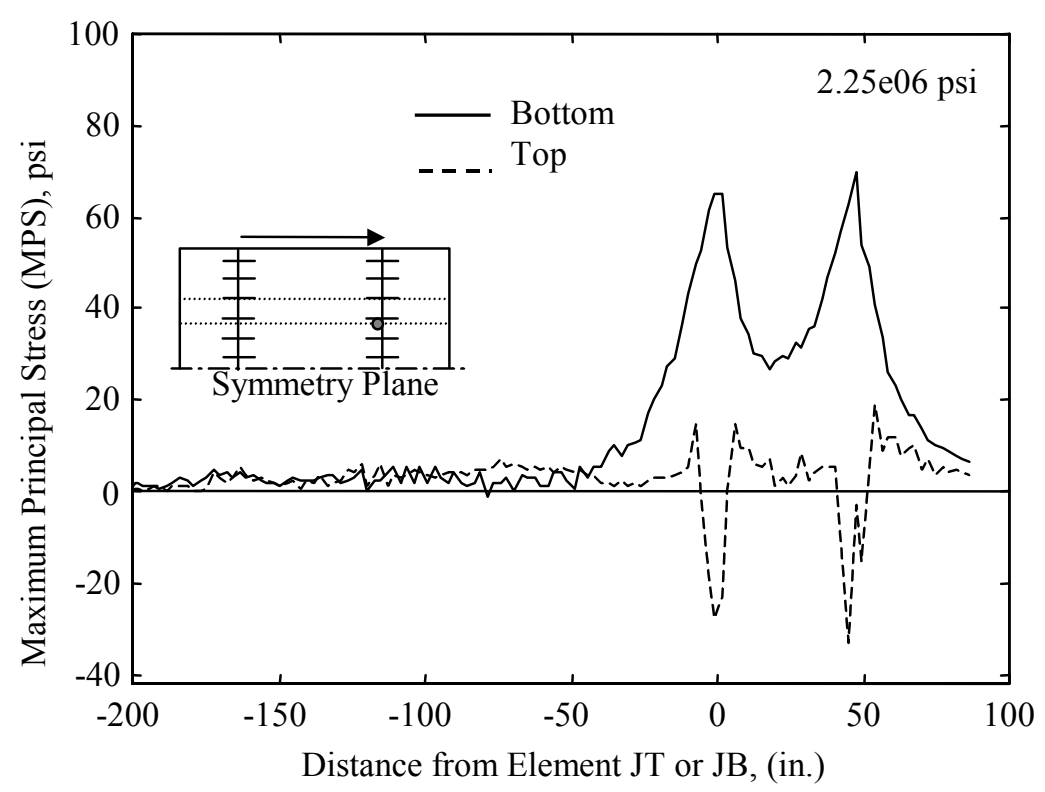

(c)

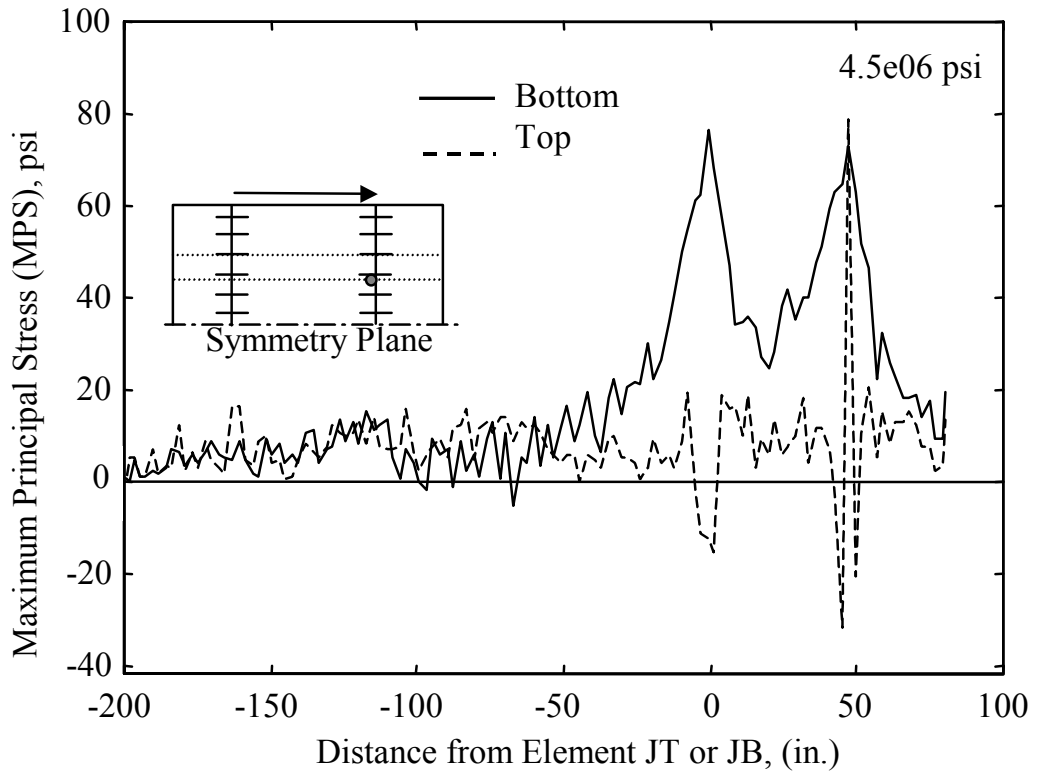

(b)

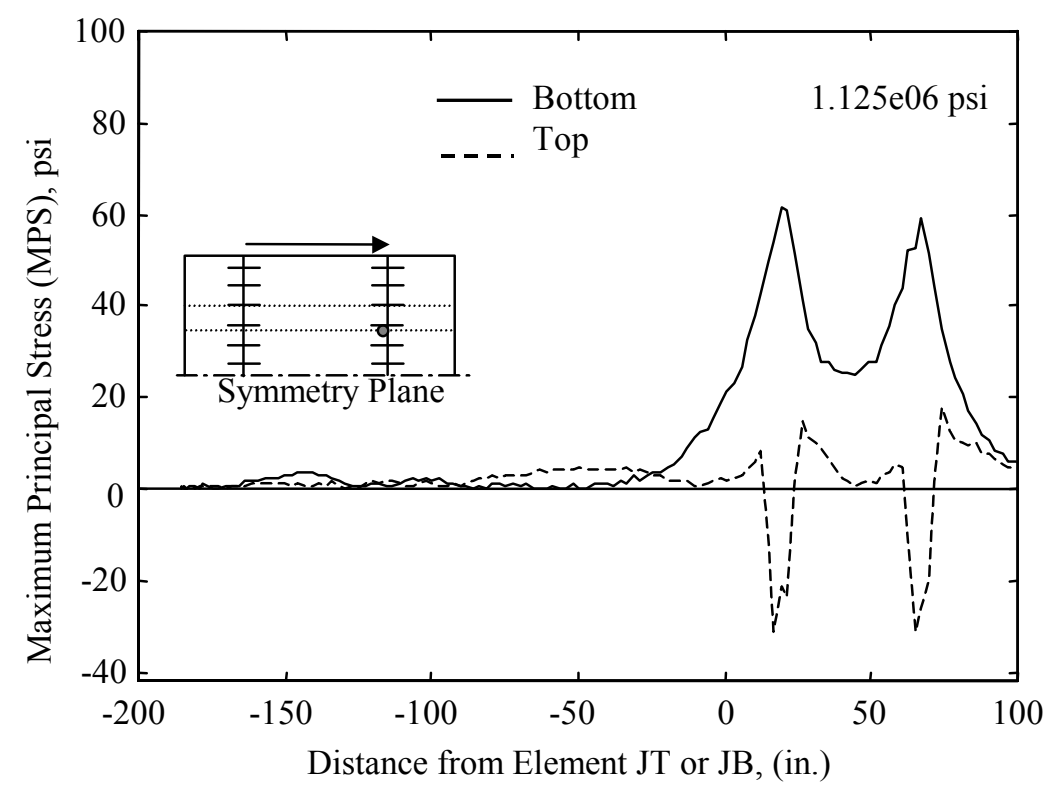

(d)

FIGURE 4.2 Effect of Concrete Modulus on Distribution of Maximum Principal Stress at the Transverse Joint 

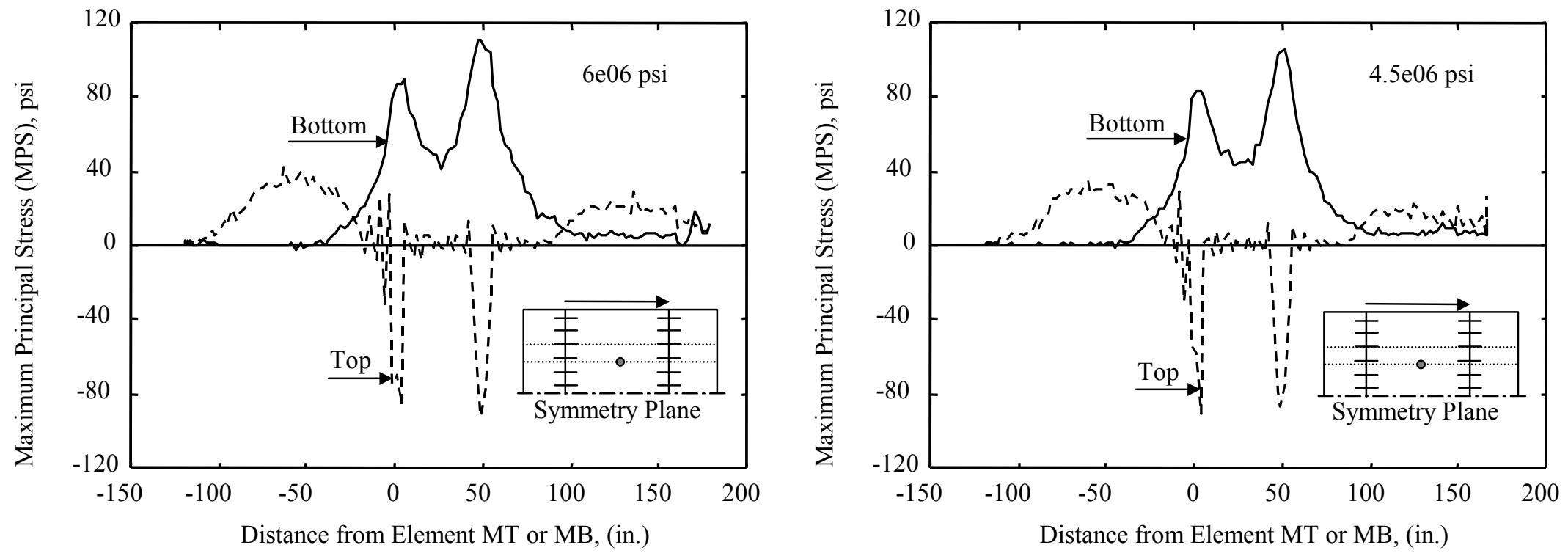

(a)

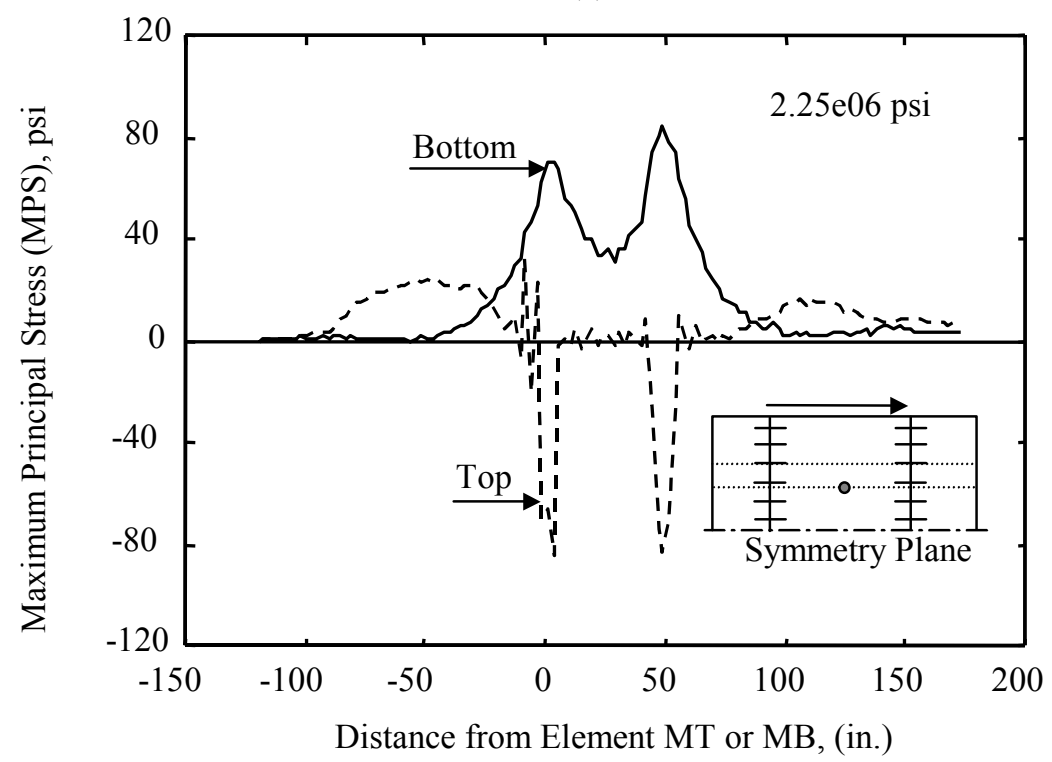

(c)

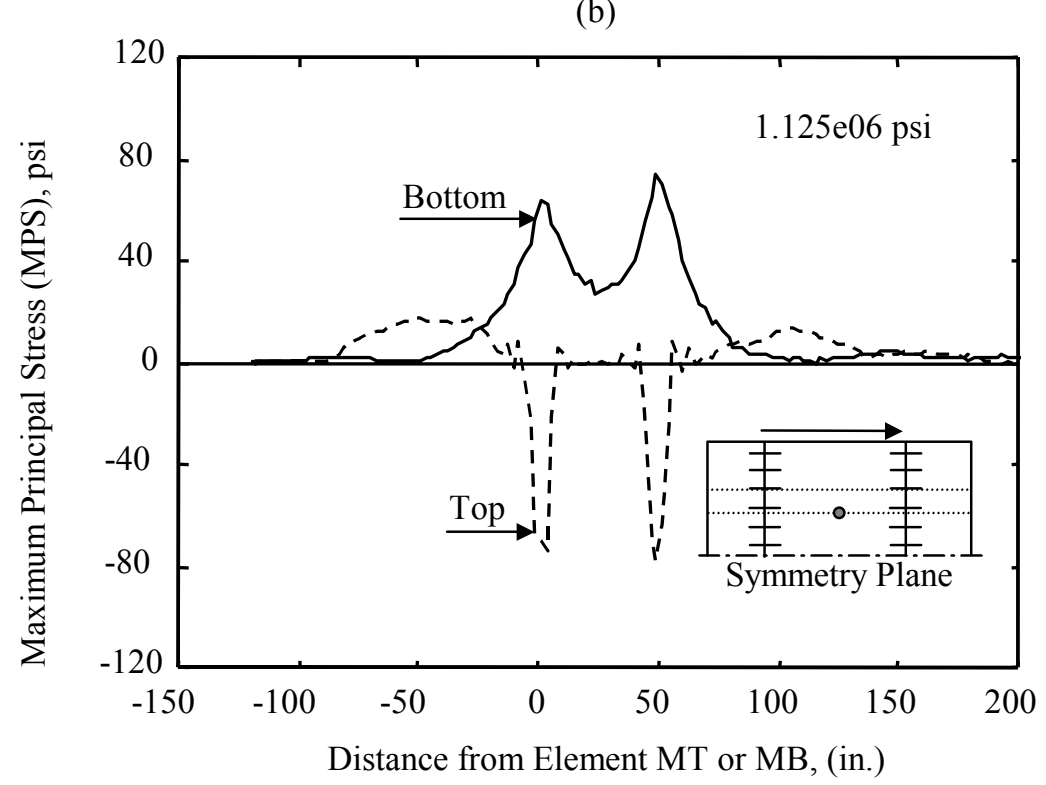

(d)

FIGURE 4.3 Effect of Concrete Modulus on Distribution of Maximum Principal Stress at the Middle of the Slab 

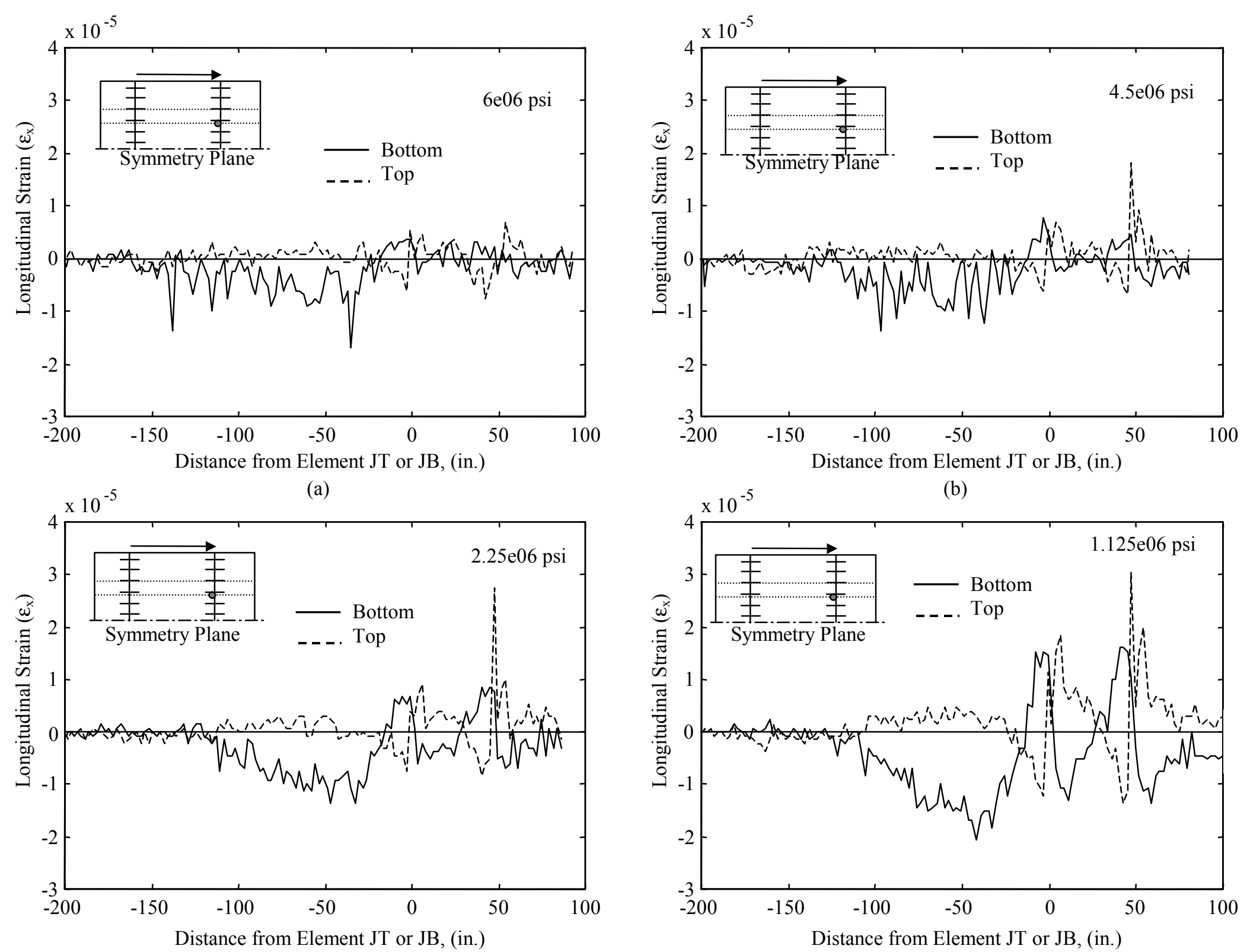

(c)

(d)

FIGURE 4.4 Effect of Concrete Modulus on Distribution of Longitudinal Strain in the Transverse Joint 

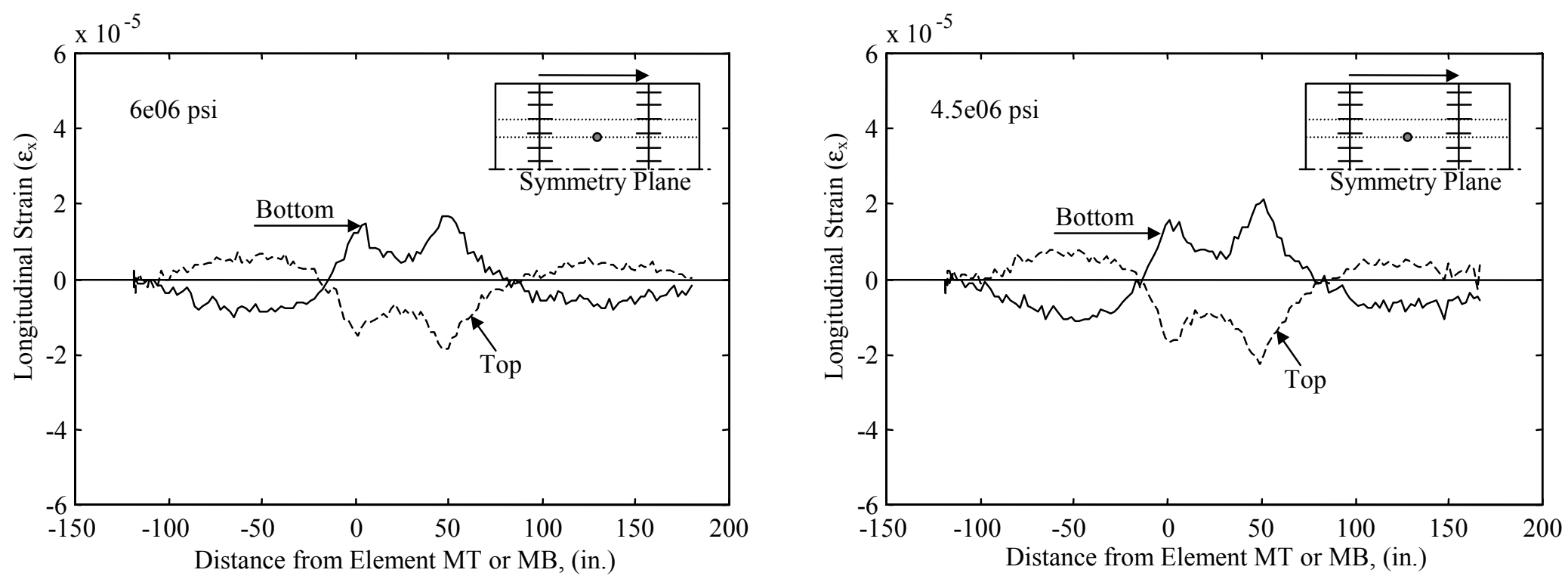

(a)

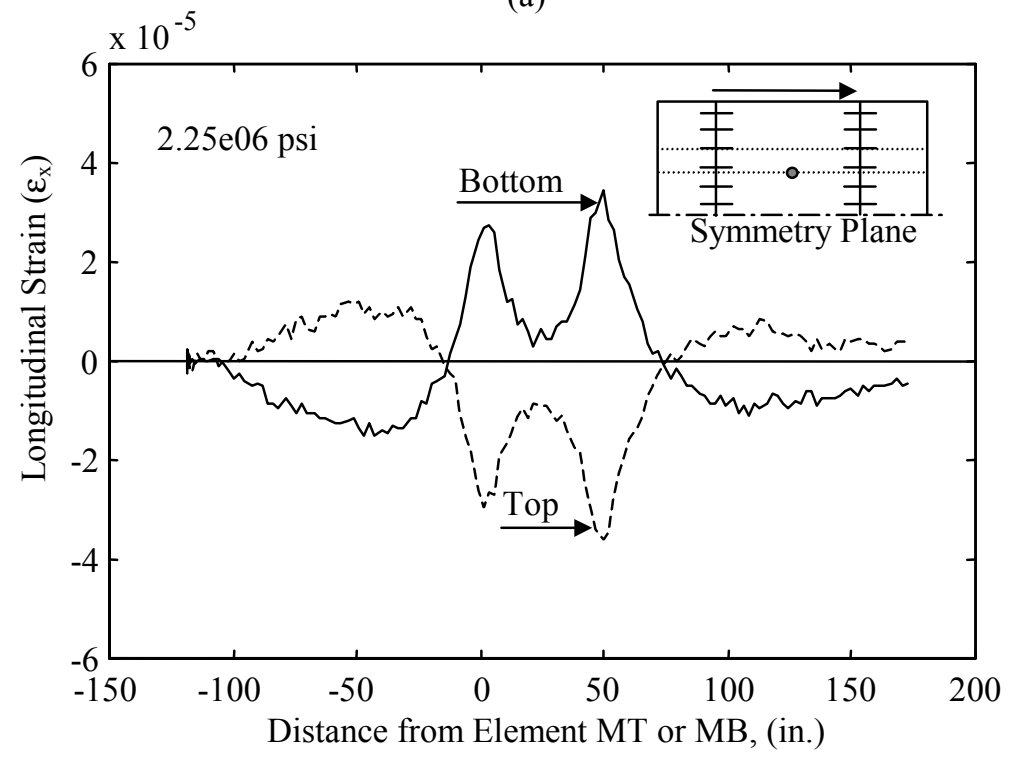

(c)

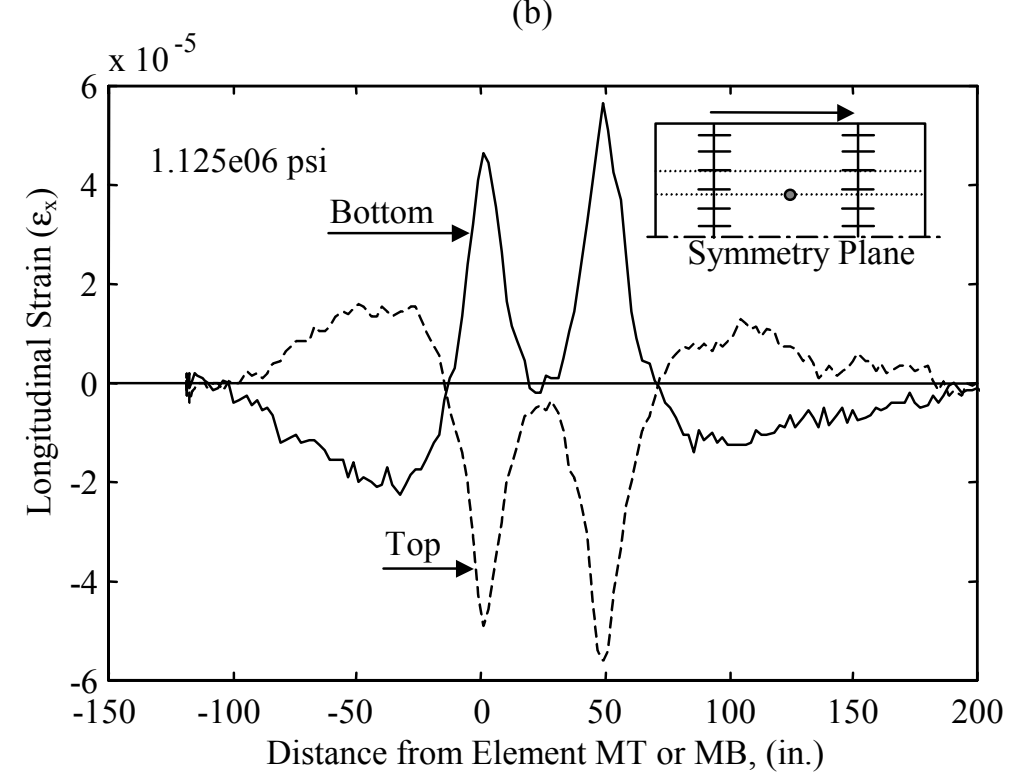

(d)

FIGURE 4.5 Effect of Concrete Modulus on Distribution of Longitudinal Strain at the Middle of the Slab 

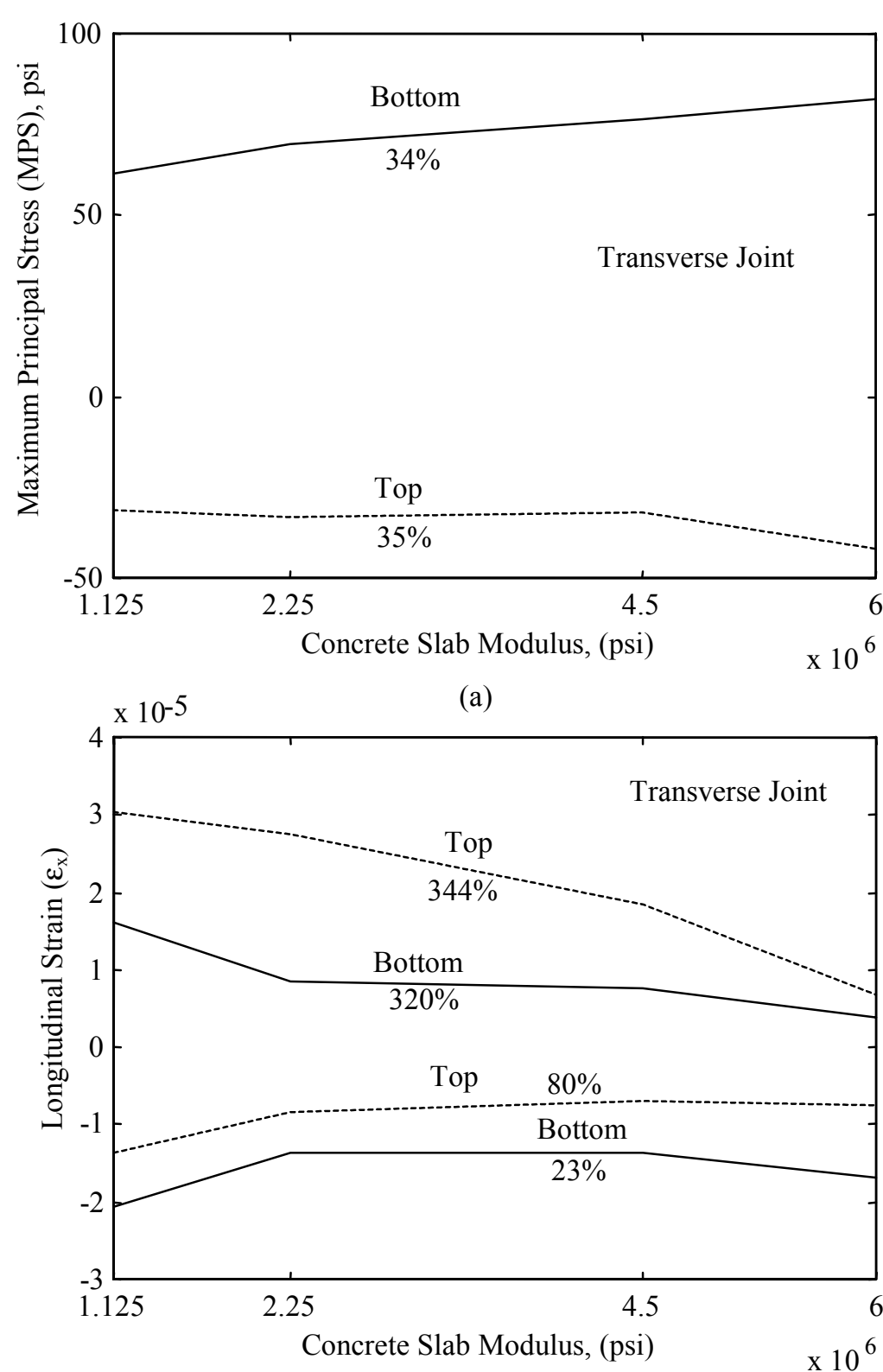

(c)
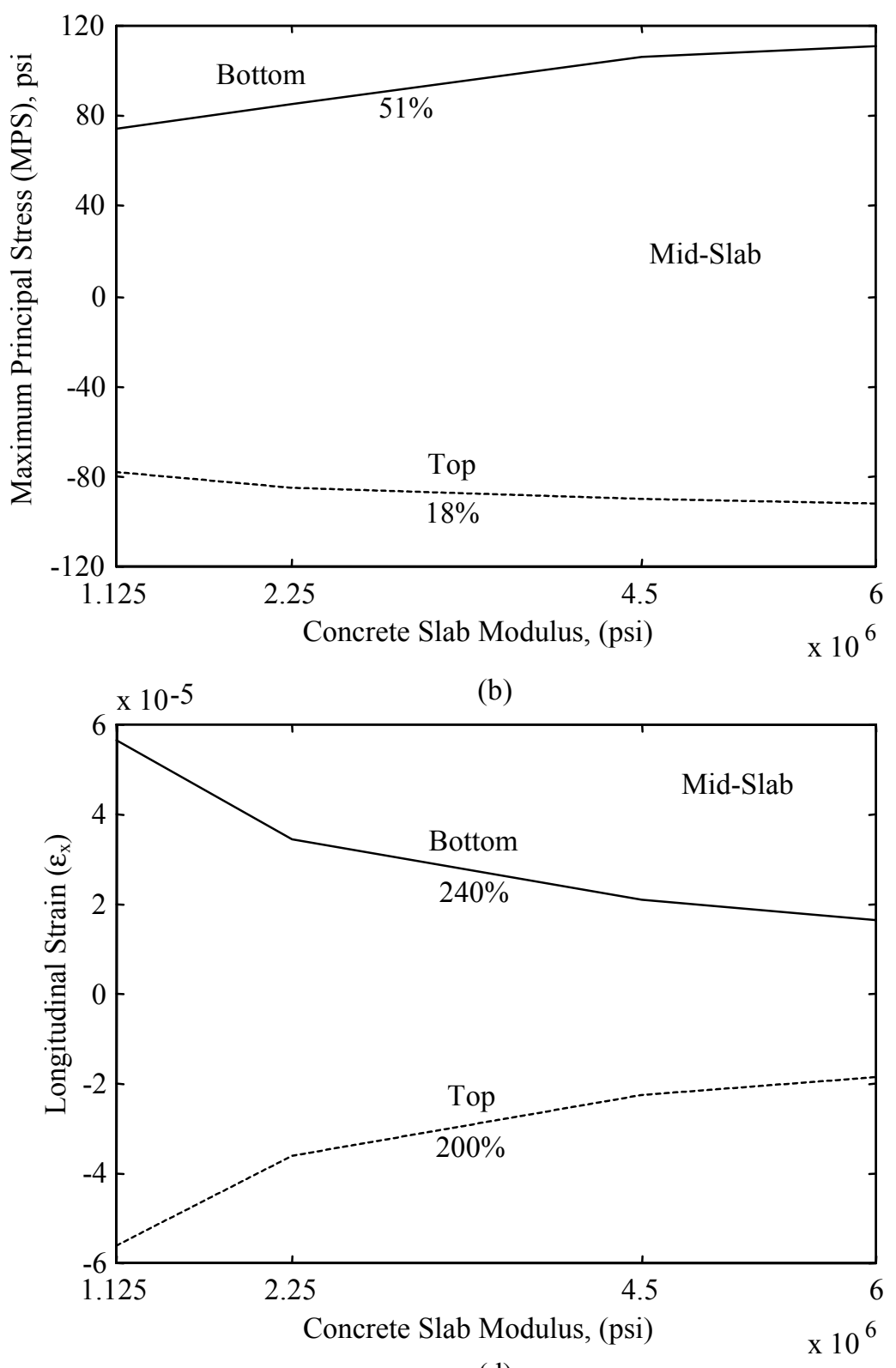

(d)

Figure 4.6 Effect of Concrete Modulus on Peak Principal Stress and Peak Longitudinal Strain in the Concrete Slab 


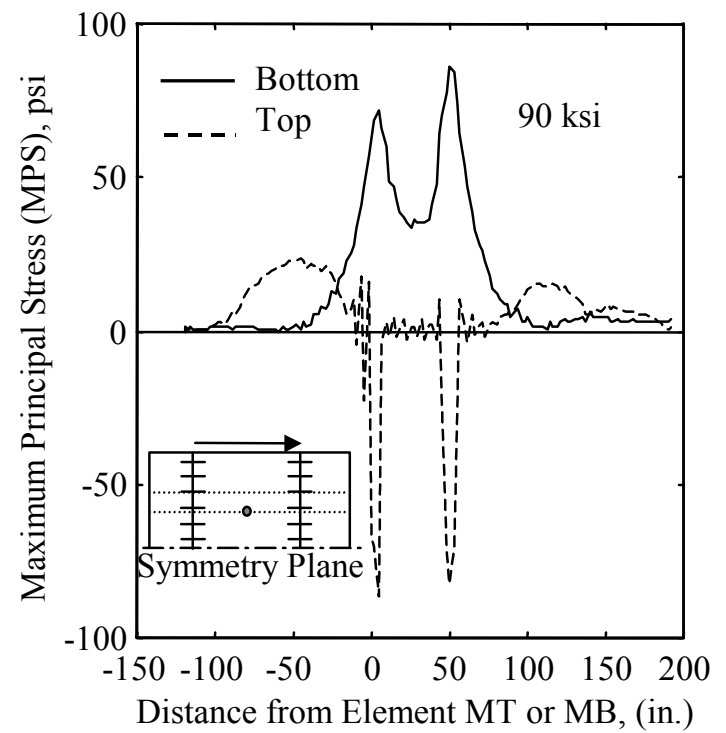

(a)

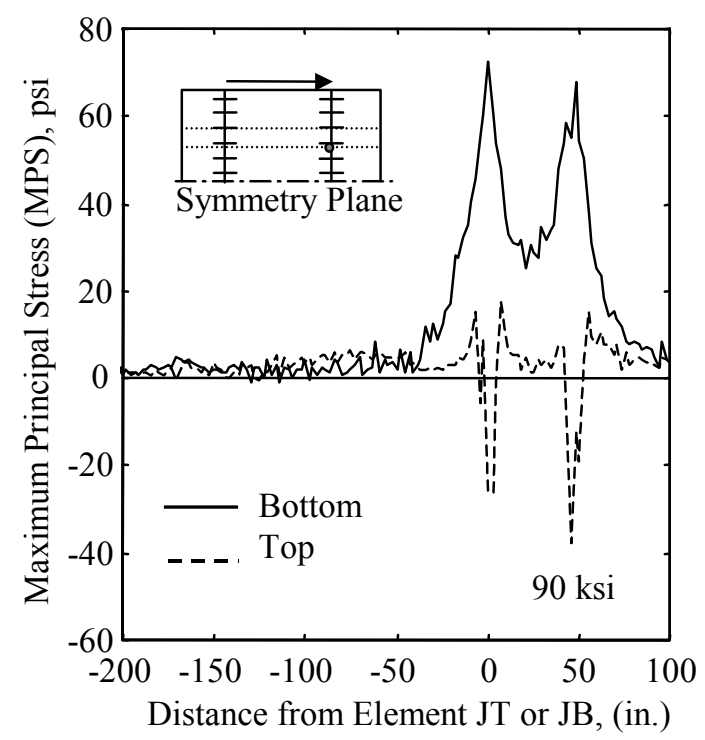

(d)

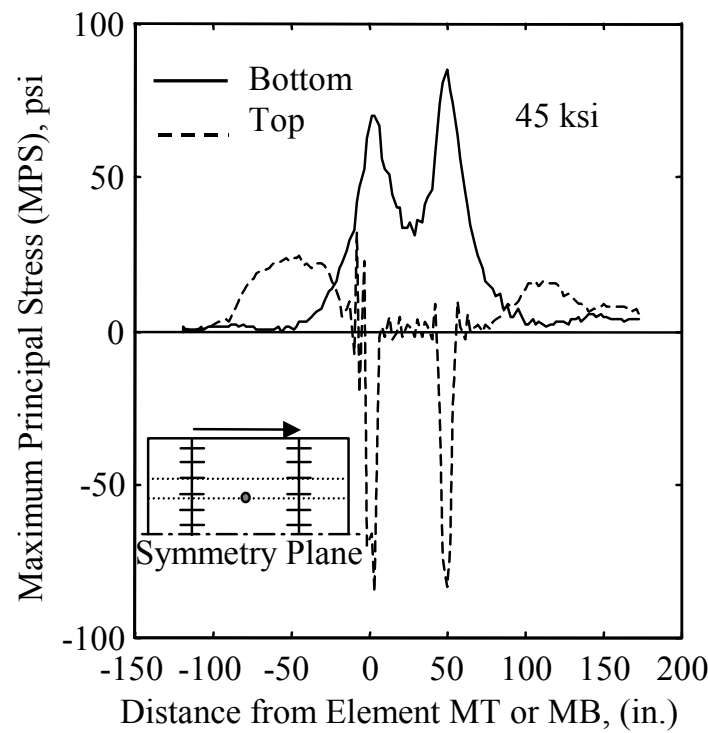

(b)

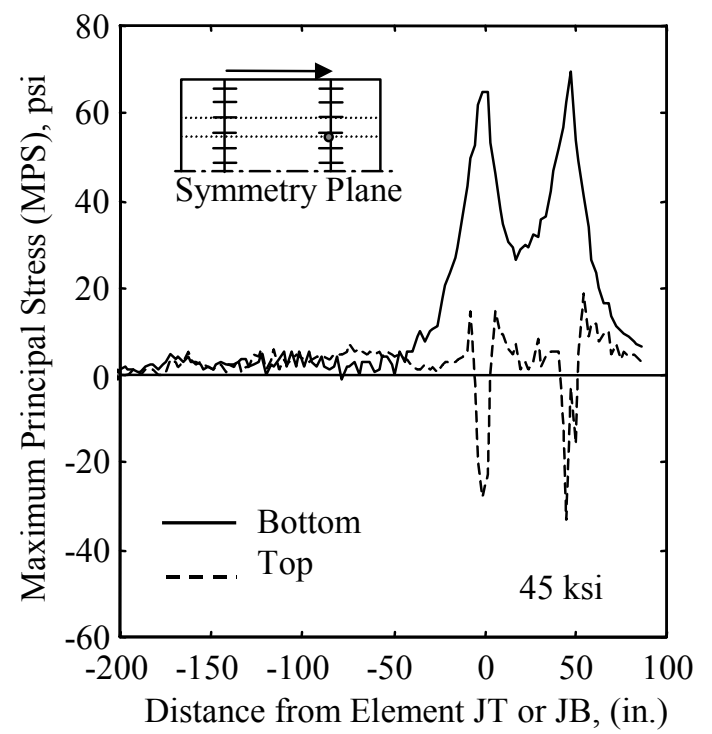

(e)

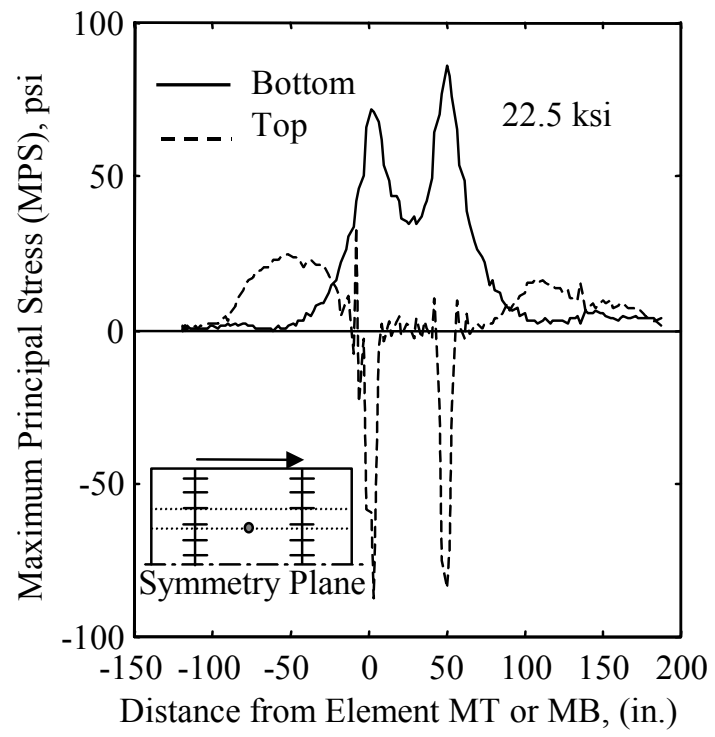

(c)

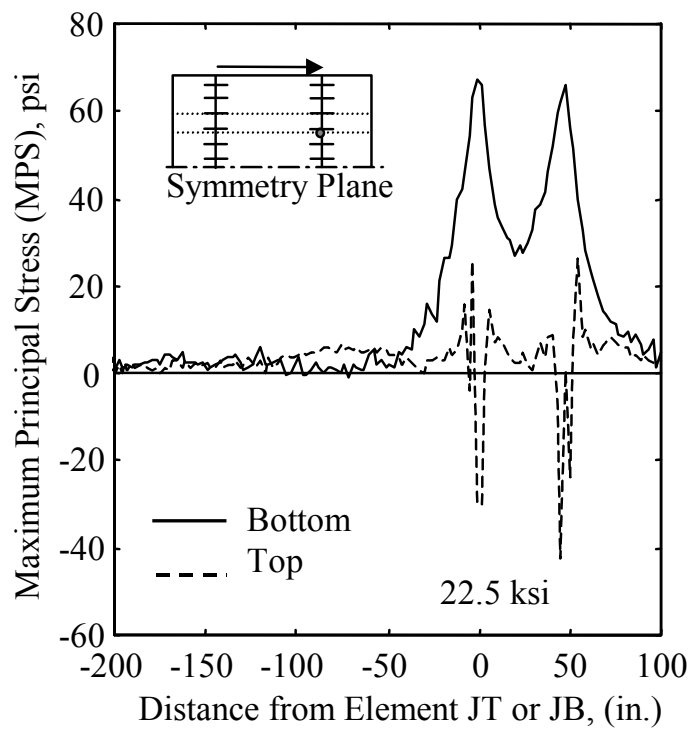

(f)

FIGURE 4.7 Effect of Base Course Modulus on Maximum Principal Stress Distribution in the Concrete Slab 


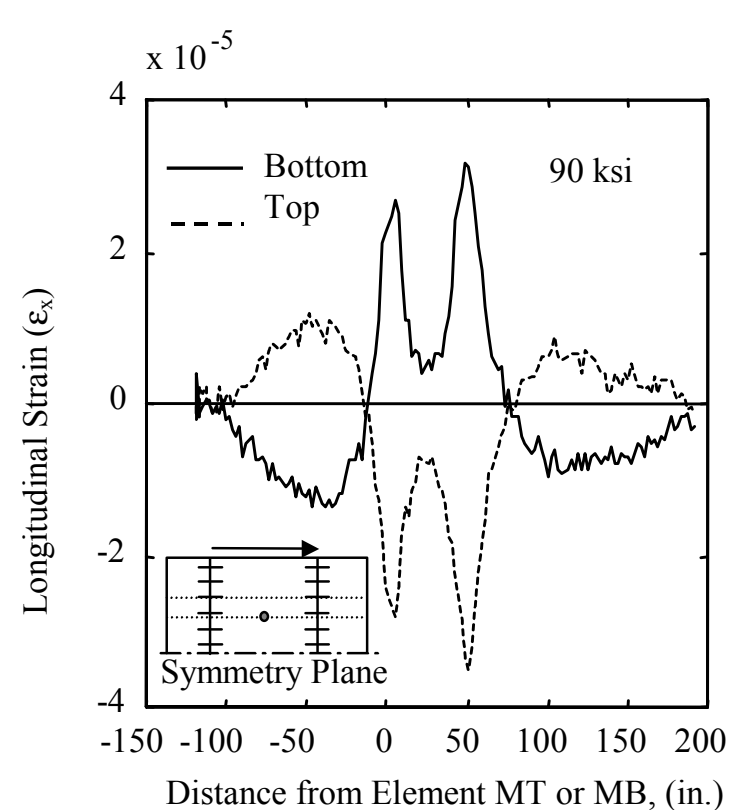

(a)

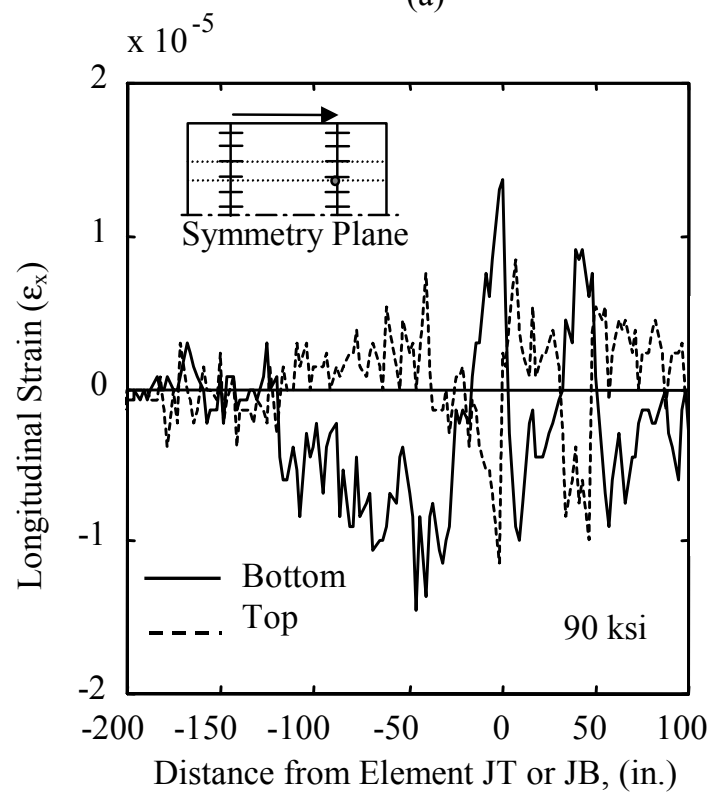

(d)

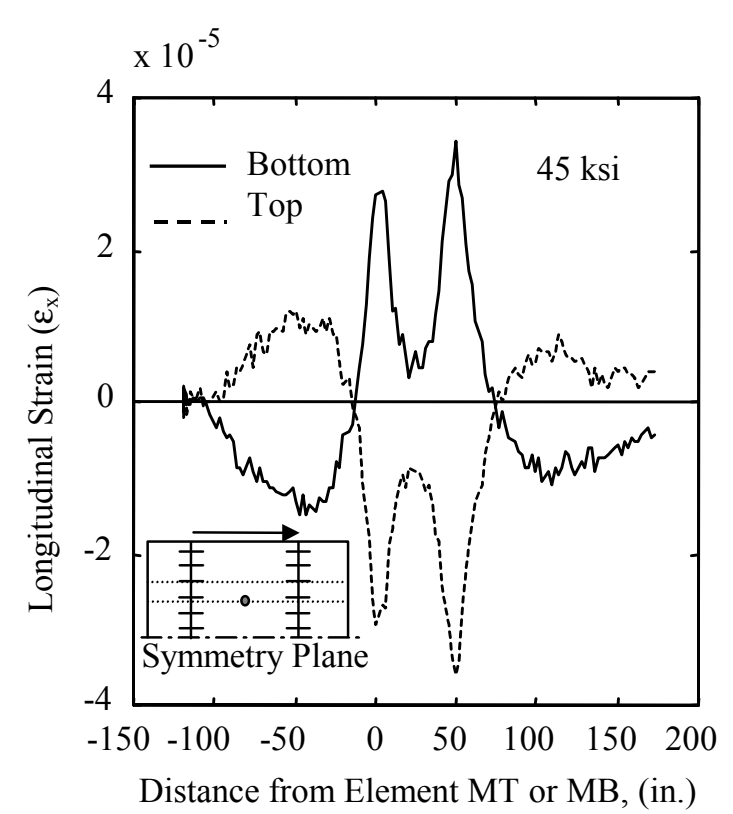

(b)

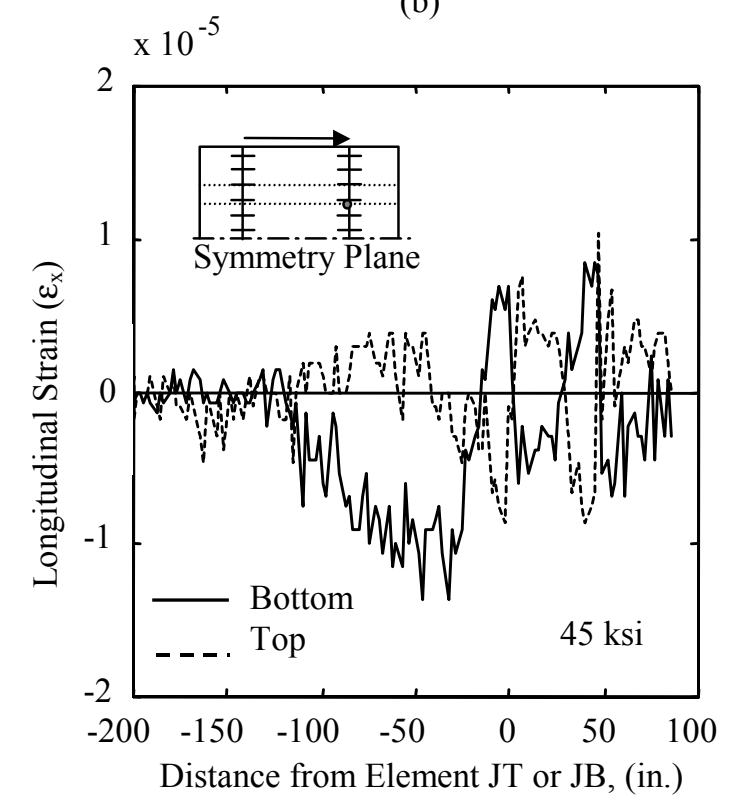

(e)

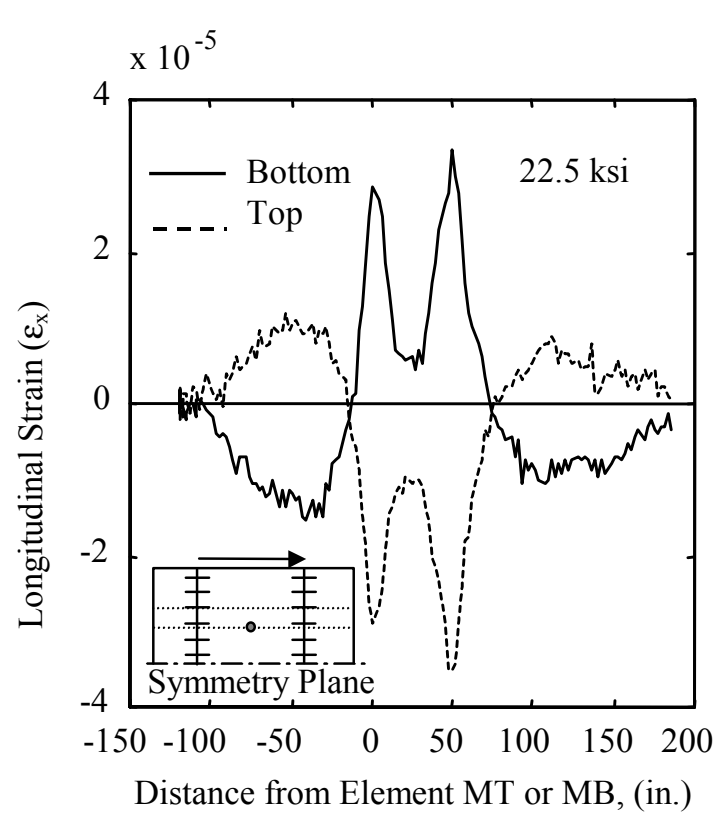

(c)

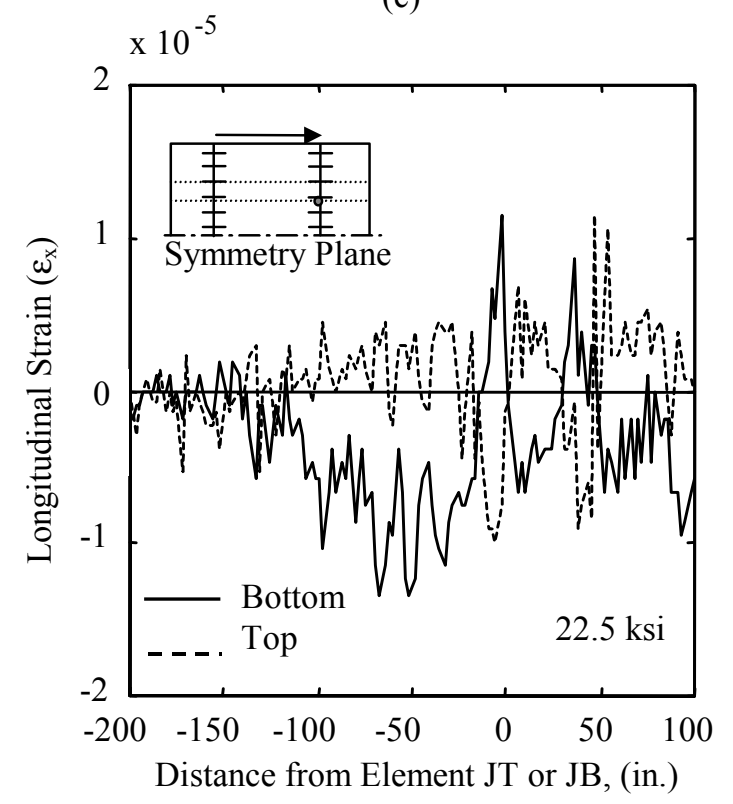

(f)

FIGURE 4.8 Effect of Base Course Modulus on Longitudinal Strain in the Concrete Slab 


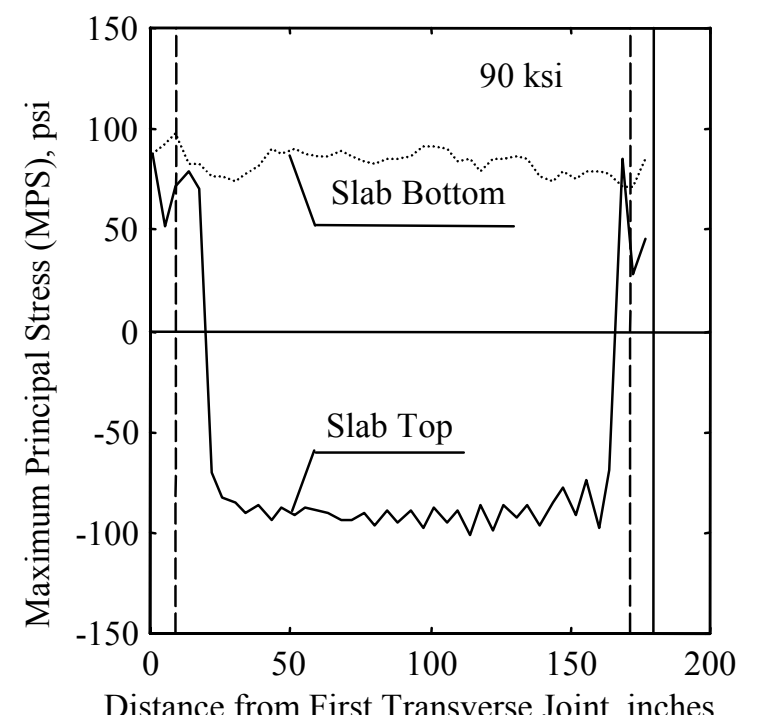

Distance from First Transverse Joint, inches

(a)

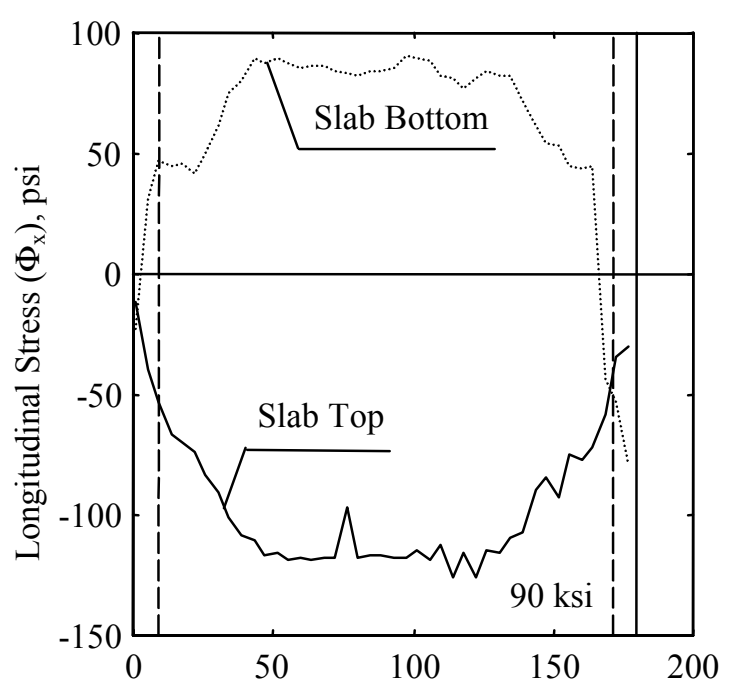

Distance from First Transverse Joint, inches

(d)

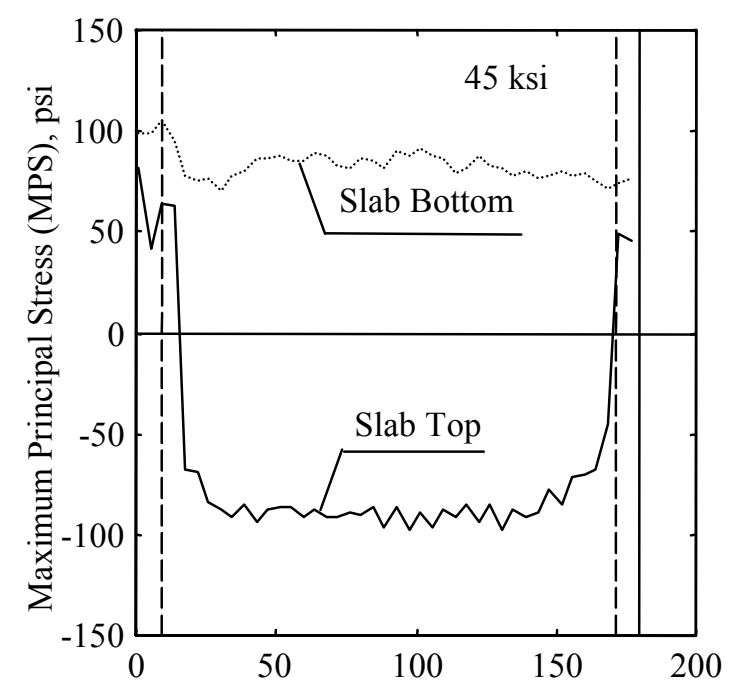

Distance from First Transverse Joint, inches

(b)

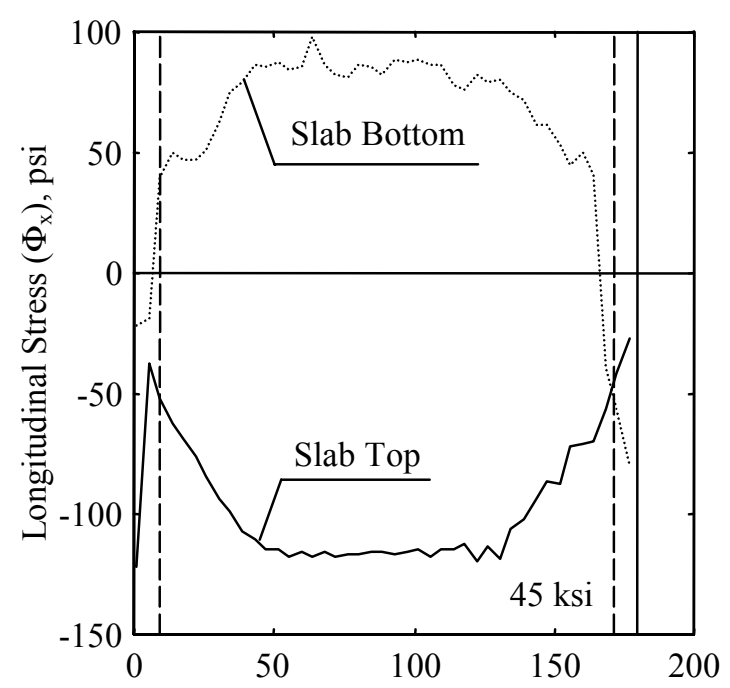

Distance from First Transverse Joint, inches

(e)

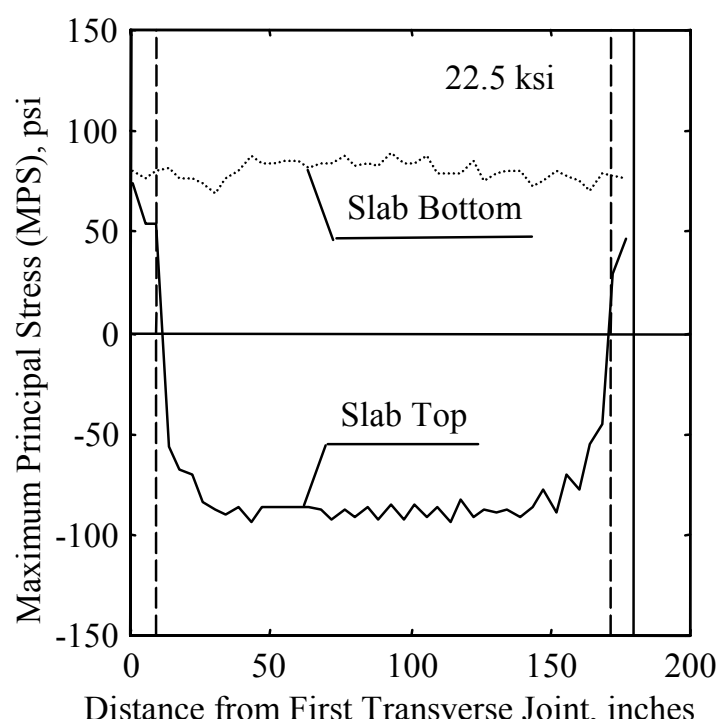

(c)

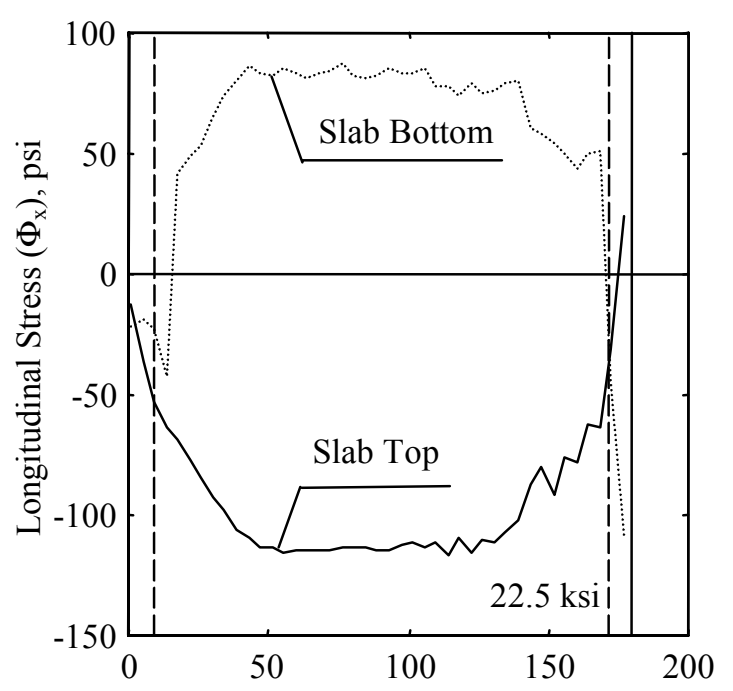

Distance from First Transverse Joint, inches

(f)

FIGURE 4.9 Effect of Base Course Modulus on the Distribution of Peak Principal and Longitudinal Stresses in the Concrete Slab 


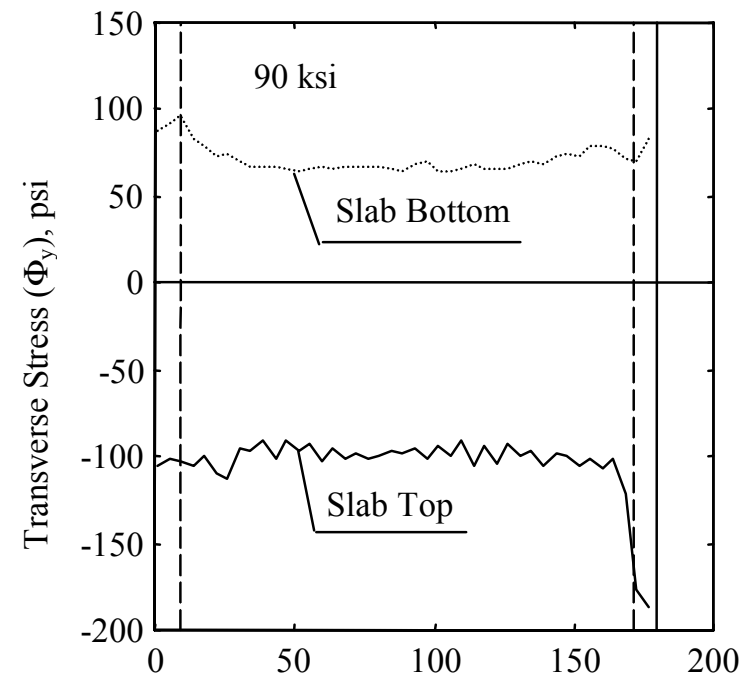

Distance from First Transverse Joint, inches

(a)

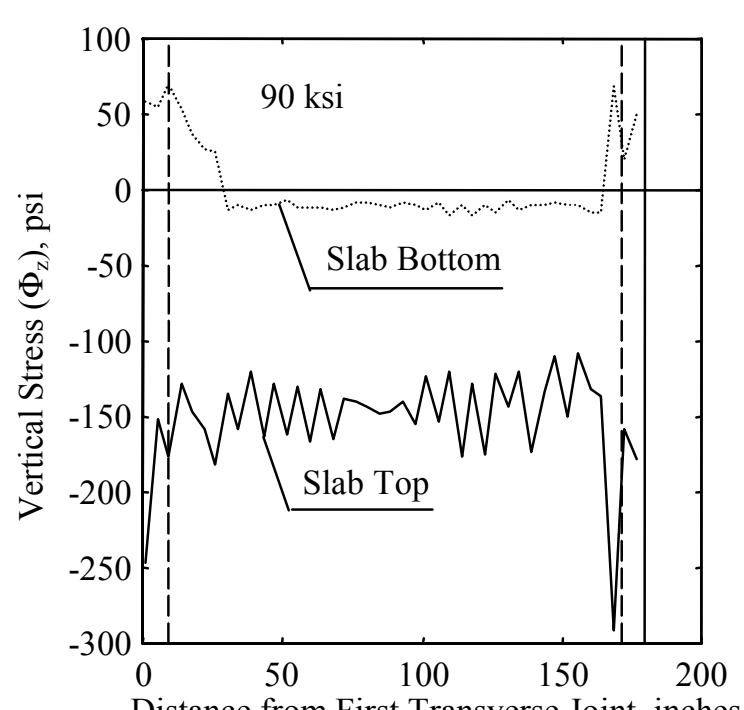

Distance from First Transverse Joint, inches

(d)

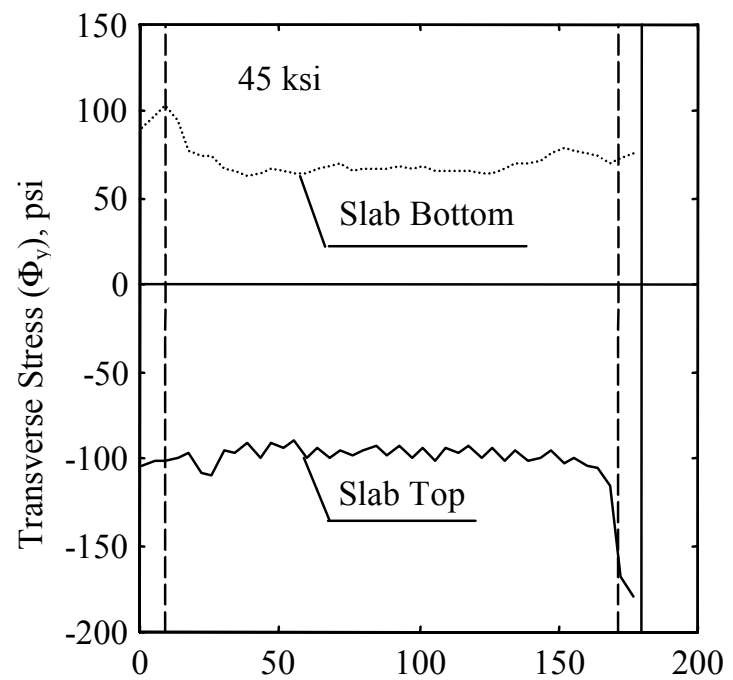

Distance from First Transverse Joint, inches

(b)

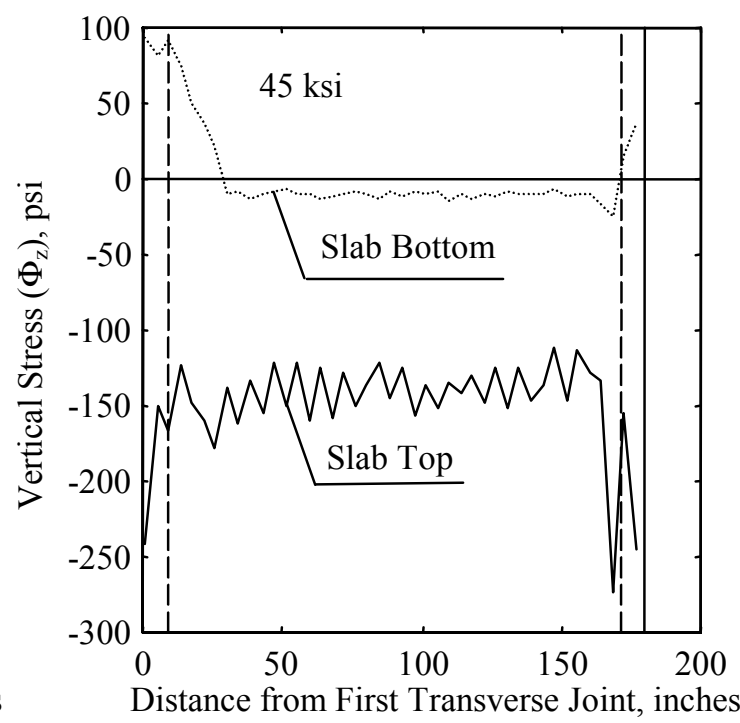

(e)

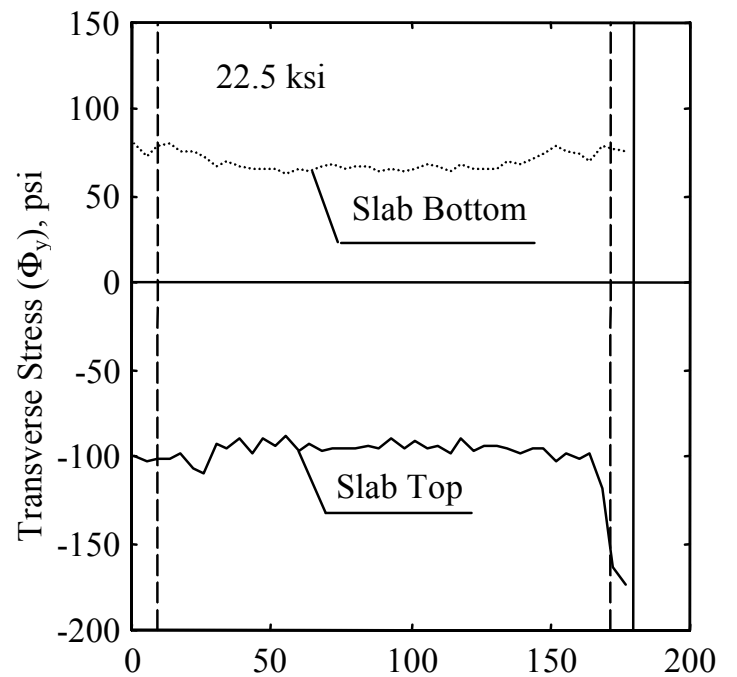

Distance from First Transverse Joint, inches

(c)

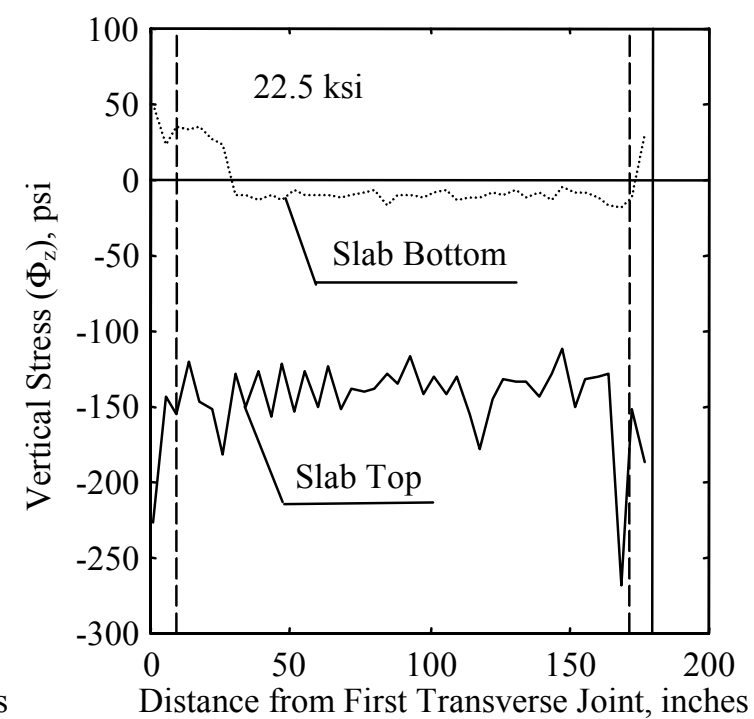

(f)

FIGURE 4.10 Effect of Base Course Modulus on the Distribution of Peak Transverse and Vertical Stresses in the Concrete Slab 


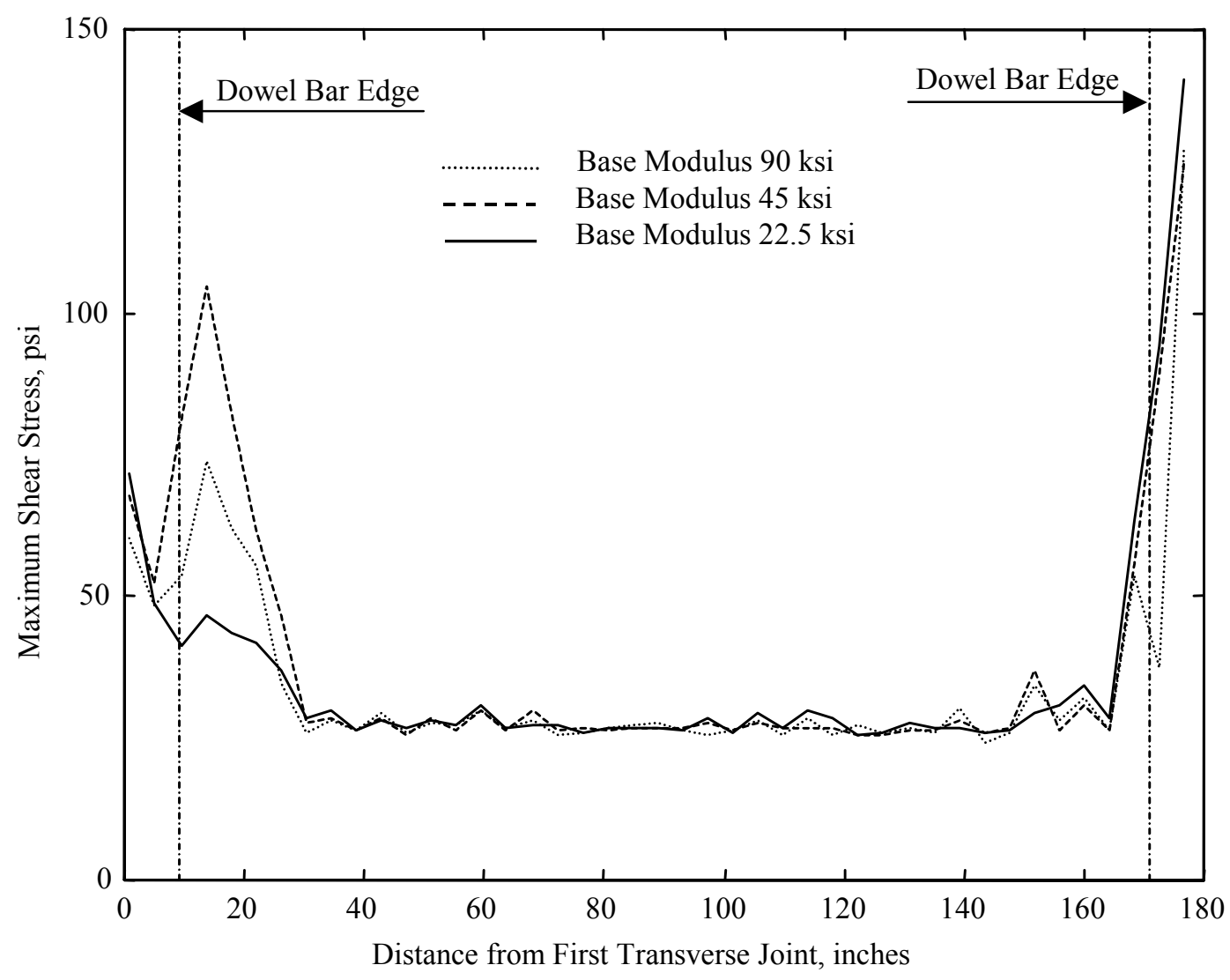

FIGURE 4.11 Effect of Base Course Modulus on Maximum Shear Stress in the Concrete Slab 


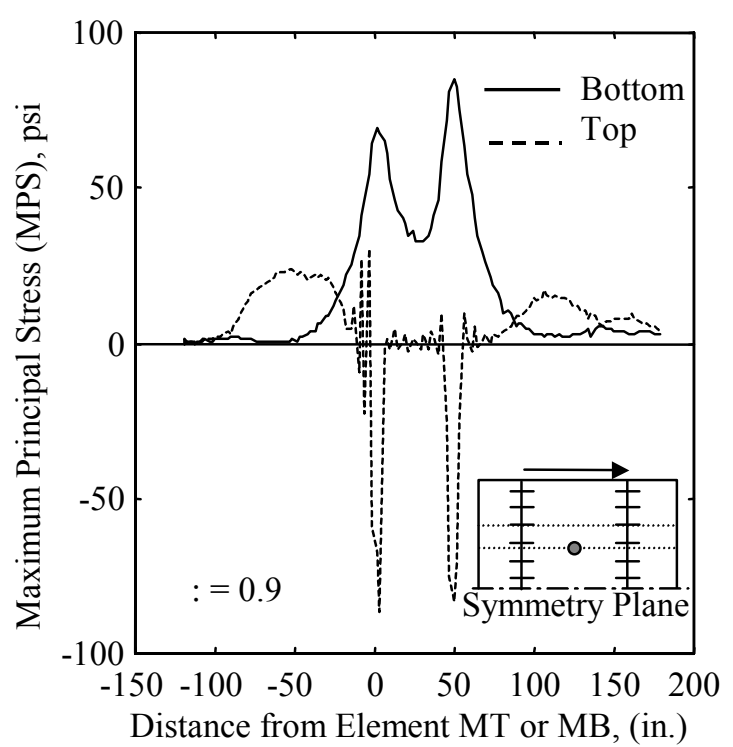

(a)

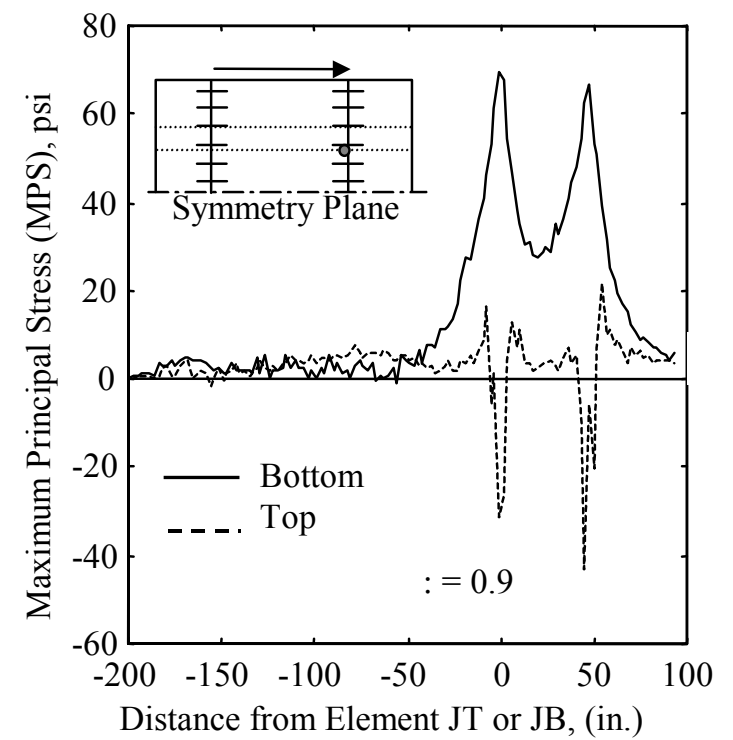

(d)

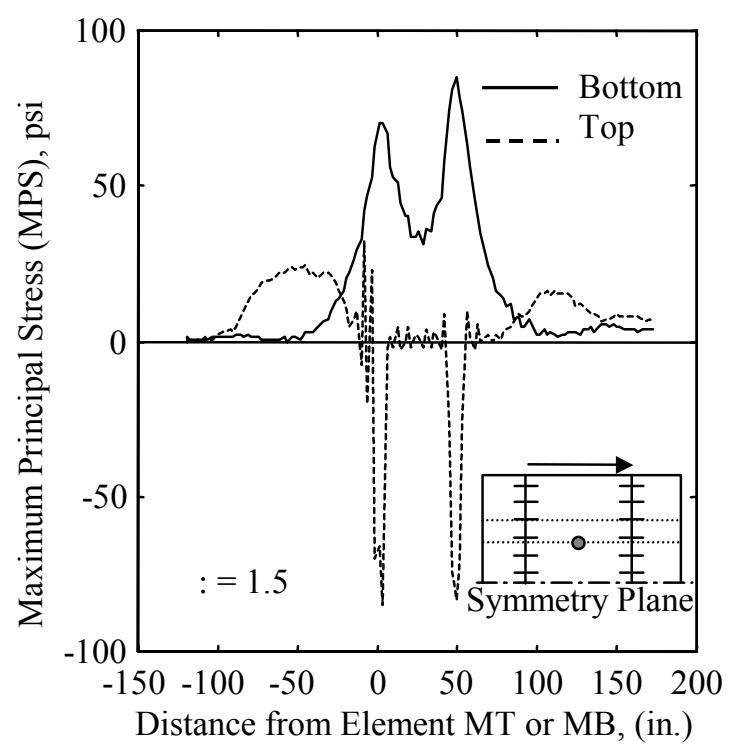

(b)

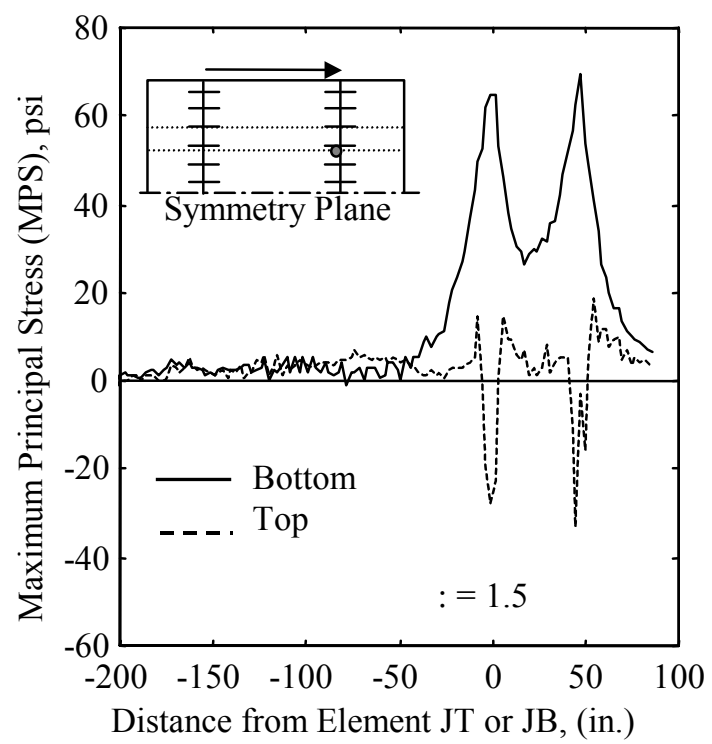

(e)

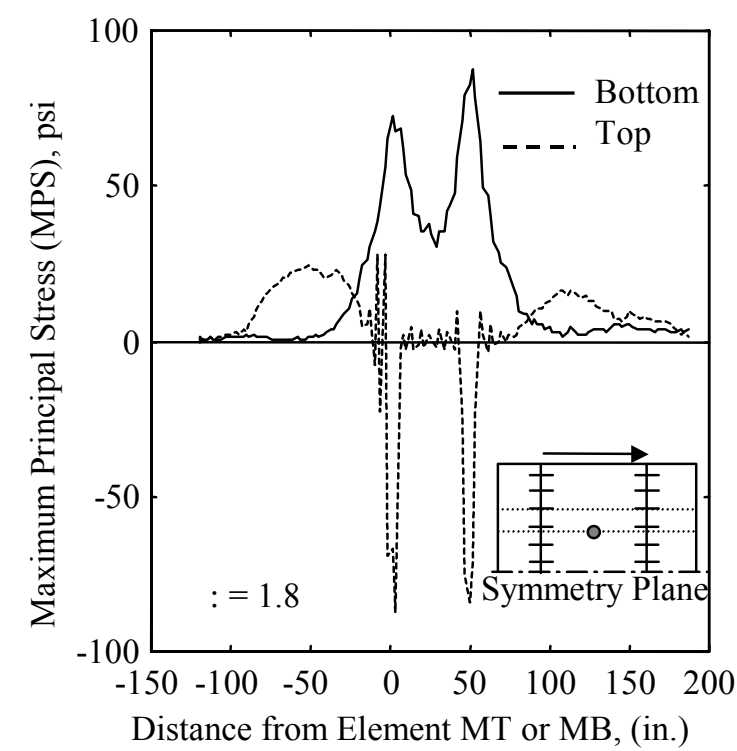

(c)

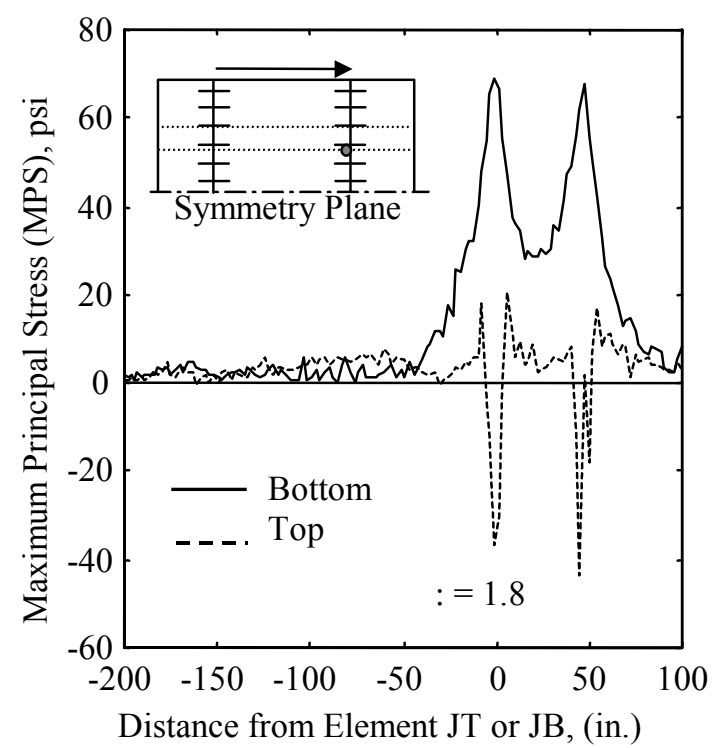

(f)

FIGURE 4.12 Effect of Friction Coefficient on Distribution of Maximum Principal Stress in the Concrete Slab 


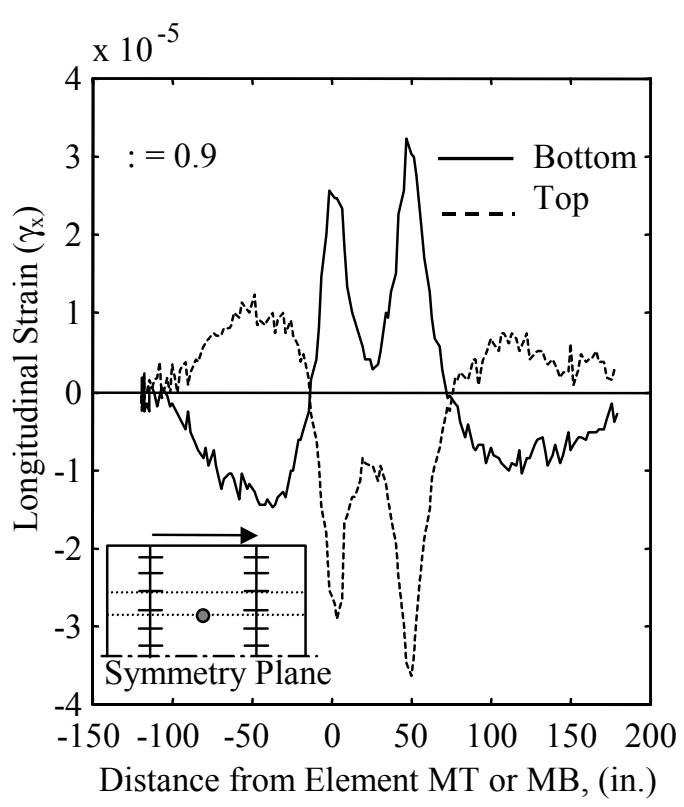

(a)

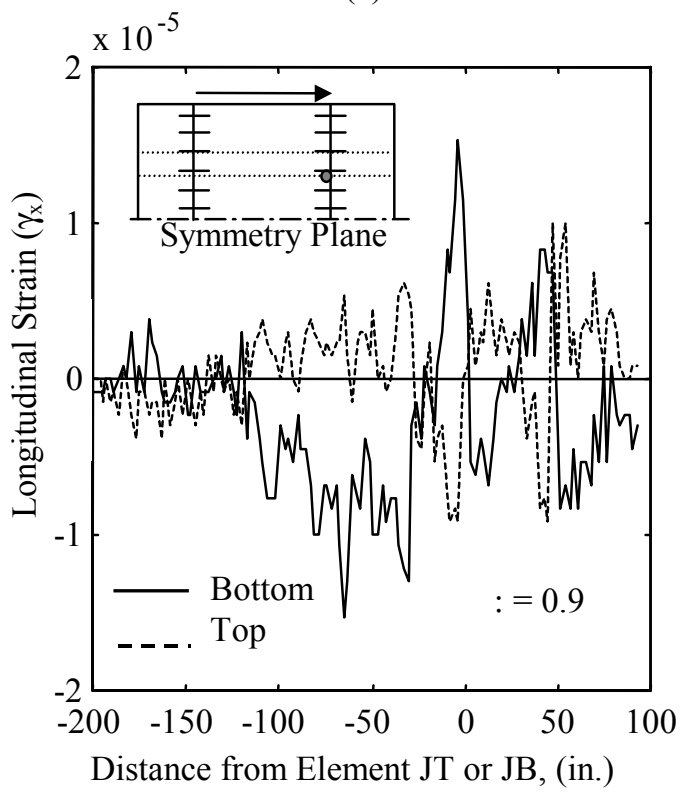

(d)

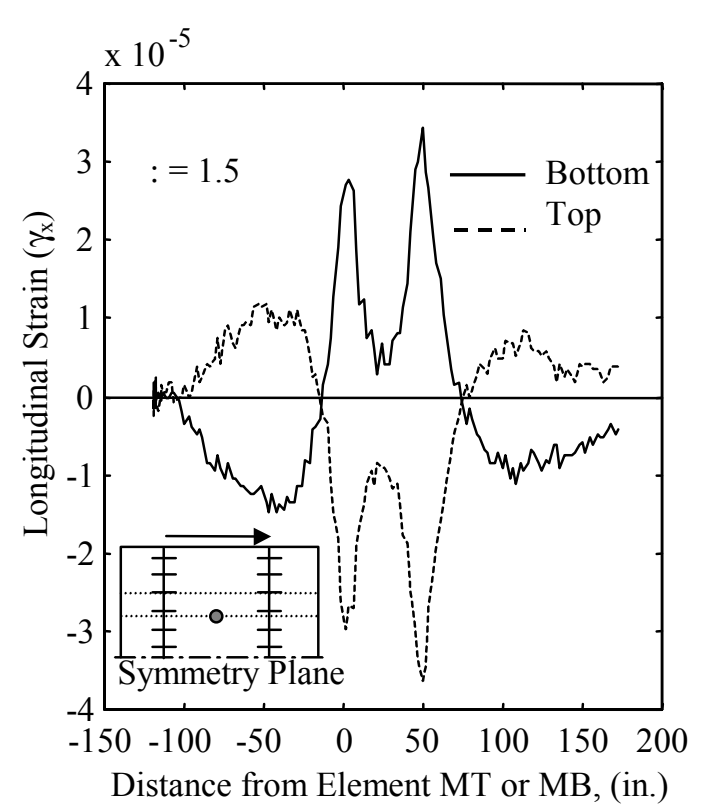

(b)

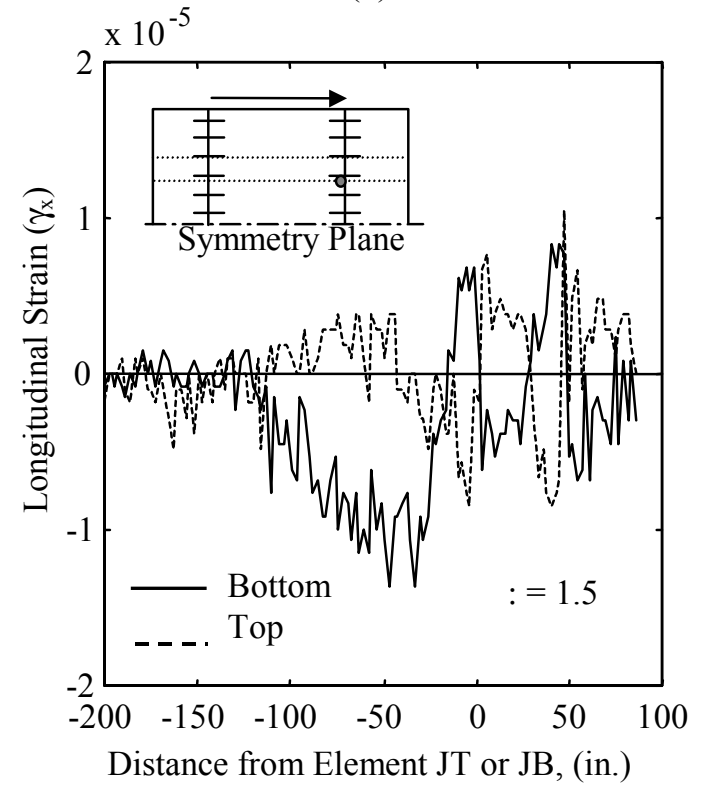

(e)

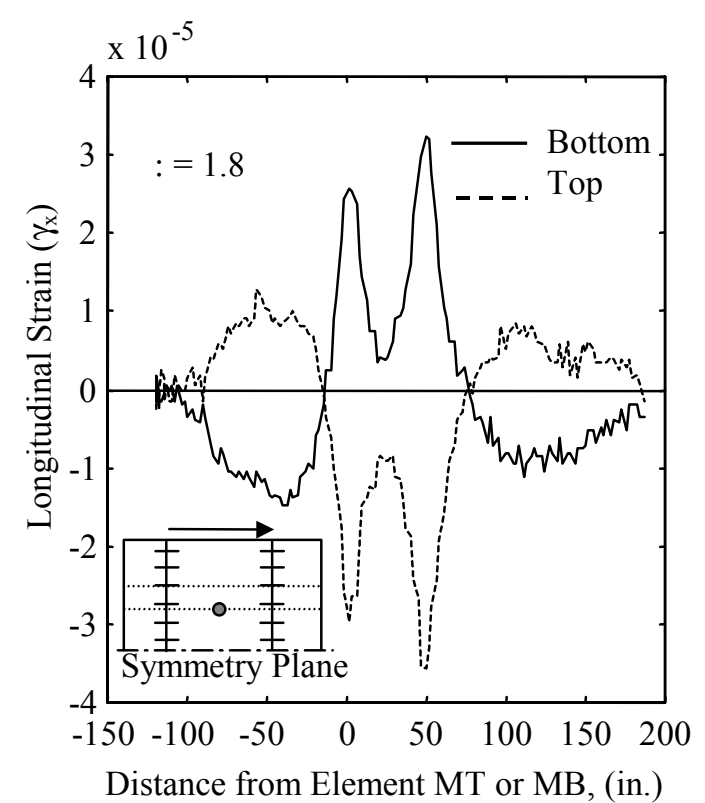

(c)

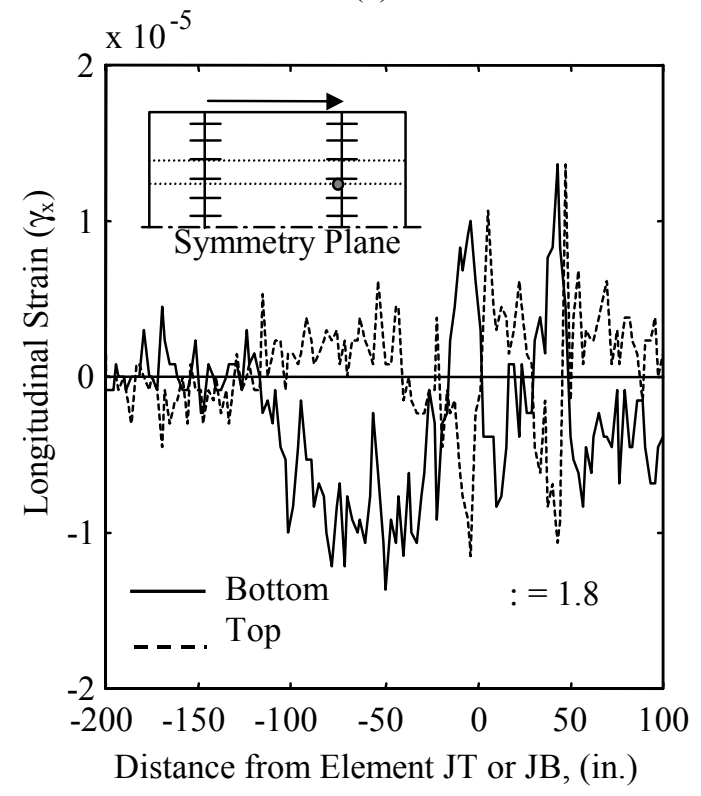

(f)

FIGURE 4.13 Effect of Friction Coefficient on Distribution of Longitudinal Strain in the Concrete Slab 


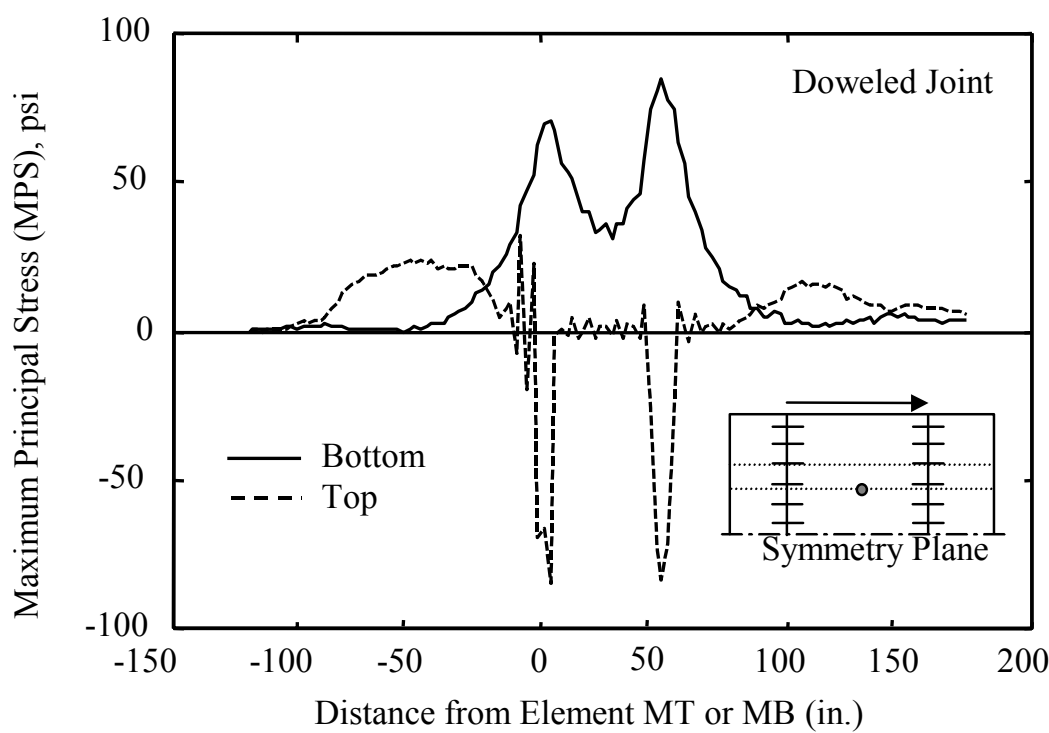

(a)

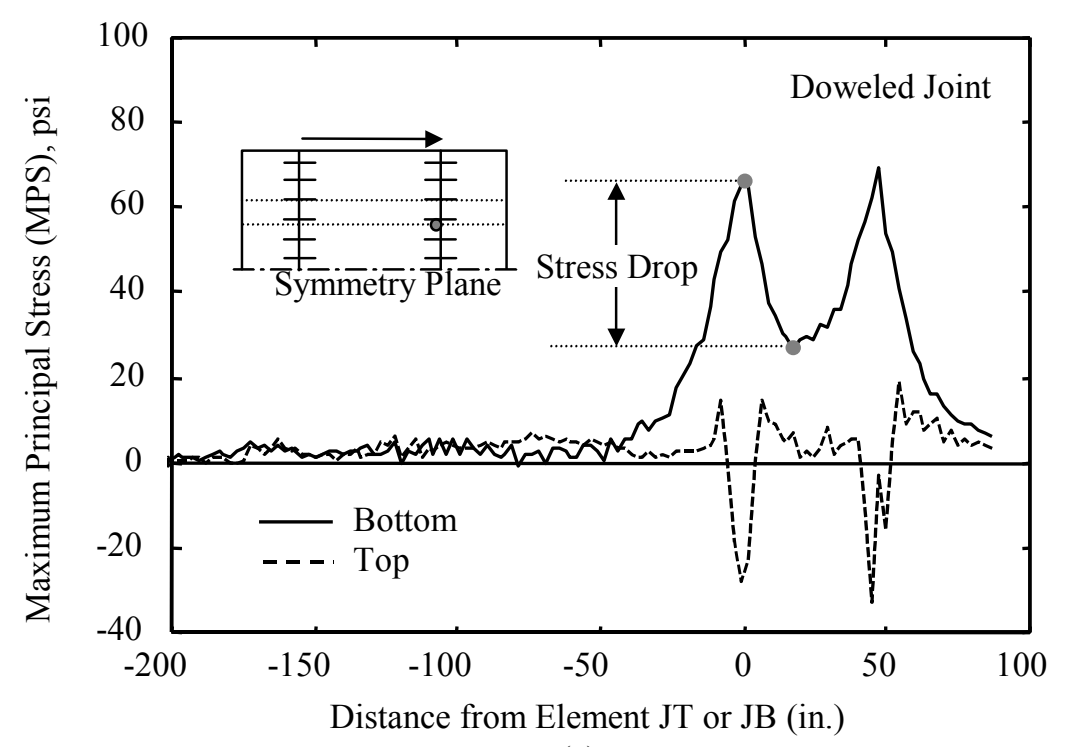

(c)

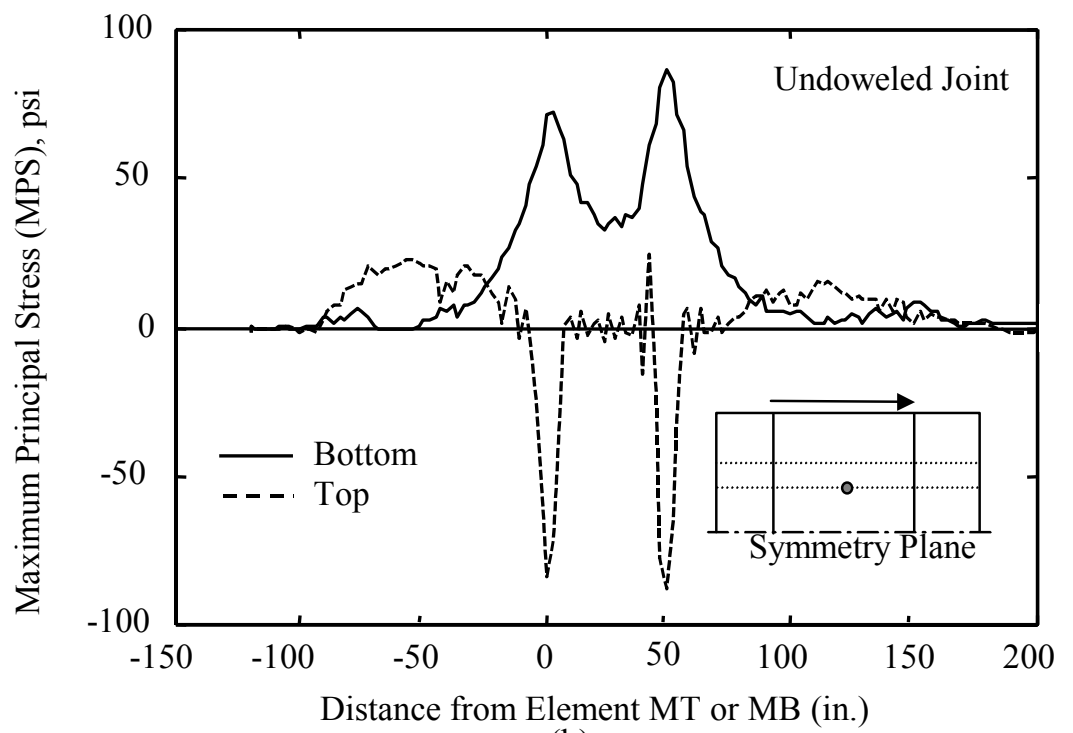

(b)

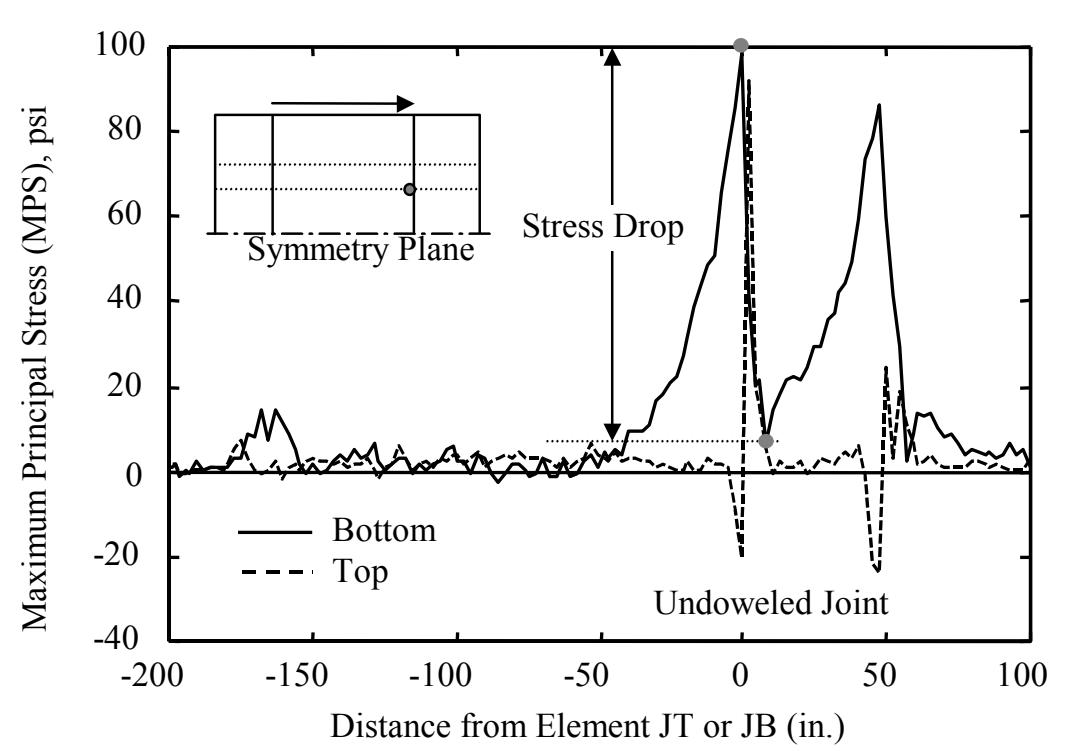

(d)

FIGURE 4.14 Effect of Dowel Bars on Distribution of Maximum Principal Stress in the Concrete Slab 


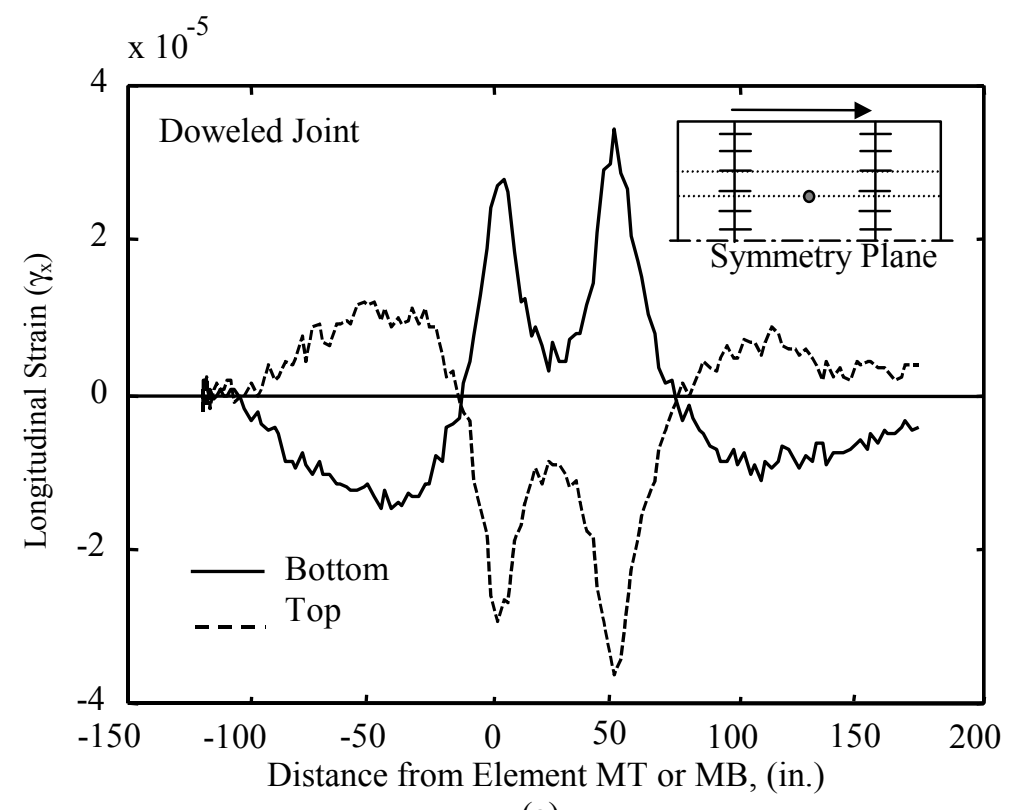

(a)

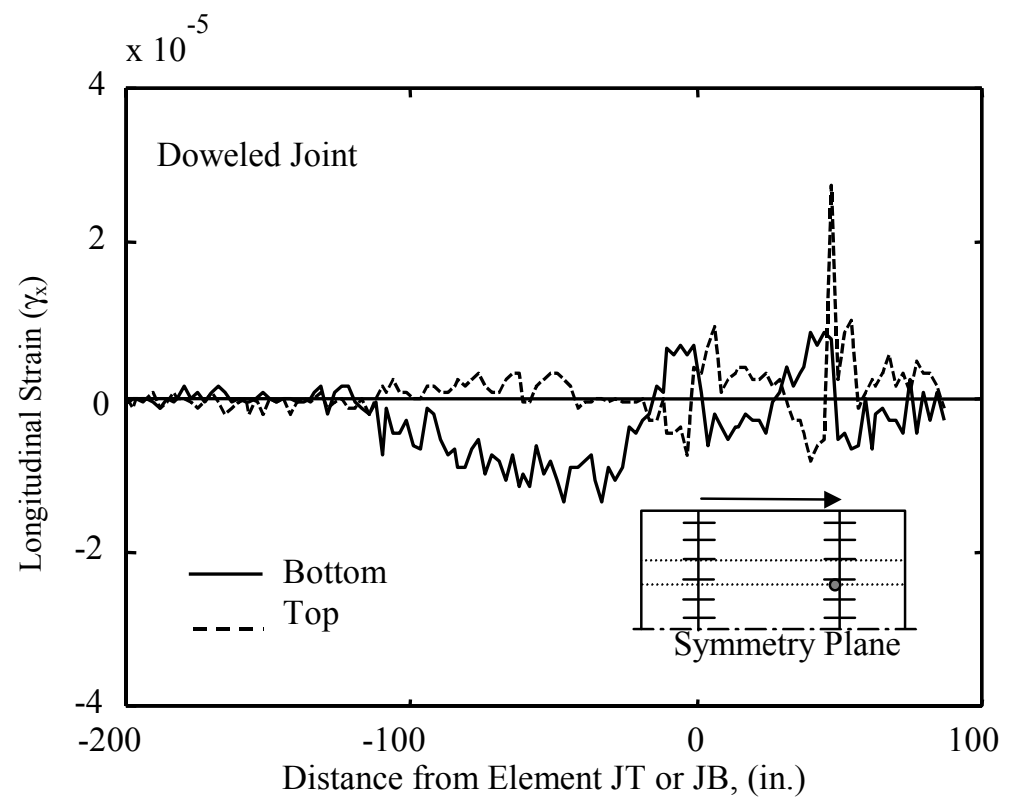

(c)

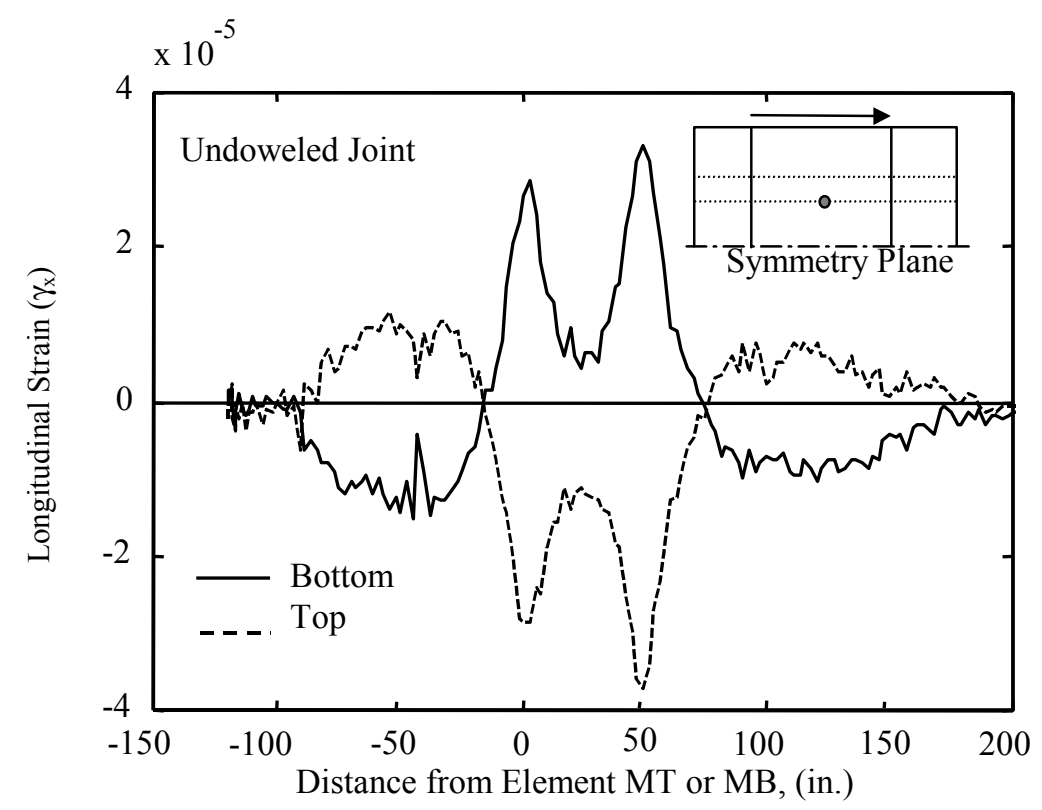

(b)

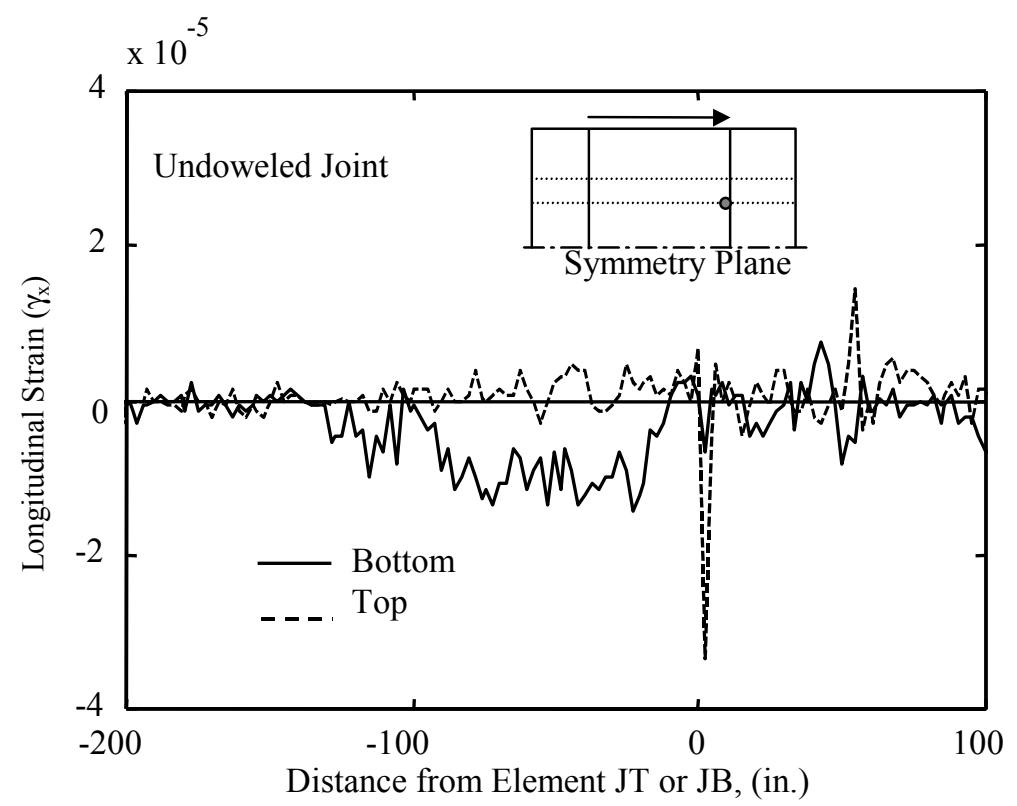

(d)

FIGURE 4.15 Effect of Dowel Bars on Distribution of Longitudinal Strain in the Slab 

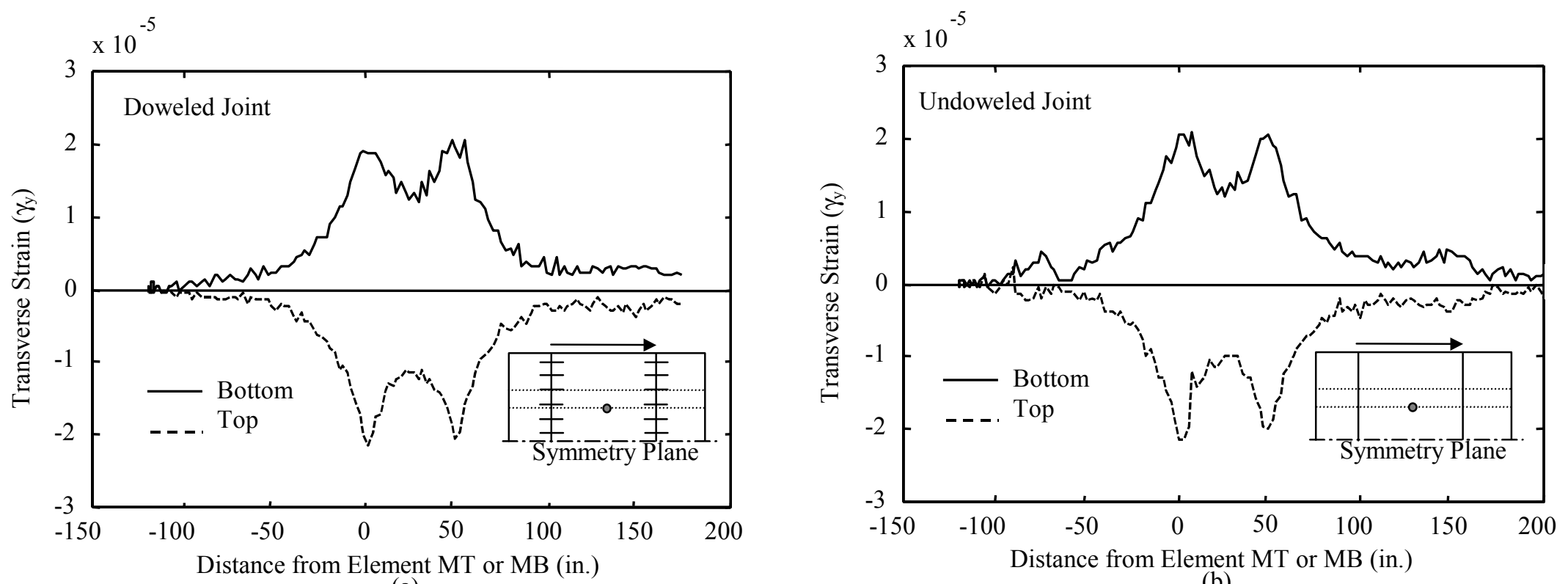

(a)

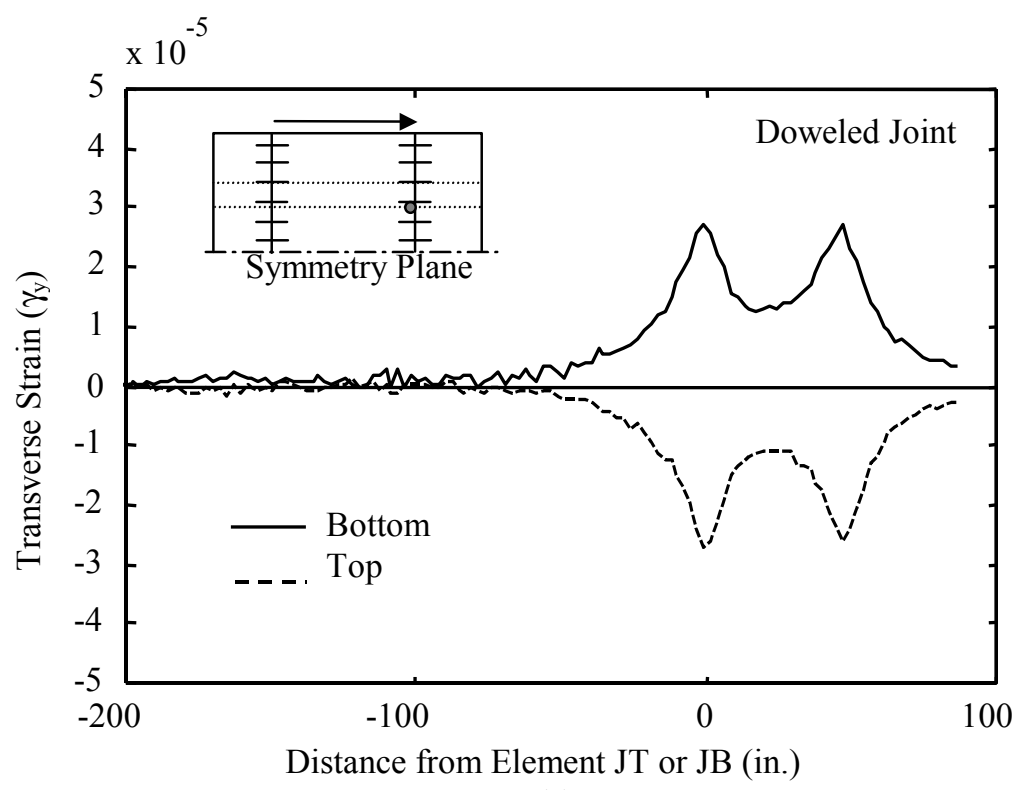

(c)

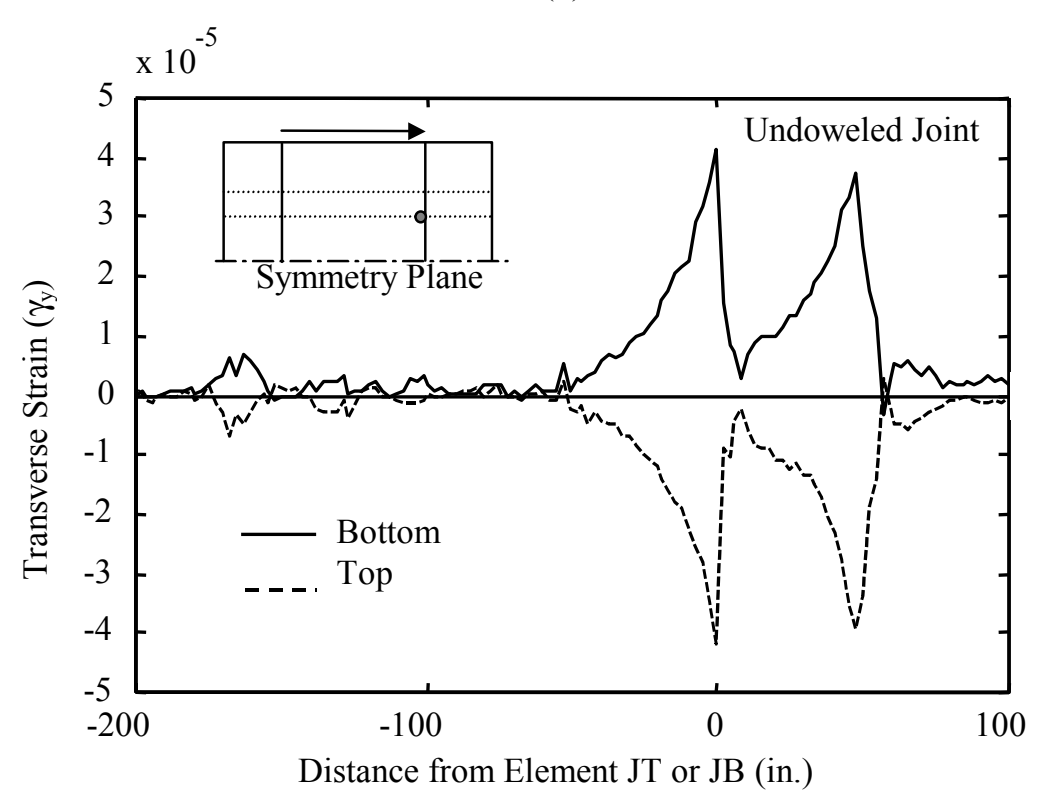

(d)

FIGURE 4.16 Effect of Dowel Bars on Distribution of Transverse Strains in the Concrete Slab 


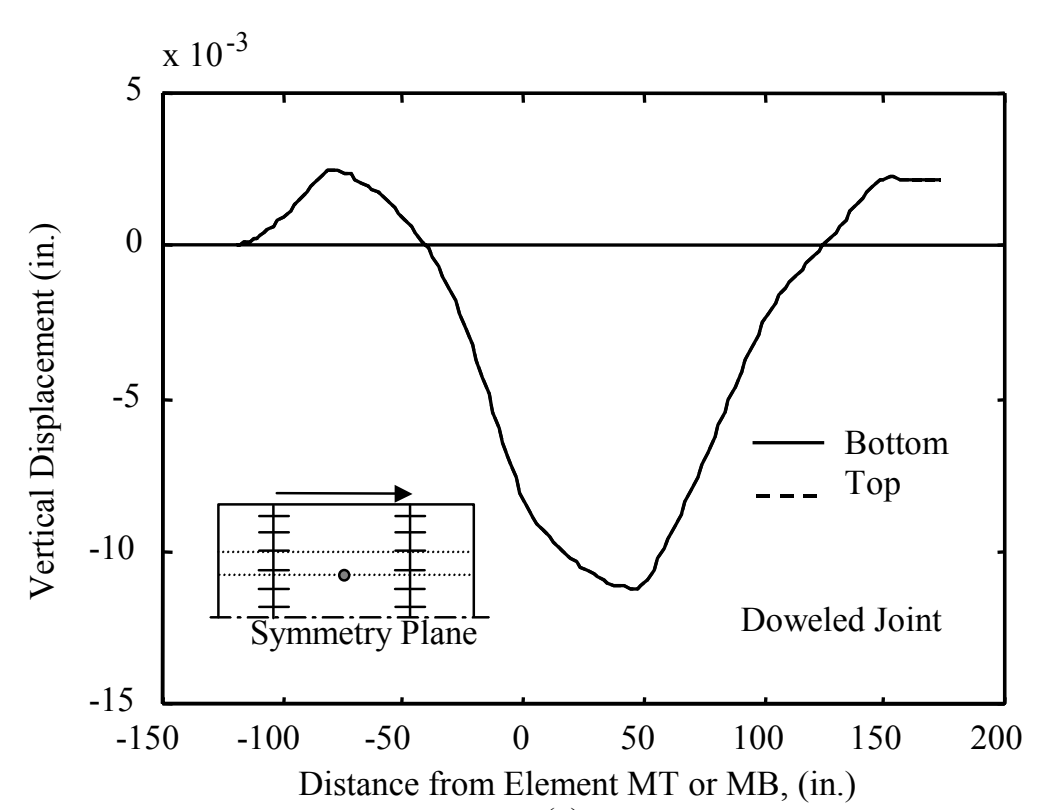

(a)

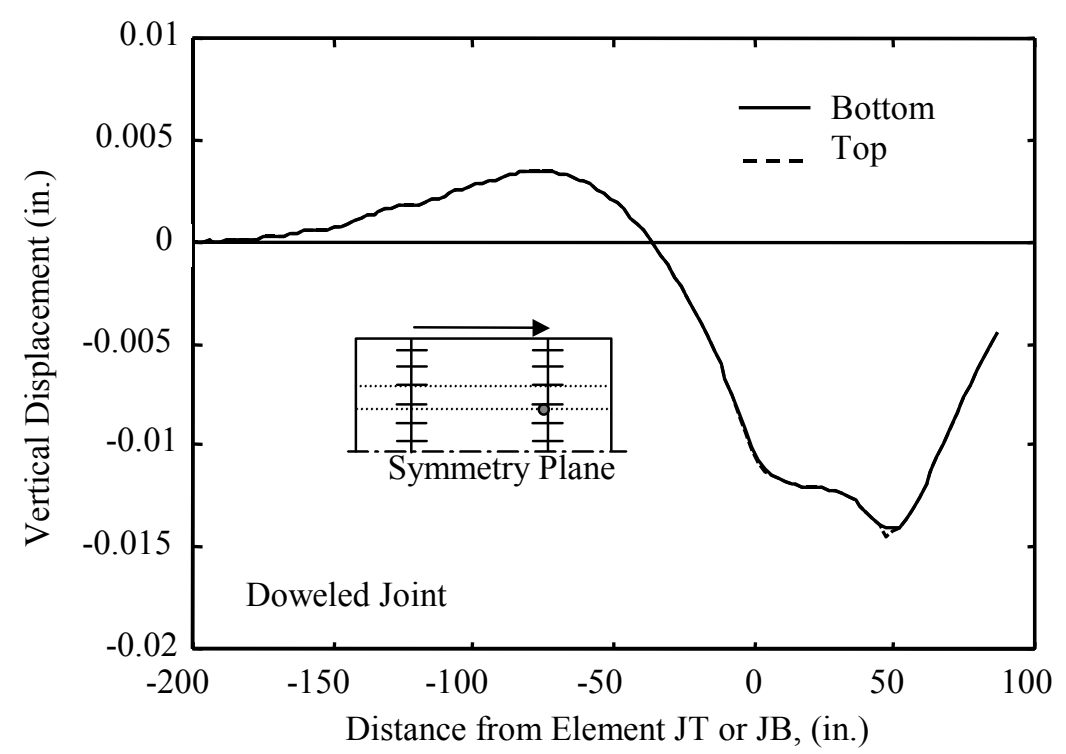

(c)

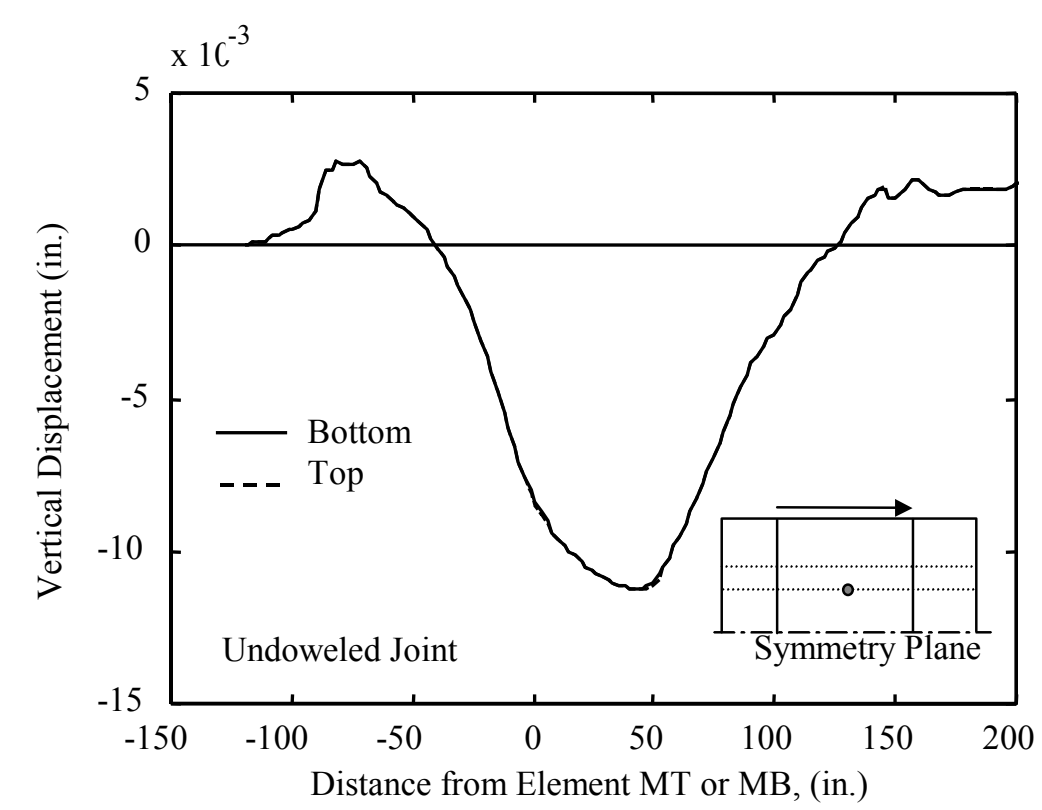

(b)

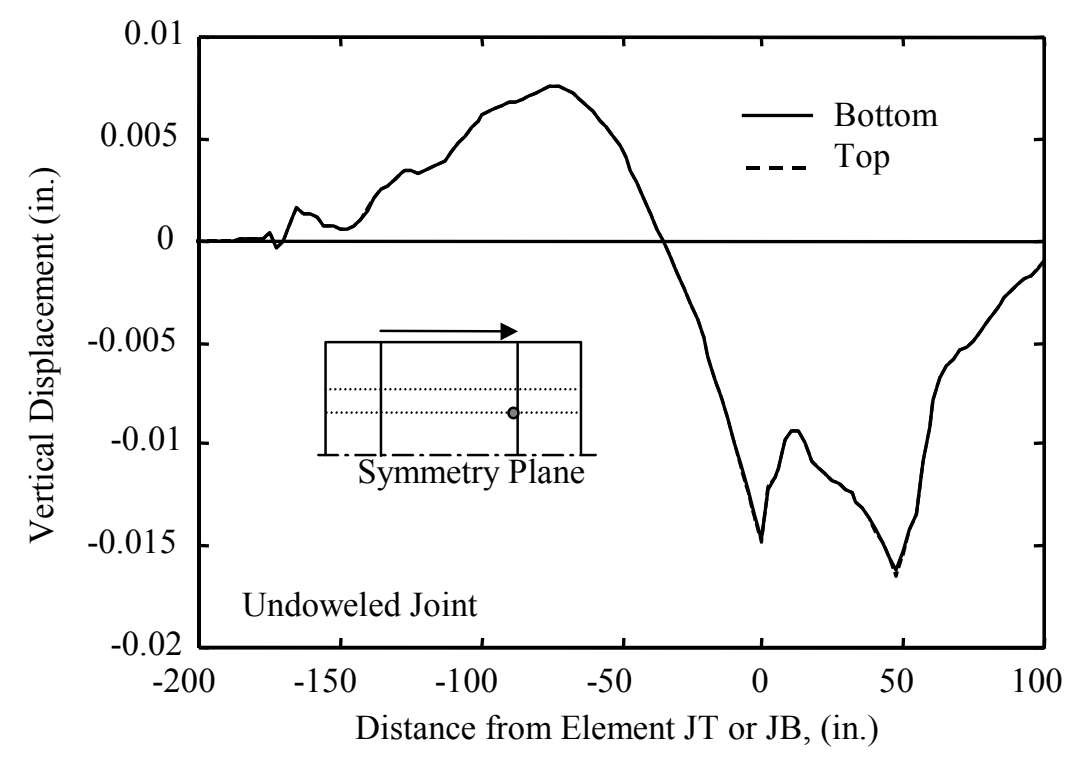

(d)

FIGURE 4.17 Effect of Dowel Bars on Distribution of Vertical Displacement in the Slab 


\section{CHAPTER FIVE}

\section{EFFECT OF DESIGN PARAMETERS \\ ON THE FINITE ELEMENT PREDICTED RESPONSE}

\subsection{Introduction}

The focus of this chapter is to investigate the behavior of rigid pavement structure under some selected design parameters these are: concrete slab length and thickness, axle load magnitude and configuration, load position, and traffic speed.

\subsection{Effect of Concrete Slab Length}

Slab length (or transverse joint spacing) is a major consideration when designing rigid pavements. To study the effect of slab length, the original length of the middle slab in the main model is modified from $4.6 \mathrm{~m}$ (15 ft.) to three other slab lengths of 3.1, 3.7, and $6.1 \mathrm{~m}(10,12$, and $20 \mathrm{ft}$.). Figure 5.1 illustrates the layout and boundary conditions of the concrete slabs studied. The following observations are noticed:

1) The reduction in slab length from 6.1 to $3.1 \mathrm{~m} \mathrm{(20} \mathrm{to} 10 \mathrm{ft}$.) has insignificant effect on the MPS, ,x, ,y, and vertical displacement histories at both mid-slab and the transverse joint, Figures 5.2 to 5.5, respectively.

2) The variations of the stress and strain distributions peaks shown in Figures 5.2 to 5.5 are summarized in Table 5.1. It is observed that changing the slab length does not affect the peaks of the stress or strain except for MPS and, ${ }_{x}$ at the joint where some changes are observed. These changes are in the range of $172 \mathrm{kPa}$ (25 psi) and 6 microstrain for MPS and ${ }_{x}$ respectively. These changes are very small and do not represent a significant variation in the response of the slab due to slab length change. 
TABLE 5.1 Effect of Slab Length on Peak Stresses and Strains Induced in the Slab

\begin{tabular}{|c|c|c|c|c|c|}
\hline \multirow{2}{*}{ Variable } & \multirow{2}{*}{$\begin{array}{c}\text { Slab Length } \\
\text { (ft.) }\end{array}$} & \multicolumn{2}{|c|}{ Transverse Joint } & \multicolumn{2}{|c|}{ Mid-Slab } \\
\hline & & Slab Top & Slab Bottom & Slab Top & Slab Bottom \\
\hline \multirow{4}{*}{$\begin{array}{c}\text { Maximum } \\
\text { Principal Stress } \\
\text { (psi) }\end{array}$} & 10 & -52.61 & 70.67 & -86.18 & 91.29 \\
\hline & 12 & -27.86 & 66.32 & -85.98 & 88.01 \\
\hline & 15 & -33.09 & 69.76 & -85.00 & 84.93 \\
\hline & 20 & -28.19 & 68.85 & -82.87 & 85.89 \\
\hline \multirow{4}{*}{$\begin{array}{c}\text { Longitudinal } \\
\text { Strain } \\
\text { (microstrain) }\end{array}$} & 10 & 14.62 & -7.63 & -35.29 & 35.76 \\
\hline & 12 & 11.44 & -13.73 & -35.29 & 32.90 \\
\hline & 15 & 10.49 & -13.73 & -36.24 & 34.33 \\
\hline & 20 & 11.44 & -14.50 & -35.29 & 33.38 \\
\hline \multirow{4}{*}{$\begin{array}{c}\text { Transverse } \\
\text { Strain } \\
\text { (microstrain) }\end{array}$} & 10 & -28.13 & 28.23 & -21.93 & 21.46 \\
\hline & 12 & -29.66 & 27.66 & -20.98 & 21.46 \\
\hline & 15 & -27.28 & 27.47 & -21.46 & 20.50 \\
\hline & 20 & -27.75 & 27.75 & -20.03 & 21.46 \\
\hline \multirow{4}{*}{$\begin{array}{c}\text { Vertical } \\
\text { Displacement } \\
\text { (in.) }\end{array}$} & 10 & $-14.0 \mathrm{e}-03$ & $-14.2 \mathrm{e}-03$ & $-11.4 \mathrm{e}-03$ & $-11.4 \mathrm{e}-03$ \\
\hline & 12 & $-14.4 \mathrm{e}-03$ & $-14.3 e-03$ & $-11.3 e-03$ & $-11.2 \mathrm{e}-03$ \\
\hline & 15 & $-14.7 \mathrm{e}-03$ & $-14.1 \mathrm{e}-03$ & $-11.2 \mathrm{e}-03$ & $-11.2 \mathrm{e}-03$ \\
\hline & 20 & $-14.0 \mathrm{e}-03$ & $-13.9 \mathrm{e}-03$ & $-11.0 \mathrm{e}-03$ & $-11.0 \mathrm{e}-03$ \\
\hline
\end{tabular}

3) The distribution of peak stresses in the slab along traffic direction for different slab lengths shows similar stress levels at mid-slab with small variations in the vicinity of the transverse joints, as shown in Figures 5.6 and 5.7. Therefore, changing the slab length does not affect the peak stresses in the slab.

4) Examination of the distribution of peak MSS along traffic direction for all slab lengths indicates that changing the slab length only affects the MSS level in the vicinity of the dowel bar edge, as shown in Figure 5.8. Compared to the $3.7 \mathrm{~m}$ (12 ft.) slab, the 3.1 and 
$4.6 \mathrm{~m}$ (10 and $15 \mathrm{ft}$.) slabs result in increases of 340 and 198 percent in the peak shear stress in the vicinity of the joint.

5) Generally, changing the slab length does not affect the response at the middle of the slab. At transverse joint locations, small variations are observed in slab response. However, this conclusion may change if thermal gradient is considered.

6) To examine the effect of slab length on rigid pavement fatigue damage, the number of vehicle passes to failure is calculated for each slab length using four different fatigue models:

a. RISC model: Majidzadeh and Ilves (1983) analyzed AASHO Road Test data and developed a power law model called RISC. They used the plate theory to calculate the stresses and to obtain the following equation:

$$
\log \mathrm{N}_{\mathrm{f}}=\log (22209)-4.29 \log (\sigma / \mathrm{MR})
$$

b. Austin Research Engineers (ARE) model: It was developed by Treybig, et al., (1977). The model takes the form of a power law. The elastic layer theory is used to calculate the stresses. Regression analysis is used to obtain the following equation: $\quad \log N_{f}=\log (23440)-3.21 \log (\sigma / M R)$

c. Vesic model: It is a power law developed by Vesic and Saxena (1969). Through analysis of AASHO Road Test Data. In this model, stresses in the wheel-path are computed using Westergaard theory. This model is given by the following equation: $\quad \log N_{f}=\log (225000)-4 \log (\sigma / M R)$

d. Darter model: It is developed as a part of the design procedure for zero maintenance JPCCP (Darter, 1977). Based on fatigue data obtained from 140 tests, a least square regression is used to obtain the following equation:

$$
\log \mathrm{N}_{\mathrm{f}}=16.61-17.61(\sigma / \mathrm{MR})
$$

Where $\mathrm{N}_{\mathrm{f}}$ is the number of vehicle passes to failure, $\sigma$ is the maximum longitudinal tensile stress at slab bottom along the wheel-path obtained from the distributions shown in Figure 5.6, and MR is the concrete modulus of rupture estimated using the following equation:

$$
\mathrm{MR}=\mathrm{k}\left(\mathrm{f}_{\mathrm{c}}\right)^{0.5}
$$


Where $\mathrm{k}$ is a constant and ranges from 8 to 10 ( $\mathrm{k}$ is assumed 8 is this study) and $\mathrm{f}_{\mathrm{c}}$ is the concrete compressive strength and is calculated from the following equation:

$$
\mathrm{E}=57000\left(\mathrm{f}_{\mathrm{c}}\right)^{0.5}
$$

Where $\mathrm{E}$ is the concrete modulus of elasticity [15513 MPa (2.25e $06 \mathrm{psi})]$. The number of vehicle passes to failure computed using the Portland Cement Association (PCA) fatigue model will be infinity because $(\sigma / M R)$ is less than 0.5 . Therefore, this model was not included in the comparison shown in Figure 5.9. The results show that the number of vehicle passes to failure computed using Darter fatigue model is higher than the three

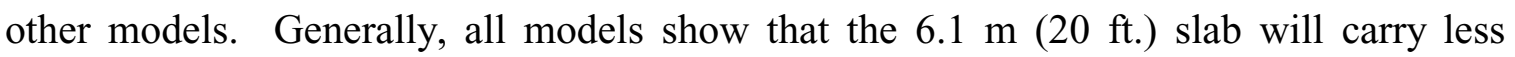
number of vehicle passes to failure than the two other slab lengths. The 3.7 and $4.6 \mathrm{~m}$ (12 and $15 \mathrm{ft}$.) have approximately the same number of vehicle passes. This illustrates that slabs of shorter lengths are less susceptible to failure. However, consideration of thermal induced stresses may change this conclusion.

\subsection{Effect of Concrete Slab Thickness}

The selection of rigid pavement slab thickness is controlled by structural and economic factors. The design slab thickness should sustain the traffic loads and the environmental conditions. In this study, the slab thickness of the three FE models with slab lengths 3.7, 4.6, and $6.1 \mathrm{~m}(12,15$, and $20 \mathrm{ft}$.) is increased from $229 \mathrm{~mm}$ to $254 \mathrm{~mm}$ (9 in. to $10 \mathrm{in}$.) representing an 11 percent increase. The following observations are noticed:

1) Increasing the slab thickness by $25 \mathrm{~mm}$ (1 in.) reduces both MPS and, induced in the slab, Figures 5.10 to 5.13. The stress reduction at the joint is more than that at the middle of the slab. The percentage of average MPS reduction is 16.4 and 20.5 percent at the middle of the slab and the joint respectively, Figures 5.10 and 5.11. This percentage is 13.2 and 22.9 for ${ }_{\mathrm{x}}$ at the middle of the slab and the joint respectively, Figures 5.12 and 5.13 .

2) The stress and strain reductions resulting from the thickness increase change with the change in slab length, Figures 5.10 to 5.13. 
3) Increasing the slab thickness reduced peak MPS, $\sigma_{x}, \sigma_{y}$, and $\sigma_{z}$ at the transverse joint, this reduction is more significant in the case of the $4.6 \mathrm{~m}$ (15 ft.) long slab [Figure 5.14 (b) and 5.15 (b and e)] than in the case of the 3.7 and $6.1 \mathrm{~m}$ (12 and $20 \mathrm{ft}$.) slabs, Figure 5.14 (a and $c$ ).

4) Increasing the slab thickness has a small effect on the peak MSS induced in the slab, Figure 5.16. Increasing the slab thickness of the $4.6 \mathrm{~m}$ ( $15 \mathrm{ft}$.) slab by $25.4 \mathrm{~mm}(1 \mathrm{in}$.) reduces the shear stress at the joints Figure 5.16 (b), however, that reduction is insignificant in case of the 3.7 and $6.1 \mathrm{~m}$ (12 and $20 \mathrm{ft}$.) slabs, Figure 5.16 (a and c).

\subsection{Effect of Axle Load Magnitude}

The magnitude of the tandem axle load is increased from 160 to $200 \mathrm{KN}(36,000$ to $45,000 \mathrm{lb}$.) representing a 25 percent increase. The loads are then moved on the $4.6 \mathrm{~m}(15 \mathrm{ft}$.) at a speed of $105 \mathrm{~km} / \mathrm{hr}(65 \mathrm{mph})$. The following observations are noticed:

1) Both the stresses and the strains induced in the concrete slab increase with the increase in the axle load. The increase in the tensile stresses induced at slab bottom is 23 and 12 percent at mid-slab and transverse joints respectively, Figure 5.17.

2) At the slab top, the transverse strain, increases by 102 and 110 percent for mid-slab and transverse joint respectively due to axle load increase, Figure 5.18. These remarkable increases may initiate longitudinal cracks that start at slab top and propagate downward.

3) The results plotted in Figure 5.19 indicate that the increase in ${ }_{x}$ due to the load magnitude increase is insignificant compared to ,y increase, Figure 5.18.

4) Examination of the peak stresses induced in the slab shows an increase in the peak tensile MPS and $\Phi_{\mathrm{x}}$ in the order of 20 percent, Figure 5.20. A lower percentage of increase is observed for $\Phi_{\mathrm{y}}$ and $\Phi_{\mathrm{z}}$, Figure 5.21.

5) Examination of the distribution of peak MSS along traffic direction shows that increasing the load magnitude by 25 percent results in a considerable MSS increase in the vicinity of the second joint, Figure 5.22. Under repetitive traffic loading cycles, these high stresses may develop fatigue cracks, especially in the vicinity of the joint. 


\subsection{Effect of Axle Load Configuration}

The model is loaded with an $80 \mathrm{KN}(18,000 \mathrm{lb})$ single axle and a $240 \mathrm{KN}(54,000 \mathrm{lb})$ tridem axle, and the results are compared with those obtained for the tandem axle. A tire inflation pressure of $7.35 \mathrm{~kg} / \mathrm{cm}^{2}$ (105 psi) is assumed in all cases. The axle configurations and wheel loads are illustrated in Figure 5.23. The results plotted in Figures 5.24 to 5.30 indicate that:

1) At the middle of the slab, increasing the number of axles decreases the peak tensile MPS and ${ }_{x}$ but increases the peak tensile ,y, Figures 5.24 (a, b and c), 5.25 (a, b, and c), and $5.26(\mathrm{a}, \mathrm{b}$, and $\mathrm{c}$ ) respectively. At the joint, changing the axle configuration from single to tridem increases the tensile stresses and strains induced at slab bottom, Figures $5.24(\mathrm{~d}$, e, and f), 5.25 (d, e, and f), and 5.26 (d, e, and f). In all cases, changing the number of axles does not cause a stress or strain change larger than 30 percent.

2) The peak tensile and compressive MPS and , $x$ for the top and bottom of the slab are plotted against the number of axle, as shown in Figure 5.27. The data points are then fitted by either a linear or a polynomial distribution. Both MPS and , distributions show a reduction in the peak stresses and strains as the axle configuration is changed from single to tridem except for the compressive MPS at slab top, which seems to be constant, Figure 5.27 (a).

3) Changing the axle configuration from single to tridem increases the number of fatigue cycles, as shown in Figures 5.24 to 5.26.

4) Examination of the distribution of peak stresses along traffic direction shows that single axle loading produce higher stress at the middle of the slab compared to tandem or tridem axle loads, Figure 5.28 (a and d) and 5.29.

5) Examination of the distribution of MSS along traffic direction shows that the stress induced by the tandem axle configuration is the highest in the area surrounding the first joint, Figure 5.30. However, at the second joint both tandem and tridem axles show a similar stress pattern, the stress increases until it reaches its maximum at the slab boundaries. On the other hand, the stress induced by the single axle load at dowel bar edges is 50 percent less than the two other axle loads. 
6) The highest peak shear stress experienced by the slab loaded using either the tandem or the tridem axle loads along the slab edge is $862 \mathrm{kPa}$ (125 psi). This stress is 80 percent of the allowable maximum shear stress value $1089 \mathrm{kPa}(158 \mathrm{psi})$ for the concrete material used in this study, Figure 5.30. This value is based on the maximum shear stress yield criterion in which MSS for uniaxial tension equals (MR/2) (Boresi, 1993). Therefore, under repetitive traffic loading, the areas in the vicinity of the transverse joints may crack due to shear.

\subsection{Effect of Loading Position}

When a load is applied along the wheel-path of a rigid pavement slab, the whole slab distributes the load over a relatively wide area of the supporting layers. Under edge loading, only a part of the slab distributes the load over a smaller soil area and therefore subjecting that area to stress concentrations. To study the effect of loading position, the original model is modified to simulate a full traffic lane width of $3.66 \mathrm{~m}$ (12 ft.) and therefore no symmetry plane is assumed. Three offsets are assumed for the tandem axle centerline from the slab centerline: $0,0.33$, and $0.67 \mathrm{~m}(0,13.14$, and $26.3 \mathrm{in}$.), as shown in Figure 5.31. In the first case, the axle load is moved along the wheel-path (symmetrically loading the slab). Whereas in the third case, the load is moved along the slab lateral edge, simulating an edge loading condition. The FE models used for these two cases are shown in Figure 5.32. The FEM used for offset $0.33 \mathrm{~m}$ (13.14 in.) is similar to that used for the zero offset case shown in Figure 5.31 (b). To study the behavior of

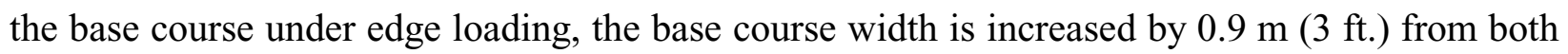
lateral sides of the slab, as shown in Figure 5.32 (a). The MPS, ${ }_{x}$, and ,y histories are compared at the elements of study illustrated in Figure 5.31. To select these elements, the MPS in the slab is examined for several elements located along the transverse centerline of the slab and the second transverse joint and the maximum stress for the zero offset model is found along the inner wheel path. While the maximum stress for the two other models is found along the outer wheelpath close to the loaded slab edge. The results plotted in Figures 5.33 to 5.38 indicate that: 
1) Generally, the edge loading condition results in higher stresses and strains compared to the two other loading positions.

2) Changing the axle centerline offset from 0 to $0.33 \mathrm{~m}$ (0 to 13.14 in.) results in a small variation in both slab and base course response compared to the case of edge loading. A summary of the peak tensile stresses and strains induced at the bottom of the slab and the base course for each loading position is presented in Table 5.2. The two locations studied in this table are mid-slab and transverse joint edge.

3) Under edge loading and for the two cases of mid-slab and joint loading, tensile stresses are observed at slab top and bottom, as shown in Figure 5.33 (c and f). These stresses are less at the joint because the load is shared between the two slabs and also due to the constraining effect of the dowel bars at the joint.

4) At the middle of the slab, the peak tensile MPS generated by edge loading is 61 and 45 percent higher than that generated by the two other loading positions with offsets 0 and $0.33 \mathrm{~m}$ (0 and 13.14 in.) respectively, Figure 5.33 (a, b, and c). This is because the loaded slab edge is unconstrained at the middle of the slab, and therefore increases the vertical displacement.

5) At the joint, the slab is constrained by the dowel bars, which reduces the vertical displacement. This in turn reduces the peak tensile MPS produced under edge loading by 25 and 12 percent compared to the two other loading position with offsets 0 and $0.33 \mathrm{~m}$ (0 and 13.14 in.) respectively, Figure 5.33 (d, e, and f).

6) Examination of ${ }_{x}$ in Figure 5.34 shows that both loading positions with offsets 0 and 0.33 m (0 and 13.14 in.) gives approximately the same results, Figure 5.34 (a, b, d, and e). Compared to the zero offset case, the peak tensile , ${ }_{x}$ induced due to edge loading is increased by 92 and 107 percent at mid-slab and the joint respectively. These results show that, the closer is the load from the slab edge the higher the possibilities of transverse crack initiations.

7) In the transverse direction, the results of, show that the smaller the offset of the axle centerline from the slab centerline the higher is, y induced, Figure 5.35. Compared to edge loading, the percentages of increase in the peak tensile ,y induced by the zero offset loading position at mid-slab and the joint are 176 and 352 percent, respectively. The 
smaller the offset between the axle and the slab centerlines the higher the possibilities of longitudinal cracks initiations, especially at transverse joints.

8) The base course is significantly affected by edge loading. The peak tensile MPS due to edge loading is approximately ten times higher than that induced by the zero offset loading position, Figure 5.36. The same observation is valid in case of ,y but with higher percentages of increase, Figure 5.38. As for , results, the effect of loading position is insignificant, Figure 5.37. The continuity of the base course in traffic direction and the absence of any constrains in this direction reduces the longitudinal strains induced by edge loading. On the other hand, the confinement of the surrounding soil strata in the transverse direction limits the movement of the base course and therefore increases ,y. The MPS distributions show that the most critical area damaged by edge loading will be in the vicinity of the middle of the slab. While the high tensile, y show the possibilities of transverse cracks development at the bottom of the base.

TABLE 5.2 Variation of Peak Tensile Stresses and Strains at the Bottom of the Slab and the Base Course for Different Loading Positions

\begin{tabular}{|c|c|c|c|c|c|c|}
\hline Location & \multicolumn{3}{|c|}{ Mid-Slab } & \multicolumn{3}{|c|}{ Transverse Joint } \\
\hline Loading Position & Wheel-Path & Middle $^{*}$ & Edge & Wheel-Path & Middle $^{*}$ & Edge \\
\hline MPS (Concrete) & 82.5505 & 91.5965 & 132.702 & 61.9951 & 55.6031 & 49.4654 \\
\hline${ }_{\mathrm{x}}$ (Concrete) & $0.315 \mathrm{e}-04$ & $0.382 \mathrm{e}-04$ & $0.606 \mathrm{e}-04$ & $0.107 \mathrm{e}-04$ & $0.107 \mathrm{e}-04$ & $0.221 \mathrm{e}-04$ \\
\hline ,y (Concrete) & $0.21 \mathrm{e}-04$ & $0.153 \mathrm{e}-04$ & $0.076 \mathrm{e}-04$ & $0.262 \mathrm{e}-04$ & $0.224 \mathrm{e}-04$ & $0.058 \mathrm{e}-04$ \\
\hline MPS (Base Course) & 1.1593 & 0.6252 & 9.3893 & 4.9825 & 5.1161 & 11.7631 \\
\hline ,x (Base Course) & $0.505 \mathrm{e}-04$ & $0.362 \mathrm{e}-04$ & $0.572 \mathrm{e}-04$ & $0.138 \mathrm{e}-03$ & $0.143 \mathrm{e}-03$ & $0.165 \mathrm{e}-03$ \\
\hline ,y (Base Course) & $0.008 \mathrm{e}-03$ & $0.028 \mathrm{e}-03$ & $0.24 \mathrm{e}-03$ & $0.009 \mathrm{e}-03$ & $0.032 \mathrm{e}-03$ & $0.282 \mathrm{e}-03$ \\
\hline
\end{tabular}

* The Middle loading position is that with $0.33 \mathrm{~m}$ (13.14 in.) offset

\subsubsection{D Distribution of Stresses and Strains Induced Under Different Loading Positions}

A 3D distribution of $\sigma_{\mathrm{x}}$ and ${ }_{\mathrm{x}}$ induced at the bottom of the slab under the three loading positions presented above is plotted in Figure 5.40. The locations of the elements used to plot each 3D distribution are shown in Figure 5.39. The vertical axis in Figure 5.40 represents the variable of 
study $\left(\sigma_{\mathrm{x}}\right.$ or $\left.{ }_{\mathrm{x}}\right)$. The two horizontal axes represent the distance of the point of study from the slab edge normal to traffic direction, and the distance of the front tire of the tandem axle assembly from the first joint. All distributions show that the highest stresses and strains magnitudes are obtained from edge loading and decrease as we move transversely away from the slab edge, as shown in Figures 5.40.

The tensile peak of each $\sigma_{\mathrm{x}}$ and , $\mathrm{x}$ history plotted in Figures 5.40 are plotted in the transverse direction for the three locations C, D, and E shown in Figure 5.39. Each group of points is fitted with an exponential curve. The vertical axes representing $\sigma_{\mathrm{x}}$ or ${ }_{\mathrm{x}}$ in Figure 5.41 are normalized with respect to the peaks obtained from the zero offset (wheel-path) case since it represents the most common loading position. This means that every peak obtained for each history curve in Figure 5.40 is divided by the wheel-path peak. Figure 5.41 can be used to compute a factor that will be multiplied by $\sigma_{\mathrm{x}}$ or ${ }_{\mathrm{x}}$ obtained from the zero offset loading position to obtain $\sigma_{\mathrm{x}}$ or ${ }_{\mathrm{x}}$ for any loading condition falling between wheel-path and edge loading, depending on the distance of the point required from the slab edge normal to traffic direction.

\subsection{Effect of Traffic Speed}

The speed of the tandem axle is changed from 16.1 to $321.9 \mathrm{~km} / \mathrm{hr}$ (10 to $200 \mathrm{mph}$ ), the results are shown in Figures 5.42 to 5.46 indicating that:

1) In general, changing the speed from 16.1 to $321.9 \mathrm{~km} / \mathrm{hr}$ (10 to $200 \mathrm{mph}$ ) has an insignificant effect on the MPS and , induced in the slab along the wheel-path.

2) At the transverse joint, the average peak tensile MPS at slab bottom for all speeds is in the order of $482.6 \mathrm{kPa}$ (70 psi), as shown in Figure 5.42, except for the 16.1 and 160.9 $\mathrm{km} / \mathrm{hr}$ (100 and $10 \mathrm{mph}$ ) speeds where the peak tensile stress is higher than this value by about 20 percent, Figure 5.42 (b and f). An $83 \mathrm{kPa}$ (12 psi) increase is observed in the tensile stress in case of the $16.1 \mathrm{~km} / \mathrm{hr}(10 \mathrm{mph})$ speed. This increase results from many data points representing a 17 percent increase. However, the tensile stress increase in case of the $160.9 \mathrm{~km} / \mathrm{hr}(100 \mathrm{mph})$ speed is only due to a single data point, which can be 
due to the numerical accuracy and therefore should not be considered. The average peak tensile MPS obtained at mid-slab bottom is larger than that observed at the joint and is in the order of $593 \mathrm{kPa}(86 \mathrm{psi})$ except for the $16.1 \mathrm{~km} / \mathrm{hr}$ (10 mph) speed where the peak MPS is $655 \mathrm{kPa}$ (95 psi) representing a 10 percent increase compared to the average value, Figure 5.43. Similar results are observed for ${ }_{\mathrm{x}}$, Figures 5.44 and 5.45. Which illustrates the insignificant effect that the traffic speed has on pavement response. These results agree with Sargand observation in which he reported that he did not observe a significant effect for speed on strain gauges readings from Ohio Test Road (Sargand, and Beegle, 1998). Examination of ${ }_{x}$ distribution at mid-slab shown in Figure 5.44, shows that the peak compressive and tensile strains for all speeds at slab top and bottom, respectively have an approximate constant magnitude of 35 microstrain, as shown in Figure 5.46 (a). This observation shows the insignificant effect traffic speed has on ${ }_{x}$ induced at mid-slab.

3) The ${ }_{x}$ at mid-slab plotted in Figure 5.45 is used to calculate the strain variation in the slab due to different speeds. This variation is equal to the difference between the peak strain induced due to the passage of the first axle and that due to the passage of the second axle, as shown Figure 5.46 (b). The strain variation for slab top and bottom is plotted against the traffic speed and fitted with two straight lines that are approximately symmetric around the zero strain line. Figure 5.46 (b) illustrates that the strain variation increases as the speed increases. Therefore, the lower speeds subjects any point in the slab to strain oscillations with equal magnitudes in a very short time duration. The higher the number of axles, the larger the number of strain oscillations any point in the slab will be subjected to, and therefore the larger the number of fatigue cycles affecting the same point. The large number of fatigue cycles affecting the pavement in a short time period may weaken the pavement and reduce its lifetime cycle. The same variation is observed for the MPS induced at mid-slab bottom shown in Figure 5.43. 


\subsection{Conclusions}

The effect of changing some slab design parameters is examined and the following is concluded:

1) The FEM results shows that changing the slab length from 3.1 to $6.1 \mathrm{~m}$ (10 to $20 \mathrm{ft}$.) does not affect pavement response to axle loading. Results from several fatigue models also show that shorter slab lengths can carry larger number of vehicle passes to failure than longer slabs.

2) Increasing the slab thickness reduces both stresses and strains induced in the concrete slab. The stress reduction is higher at the transverse joint than at the middle of the slab. Therefore, the thickness increase may reduce joint damage.

3) Increasing the axle load by 25 percent for the same axle type and tire pressure can increase the possibilities of shear and fatigue cracks.

4) Although increasing the number of axles reduces the stresses in the pavement, it subjects the pavement structure to a larger number of fatigue cycles. Increasing the axle load magnitude is much more damaging to the pavement than increasing the number of axles.

5) Edge loading is the most damaging loading position to concrete slabs supported by unjointed asphalt concrete shoulders (unconstrained slab edge). Results show that the base course is significantly damaged by edge loading.

6) The traffic speed has insignificant effect on the response of rigid pavement slabs. 


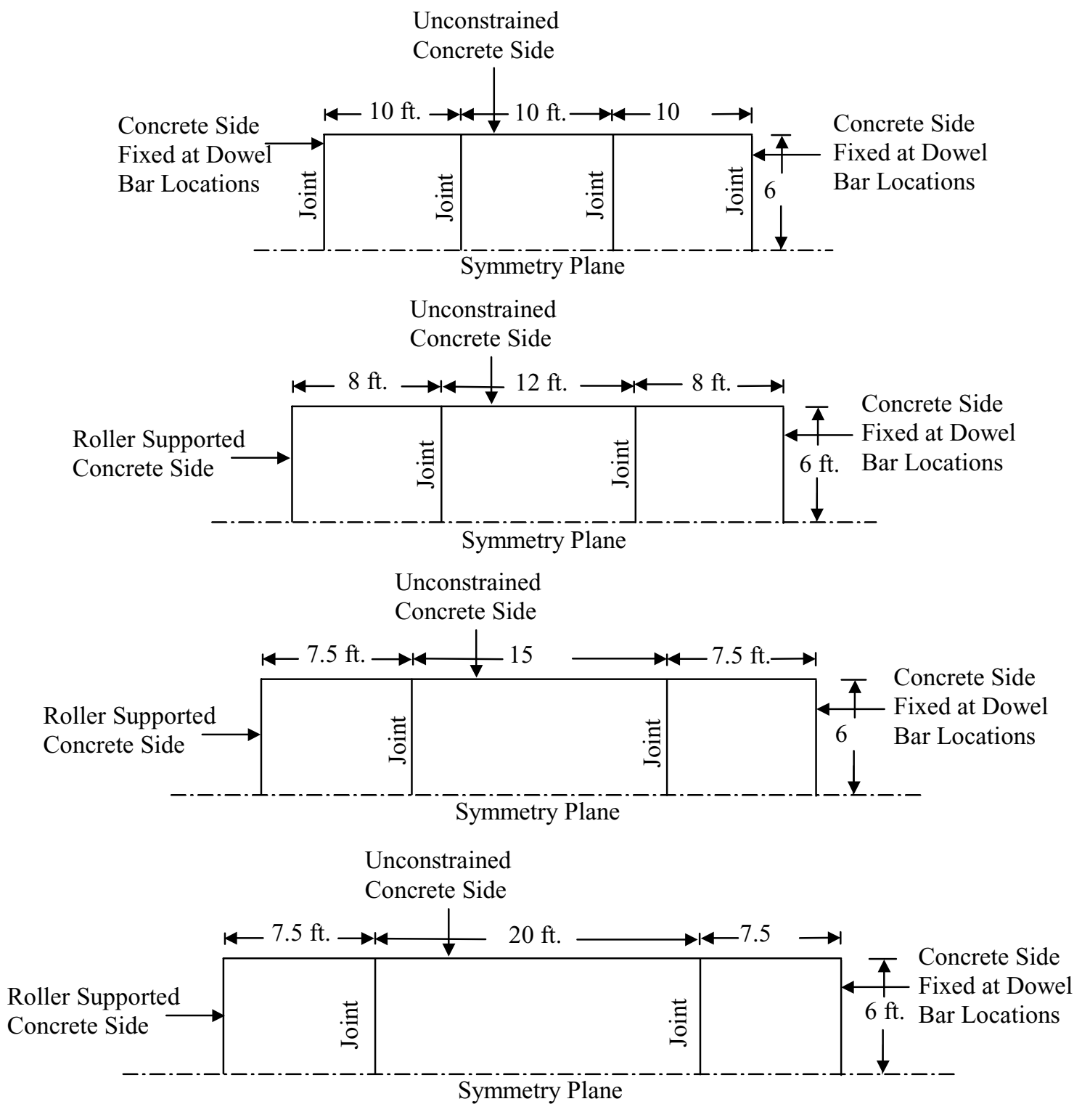

FIGURE 5.1 Dimensions and Boundary Conditions of the Concrete Slabs Studied 


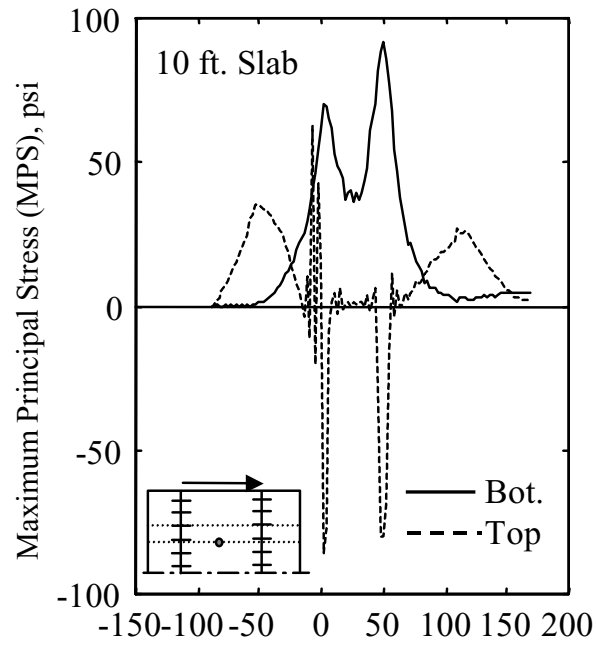

(a)

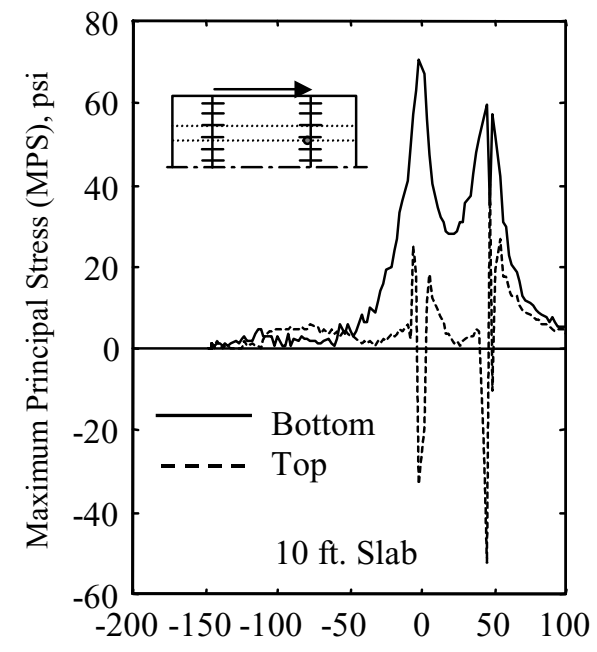

(e)
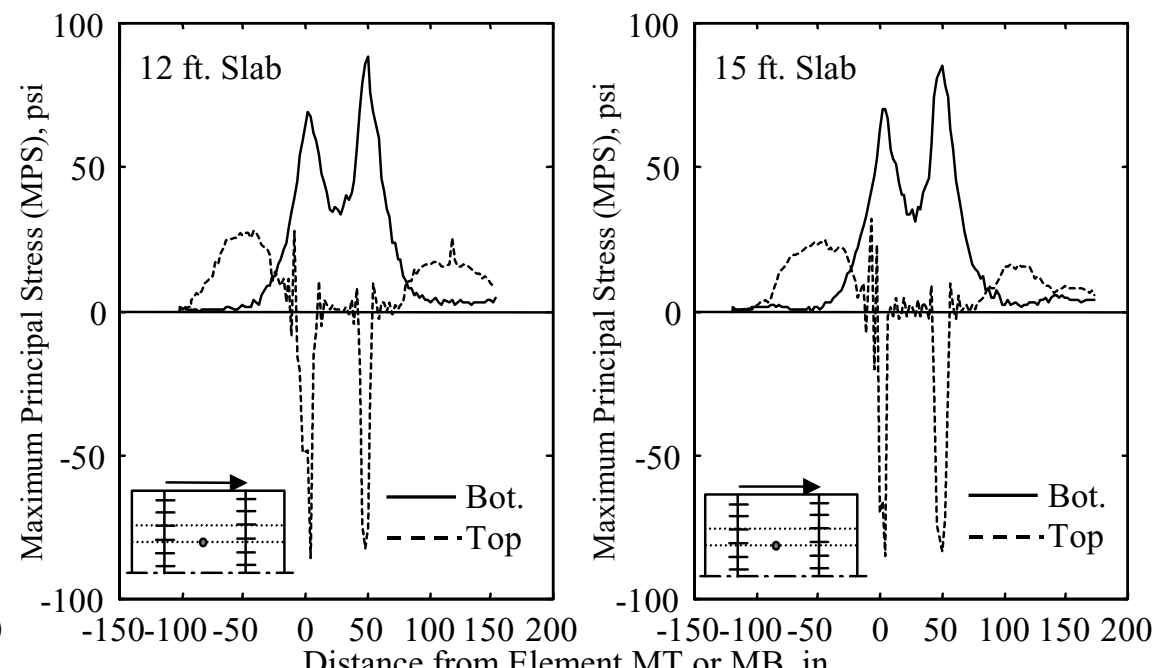

(b)
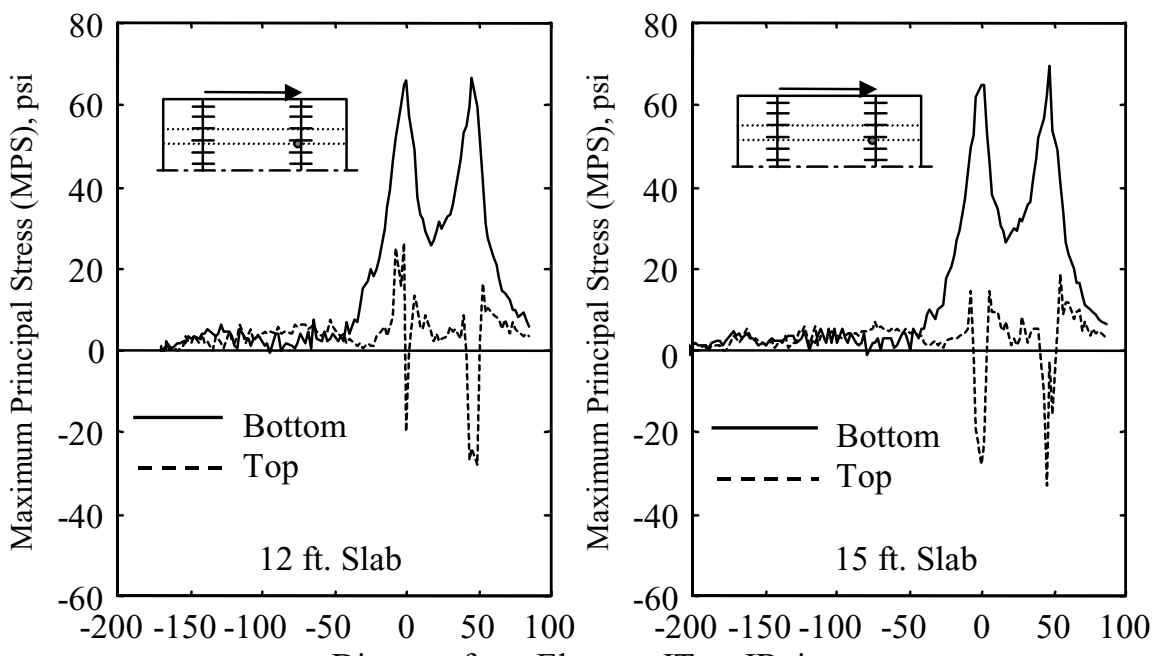

(f)

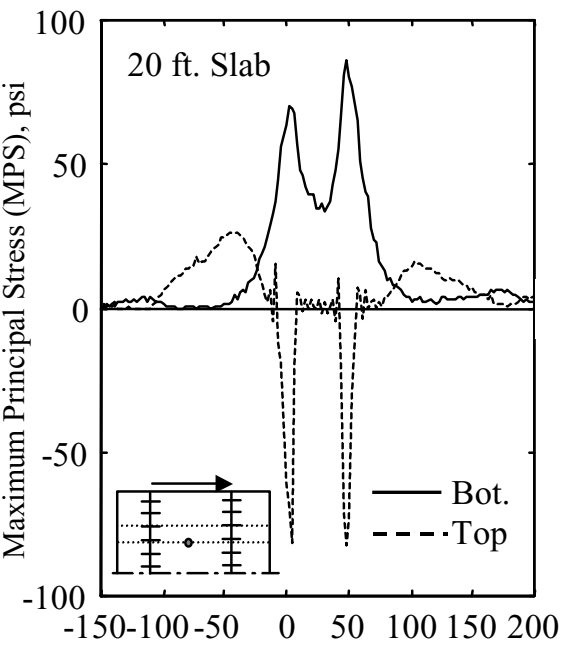

(d)

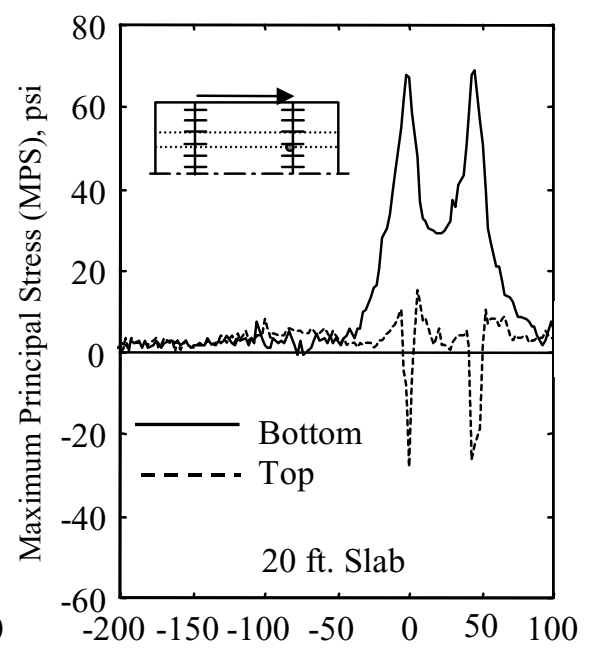

(h)

FIGURE 5.2 Effect of Slab Length on Maximum Principal Stress Induced in the Concrete Slab 

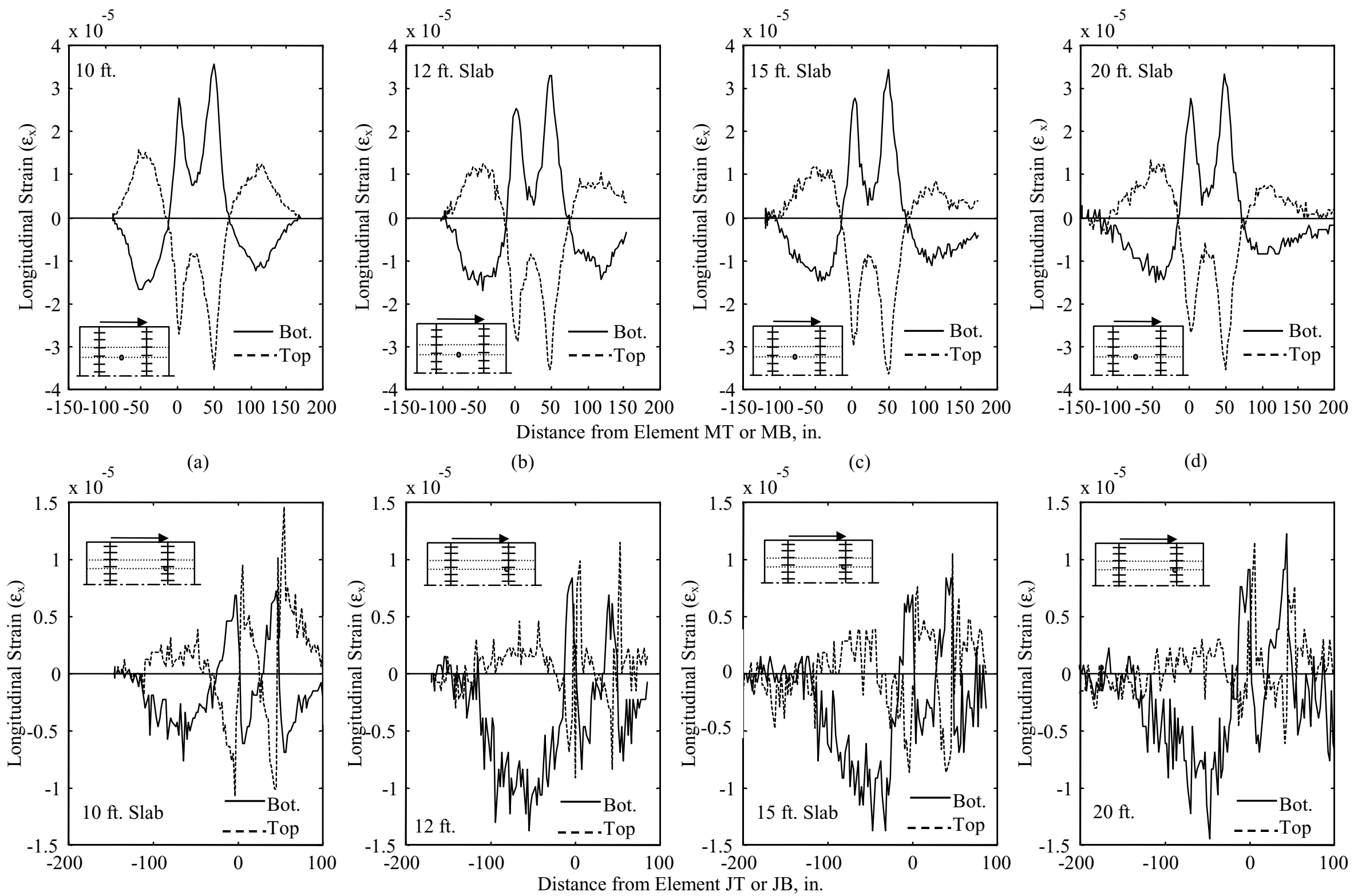

(e)

(f)

(g)

(h)

FIGURE 5.3 Effect of Slab Length on Longitudinal Strain Induced in the Concrete Slab 


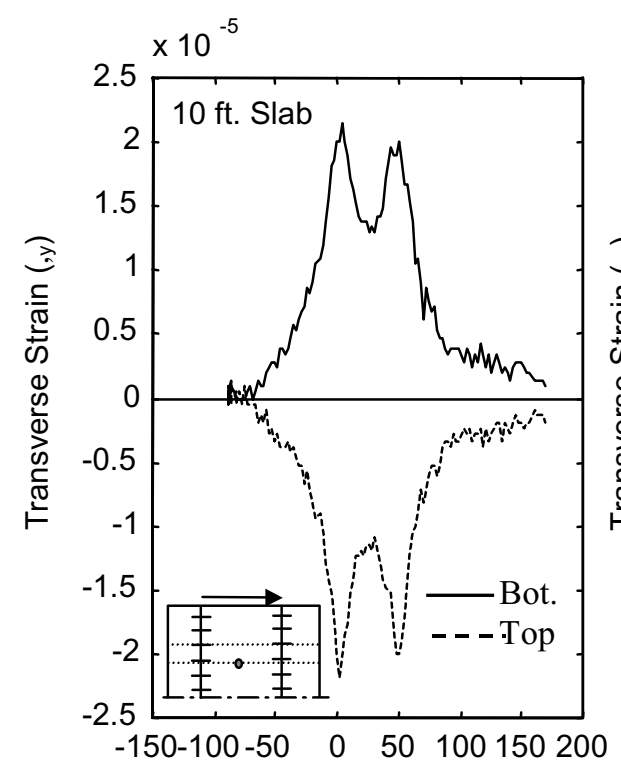

(a)

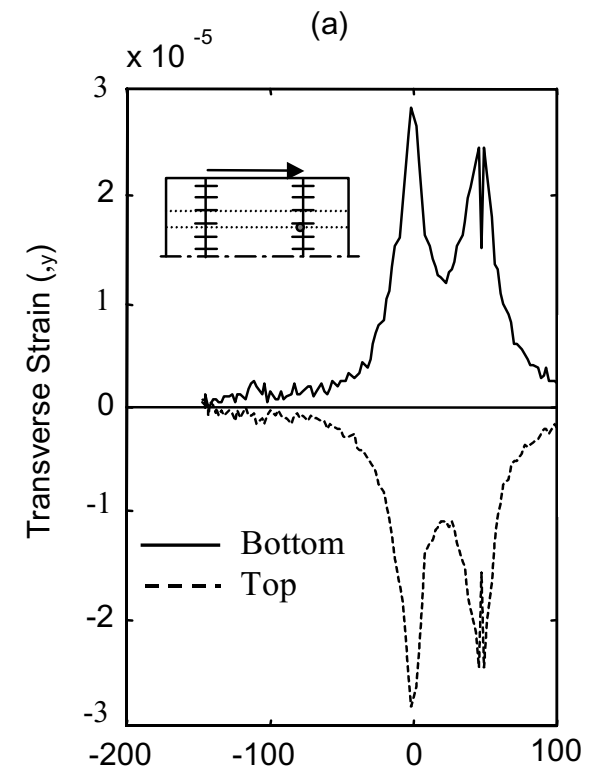

(e)
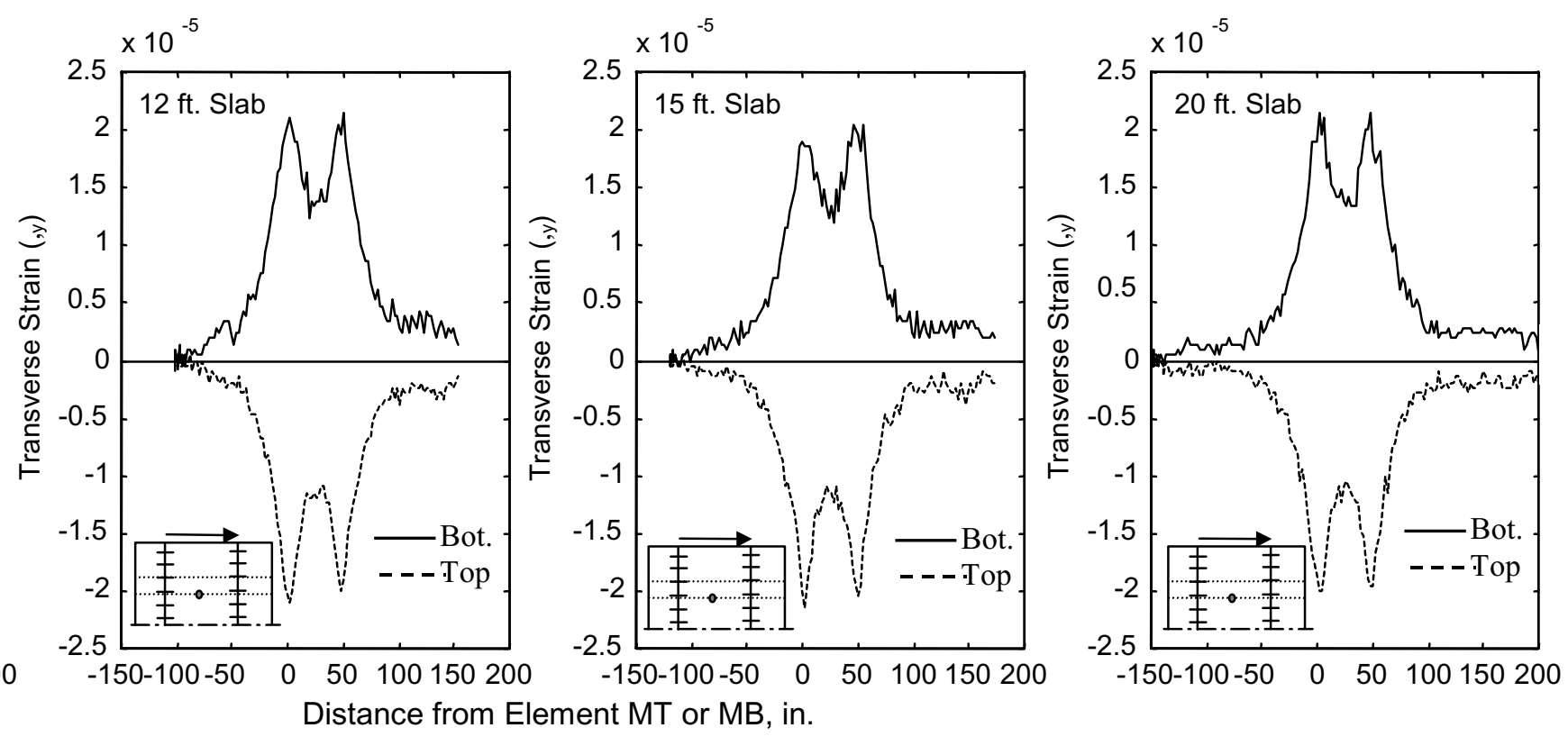

(b)
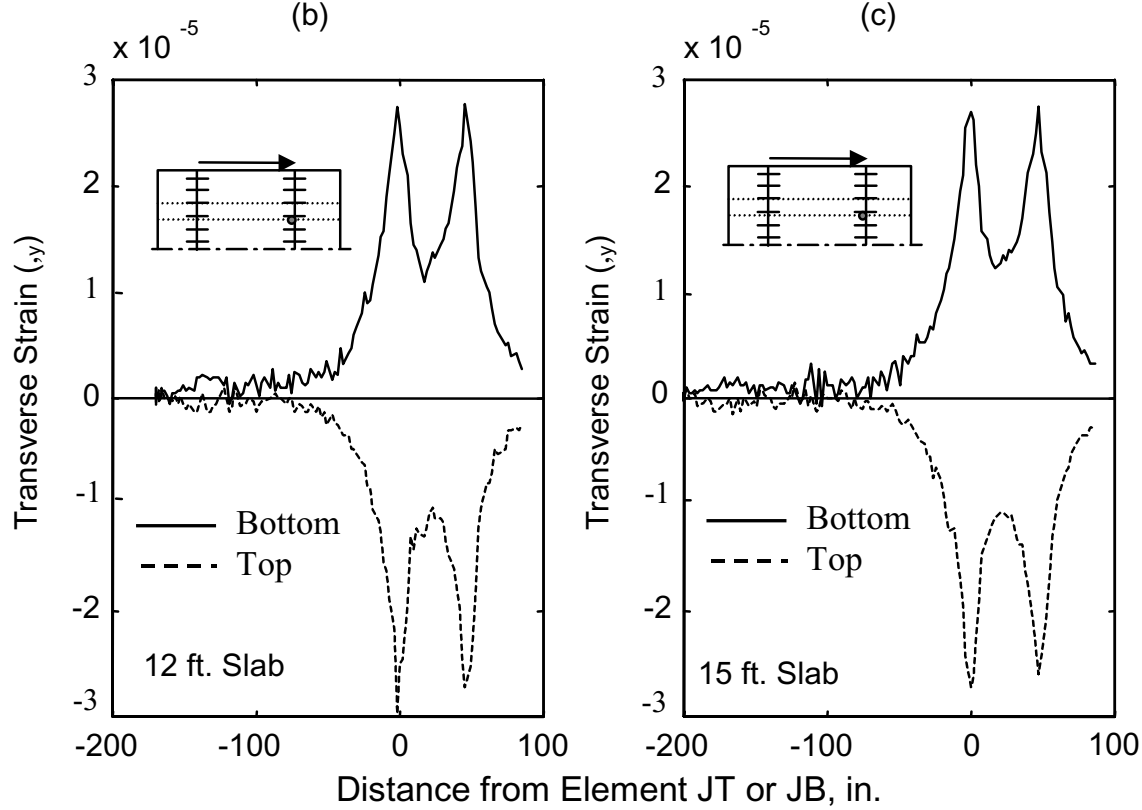

(g)

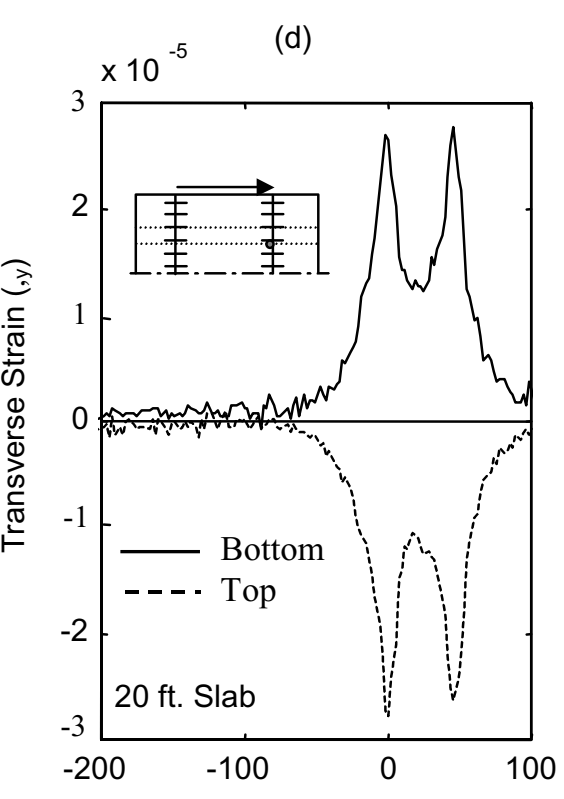

(h)

FIGURE 5.4 Effect of Slab Length on Transverse Strain Induced in the Concrete Slab 


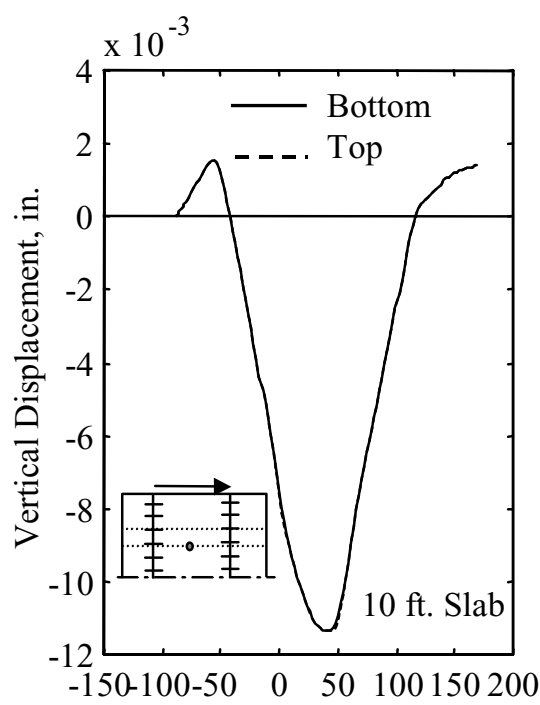

(a)

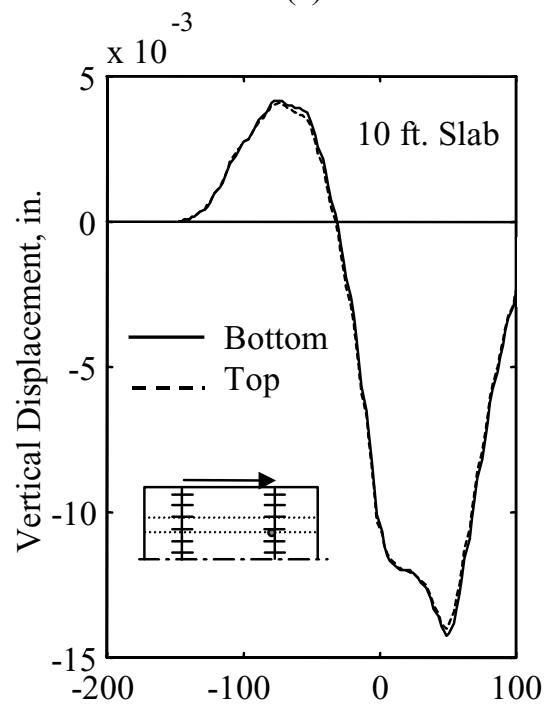

(e)
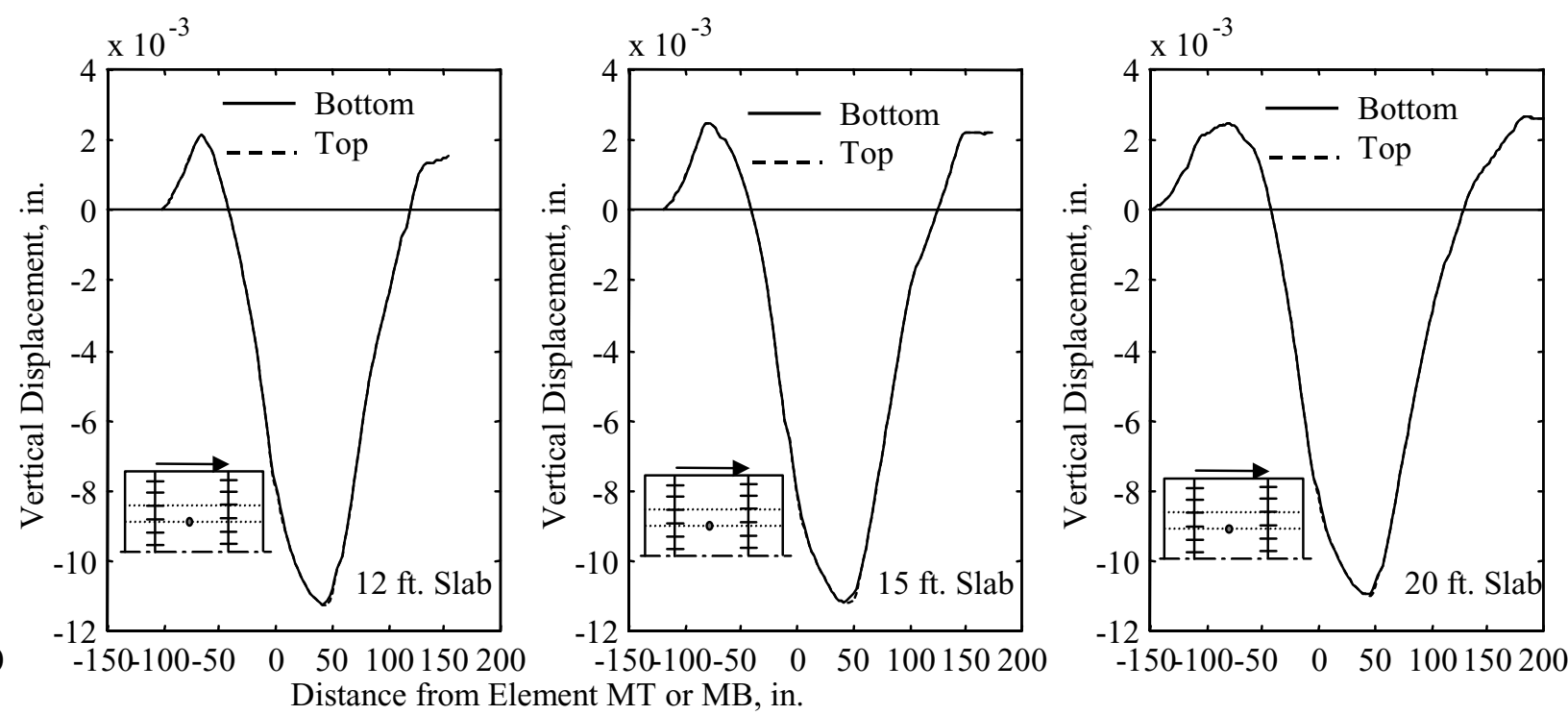

(b)
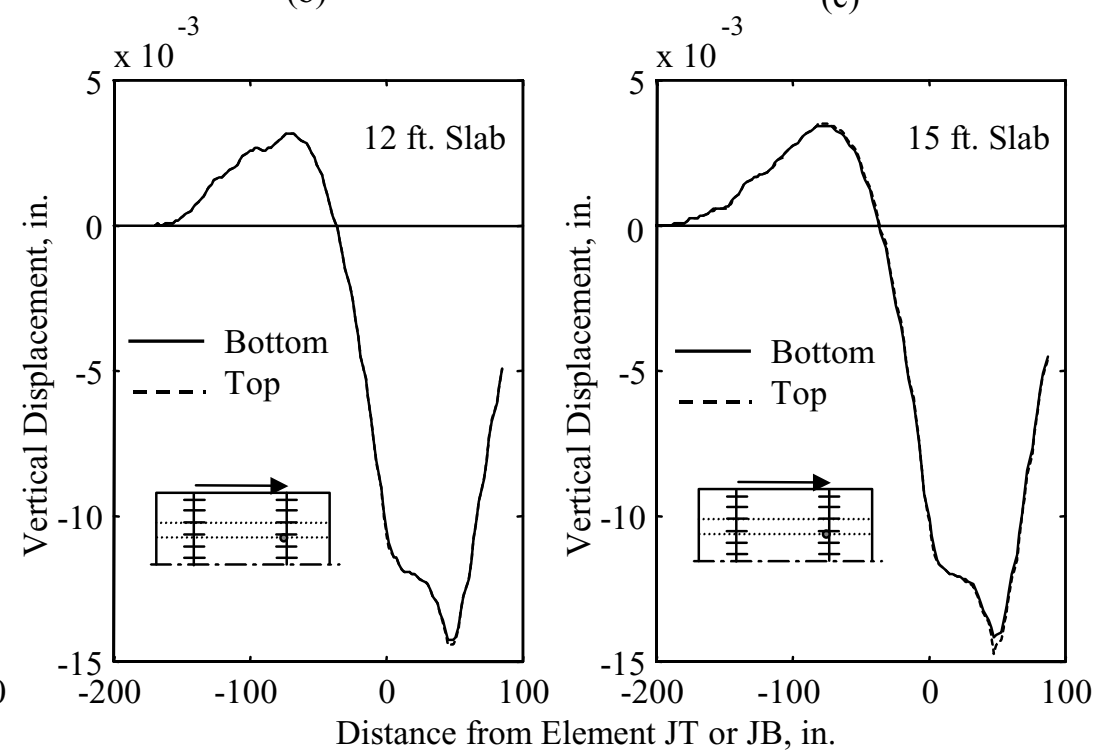

(g)

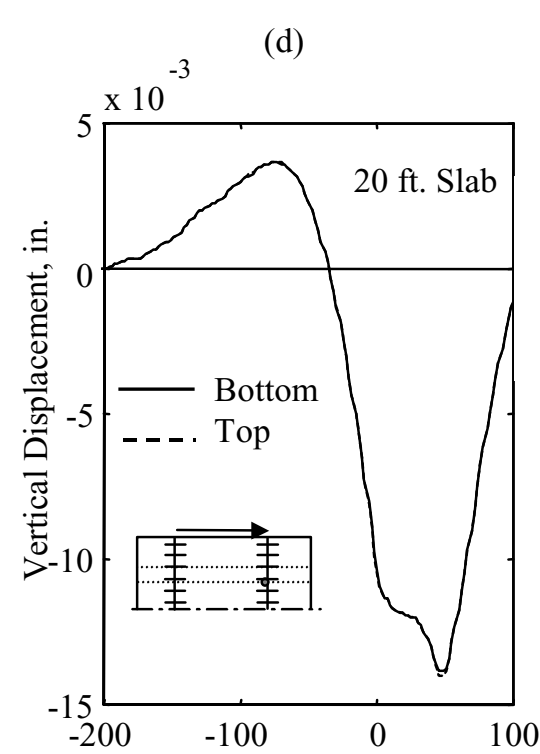

(h)

FIGURE 5.5 Effect of Slab Length on Vertical Displacement Induced in the Concrete Slab 


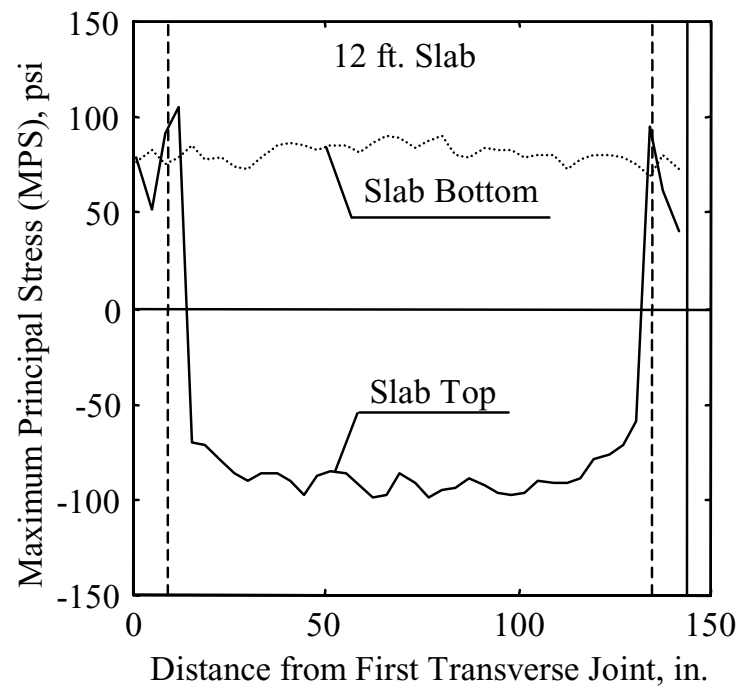

(a)

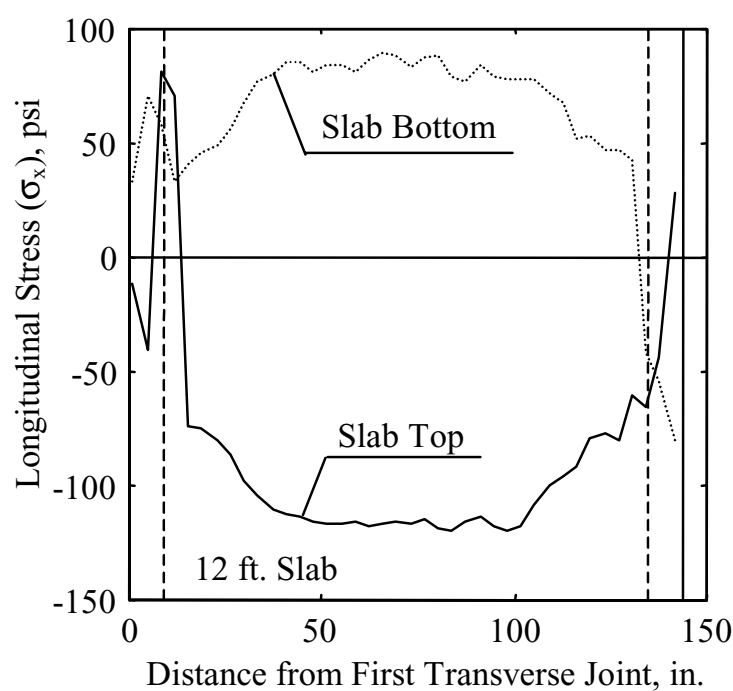

(d)

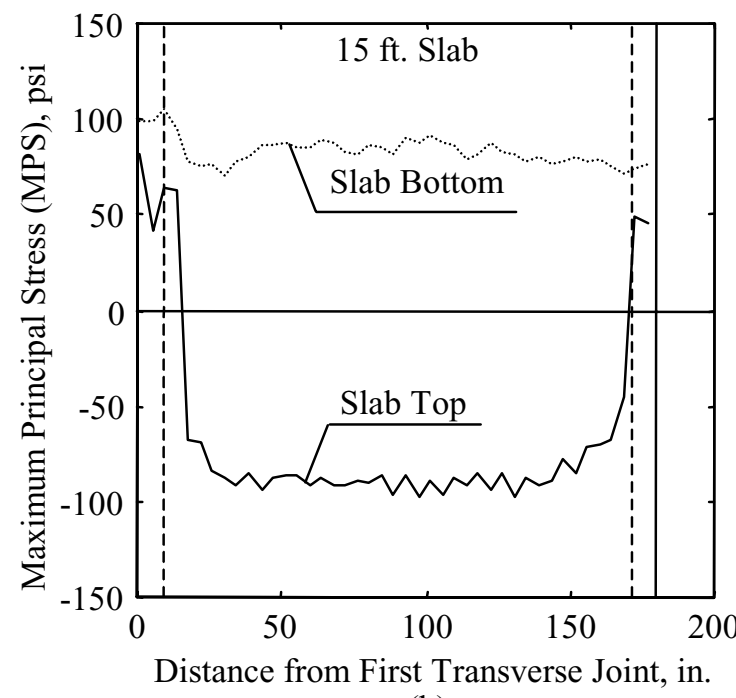

(b)

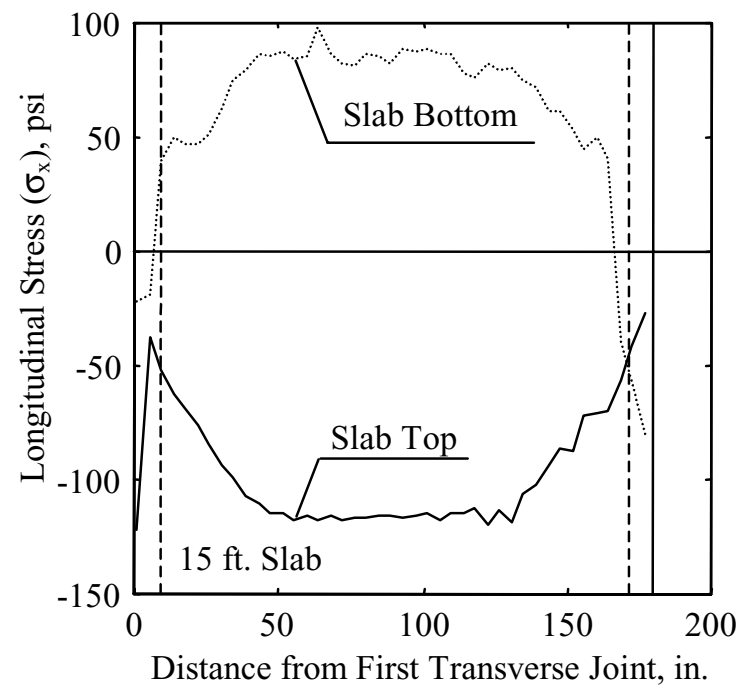

(e)

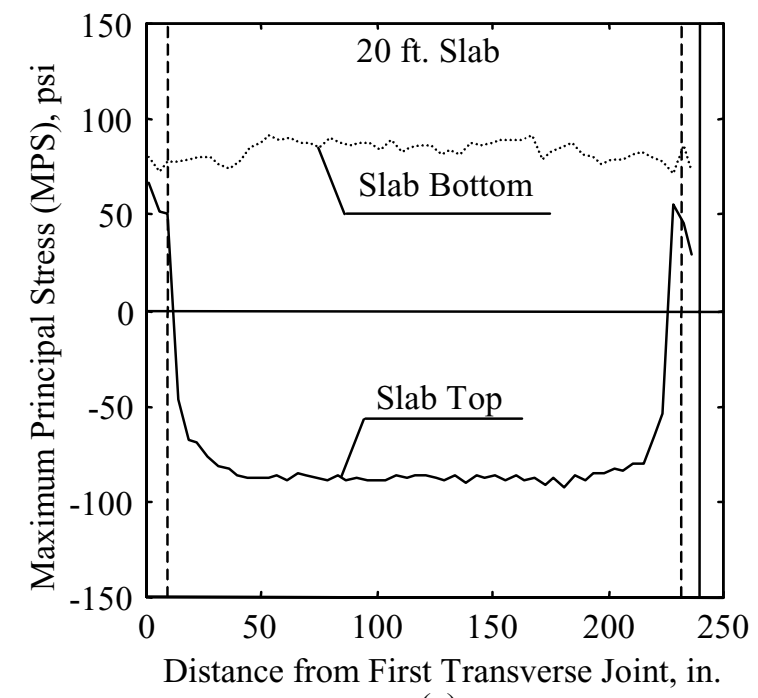

(c)

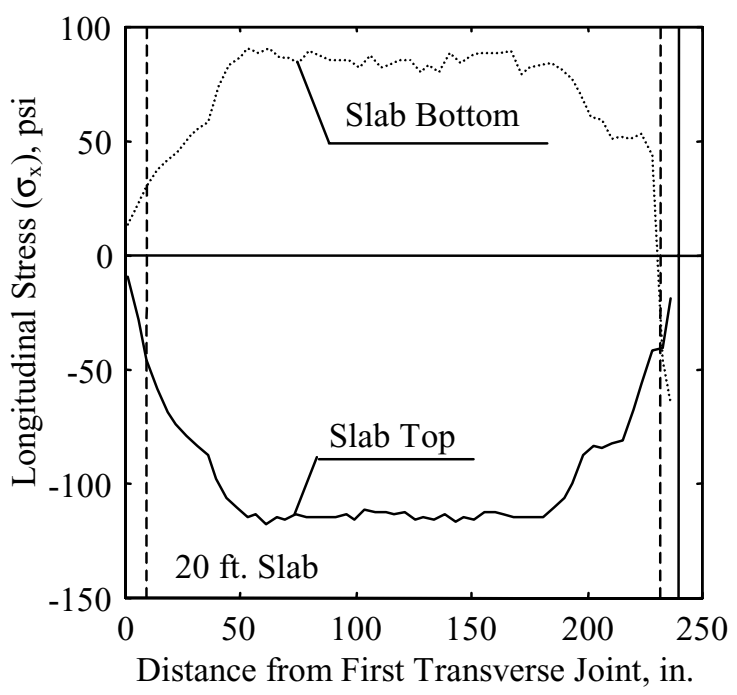

(f)

FIGURE 5.6 Effect of Slab Length on Distribution of Peak MPS and $\sigma_{\mathrm{x}}$ in the Concrete Slab 


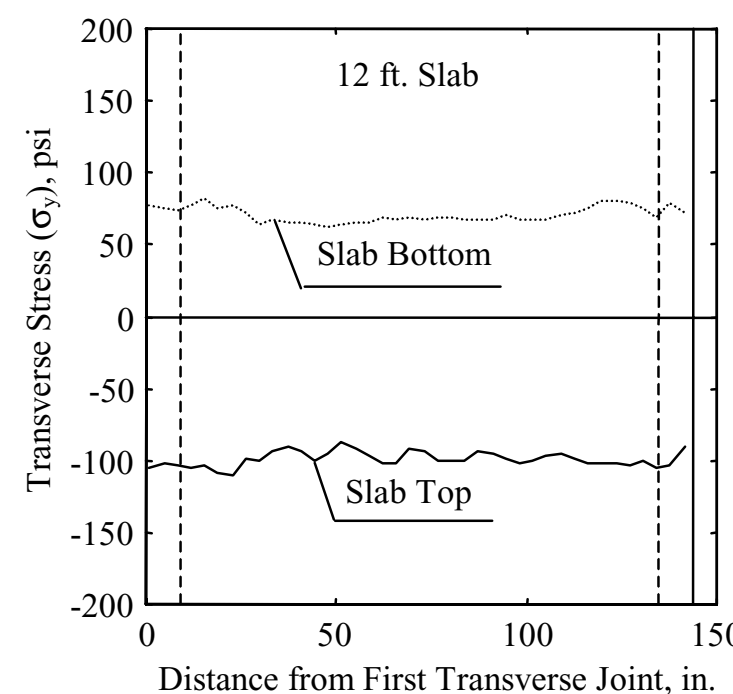

(a)

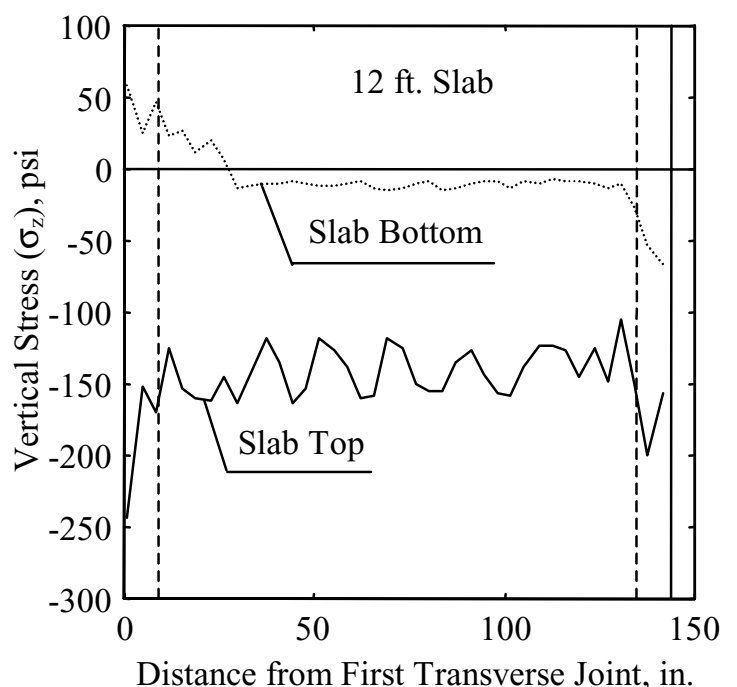

(d)

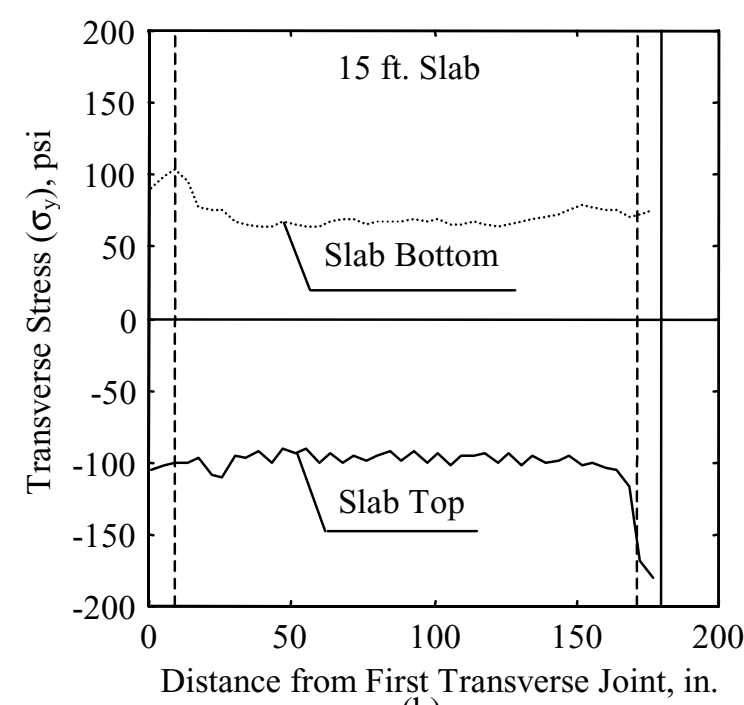

(b)

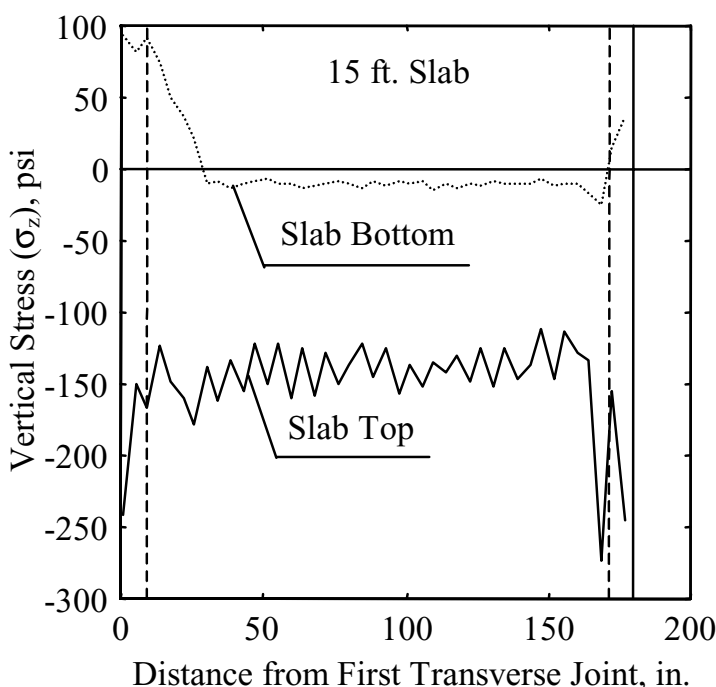

(e)

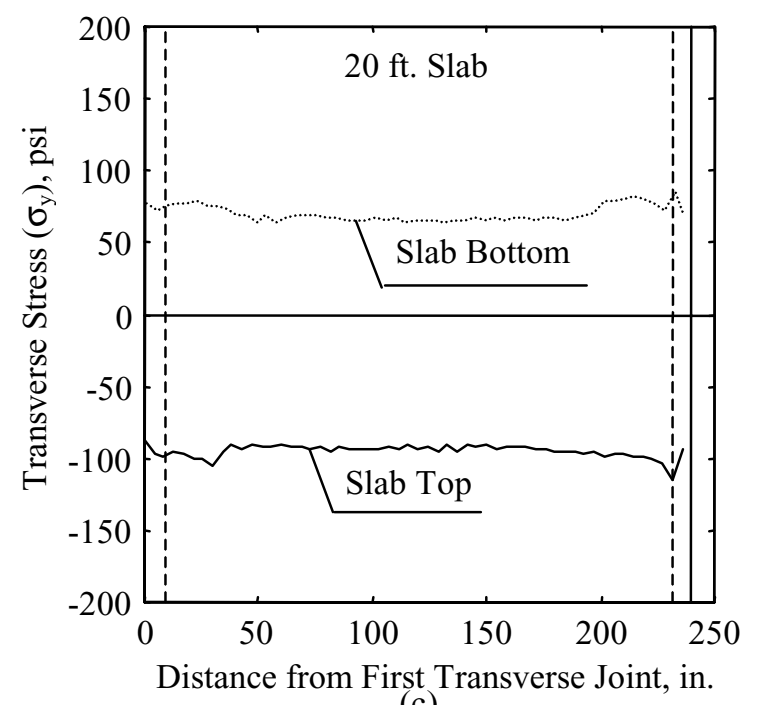

(c)

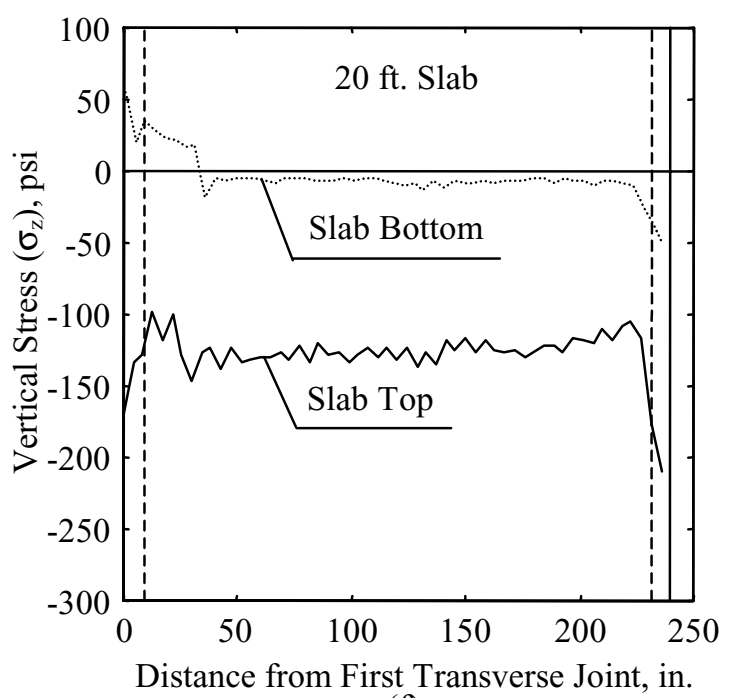

(f)

FIGURE 5.7 Effect of Slab Length on Distribution of Peak $\sigma_{y}$ and $\sigma_{z}$ in the Concrete Slab 


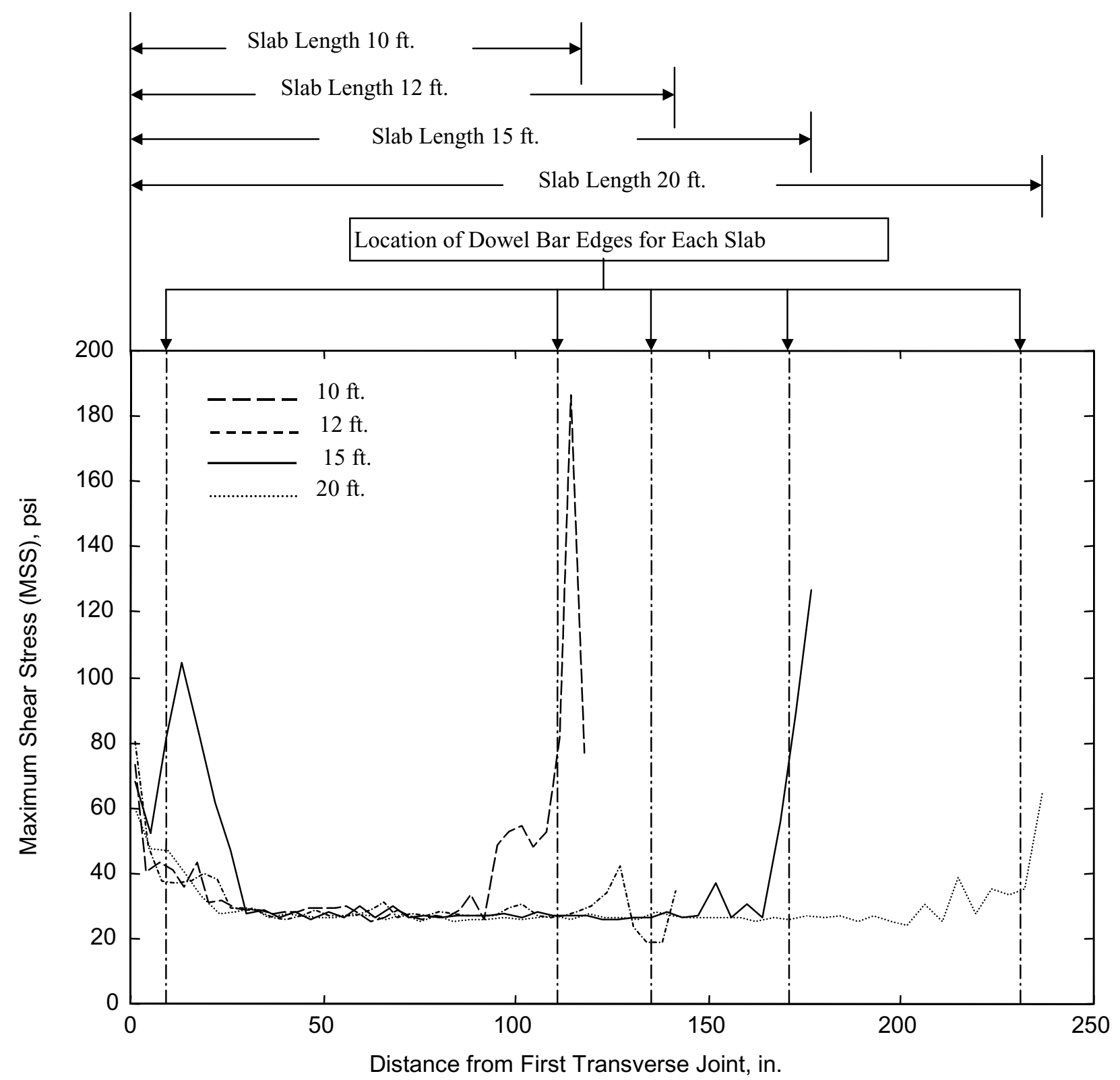

FIGURE 5.8 Effect of Slab Length on Maximum Shear Stress in the Concrete Slab 

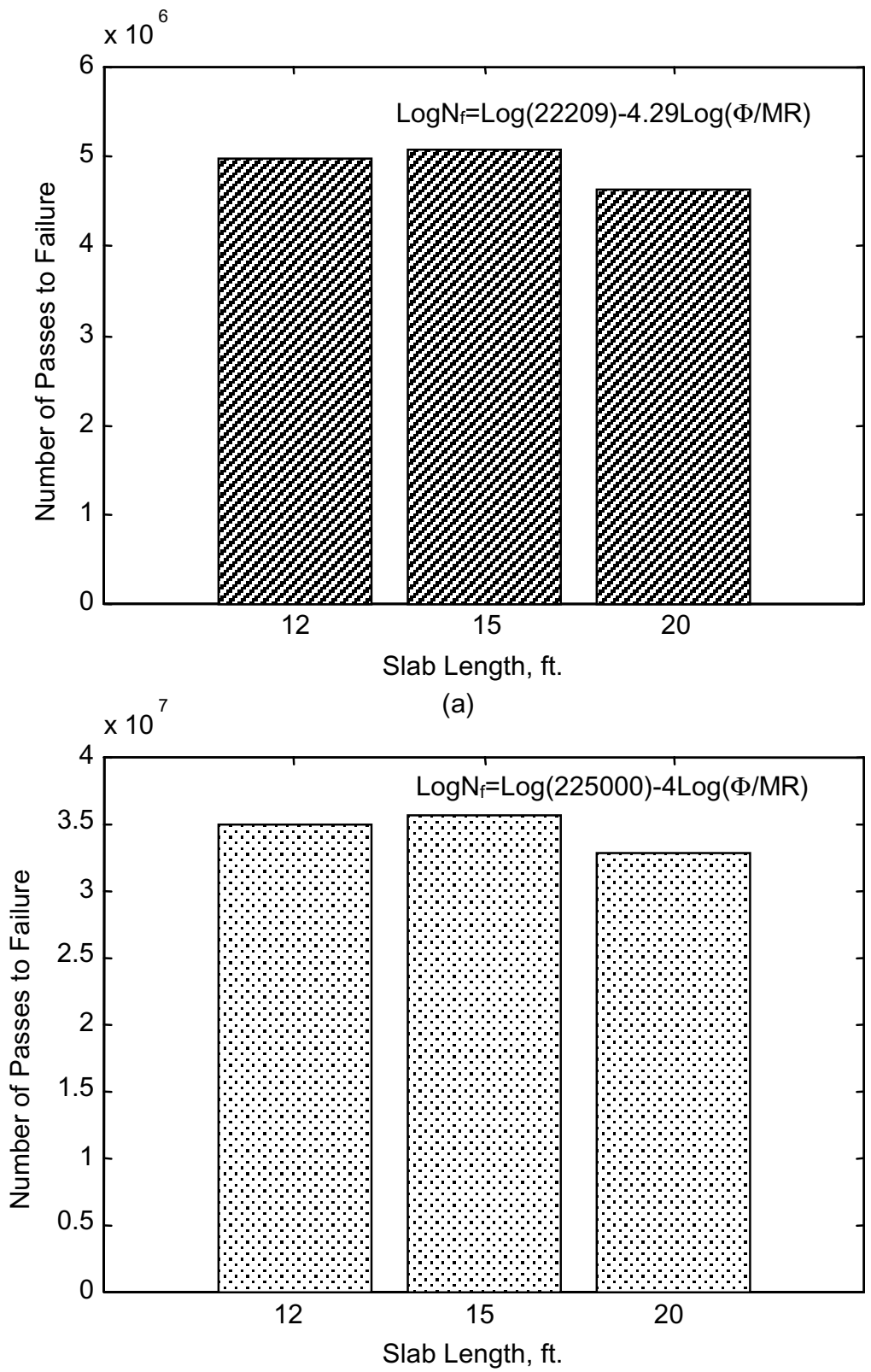

(c)

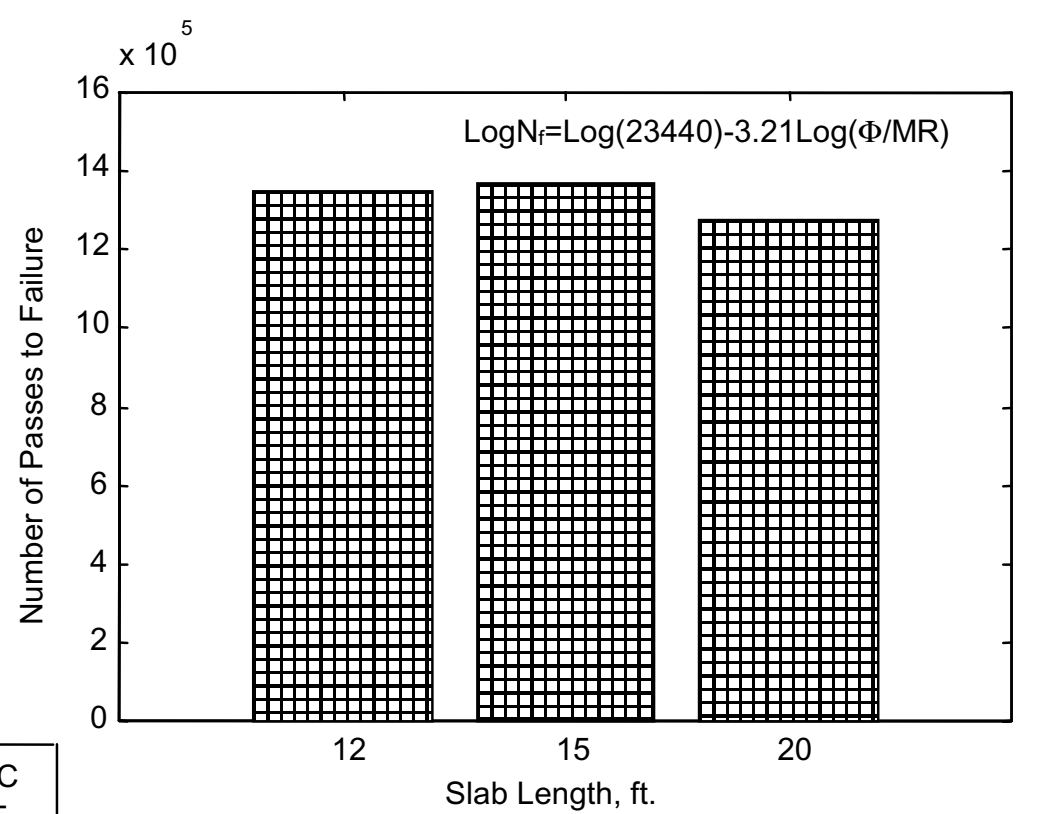
$\times 10^{11} \quad$ (b)
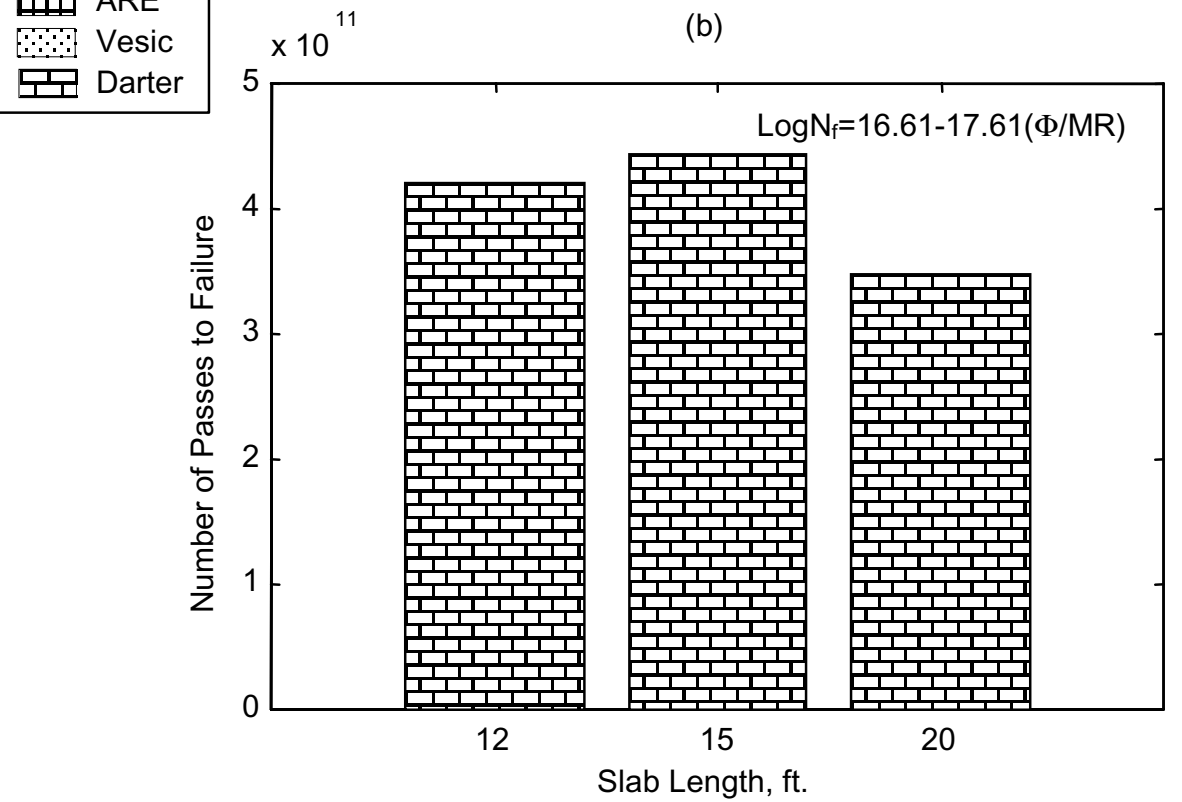

(d)

FIGURE 5.9 Effect of Slab Length on Rigid Pavement Fatigue Damage Using Four Fatigue Models 


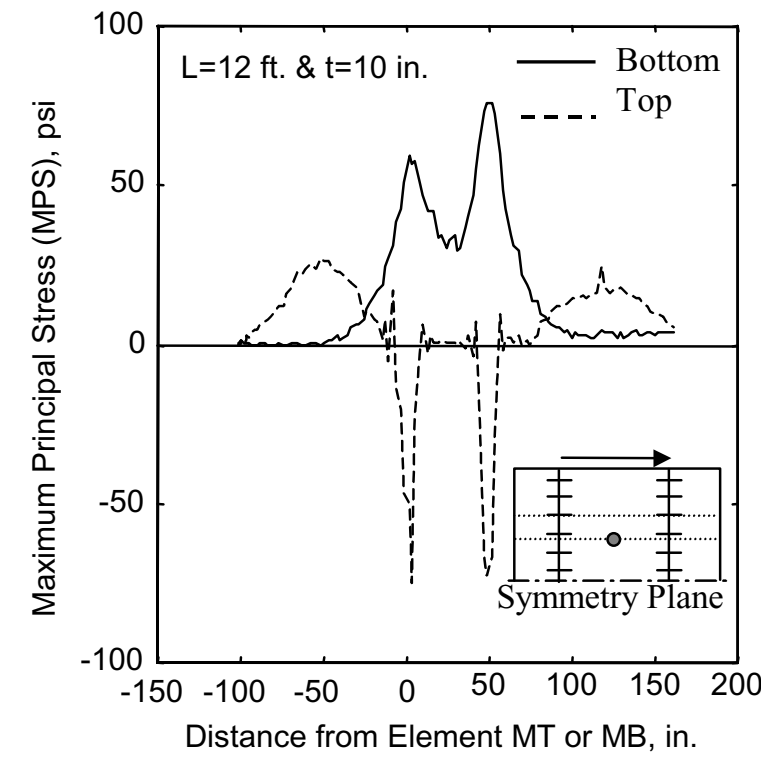

(a)

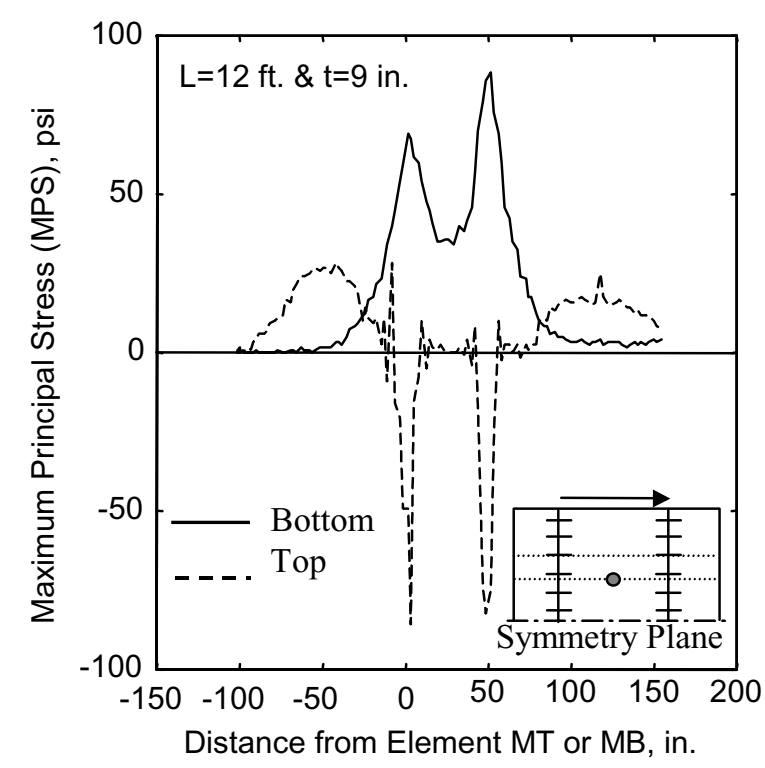

(d)

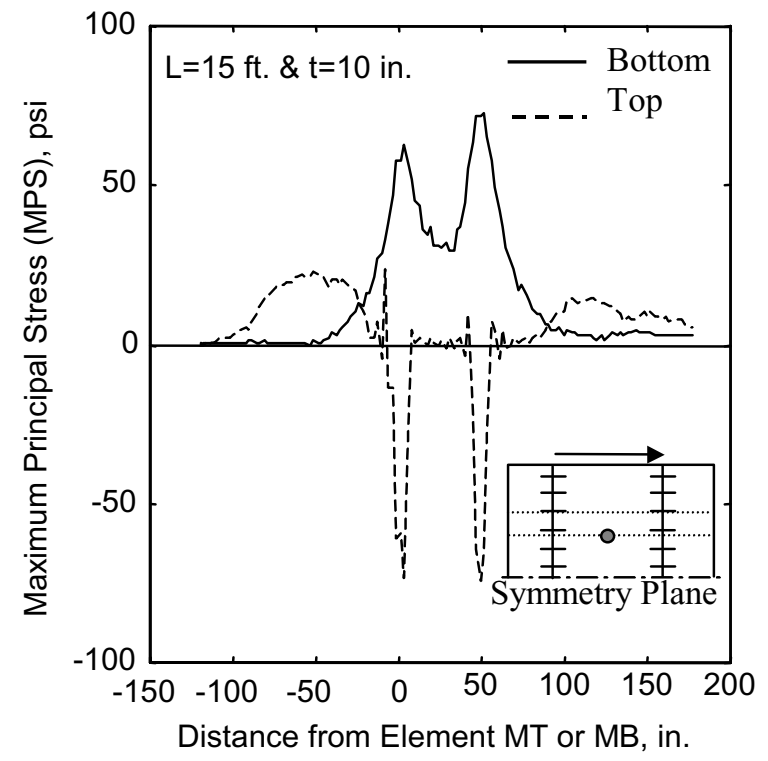

(b)

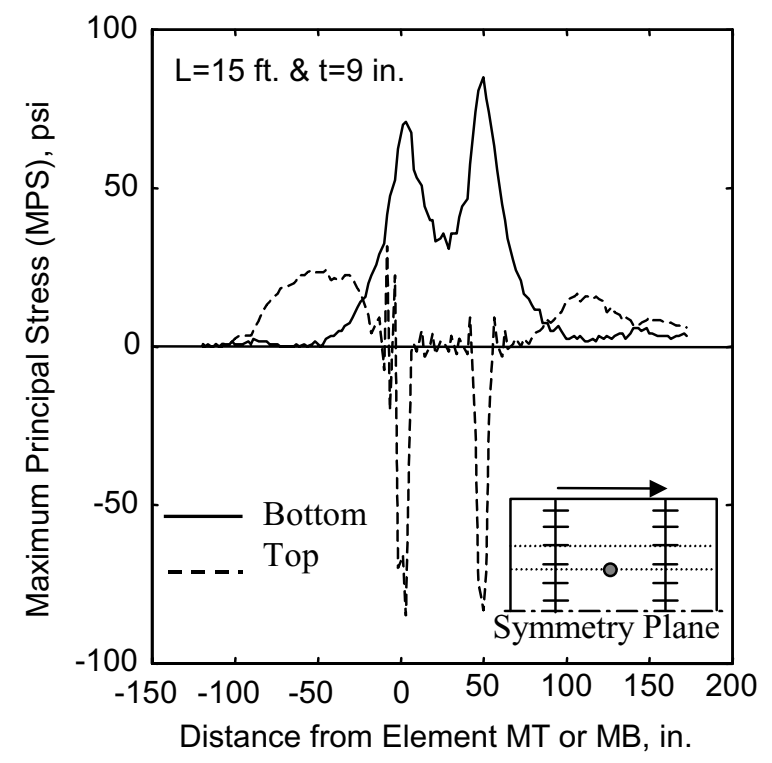

(e)

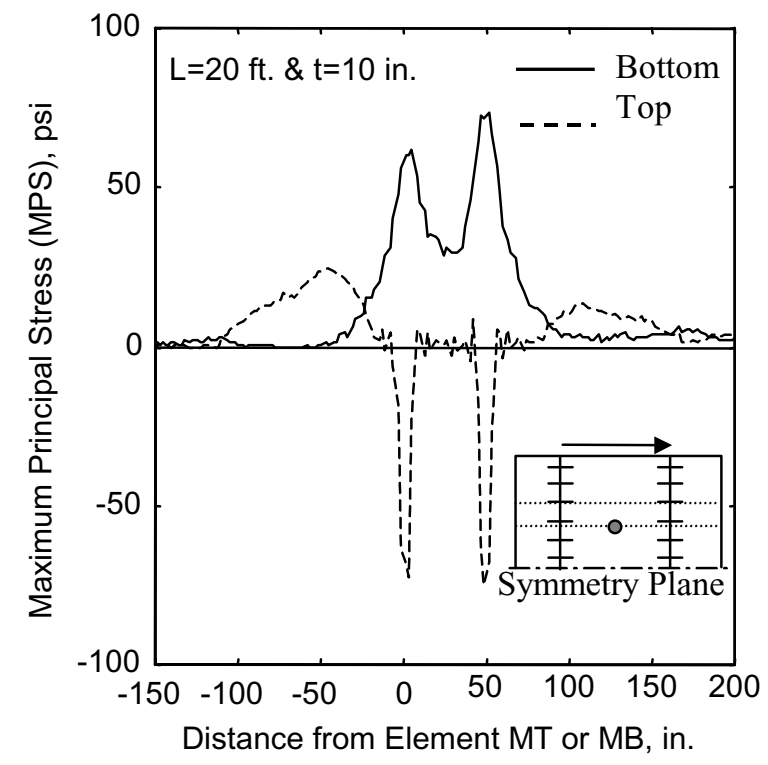

(c)

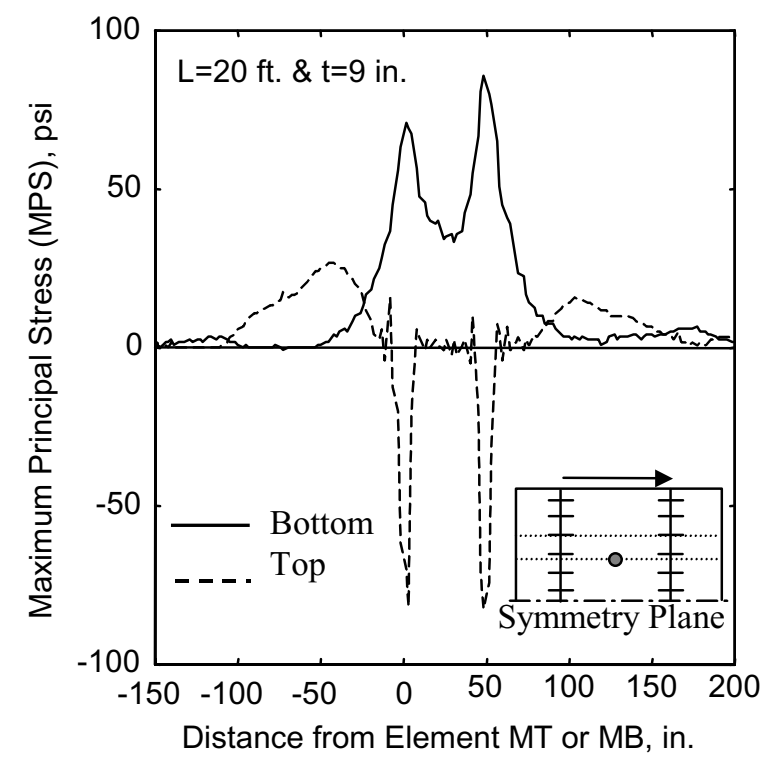

(f)

FIGURE 5.10 Effect of Slab Thickness on Distribution of MPS at the Middle of the Concrete Slab 


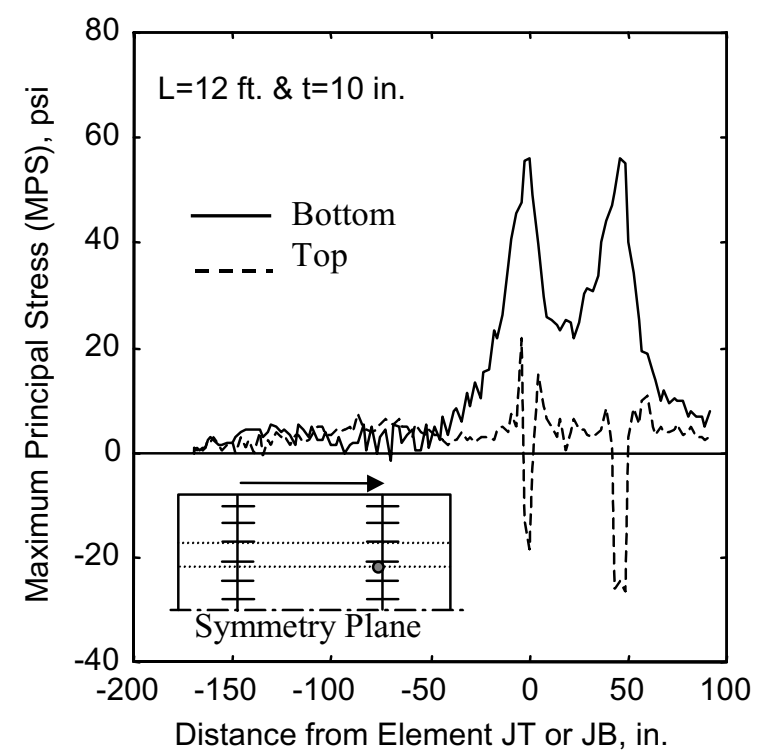

(a)

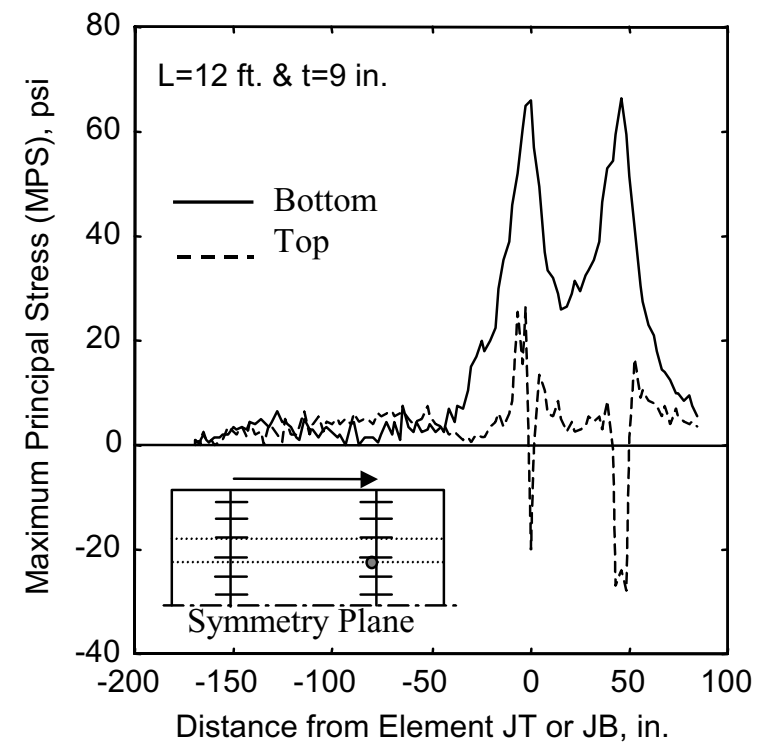

(d)

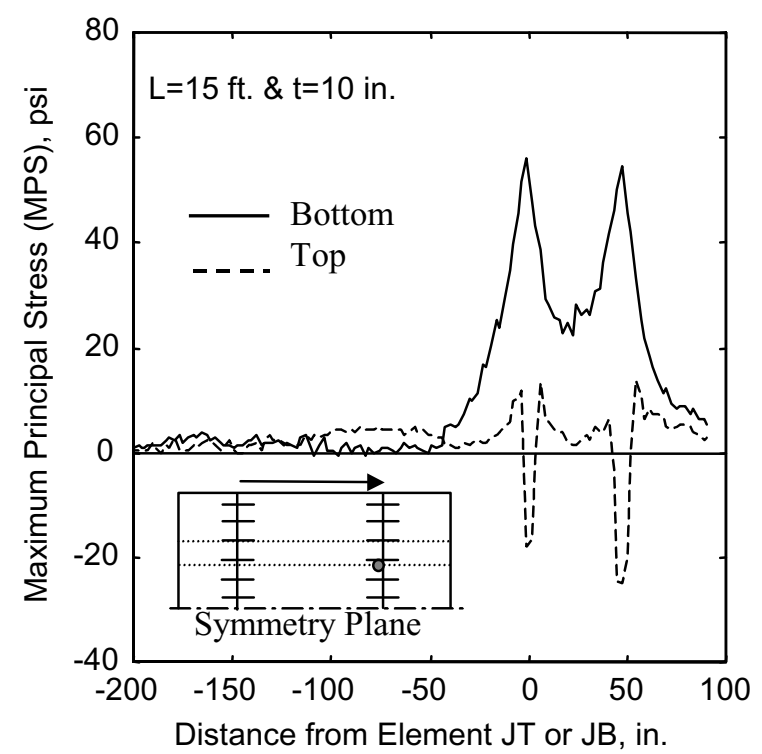

(b)

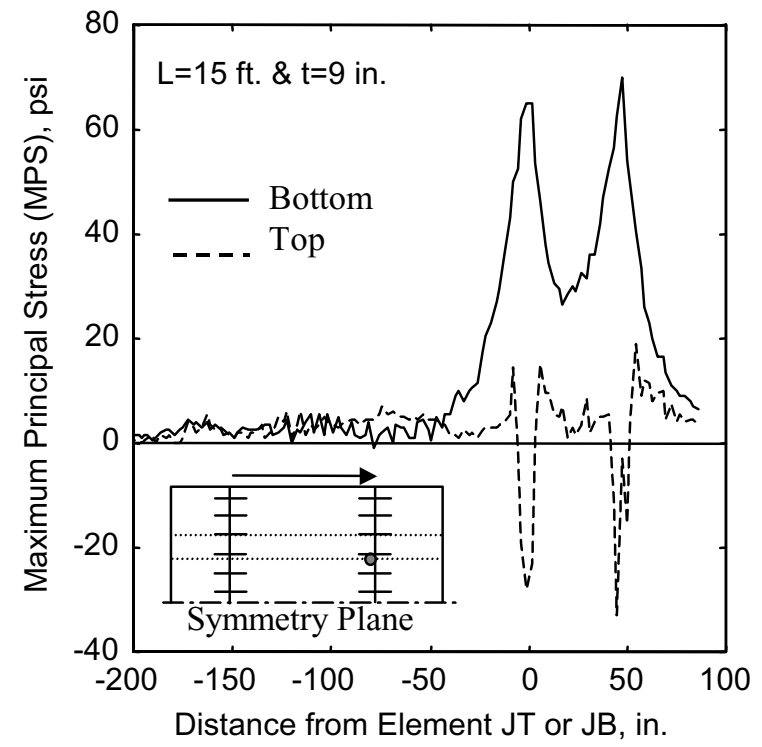

(e)

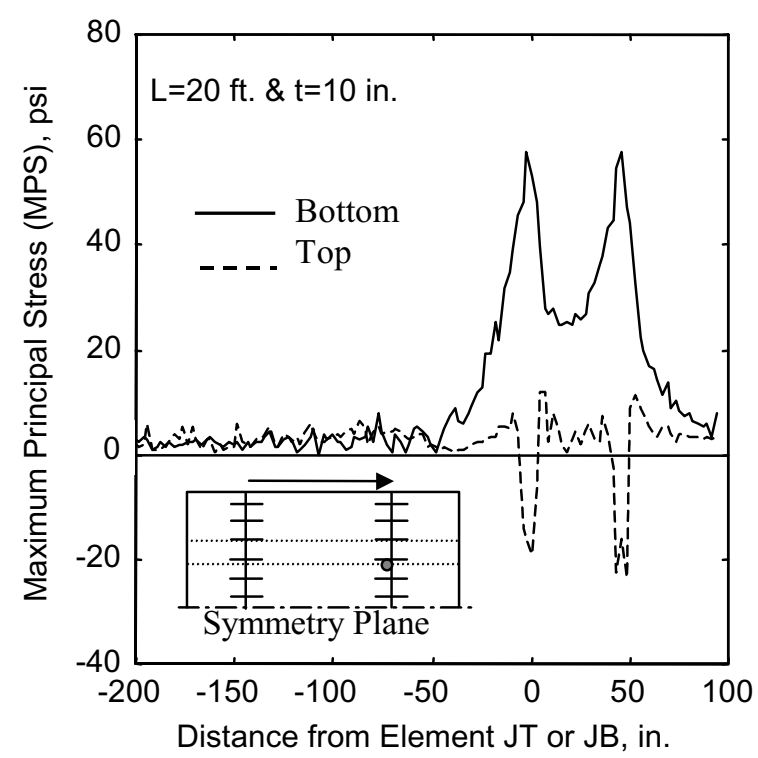

(c)

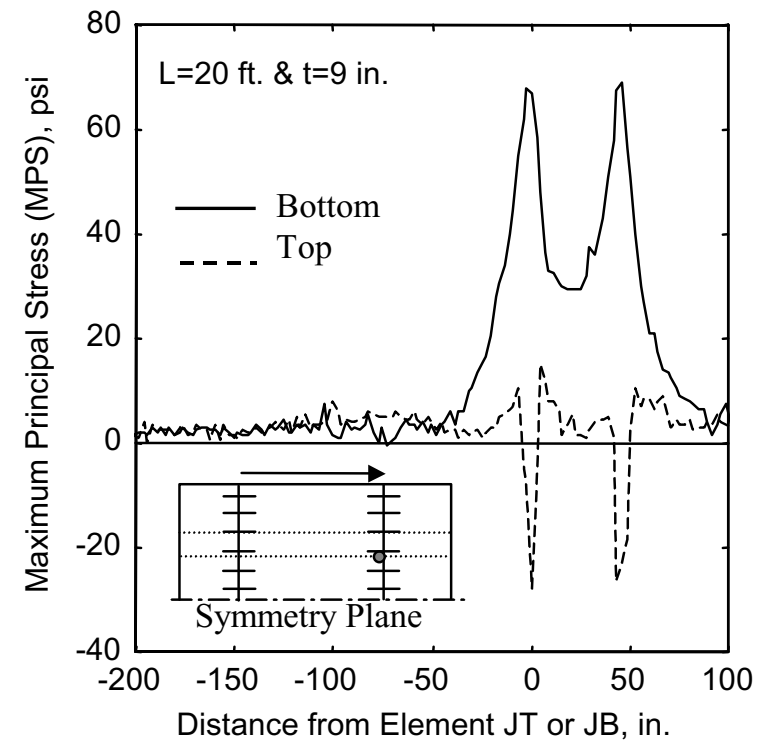

(f)

FIGURE 5.11 Effect of Slab Thickness on Distribution of MPS in the Concrete Slab at the Transverse Joint 


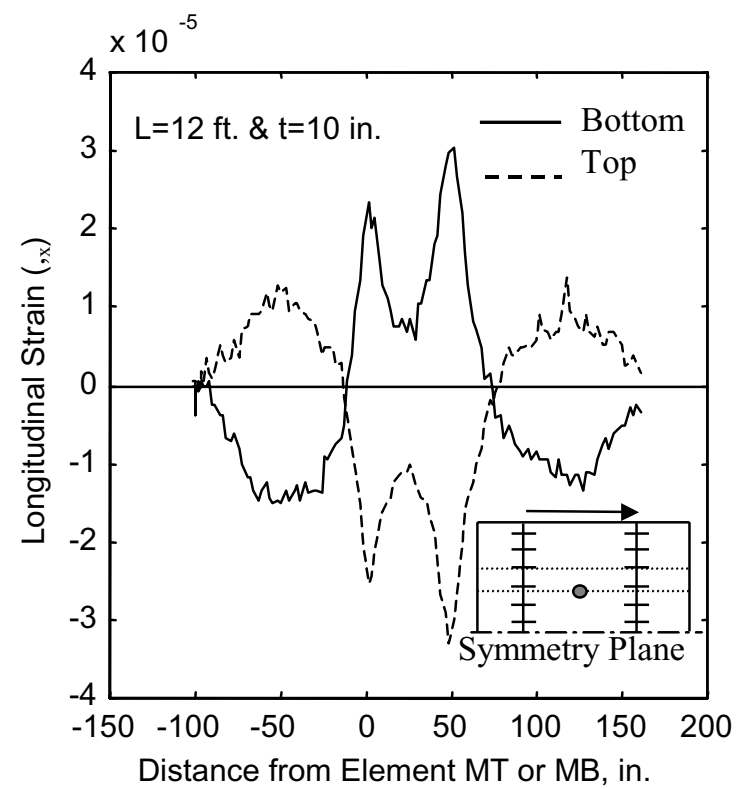

(a)

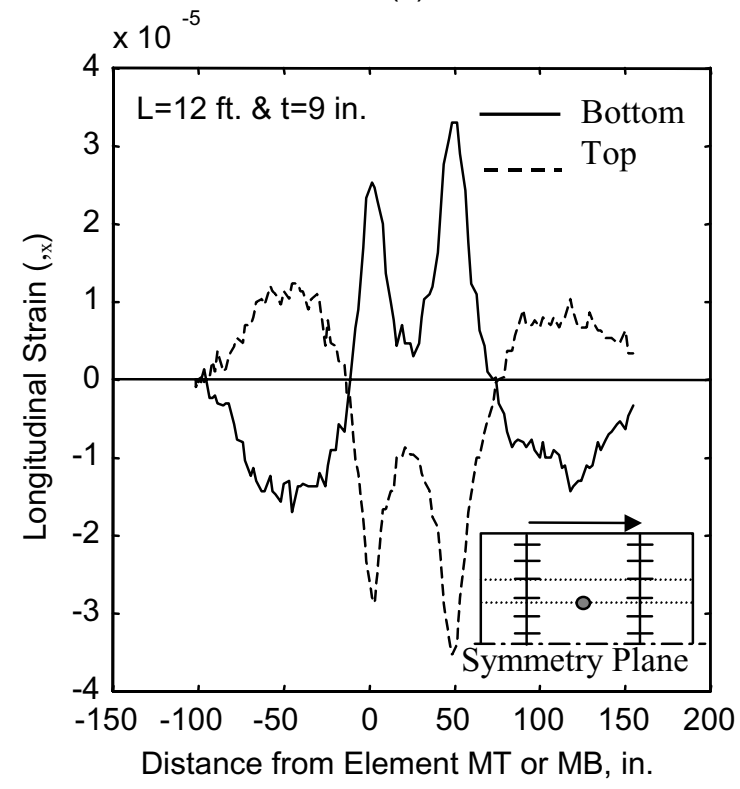

(d)

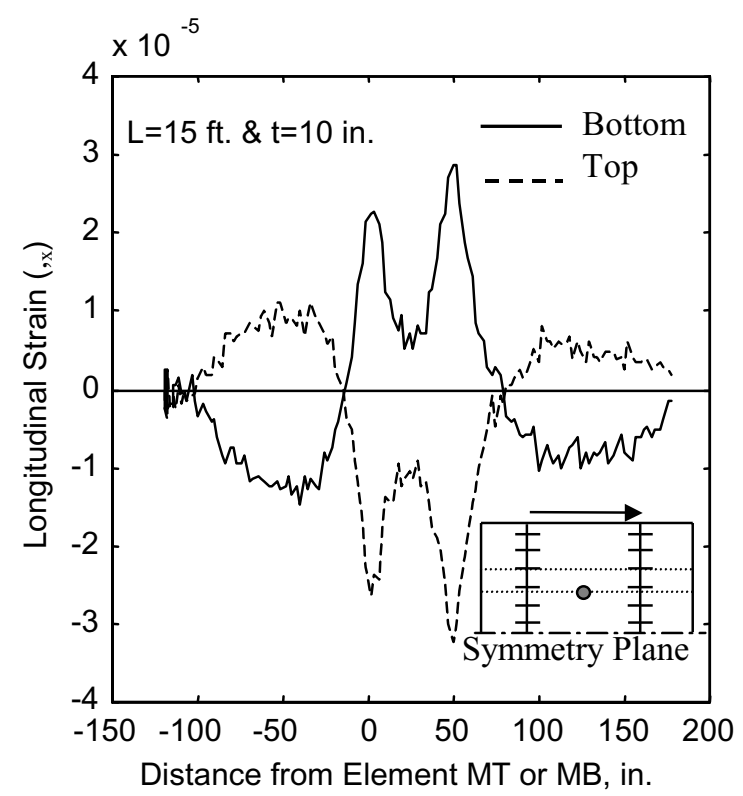

(b)

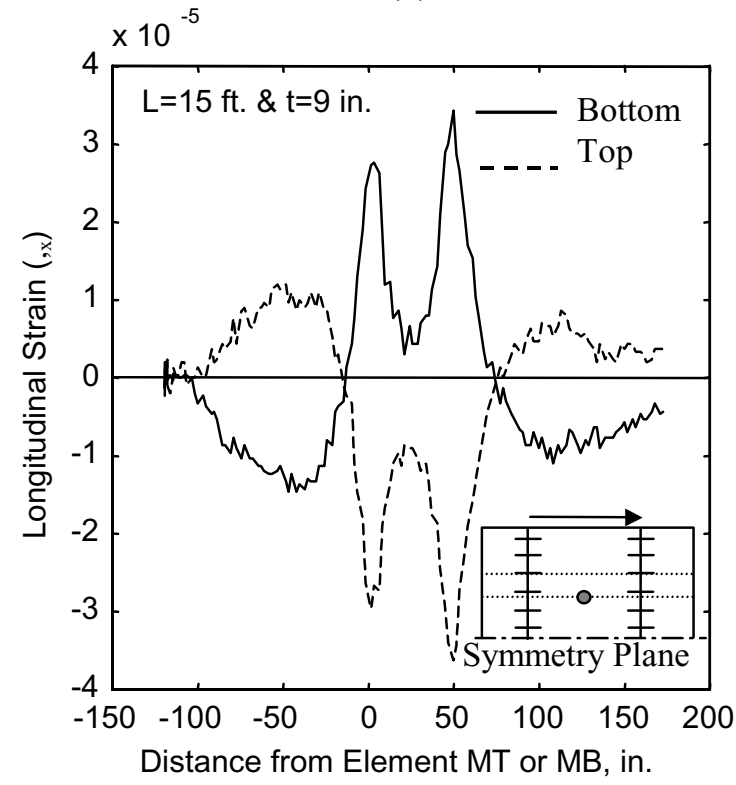

(e)

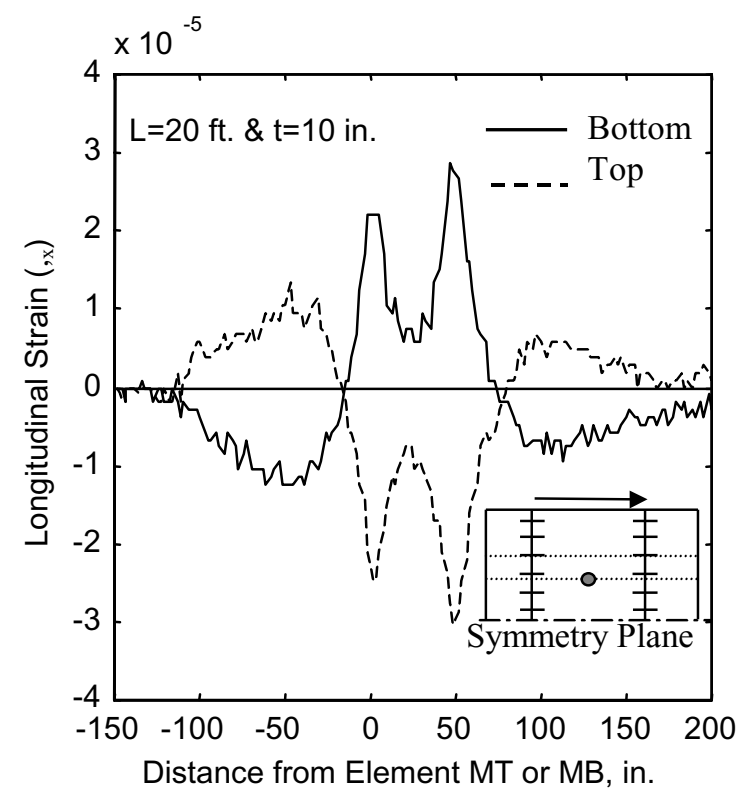

(c)

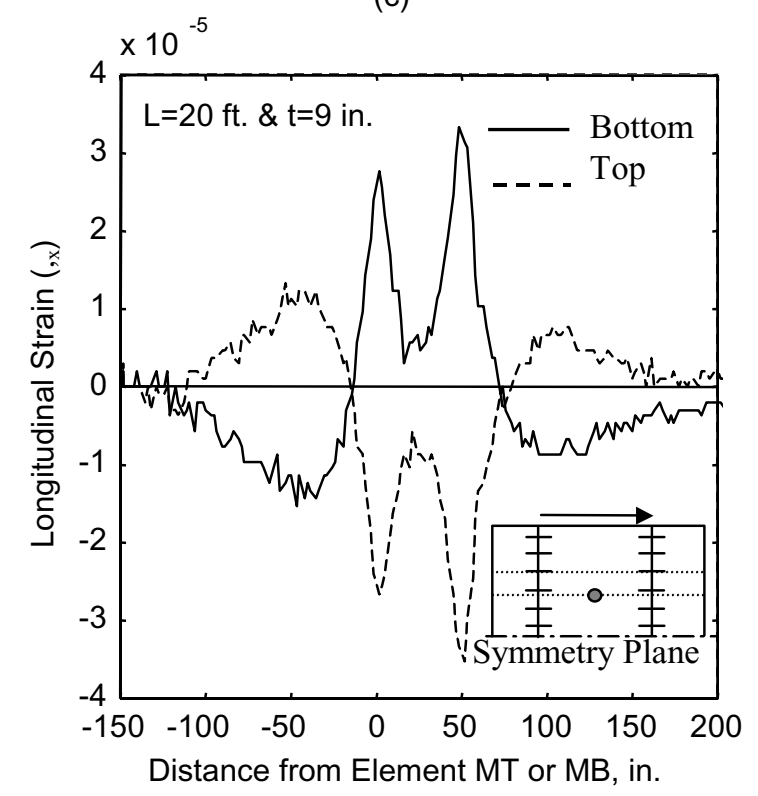

(f)

FIGURE 5.12 Effect of Slab Thickness on Distribution of ${ }_{x}$ in the middle of the Concrete Slab 

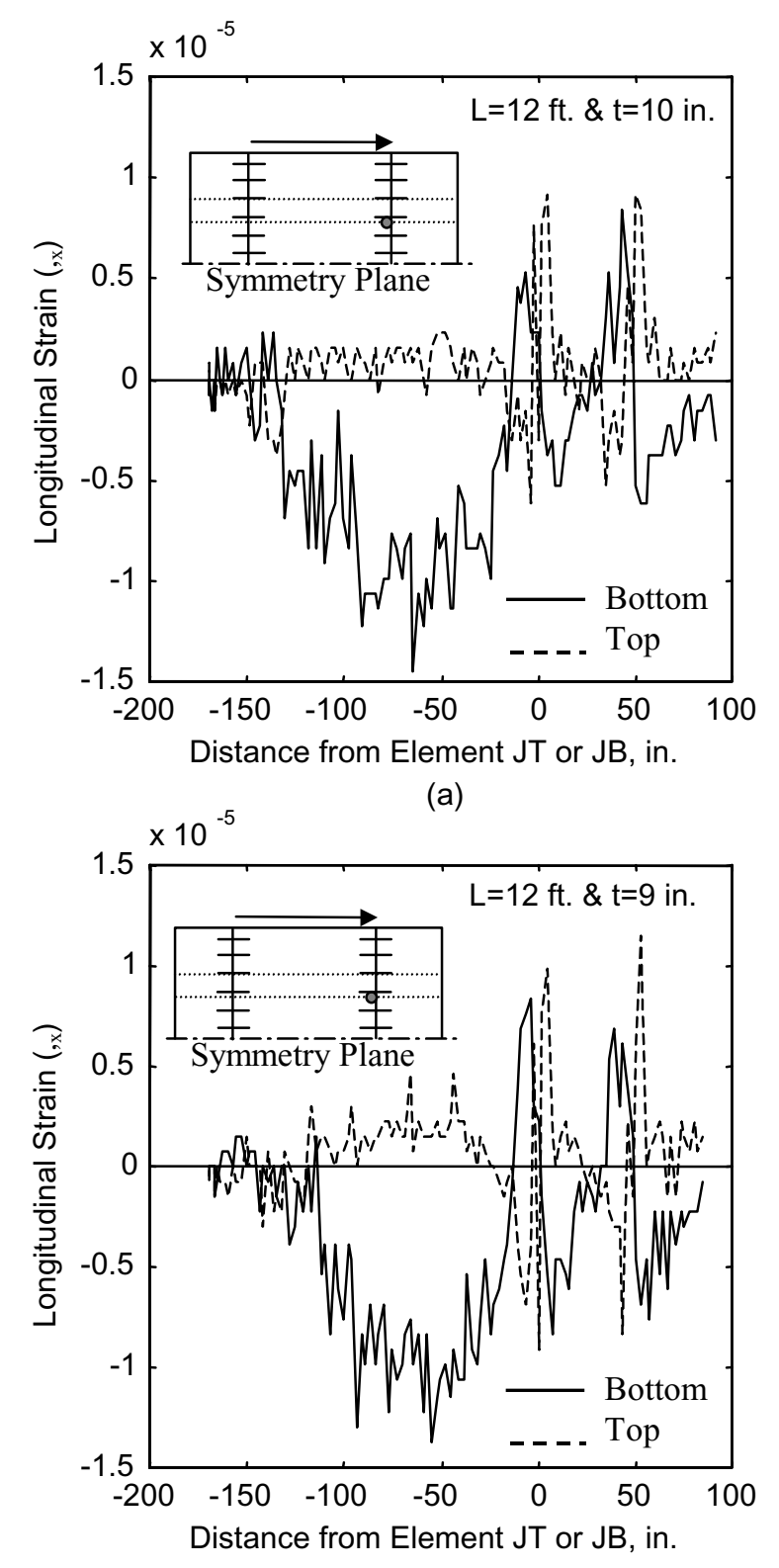

(d)

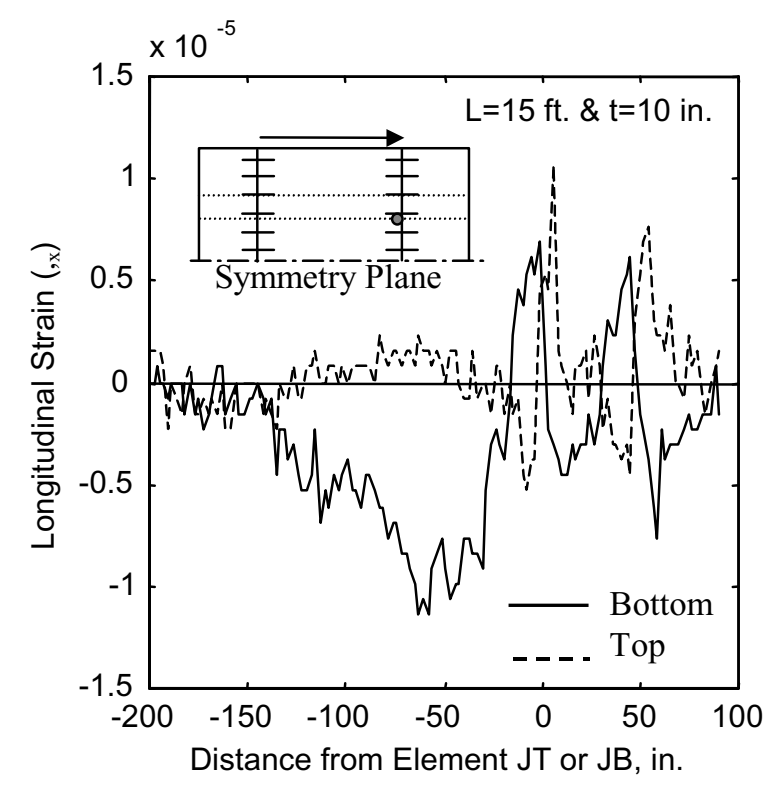

(b)

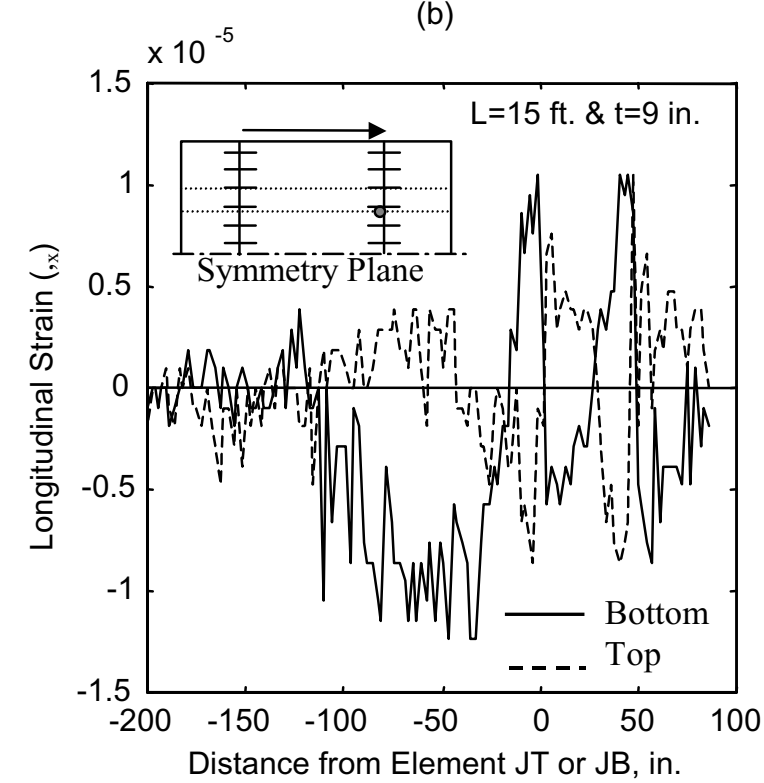

(e)

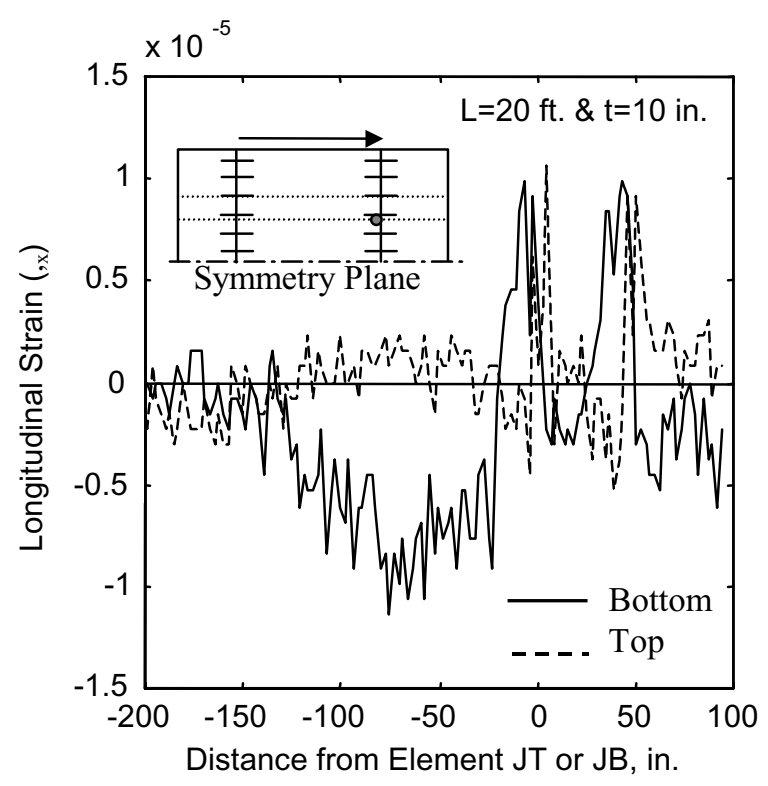

(c)

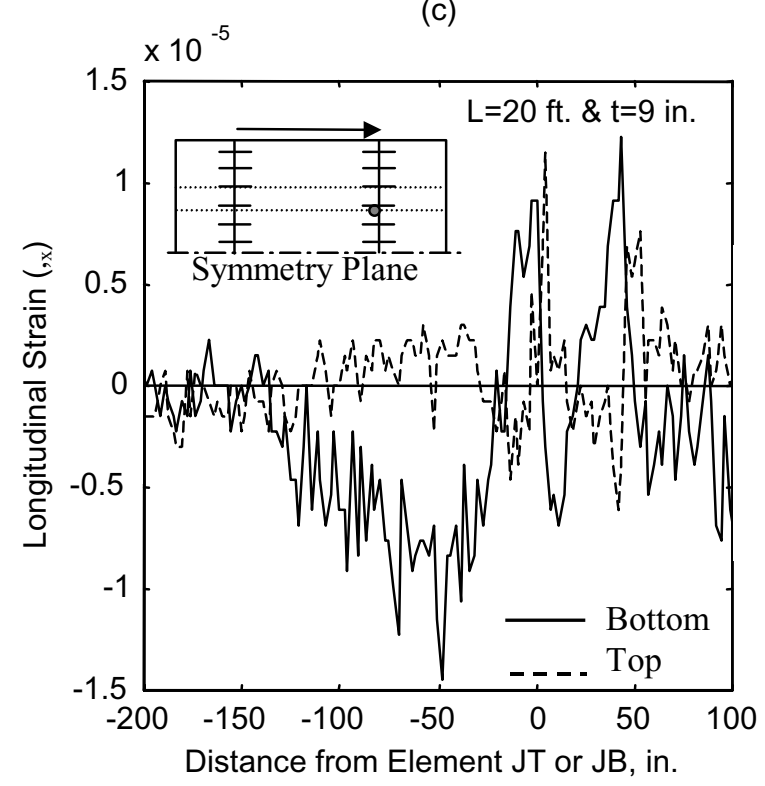

(f)

FIGURE 5.13 Effect of Slab Thickness on Distribution of , ${ }_{x}$ in the Concrete Slab at the Transverse Joint 


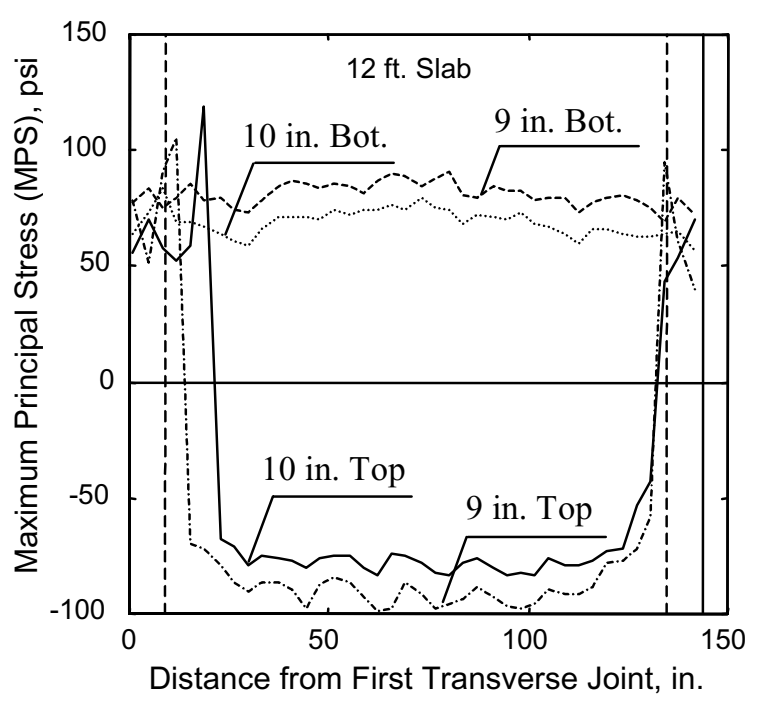

(a)

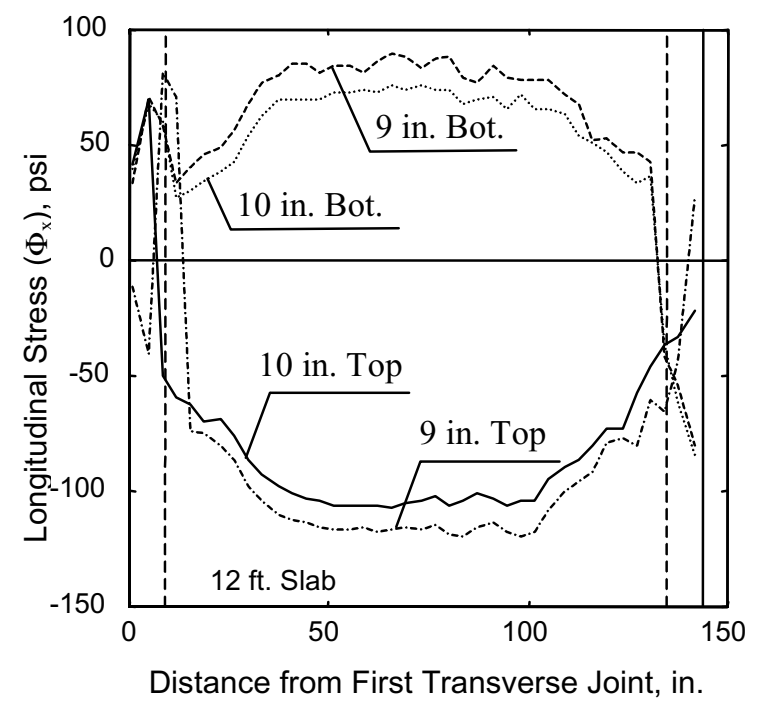

(d)

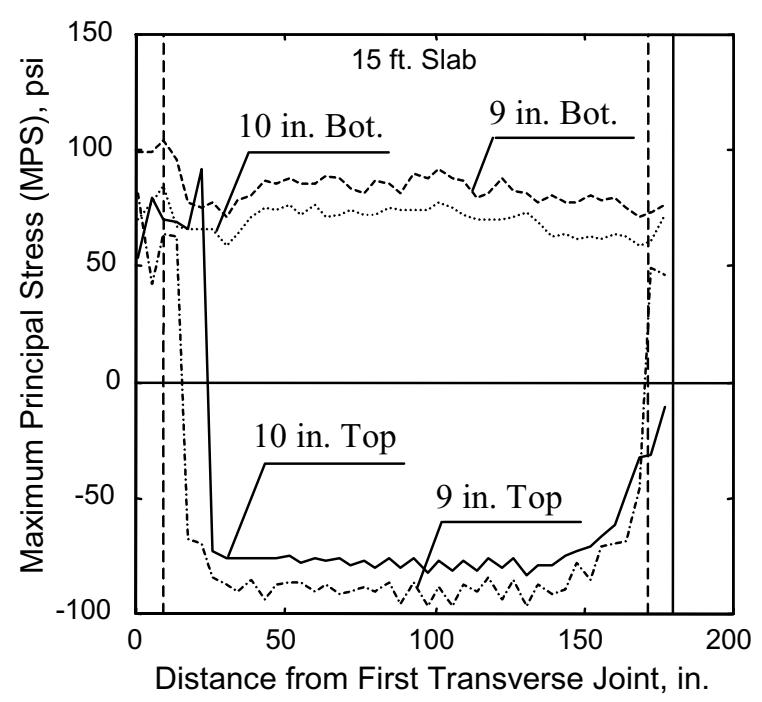

(b)

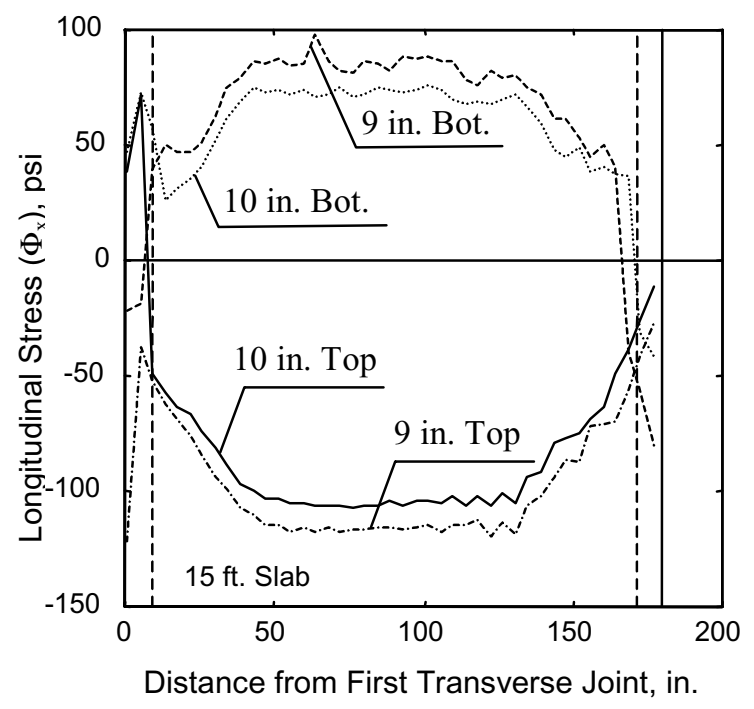

(e)

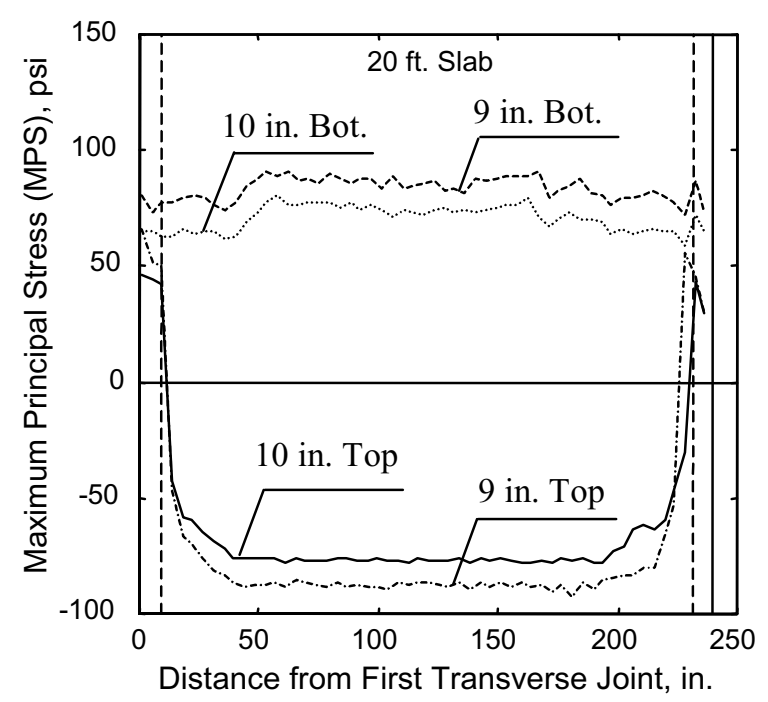

(c)

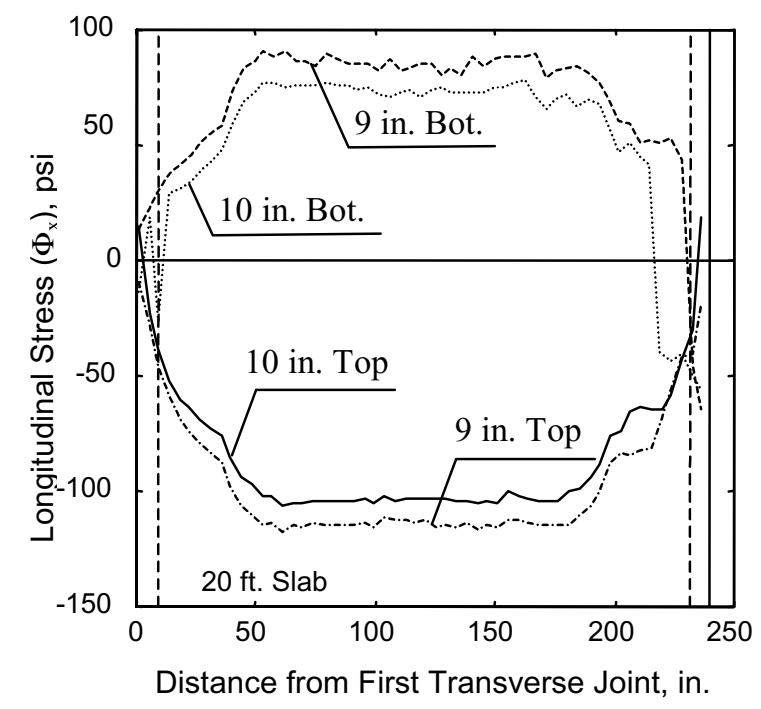

(f)

FIGURE 5.14 Effect of Slab Thickness on Distribution of Peak MPS and $\Phi_{\mathrm{x}}$ in the Concrete Slab 


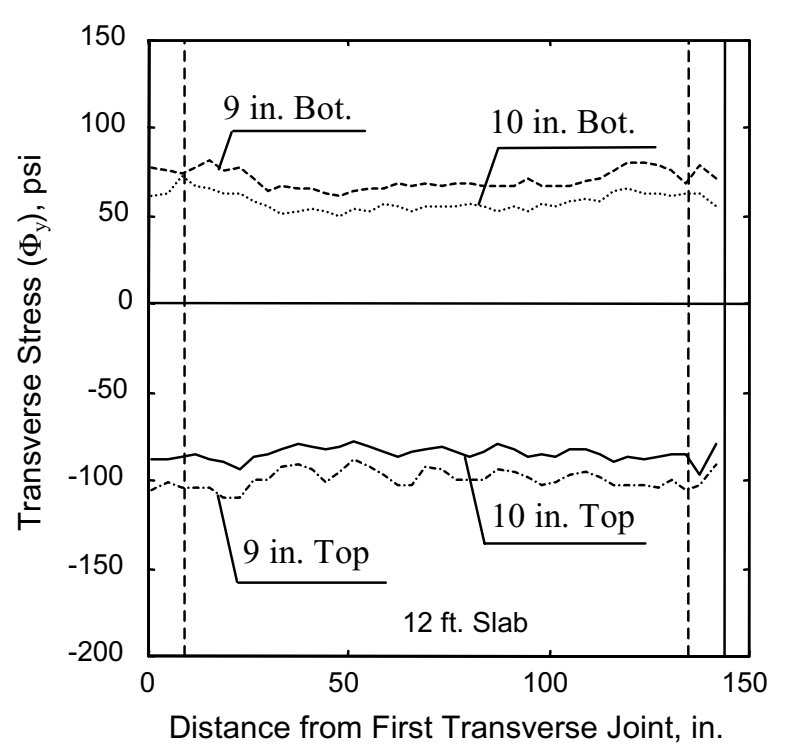

(a)

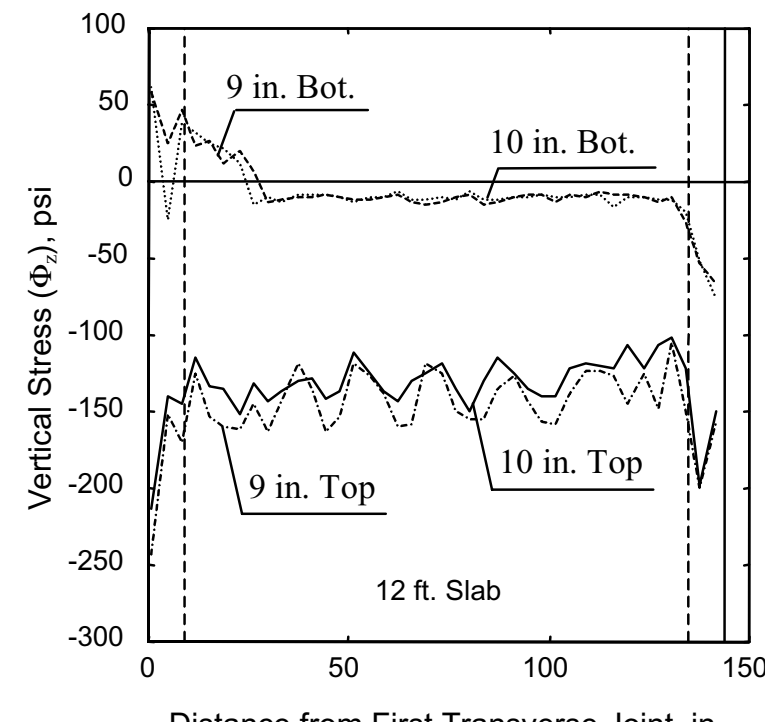

(d)

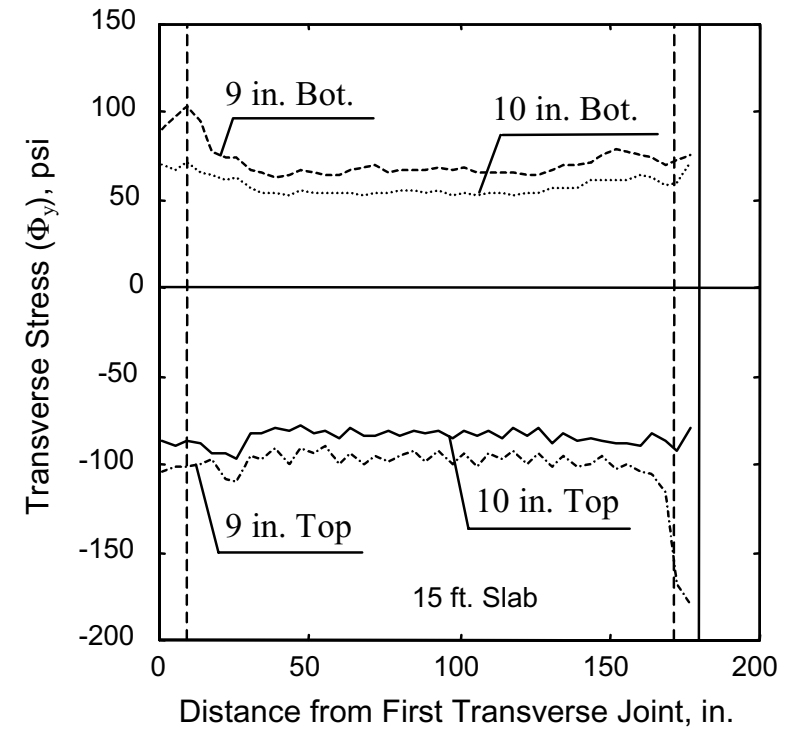

(b)

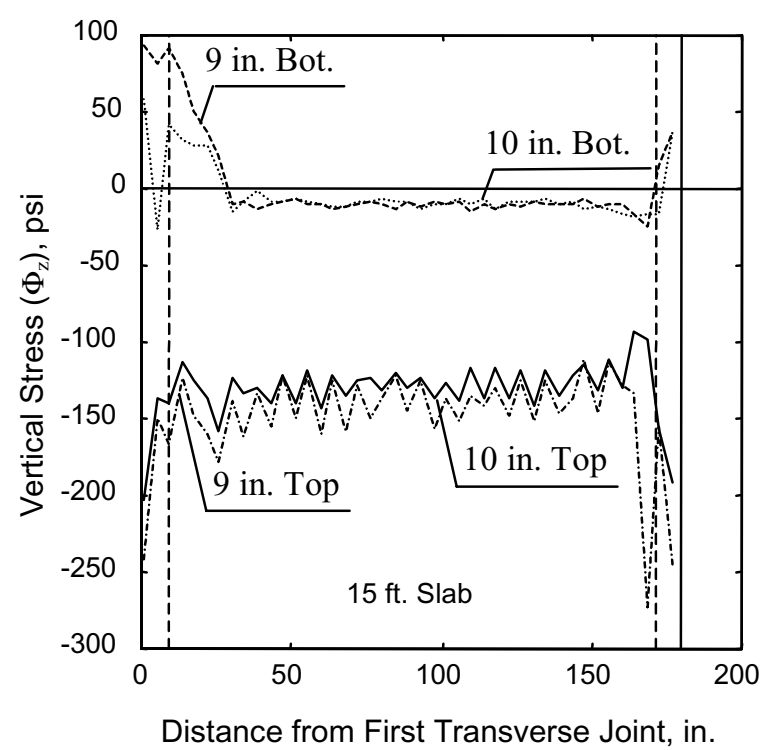

(e)

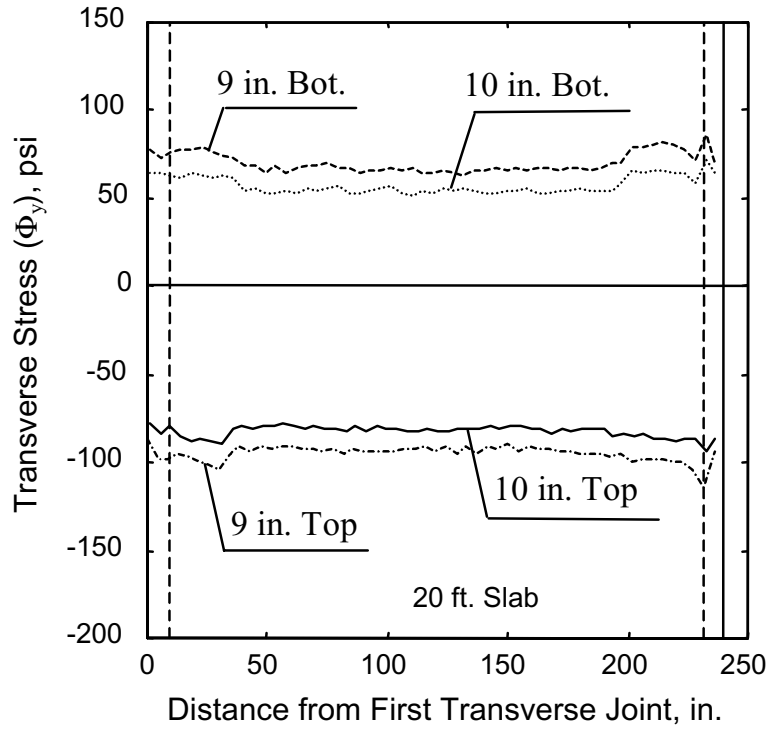

(c)

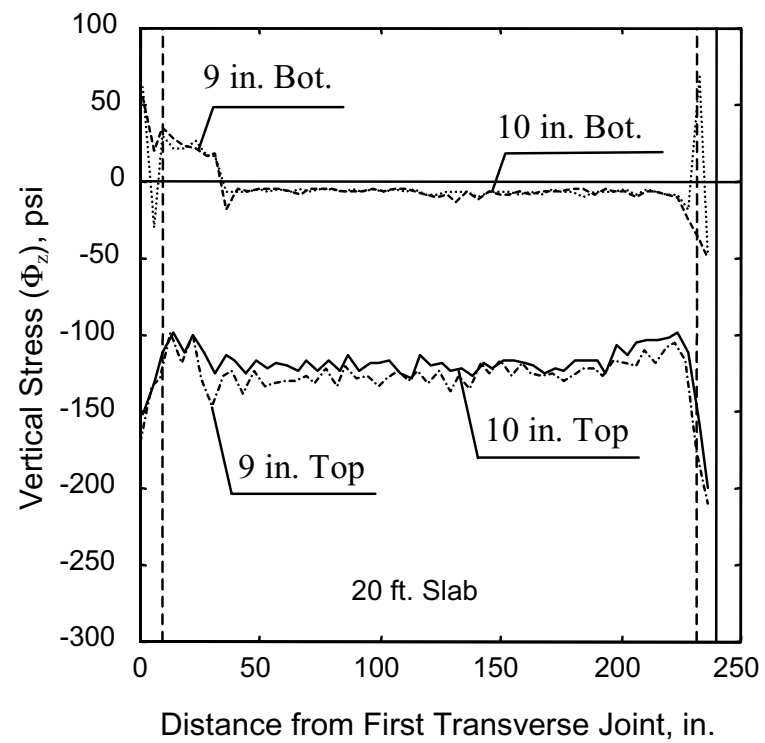

(f)

FIGURE 5.15 Effect of Slab Thickness on Distribution of Peak $\Phi_{\mathrm{y}}$ and $\Phi_{\mathrm{z}}$ in the Concrete Slab 


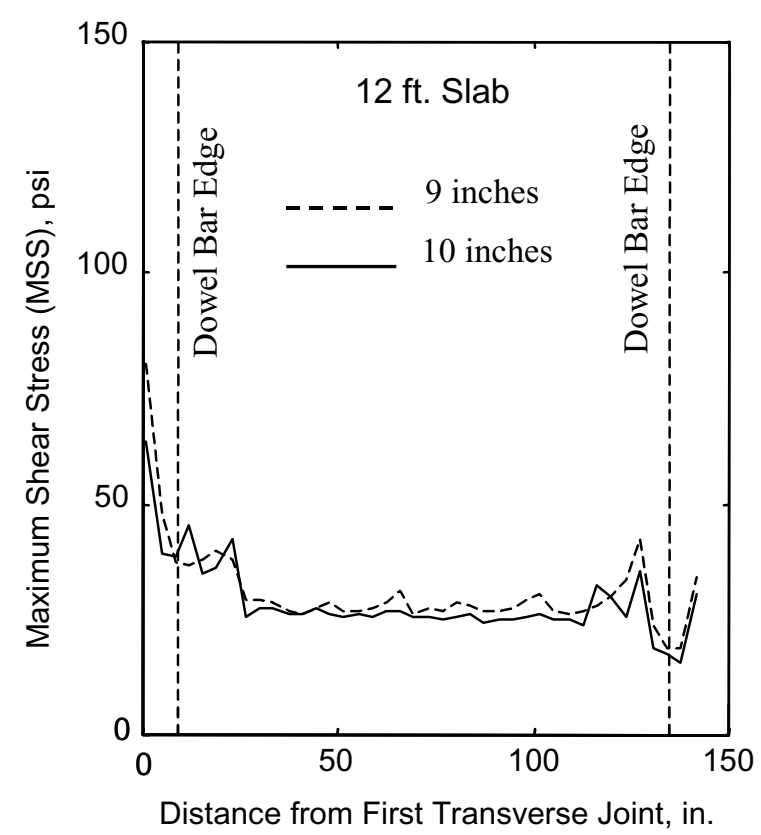

(a)

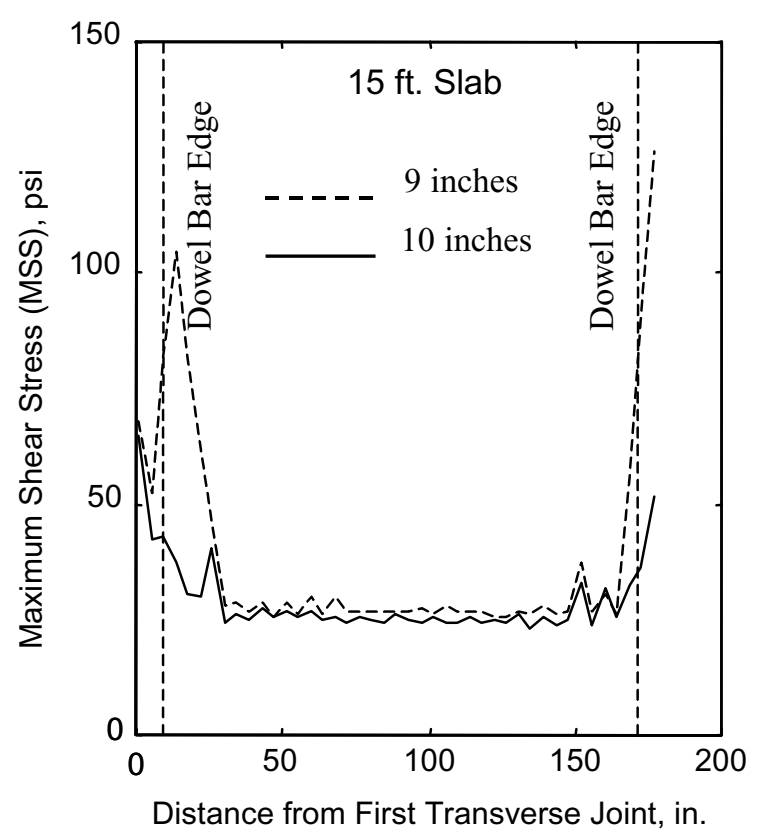

(b)

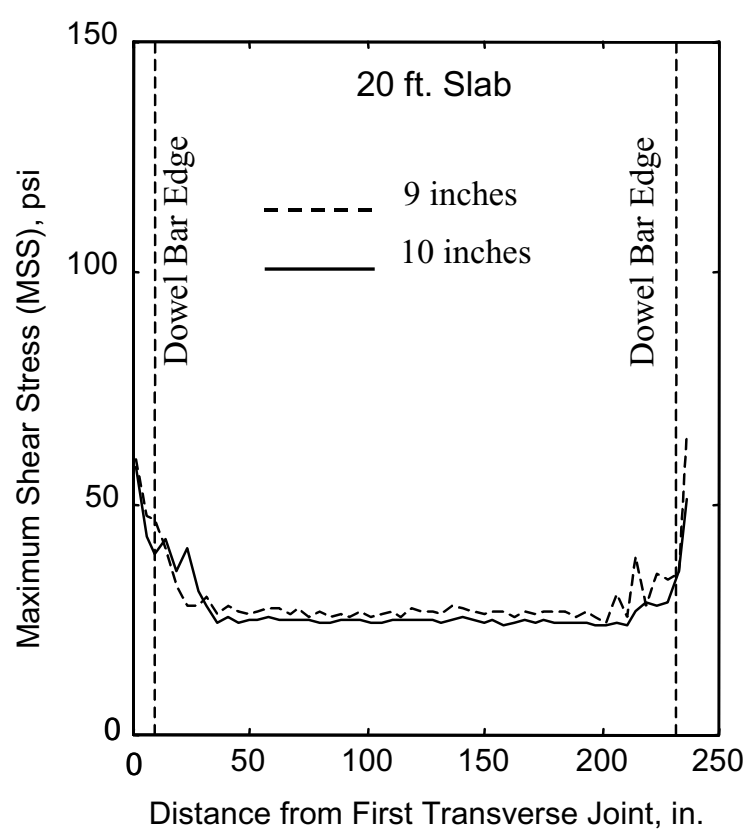

(c)

FIGURE 5.16 Effect of Slab Thickness on Maximum Shear Stress Induced in the Concrete Slab 


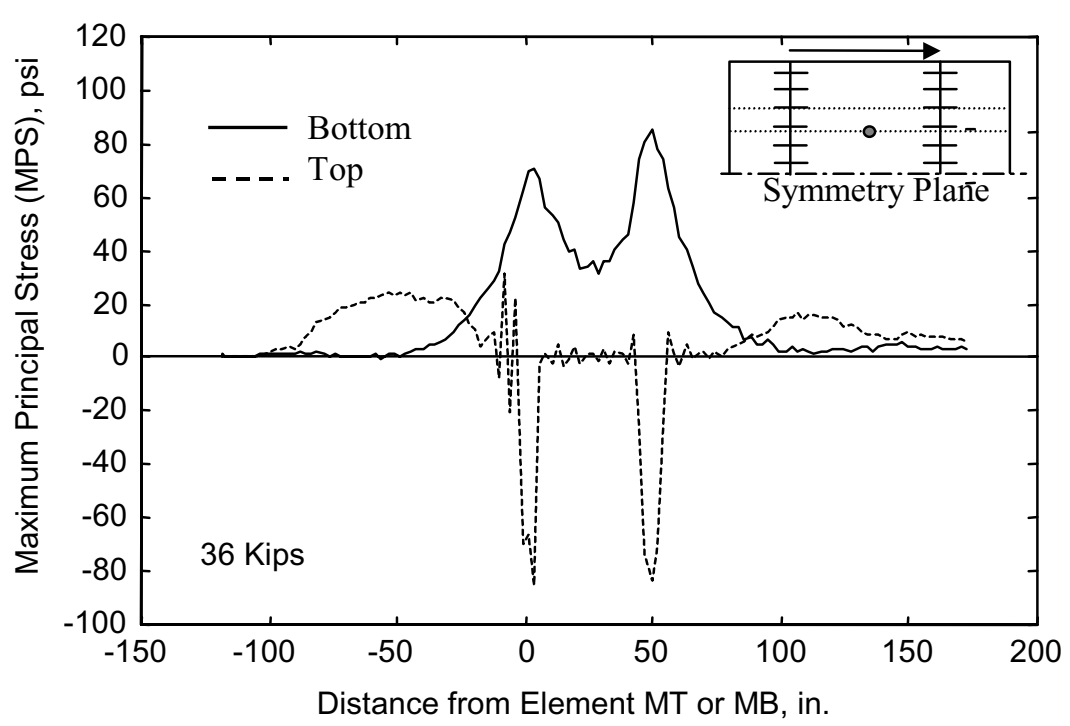

(a)

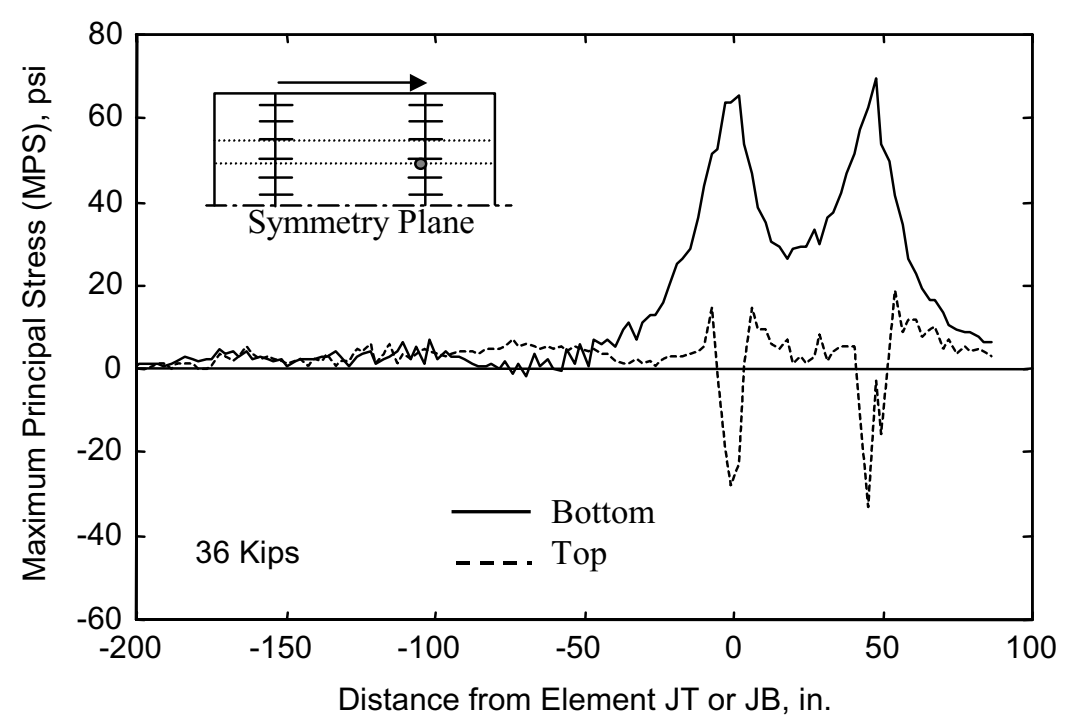

(c)

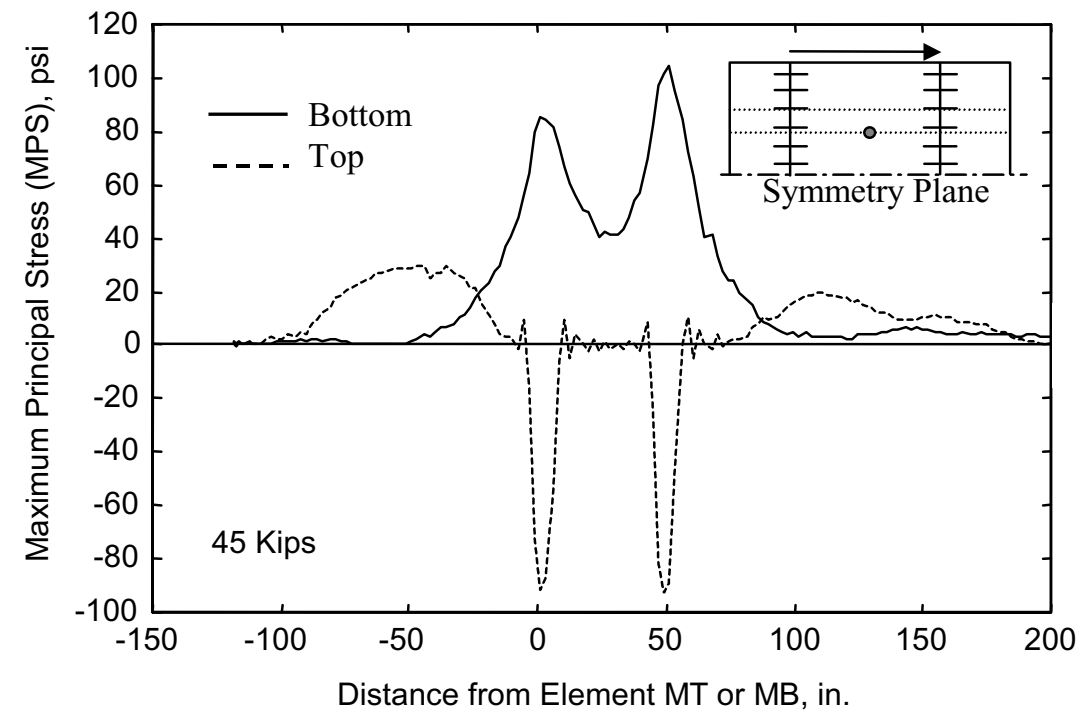

(b)

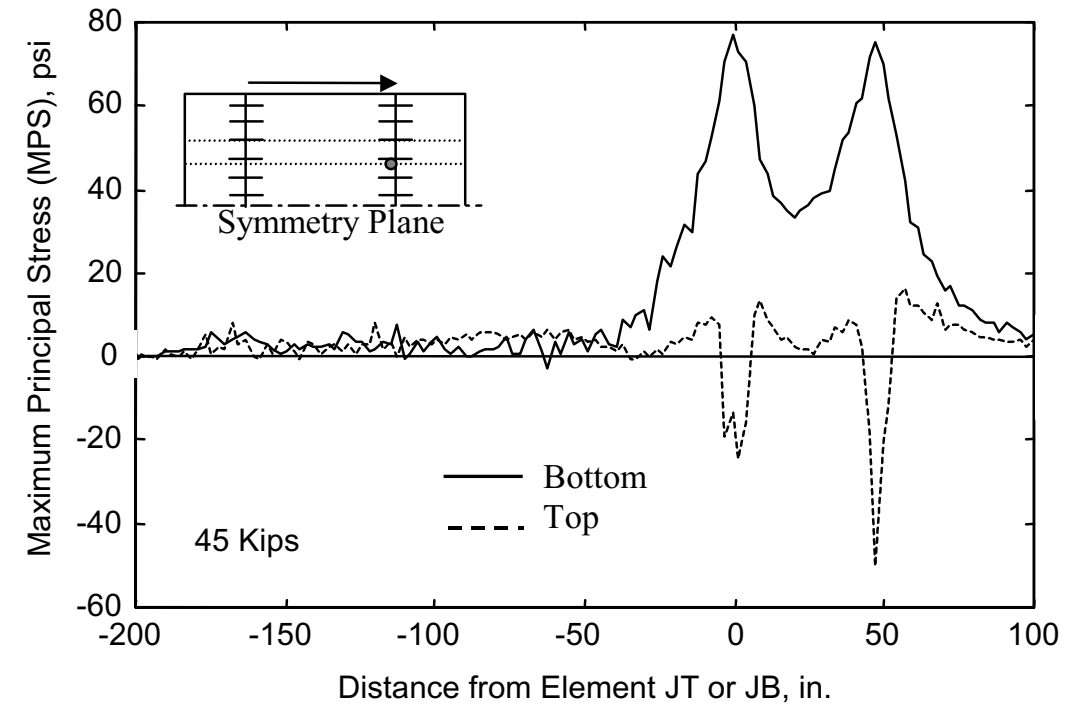

(d)

FIGURE 5.17 Effect of Axle Load Magnitude on Distribution of MPS in the Concrete Slab 


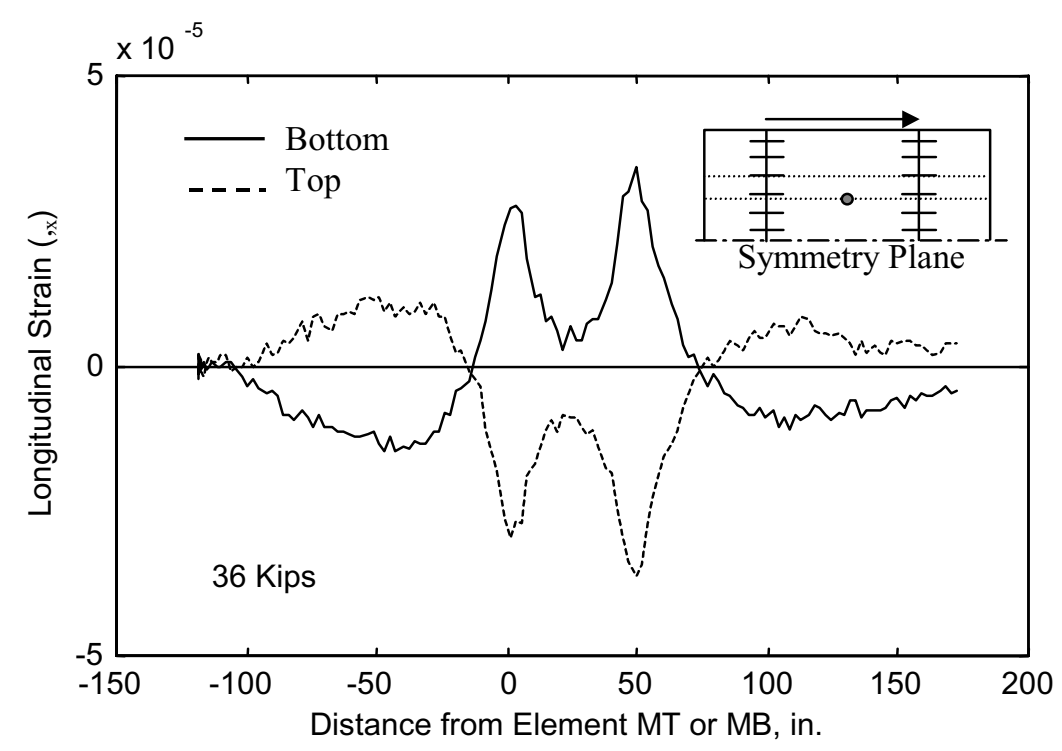

(a)

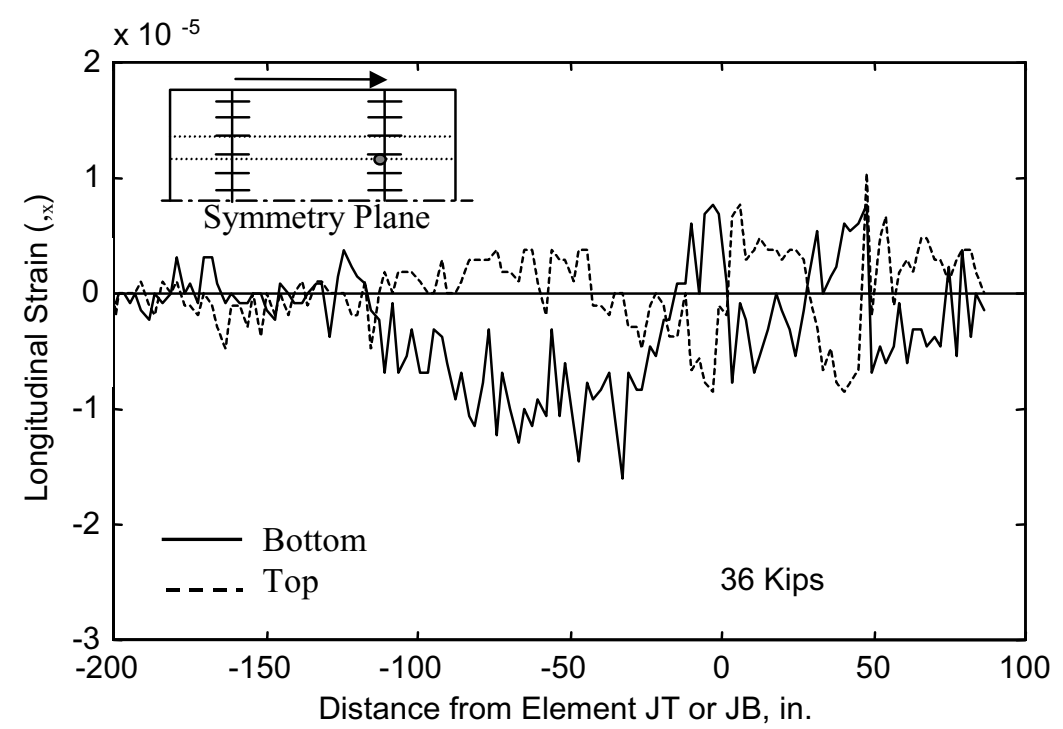

(c)

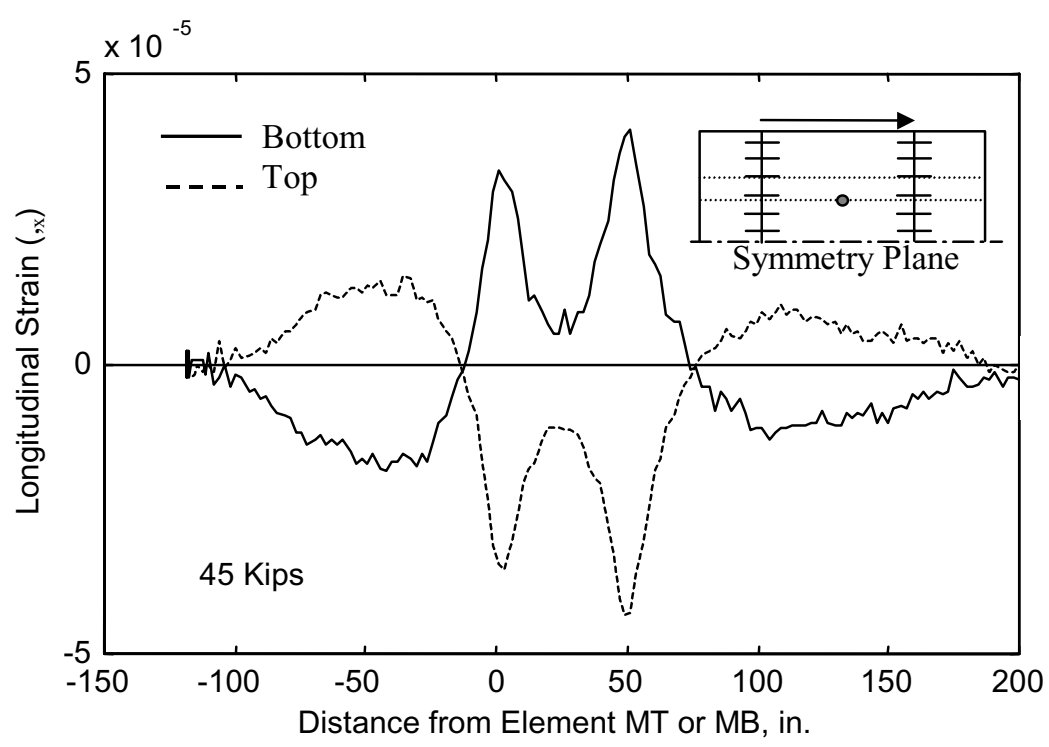

(b)

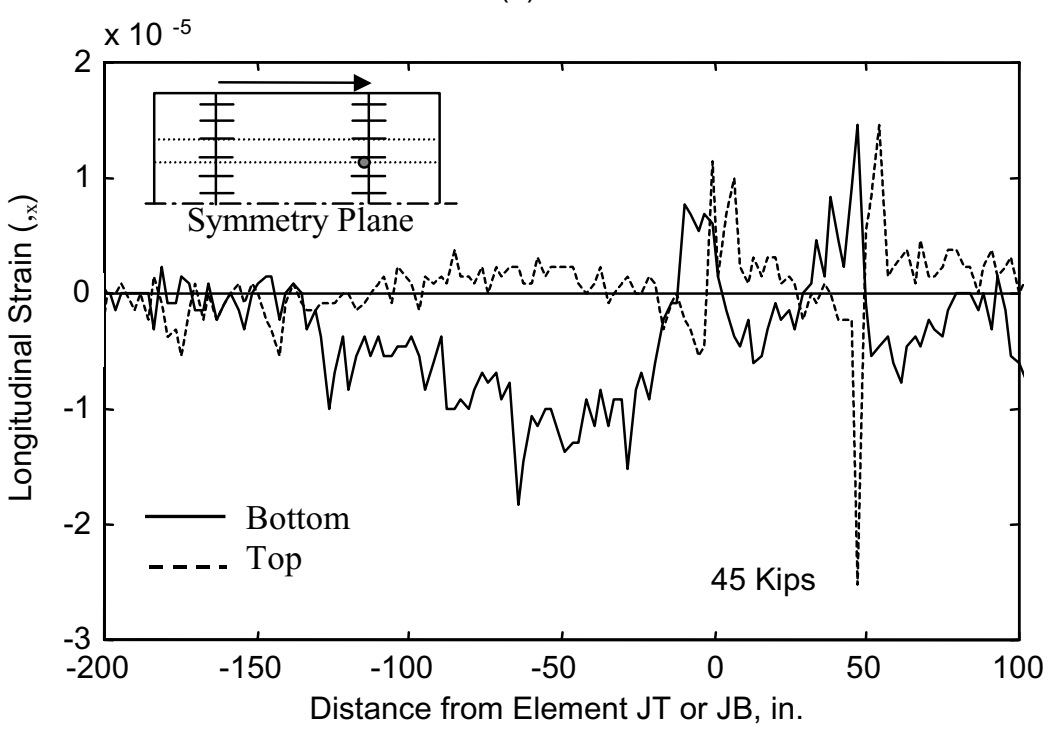

(d)

FIGURE 5.18 Effect of Axle Load Magnitude on Distribution of Longitudinal Strain in the Concrete 

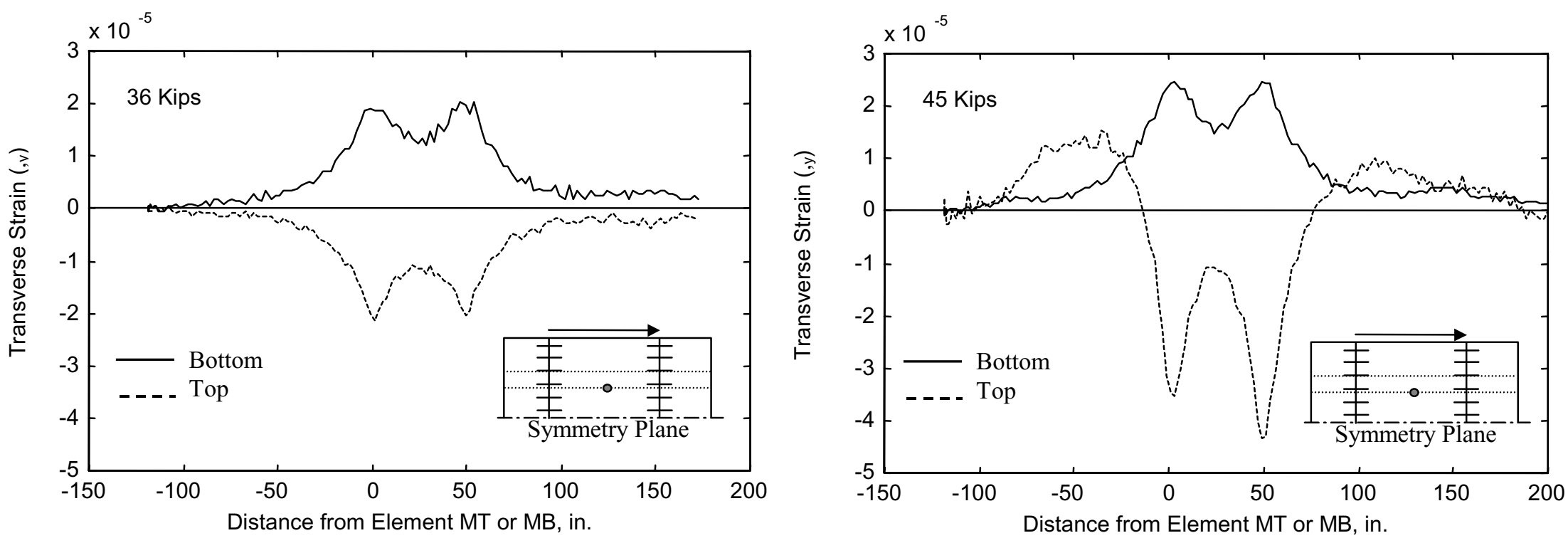

(a)
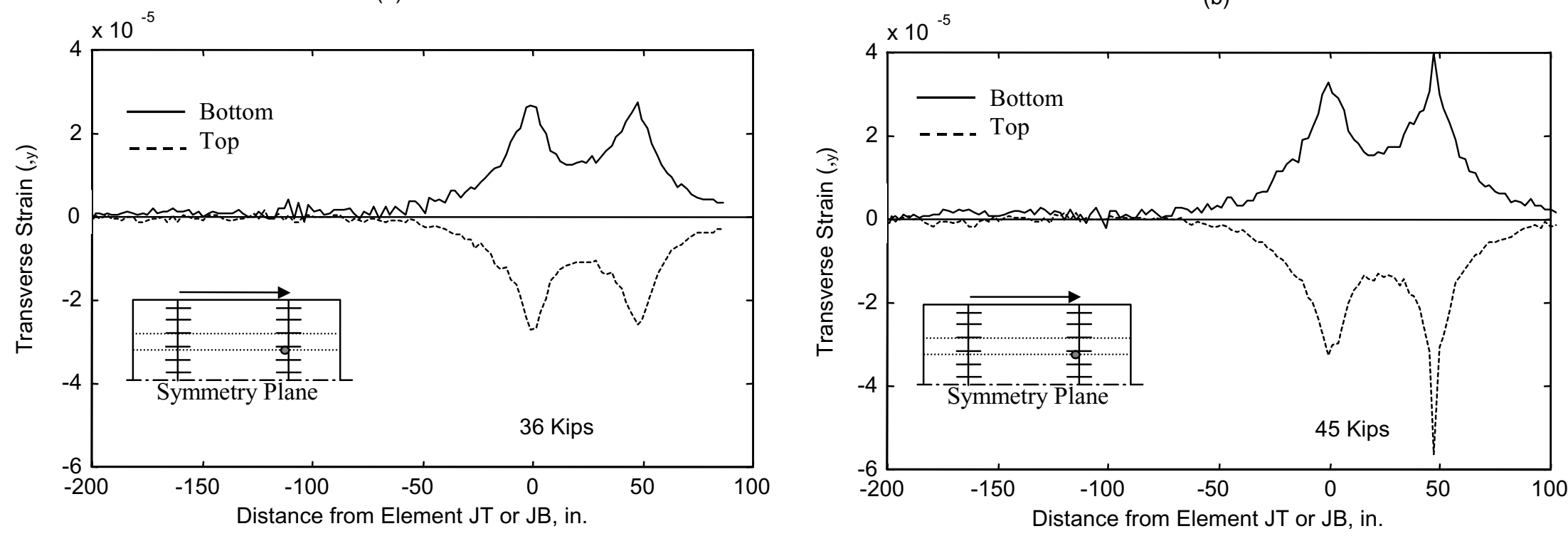

(c)

(d)

FIGURE 5.19 Effect of Axle Load Magnitude on Distribution of Transverse Strain in the Concrete Slab 

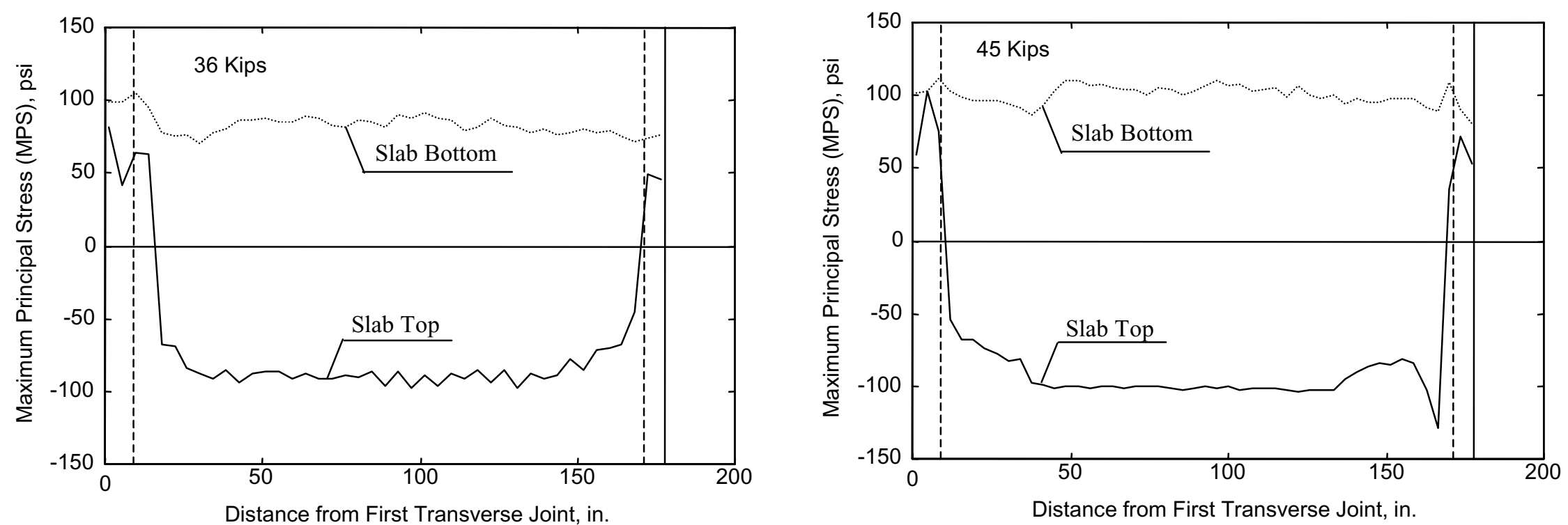

(a
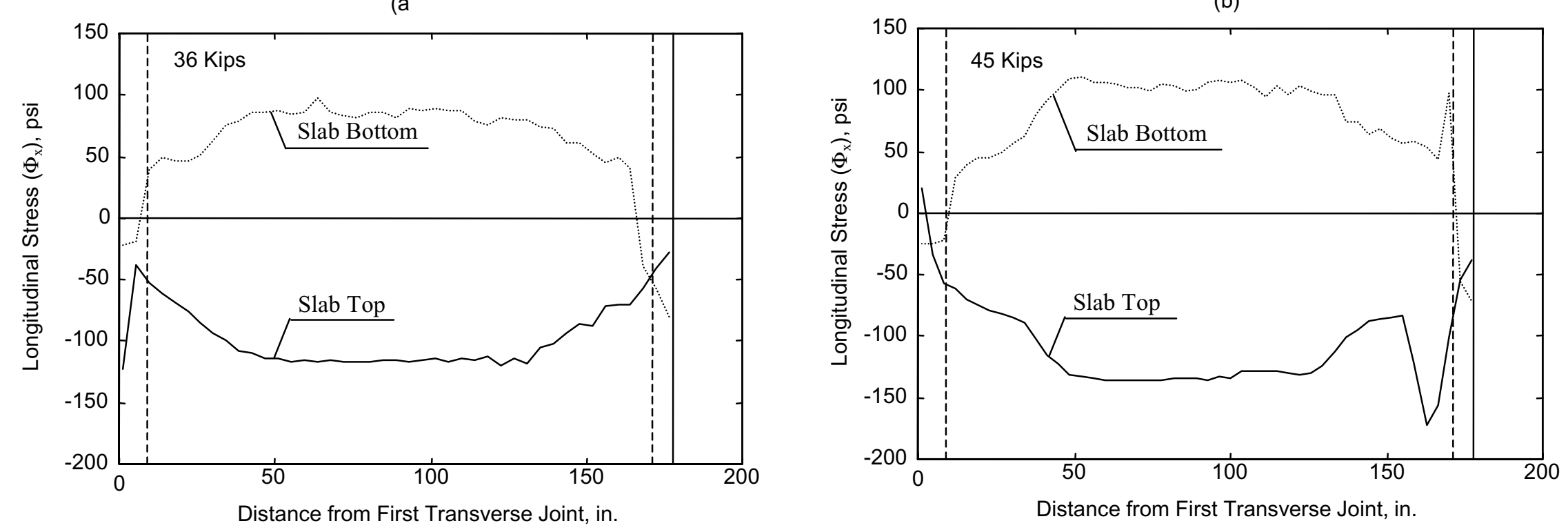

(d)

FIGURE 5.20 Effect of Axle Load Magnitude on the Distribution of Peak MPS and $\Phi_{\mathrm{x}}$ in the Concrete Slab 


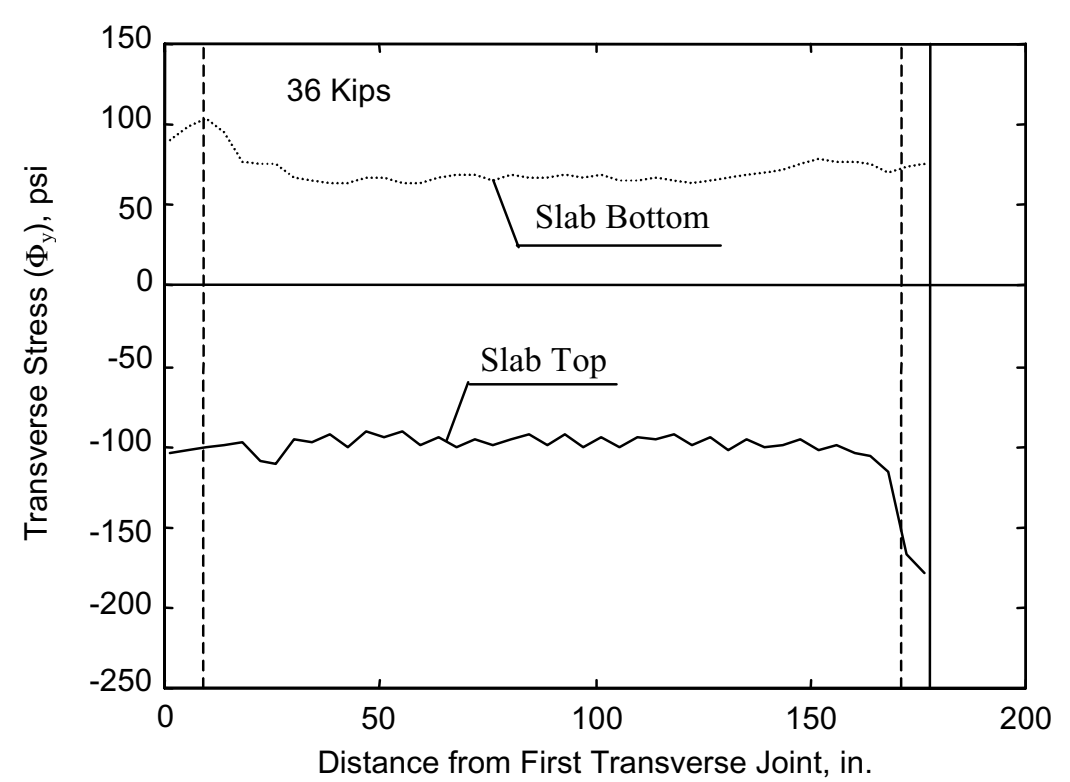

(a)

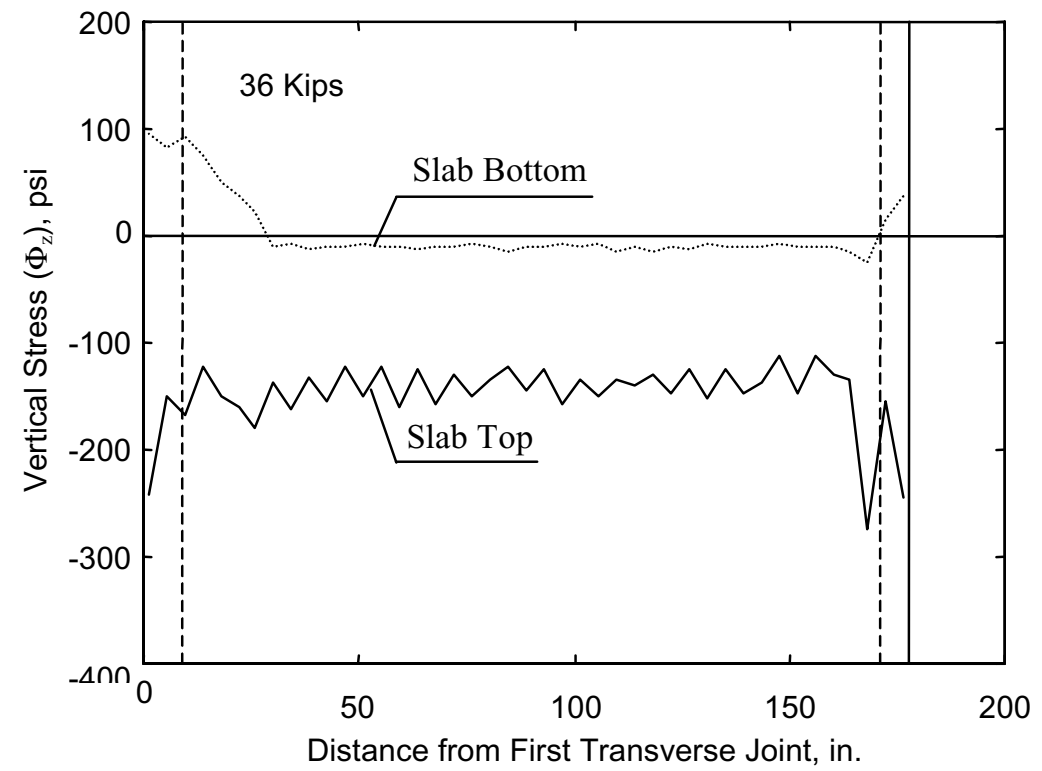

(c)

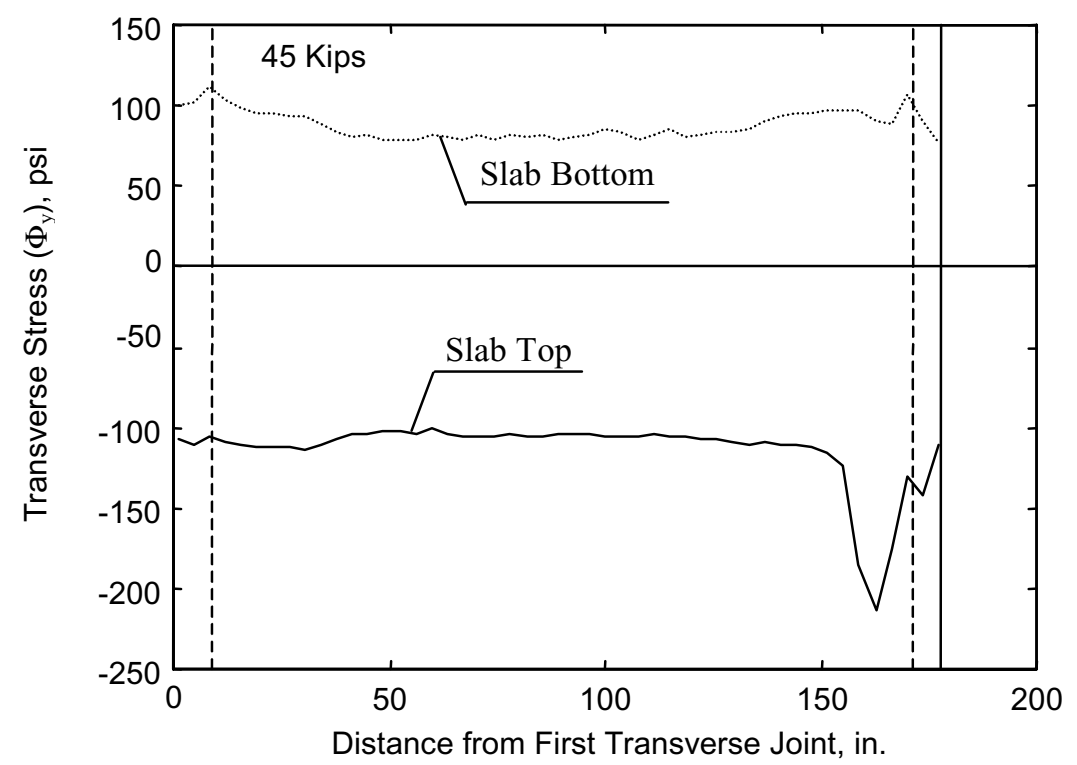

(b)

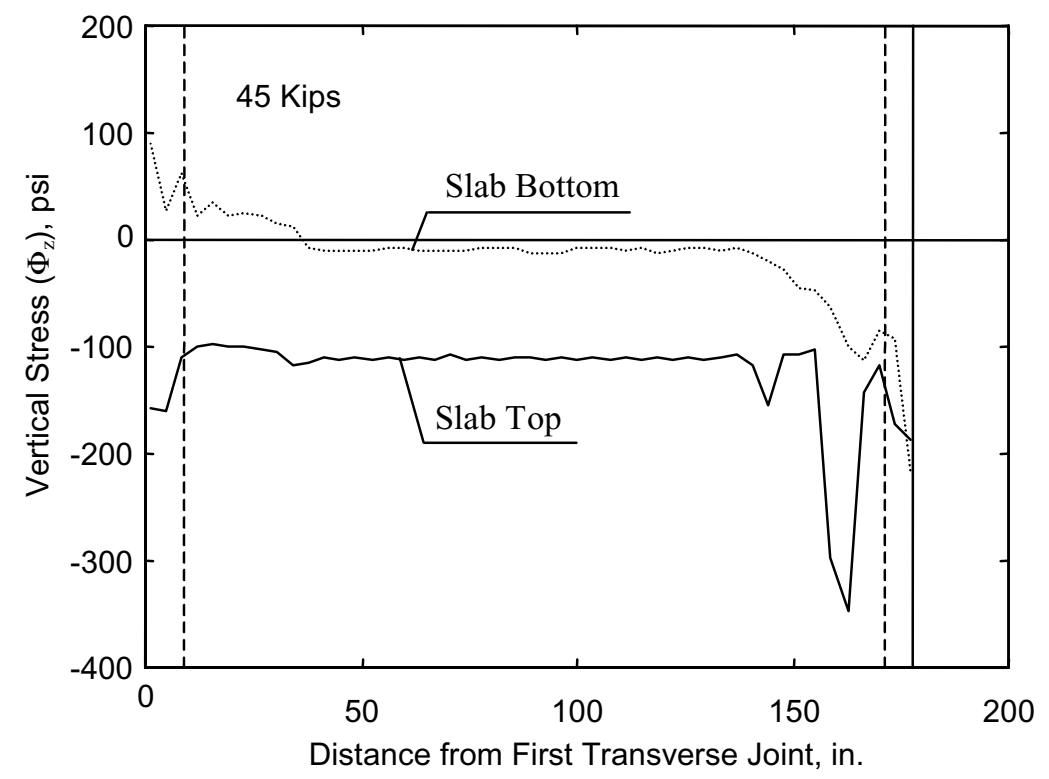

(d)

FIGURE 5.21 Effect of Axle Load Magnitude on the Distribution of Peak $\Phi_{\mathrm{y}}$ and $\Phi_{\mathrm{z}}$ in the Concrete 


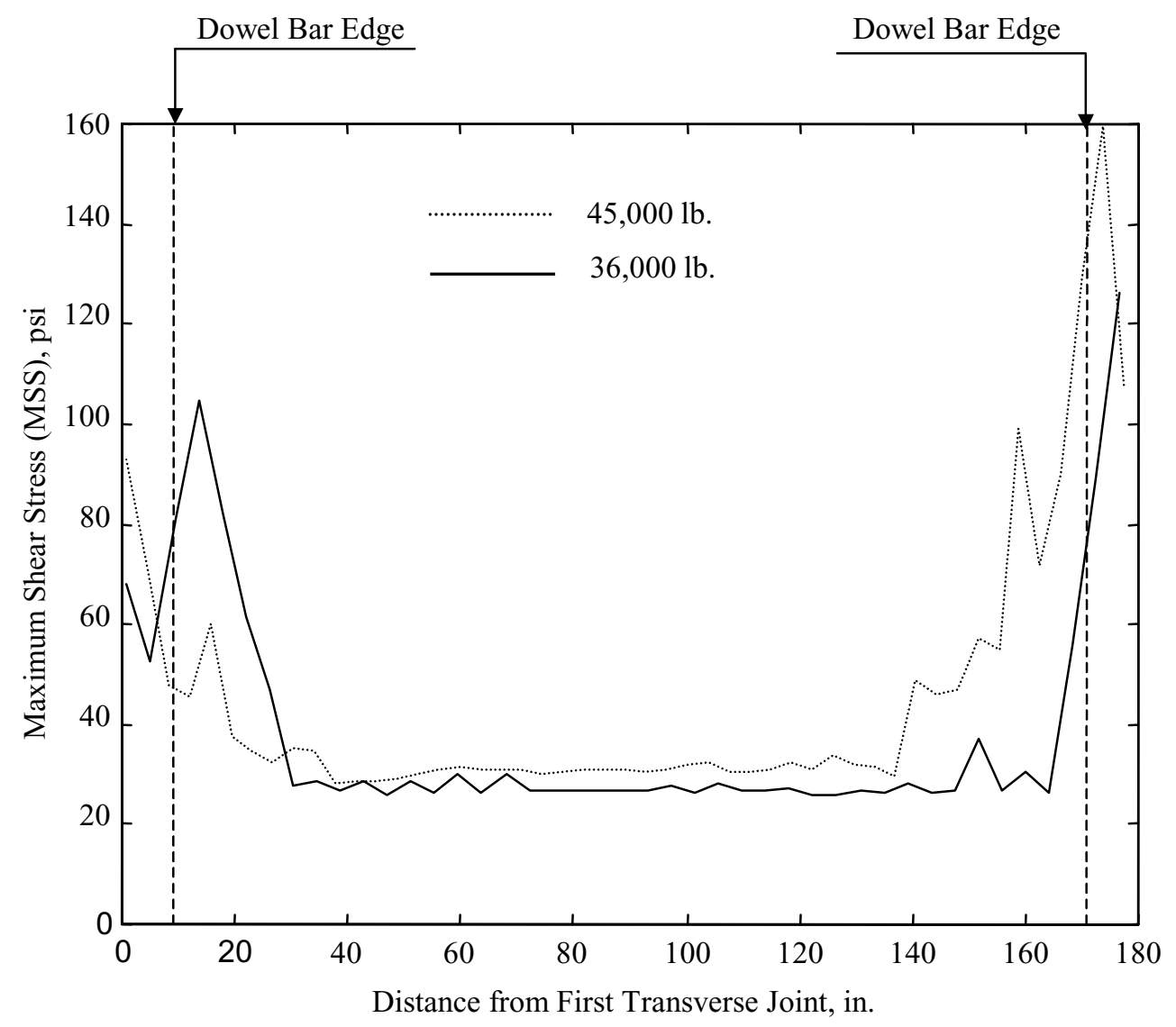

FIGURE 5.22 Effect of Tandem axle Load Magnitude on MSS Induced in the Concrete Slab 


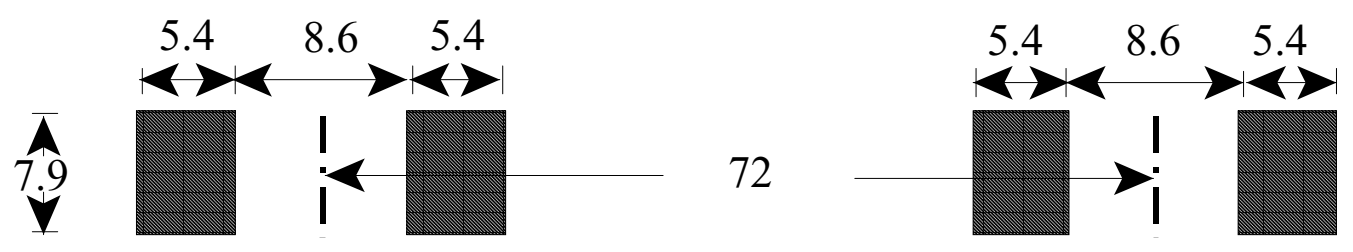

(a) Single axle configuration (axle load $=18,000 \mathrm{lb}$, tire pressure $=105 \mathrm{psi}$ )

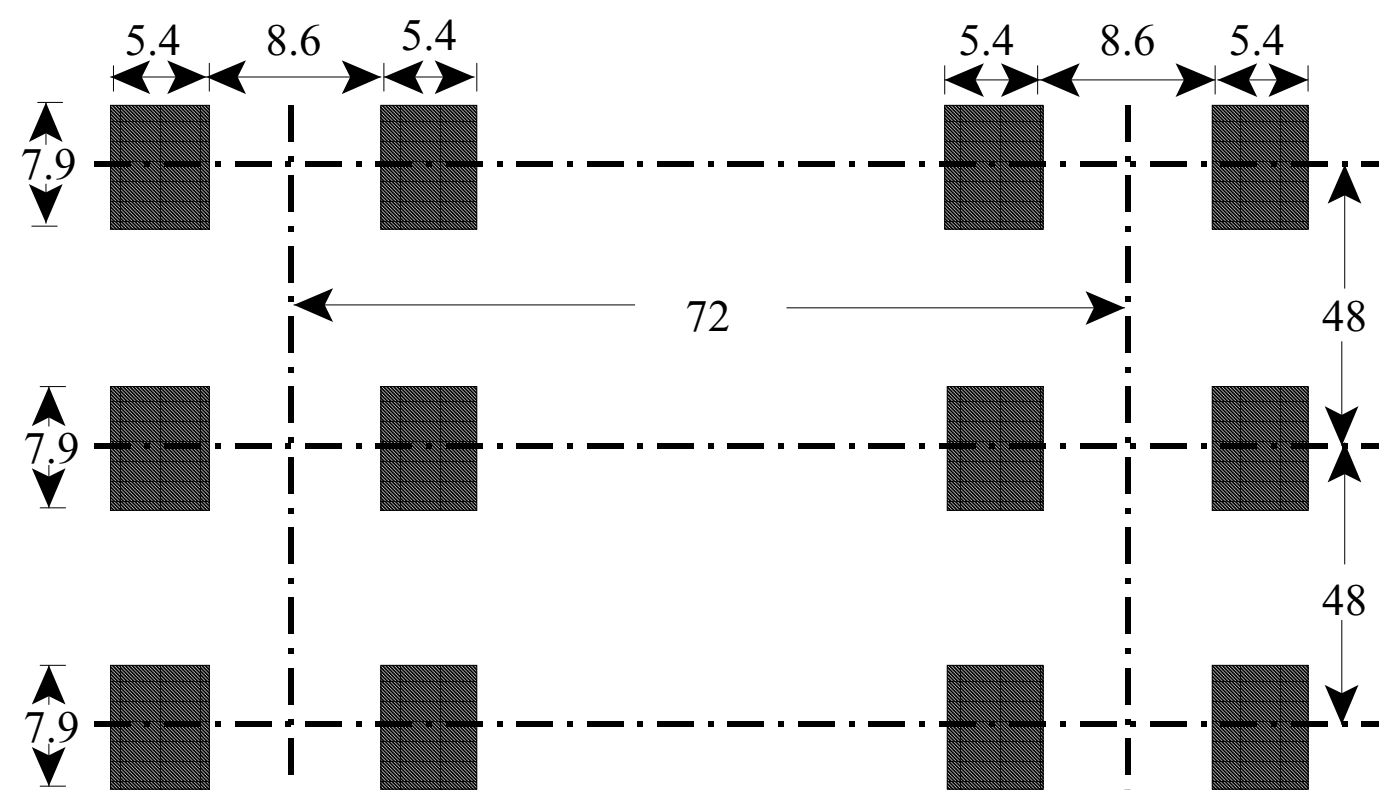

(b) Tridem axle configuration (axle load $=54,000 \mathrm{lb}$, tire pressure $=105 \mathrm{psi}$ )

FIGURE 5.23 Single and Tridem Axle Configuration and Wheel Loads Dimensions in inches 


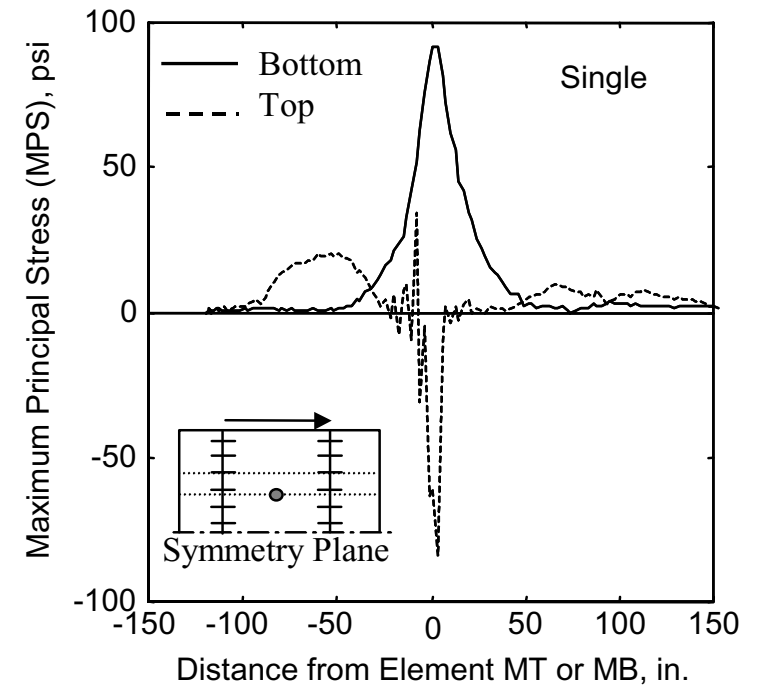

(a)

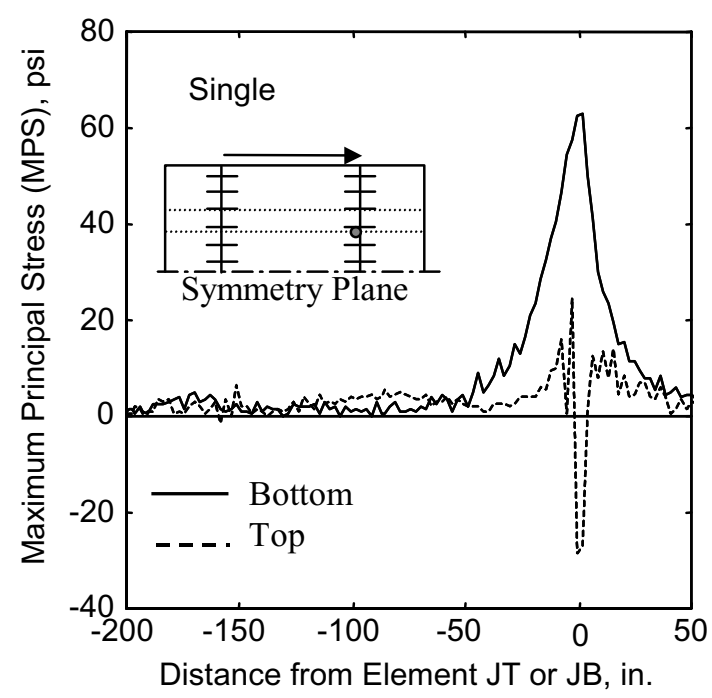

(d)

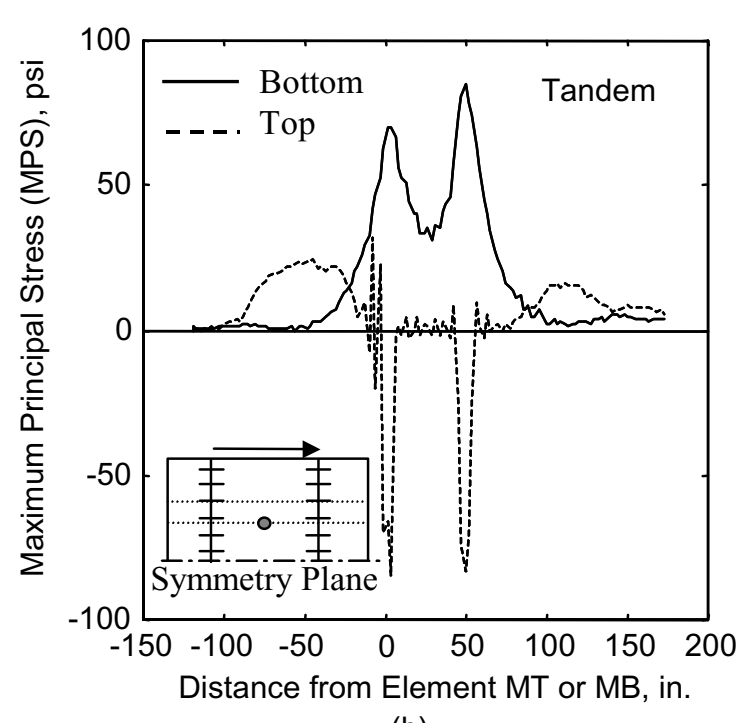

(b)

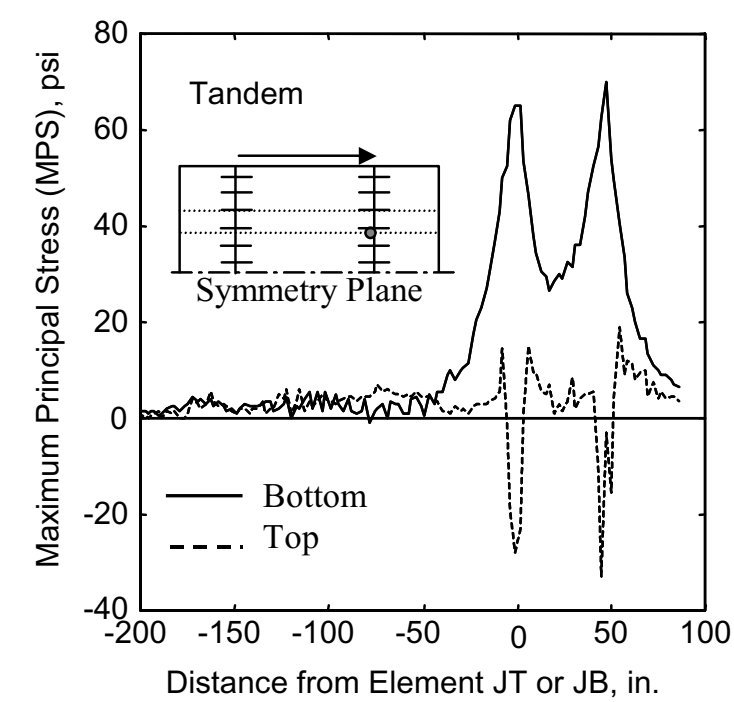

(e)

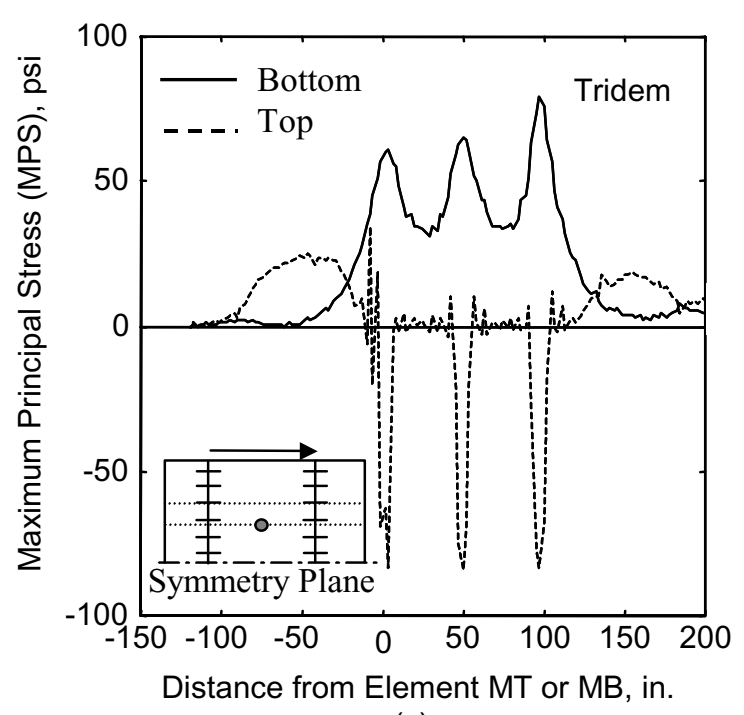

(c)

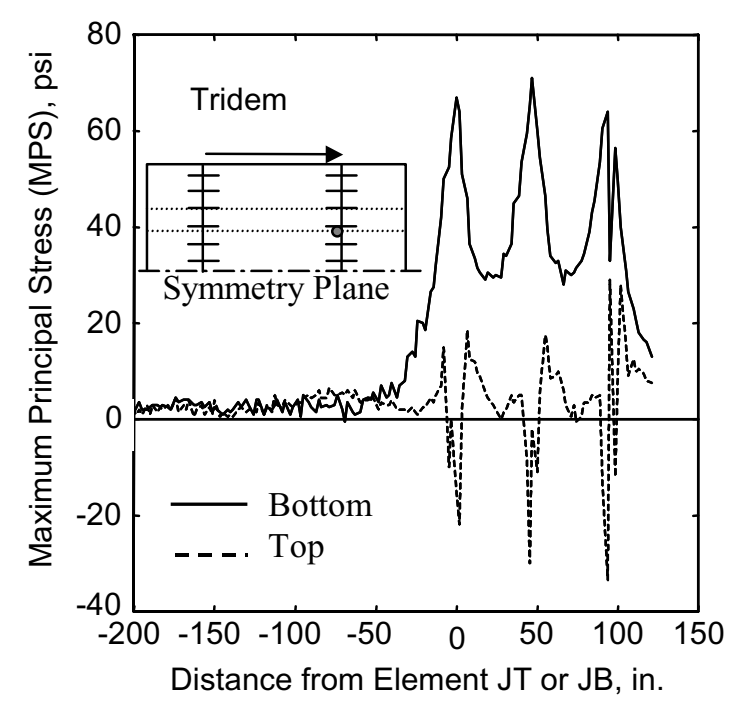

(f)

FIGURE 5.24 Effect of Axle Configuration on Distribution of Maximum Principal Stress in the Concrete Slab 


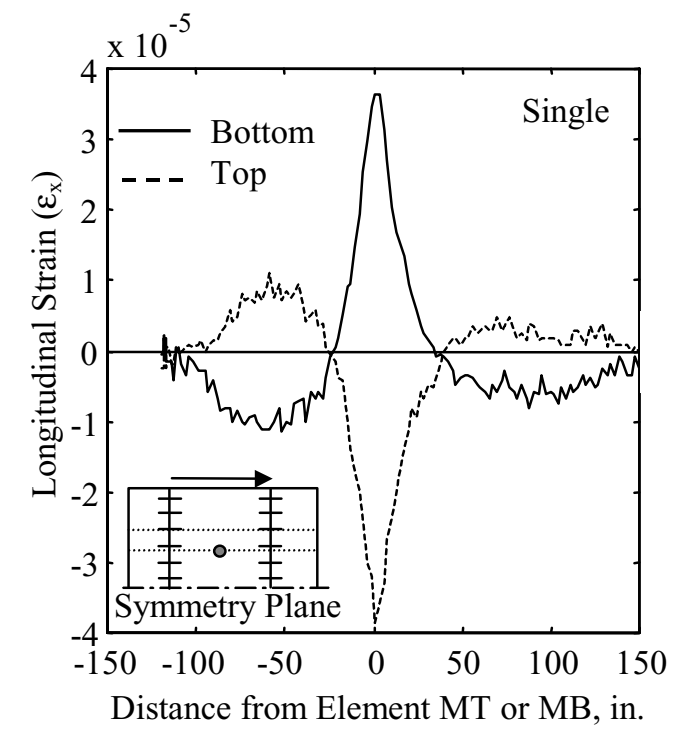

(a)

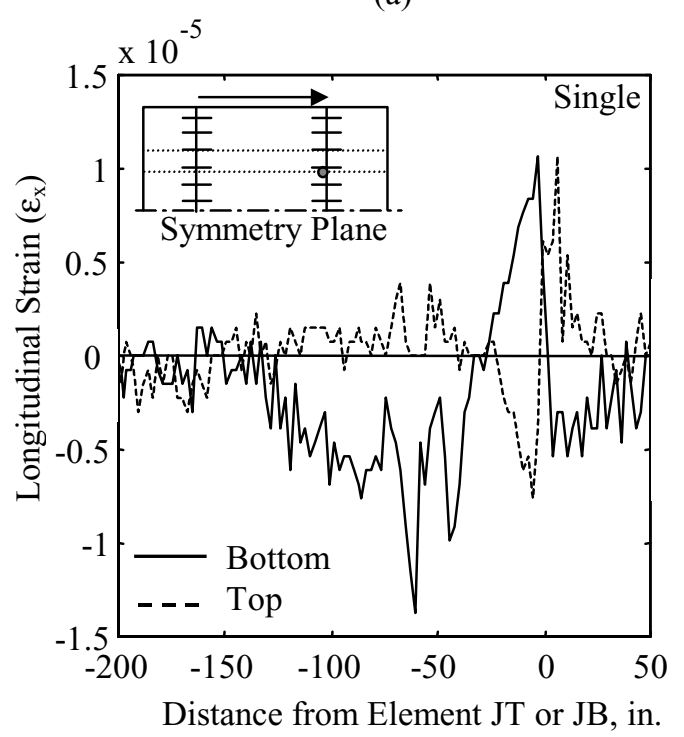

(d)

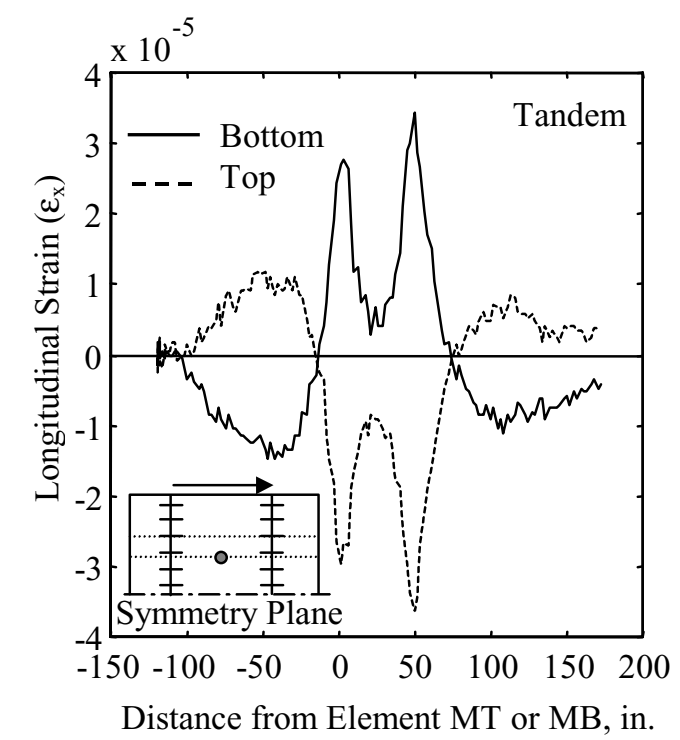

(b)

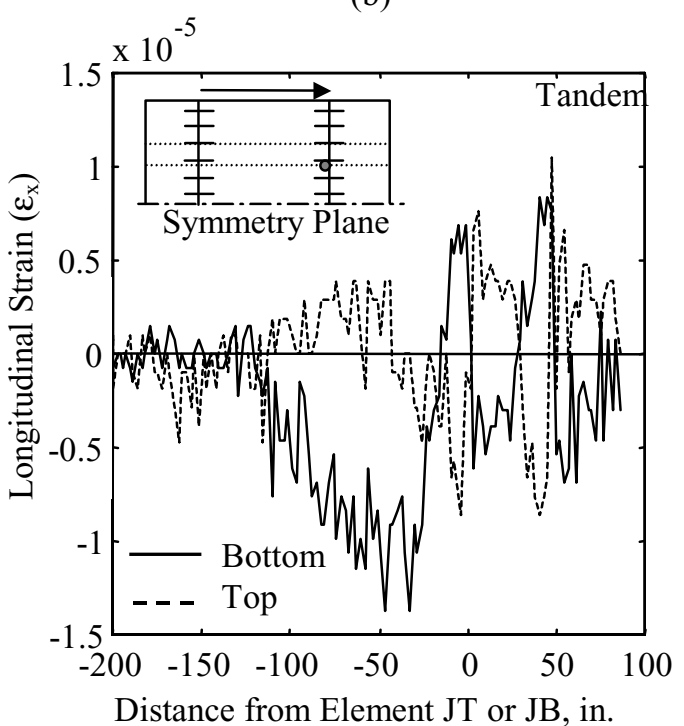

(e)

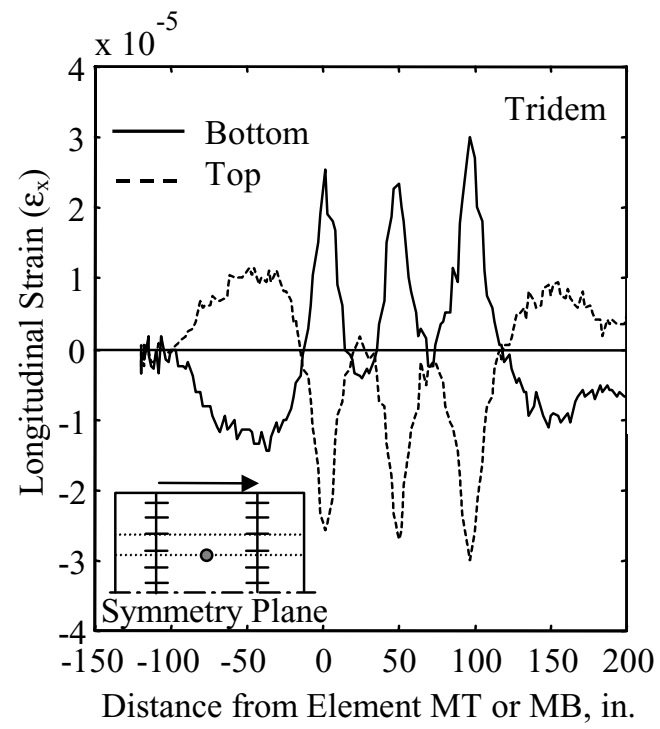

(c)

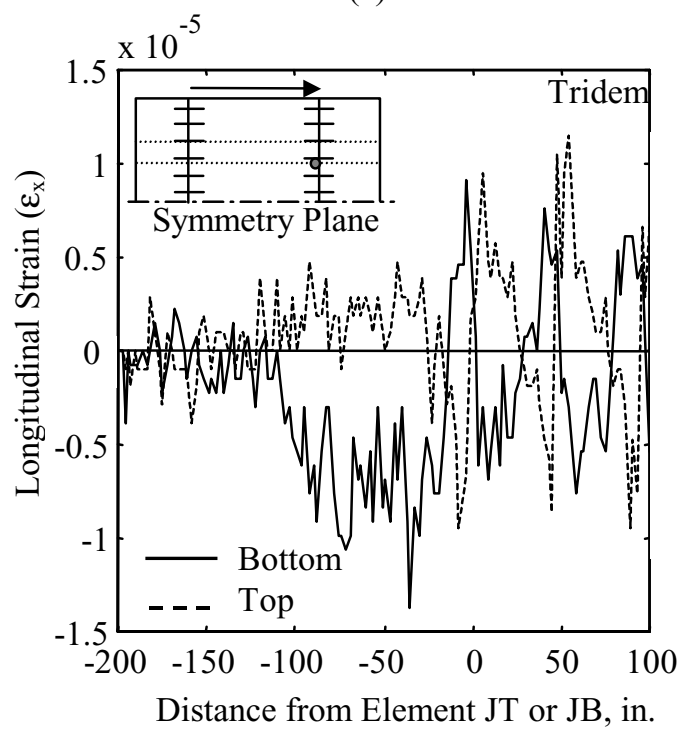

(f)

FIGURE 5.25 Effect of Axle Configuration on Distribution of Longitudinal Strain in the Concrete Slab 


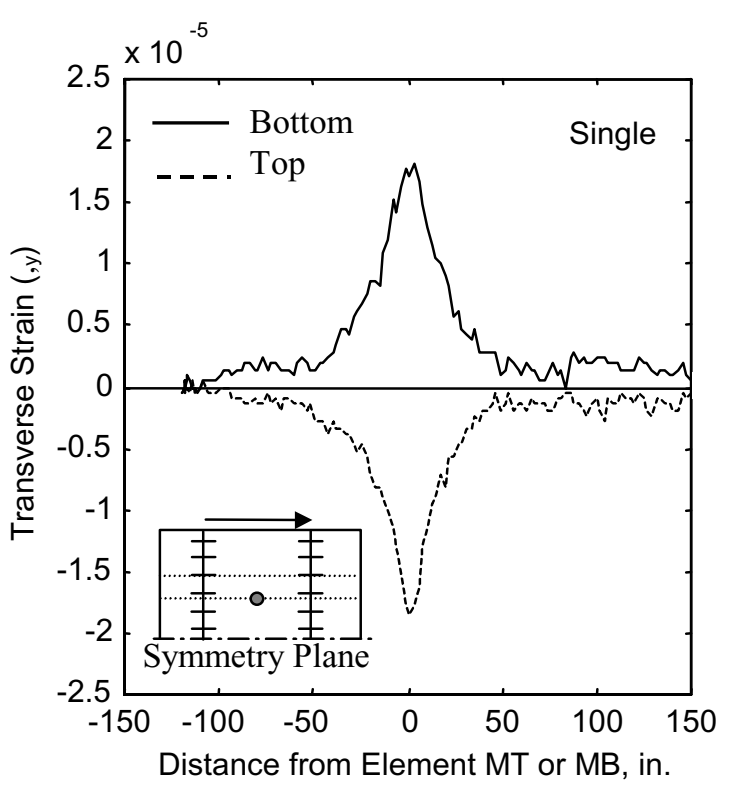

(a)

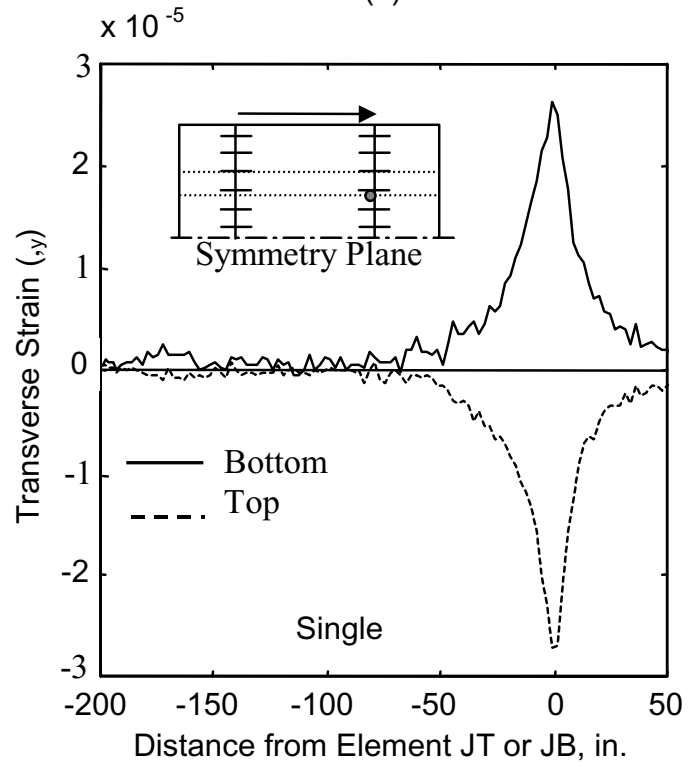

(d)

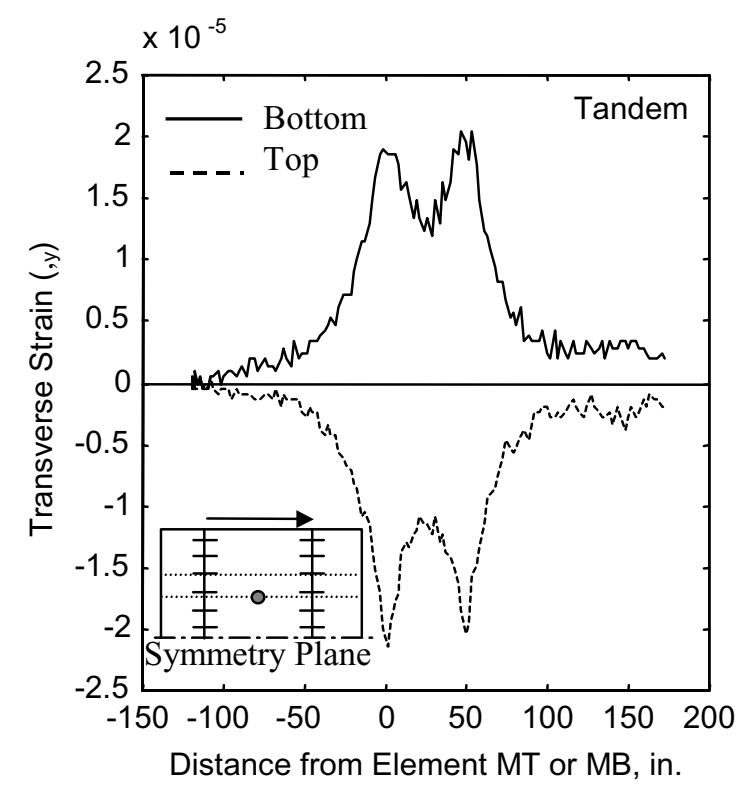

(b)

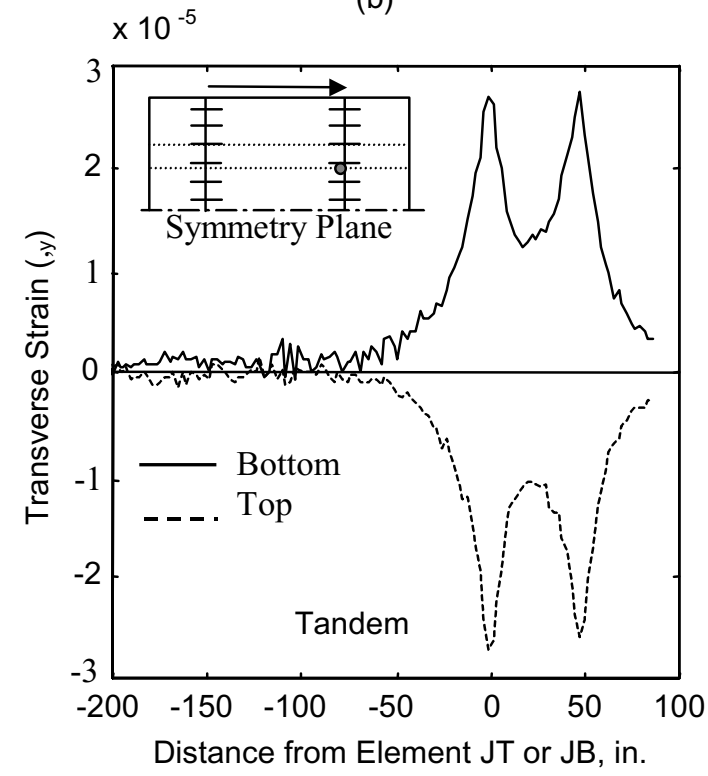

(e)

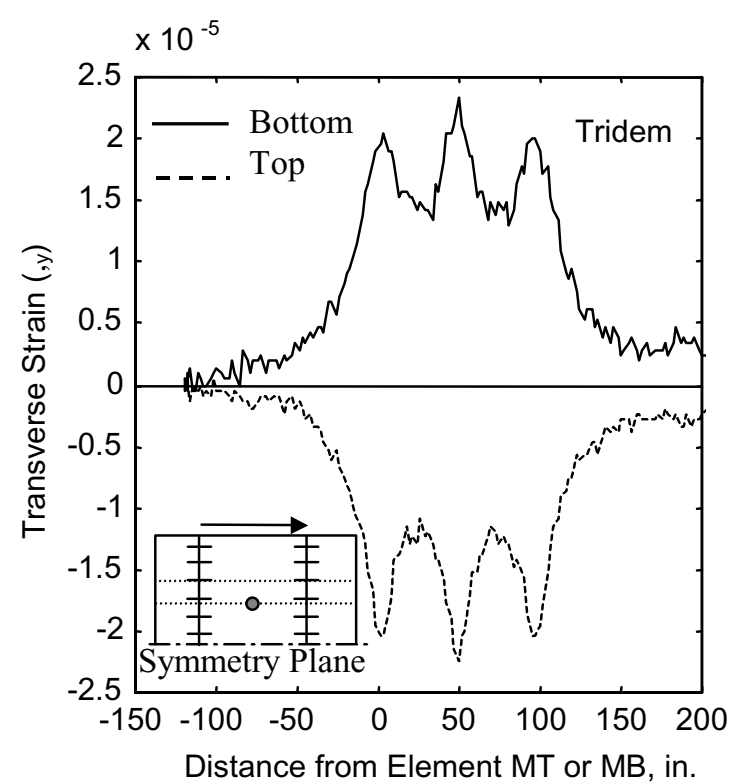

(c)

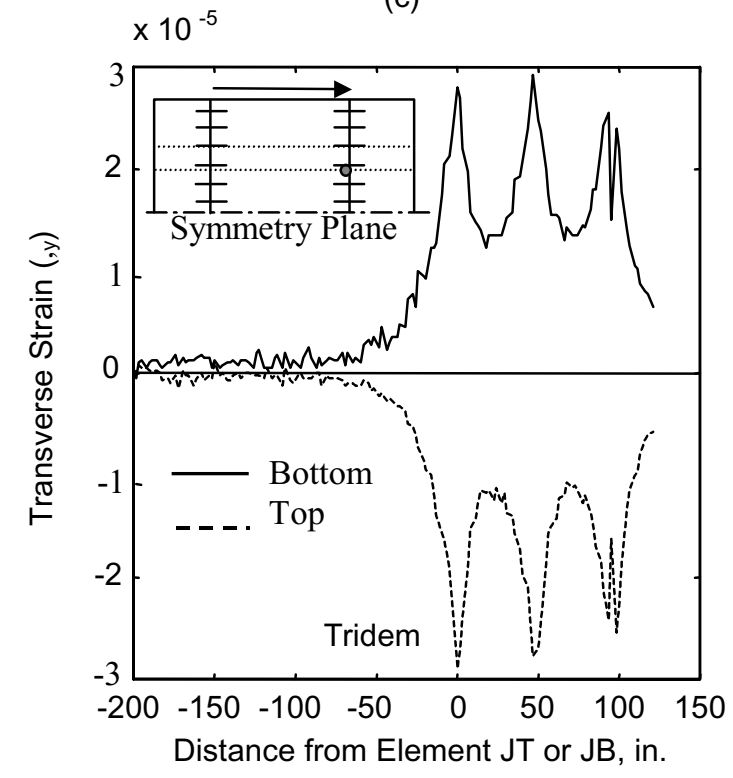

(f)

FIGURE 5.26 Effect of Axle Configuration on Distribution of Transverse Strain in the Concrete Slab 


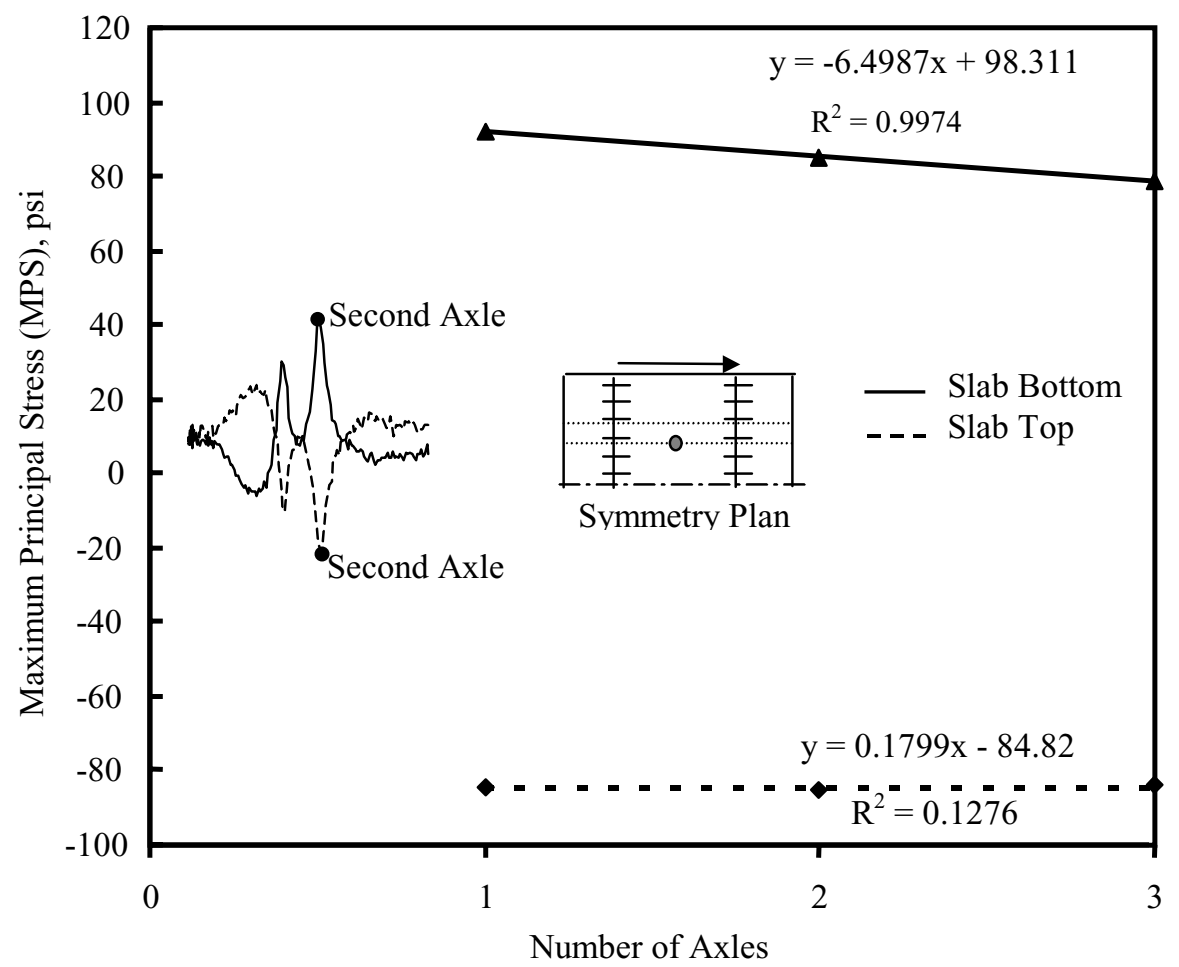

(a) Peak Maximum Principal Stress

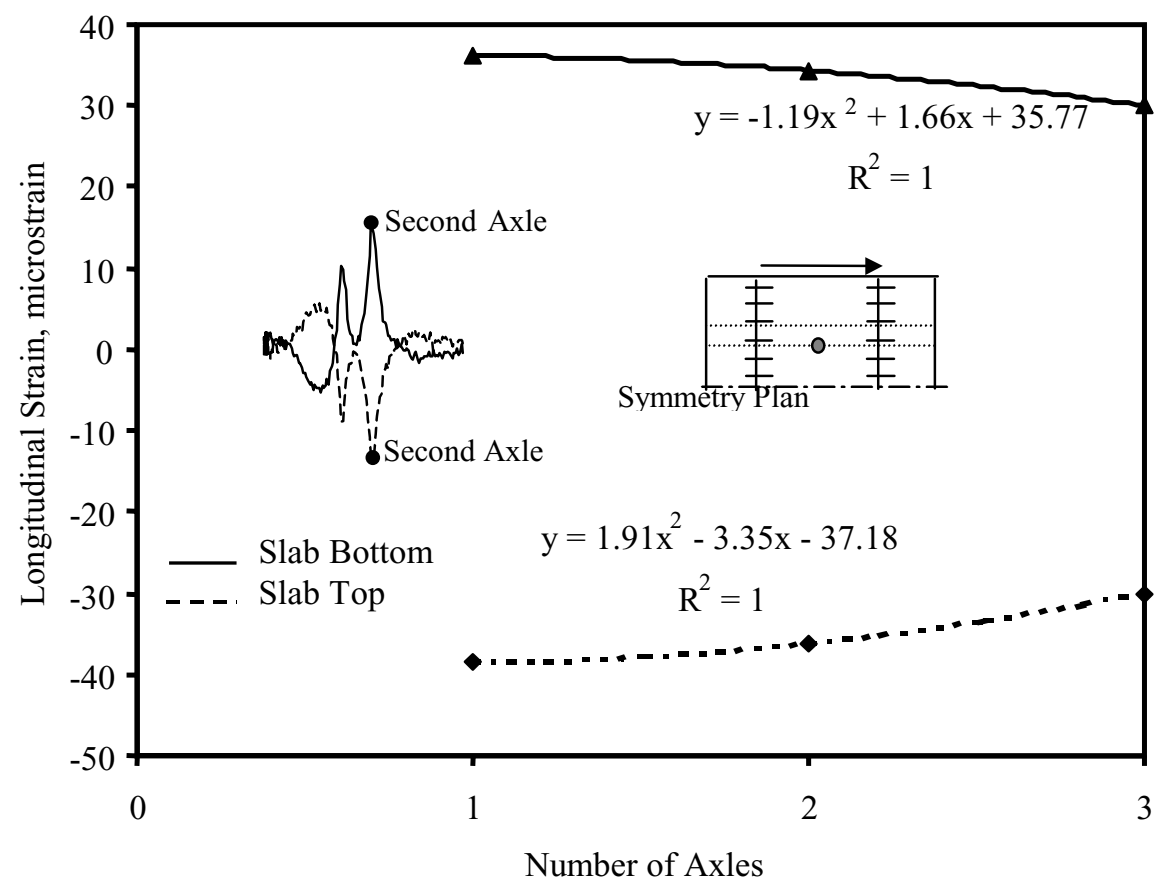

(b) Peak Longitudinal Strain

FIGURE 5.27 Effect of Number of Axles on Maximum

Traffic Induced Longitudinal Strains in the Slab 


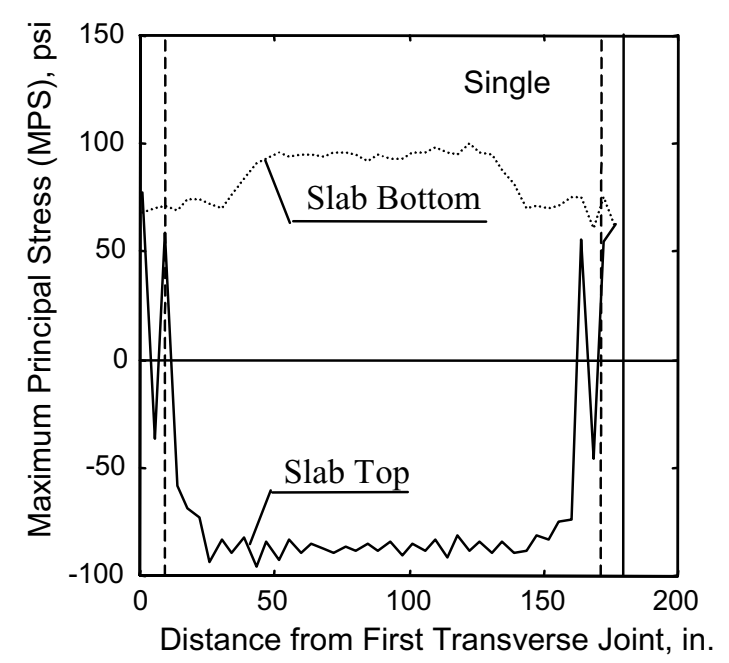

(a)

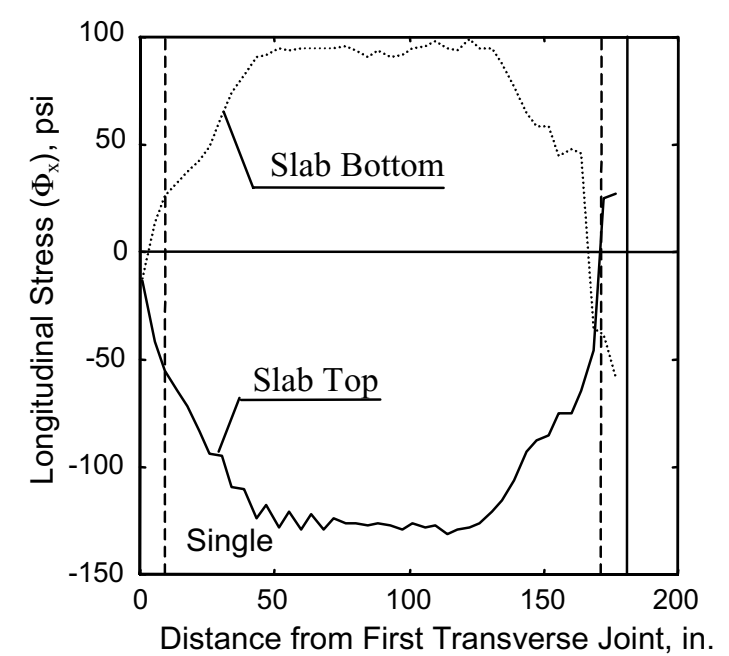

(d)

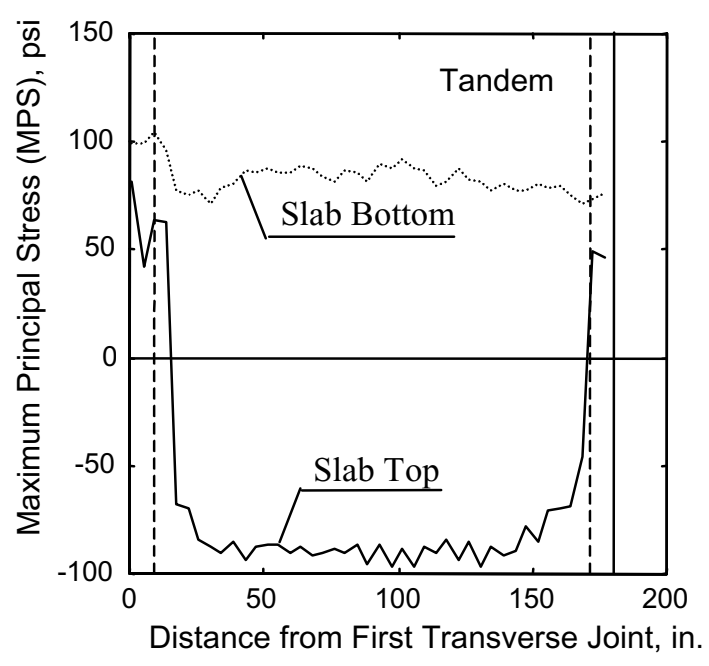

(b)

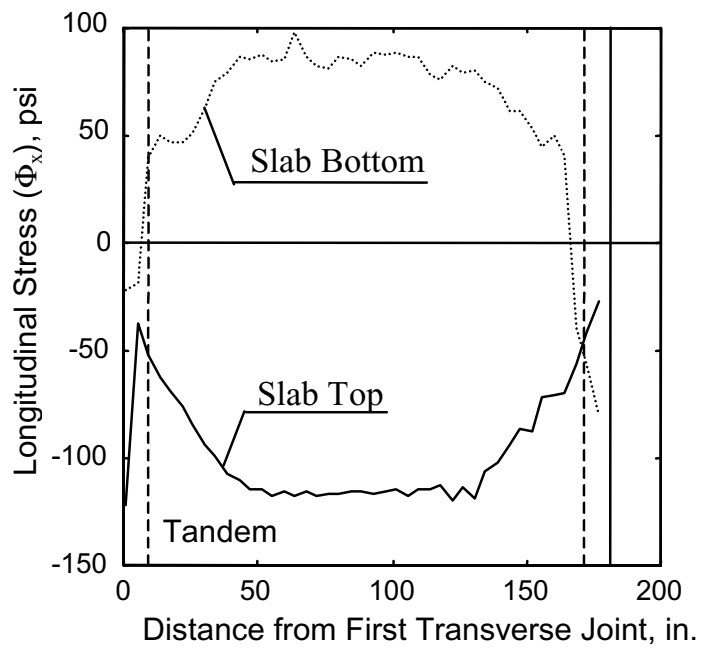

(e)

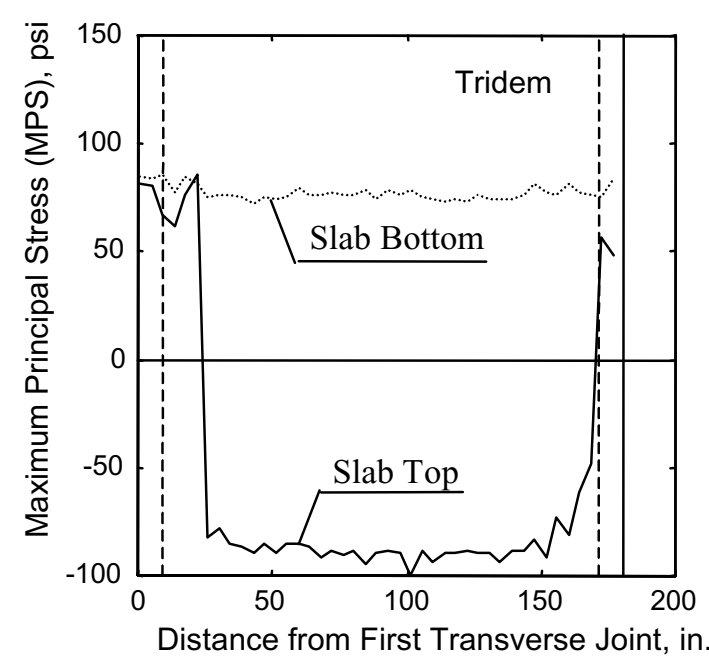

(c)

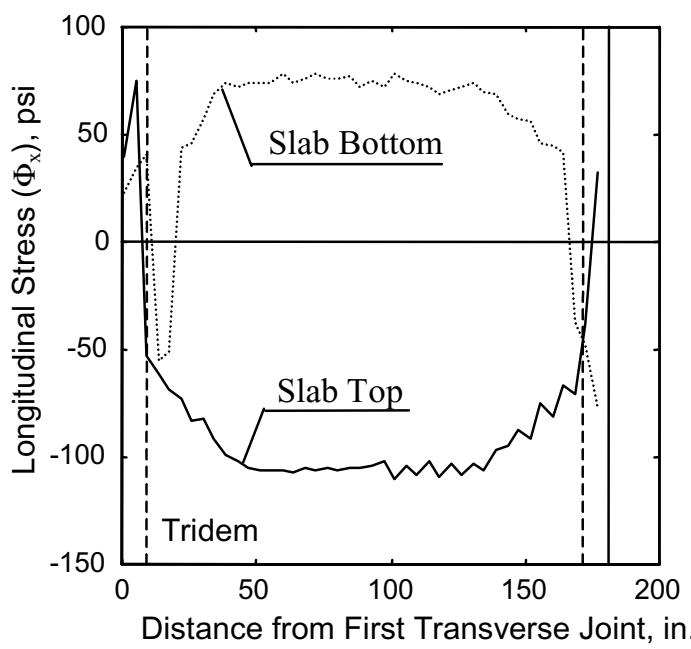

(f)

FIGURE 5.28 Effect of Axle Configuration on Distribution of Peak MPS and $\Phi_{\mathrm{x}}$ Along Traffic 


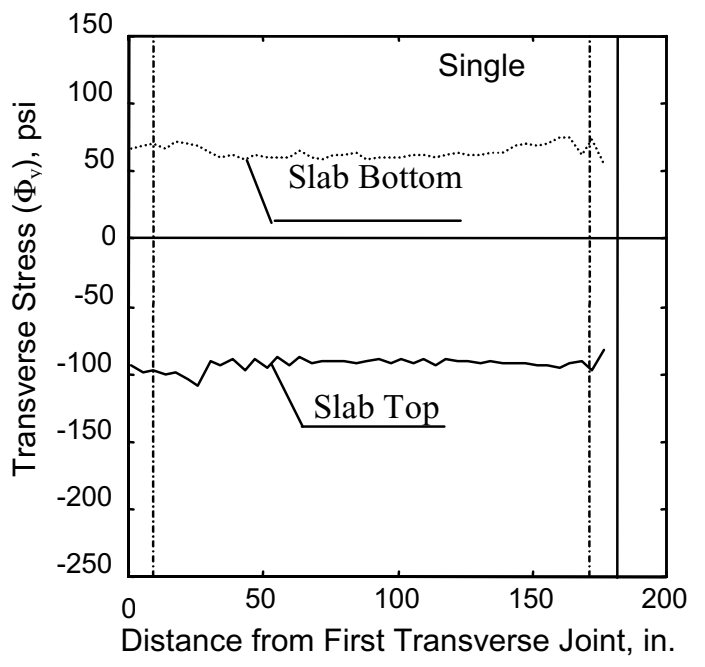

(a)

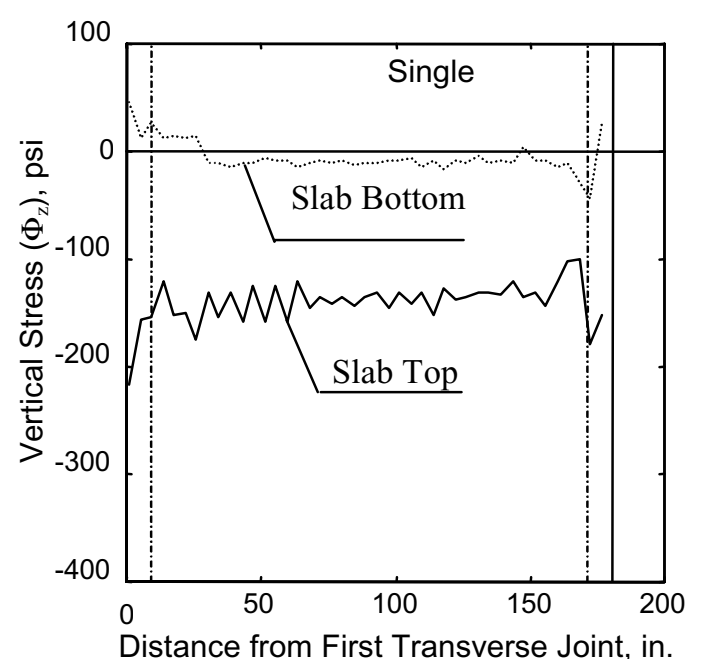

(d)

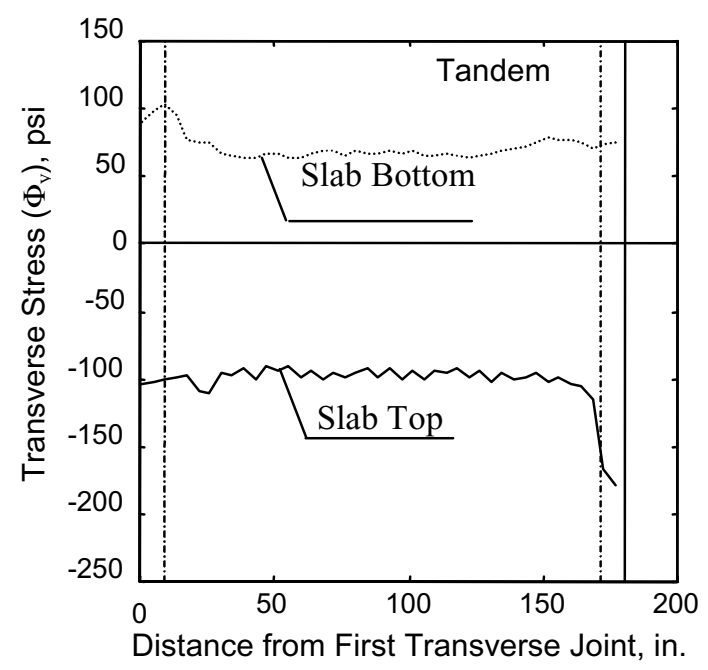

(b)

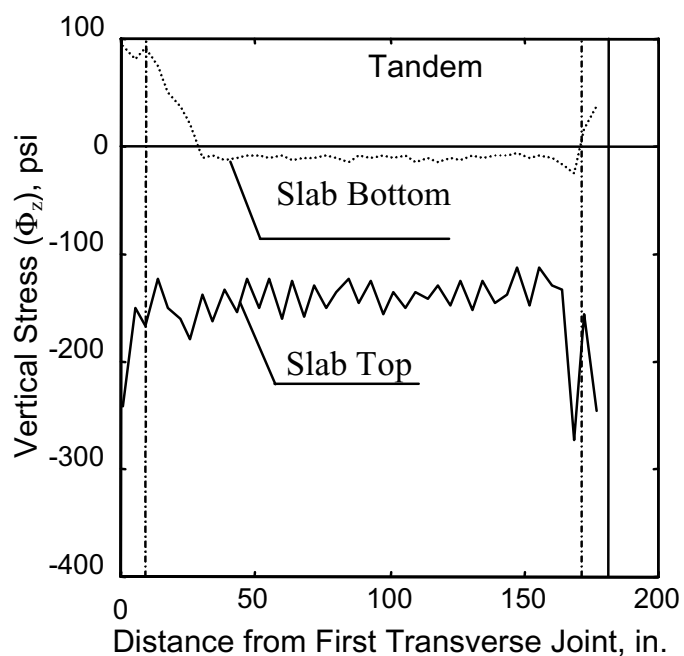

(e)

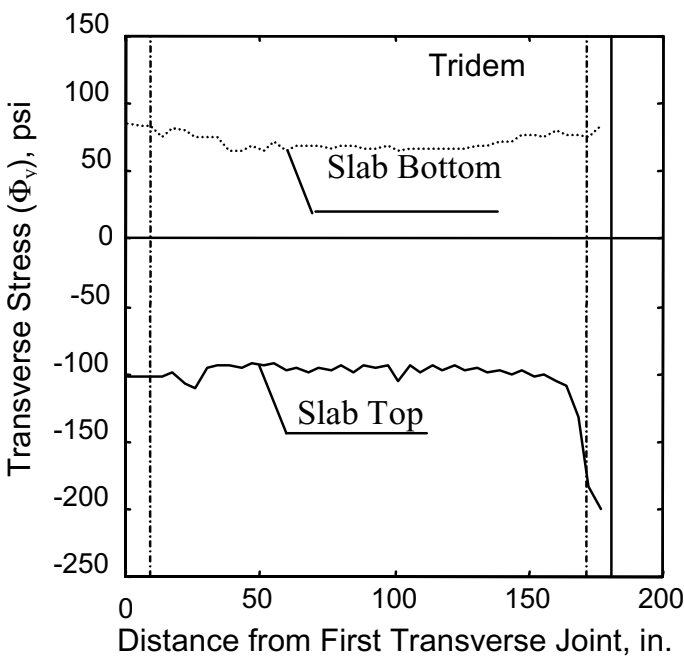

(c)

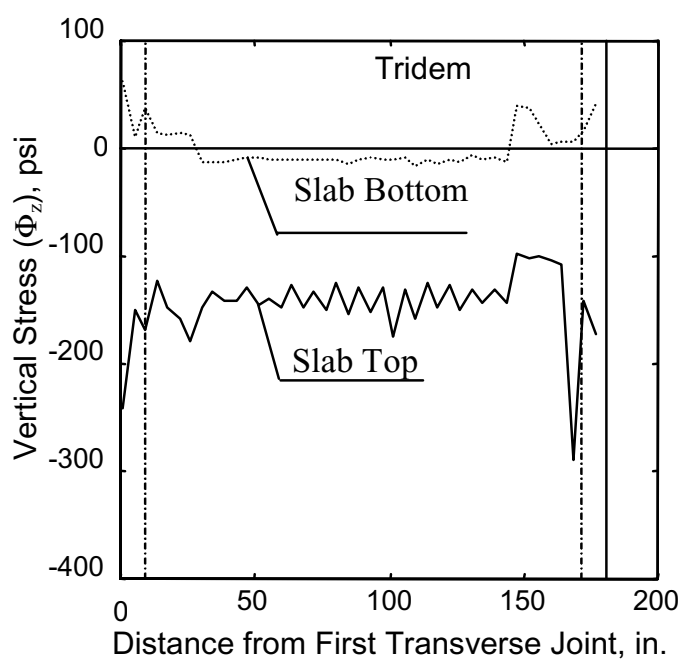

(f)

FIGURE 5.29 Effect of Axle Configuration on Distribution of Peak $\Phi_{\mathrm{y}}$ and $\Phi_{\mathrm{z}}$ Along Traffic 


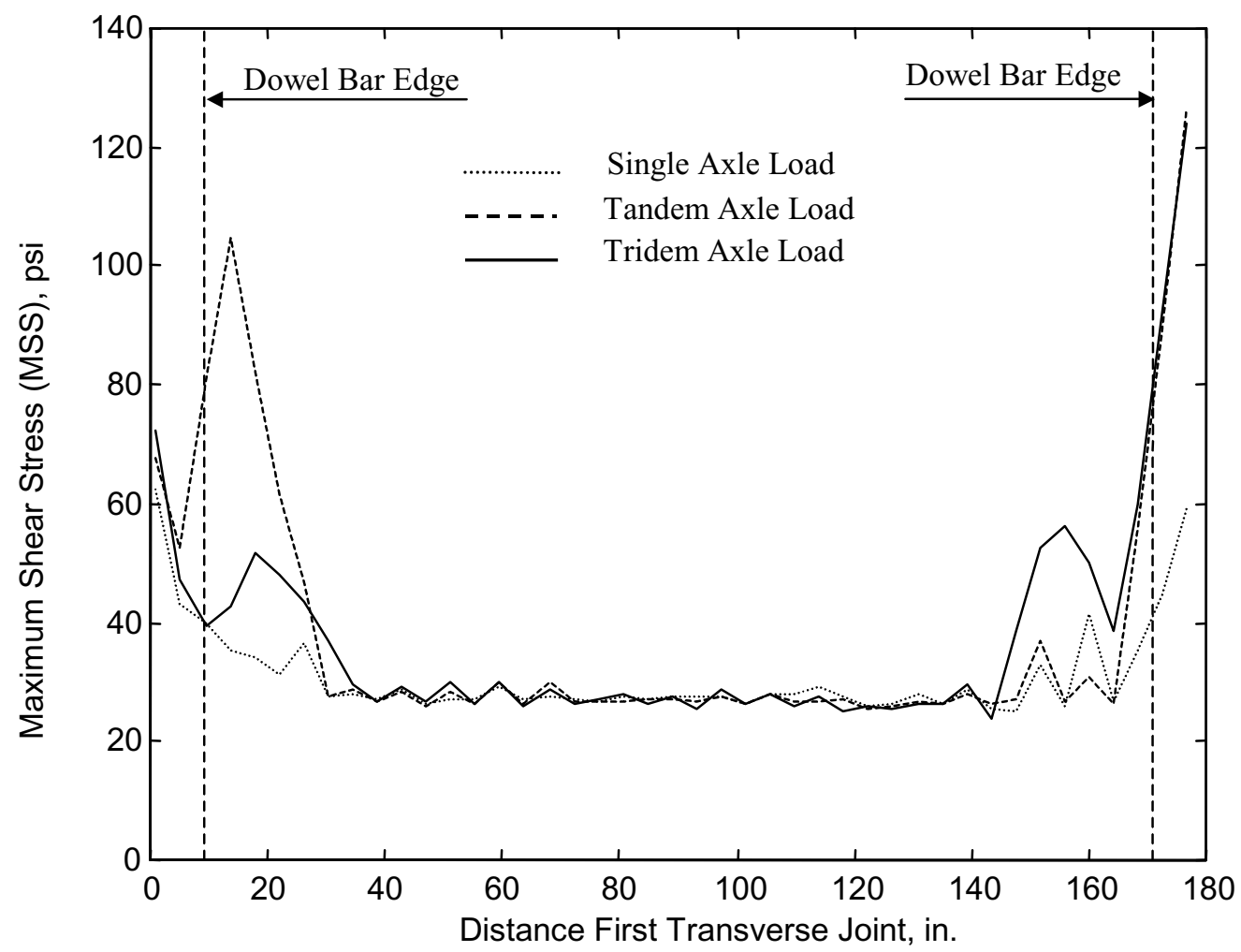

FIGURE 5.30 Effect of Axle Configuration on MSS in the Concrete Slab 


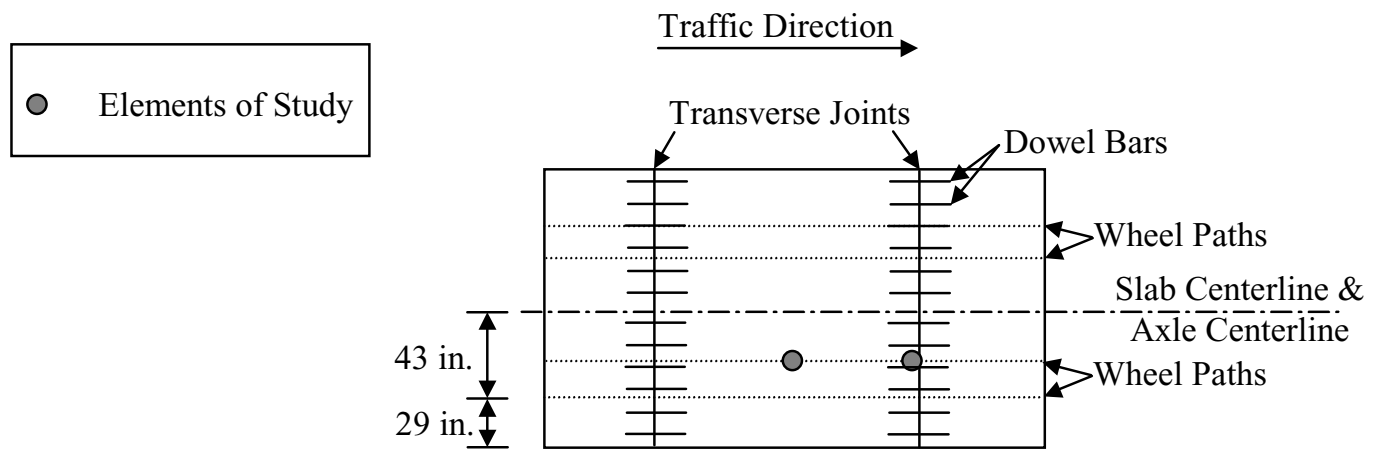

(a) Axle Center Line Offset $=0$

(Wheel-path Loading Condition)

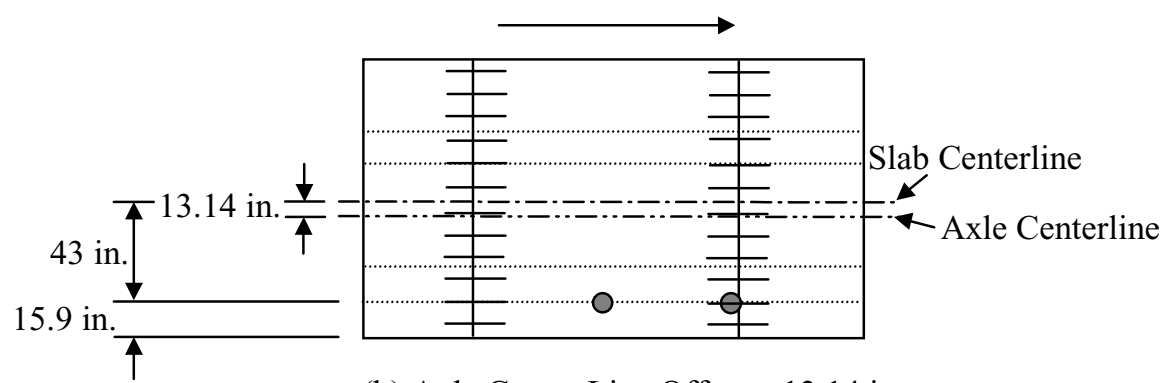

(b) Axle Center Line Offset $=13.14$ in.

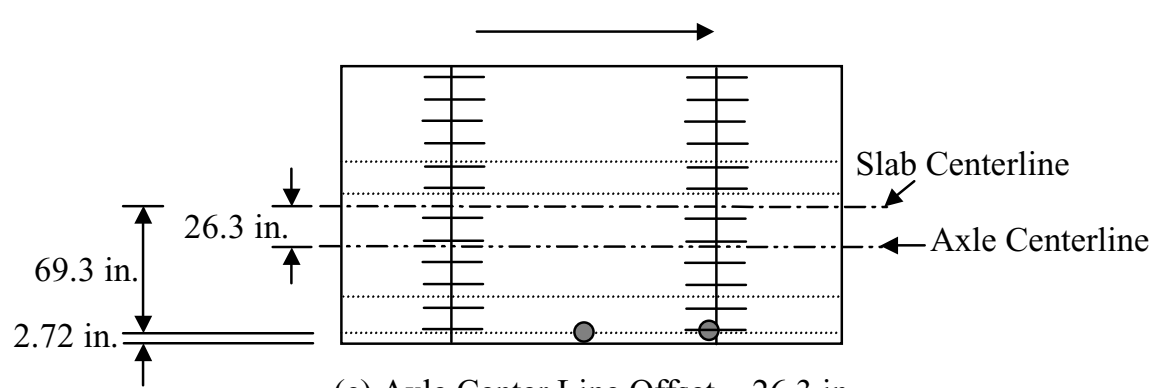

(c) Axle Center Line Offset $=26.3$ in.

(Edge Loading Condition)

FIGURE 5.31 Locations of the Points of Study for the Three Models Used to Study the Effect of Loading Position 


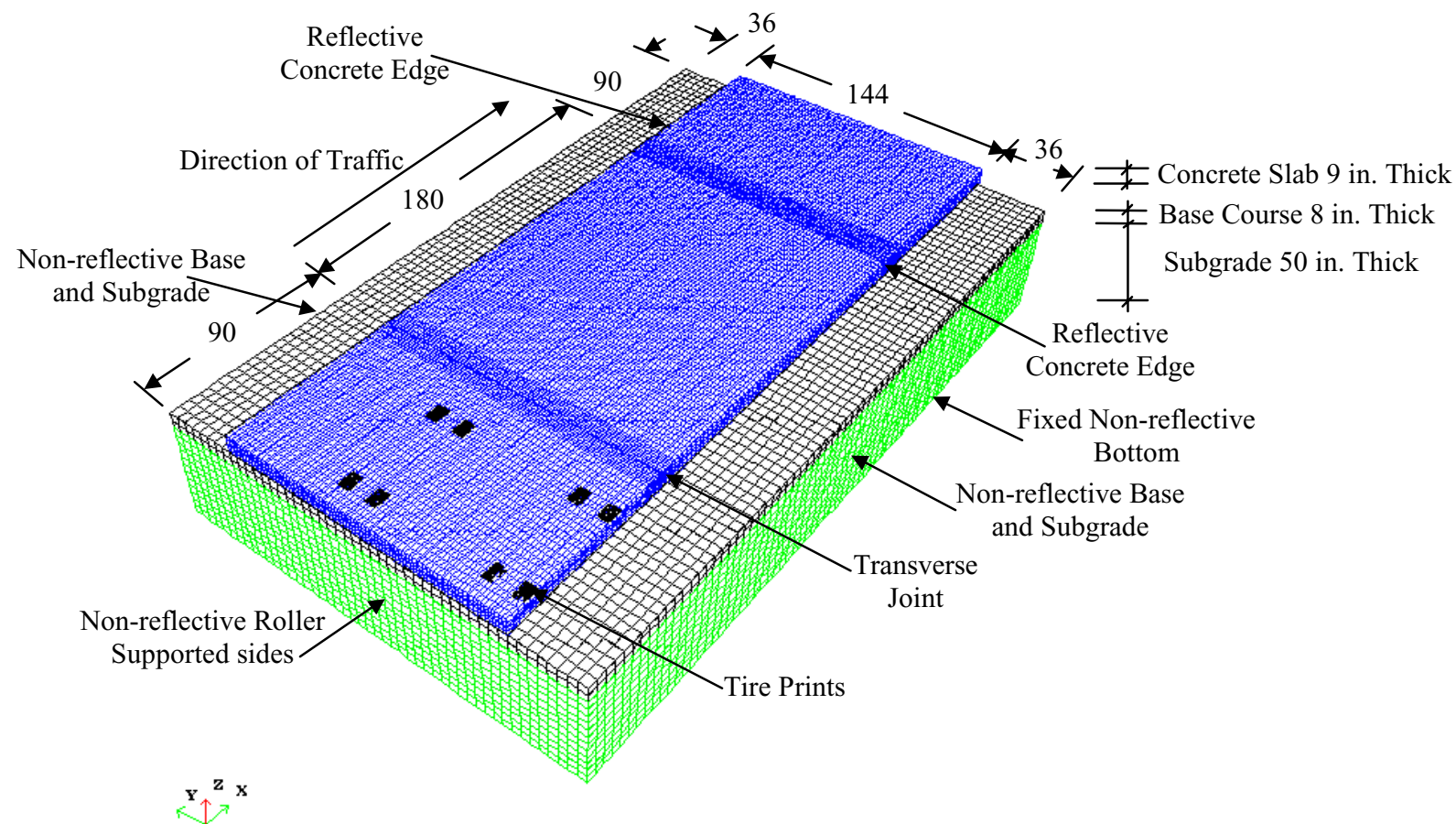

(a) Finite Element Mesh of the Edge Loading Condition

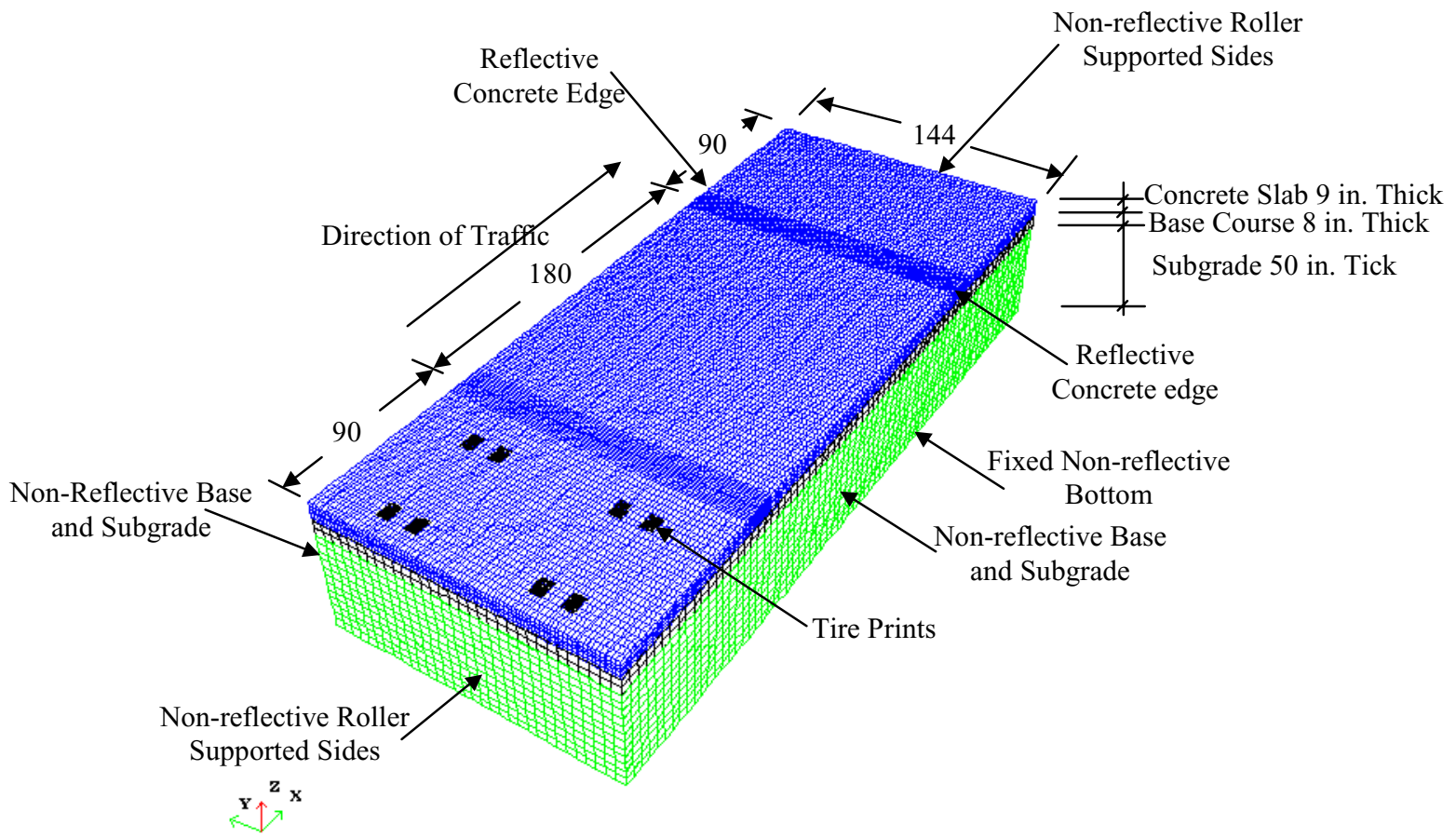

( b) Finite Element Mesh of the Zero Offset Condition

Dimensions in Inches

FIGURE 5.32 Finite Element Models used in the Loading Position Study 


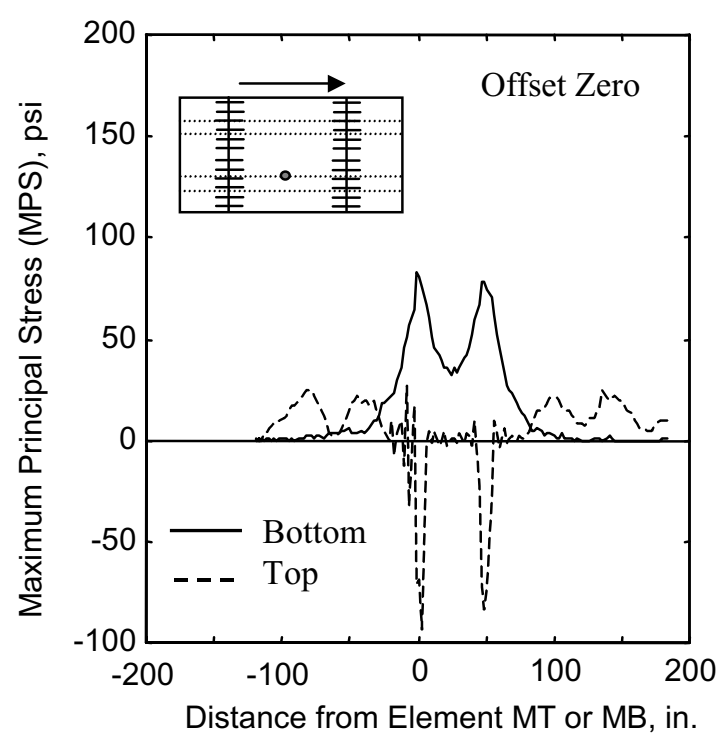

(a)

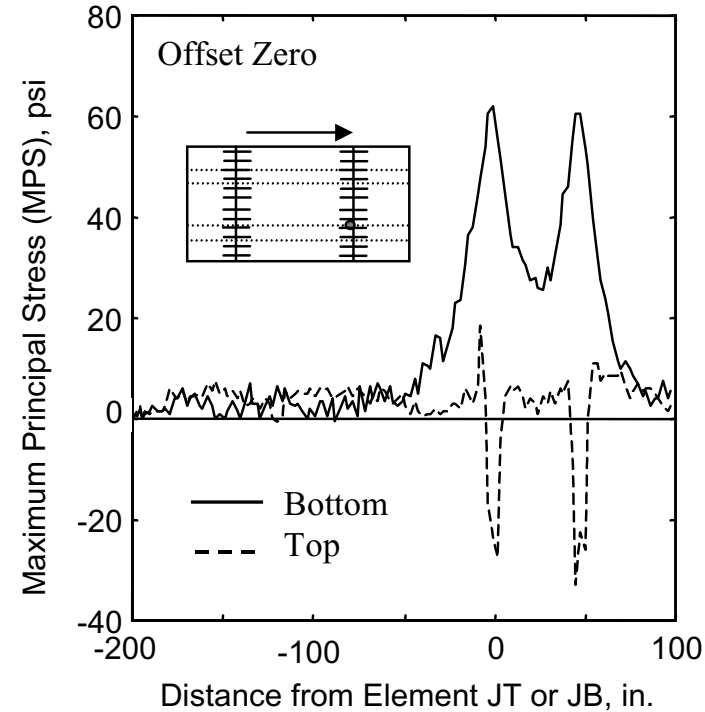

(d)

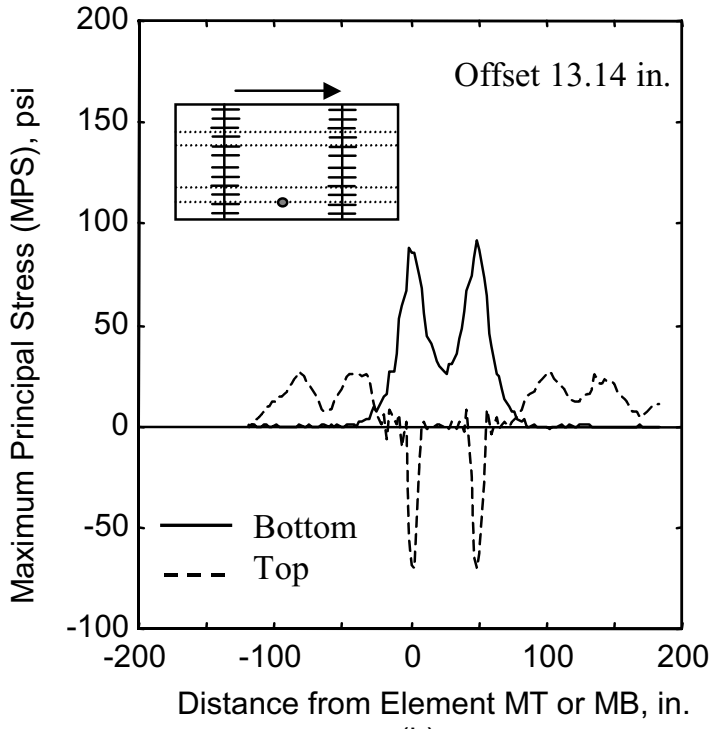

(b)

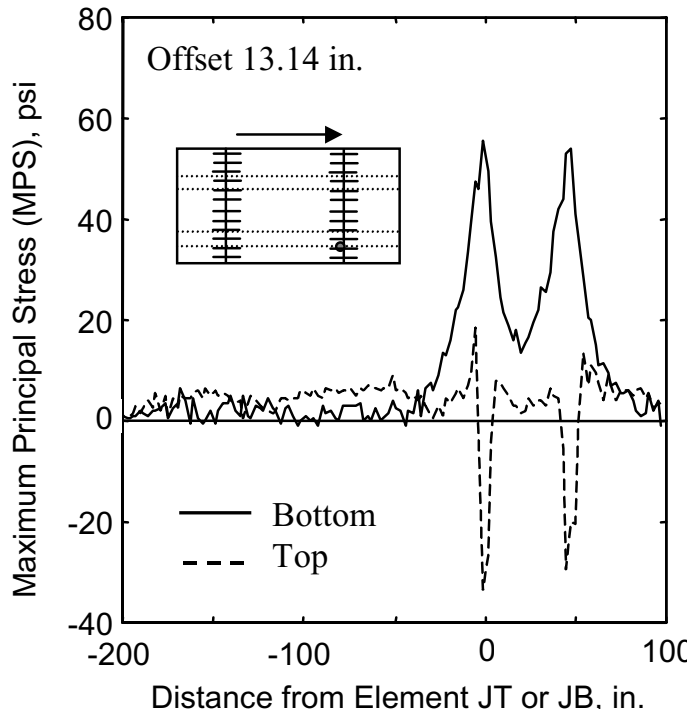

(e)

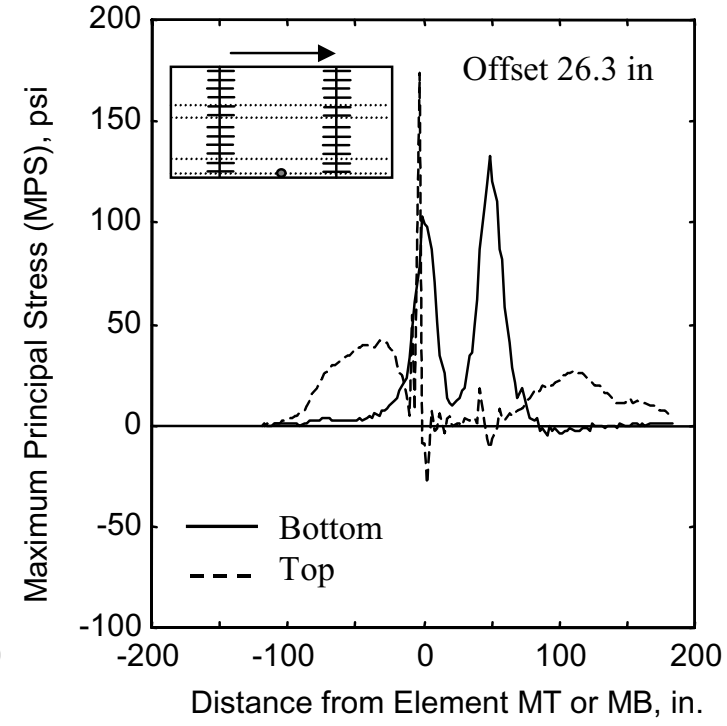

(c)

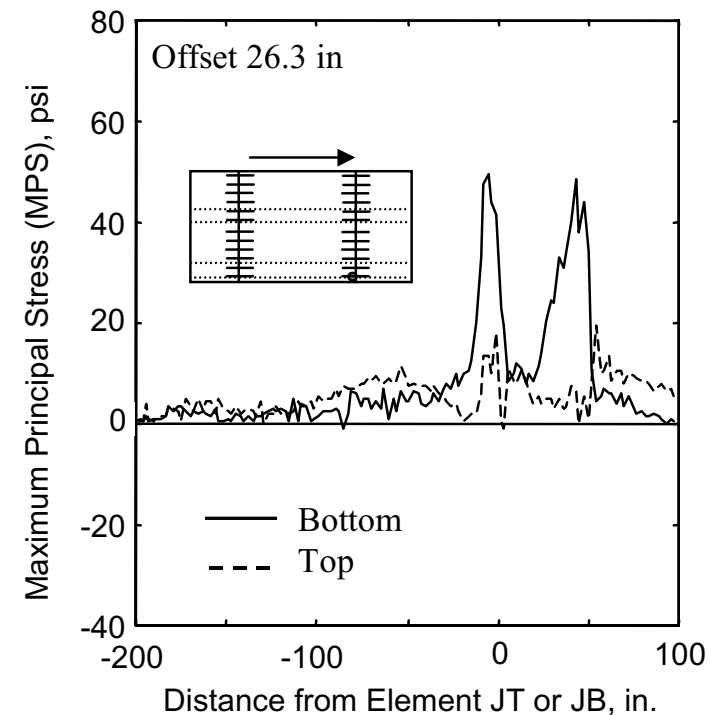

(f)

FIGURE 5.33 Effect of Loading Position on Distribution of MPS in the Concrete Slab 

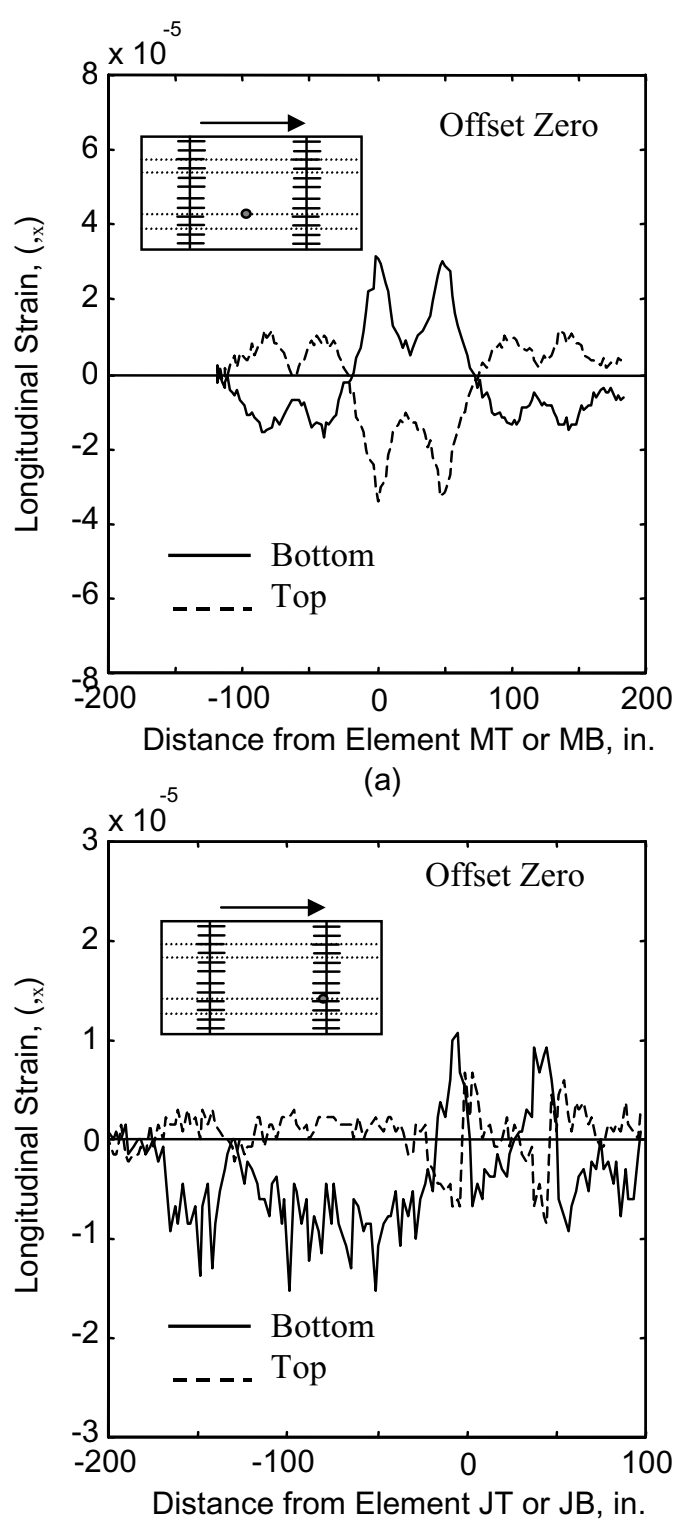

(d)
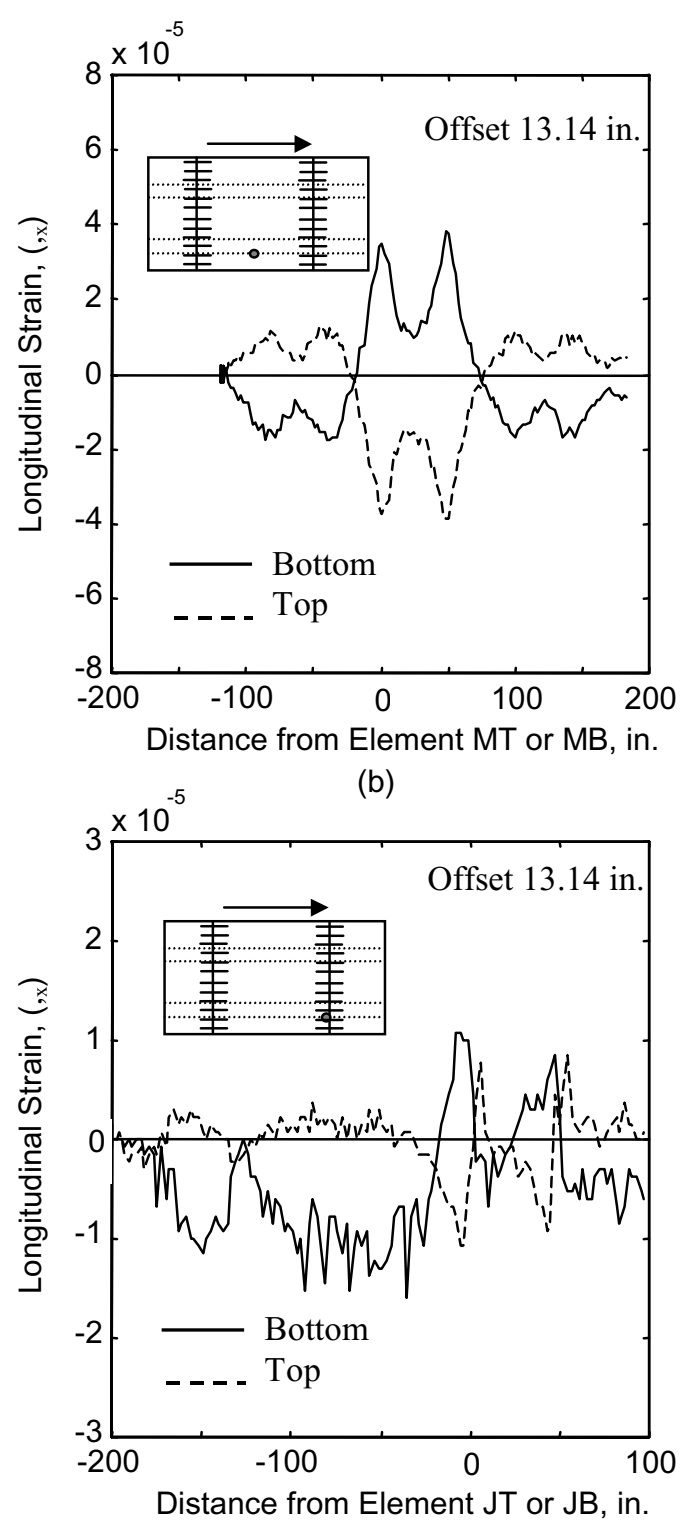

(e)

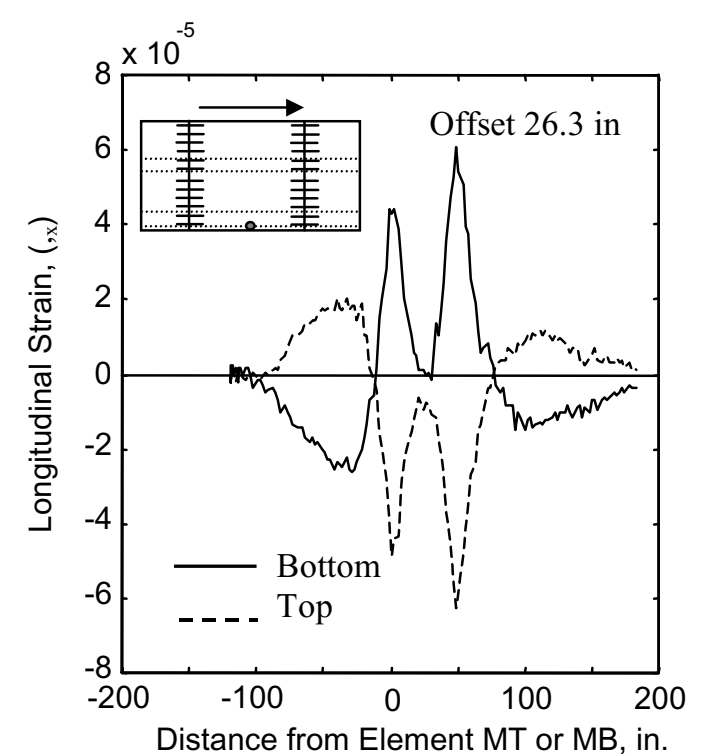

(c)

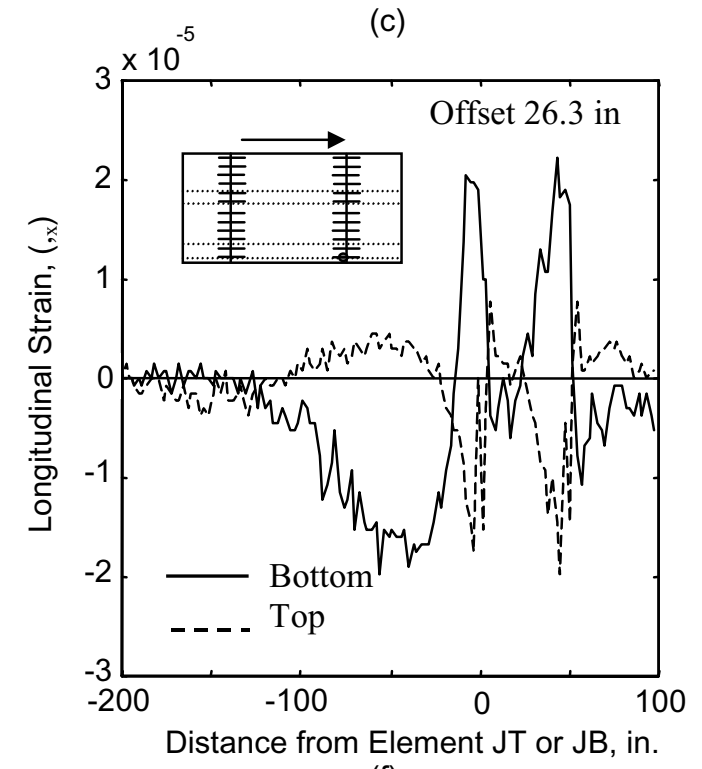

(f)

FIGURE 5.34 Effect of Loading Position on Distribution of $\varepsilon_{\mathrm{x}}$ in the Concrete Slab 

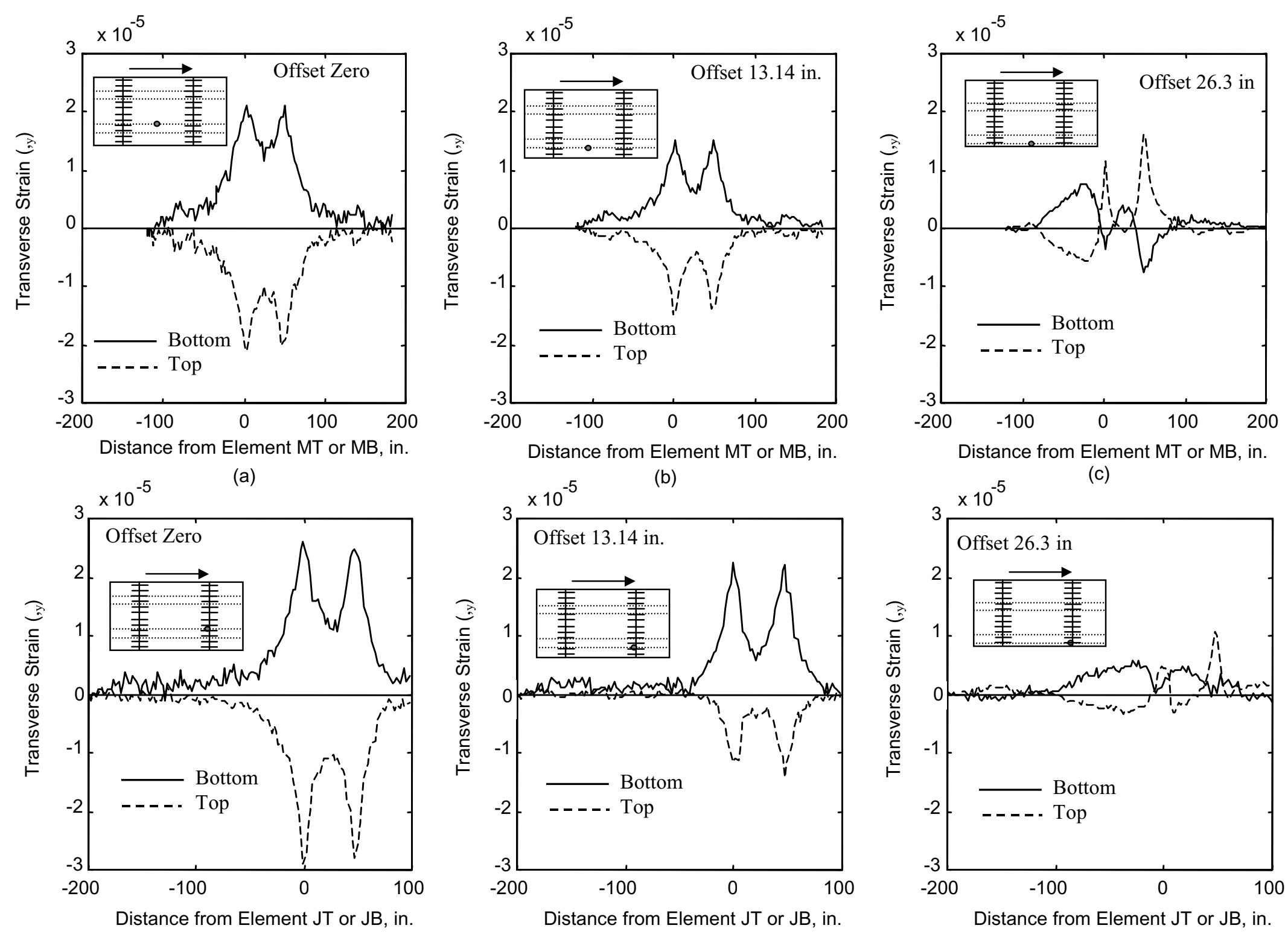

(d)

(e)

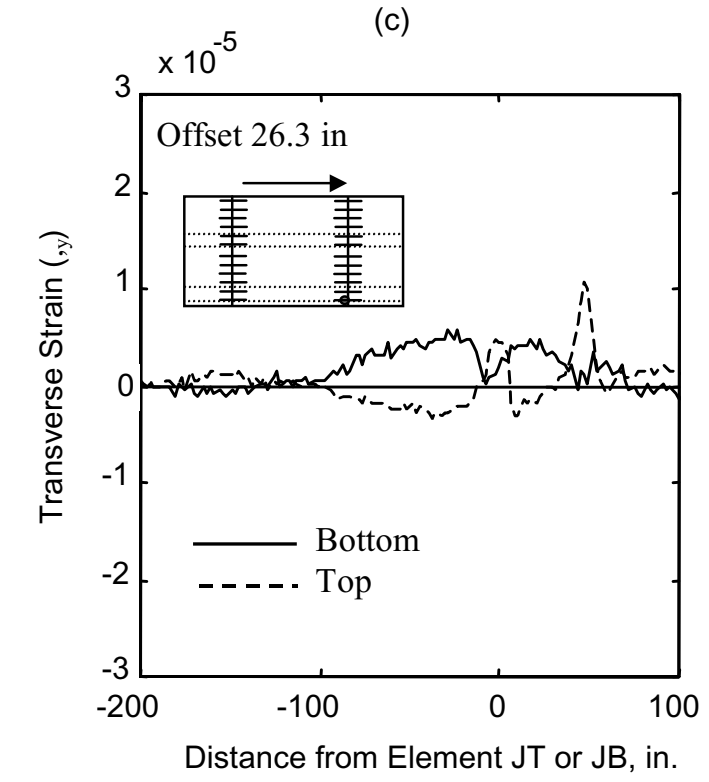

FIGURE 5.35 Effect of Loading Position on Distribution of $\varepsilon_{\mathrm{y}}$ in the Concrete Slab 


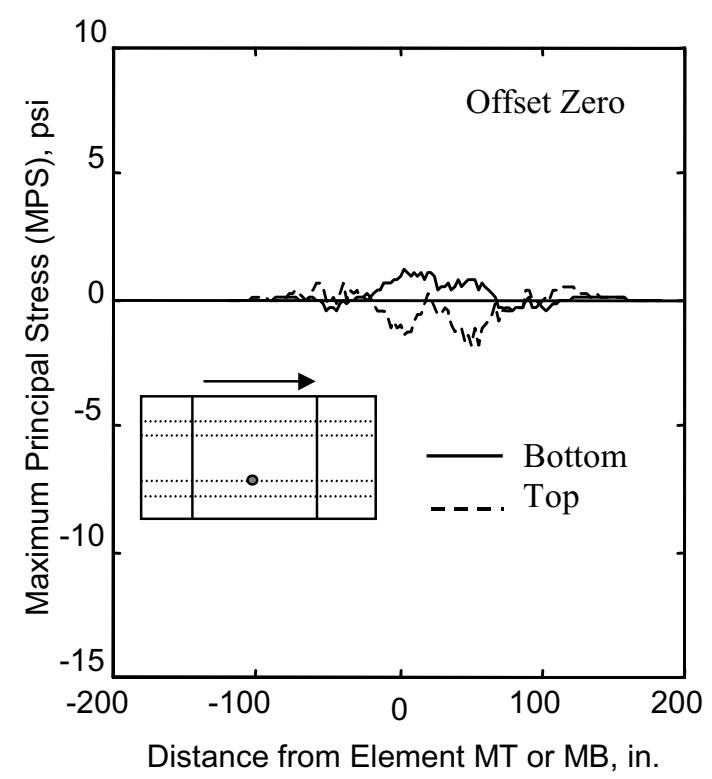

(a)

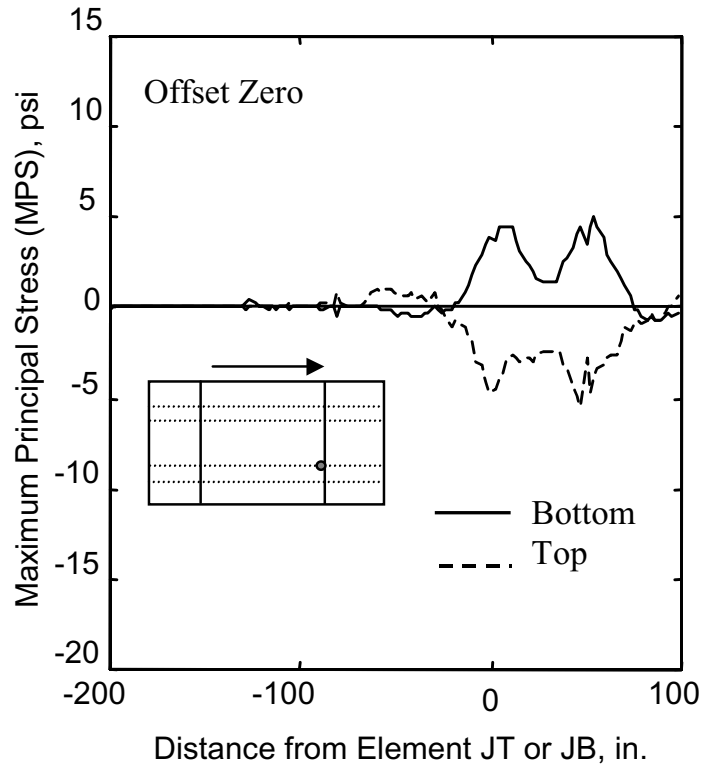

(d)

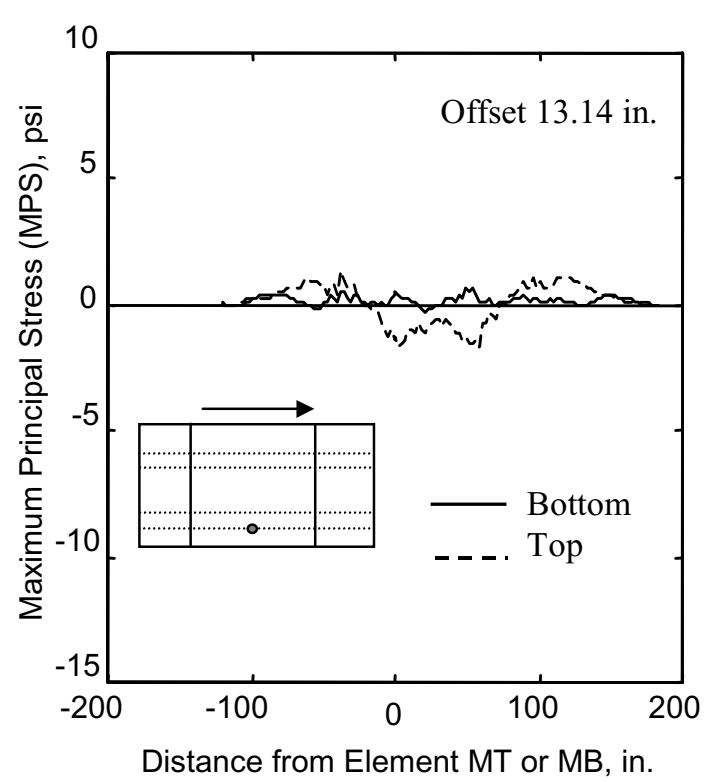

(b)

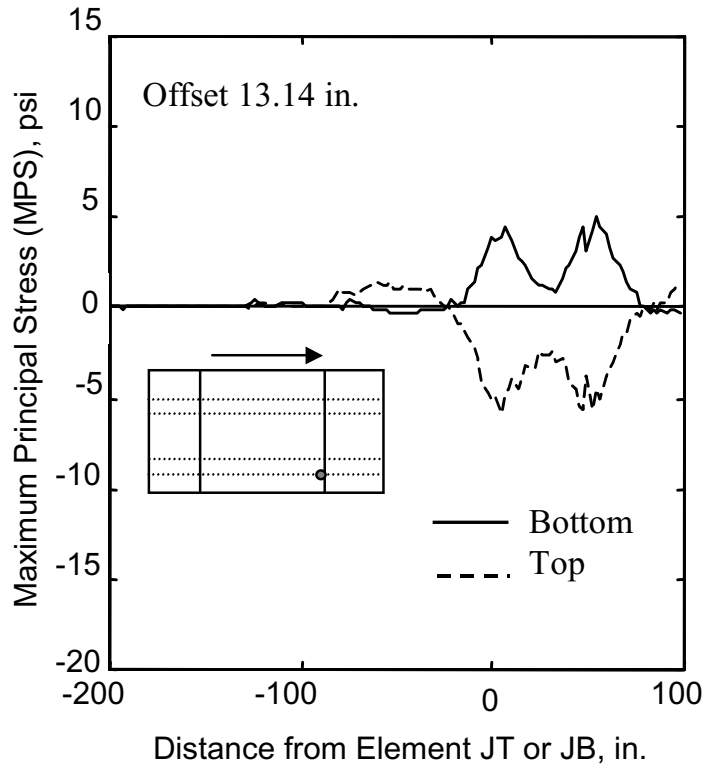

(e)

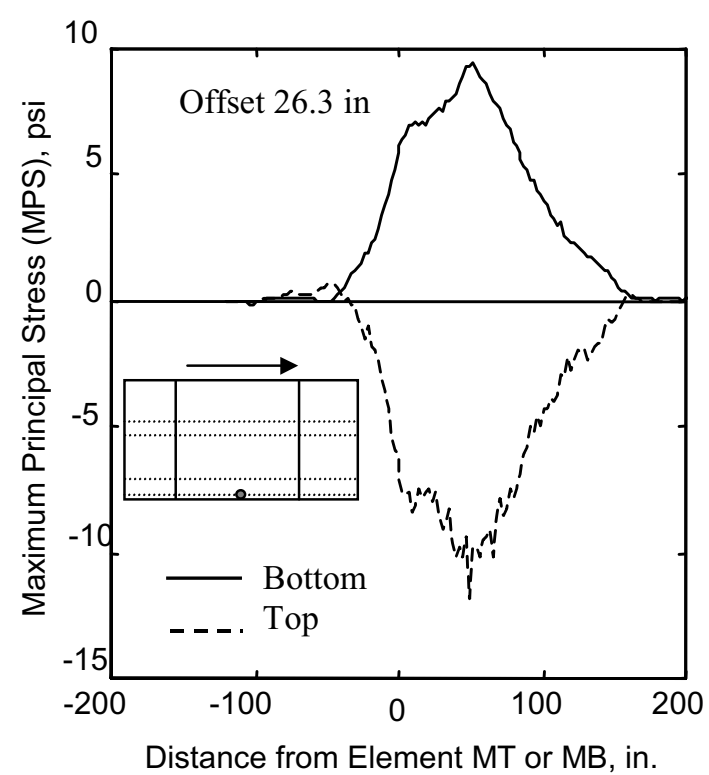

(c)

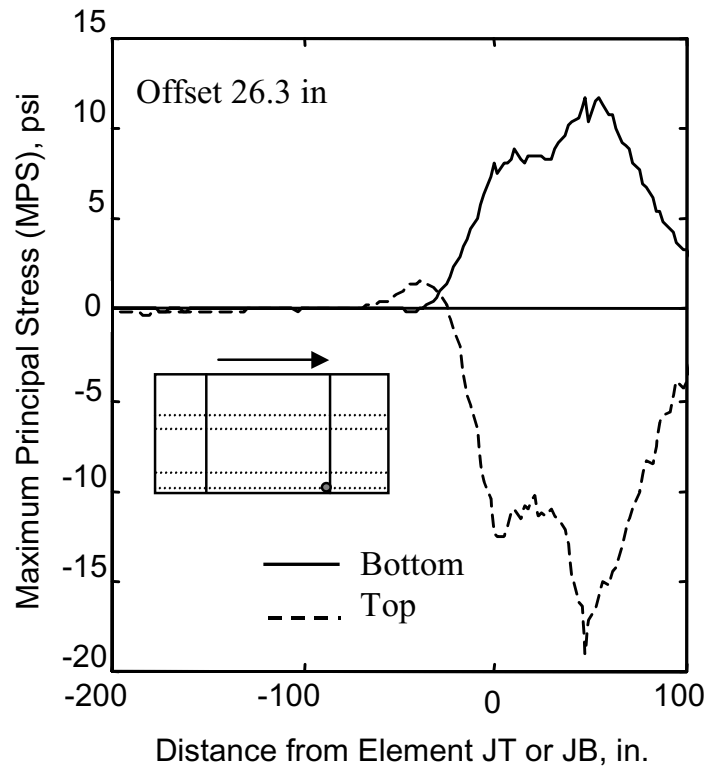

(f)

FIGURE 5.36 Effect of Loading Position on Distribution of MPS in the Base Course 

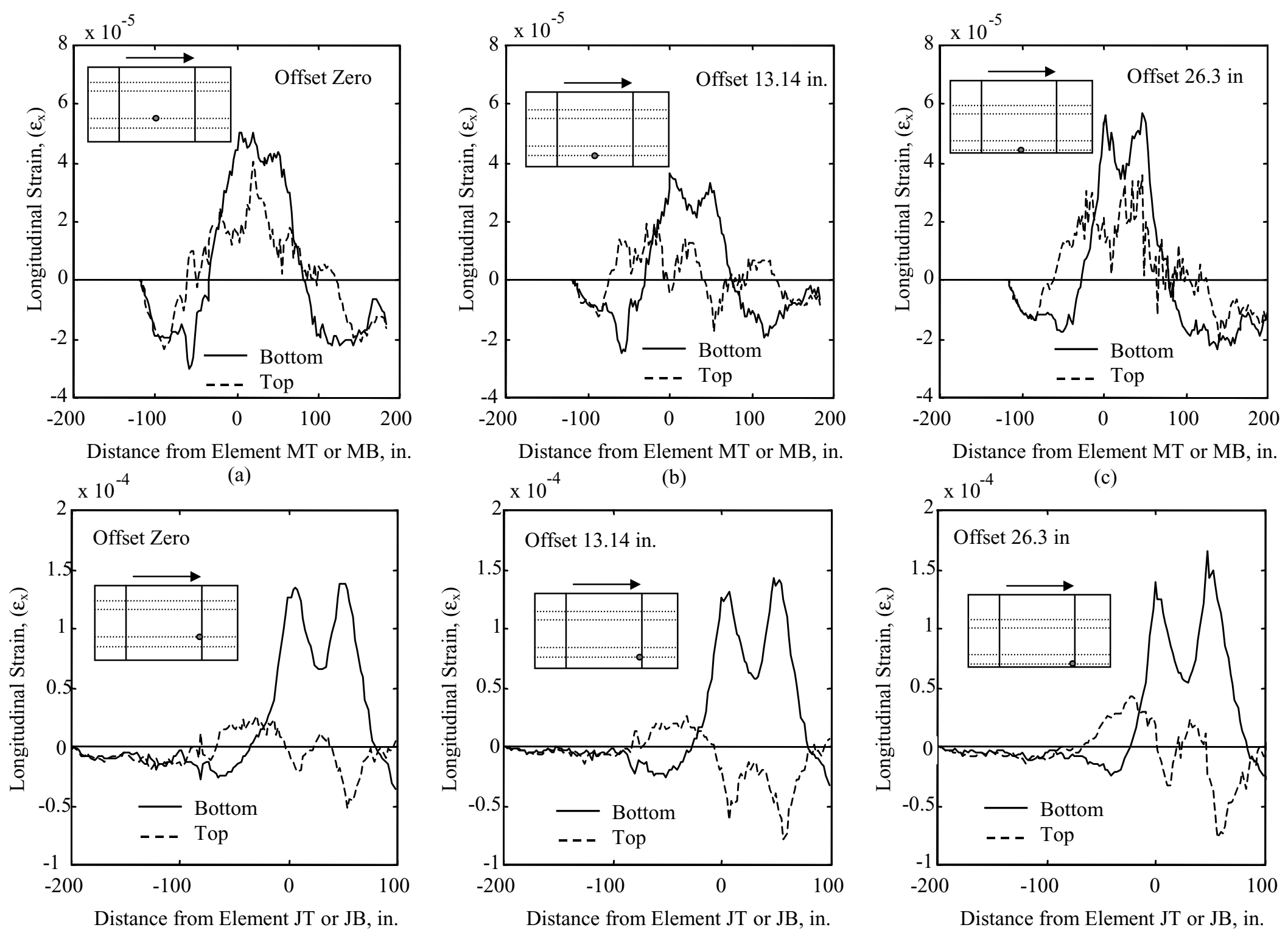

(d)

(e)

(f)

FIGURE 5.37 Effect of Loading Position on Distribution of $\varepsilon_{\mathrm{X}}$ in the Base Course 


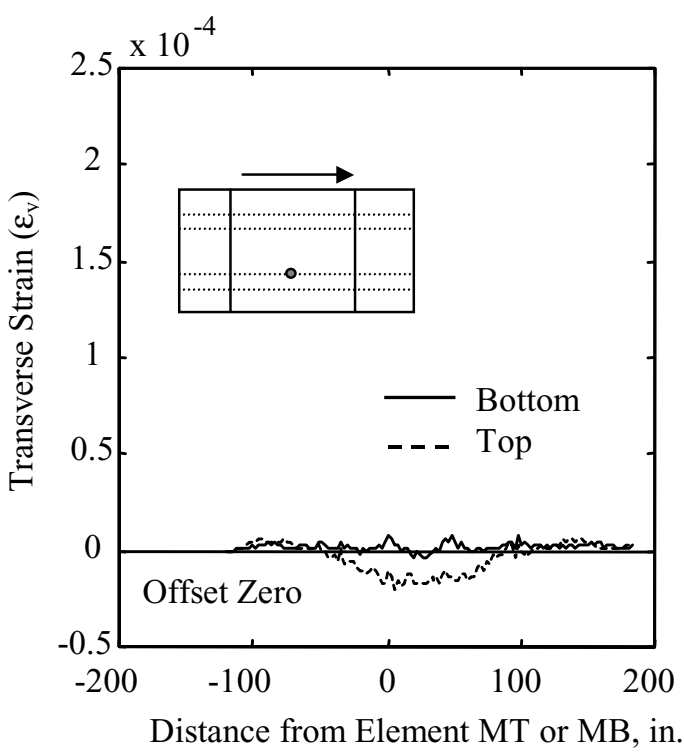

(a)

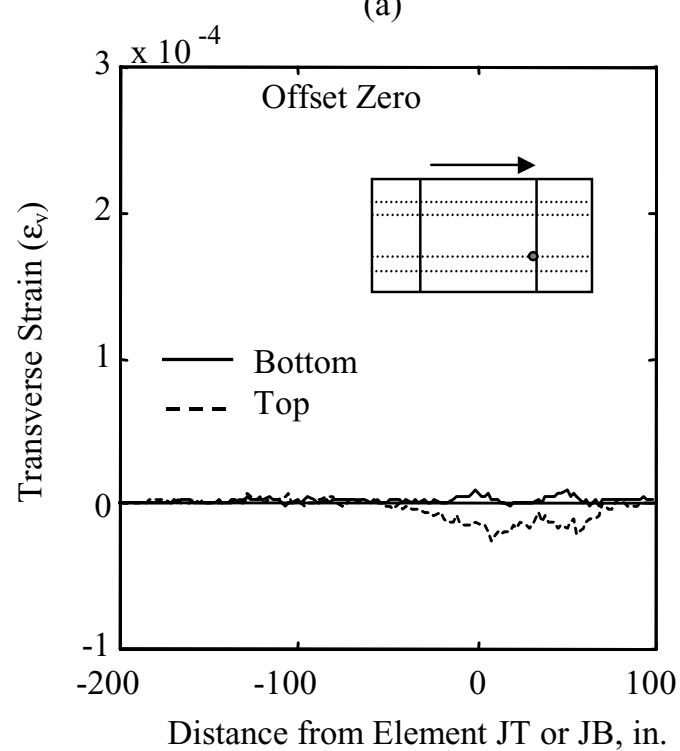

(d)

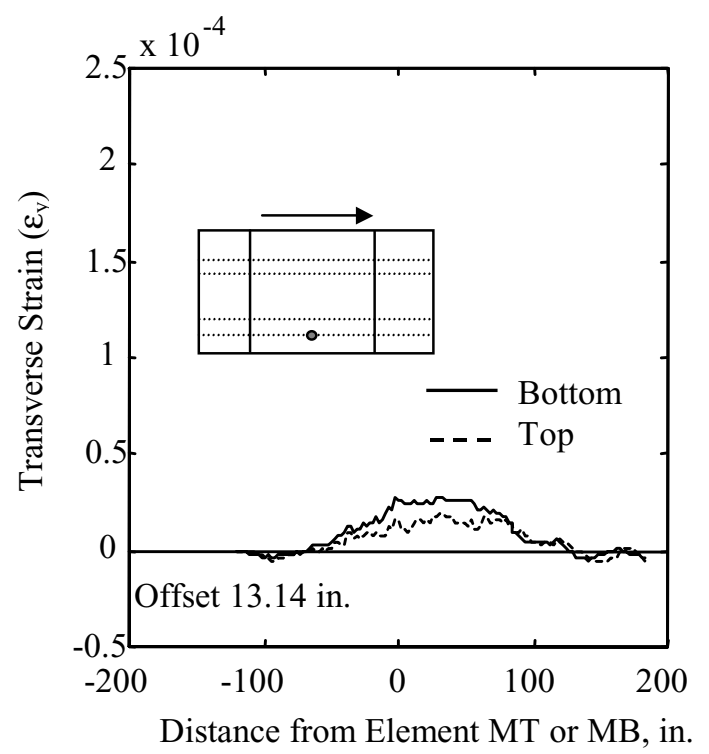

(b)

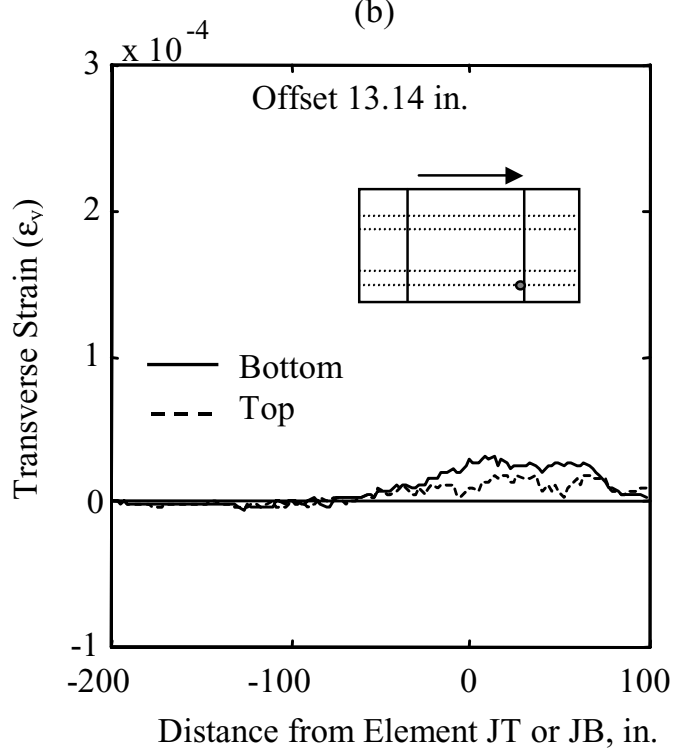

(e)

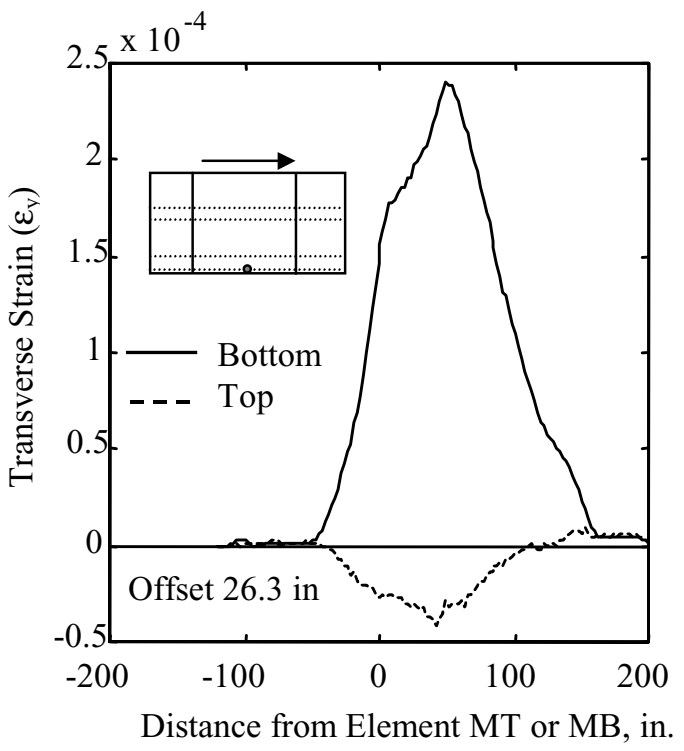

(c)

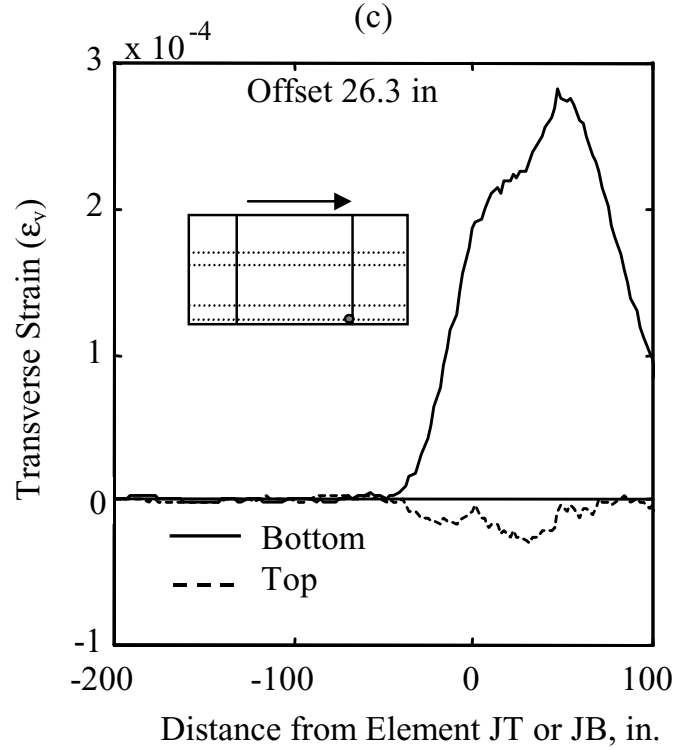

(f)

FIGURE 5.38 Effect of Loading Position on Distribution of $\varepsilon_{\mathrm{y}}$ in the Base Course 

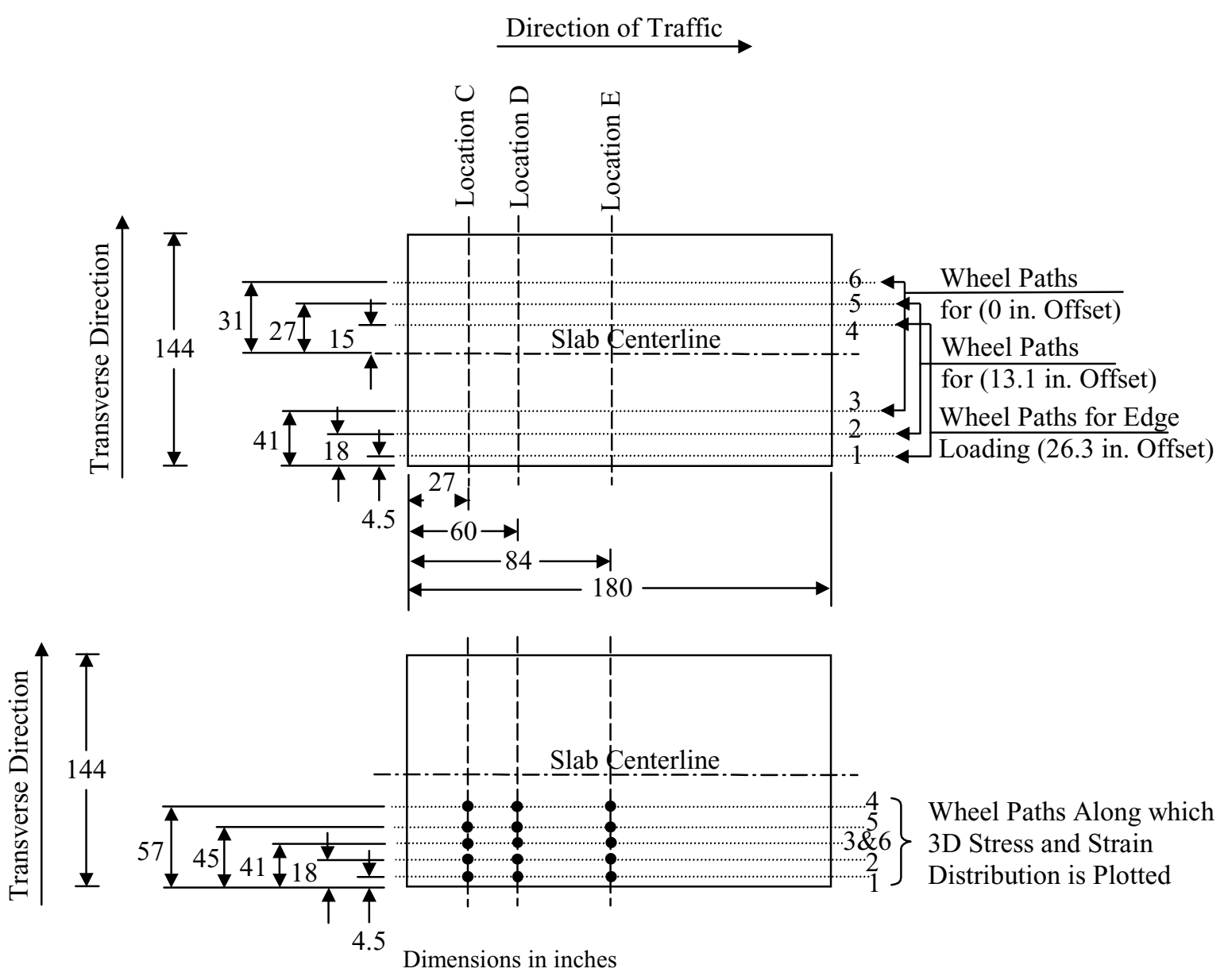

- Elements along which Stress and Strain Histories are Obtained from the Three FE Models

FIGURE 5.39 Locations of the Elements Used to Plot the 3D Stress and Strain Distributions 

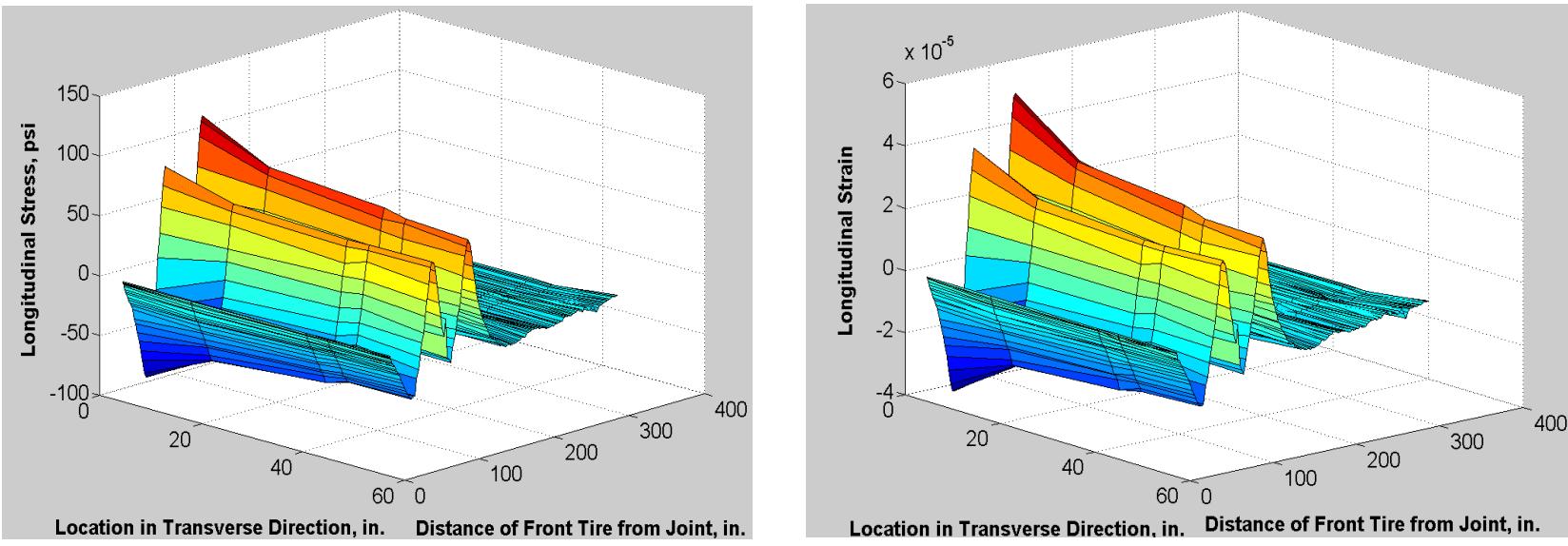

(a) Location C 27 in. from Transverse Joint
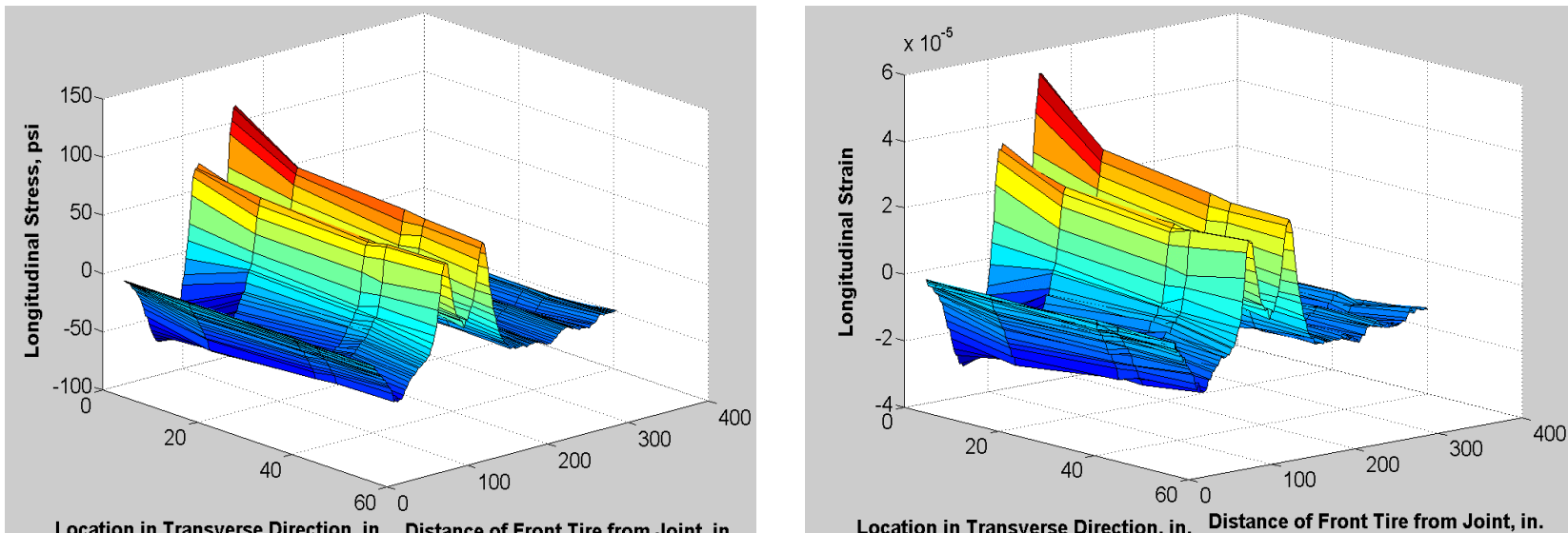

(b) Location D 60 in. from Transverse Joint
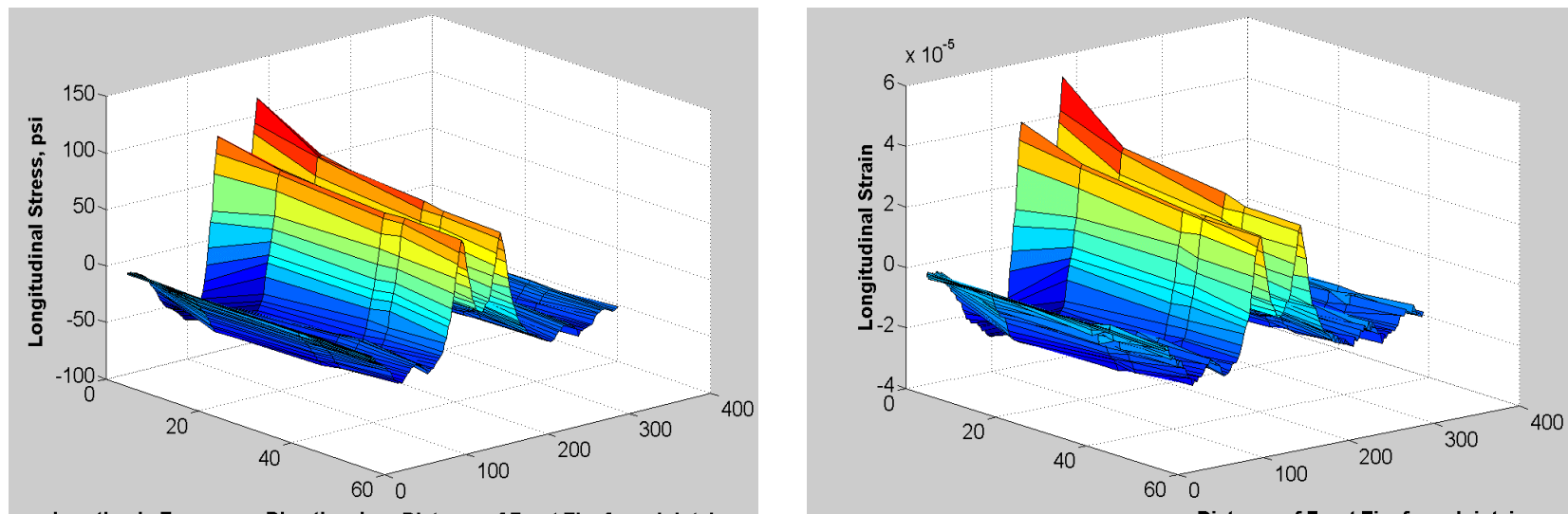

(c) Location E 84 in. from Transverse Joint

FIGURE 5.40 Effect of Load Position on Distribution of $\sigma_{\mathrm{x}}$ and $\varepsilon_{\mathrm{x}}$ at Slab Bottom 


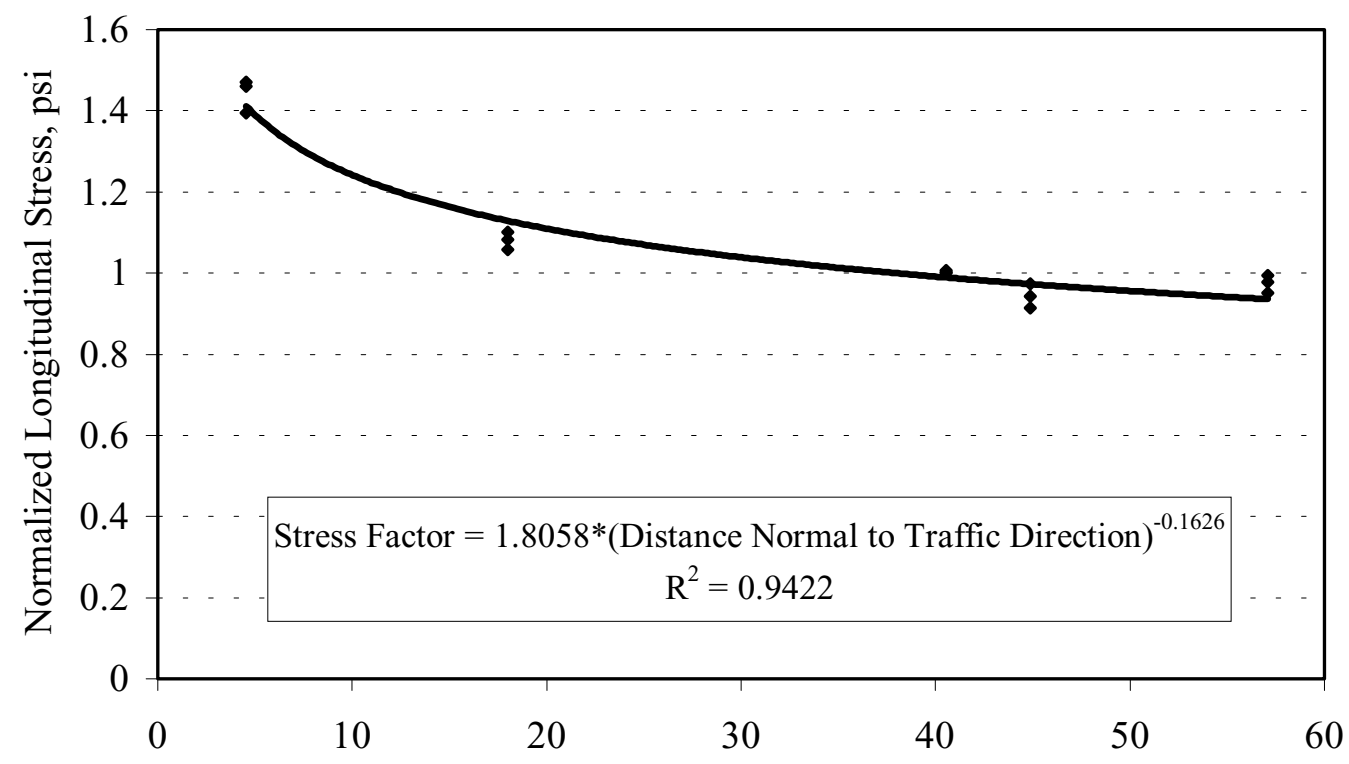

Distance Normal to Traffic Direction, in.

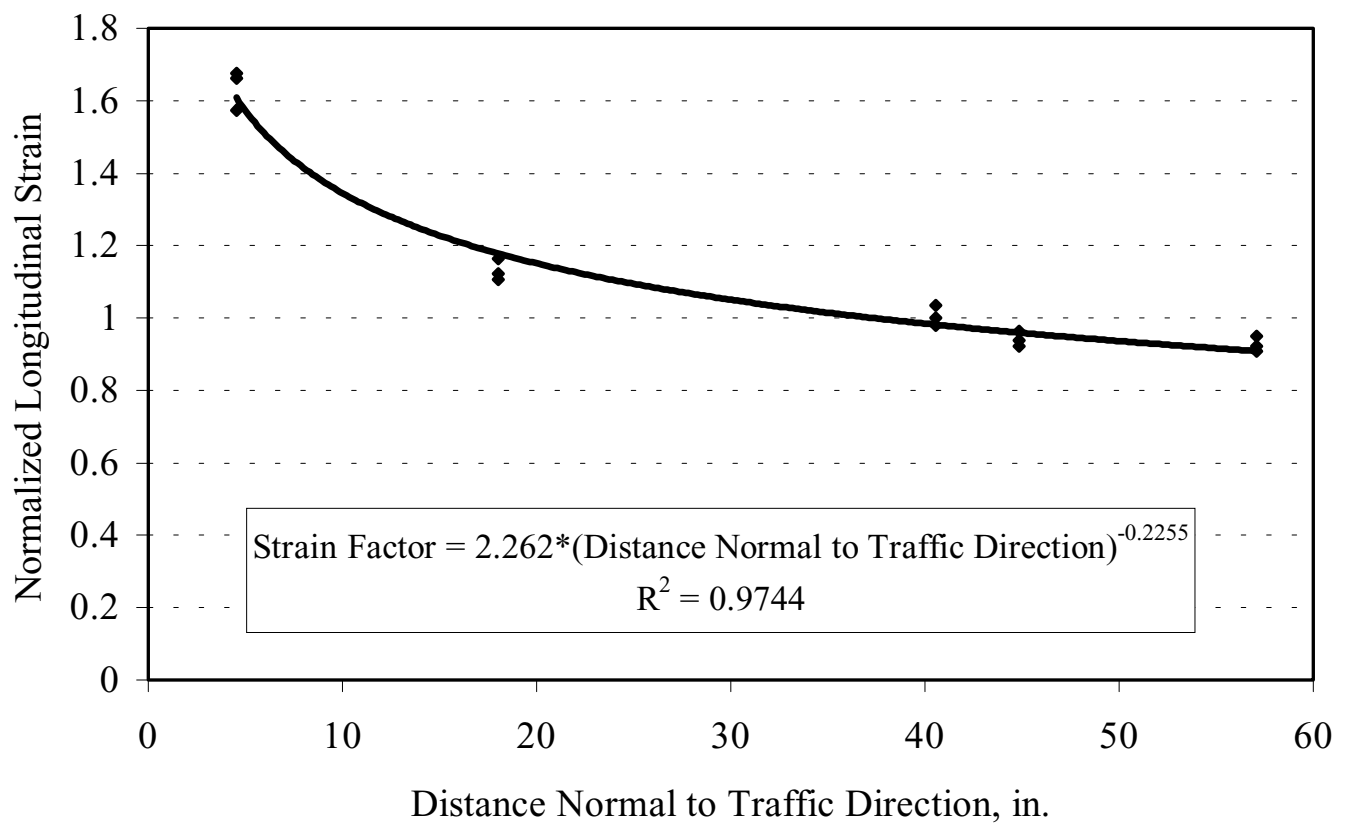

FIGURE 5.41 Multiplication Factors used to Calculate $\sigma_{\mathrm{x}}$ and $\varepsilon_{\mathrm{x}}$ for any Loading Position 


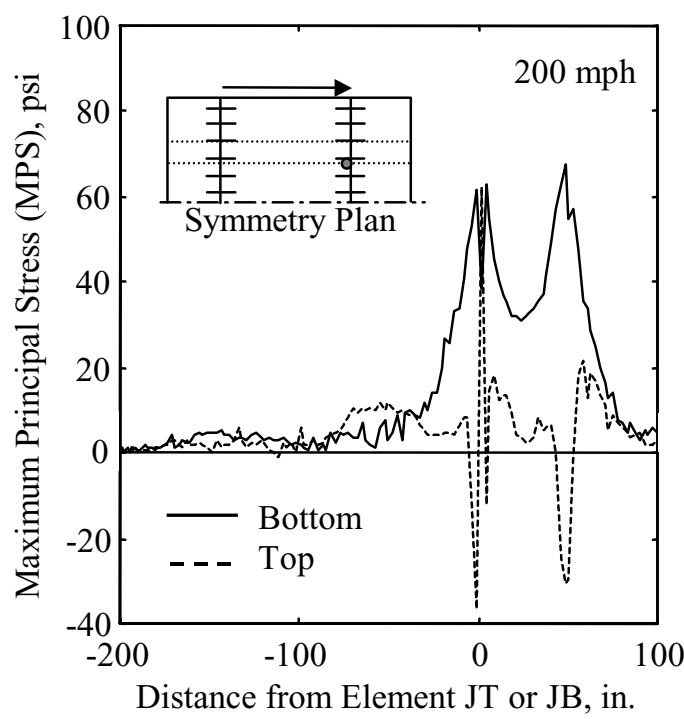

(a)

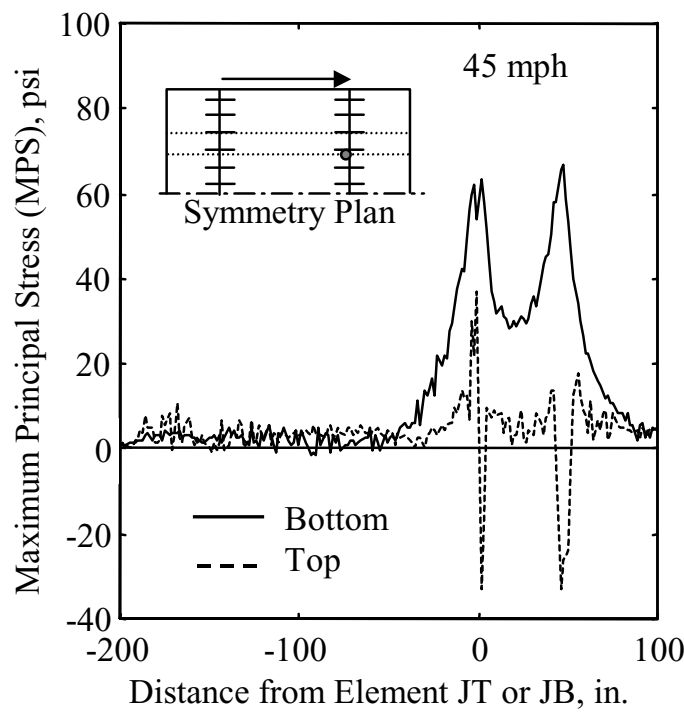

(d)

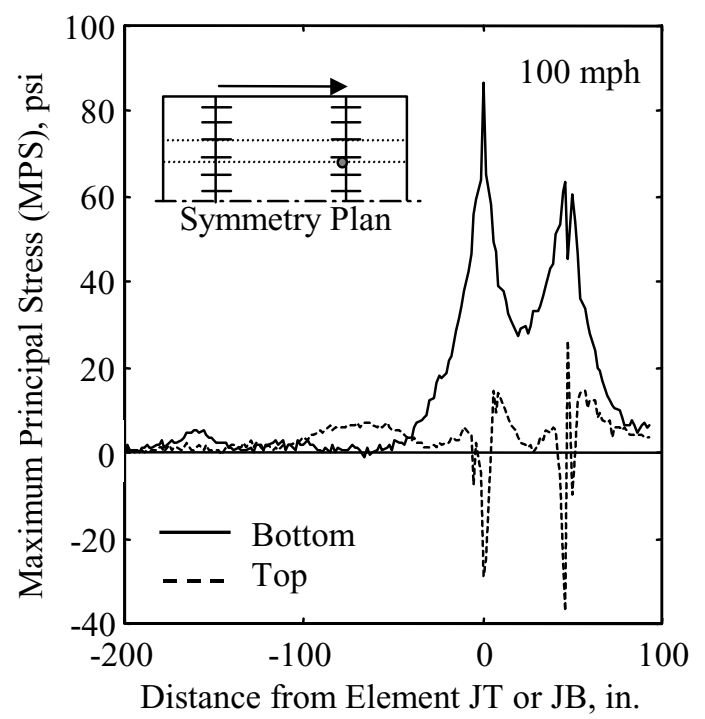

(b)

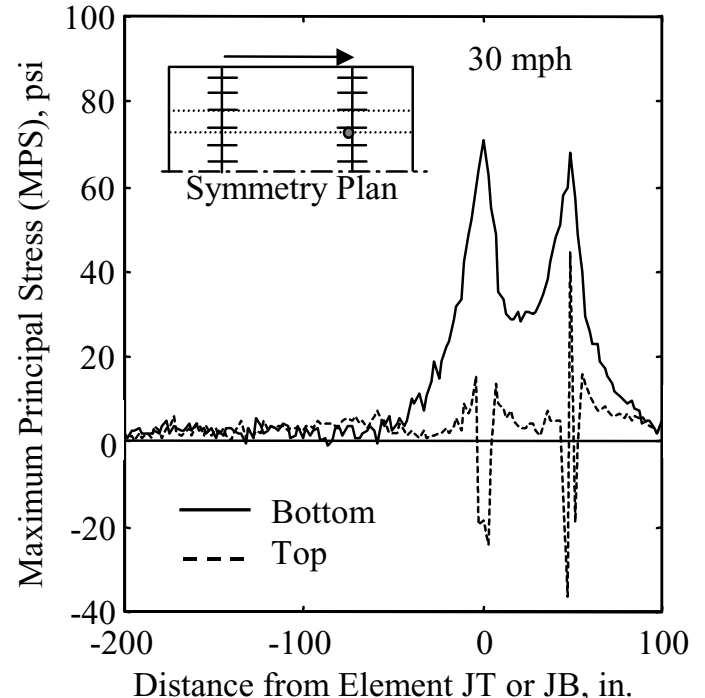

(e)

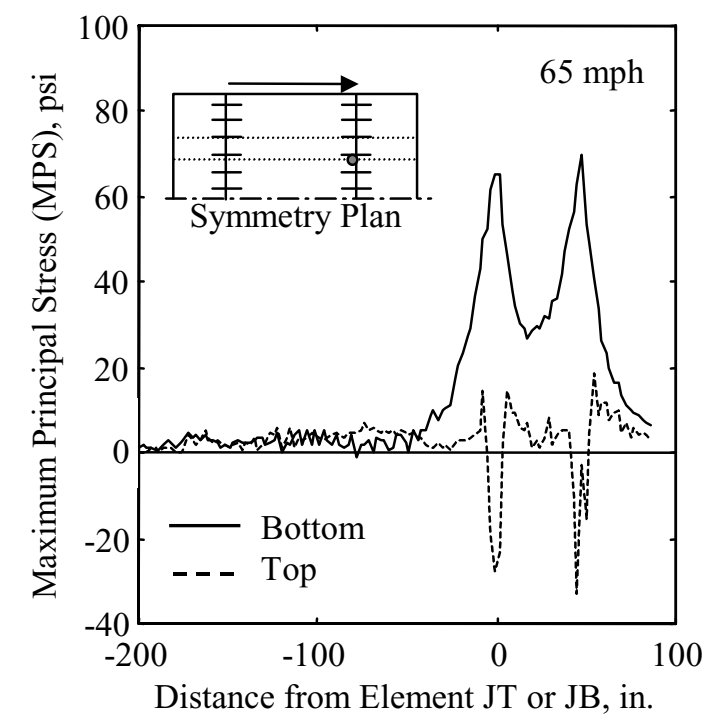

(c)

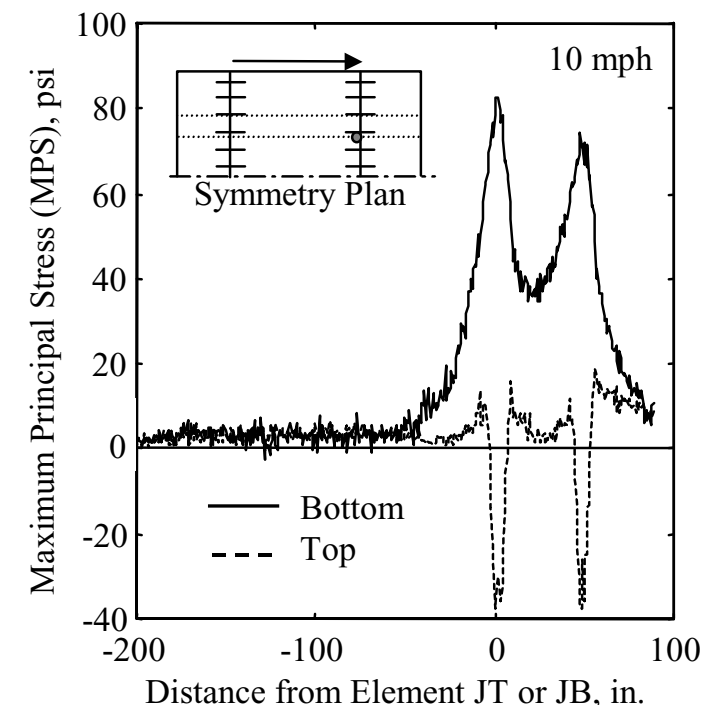

(f)

FIGURE 5.42 Effect of Traffic Speed on Distribution of MPS at the Transverse Joint 


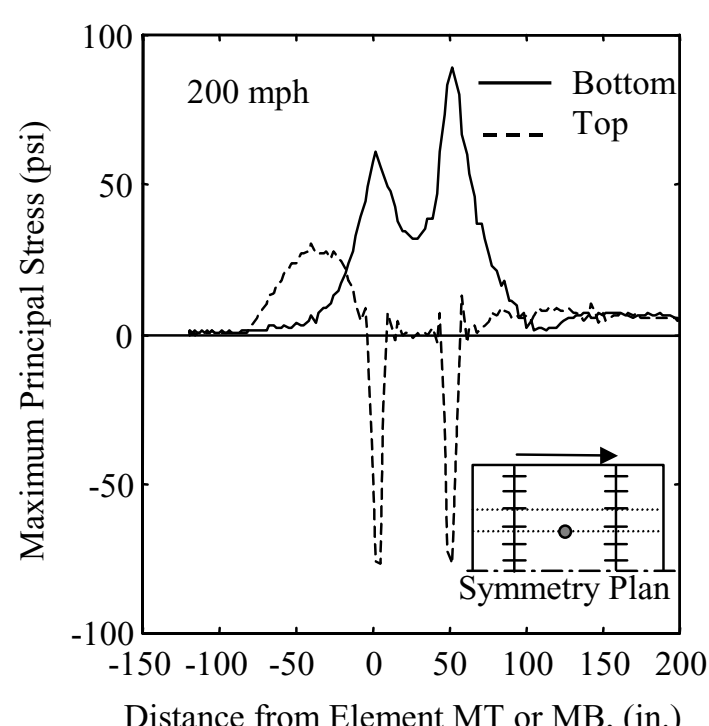

(a)

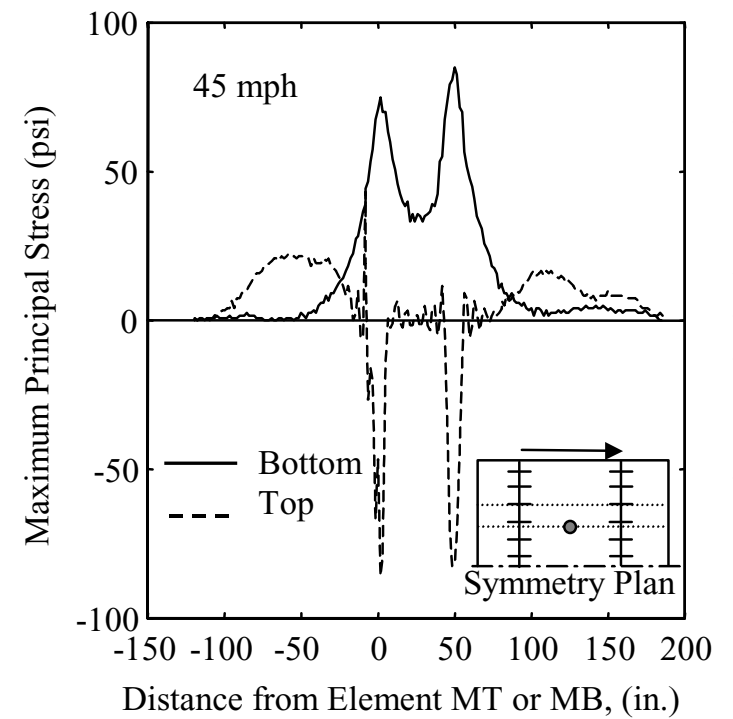

(d)
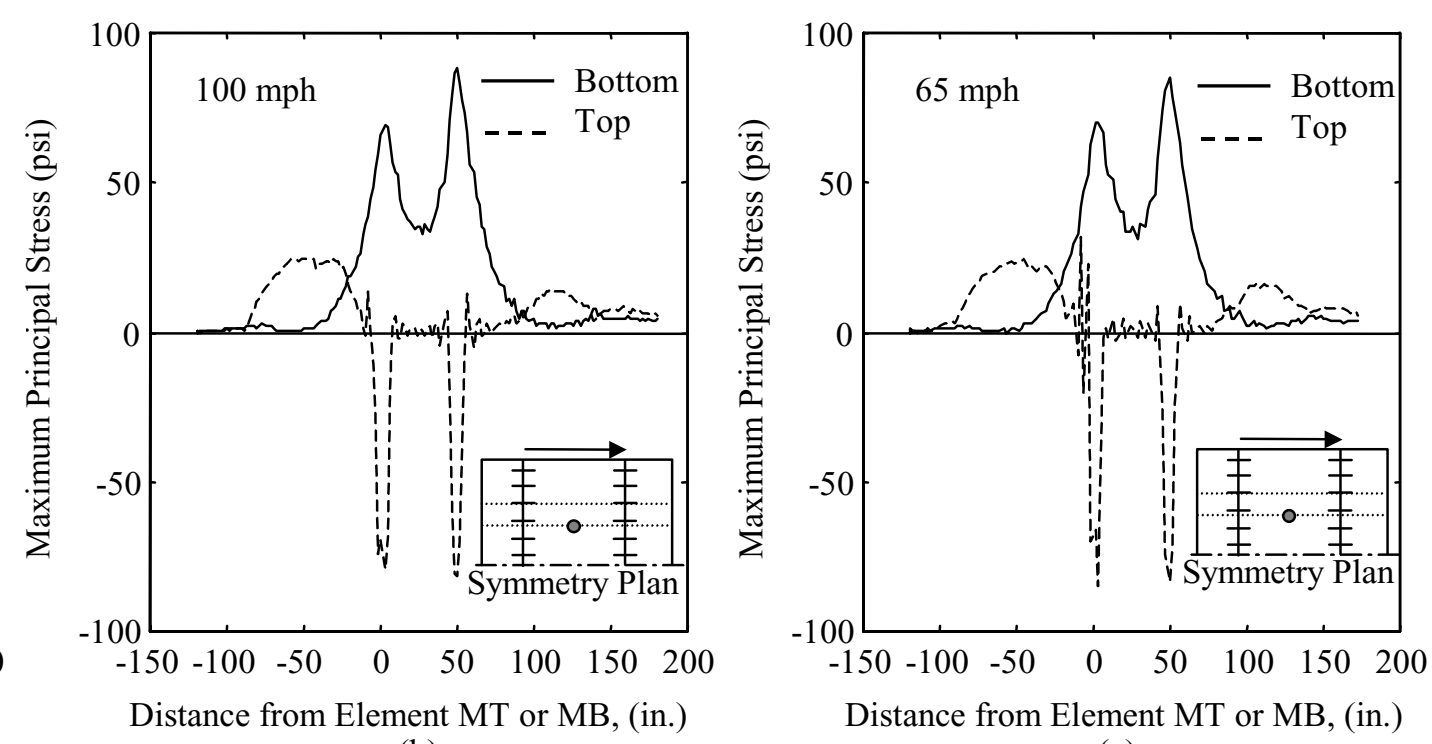

(c)

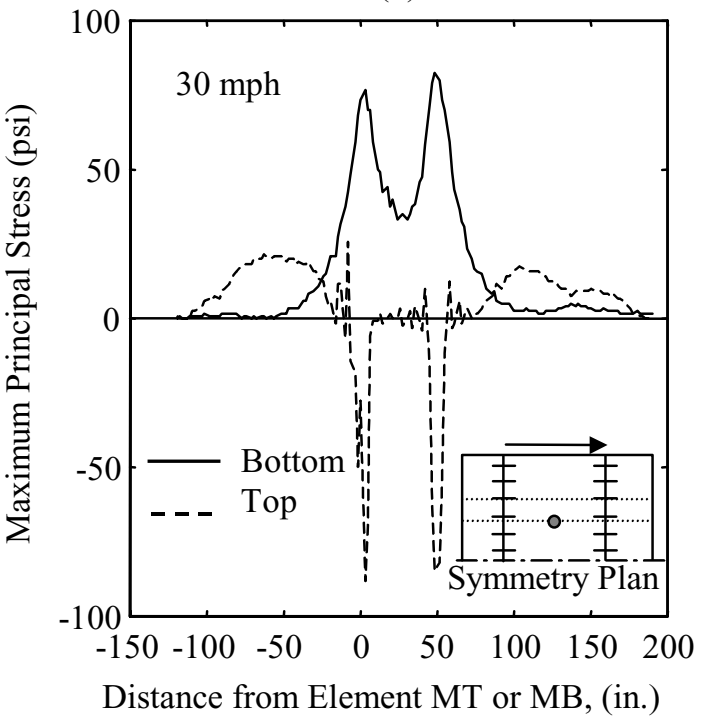

(e)

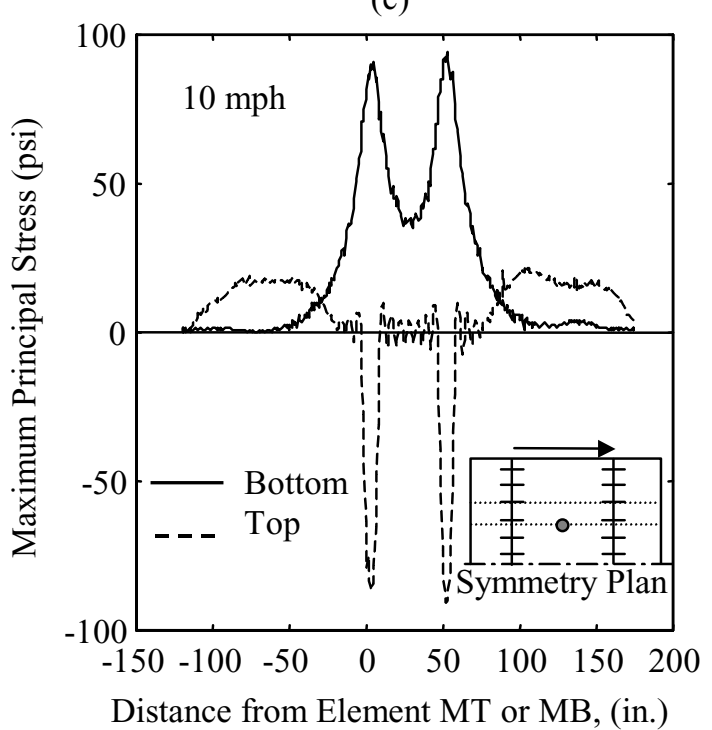

(f)

FIGURE 5.43 Effect of Traffic Speed on Distribution of MPS at the Middle of the Slab 

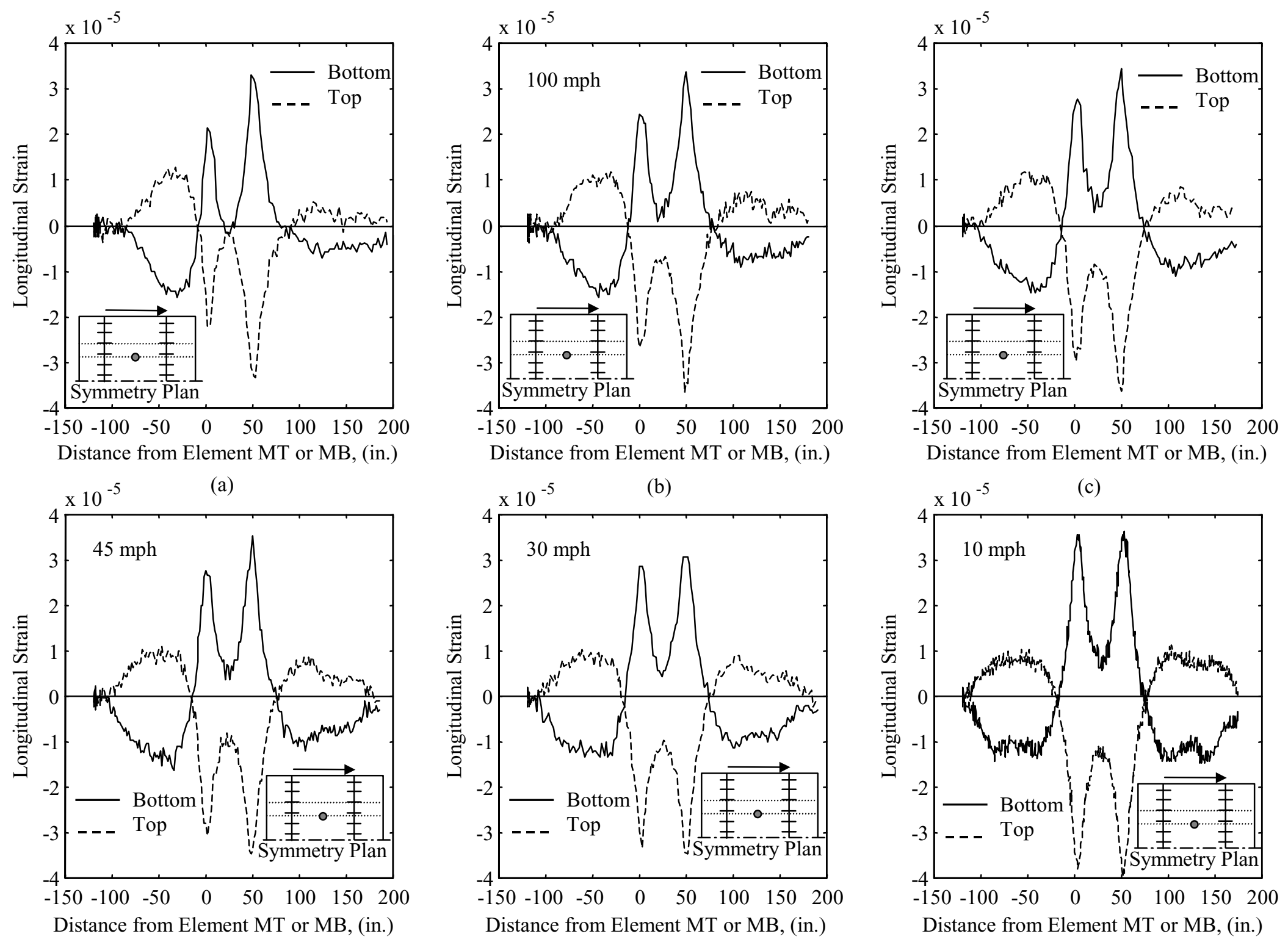

(d)

(e)

(f)

FIGURE 5.44 Effect of Traffic Speed on Distribution of Longitudinal Strain at the Middle of the Concrete Slab 

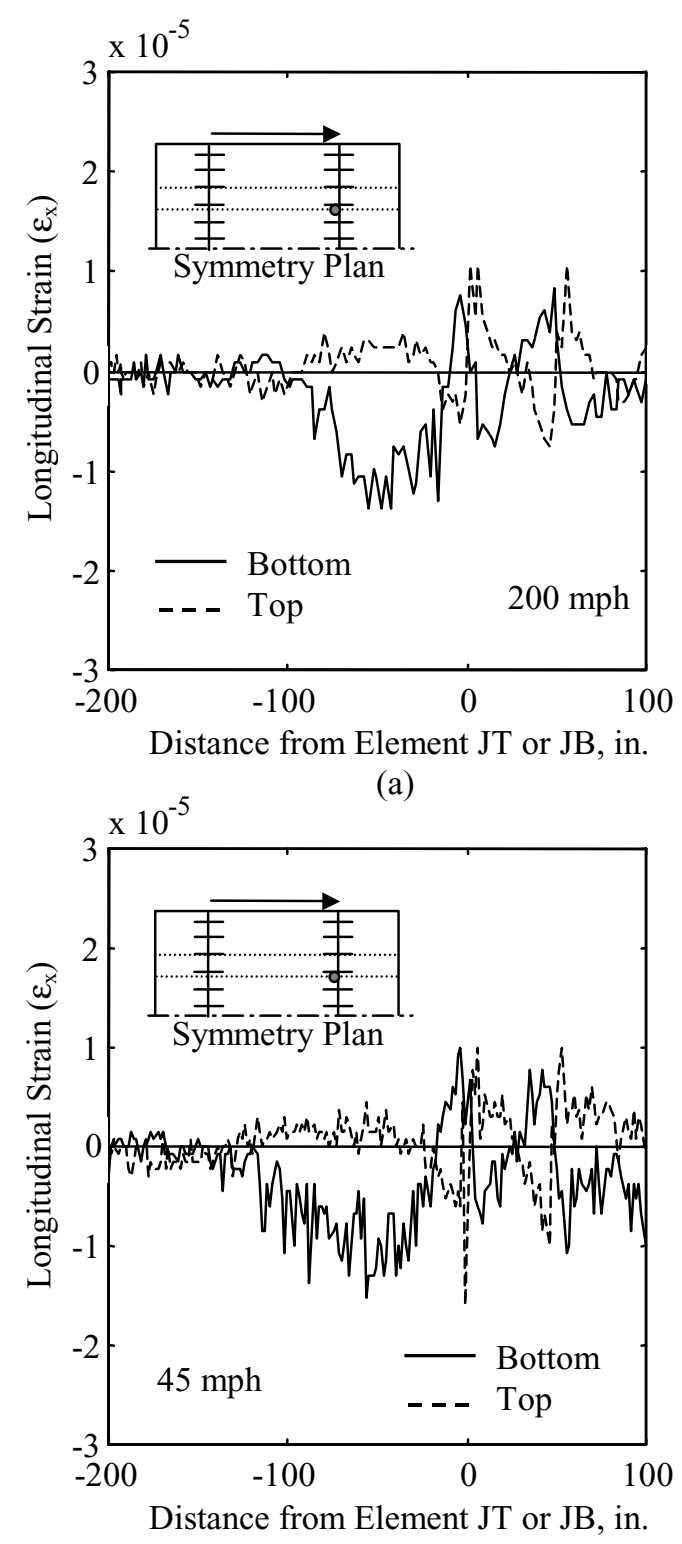

(d)
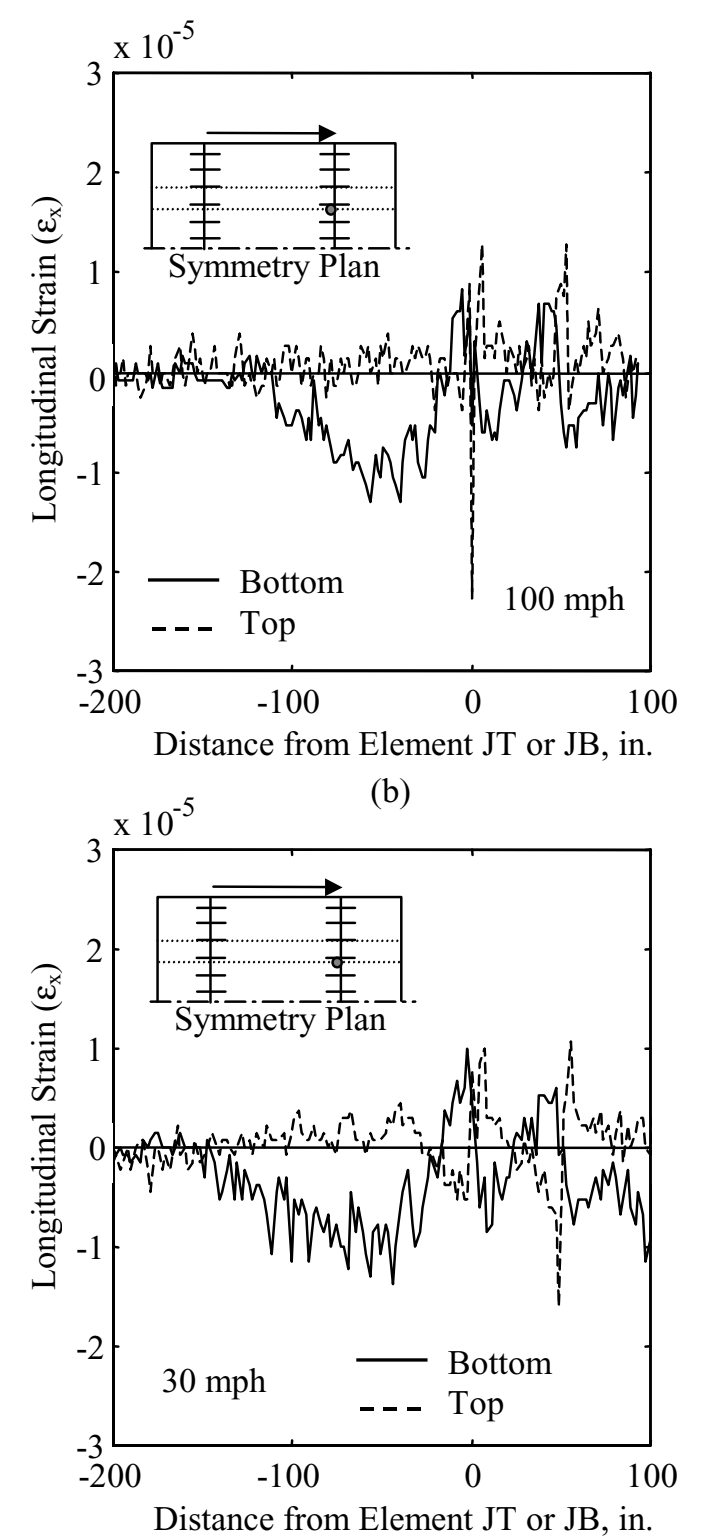

(e)

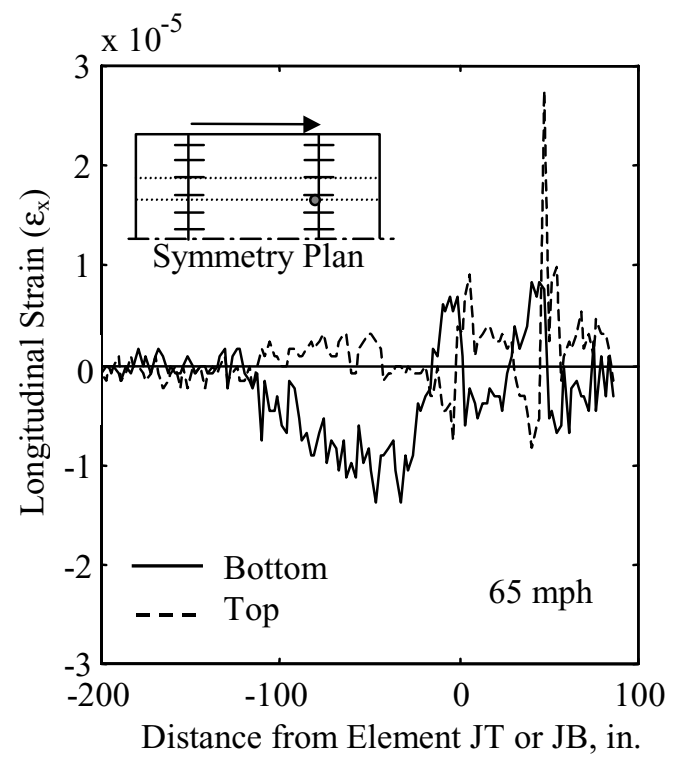

(c)

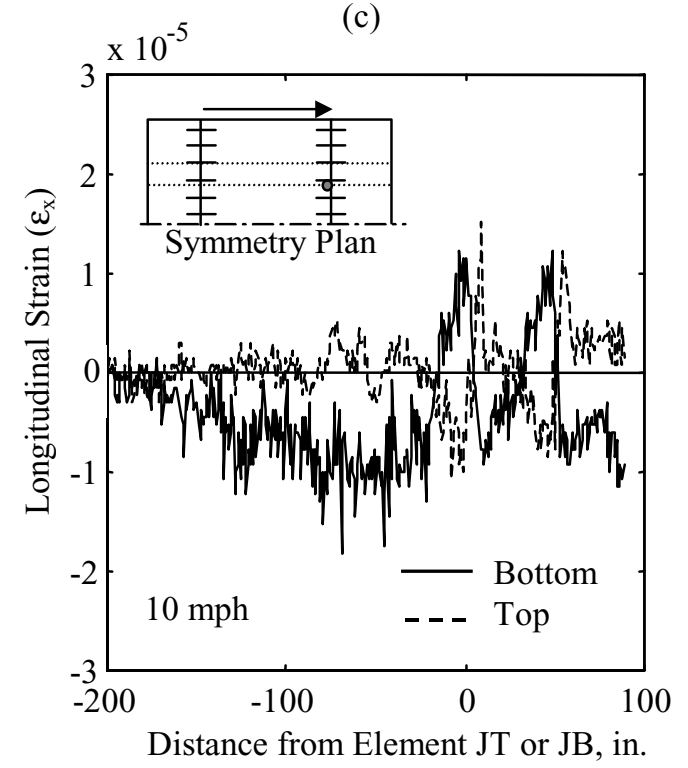

(f)

FIGURE 5.45 Effect of Traffic Speed on Distribution of $\varepsilon_{\mathrm{x}}$ in the Concrete Slab at the Transverse Joint 


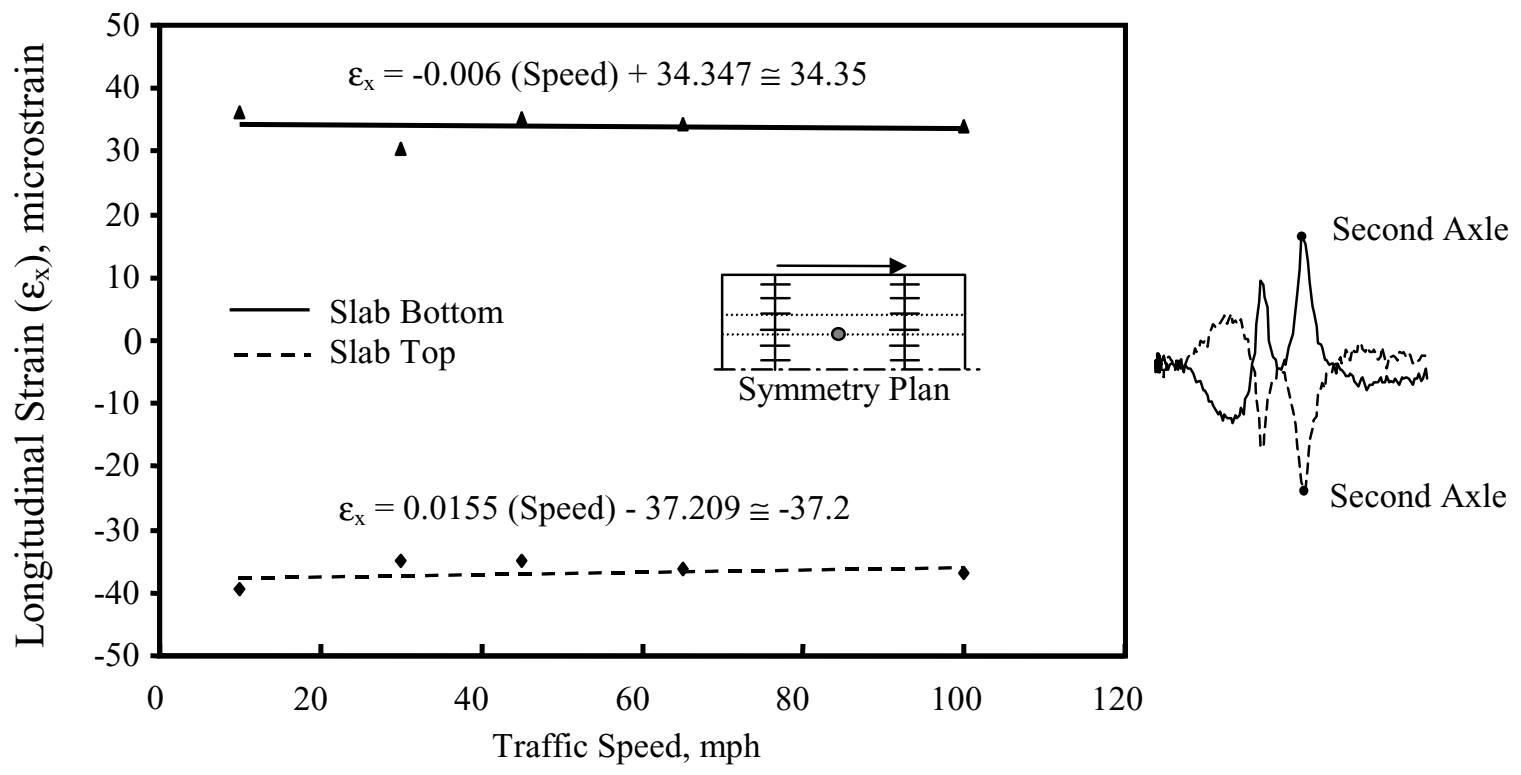

(a) Effect of Traffic Speed on Maximum Longitudinal Strain
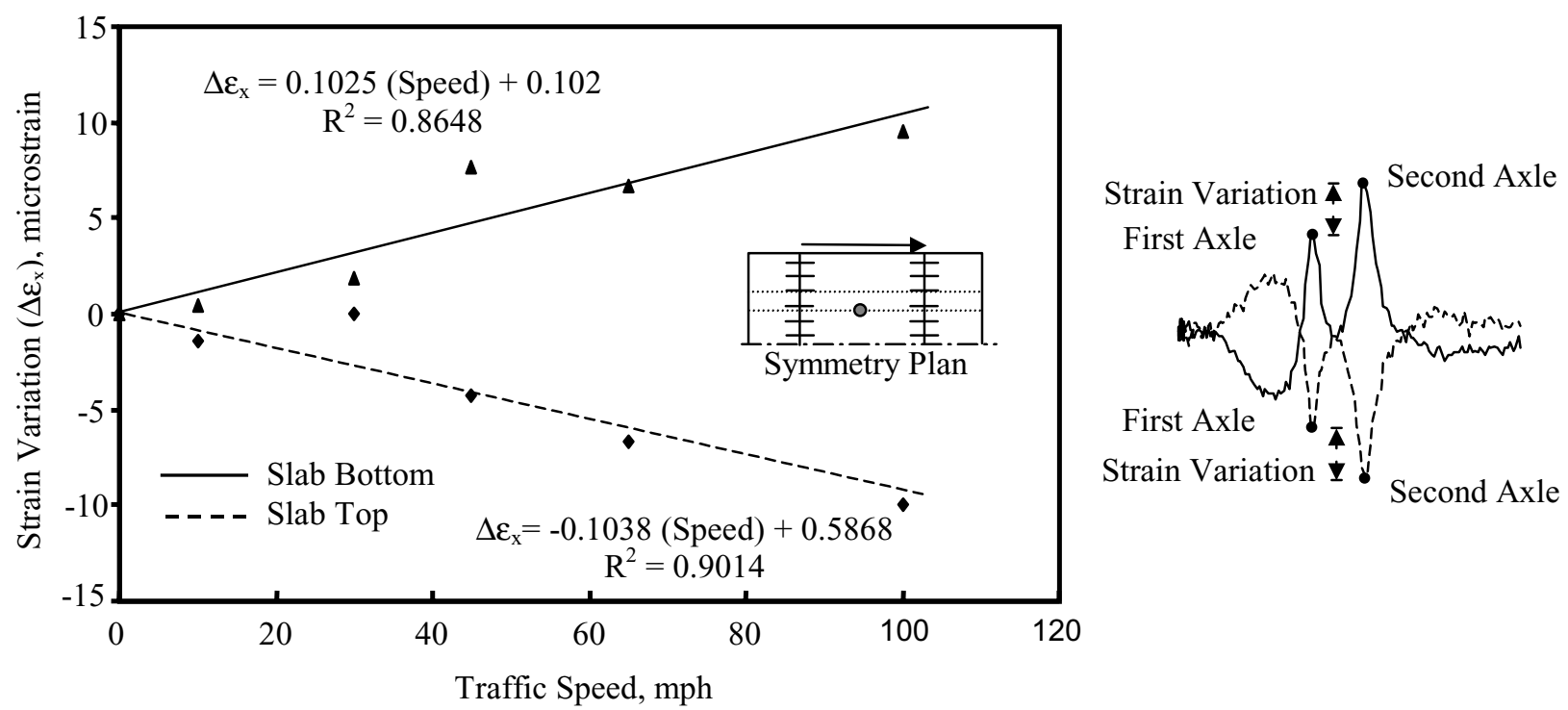

FIGURE 5.46 Effect of Traffic Speed on Maximum Traffic Induced Longitudinal Strains in the Slab 


\section{CHAPTER SIX}

\section{EFFECT OF NONLINEAR THERMAL GRADIENT ON JOINTED PLAIN CONCRETE PAVEMENT SUBJECTED TO MOVING AXLE LOADS}

\subsection{Introduction}

Temperature gradient through the slab thickness produces slab curling or slab warping, depending on whether the applied gradient is negative (slab top is cooler than its bottom) or positive (slab bottom is cooler than its top). In either case, the contact area between the slab and base will be governed by the slab own-weight, moduli of elasticity of the base and subgrade, and the efficiency of dowel bar support at the two transverse joints. A complex state of stresses exists at the transverse joints due to the $3 \mathrm{D}$ nature of slab deformation that have not been accounted for in previous studies that modeled dowel bars using 2D springs or beam elements. The 3D nature of the reactions developed at dowel bars necessitates their representation using 3D elements.

In this study, three types of loads which govern slab deformation are applied to the FEM: thermal load due to experimentally measured nonlinear thermal gradient, self weight load, and axle loads applied on moving tire-prints. All layers are represented using linear elastic material models. The coefficient of thermal expansion used in this study is $6 \mathrm{e}-06{ }^{\circ} \mathrm{F}$. The FE models used in this study are based on a previous FEM developed by Shoukry (Shoukry, 2000) for the study of rigid pavement response to FWD load. Model geometry is similar to the original model presented in Chapter Two except that the foundation layers (base and subgrade) width is widened

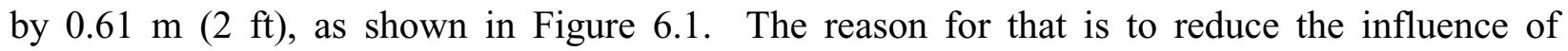
boundary conditions on the concrete slab response. In this study, first the thermal gradient is applied for a certain time on the model. The axle loads are then applied on the model to study the combined effect of thermal gradient and moving traffic loads. Figure 6.1 shows the FE mesh used in this study and the same mesh deformed due to positive or negative thermal gradients before the application of axle loads. 
The thermal gradient profiles applied through the slab thickness in this study are shown in Figure 6.2. Those cases include experimentally measured nonlinear thermal gradients obtained from (Richardson and Armaghani, 1988 and Thomas-Yu, 1998) that were digitized and fitted to polynomial expressions (Shoukry, 2000) that can be used in the FE program. The nonlinear gradients considered in this study are:

1) Negative thermal gradient of $-5^{\circ} \mathrm{C}\left(-9^{\circ} \mathrm{F}\right)$ (Richardson and Armaghani, 1988) measured at midnight given by: Tneg $9=0.0121 \mathrm{z}^{3}-0.237 \mathrm{z}^{2}-2.1394 \mathrm{z}-6.2323$

2) Negative thermal gradient of $-6.7^{\circ} \mathrm{C}\left(-12^{\circ} \mathrm{F}\right)$ (Thomas-Yu, 1998) measured at 5:30 am. given by: $\quad$ Tneg $12=0.0022(\mathrm{z})^{3}-0.029 \mathrm{z}^{2}-1.767 \mathrm{z}-7.155$

3) Negative thermal gradient of $-14.45^{\circ} \mathrm{C}\left(-26^{\circ} \mathrm{F}\right)$ given by:

Tneg26 $=-0.0107(\mathrm{z}+9)^{3}-0.3321(\mathrm{z}+9)^{2}-4.9903(\mathrm{z}+9)+16.9167$

${ }^{\circ} \mathrm{F}$

4) Positive thermal gradient of $+7.14^{\circ} \mathrm{C}\left(+13^{\circ} \mathrm{F}\right)$ (Thomas- $\left.Y u, 1998\right)$ measured at $10: 30$ am. given by: $\mathrm{Tpos} 13=-0.01(\mathrm{z})^{3}+0.1246 \mathrm{z}^{2}+3.3608 \mathrm{z}+11.662 \quad{ }^{\circ} \mathrm{F}$

5) Positive thermal gradient of $+10^{\circ} \mathrm{C}\left(+18^{\circ} \mathrm{F}\right)$ (Richardson and Armaghani, 1988) measured at $12 \mathrm{am}$. given by: Tpos $18=0.0214(\mathrm{z})^{3}+0.4806 \mathrm{z}^{2}-4.6443 \mathrm{z}+12.7058^{\circ} \mathrm{F}$

6) Positive thermal gradient of $+14.45^{\circ} \mathrm{C}\left(+26^{\circ} \mathrm{F}\right)$ (Richardson and Armaghani, 1988) measured at $4 \mathrm{pm}$. given by: $\operatorname{Tpos} 26=0.0107(\mathrm{z})^{3}+0.3321 \mathrm{z}^{2}-4.9903 \mathrm{z}+16.9167^{\circ} \mathrm{F}$

7) A reference case subjected to axle loads only without thermal gradient.

Where $\mathrm{z}$ is the depth of the point at which temperature change is recorded measured from the slab top. The axle loads are applied over tire contact patches that move at a speed of $105 \mathrm{~km} / \mathrm{hr}$ $(65 \mathrm{mph})$. The study performed in this chapter to investigate the effect of combined thermal gradient and axle load on pavement response follows the layout shown in Table 6.1. All the studies were performed using an axle load moving along the wheel-path (axle loads symmetrically load the slab) of the FEM shown in Figure 6.1. To study the cases of edge loading a full model simulating a full traffic lane width of $3.66 \mathrm{~m}(12 \mathrm{ft}$.) without symmetry plan is used and is shown in Figure 5.33 (a). 


\subsection{Method of Presenting the Results in this Chapter}

The response of the pavement model to combined thermal and axle loads is examined for a set of elements, along line A-A in Figure 6.3, located along the inner wheel-path on the top and bottom of the slab from the transverse joint to the middle of the slab. Five loading cases are studied as shown in Figure 6.3 these are:

1) The pavement is subjected to thermal gradient only before the application of the axle load.

2) The rear axle of each axle assembly loads the transverse joint.

3) The front axle of each assembly is located along the transverse centerline of the middle slab.

4) The axles symmetrically load the middle slab with respect to its transverse centerline.

5) The front axle of the tandem assembly loads the second transverse joint. This case is not studied for tridem axle.

The value of a certain variable, e.g. longitudinal stress along the traffic direction, $\Phi_{\mathrm{x}}$, corresponding to each loading case shown in Figure 6.3, is then gathered for all the elements located along line A-A and plotted versus the distance of the element from the transverse joint.

Table 6.1 Cases of Study Performed Under Combined Nonlinear Thermal Gradient and Moving Axle Load

\begin{tabular}{|c|c|c|c|c|c|c|c|c|c|c|}
\hline \multirow{2}{*}{$\begin{array}{c}\text { Slab } \\
\text { Length }\end{array}$} & \multirow{2}{*}{$\begin{array}{c}\text { Slab } \\
\text { Thickness }\end{array}$} & \multirow{2}{*}{$\begin{array}{c}\text { Axle } \\
\text { Configuration }\end{array}$} & \multirow{2}{*}{$\begin{array}{l}\text { Loading } \\
\text { Position }\end{array}$} & \multicolumn{7}{|c|}{ Nonlinear Thermal Gradient $\left({ }^{0} \mathbf{F}\right)$} \\
\hline & & & & -9 & -12 & -26 & $\mathbf{0}$ & +13 & +18 & +26 \\
\hline $15 \mathrm{ft}$. & 9 in. & Tandem & Wheel-Path & $\mathrm{x}$ & $\mathrm{x}$ & $\mathrm{x}$ & $\mathrm{x}$ & $\mathrm{x}$ & $\mathrm{x}$ & $\mathrm{x}$ \\
\hline $15 \mathrm{ft}$. & 9 in. & Tridem & Wheel-Path & & $\mathrm{x}$ & & $\mathrm{x}$ & & & $\mathrm{x}$ \\
\hline $15 \mathrm{ft}$. & 9 in. & Tandem & Edge & & $\mathrm{x}$ & & $\mathrm{x}$ & & & $\mathrm{x}$ \\
\hline $15 \mathrm{ft}$. & $11 \mathrm{in.}$ & Tridem & Wheel-Path & & $\mathrm{x}$ & & * & & & $\mathrm{x}$ \\
\hline $20 \mathrm{ft}$. & $11 \mathrm{in.}$ & Tridem & Wheel-Path & & $\mathrm{x}$ & & $*$ & & & $\mathrm{x}$ \\
\hline $20 \mathrm{ft}$. & 9 in. & Tandem & Wheel-Path & & $\mathrm{x}$ & & $\mathrm{x}$ & & & $\mathrm{x}$ \\
\hline
\end{tabular}

\footnotetext{
* These two models were developed for a $254 \mathrm{~mm}$ (10 in.) thick slab.
} 


\subsection{Pavement Response Due to Combined Thermal Gradient and Moving Load}

As was previously described by Shoukry (2000), nonlinear negative thermal gradient of $6.7^{\circ} \mathrm{C}$ $\left(12^{\circ} \mathrm{F}\right)$ produced slab curling as illustrated in Figure 6.1. As the slab curls, its corners separate from the base, which leads to a reduction in the area of contact between the slab and base. Figure 6.4 illustrates the fringe distribution of vertical displacement for different tandem axle positions along the slab. The thermal deformation of the slab before the application of the axle loads is shown in Figure 6.4 (a). The blue fringes observed at the center of the slab indicate the downward displacement of the slab, whereas the red fringes indicate the upward displacement with a maximum occurring along the corners of the slab where the slab separates from the base. Figure 6.4 (b, c, and d) shows the displacement patterns as the load starts moving. It can be observed that the maximum downward displacement is below the loaded area but slab/base separations are still observed at the corners. During the thermal deformation due to $10^{\circ} \mathrm{C}\left(18^{\circ} \mathrm{F}\right)$ positive thermal gradient, the center of the slab is lifted against its own weight, as shown in Figure 6.1. The slab loses all the contact with the base course and becomes supported only at its four corners. The contact area with the base in this case depends on the magnitude of base deformation and dowel bar and tie bar supports at both transverse and longitudinal joints respectively. Figure 6.6 illustrates the fringe distribution of vertical displacement for different tandem axle positions along the slab. The thermal deformation of the slab before the application of the axle loads is shown in Figure 6.6 (a). The upward displacement reaches its peak at the center, whereas the downward displacement is maximum at slab corners where the slab is supported on the base. As the tandem axle loads the joint, the upward displacement at the slab center decreases and the supporting area at the unloaded joint is reduced which appears in the form of reduction in the dark colors at the corners of that joint, Figure 6.6 (b). During mid-slab loading, the slab/base contact area is significantly increased and the upward displacement of the slab center is reduced, Figure 6.6 (c). As the tandem axle loads the second joint, the slab center starts to deform upward again, Figure $6.6(d)$.

The vertical displacement profiles at slab bottom are investigated under three negative thermal gradients of $5,6.7$, and $14.45^{\circ} \mathrm{C}\left(9,12\right.$, and $\left.26^{\circ} \mathrm{F}\right)$ and three positive gradients of 7.14 , 10, and $14.45^{\circ} \mathrm{C}\left(13,18\right.$, and $\left.26^{\circ} \mathrm{F}\right)$, as shown in Figures 6.6 and 6.7 , respectively. The vertical 
displacement values corresponding to loading cases 1, 2, and 4 shown in Figure 6.3 are gathered for all the elements located along the slab edge and the inner wheel-path. These displacement profiles are plotted versus the distance of the element from the first transverse joint in Figures 6.6 and 6.7. The results shown in Figures 6.6 and 6.7 show the significant change in the curvature of the slab with the change in the thermal gradient from positive to negative. The slab curvature is also affected by the position of the load along the slab. In all cases, the curvature change from upward to downward or the opposite is the most dangerous since it subjects the concrete slab to fatigue cycles each time a truck loads the slab.

Table 6.2 shows a comparison between the differential displacement $(\Delta)$ between the highest and the lowest point in the slab due to the two thermal gradients of +14.45 and $-14.45^{\circ} \mathrm{C}(+26$ and $26^{\circ} \mathrm{F}$ ) shown in Figures 6.6 and 6.7. These two gradients are selected since they produce the highest $\Delta$ in the slab. As shown in Figures 6.6 and 6.7, letter A indicates the lowest point in the slab, while letter B indicates the highest point.

TABLE 6.2 Effect of Thermal Gradient on Differential Displacement in the Slab

\begin{tabular}{|c|c|c|c|c|}
\hline \multirow{2}{*}{$\begin{array}{c}\text { Loading } \\
\text { Condition }\end{array}$} & \multicolumn{2}{|c|}{$\left.+\mathbf{1 4 . 4 5}^{\mathbf{0}} \mathbf{C} \mathbf{( + 2 6}^{\mathbf{0}} \mathbf{F}\right)$} & \multicolumn{2}{c|}{$\left.\mathbf{1 4 . 4 5}^{\mathbf{0}} \mathbf{C ~ ( - 2 6} \mathbf{~}^{\mathbf{F}}\right)$} \\
\cline { 2 - 5 } & Slab Edge & Wheel-Path & Slab Edge & Wheel-Path \\
\hline Case 1 & 0.02069 & 0.03014 & 0.04154 & 0.03896 \\
\hline Case 2 & 0.02854 & 0.04563 & 0.04795 & 0.04247 \\
\hline Case 4 & 0.00925 & 0.01542 & 0.05366 & 0.05235 \\
\hline
\end{tabular}

The results shown in Table 6.2 indicate that under positive gradient, the maximum $\Delta$ occurs under joint loading along the wheel-path. However, under negative gradient, the maximum $\Delta$ is observed under mid-slab loading along the slab edge. In general, $\Delta$ due to negative gradient under any loading condition is always higher than that due to positive gradient under the same loading condition except for the case of joint loading along the wheel-path. These results indicate that the negative gradient (night-time curling of the slab) is the most dangerous to the slab especially that most of the heavy traffic on highways is at night. In a similar study, Channakeshava and Barzegar (1993) indicated that the night-time curling may lead to the loss of support at the joints which leads to slabs faulting at the transverse joints (1993). He also 
reported that night-time curling widens the joint, hence allowing entry of water at the joint, which may also lead to loss of support due to pumping.

The overall displacement profile along the model length is illustrated in Figure 6.8 for the two thermal gradients of -14.45 and $+14.45^{\circ} \mathrm{C}\left(-26\right.$ and $\left.+26^{\circ} \mathrm{F}\right)$. Two vertical centerlines are plotted in each figure showing the locations of the two transverse joints. The figure also shows the vertical displacement along the slab edge. These distributions are plotted versus the distance of the element from the FEM side boundaries. The results shown in Figure 6.8 indicate that the load is perfectly transferred at the two joints. The results also show the change in the displacement profile of the mid slab with the change in loading case. It is also observed that the displacement along the slab edge is always different from that along the wheel-path. This difference is reduced under positive gradient as the axle load is introduced, as shown in Figure 6.8 (c, e, and g), while under negative gradient this difference is always constant and is not affected by the introduction of the axle load. This observation shows that the passage of the axle load reduces the vertical displacement change in the transverse direction, which means that the curvature of the slab in the transverse direction under positive gradient will be smaller than under negative gradient. The smaller slab curvature means a higher area of contact with the base course and therefore lower possibilities for the loss of support.

\subsection{Parametric Study}

\subsubsection{Effect of Varying the Thermal Gradient}

\subsubsection{Stress and strain histories in the concrete slab}

The response of a $4.6 \mathrm{~m}$ (15 ft.) long concrete slab is studied under the effect of combined moving tandem axle load and the six nonlinear thermal gradients described in section 6.1 in addition to the reference case with axle loads only without thermal gradient. To find the locations of the maximum stresses and strains along the wheel-path, the MPS, $\sigma_{\mathrm{x}}, \sigma_{\mathrm{y}}, \varepsilon_{\mathrm{x}}$, and $\varepsilon_{\mathrm{y}}$ histories for the seven gradients are plotted versus the location from the element of study. The elements studied are located at 0.69, 1.5, 2.3, and $4.3 \mathrm{~m}(27,60,90$, and 170 in.) from the first 
joint. The element at $4.3 \mathrm{~m}$ (170 in.) is located at $0.25 \mathrm{~m}$ (10 in.) from the second transverse joint edge. The results are shown in Figures 6.9 to 6.18. The comparison between the four elements of study shows the following:

1) For the specific cases of loading used in this study, the maximum tensile MPS, $\sigma_{x}$, and $\sigma_{\mathrm{y}}$ are caused by the combined positive gradient and axle load. These are located at the bottom of the middle of the slab, as shown in Figures 6.10 (c), 6.12 (c) and 6.14 (c), respectively. On the other hand, the magnitudes of $\varepsilon_{\mathrm{x}}$ change from tensile to compressive strain as the load moves from the middle of the slab to the joint with the peak $\varepsilon_{\mathrm{x}}$ observed at the joint, as shown in Figures 6.15 and 6.16. These results agree with Masad, et al., 1996 results where the maximum $\varepsilon_{\mathrm{x}}$ occurred at the slab edge while the minimum occurred at the slab center. The results also show that for each gradient, the magnitude of $\varepsilon_{\mathrm{y}}$ at the four elements is approximately constant, as shown in Figures 6.17 and 6.18.

2) Increasing the absolute value of the thermal gradient increases the stresses and the strains induced at both slab top and bottom.

3) Examination of the $\sigma_{x}$ induced at the middle of the slab shows that under combined positive gradient and axle load the slab bottom is subjected to pure tensile stress, as shown in Figure 6.12 (c). However, under combined negative gradient and axle load, the slab bottom is subjected to compressive stresses, as illustrated in Figures 6.12 (g). The opposite is true for slab top. This illustrates that the stress induced in a thermally deformed slab subjected to axle loads can be reversed between day and night. The higher the difference between day-time and night-time thermal gradients, the higher the stress reversal. It is also observed that the intensity of this reversal is increased each time a truck loads the slab.

\subsubsection{Thermal stresses induced in the concrete slab}

The effect of changing the thermal gradient on the thermal stresses induced in the slab is studied along two cross sections A-A and B-B, as shown in Figure 6.19. The values of $\Phi_{\mathrm{x}}$ and $\Phi_{\mathrm{y}}$ corresponding to loading case 1 previously shown in Figure 6.3 are gathered for all the elements located at slab top and bottom along sections A-A and B-B, respectively. The $\Phi_{\mathrm{x}}$ and $\Phi_{\mathrm{y}}$ 
distributions are then plotted versus either the longitudinal distance along line A-A or the transverse distance along line B-B elements from the slab edge respectively, as shown in Figure 6.19, which shows that:

1) In general, the stress induced in the longitudinal direction, i.e. $\Phi_{\mathrm{x}}$, is always higher than that induced in the transverse direction, i.e. $\Phi_{\mathrm{y}}$. Except for slab top when subjected to negative gradient. In this case, $\Phi_{\mathrm{x}}$ and $\Phi_{\mathrm{y}}$ have approximately the same magnitude, as shown in Figure 6.19 (b and d). This observation shows that $\Phi_{\mathrm{x}}$ is the governing stress whether the pavement is subjected to positive or negative gradients.

2) The stress induced under positive thermal gradient is tensile at slab bottom and compressive on its top for both $\Phi_{\mathrm{x}}$ and $\Phi_{\mathrm{y}}$, as shown in Figure 6.19 (a and c). The opposite is true for negative thermal gradient, as shown in Figure 6.19 (b and d).

3) The stress profiles at slab top under negative gradient intersect each other, as shown in Figure 6.19 ( $\mathrm{b}$ and $\mathrm{d})$. This is due to the difference in curvature of the $14.45^{\circ} \mathrm{C}\left(26^{\circ} \mathrm{F}\right)$ from that of the two other negative gradients, as shown in Figure 6.3. The same observation is valid for the case of $6.7^{\circ} \mathrm{C}\left(12^{\circ} \mathrm{F}\right)$ but with a lower extent since the change in gradient profile curvature between the $6.7^{\circ} \mathrm{C}\left(12^{\circ} \mathrm{F}\right)$ and the $5^{\circ} \mathrm{C}\left(9^{\circ} \mathrm{F}\right)$ is less than that of the $14.45^{\circ} \mathrm{C}\left(26^{\circ} \mathrm{F}\right)$. This effect can still be observed at slab bottom but is not as clear as it is at slab top due to the higher stress magnitude at the bottom. It can be concluded that the curvature of the nonlinear thermal gradient profile affects the resulting thermal stress profiles.

\subsubsection{Comparison between combined, thermal, and axle stresses}

Table 6.3 shows the comparison performed between the stress due to combined thermal and axle loads, the thermal stress, and the stress due to the axle load only without thermal gradient (the reference case in this study and as indicated by shaded cells in Table 6.3). In this comparison, the MPS, $\sigma_{\mathrm{x}}$, and $\sigma_{\mathrm{y}}$ histories induced at the element located at mid-slab under the positive and negative gradients shown in Figure 6.10 (a, c, e, and g), 6.12 (a, c, e, and g) and 6.14 (a, c, e, and g) are used to obtain:

1) The thermal stress due to the thermal load only before the application of the axle loads (the starting point of all the stress profiles in Figures 6.10, 6.12, and 6.14). 
2) The maximum stress due to combined thermal and axle loads obtained from Figures $6.10,6.12$, and 6.14 .

The comparison presented in Table 6.3 shows that the maximum stresses due to combined thermal and axle loads are higher than those due to thermal gradient only. For positive thermal gradients, the stress due to axle load (the difference between maximum combined stress and thermal stress) is higher than the axle stress obtained from the reference model subjected to axle load only $\left(0^{\circ} \mathrm{F}\right)$. The opposite is true for negative thermal gradients. This shows that the thermal stresses should be considered during the design, particularly when the pavement is subjected to positive gradient. In this case, the actual stresses developed in the pavement will be higher than the design stresses based on axle loads only without thermal gradient. Therefore, a correction factor should be applied to take into consideration the effect of thermal gradient. Table 6.3

shows the correction factor that should be multiplied by the stress induced under axle load only without thermal gradient (the reference case in this study) to take into account the effect of nonlinear thermal gradient. As an example, the correction factor for the MPS induced under the $+14.45^{\circ} \mathrm{C}\left(+26^{\circ} \mathrm{F}\right)$ is calculated as follow: $1+[(207.43-95.4) / 95.4]=2.174$. It can be observed that this factor is always higher than one under positive gradient and less than one for the negative gradients. The calculated correction factors together with the stresses presented in Table 6.3 are plotted in Figure 6.20. This figure can be used to interpolate the magnitudes of the stress and the correction factor for any thermal gradient that falls between -14.45 and $+14.45^{\circ} \mathrm{C}(-26$ and $+26^{\circ} \mathrm{F}$ ). Examination of the tensile stresses at slab bottom due to combined positive gradient and axle loads shows that the MPS at slab bottom is always governed by $\sigma_{x}$, which is generally larger than $\sigma_{\mathrm{y}}$. In this case, $\sigma_{\mathrm{y}}$ is in the range of 80 percent of MPS.

\subsubsection{Effect of Axle Configuration}

The effect of changing the axle load and configuration from tandem to tridem is investigated for two thermal gradients of $-6.7^{\circ} \mathrm{C}$ and $+14.45^{\circ} \mathrm{C}\left(-12^{\circ} \mathrm{F}\right.$ and $\left.+26^{\circ} \mathrm{F}\right)$ in addition to the reference case of $0^{\circ} \mathrm{F}$. The results are shown in Figures 6.21 to 6.23. The tandem and tridem axle configurations and wheel loads were previously shown in Figures 2.5 and 5.24, respectively. 
TABLE 6.3 Effect of Varying the Thermal Gradient on Thermal and Maximum Combined Stresses in the Slab

\begin{tabular}{|c|c|c|c|c|c|c|c|}
\hline \multirow{2}{*}{ Variable } & \multicolumn{7}{|c|}{ Thermal Gradient $\left({ }^{0} \mathbf{F}\right)$} \\
\hline & +13 & +18 & +26 & $\mathbf{0}$ & -9 & -12 & -26 \\
\hline \multicolumn{8}{|c|}{ Maximum Principal Stress (psi) } \\
\hline ThS (Slab Bottom) & 24.13 & 52.6 & 77.28 & 0 & 0.83 & 0.065 & 1.09 \\
\hline MCS (Slab Bottom) & 131.63 & 166.33 & 207.43 & 95.4 & 64.14 & 43.36 & 3.45 \\
\hline Correction Factor & 1.38 & 1.744 & 2.174 & & 0.672 & 0.4545 & 0.036 \\
\hline ThS (Slab Top) & -0.053 & -0.198 & -0.021 & 0 & 48.08 & 54.94 & 59.77 \\
\hline MCS (Slab Top) & -106.99 & -113.42 & -121.65 & -90.31 & 76.64 & 88.37 & 113.14 \\
\hline Correction Factor & 1.1847 & 1.256 & 1.347 & & -0.849 & -0.9785 & -1.2528 \\
\hline \multicolumn{8}{|c|}{ Longitudinal Stress (psi) } \\
\hline ThS (Slab Bottom) & 24.13 & 52.60 & 77.28 & 0 & -35.48 & -54.19 & -118.48 \\
\hline MCS (Slab Bottom) & 128.92 & 165.34 & 205.32 & 93.06 & -68.41 & -91.89 & -175.31 \\
\hline Correction Factor & 1.385 & 1.777 & 2.206 & & -0.735 & -0.987 & -1.884 \\
\hline ThS (Slab Top) & -93.45 & -97.98 & -126.04 & 0 & 48.06 & 54.9 & 59.72 \\
\hline MCS (Slab Top) & -218.83 & -231.04 & -278.07 & -115.42 & 76.61 & 88.09 & 112.36 \\
\hline Correction Factor & 1.896 & 2.002 & 2.409 & & -0.664 & -0.7632 & -0.973 \\
\hline \multicolumn{8}{|c|}{ Transverse Stress (psi) } \\
\hline ThS (Slab Bottom) & 20.41 & 36.01 & 45.94 & 0 & -13.497 & -30.51 & -72.02 \\
\hline MCS (Slab Bottom) & 105.69 & 137.47 & 164.72 & 71.87 & -14.17 & -35.11 & -89.59 \\
\hline Correction Factor & 1.471 & 1.913 & 2.29 & & -0.197 & -0.489 & -1.247 \\
\hline ThS (Slab Top) & -66.93 & -68.24 & -78.62 & 0 & 32.627 & 39.71 & 34.95 \\
\hline MCS (Slab Top) & -178.95 & -190.47 & -219.45 & -96.21 & -63.799 & -51.99 & -36.6 \\
\hline Correction Factor & 1.86 & 1.9797 & 2.281 & & 0.663 & 0.54 & 0.38 \\
\hline
\end{tabular}

ThS $=$ Thermal Stress prior to the application of the axle load.

MCS = Maximum Combined Stress due to combined thermal gradient and axle load.

The axles are moved on the original model at a speed of $105 \mathrm{~km} / \mathrm{hr}(65 \mathrm{mph})$. The values of MPS, $\Phi_{\mathrm{x}}$, and $\Phi_{\mathrm{y}}$ corresponding to the loading cases shown in Figure 6.3 are gathered for all the elements located along line A-A and plotted versus the distance of the element from the transverse joint. The results shown in Figures 6.21 to 6.23 indicate that: 
1) The critical loading condition under the effect of axle loads (without thermal gradients) is case 3 as shown in Figures 6.21 (b), 6.22 (b), and 6.23 (b). In this case, increasing the number of axles from tandem to tridem reduced the peak $\Phi_{\mathrm{x}}$ by 33 and 50 percent at slab top and bottom respectively, while it reduced MPS at slab bottom by 32 percent. For loading case 2 , the tridem axle produces higher MPS and $\sigma_{\mathrm{y}}$ especially at slab bottom, Figures 6.21 (a) and 6.23 (a). The two axles result in the same response under case 4, Figures 6.21 (c), 6.22 (c), and 6.23 (c).

2) Under combined positive gradient and axle load, the stress change due to increasing the number of axles from tandem to tridem is small, as shown in Figures 6.21 (d, e, f), 6.22 $(\mathrm{d}, \mathrm{e}, \mathrm{f})$, and 6.23 (d, e, f).

3) Under combined negative gradient and axle load, the critical loading condition is case 2. In this case, the tridem axle reduced the maximum tensile MPS and $\Phi_{\mathrm{x}}$ at slab top by 42.6 and 43.1 percent respectively, as shown in Figure $6.21(\mathrm{~g})$ and $6.22(\mathrm{~g})$.

For the cases of a single tandem axle or a single tridem axle studied in this section, it is concluded that the tridem axle reduces the high tensile stresses observed at mid-slab top during joint loading in case of negative gradient. However under positive gradient changing the axle configuration from tandem to tridem has a small effect on the maximum tensile stresses induced in the slab.

\subsubsection{Effect of Loading Position}

The effect of thermal gradients of $-6.7^{\circ} \mathrm{C}$ and $+14.45^{\circ} \mathrm{C}\left(-12^{\circ} \mathrm{F}\right.$ and $\left.+26^{\circ} \mathrm{F}\right)$ as well as the reference case of $0^{\circ} \mathrm{F}$ is examined for tandem axle cases: a) wheel-path loading, and b) edge loading. The values of MPS, $\Phi_{\mathrm{x}}$, and $\Phi_{\mathrm{y}}$ corresponding to each loading case, shown in Figure 6.3, are gathered for all the elements located along line A-A and plotted versus the distance of the element from the transverse joint as shown in Figures 6.24 to 6.26. The results indicate that:

1) Generally, the edge loading condition produce higher stresses.

2) The stress induced by the axle load increases when combined with positive gradient but is reduced when combined with negative gradient. Combining the edge load with a positive thermal gradient approximately doubled the MPS and $\Phi_{\mathrm{x}}$ induced due to traffic load only. 
3) In all cases, loading case 3 is the critical, as shown in Figures 6.24 (b, e, and h), 6.25 (b, $\mathrm{e}$, and $\mathrm{h}$ ), and 6.26 (b, e, and h). On the other hand, the high tensile stress observed at mid-slab top due to combined joint loading (case 2) and negative gradient, and which is shown in Figures $6.24(\mathrm{~g})$ and $6.25(\mathrm{~g})$, may lead to top down crack especially under edge load. Similar results were obtained by Channakeshava and Barzegar (1993), who indicated that corner loading leads to structural corner cracks, which may appear at normal service loads under severe loss of support conditions at the joint which may initiate from night-time curling of the slabs.

4) When compared to positive gradient, the percentage of increase of the maximum tensile $\Phi_{\mathrm{x}}$ due to edge loading over that due to wheel-path loading is higher under negative thermal gradient. This percentage is 86 and 37 percent for negative and positive gradient respectively, as shown in Figure 6.25 (e and h). In absence of thermal gradient, this percentage is 54 percent, as shown in Figure 6.25 (b). The high percentage of increase in the tensile $\Phi_{\mathrm{x}}$ due to combined negative gradient and edge load associated with the high truck intensity on highways during night-time may lead to transverse cracks.

5) The magnitude of $\Phi_{y}$ due to wheel-path loading is significantly higher than that due to edge loading, as shown in Figure 6.26. For the three gradients, the magnitude of $\Phi_{\mathrm{y}}$ induced under edge loading is very small, which shows that the MPS in this case is governed by $\Phi_{\mathrm{x}}$.

In conclusion, the results indicate that the application of edge load at mid span of the slab produces the largest MPS and $\Phi_{\mathrm{x}}$ at slab bottom.

\subsubsection{Effect of Slab Length}

The effect of changing the concrete slab length from 4.6 to $6.1 \mathrm{~m}$ (15 to $20 \mathrm{ft}$.) is investigated under the tandem axle load combined with two thermal gradients of $-6.7^{\circ} \mathrm{C}$ and $+14.45^{\circ} \mathrm{C}\left(-12^{\circ} \mathrm{F}\right.$ and $+26^{\circ} \mathrm{F}$ ) in addition to the reference case. The slab thickness studied in this case is $229 \mathrm{~mm}(9$ in.). The values of MPS, $\Phi_{\mathrm{x}}$, and $\Phi_{\mathrm{y}}$ corresponding to the loading cases shown in Figure 6.3 are gathered for the elements line A-A and plotted versus the distance of each element from the transverse joint as shown in Figures 6.27, 6.28, and 6.29. The results indicate that: 
1) Generally, the stress developed in the $6.1 \mathrm{~m}(20 \mathrm{ft}$.) slab is higher than that induced under the $4.6 \mathrm{~m}$ (15 ft.) slab. The stress increase of the longer slab is the highest when the axle load is combined with thermal gradient, especially the positive gradient. Similar results were obtained by Masad, et al., 1996 who indicated that positive curling stresses increase with an increase in slab length.

2) When the slab is studied under axle load only, similar stresses are obtained for the two slab lengths with an average change of 3.2 percent, Figure $12(a, b)$.

3) When subjected to positive gradient only (case 1), the $6.1 \mathrm{~m} \mathrm{(20} \mathrm{ft.)} \mathrm{slab} \mathrm{results} \mathrm{in} \mathrm{a} 44$ percent increase in the tensile MPS and $\Phi_{\mathrm{x}}$ induced at slab bottom compared to the $4.6 \mathrm{~m}$ (15 ft.) slab, as shown in Figures 6.27 (d) and 6.28 (d). On the other hand, the percentage

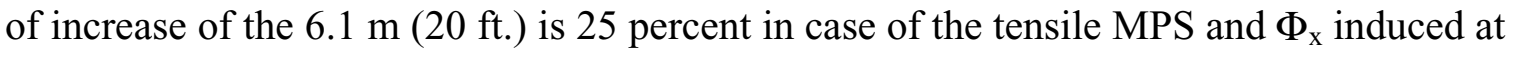
slab top when the slabs are subjected to negative gradient only, as shown in Figures 6.27 $(\mathrm{g})$ and $6.28(\mathrm{~g})$. The change in slab length has a negligible effect on $\Phi_{\mathrm{y}}$ due to thermal gradient only, as shown in Figures 6.29 (d) and $6.29(\mathrm{~g})$. These results show that the change in slab length only affects MPS and $\Phi_{x}$ and has a small effect on $\Phi_{y}$, which is an indication of the higher possibilities of crack initiation in the transverse direction due to the higher $\Phi_{\mathrm{x}}$. This observation agrees with an analysis of the Long-Term Pavement Performance (LTPP) sections and which showed that transverse cracks are always observed in slabs longer than $5.5 \mathrm{~m}$ (18 ft.) (Owusu-Antwi, et al., 1990).

4) The critical loading case for the combined positive gradient and axle load is case 4 . The percentages of increase in the maximum tensile MPS, $\Phi_{\mathrm{x}}$, and $\Phi_{\mathrm{y}}$ induced in the $6.1 \mathrm{~m}$ (20 ft.) slab compared to the $4.6 \mathrm{~m}$ (15 ft.) are 11, 11.1, and 0 percent respectively, as shown in Figures 6.27 (f), 6.28 (f), and 6.29 (f), respectively. These results show that combining the thermal gradient with axle loads still affects MPS and $\Phi_{\mathrm{x}}$ only.

5) For combined negative gradient and axle load, the critical loading case is case 2 (joint

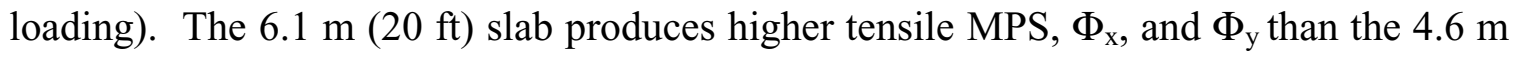
(15 ft.) slab with percentages of increase of $11.3,11.5$, and 17.3 percent, as shown in Figures $6.27(\mathrm{~h}), 6.28(\mathrm{~h})$, and $6.29(\mathrm{~h})$, respectively.

Although the stresses due to combined thermal and axle loads are higher than those due to thermal gradient only, it is observed that the percentages of stress increase of the $6.1 \mathrm{~m}(20 \mathrm{ft}$.) 
slab compared to the $4.6 \mathrm{~m}(15 \mathrm{ft}$.) are higher under the thermal gradient only which shows that longer slabs are greatly affected by thermal stresses.

To examine the effect of slab length on rigid pavement fatigue damage, the number of vehicle passes to failure for slabs 4.6 and $6.1 \mathrm{~m}$ (15 and $20 \mathrm{ft}$.) is studied using four different fatigue models RISC model (Majidzadeh and Ilves, 1983), Austin Research Engineers (ARE) model (Treybig, et al., 1977), Vesic model (Vesic and Saxena, 1969), and Darter model (Darter, 1977). The results shown in Table 6.4 show that the $6.1 \mathrm{~m}$ (20 ft.) slab will carry less number of vehicle passes to failure than the $4.6 \mathrm{~m}(15 \mathrm{ft}$.) slab. The percentages of increase in the number of

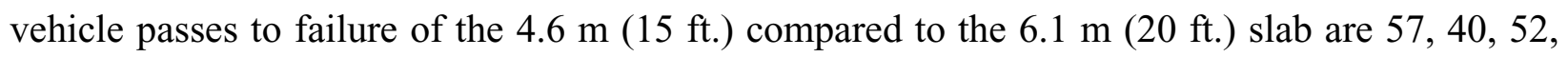
and 1433 percent for RISC, ARE, VESIC, and DARTER models respectively. These results show that the difference in the number of vehicle passes to failure between the $4.6 \mathrm{~m}(15 \mathrm{ft}$.) slab and the $6.1 \mathrm{~m}$ (20 ft.) slab is the very high when computed using DARTER fatigue model.

TABLE 6.4 Effect of Slab Length on Rigid Pavement Fatigue Damage

\begin{tabular}{|c|c|c|c|}
\hline \multirow{2}{*}{ Fatigue Model } & \multirow{2}{*}{ Fatigue Model Equation } & \multicolumn{2}{|c|}{ Number of Vehicle Passes to Failure } \\
\cline { 3 - 4 } & & $\mathbf{1 5}$ ft. Slab & $\mathbf{2 0}$ ft. Slab \\
\hline RISC & $\log \mathrm{N}_{\mathrm{f}}=\log (22209)-4.29 \log (\Phi / \mathrm{MR})$ & 189,380 & 120,587 \\
\hline $\mathrm{ARE}$ & $\log \mathrm{N}_{\mathrm{f}}=\log (23440)-3.21 \log (\Phi / \mathrm{MR})$ & 116,529 & 83,129 \\
\hline VESIC & $\log \mathrm{N}_{\mathrm{f}}=\log (225000)-4 \log (\Phi / \mathrm{MR})$ & $1,659,837$ & $1,089,642$ \\
\hline DARTER & $\log \mathrm{N}_{\mathrm{f}}=16.61-17.61(\Phi / \mathrm{MR})$ & 840,723 & 54,839 \\
\hline
\end{tabular}

The 4.6 and $6.1 \mathrm{~m}$ (15 and $20 \mathrm{ft}$.) slab lengths are then studied under a tridem axle load of 24.5 tons $(54,000 \mathrm{lb})$ and the slab thickness is increased to $279 \mathrm{~mm}(11 \mathrm{in}$.). The same thermal gradients used above are combined with the tridem axle load. The $\Phi_{\mathrm{x}}$ results plotted for line AA and the four loading cases indicate that the change in axle configuration and slab thickness reduced the stresses induced in the slab and that cases 2 and 4 are still the two critical loading conditions, as shown in Figure $6.30(\mathrm{~d}, \mathrm{~g})$. The comparison between the critical stresses in Figures 6.28 and 6.30 show that the average percentage of reduction in $\Phi_{\mathrm{x}}$ as a result of reducing the slab length from 6.1 to $4.6 \mathrm{~m}$ (20 to $15 \mathrm{ft}$.) for the $279 \mathrm{~mm}$ (11 in.) is 20 percent, Figure 6.30 (g), compared to only 9 percent for the $229 \mathrm{~mm}$ (9 in.) thick slabs subjected to tandem axle load, Figure 6.28 (f). However, the reduction in the peak stress induced in case of the thicker slabs 
compared to the case of the thinner ones is very small with respect to the high cost associated with the thickness increase.

The above results demonstrate that thermal gradient should be accounted for during the design of rigid pavement slab length since the design based on axle loads only does not reflect the exact response of different slab lengths under the actual loads existing in the field. The comparison between the $4.6 \mathrm{~m}$ ( $15 \mathrm{ft}$.) and the $6.1 \mathrm{~m}$ (20 ft.) slabs show that accompanying the increase in slab thickness by a change in the axle load and configuration from tandem to tridem does not significantly reduce the stresses in the slab.

\subsubsection{Effect of Slab Thickness}

The effect of changing the thickness of a $4.6 \mathrm{~m}$ (15 ft.) long slab from 229 to $279 \mathrm{~mm}$ (9 to 11 in.) is studied under a tridem axle load combined with two thermal gradients of $-6.7^{\circ} \mathrm{C}$ and $+14.45^{\circ} \mathrm{C}\left(-12^{\circ} \mathrm{F}\right.$ and $\left.+26^{\circ} \mathrm{F}\right)$. The distributions of MPS, $\Phi_{\mathrm{x}}$, and $\Phi_{\mathrm{y}}$ along line A-A corresponding to the four loading cases shown in Figure 6.3 are plotted versus the distance from the first transverse joint, as shown in Figures 6.31 to 6.33 . The results show the following:

1) Generally, increasing the slab thickness reduces both the thermal stresses and the stresses due to combined thermal and axle loads.

2) Under thermal gradient only, the critical stress is developed under the effect of positive gradient. In this case, the percentages of stress reduction as a result of increasing the thickness are for MPS 17.1 percent at the slab bottom, for $\Phi_{\mathrm{x}} 21.6$ and 12.8 percent, and for $\Phi_{\mathrm{y}} 14.9$ and 32 percent at slab top and bottom respectively, as shown in Figures 6.31 (a), 6.32 (a), and 6.33 (a). As for the negative gradient, the percentages of decrease fall in the same range except for $\Phi_{\mathrm{y}}$ induced at slab bottom where the reduction is 55.7 percent, as shown in Figure 6.33 (b). These observations shows that $\Phi_{\mathrm{y}}$ at slab bottom is highly reduced by the thickness increase.

3) Loading cases 2 and 4 are critical for the negative and positive gradients respectively. The stress reduction due to thickness increase is calculated for all the critical cases and the results show that under positive gradient, the reduction in $\Phi_{\mathrm{y}}$ is the highest at the slab 
bottom and is 43.7 percent, while the reduction in MPS and $\Phi_{\mathrm{x}}$ is only 10.2 and 9.3 percent. The same observation is valid for the negative gradient where the reduction in $\Phi_{\mathrm{y}}$ at slab bottom is the highest and is of the order of 35 percent. As for MPS and $\Phi_{\mathrm{x}}$ this percentage is 33 and 25.1 percent. This shows that the thickness increase can be an effective method of reducing $\Phi_{\mathrm{y}}$ and therefore reducing the possibilities of longitudinal cracks.

In conclusion, a 22 percent increase in slab thickness significantly reduced $\Phi_{\mathrm{y}}$ induced at slab bottom under both combined thermal and axle stresses, and thermal stresses.

\subsection{Conclusions}

Based on the results presented in this chapter, the following conclusions can be made:

1) Under the specific thermal gradients and loading conditions examined in this study, the maximum tensile MPS, $\sigma_{\mathrm{x}}$, and $\sigma_{\mathrm{y}}$ are produced by the combined positive gradient and axle load and are located at the bottom of the middle of the slab.

2) Increasing the absolute value of the thermal gradient through the slab thickness increases the stresses and the strains induced at both slab top and bottom.

3) The thermal gradient change from positive to negative or the opposite significantly changes the curvature of the slab. The introduction of axle loads also affects the curvature of the slab. This effect is increased as the magnitude of the thermal gradient increases.

4) The study of the differential displacement $(\Delta)$ between the highest and the lowest point along the slab length shows that $\Delta$ due to negative gradient along either the wheel-path or the slab edge is always higher than that due to positive gradient except for the case of joint loading measured along the wheel-path. The high magnitude of $\Delta$ produced by negative gradient associated with the high intensity of trucks during night-time may lead to the loss of support at the joint and therefore joint faulting.

5) The variation of thermal gradient through the slab thickness from positive to negative between day and night subjects the slab to stress reversals from tensile to compressive or 
the opposite. The larger the difference between the positive and the negative gradient developed in the slab, the larger the magnitude of stress reversal. Results also show that the magnitude of stress reversal increases each time a truck loads the slab.

6) The thermal stresses induced in the slab are governed by the magnitude of $\sigma_{x}$ for both negative and positive gradients since $\sigma_{\mathrm{x}}$ is always higher than $\sigma_{\mathrm{y}}$.

7) The thermal stress profile is affected by the curvature of the nonlinear thermal gradient through the slab thickness.

8) The combined stresses obtained for different gradients show that the thermal stresses should not be ignored during the design. The correction factors presented in this study take into consideration the effect of nonlinear thermal gradient if rigid pavement slabs are designed under traffic induced stresses only.

9) Mid-slab loading is the most critical loading case under edge loading. The difference in the magnitude of the maximum stress between edge and wheel-path loading positions increases with the introduction of thermal gradient.

10) The results from the loading position study indicate that the combined corner load and negative thermal gradient subject the mid-slab top to high tensile stress that may initiate top down cracks.

11) Combining a single tridem axle with negative gradient reduces the high tensile stresses observed at mid-slab top during joint loading and therefore reduces the possibilities of top-down crack initiation.

12) Increasing the slab length increases the stresses induced in the slab, especially the thermal stresses. The results obtained from different fatigue models show that the $4.6 \mathrm{~m}$ (15 ft.) slabs will carry a higher number of vehicle passes to failure than the 6.1 (20 ft.) slabs.

13) The selection of a rigid pavement slab length during the design should be controlled not only by the design-axle-load, but also by the maximum positive and negative thermal gradient occurring since studying the response of the slab under axle load only does not differentiate between the responses of slabs with different lengths.

14) Increasing the slab thickness is an effective method to reduce both thermal and combined stresses. The results from this study show that thickness increase significantly reduces the transverse stress in the slab and therefore might reduce the chances of longitudinal crack initiation. 


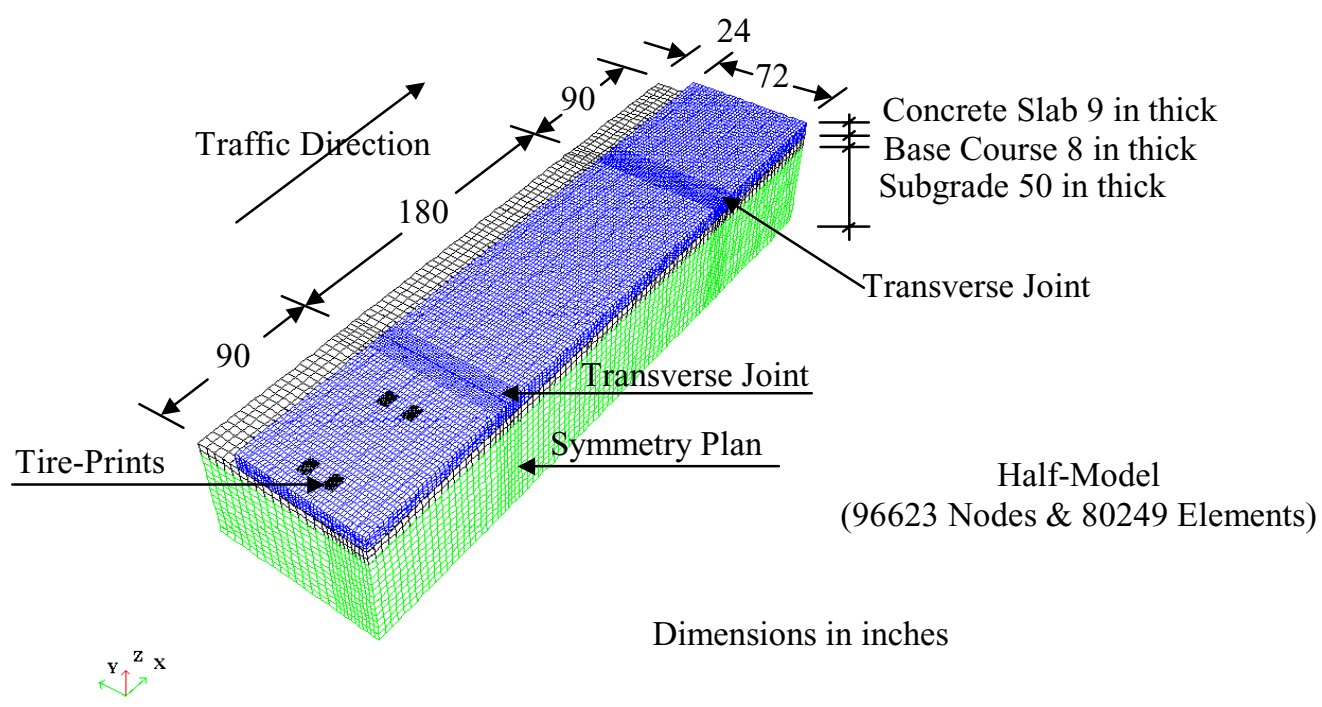

FIGURE 6.1(a) Finite Element Mesh Used to Model the Rigid Pavement Structure
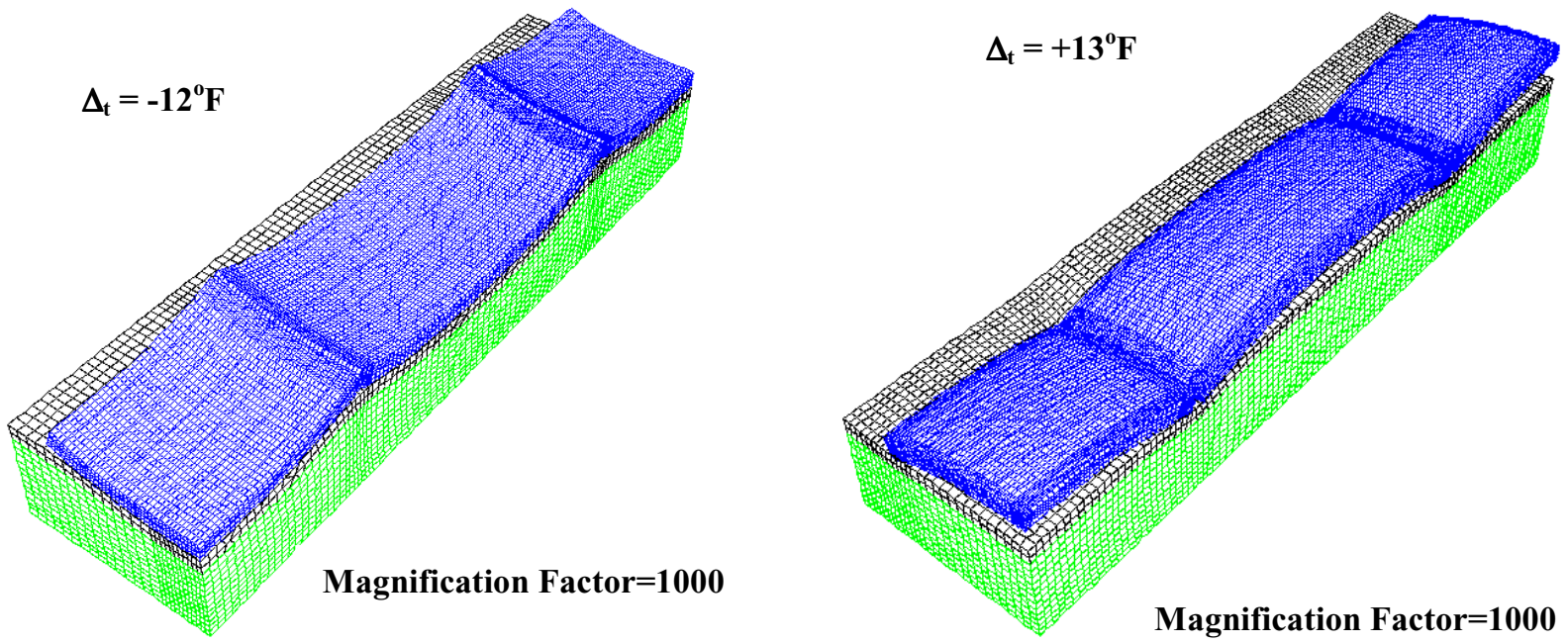

FIGURE 6.1(b) Deformed Mesh Due to a Nonlinear Gradient of $-12^{\circ} \mathrm{F}$

FIGURE 6.1(c) Deformed Mesh Due to a Nonlinear Gradient of $+13^{\circ} \mathrm{F}$ 

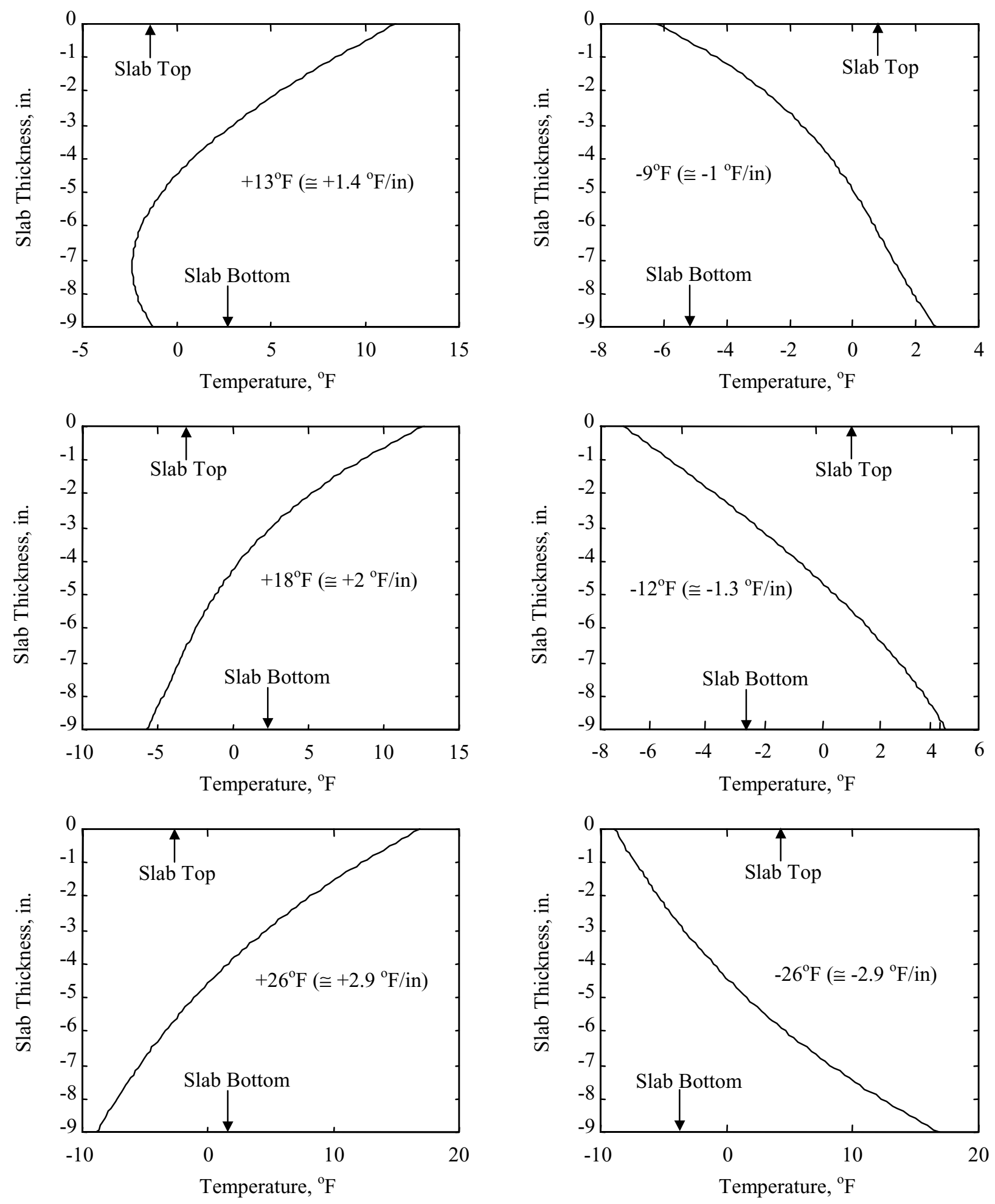

FIGURE 6.2 Nonlinear Thermal Gradient Profiles 


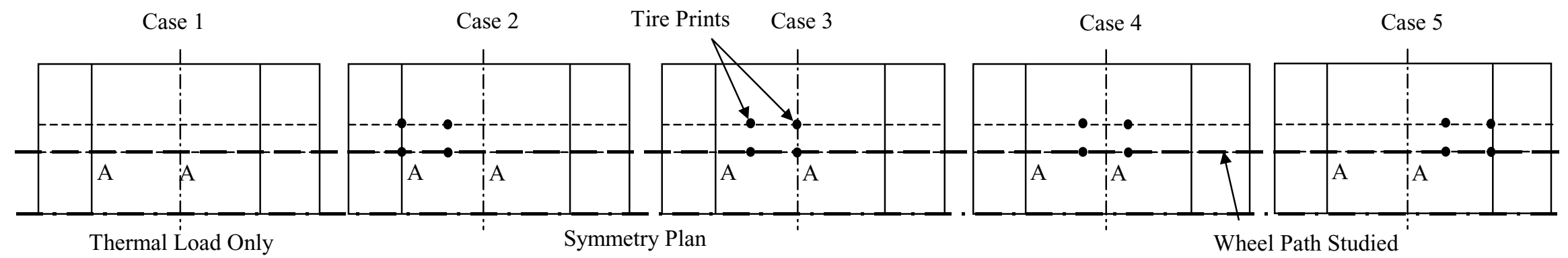

(a) Tandem Axle Loading Positions

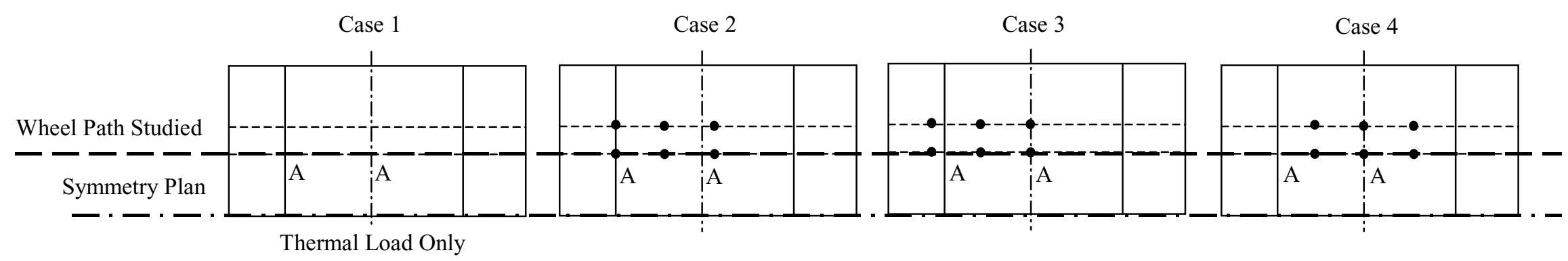

(b) Tridem Axle Loading Positions

FIGURE 6.3 Loading Positions Studied 

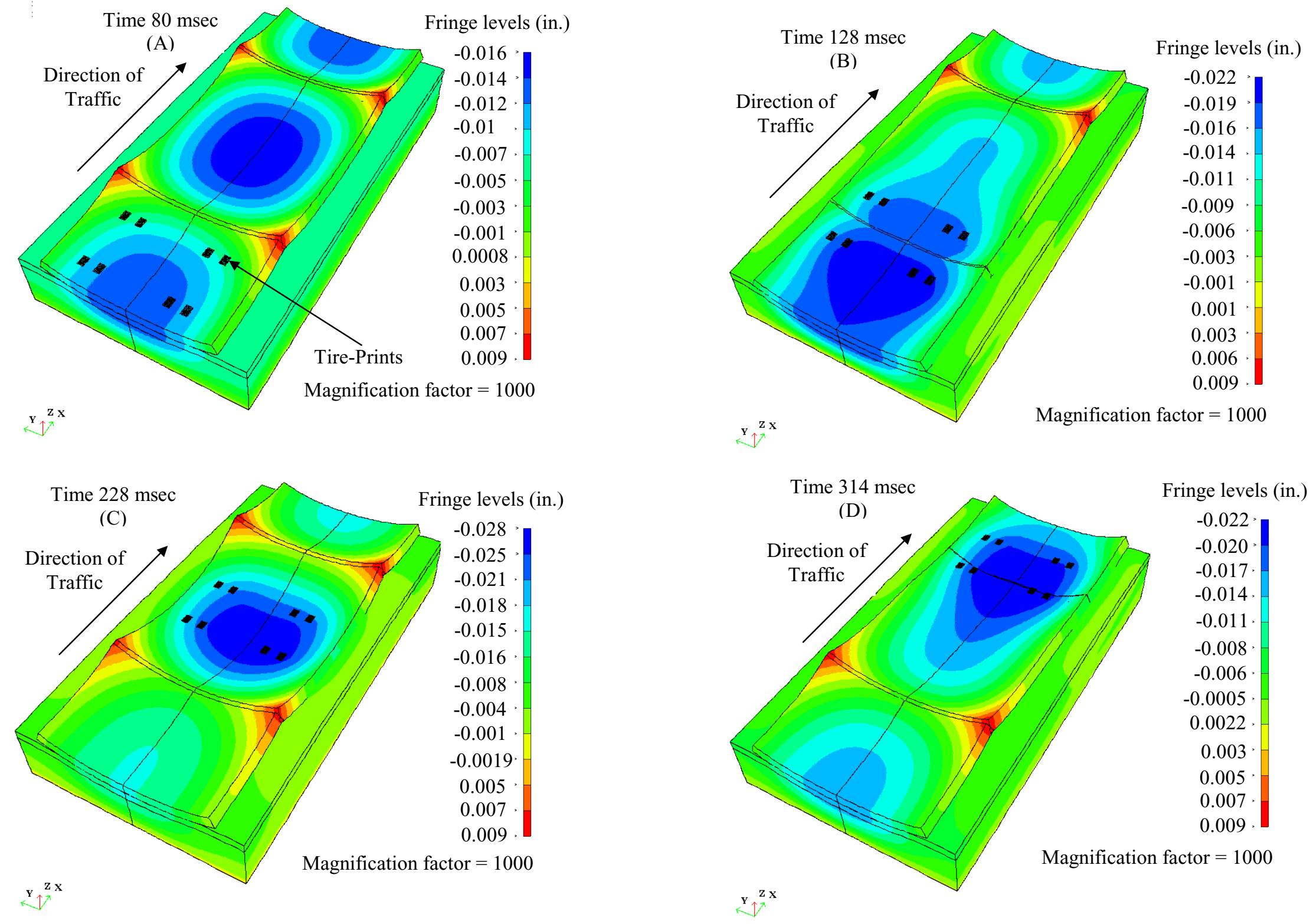

FIGURE 6.4 Variation of Vertical Displacement Distribution Due to Combined Thermal Gradient of $-12^{\circ} \mathrm{F}$ and Tandem Axle Load 

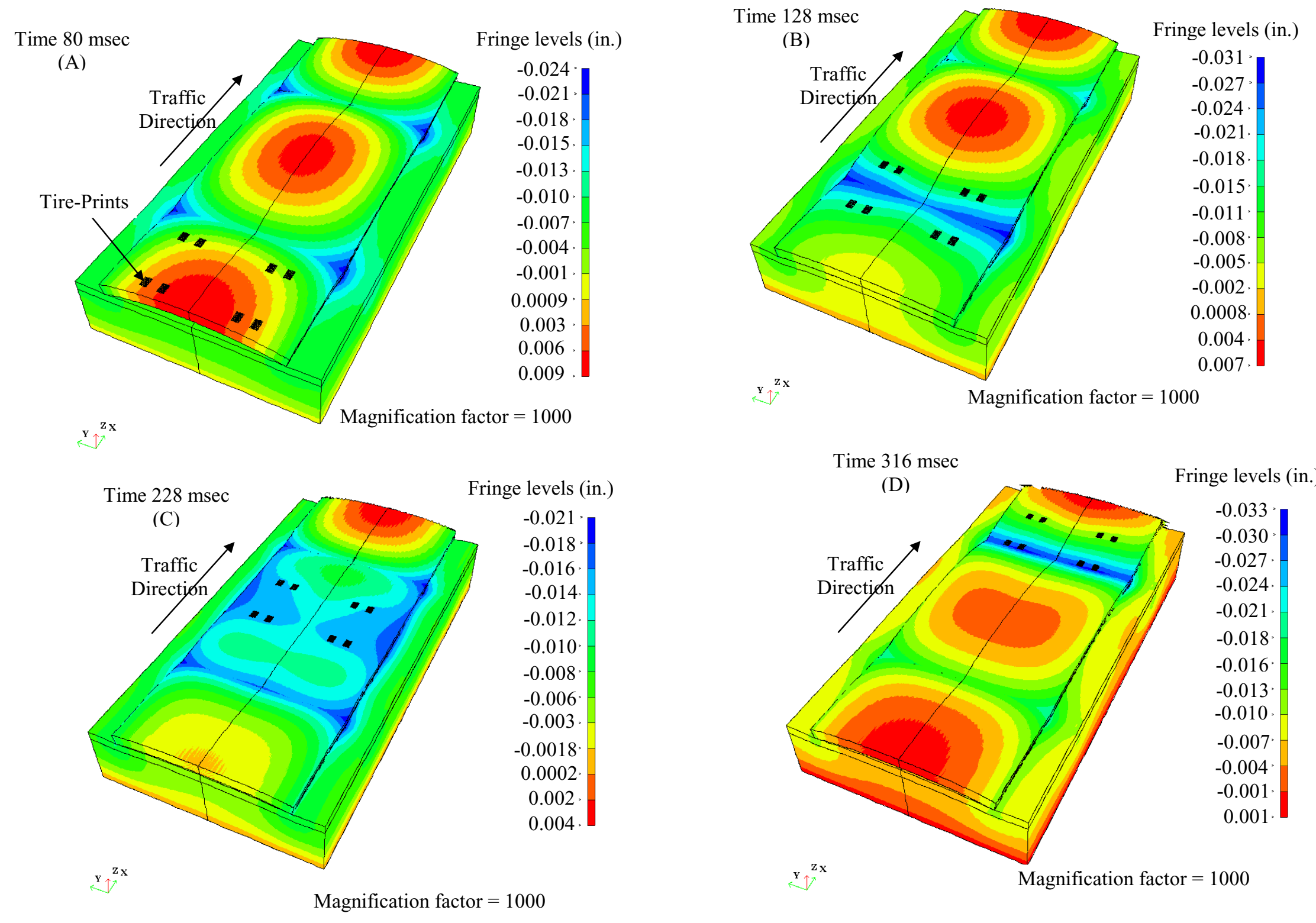

FIGURE 6.5 Variation of Vertical Displacement Distribution Due to Combined Thermal Gradient of $+18^{\circ}$ F and Tandem Axle Load 


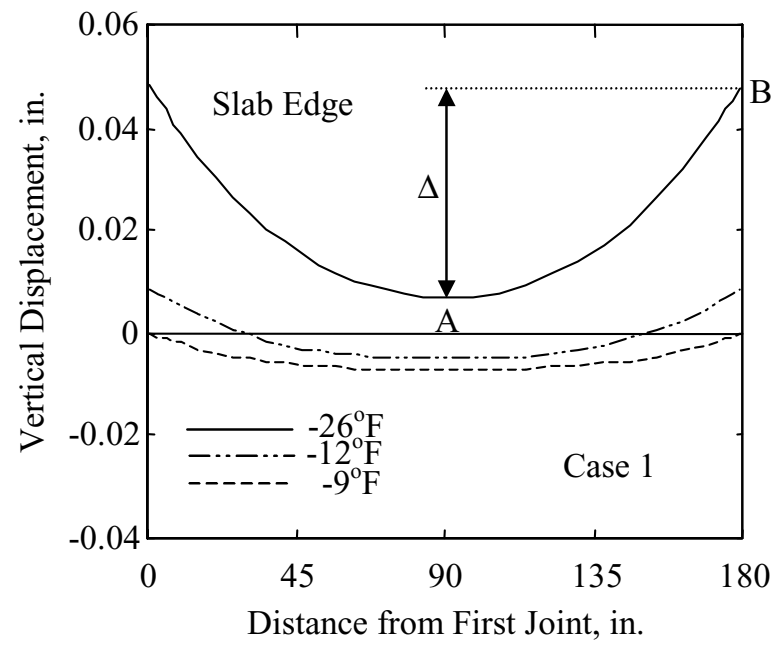

(a)

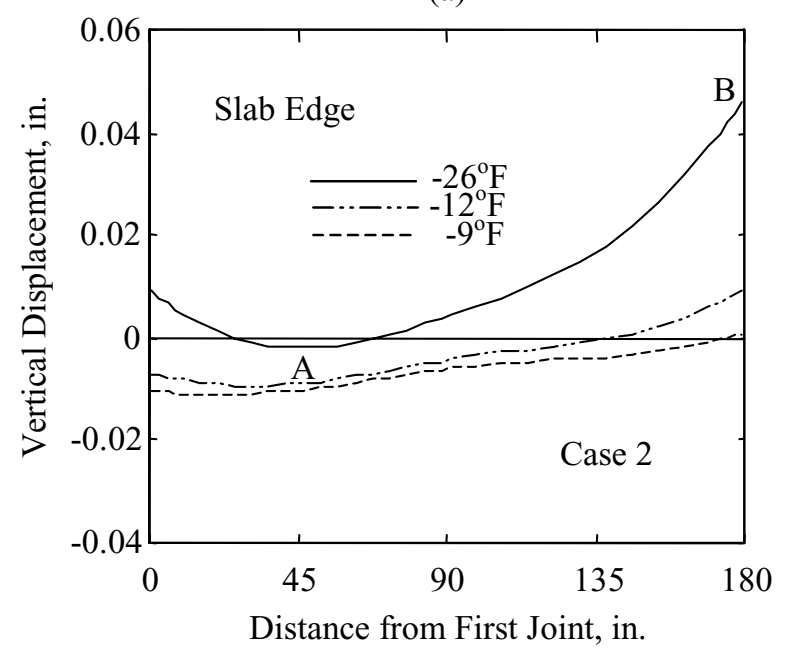

(c)

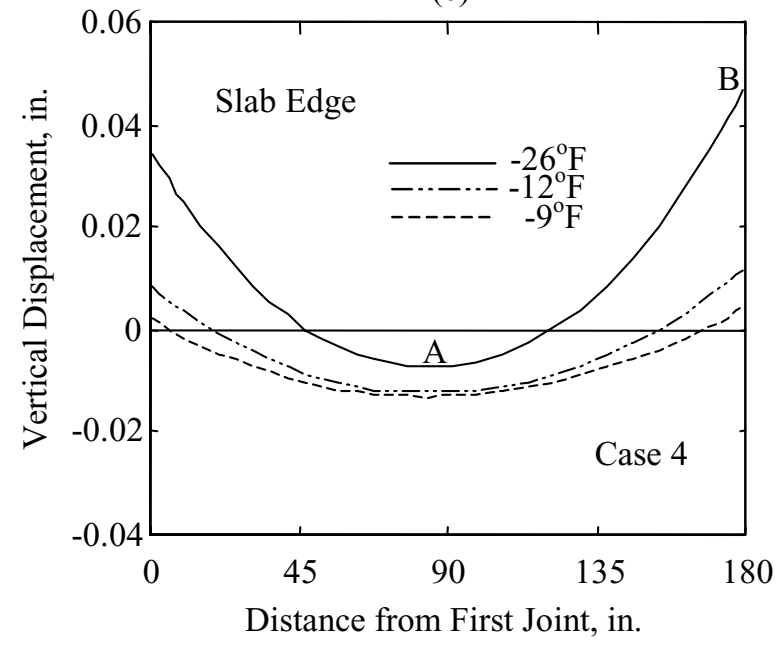

(e)

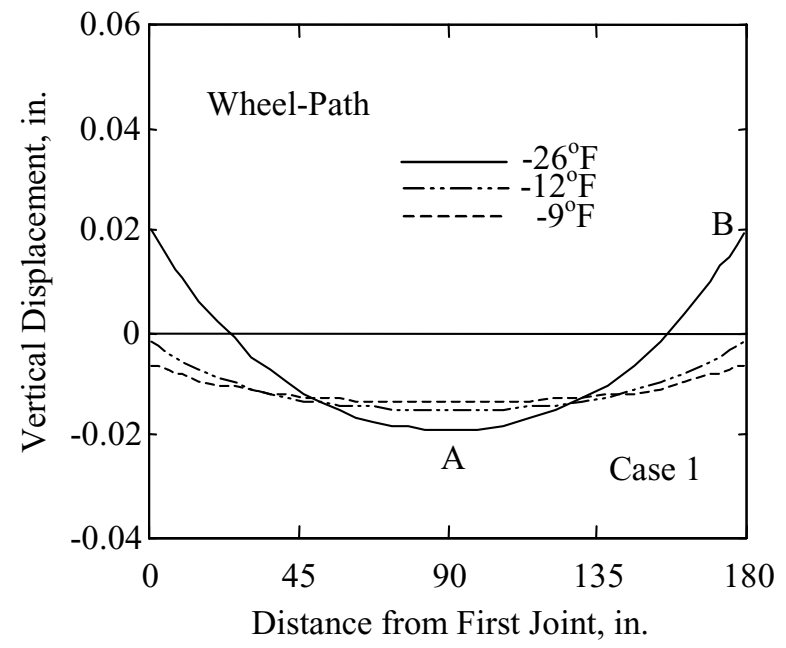

(b)

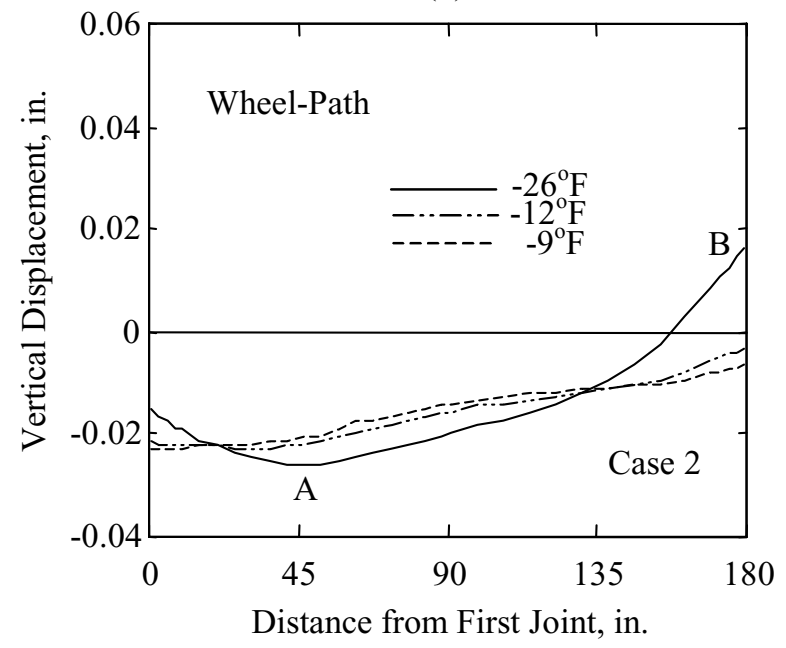

(d)

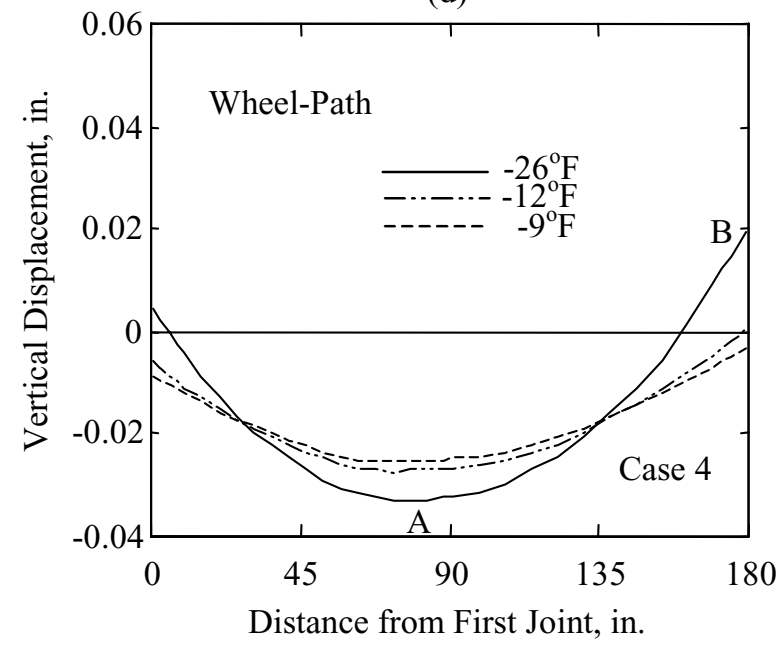

(f)

FIGURE 6.6 Effect of Negative Thermal Gradient on Vertical Displacement Profiles 


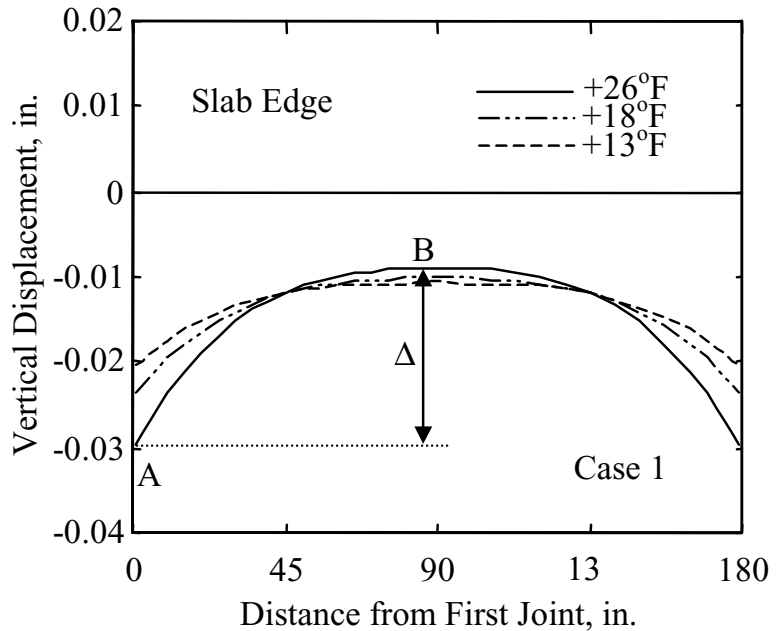

(a)

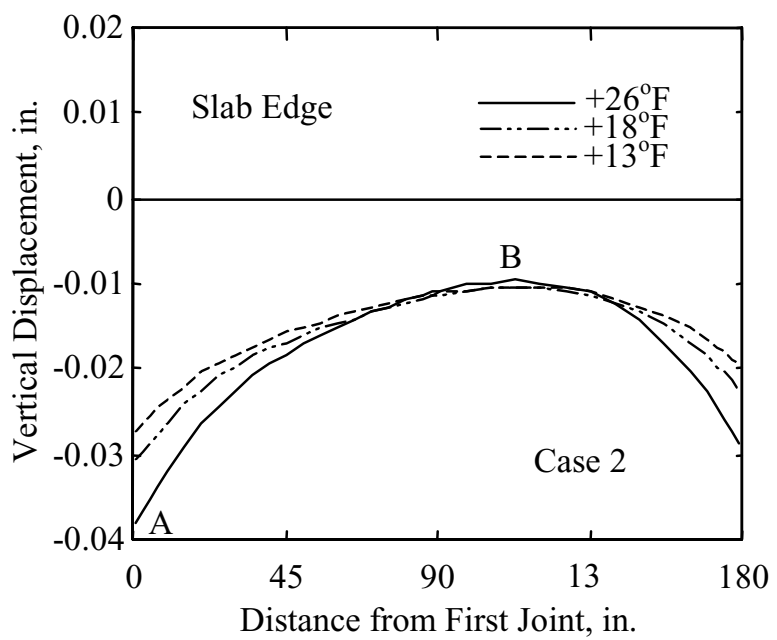

(c)

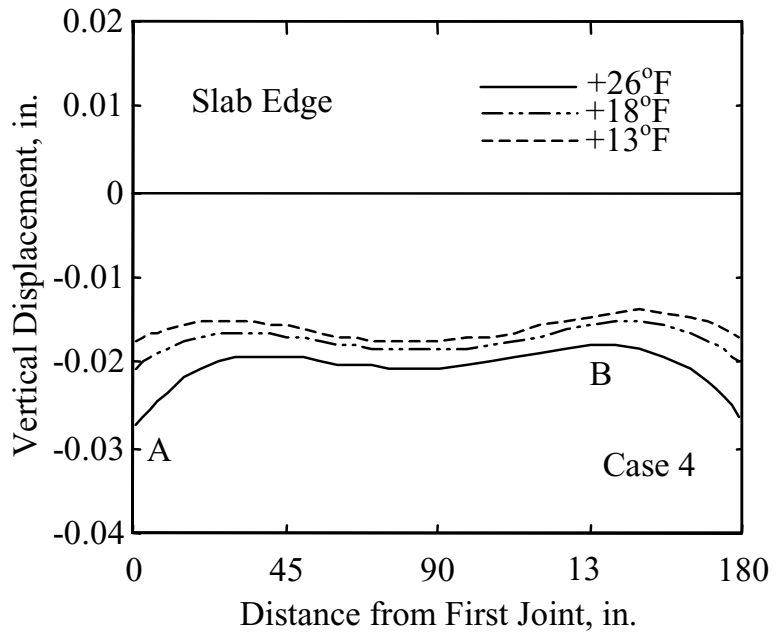

(e)

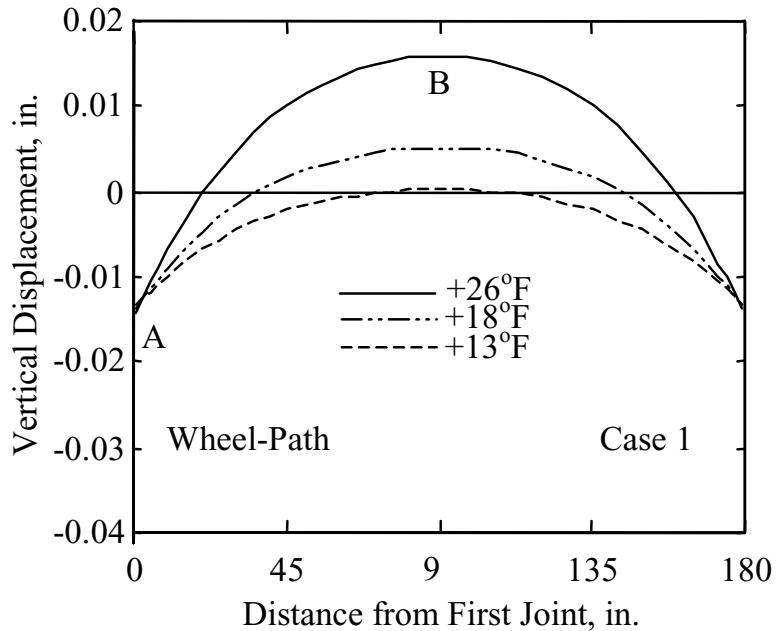

(b)

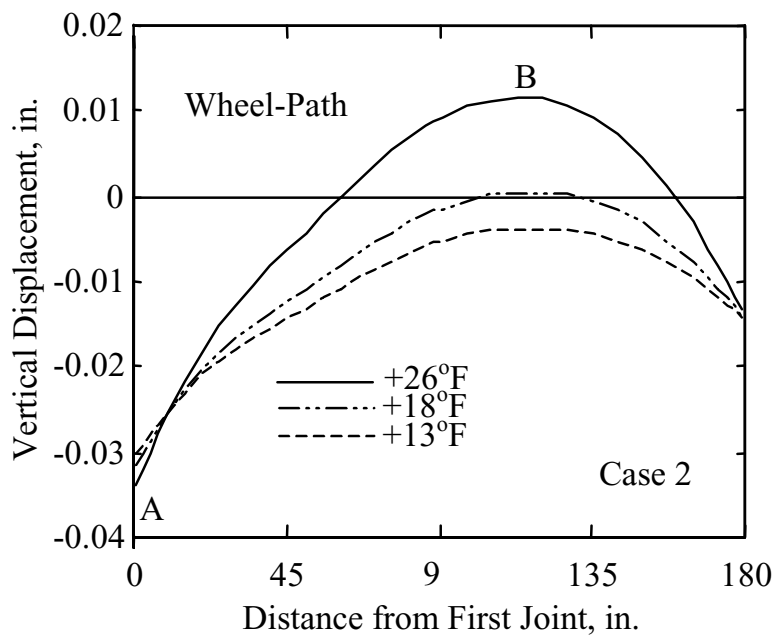

(d)

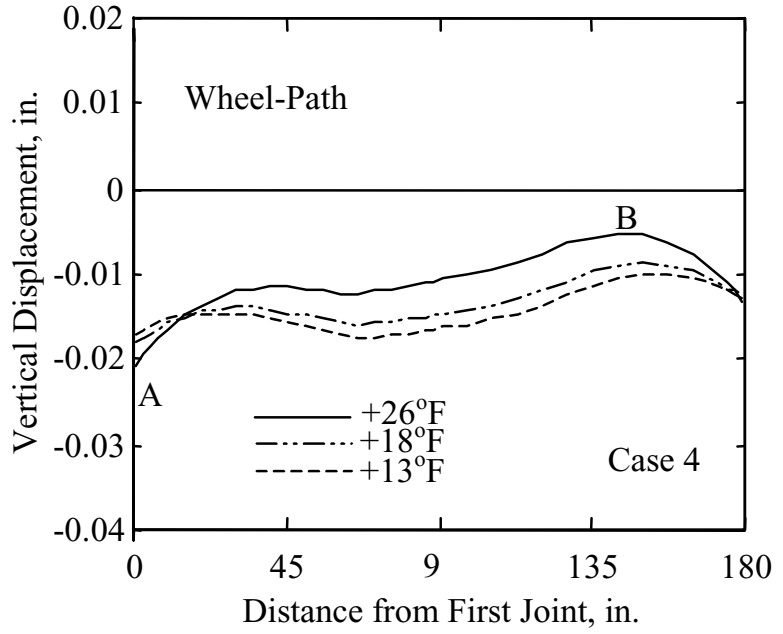

(f)

FIGURE 6.7 Effect of Positive Thermal Gradient on Vertical Displacement Profiles 


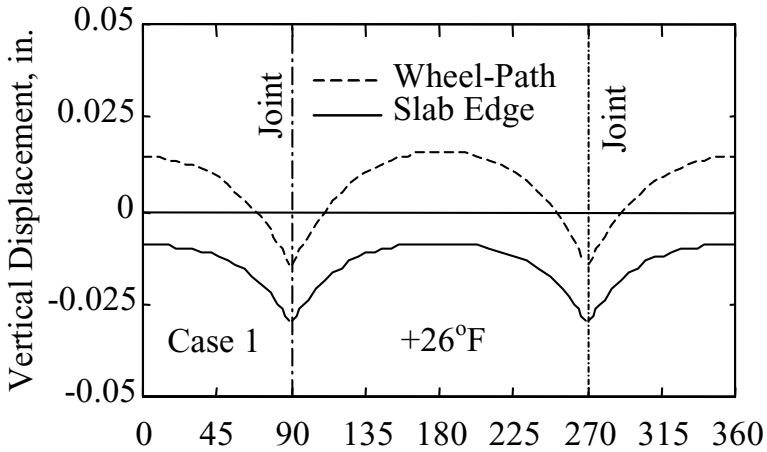

(a)

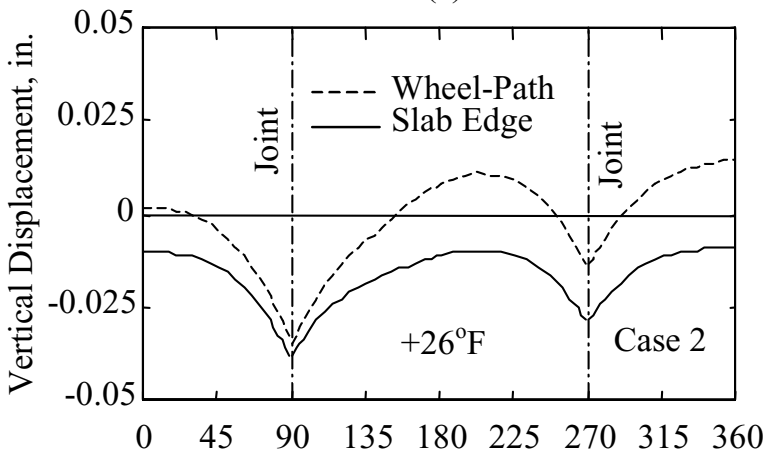

(c)

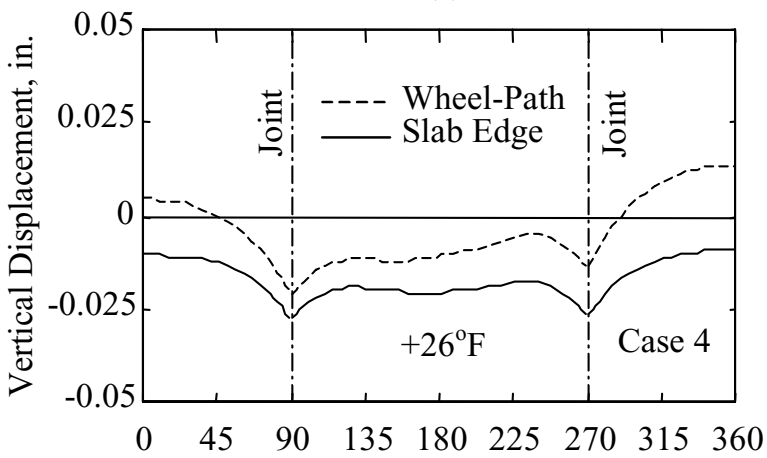

(e)

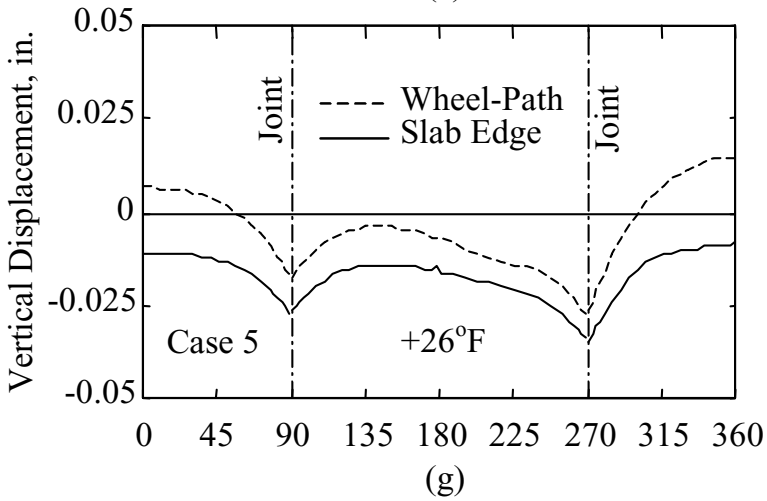

Distance from Model Boundaries, in.

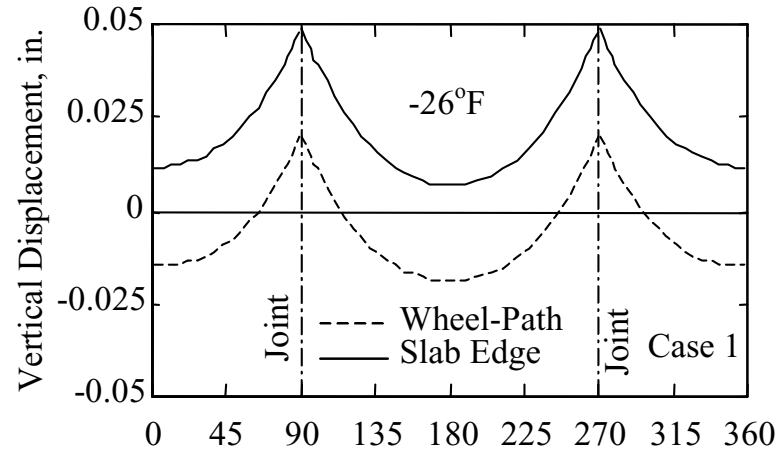

(b)

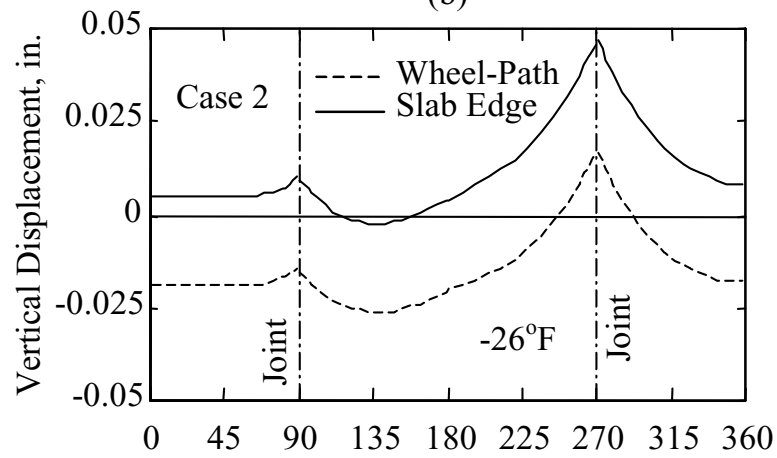

(d)

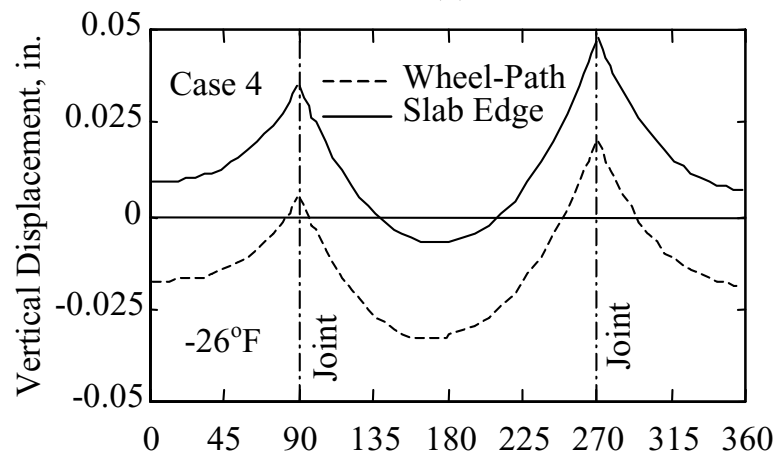

(f)

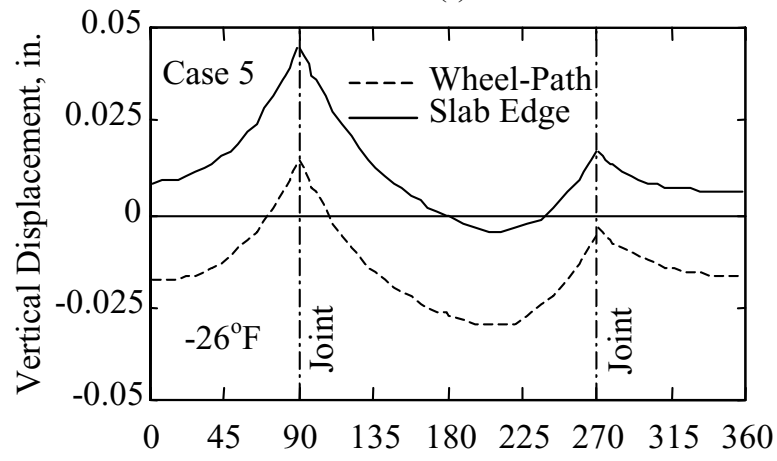

(h)

Distance from Model Boundaries, in.

\section{FIGURE 6.8 Vertical Displacement Profiles Along Traffic Direction}




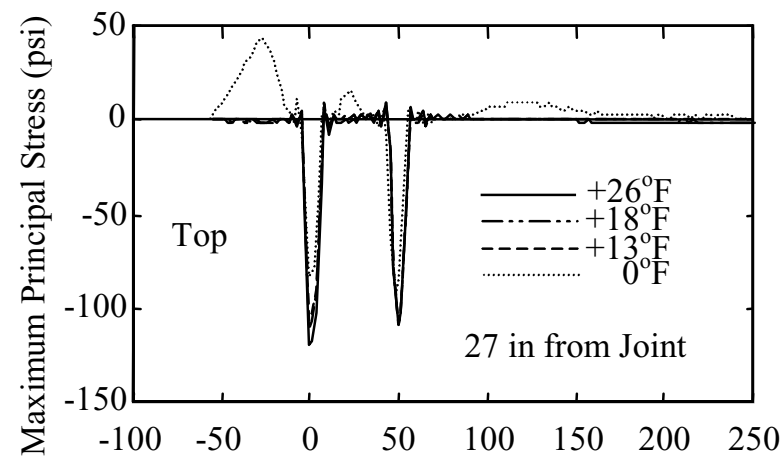

(a)

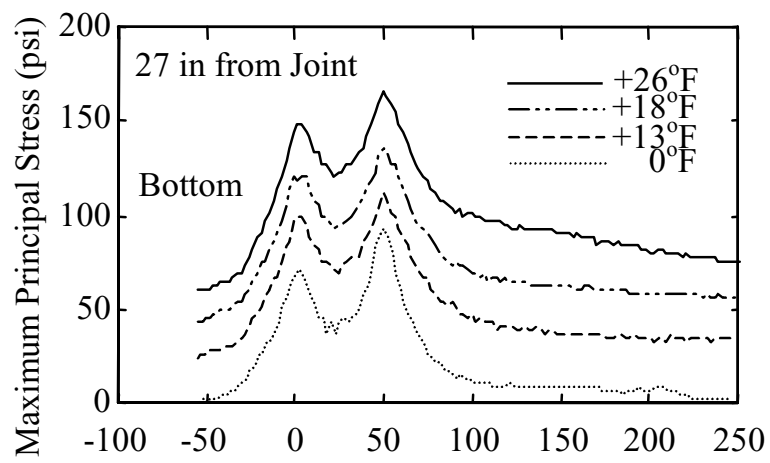

(c)

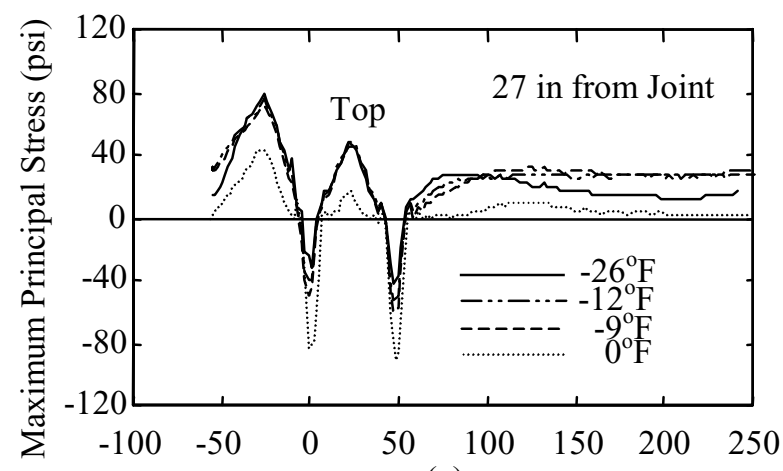

(e)

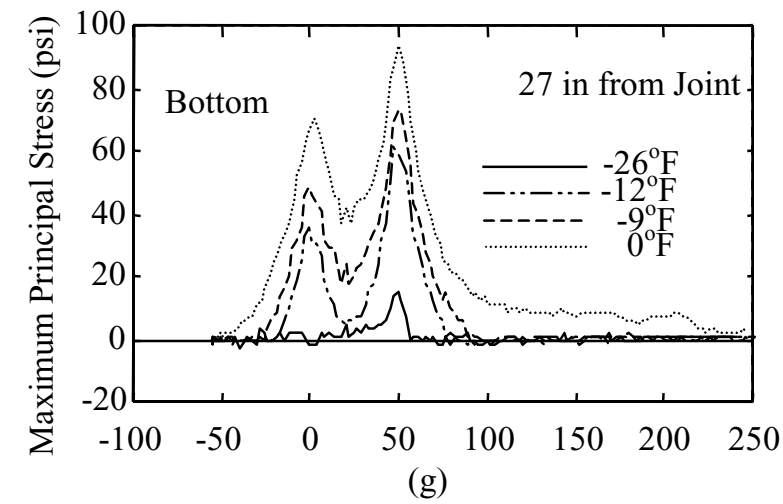

Distance from Element at 27 in. from Joint, (in.)

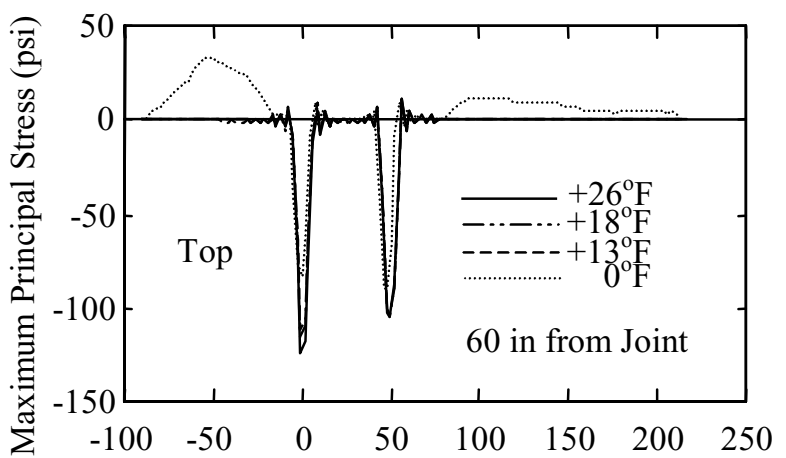

(b)

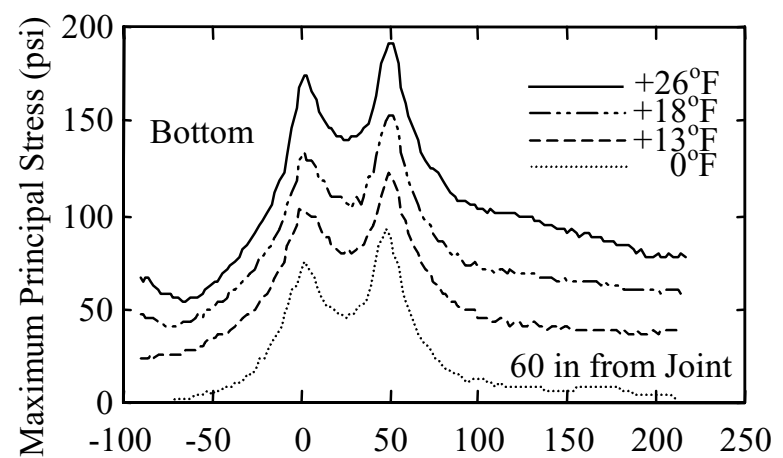

(d)

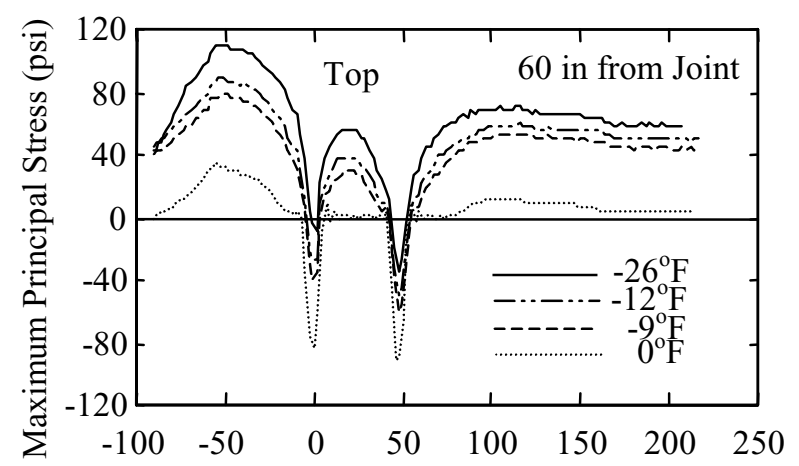

(f)

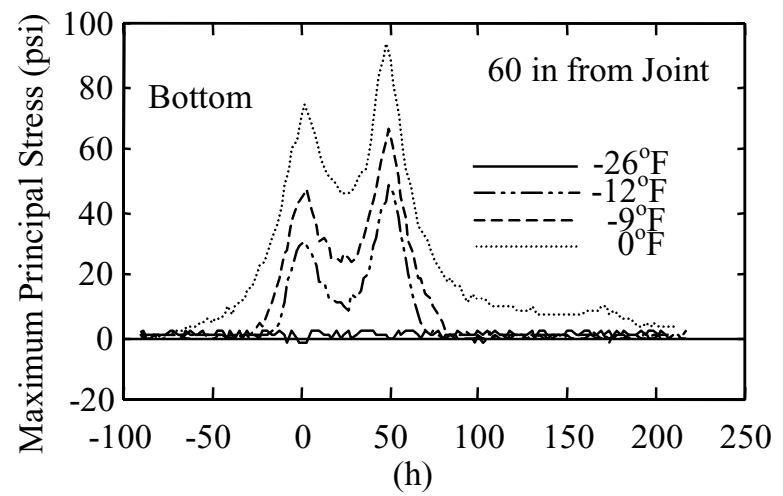

Distance from Element at 60 in. from Joint, (in.)

FIGURE 6.9 MPS Distribution at $27 \& 60$ in. from the Transverse Joint 


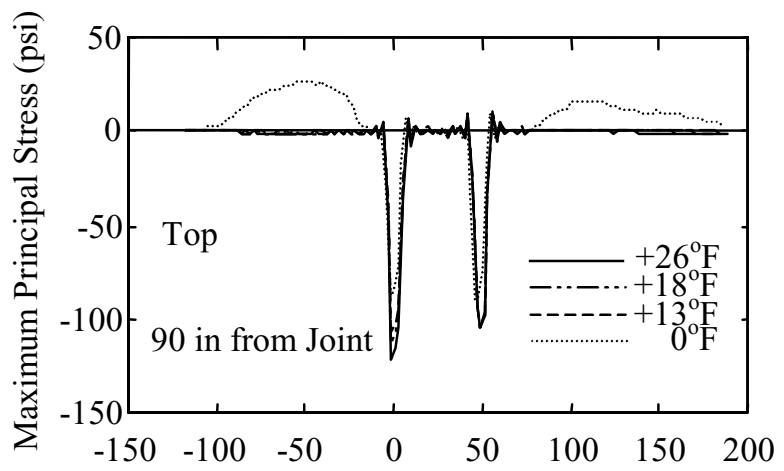

(a)

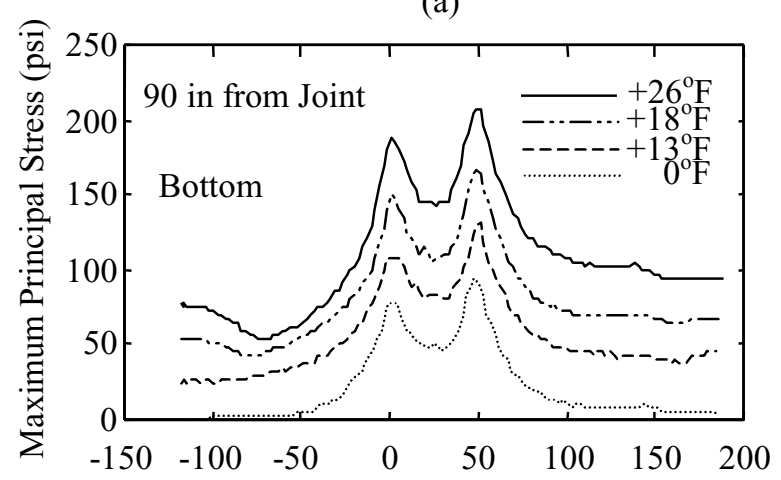

(c)

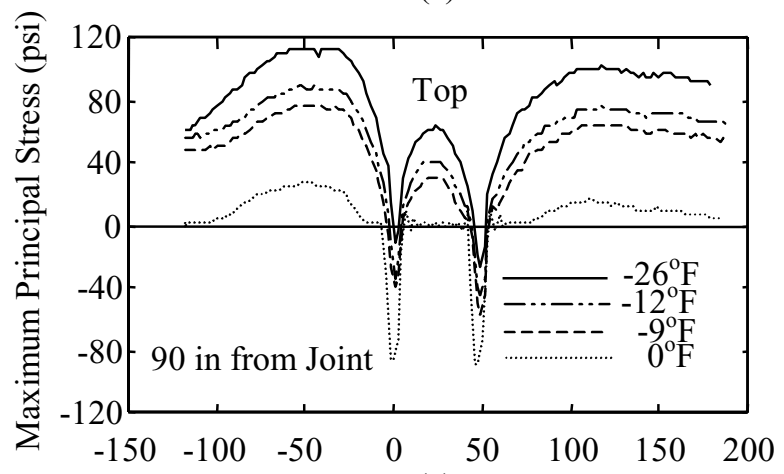

(e)

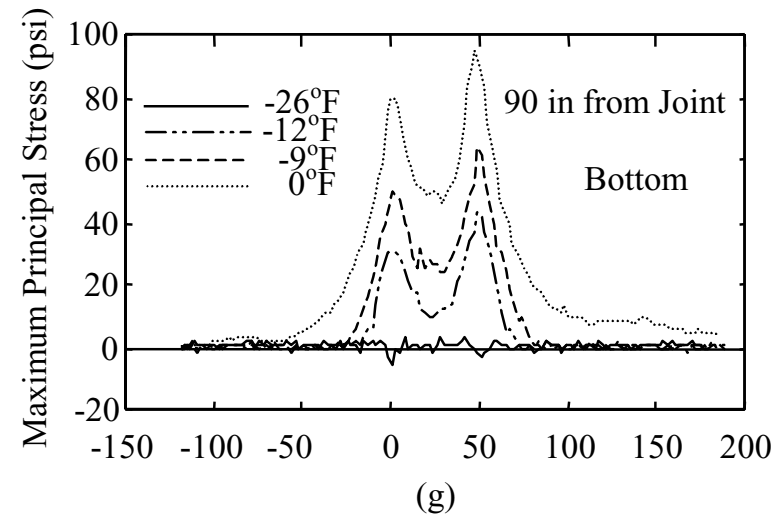

Distance from Element at 90 in. from Joint, (in.)

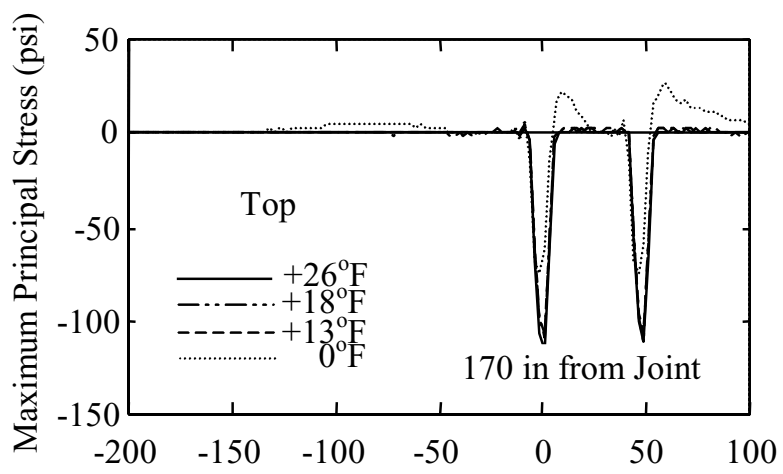

(b)

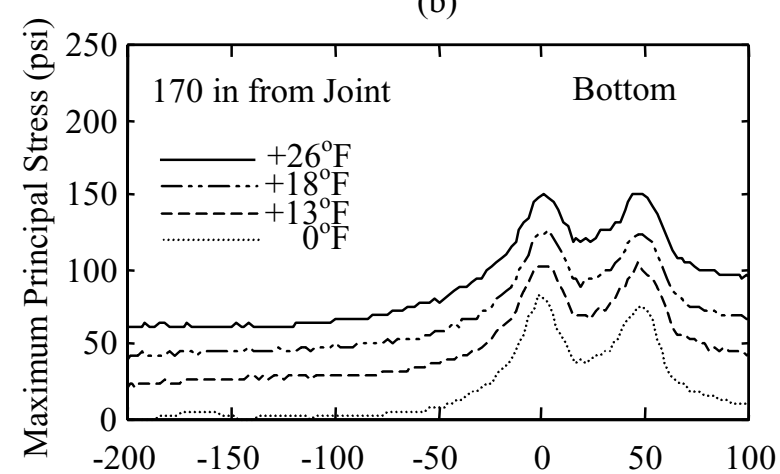

(d)

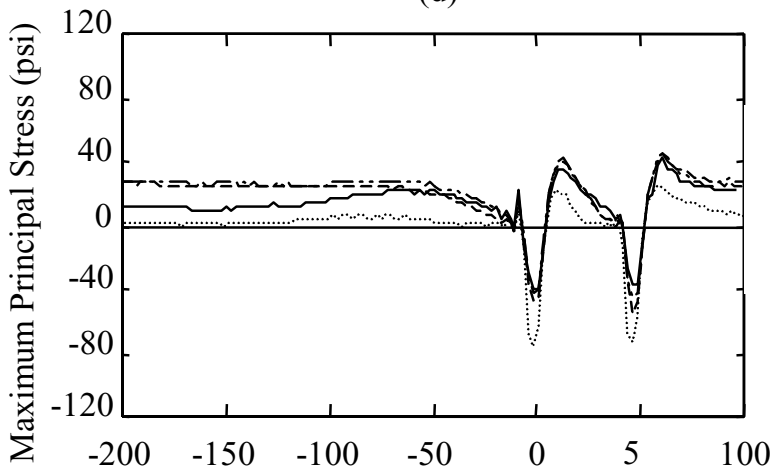

(f)

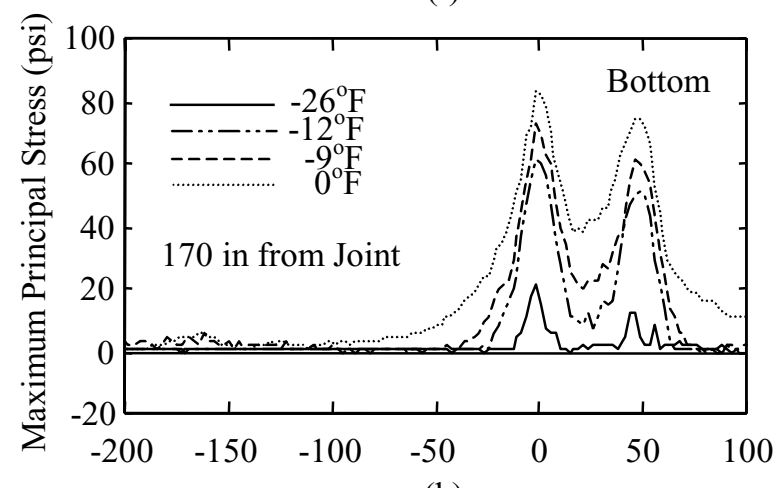

(h)

Distance from Element at 170 in. from Joint, (in.)

FIGURE 6.10 MPS Distribution at 90 \& 170 in. from the Transverse Joint 


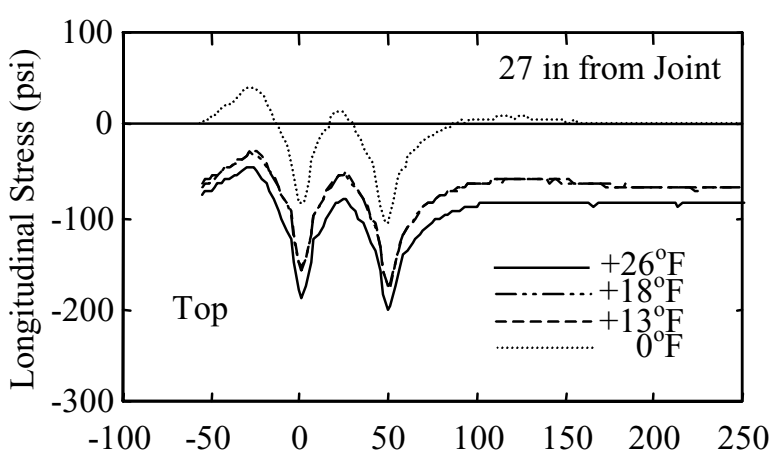

(a)
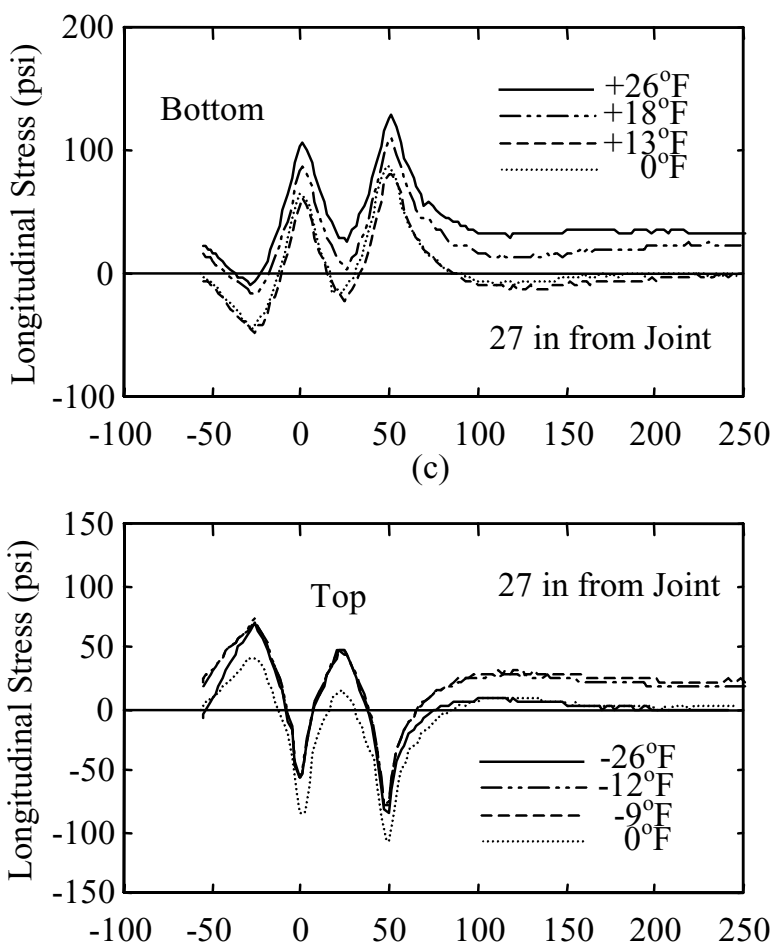

(e)

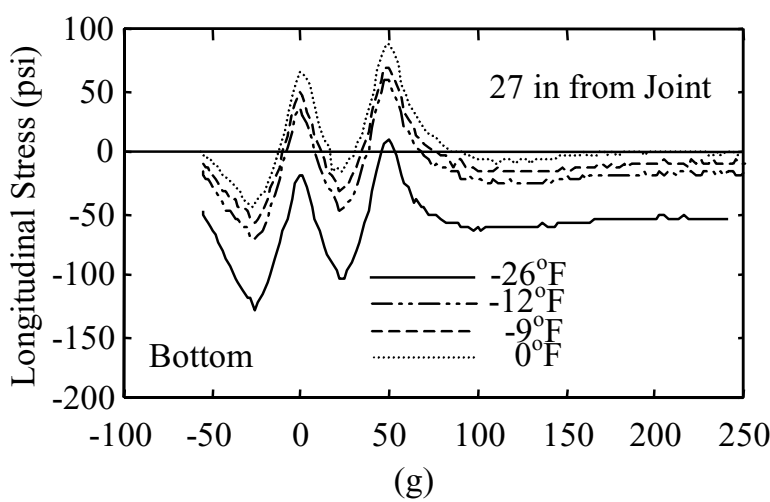

Distance from Element at 27 in. from Joint, (in.)

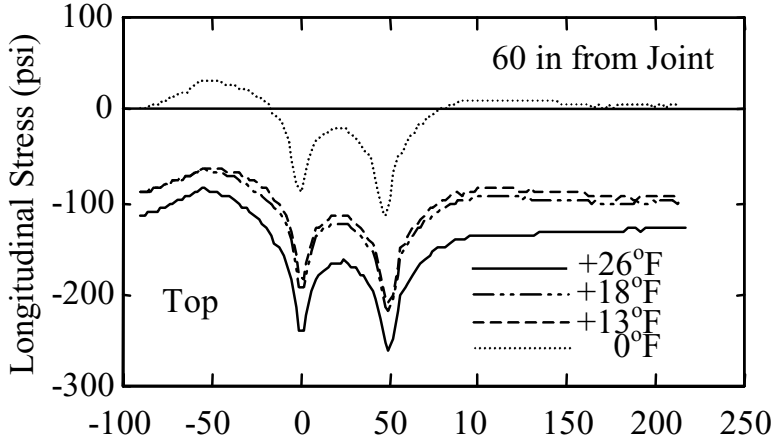

(b)
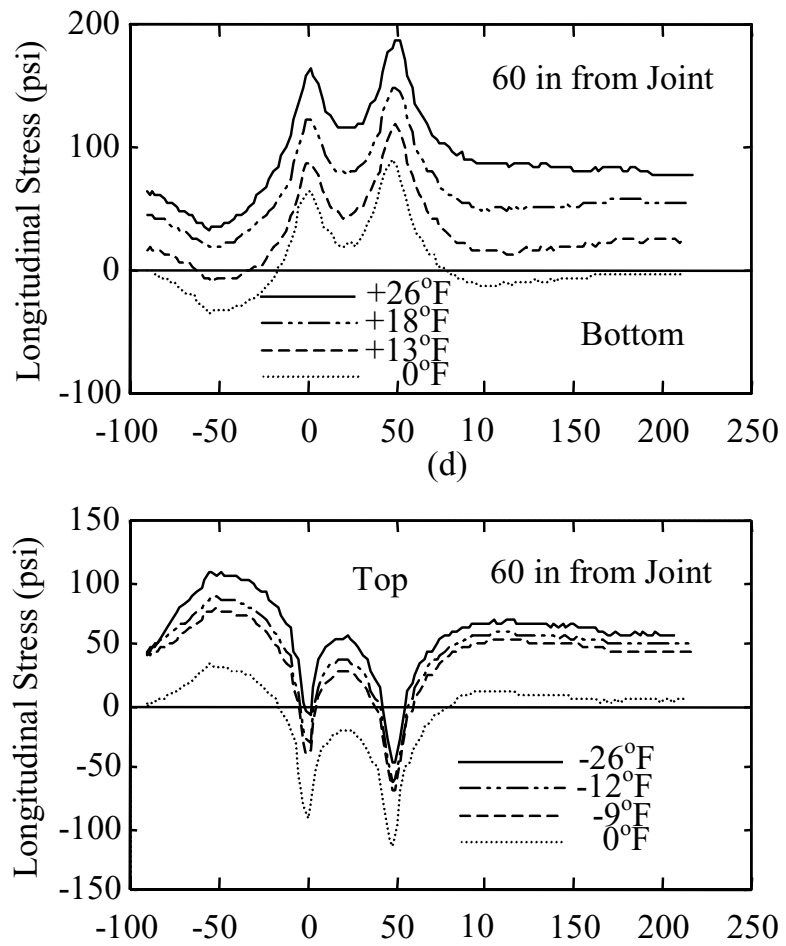

(f)

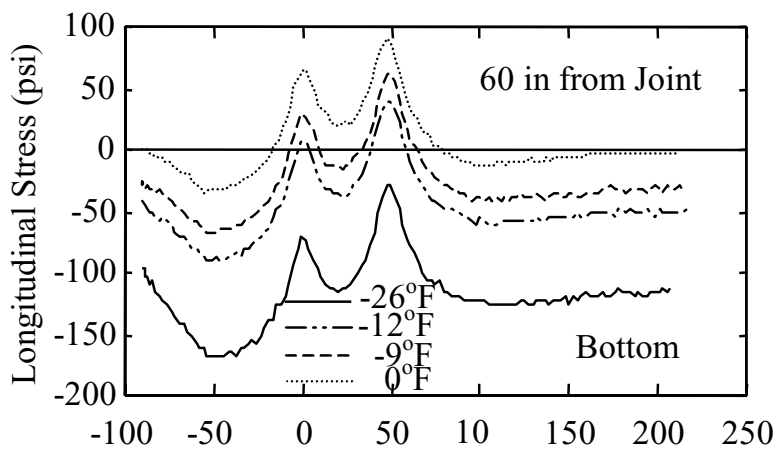

(h)

Distance from Element at 60 in. from Joint, (in.)

FIGURE $6.11 \sigma_{\mathrm{x}}$ Distribution at $27 \& 60$ in. from the Transverse Joint 


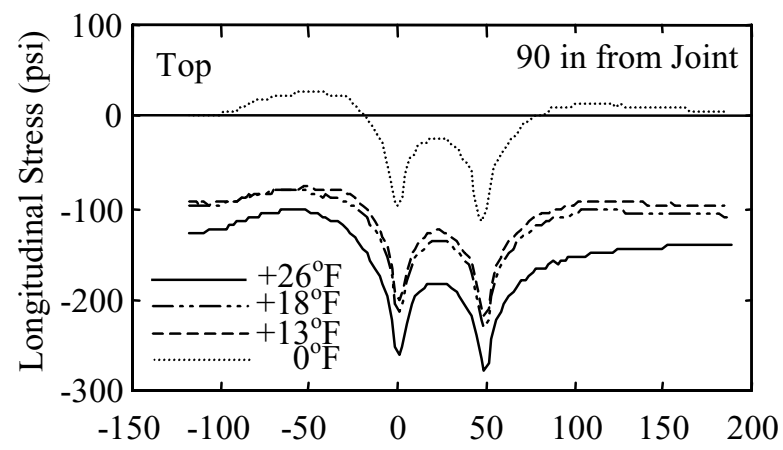

(a)

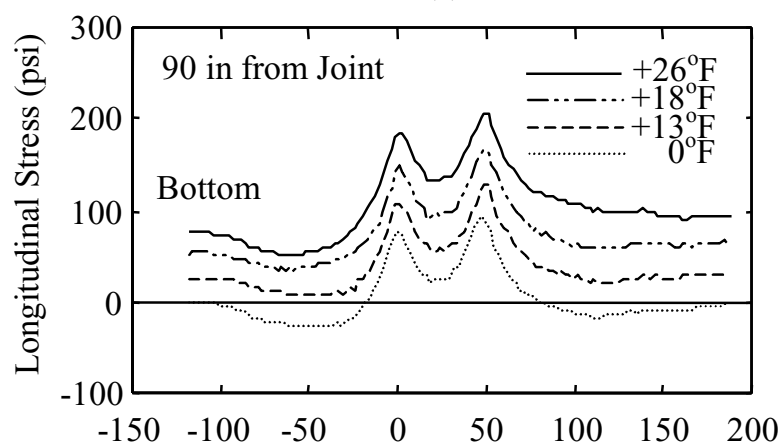

(c)

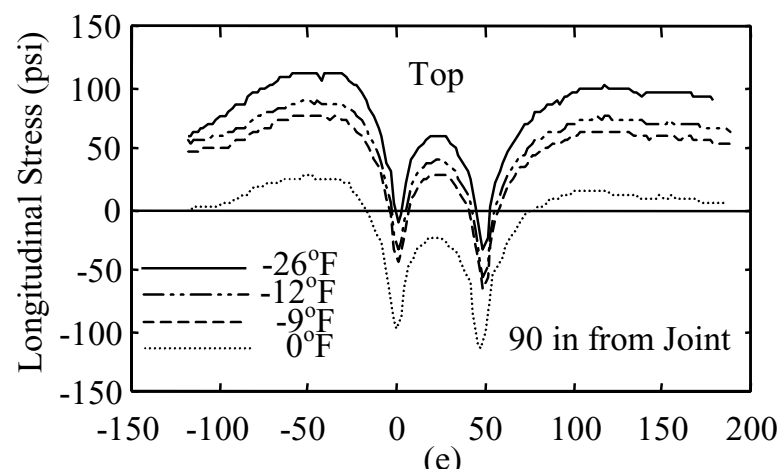

(e)

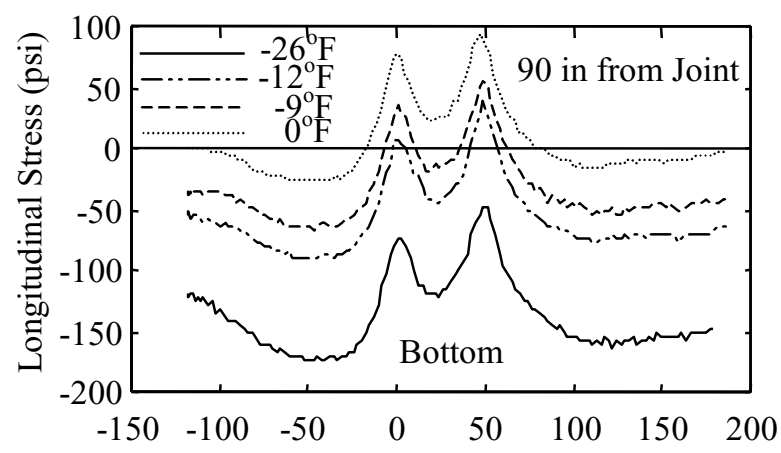

(g)

Distance from Element at 90 in. from Joint, (in.)

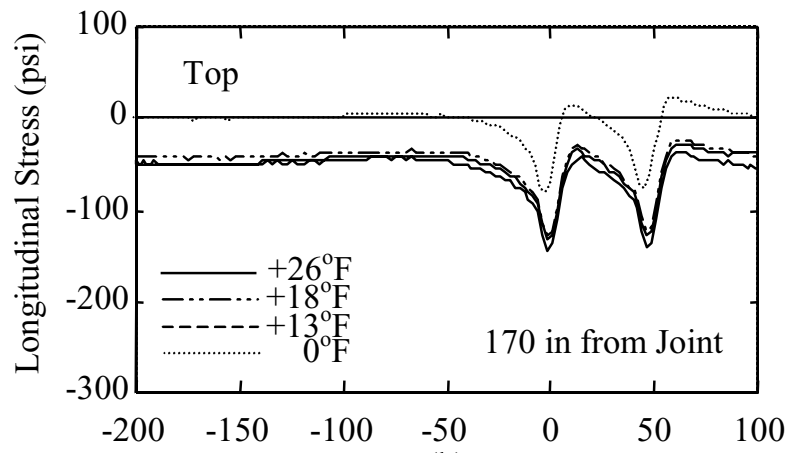

(b)

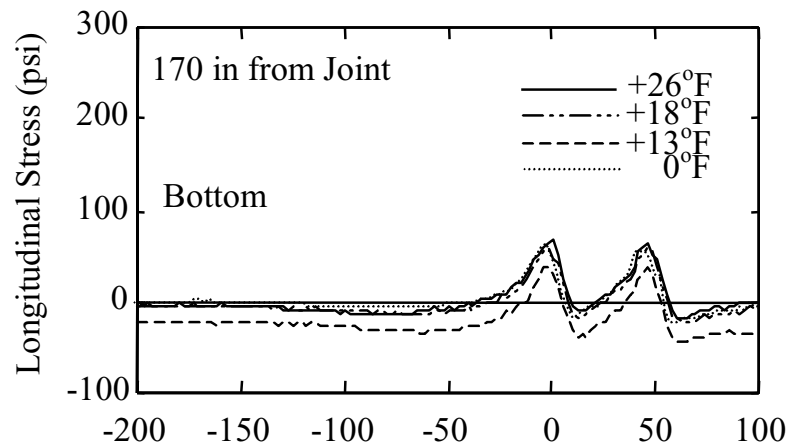

(d)
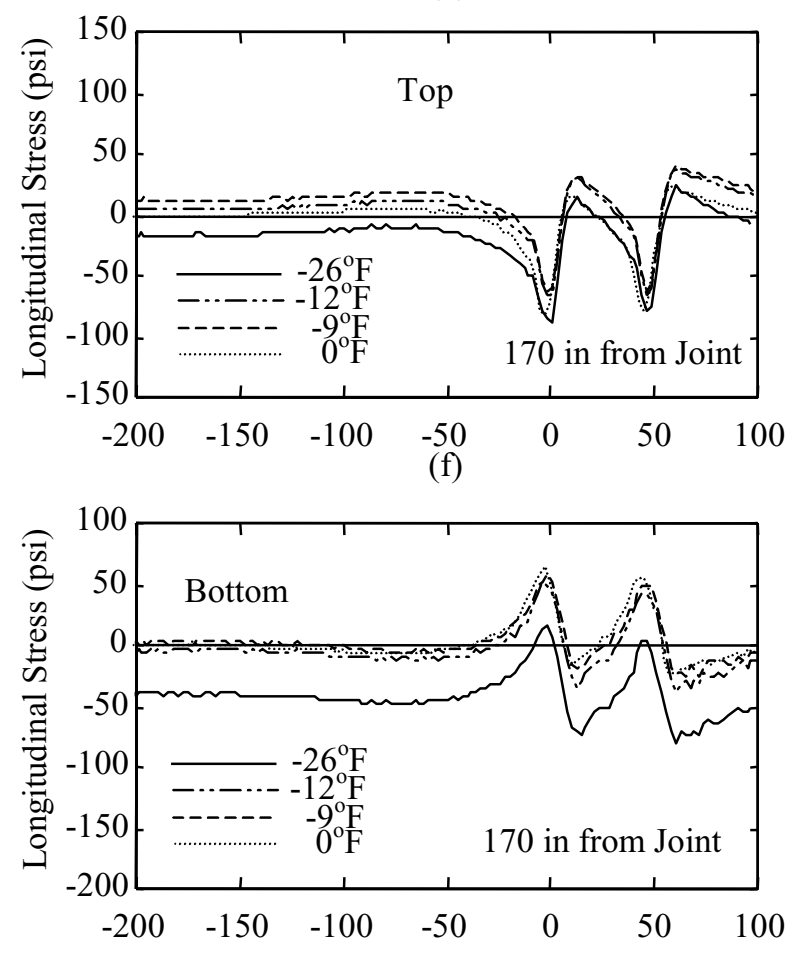

(h)

Distance from Element at 170 in. from Joint, (in.)

FIGURE $6.12 \sigma_{\mathrm{x}}$ Distribution at $90 \& 170$ in. from the Transverse Joint 

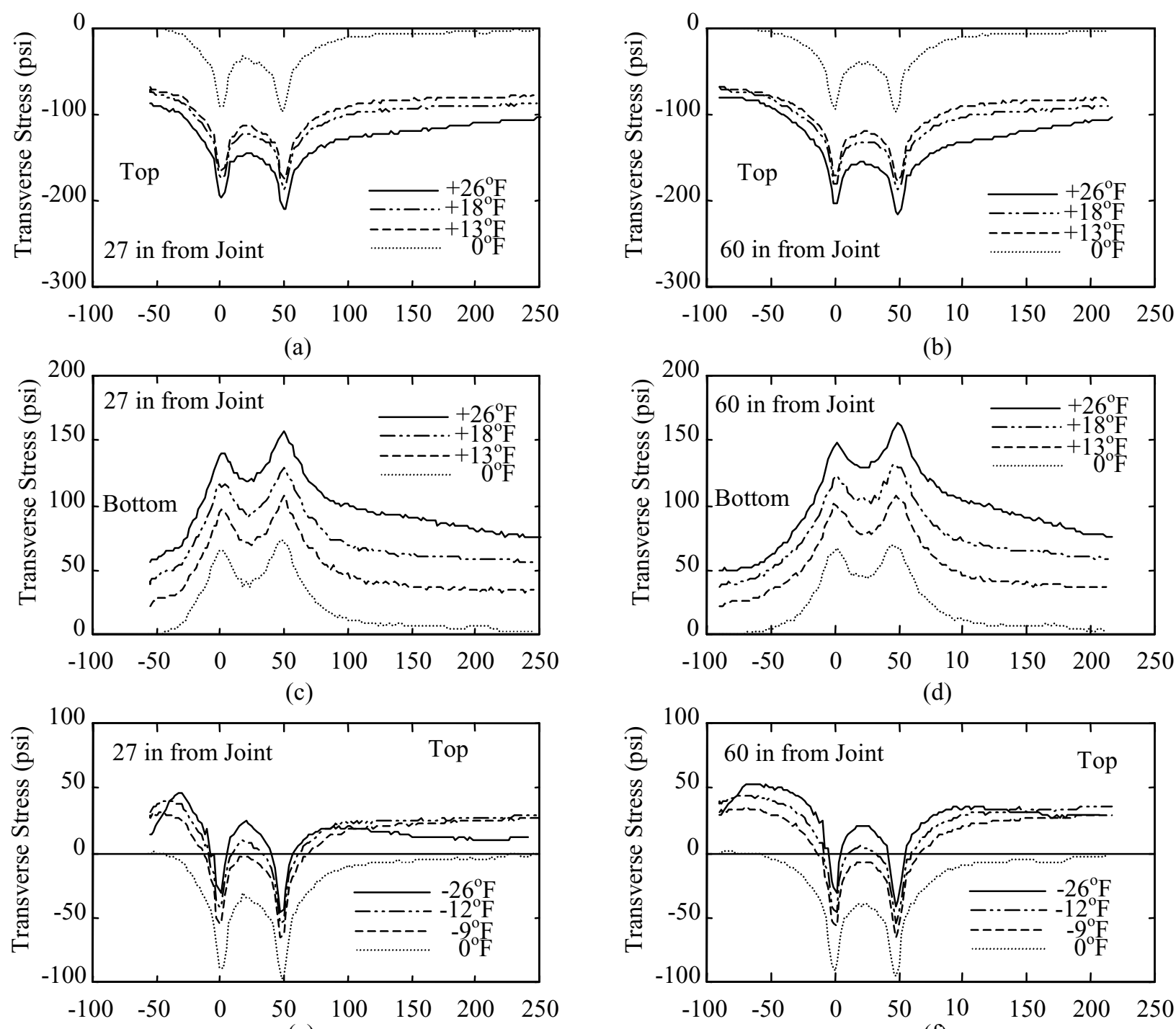

(e)
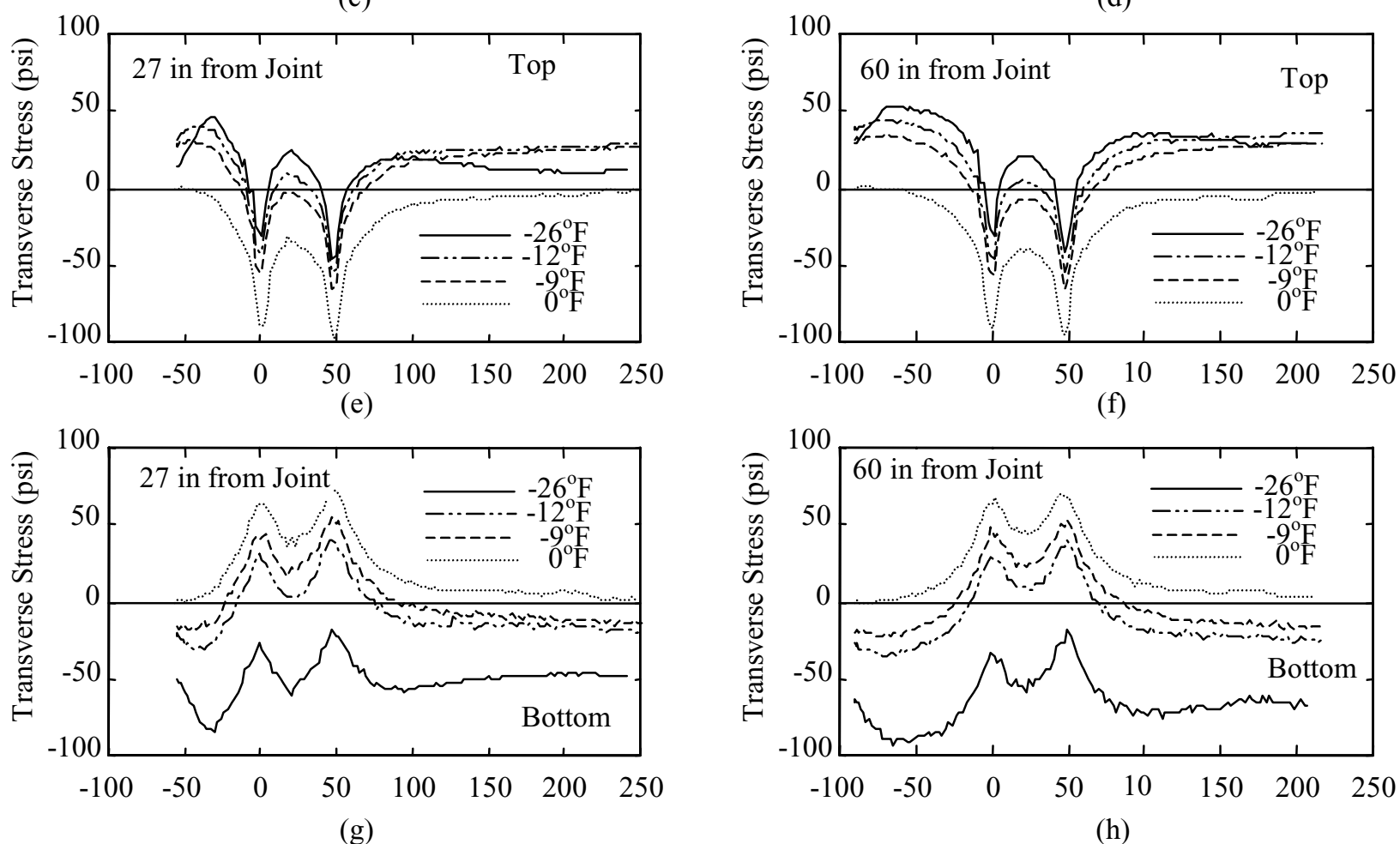

Distance from Element at 27 in. from Joint, (in.)

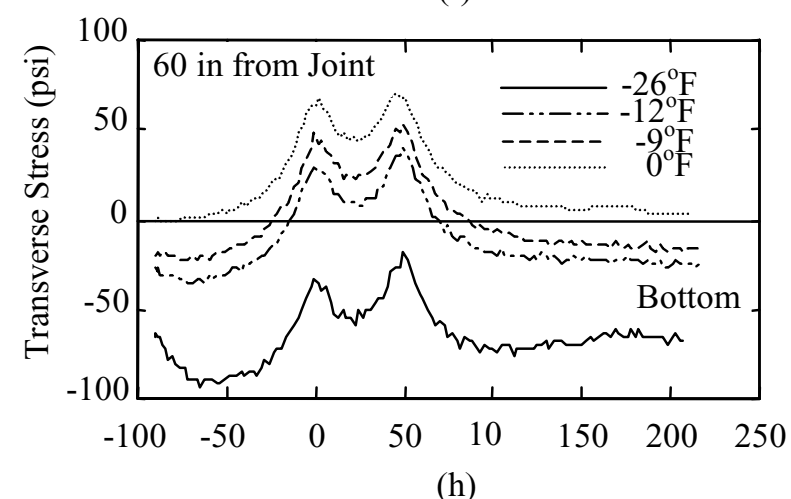

Distance from Element at 60 in. from Joint, (in.)

FIGURE $6.13 \sigma_{\mathrm{y}}$ Distribution at $27 \& 60$ in. from the Transverse Joint 

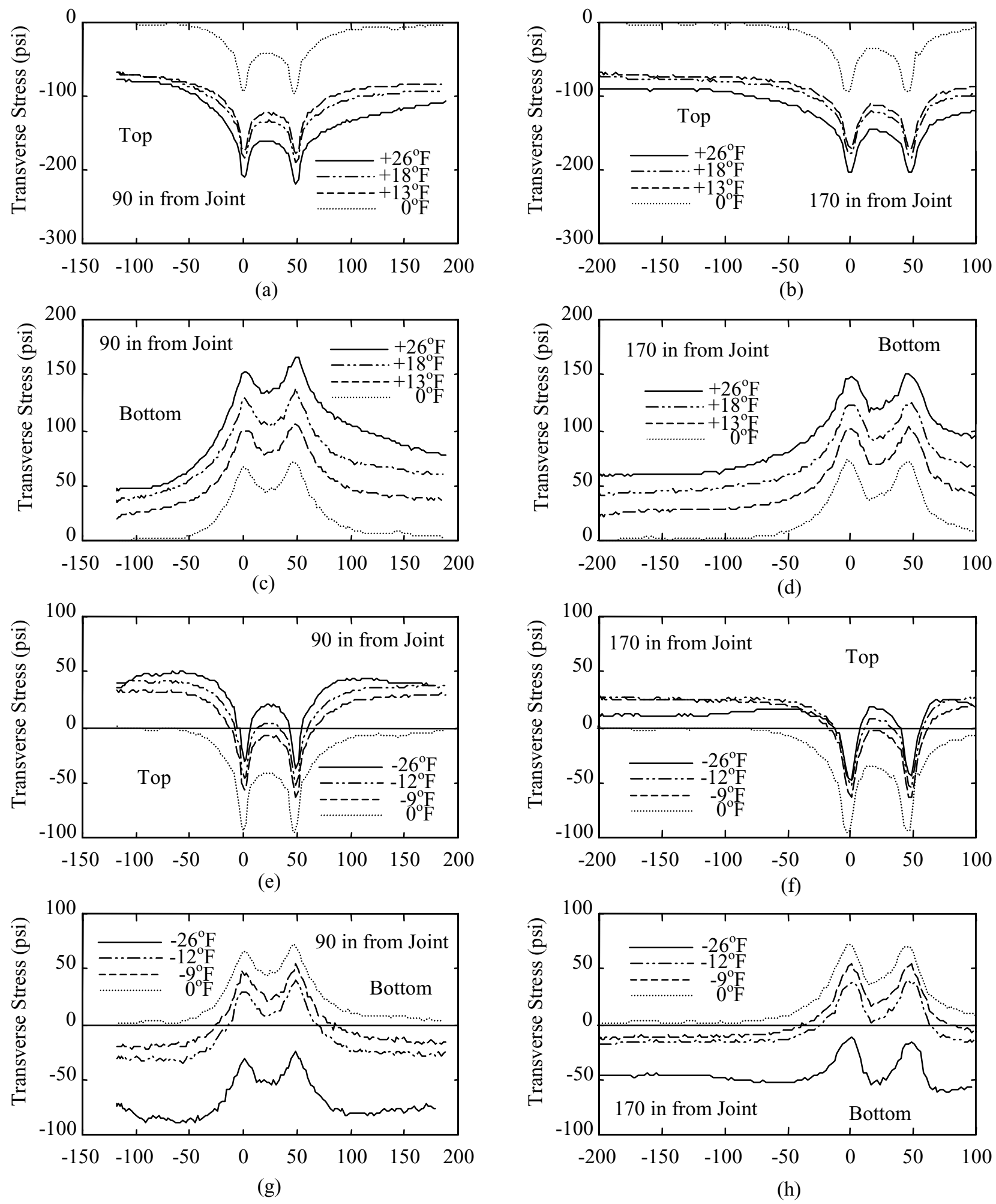

Distance from Element at 90 in. from Joint, (in.)

Distance from Element at 170 in. from Joint, (in.)

\section{FIGURE $6.14 \sigma_{\mathrm{y}}$ Distribution at $90 \& 170$ in. from the Transverse Joint}




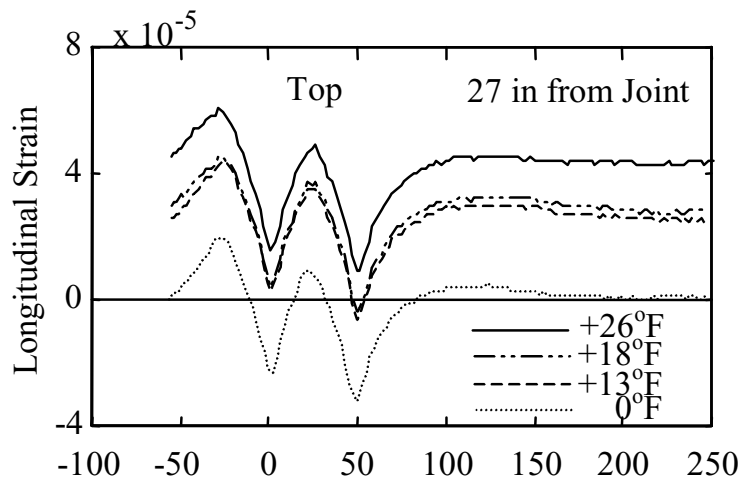

(a)
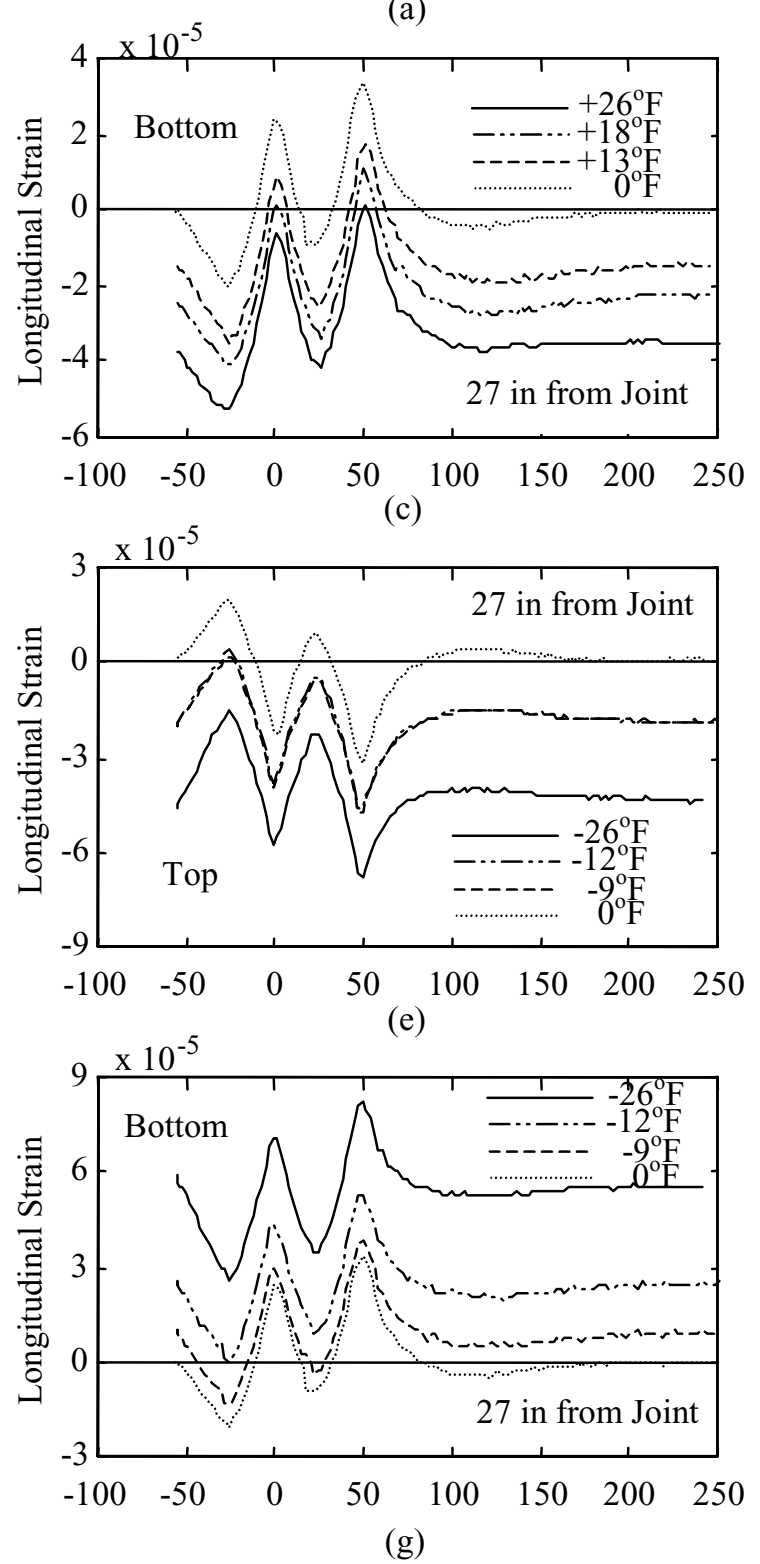

Distance from Element at 27 in. from Joint, (in.)

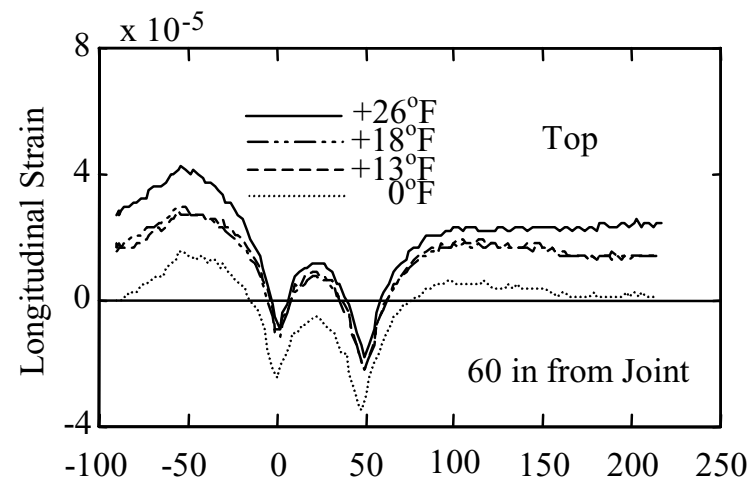

(b)
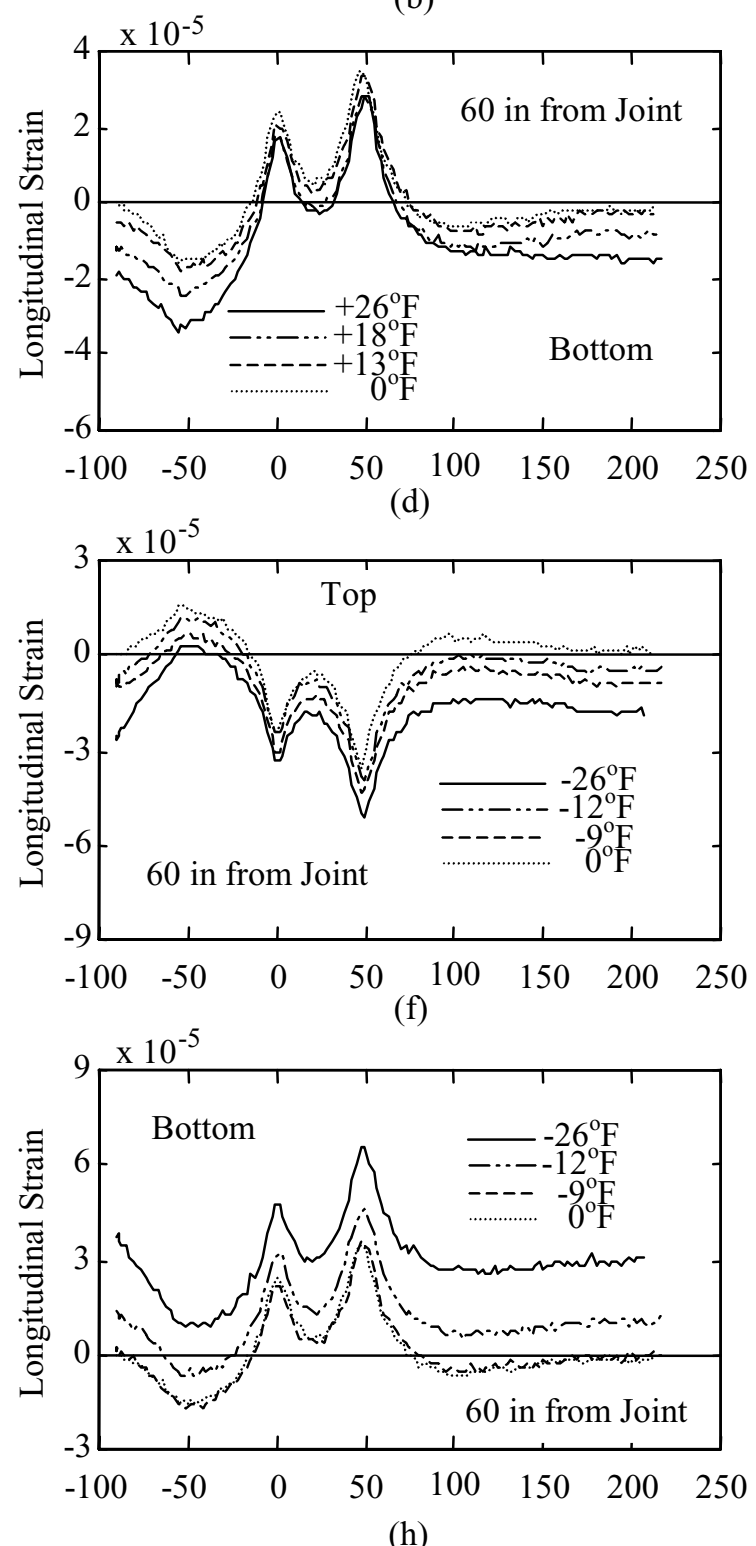

Distance from Element at 60 in. from Joint, (in.)

FIGURE $6.15 \varepsilon_{\mathrm{x}}$ Distribution at $27 \& 60$ in. from the Transverse Joint 

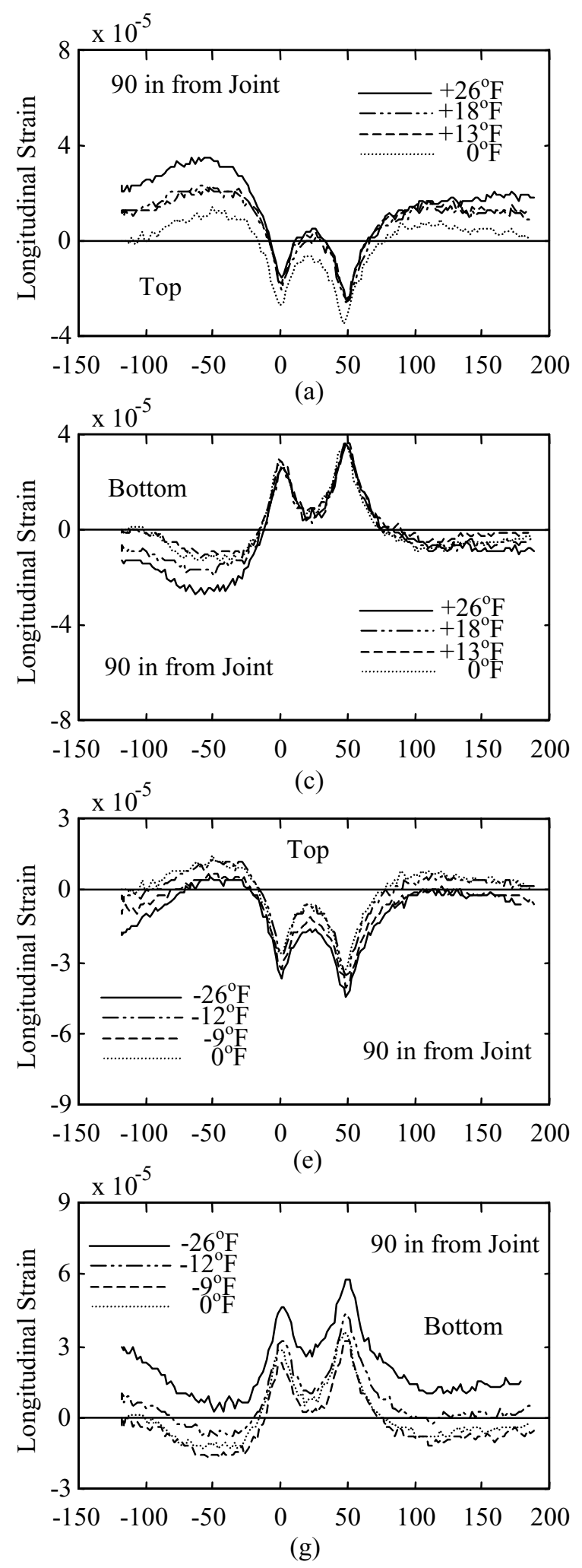

Distance from Element at 90 in. from Joint, (in.)
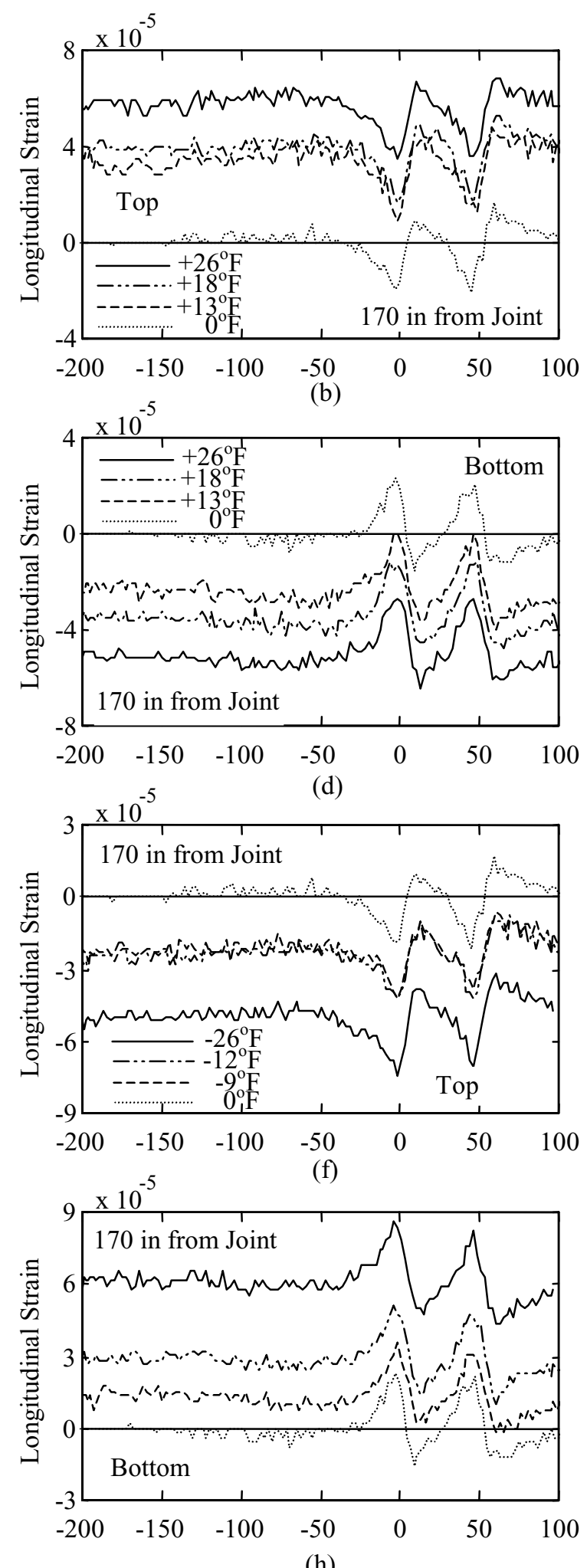

Distance from Element at 170 in. from Joint, (in.)

FIGURE $6.16 \varepsilon_{\mathrm{x}}$ Distribution at $90 \& 170$ in. from the Transverse Joint 

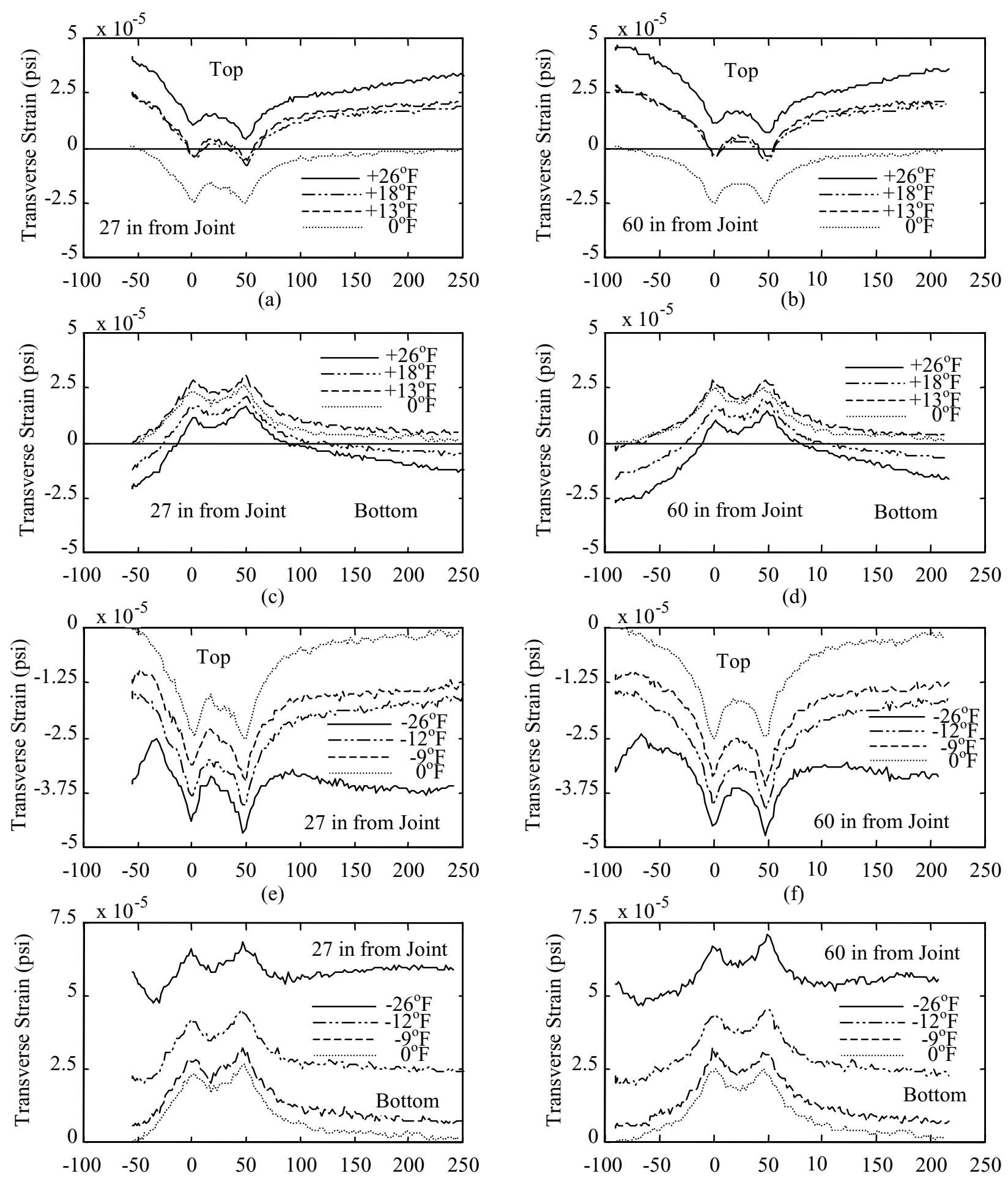

Distance from Element at 27 in. from Joint, (in.)

(g)

Distance from Element at 60 in. from Joint, (in.) (h)

FIGURE $6.17 \varepsilon_{\mathrm{y}}$ Distribution at $27 \& 60 \mathrm{in}$. from the Transverse Joint 


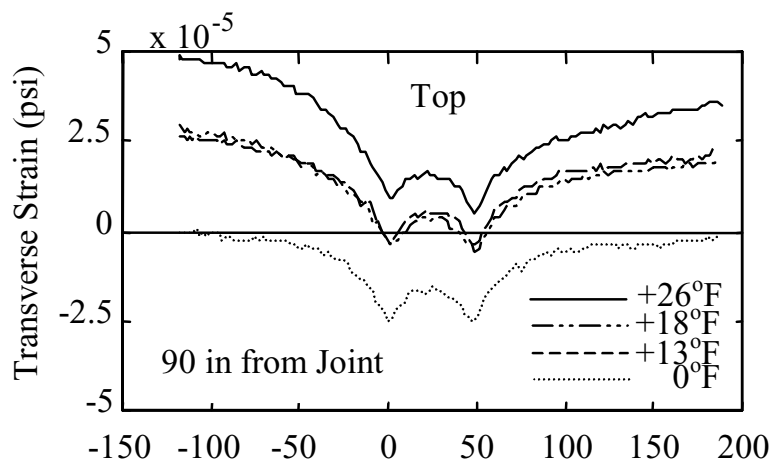

(a)
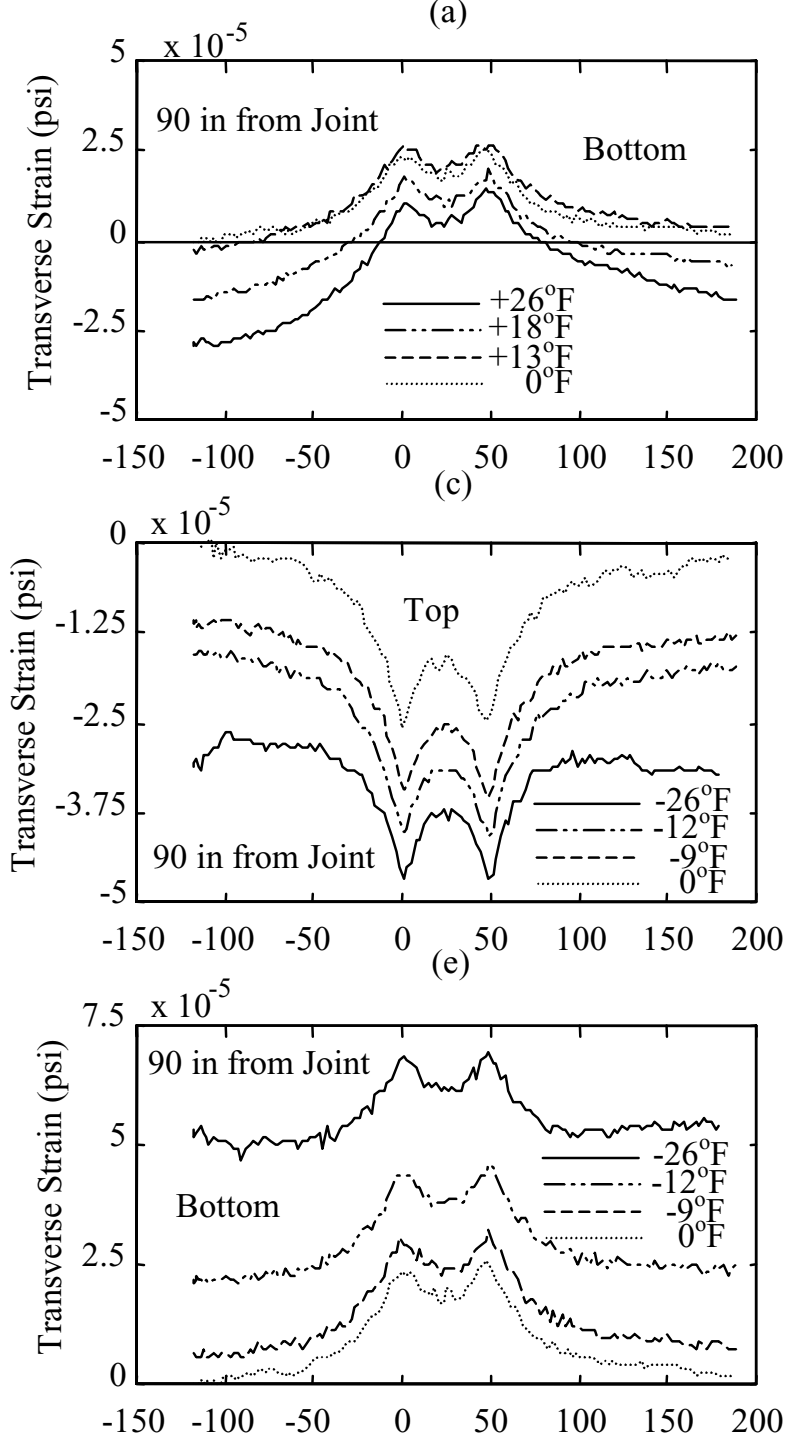

(g)

Distance from Element at 90 in. from Joint, (in.)
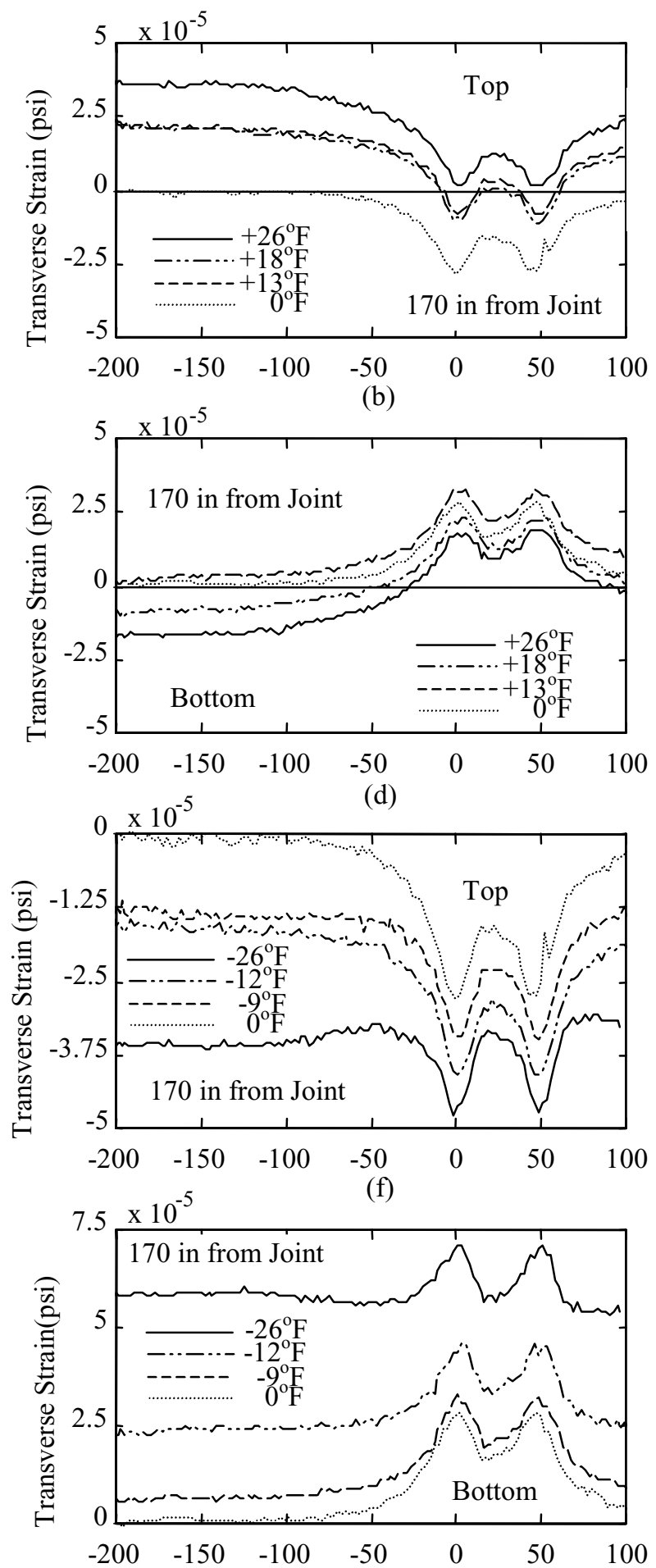

(h)

Distance from Element at 170 in. from Joint, (in.)

FIGURE $6.18 \varepsilon_{\mathrm{y}}$ Distribution at $90 \& 170$ in. from the Transverse Joint 


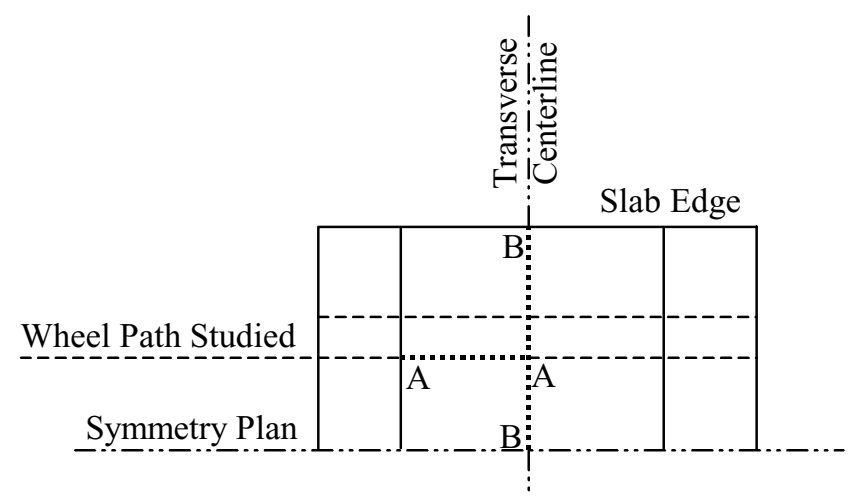

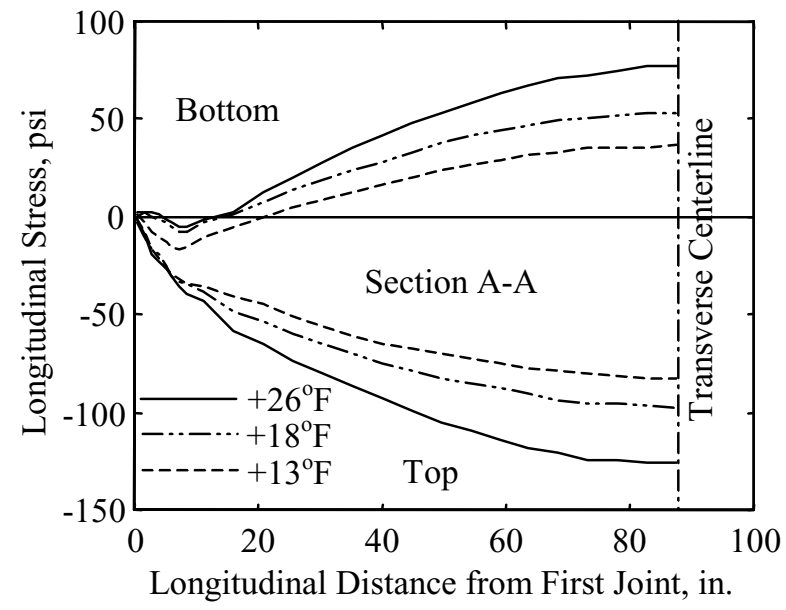

(a)

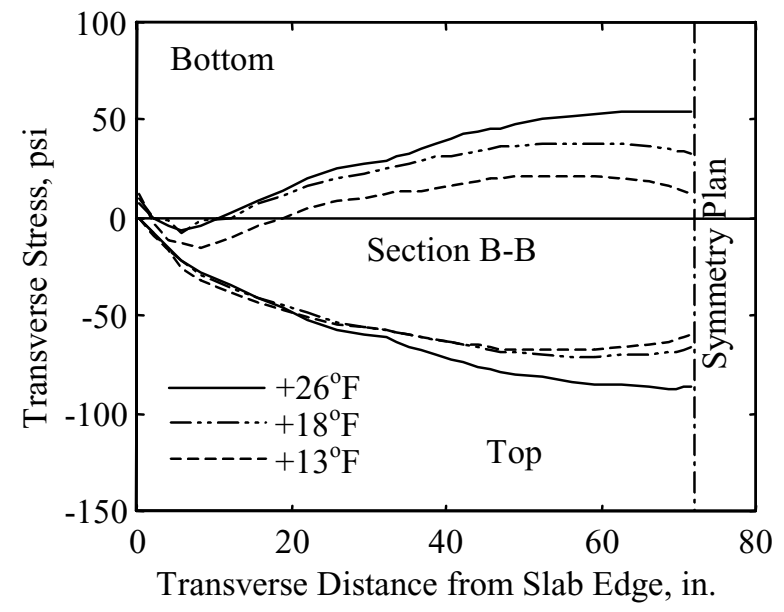

(c)

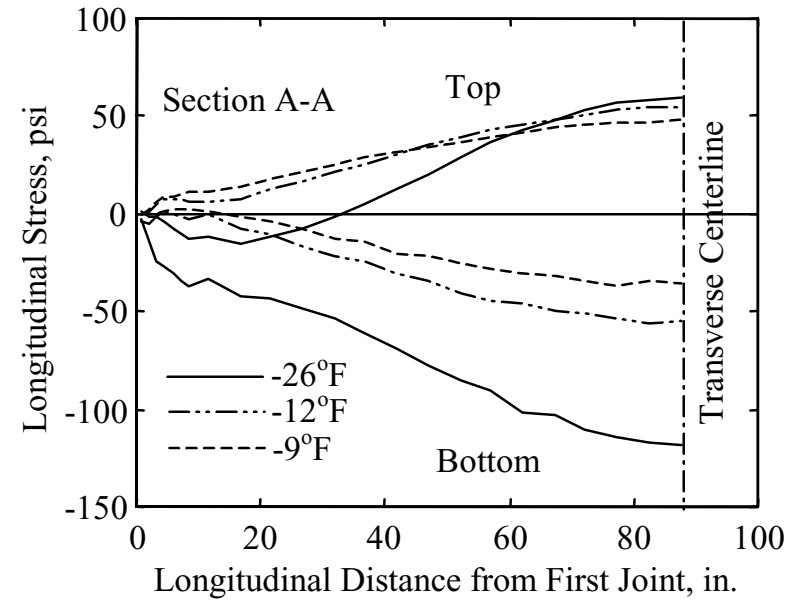

(b)

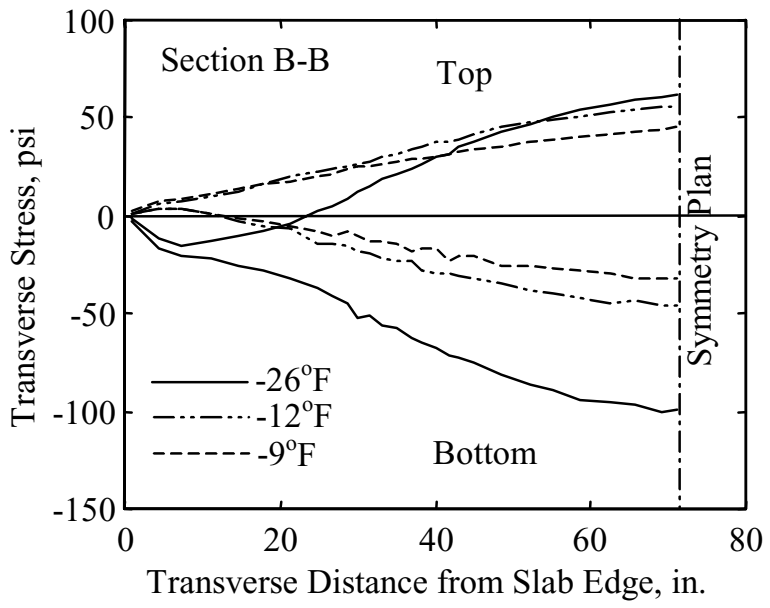

(d)

FIGURE 6.19 Variation of Thermal Stresses Induced in the Slab with Different Thermal Gradients 


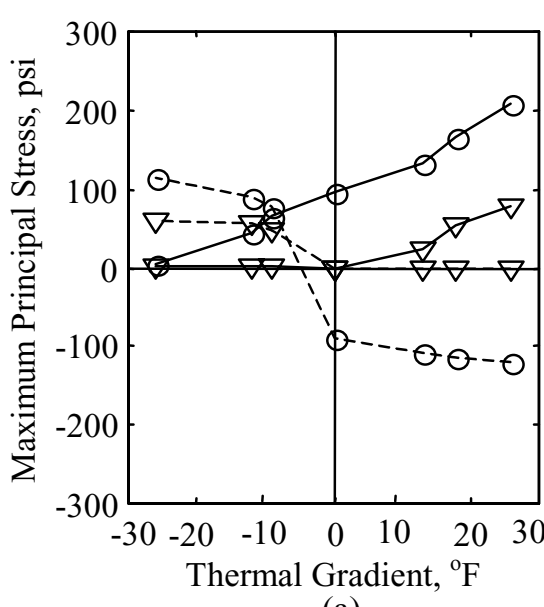

(a)

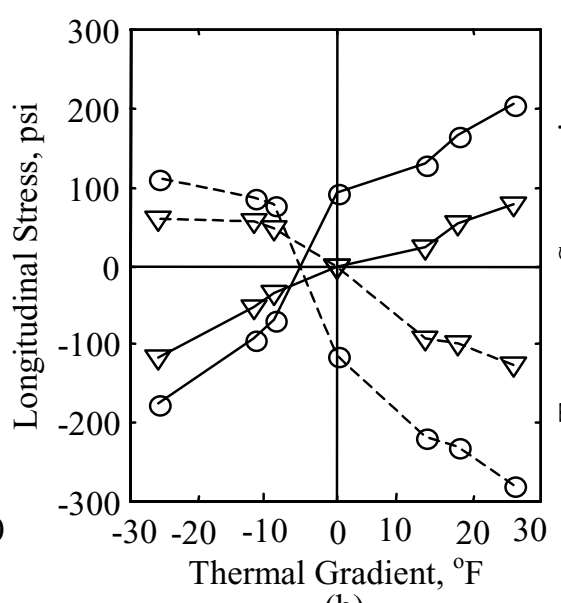

(b)

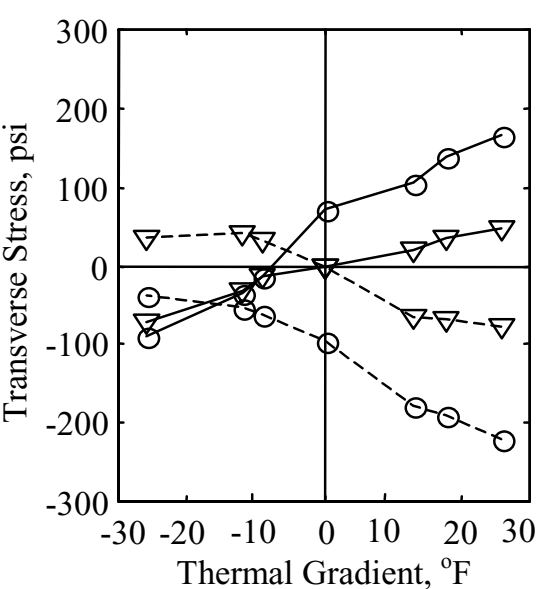

(c)

$\checkmark$ Thermal Stress at Slab Bottom

-- --- Thermal Stress at Slab Top

- Combined Stress at Slab Bottom

--O-- Combined Stress at Slab Top

FIGURE 6.20(a) Comparison Between Combined and Thermal Stresses

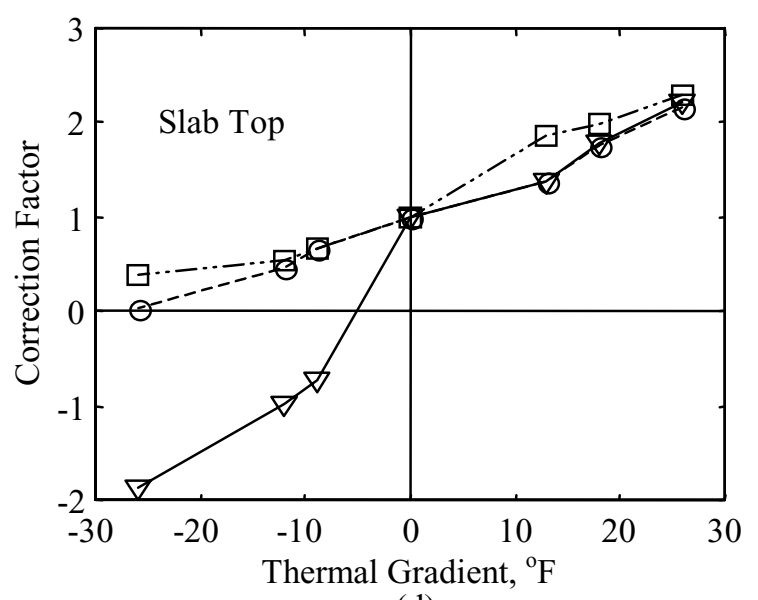

(d)

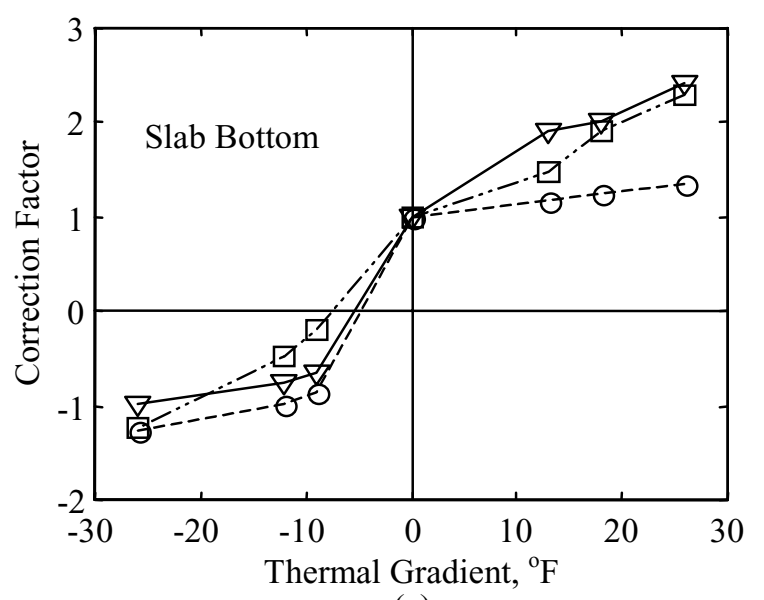

(e) $\nabla$ Maximum Principal Stress

--O-- Longitudinal Stress

- $\boxminus$.. Transverse Stress

FIGURE 6.20(b) Computed Stresses Correction Factors 


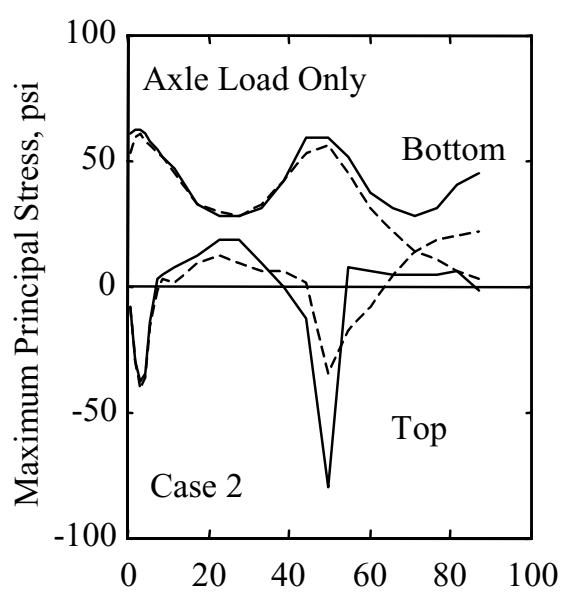

(a)

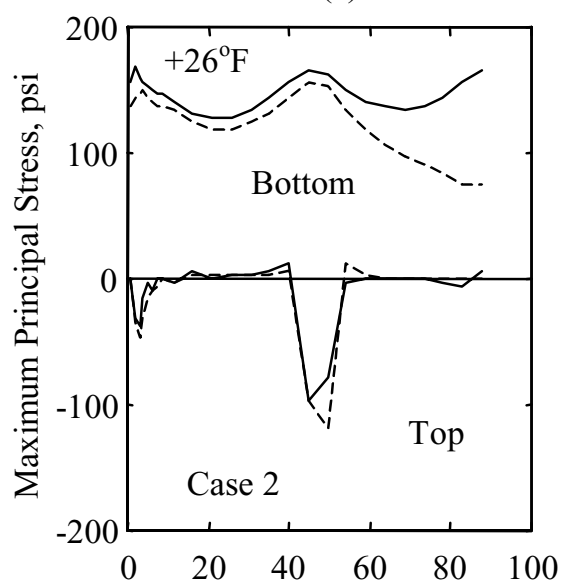

(d)

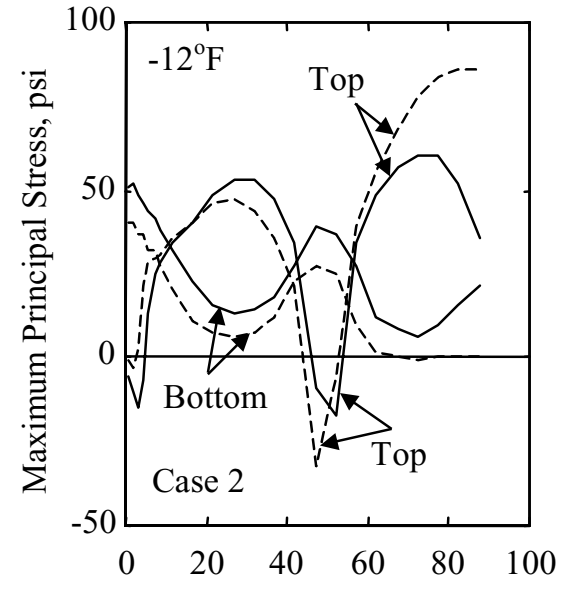

(g)

Distance from First Joint, in.

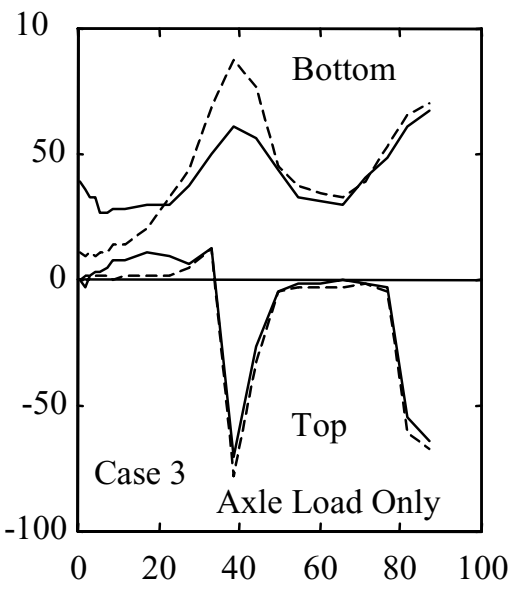

(b)

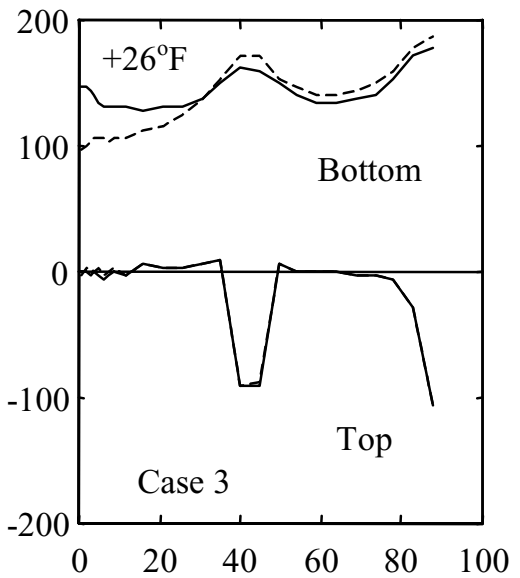

(e)

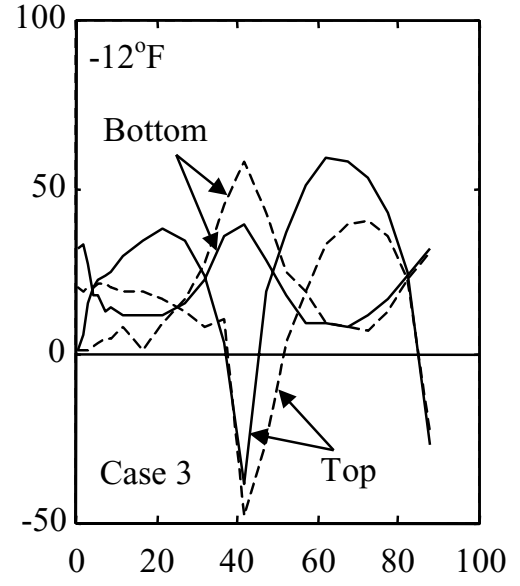

(h)

Distance from First Joint, in.

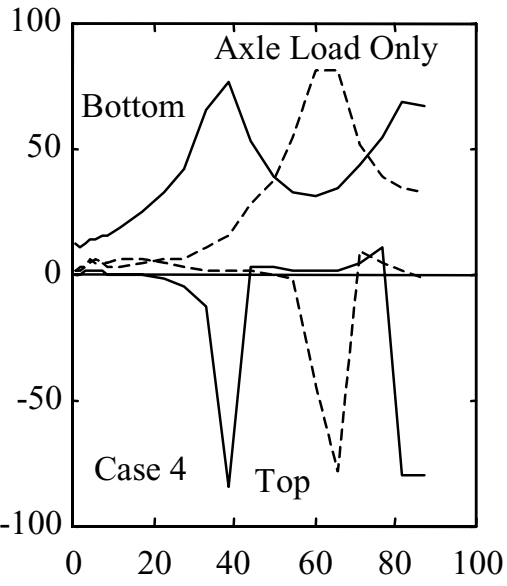

(c)

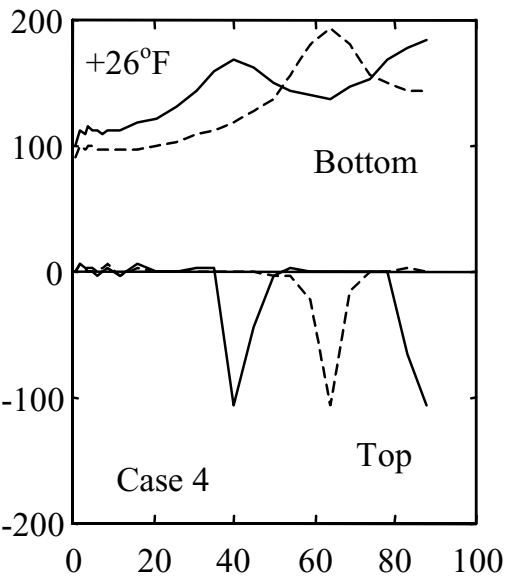

(f)

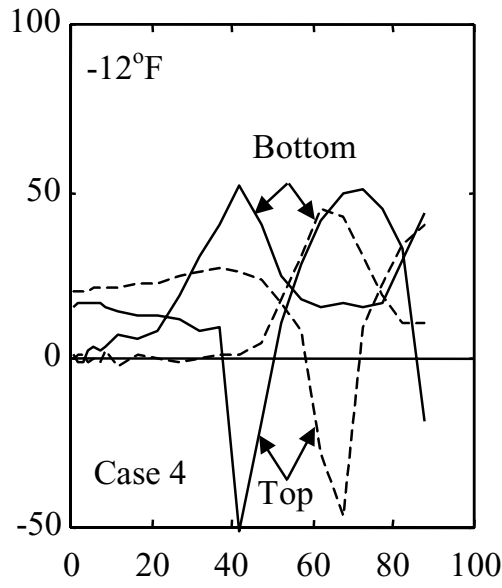

(i)

Distance from First Joint, in.

----- Tandem Axle Tridem Axle

FIGURE 6.21 Effect of Axle Configuration on the MPS Profile along Wheel Path (15 ft. Long \& 9in Thick Slabs) 

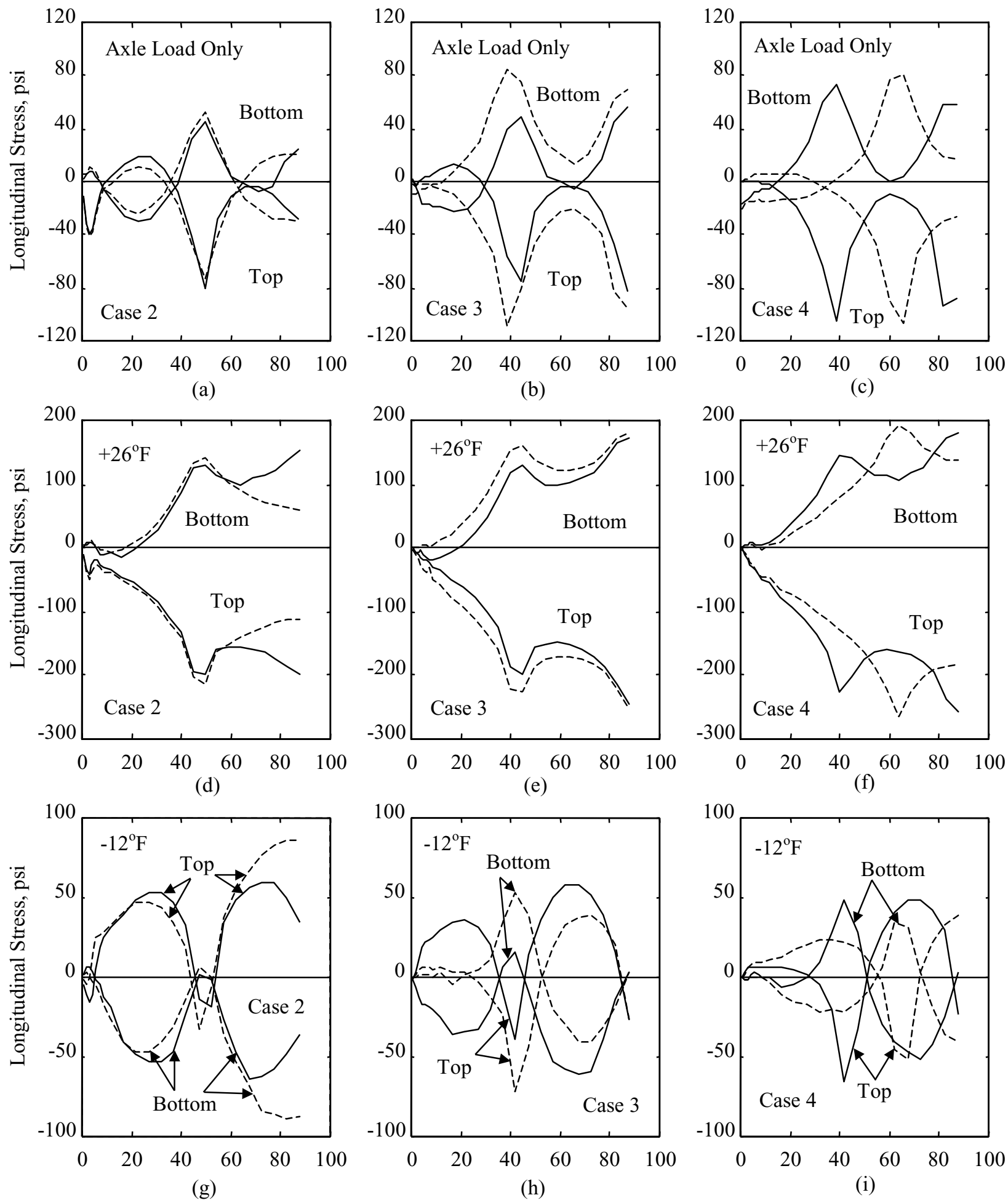

Distance from First Joint, in.

Distance from First Joint, in.

Distance from First Joint, in.

----- Tandem Axle

— Tridem Axle

FIGURE 6.22 Effect of Axle Configuration on $\sigma_{x}$ Profile along Wheel Path

(15 ft. Long \& 9in Thick Slabs) 


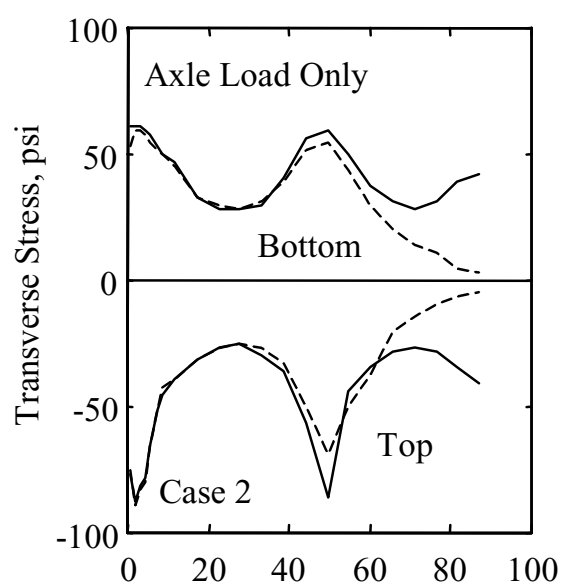

(a)

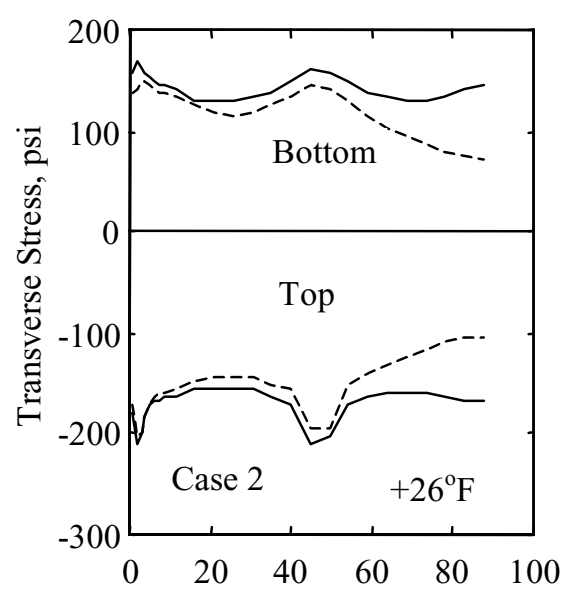

(d)

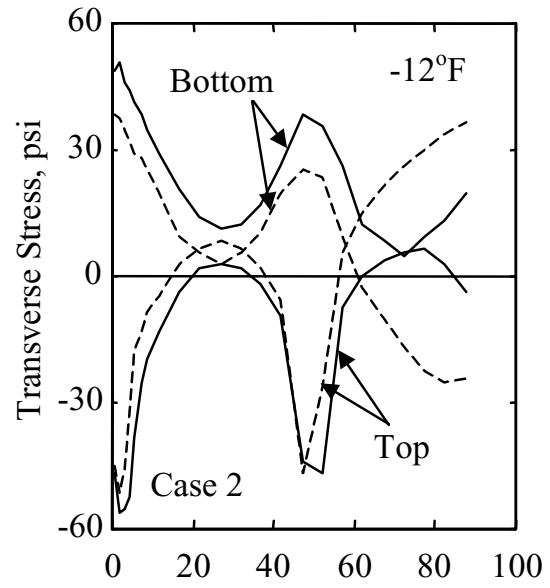

(g)

Distance from First Joint, in.

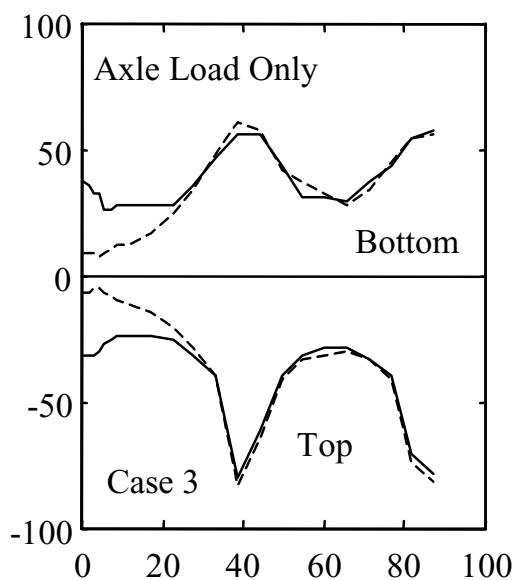

(b)

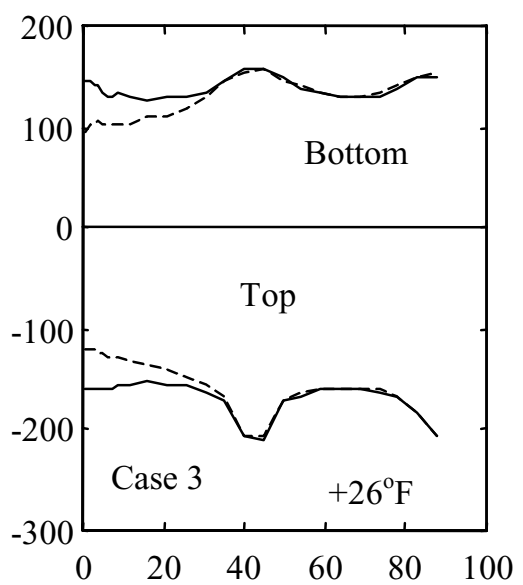

(e)

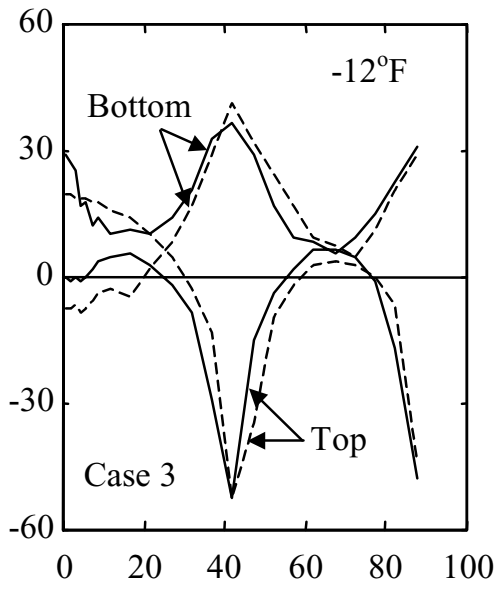

(h)

Distance from First Joint, in.

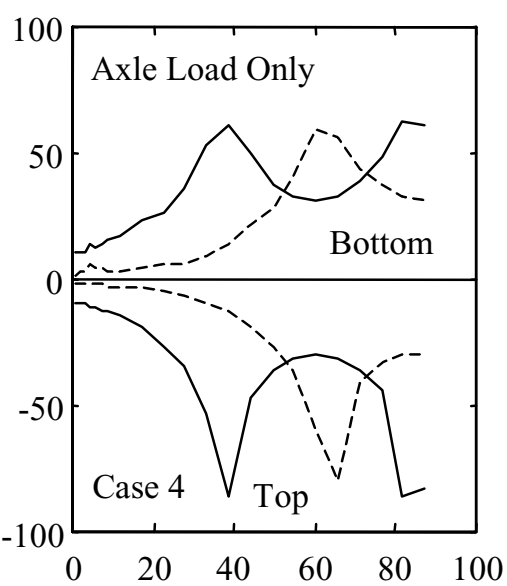

(c)

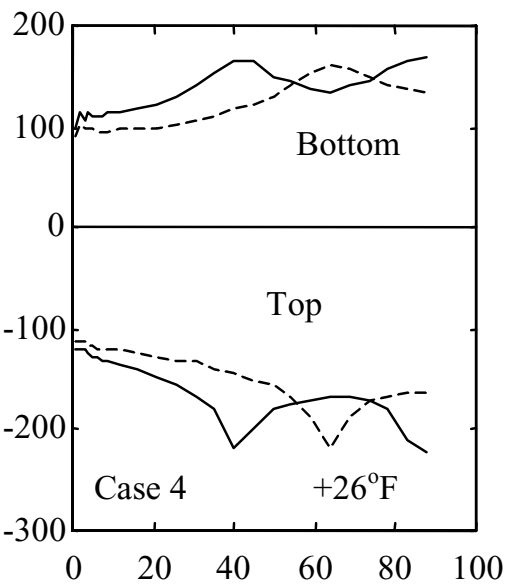

(f)

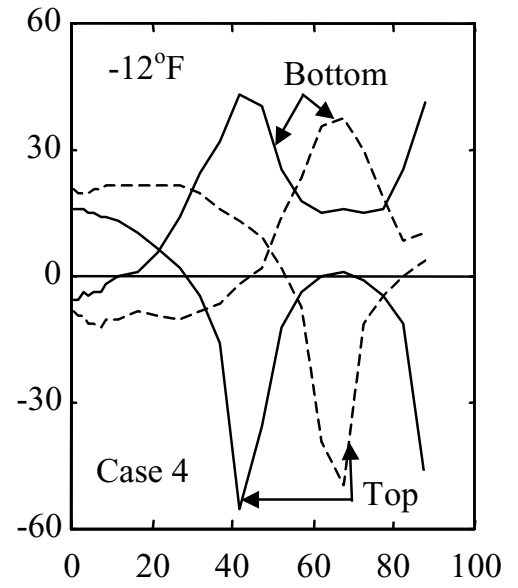

(i)

Distance from First Joint, in.

Tandem Axle

Tridem Axle

FIGURE 6.23 Effect of Axle Configuration on $\sigma_{\mathrm{y}}$ Profile along Wheel Path (15 ft. Long \& 9in Thick Slabs) 


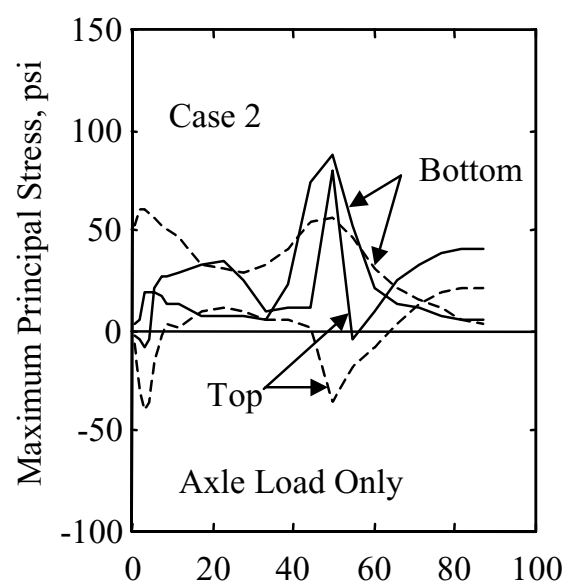

(a)

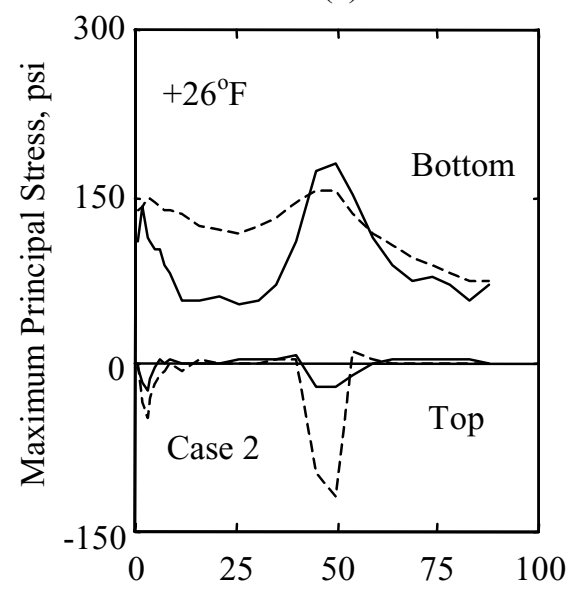

(d)

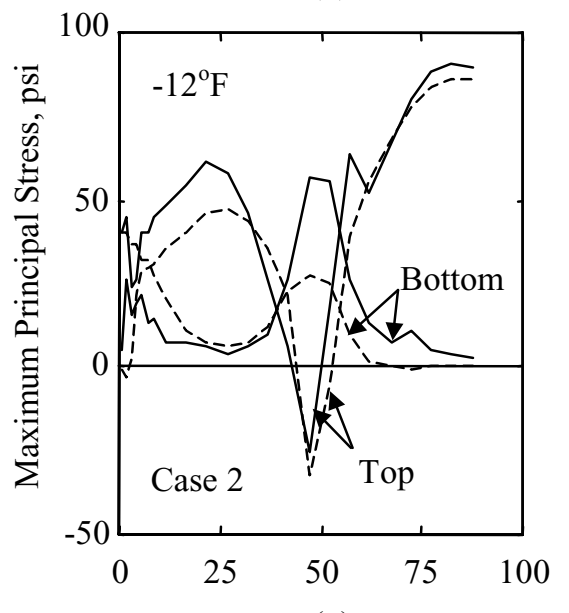

(g)

Distance from First Joint, in.

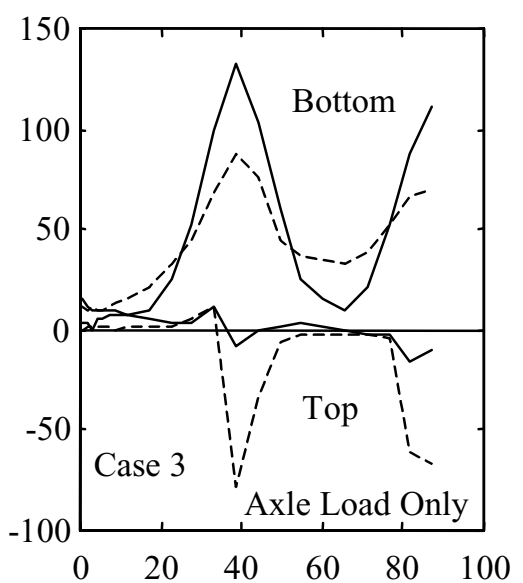

(b)

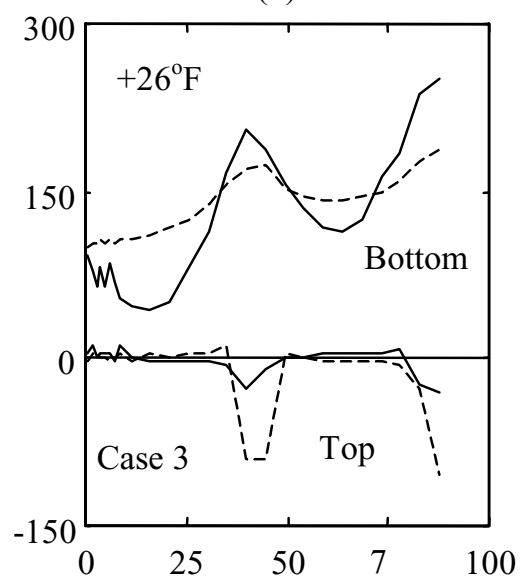

(e)

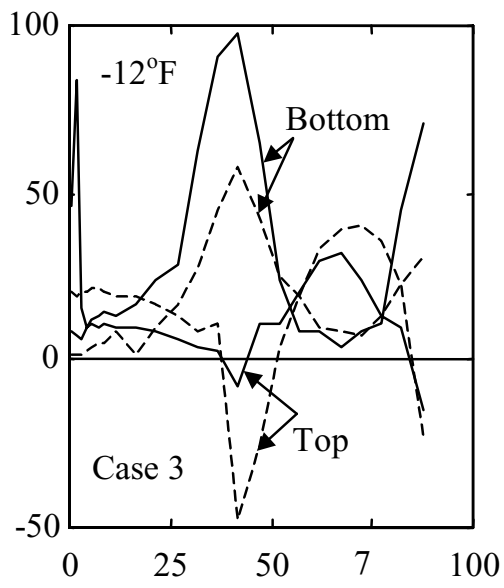

(h)

Distance from First Joint, in.

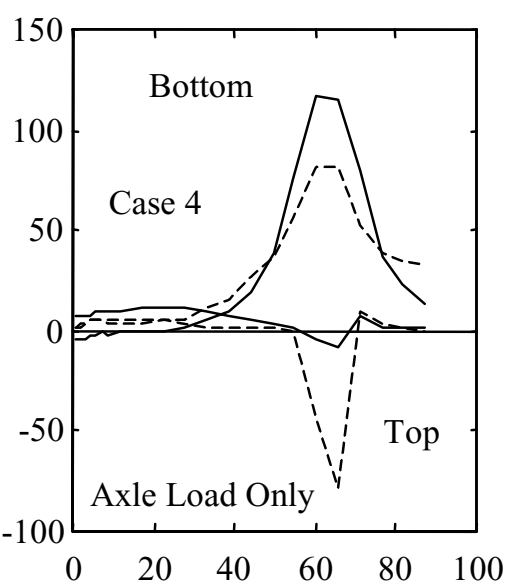

(c)

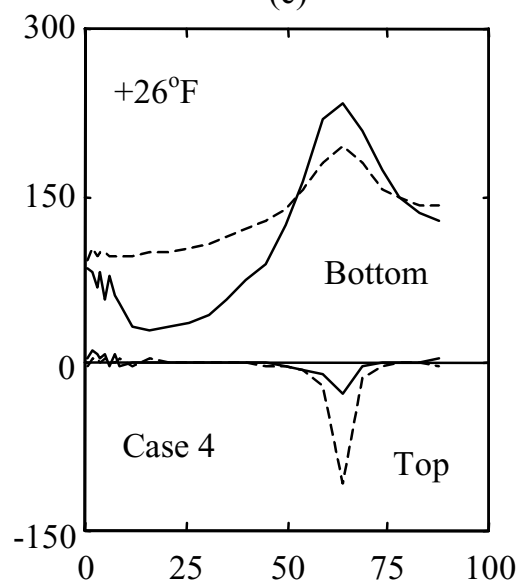

(f)

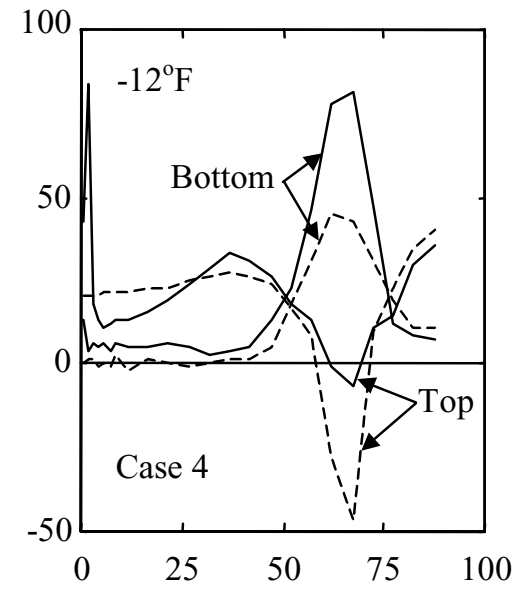

(i)

Distance from First Joint, in.

Wheel-Path

Edge Load

FIGURE 6.24 Effect of Loading Position on the MPS Profile along Wheel Path (15 ft. Long \& 9in Thick Slabs Subjected to Tandem Axle Load) 

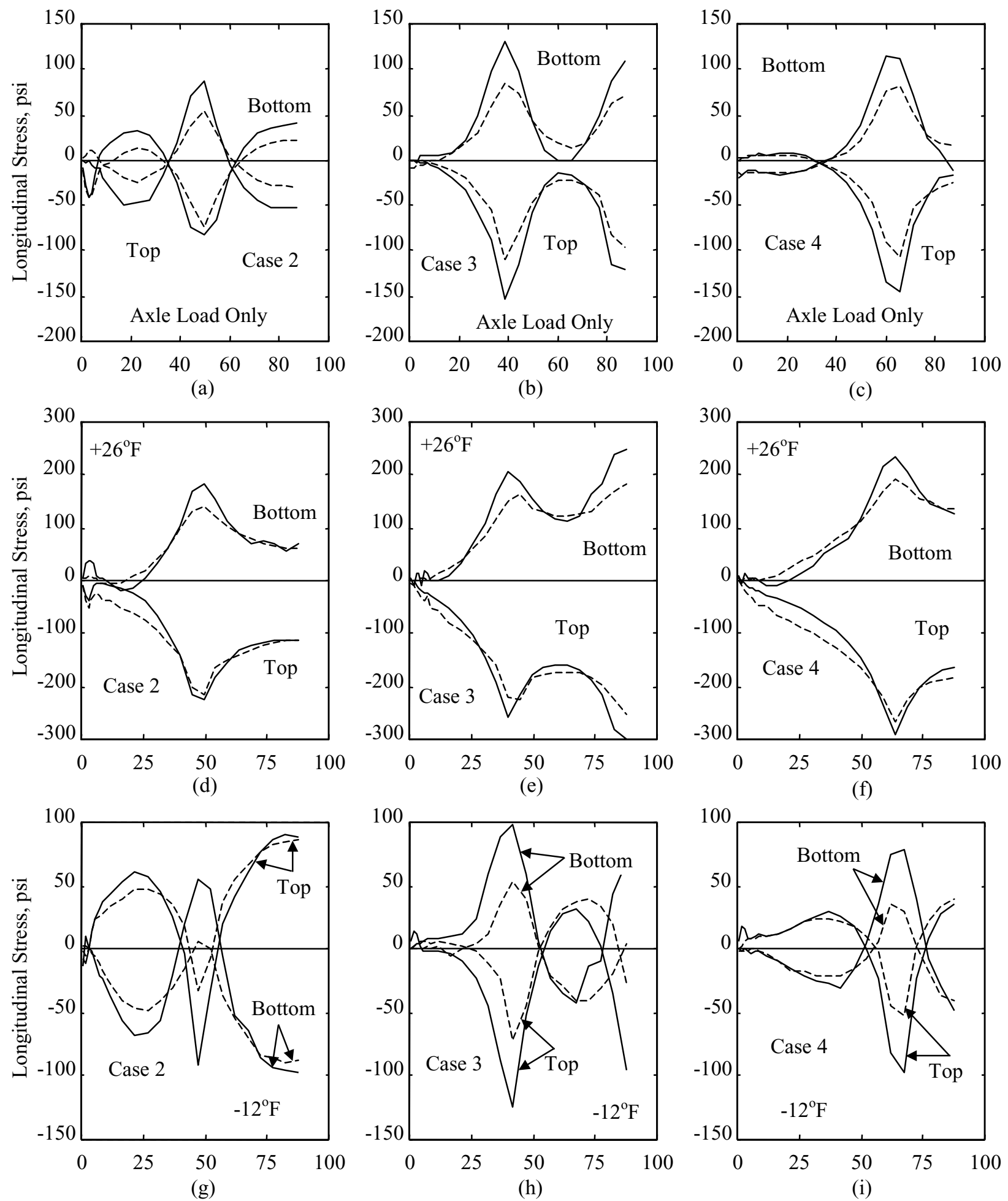

Distance from First Joint, in.

Distance from First Joint, in.

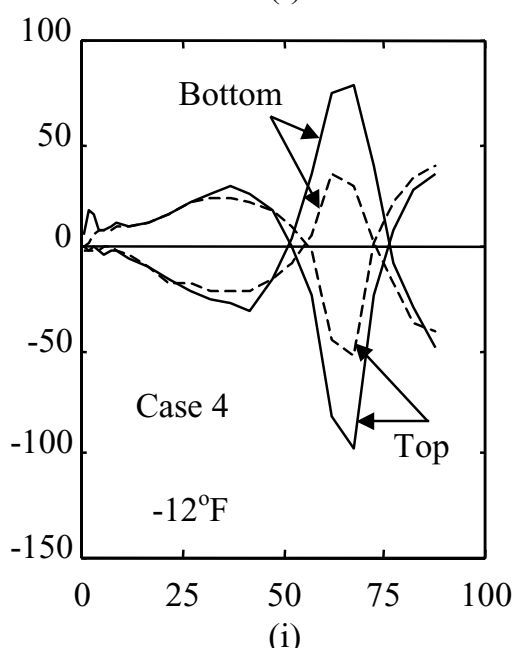

Distance from First Joint, in.

----- Wheel-Path Edge Load

FIGURE 6.25 Effect of Loading Position on $\sigma_{x}$ Profile along Wheel Path (15 ft. Long \& 9in Thick Slabs Subjected to Tandem Axle Load) 


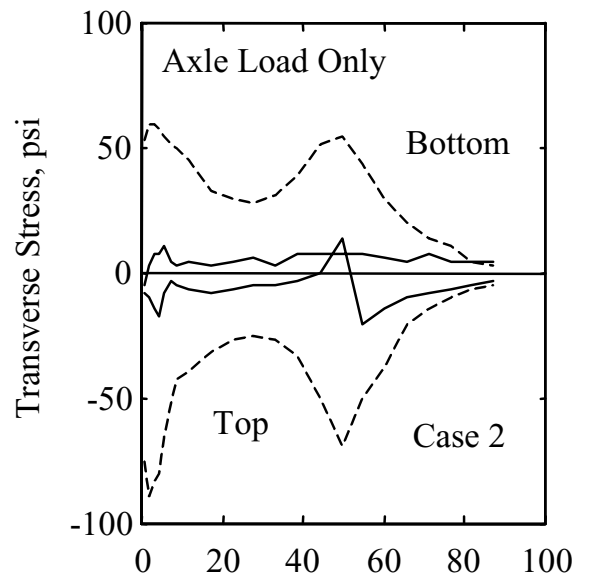

(a)

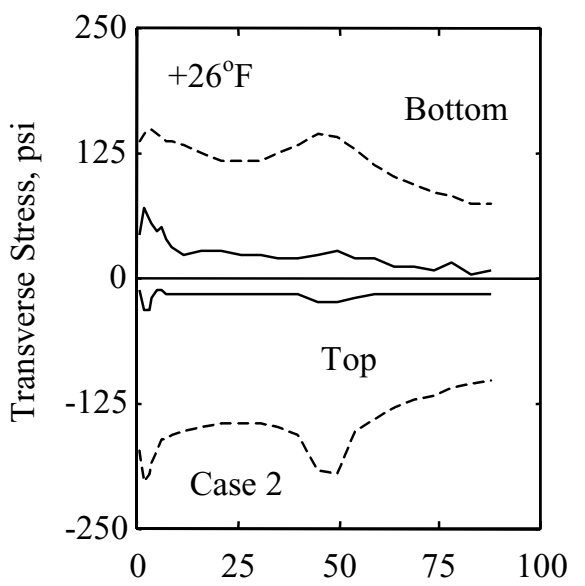

(d)

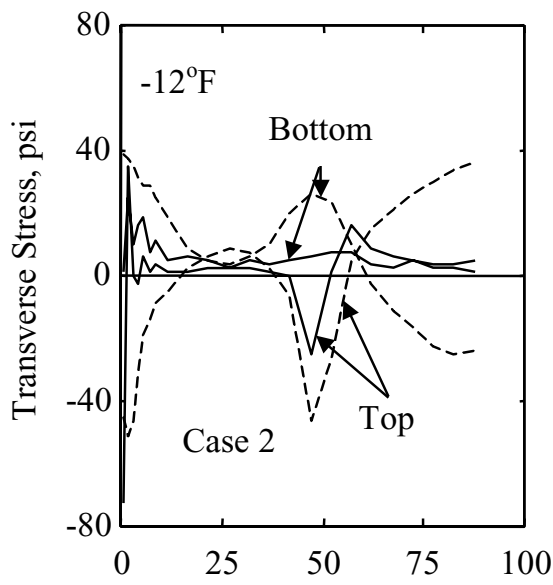

(g)

Distance from First Joint, in.

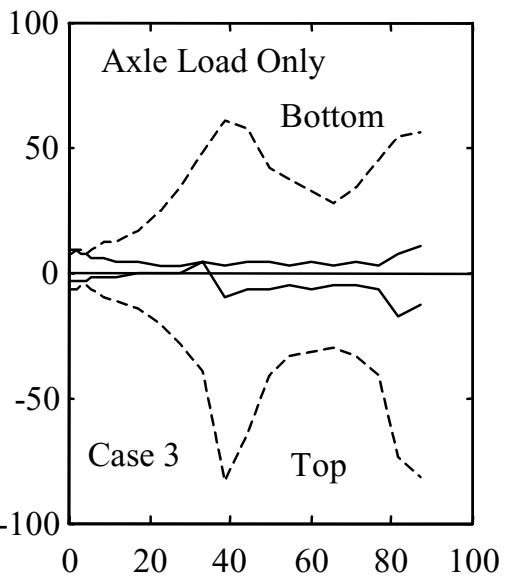

(b)

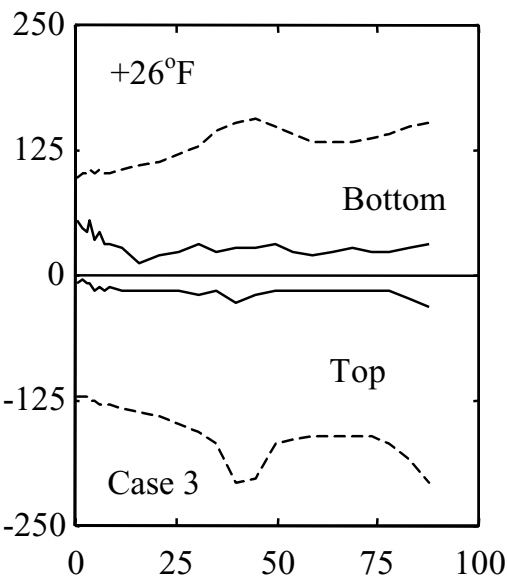

(e)

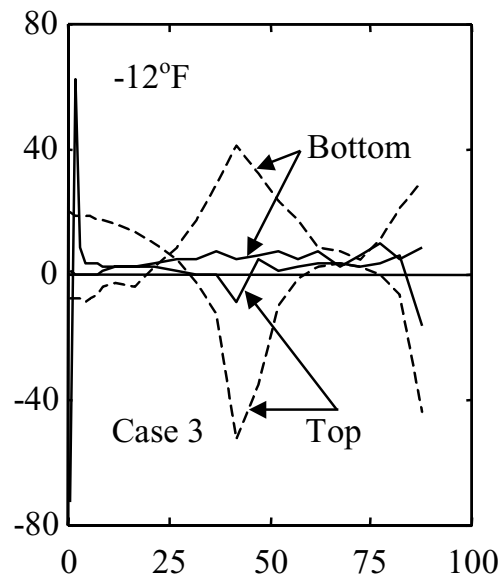

(h)

Distance from First Joint, in.

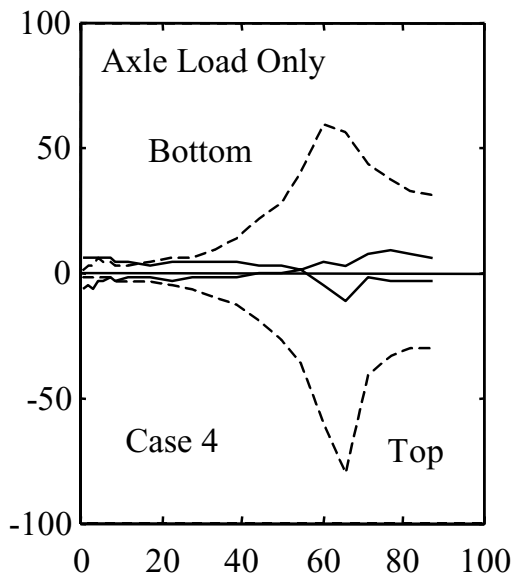

(c)

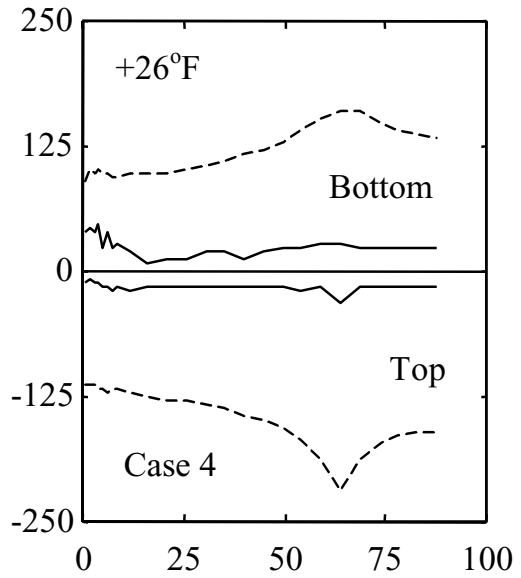

(f)

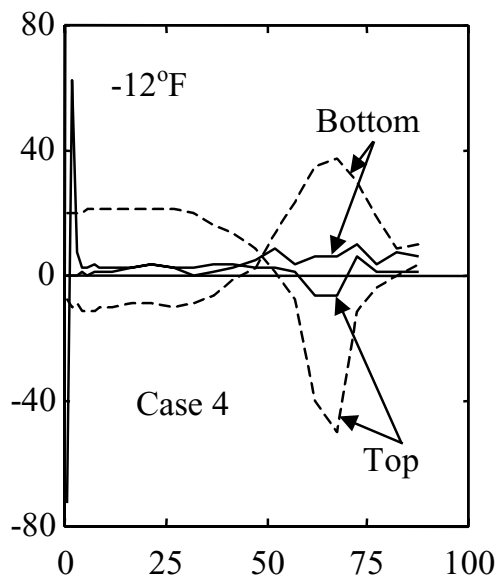

(i)

Distance from First Joint, in.

----- Wheel-Path

Edge Load

FIGURE 6.26 Effect of Loading Position on $\sigma_{\mathrm{y}}$ Profile along Wheel Path (15 ft. Long \& 9in Thick Slabs Subjected to Tandem Axle Load) 


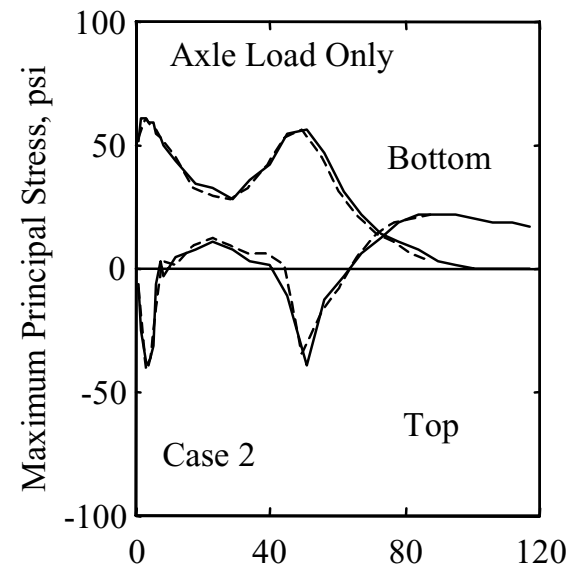

(a)

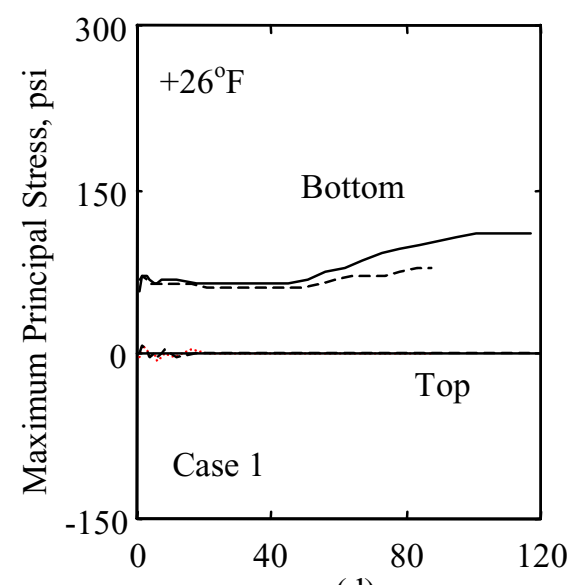

(d)

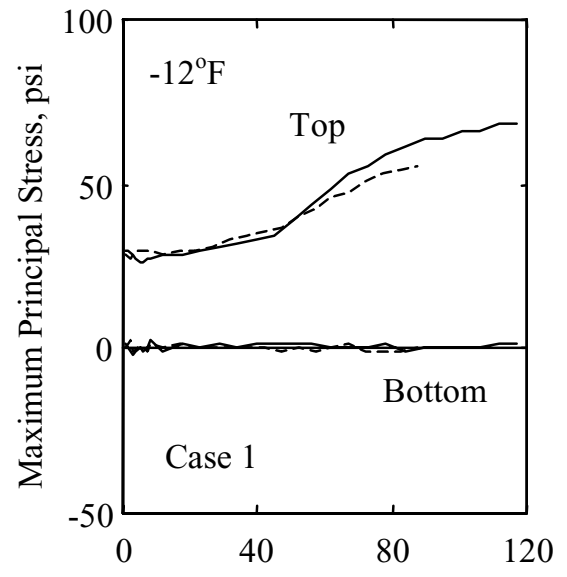

(g)

Distance from First Joint, in.

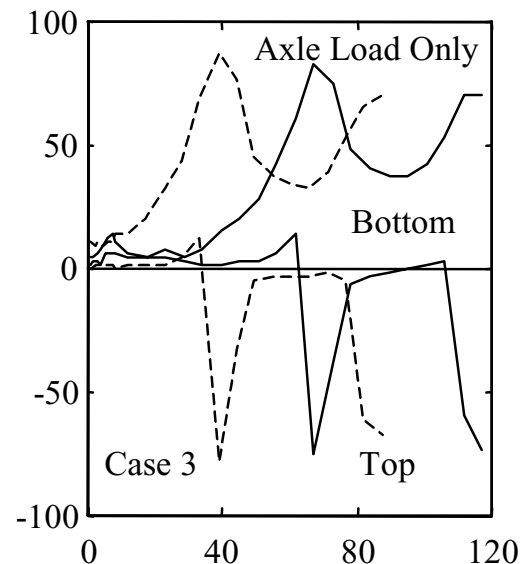

(b)
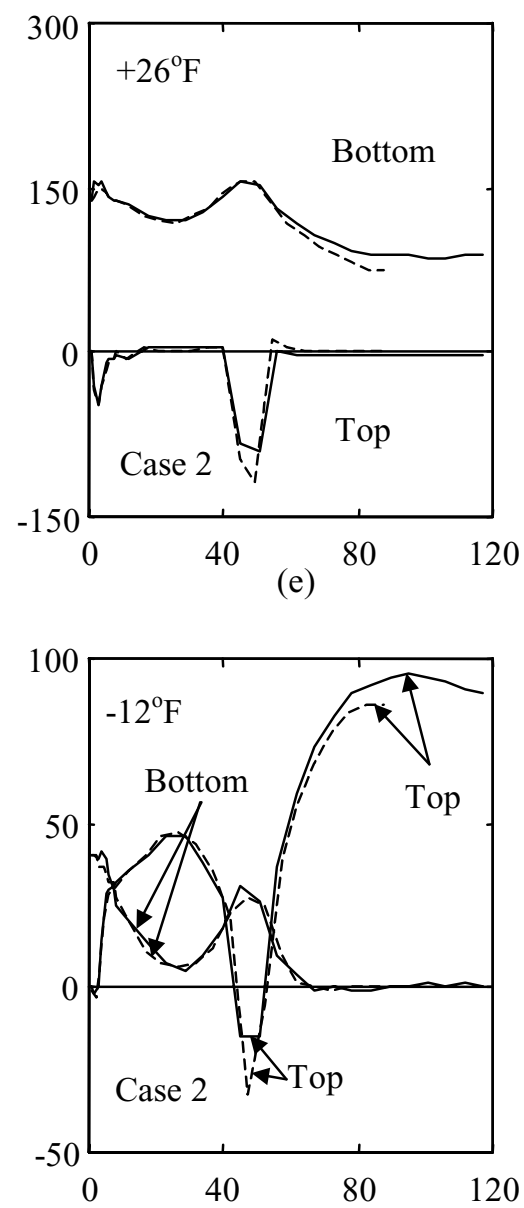

(h)

Distance from First Joint, in.

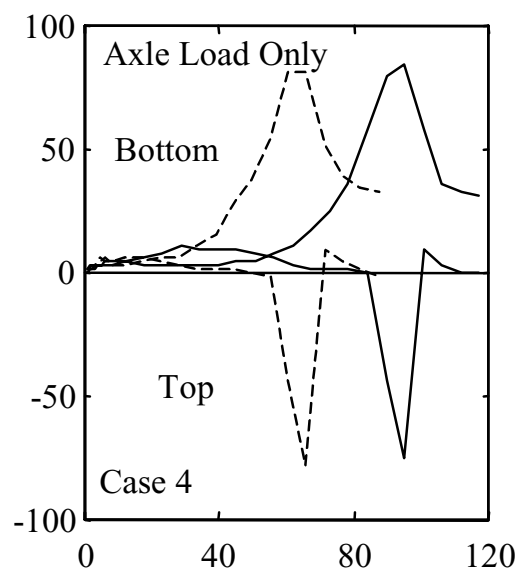

(c)
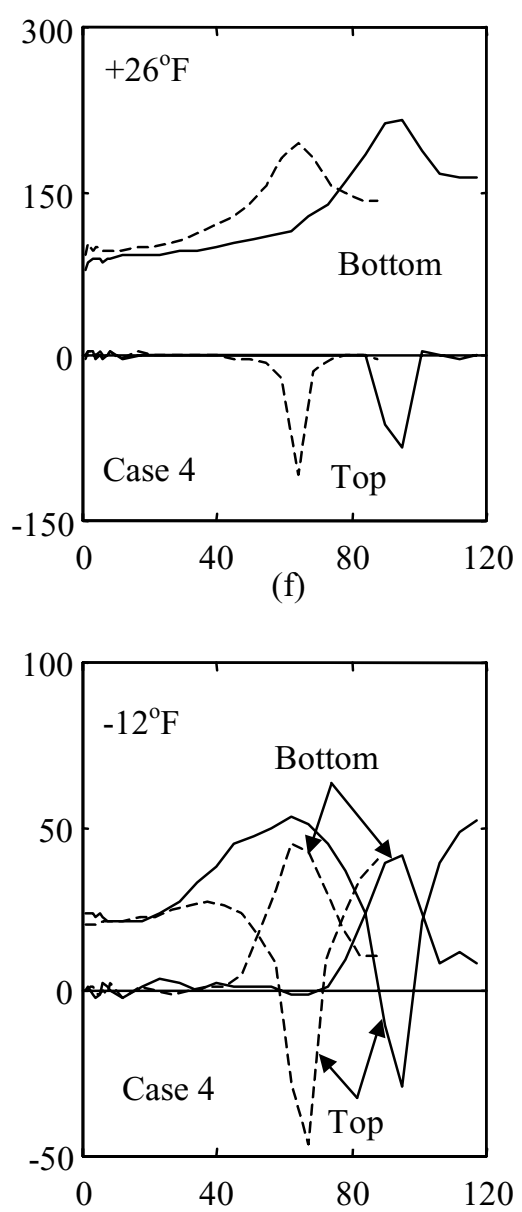

(i)

Distance from First Joint, in.

----- $15 \mathrm{ft}$. Slab

$20 \mathrm{ft}$. Slab

FIGURE 6.27 Effect of Slab Length on the MPS Profile along Wheel Path (9in Thick Slabs \& Tandem Axle) 


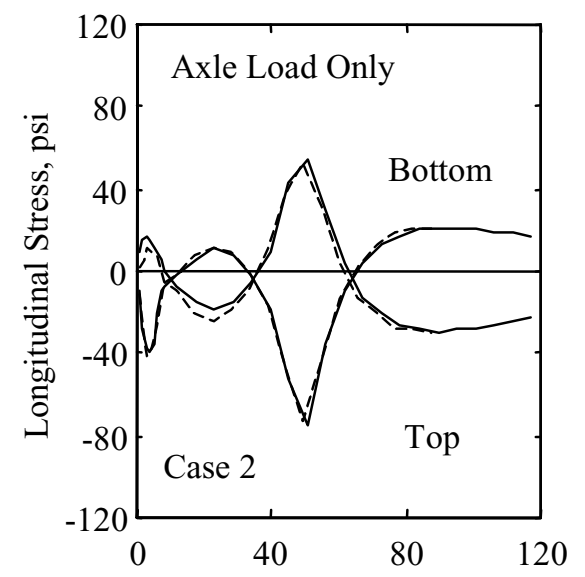

(a)

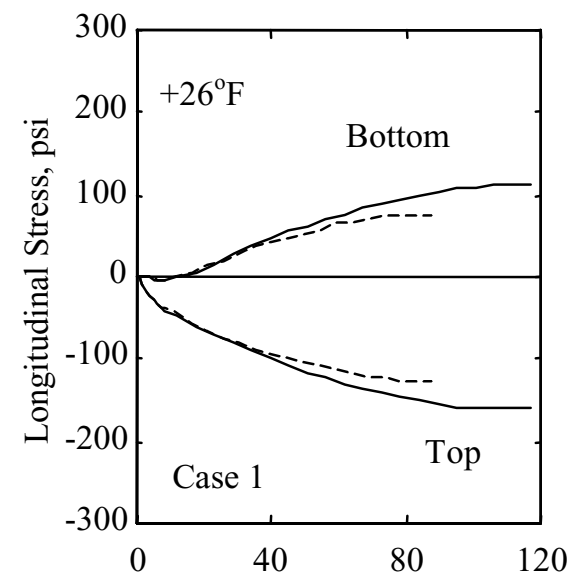

(d)

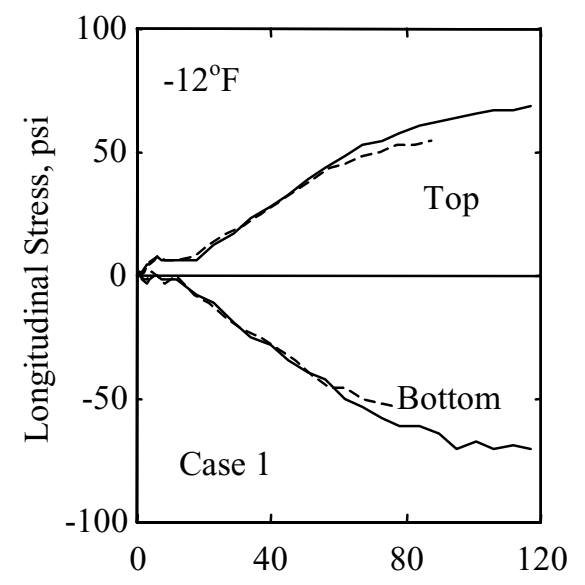

(g)

Distance from First Joint, in.

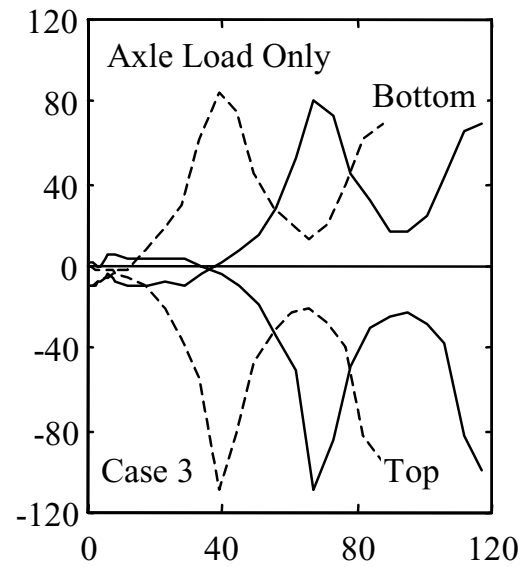

(b)

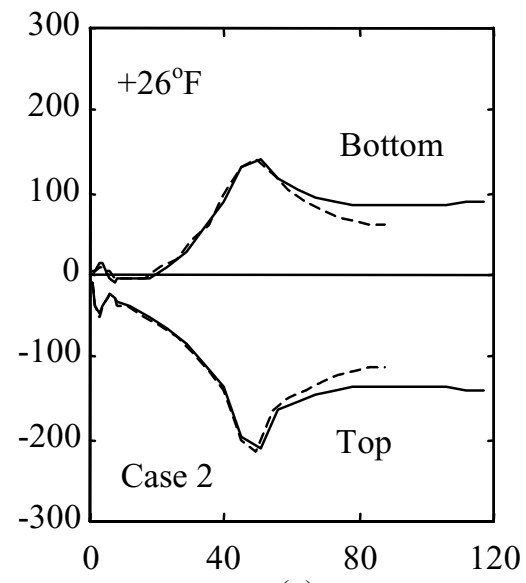

(e)

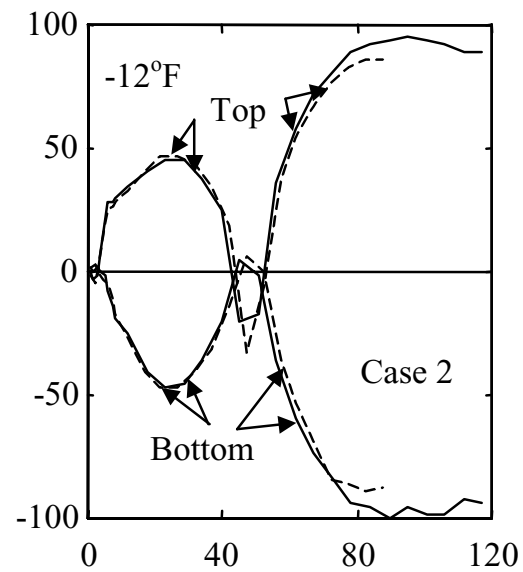

(h)

Distance from First Joint, in.

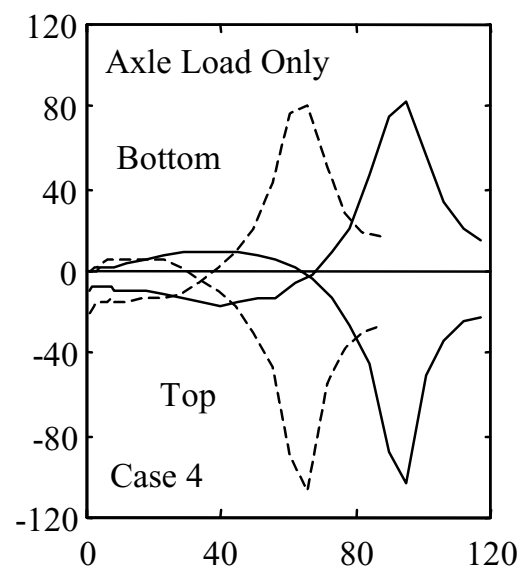

(c)

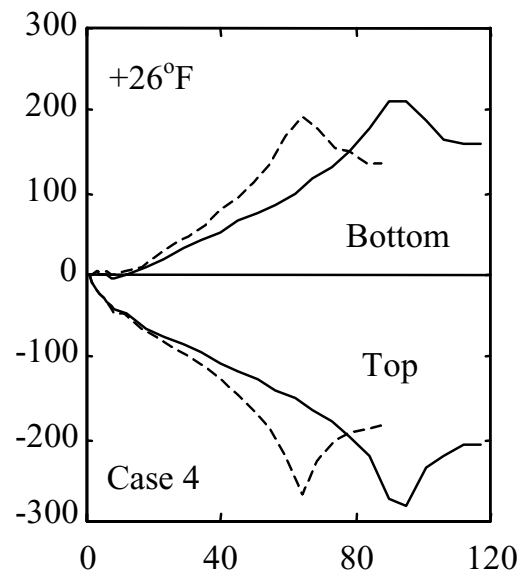

(f)

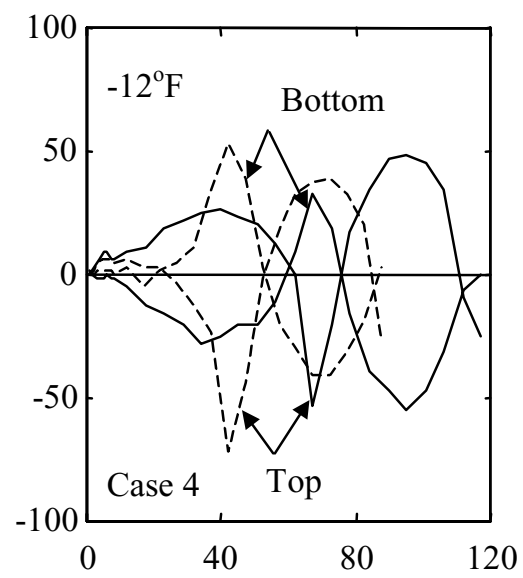

(i)

Distance from First Joint, in.

----- $15 \mathrm{ft}$. Slab $20 \mathrm{ft}$. Slab

FIGURE 6.28 Effect of Slab Length on $\sigma_{\mathrm{x}}$ Profile along Wheel Path (9in Thick Slabs \& Tandem Axle) 


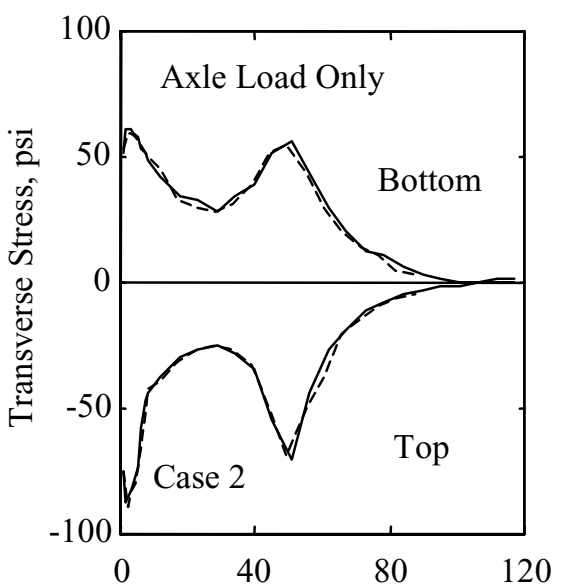

(a)

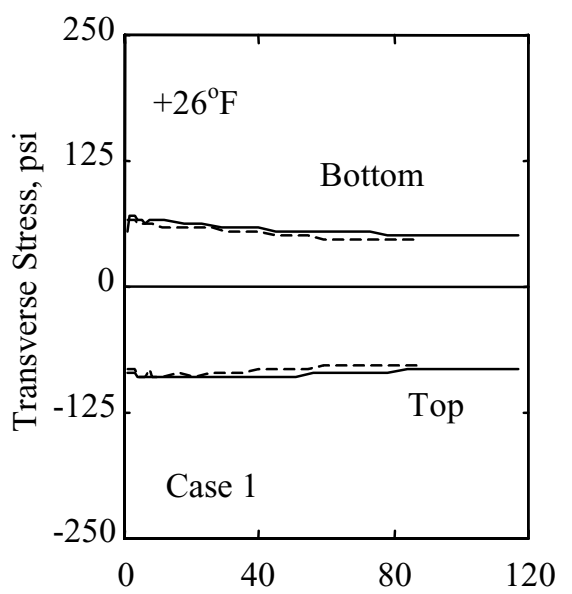

(d)

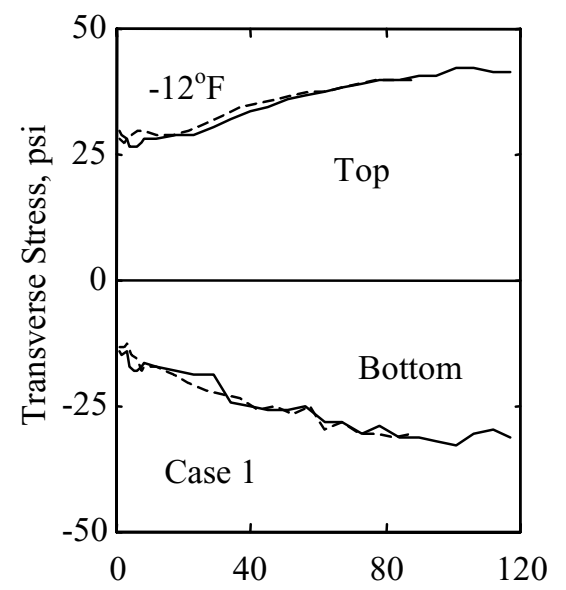

(g)

Distance from First Joint, in.

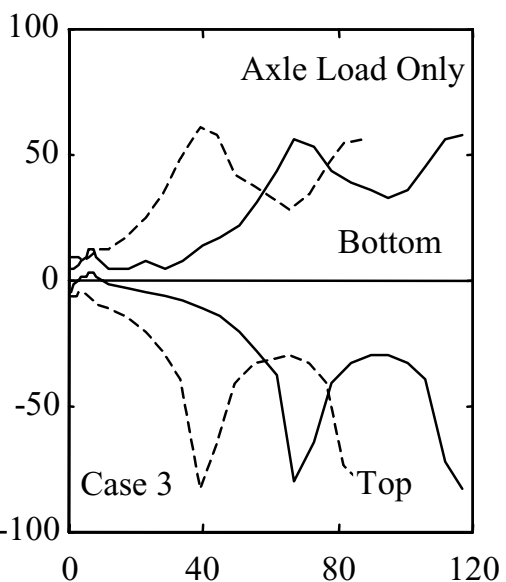

(b)

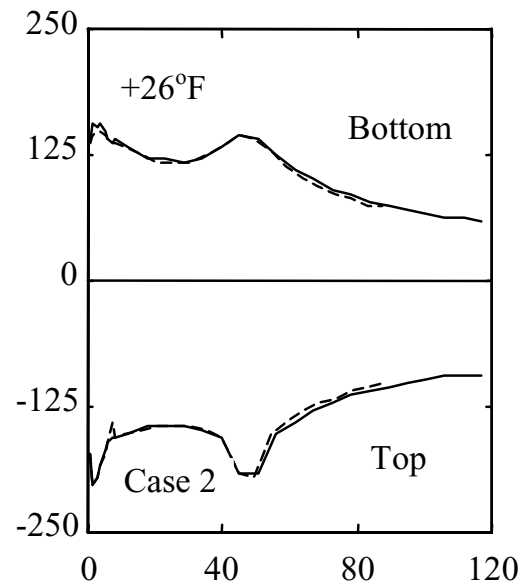

(e)

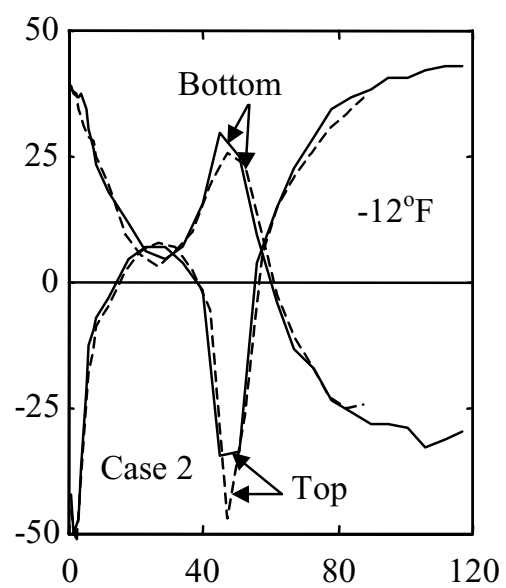

(h)

Distance from First Joint, in.

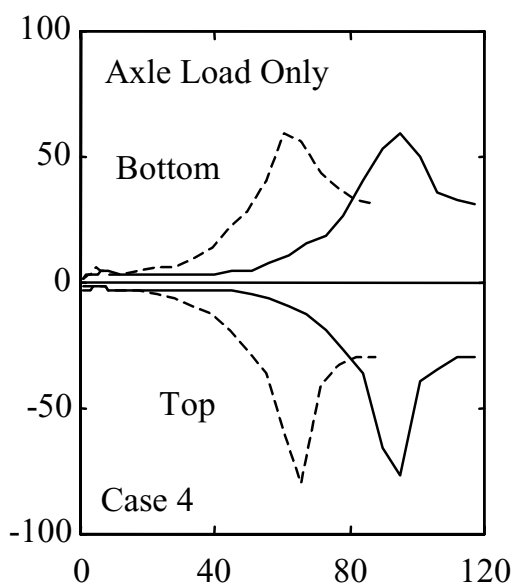

(c)

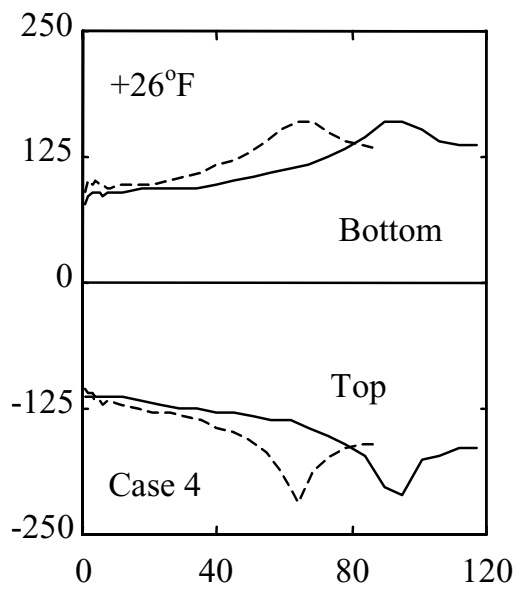

(f)

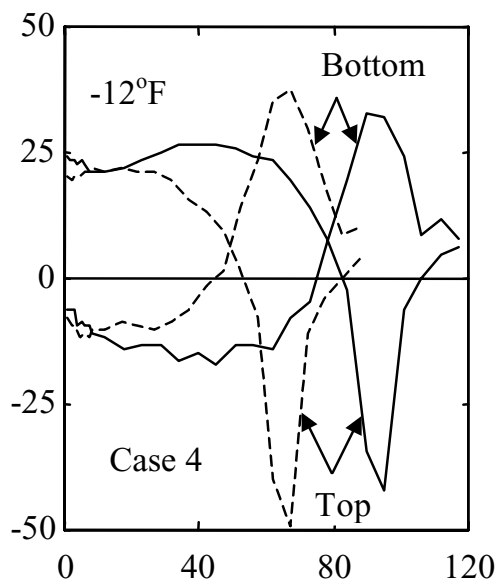

(i)

Distance from First Joint, in.

$15 \mathrm{ft}$. Slab

$20 \mathrm{ft}$. Slab

FIGURE 6.29 Effect of Slab Length on $\sigma_{y}$ Profile along Wheel Path

(9in Thick Slabs \& Tandem Axle) 


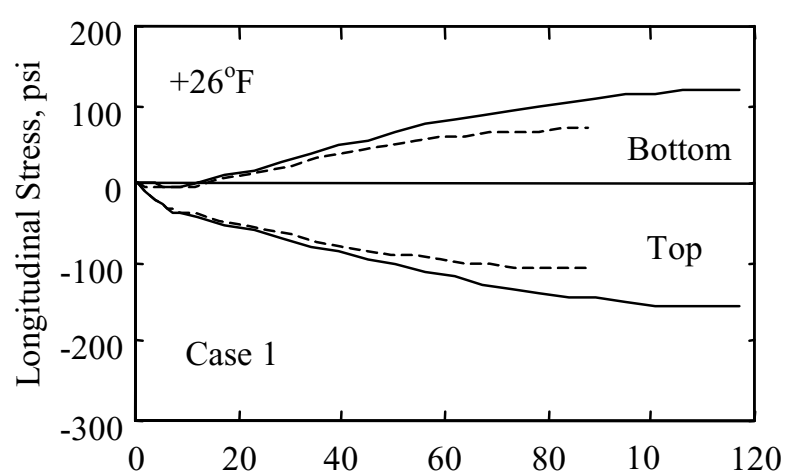

(a)

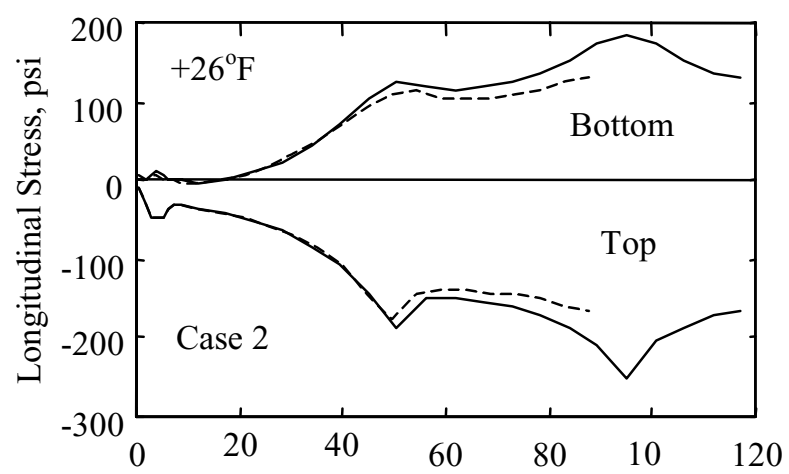

(c)

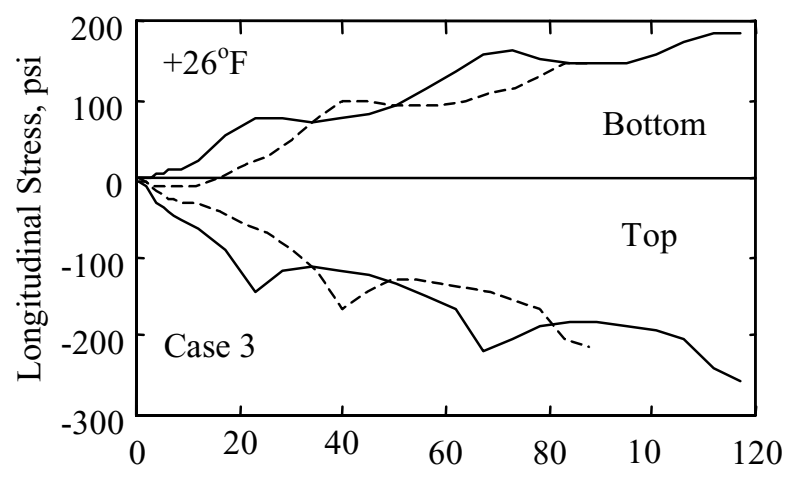

(e)

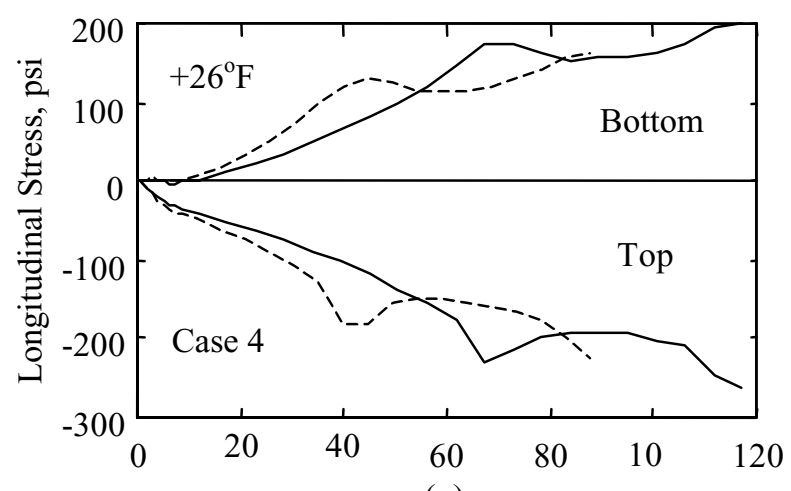

(g)

Distance from First Joint, in.

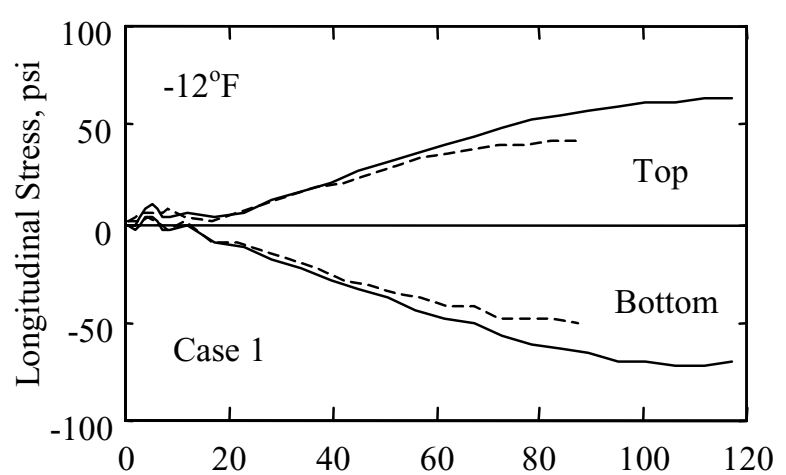

(b)

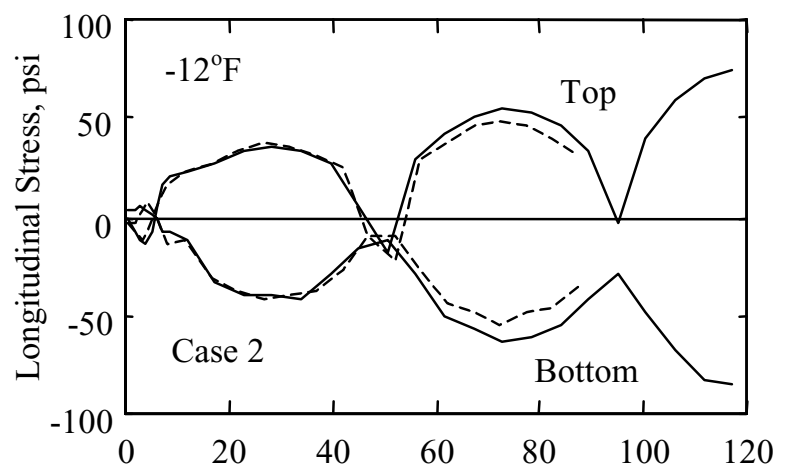

(d)

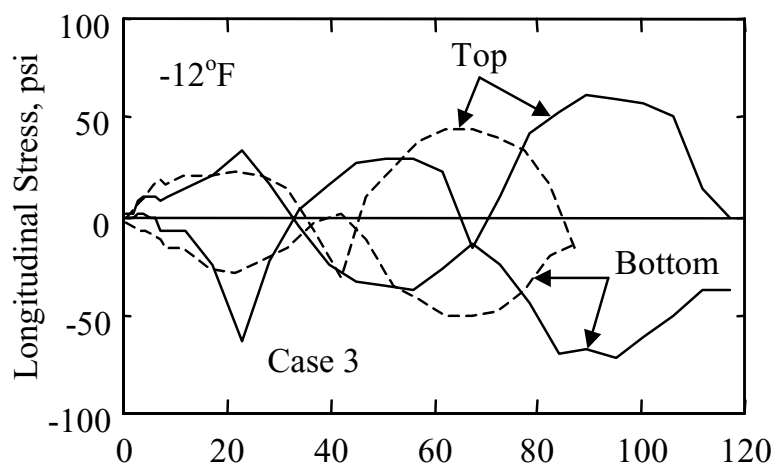

(f)

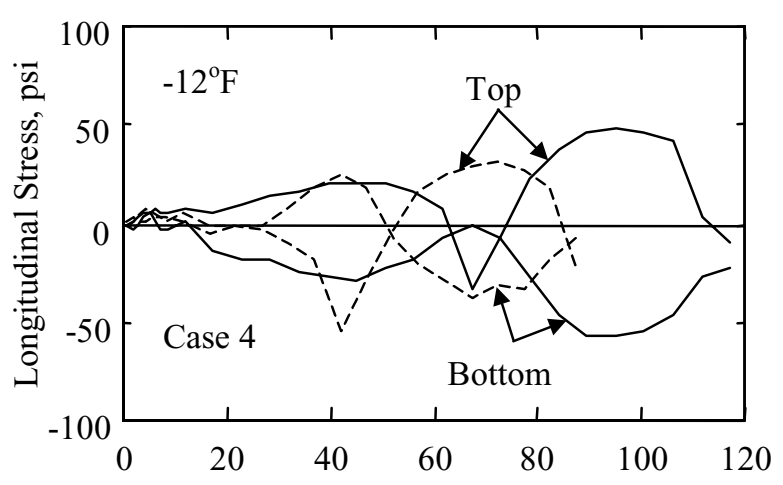

(h)

Distance from First Joint, in. $20 \mathrm{ft}$. Slab

FIGURE 6.30 Effect of Slab Length on the Stress Profile along Wheel-Path (11 in. Thick Slab \& Tridem Axle 54,000 lb) 


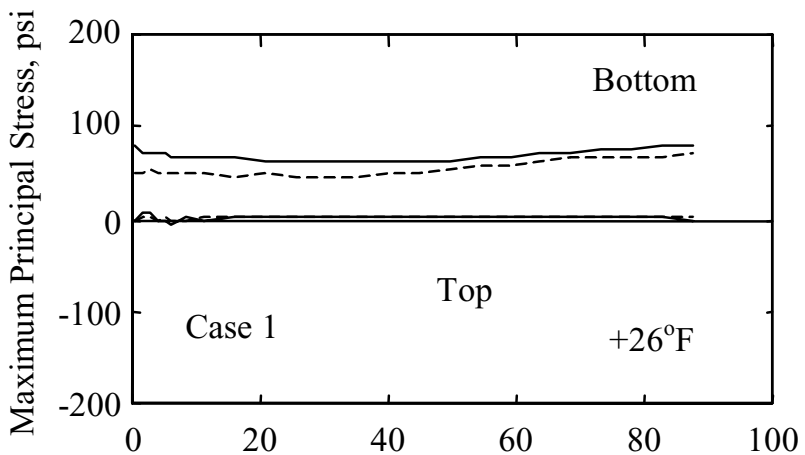

(a)

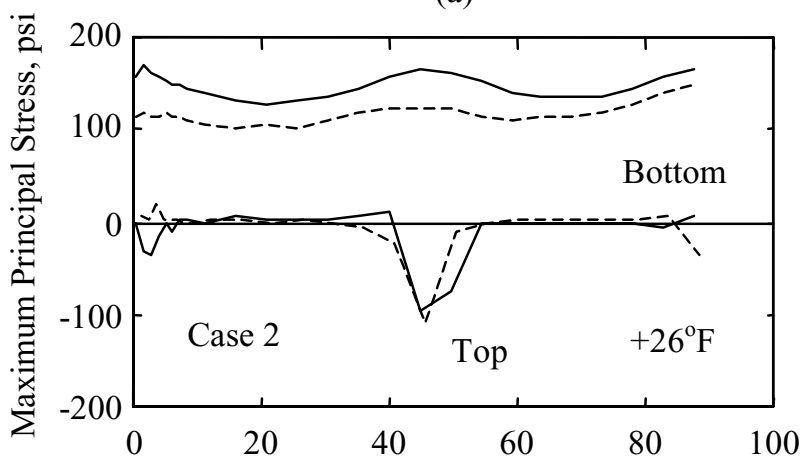

(c)

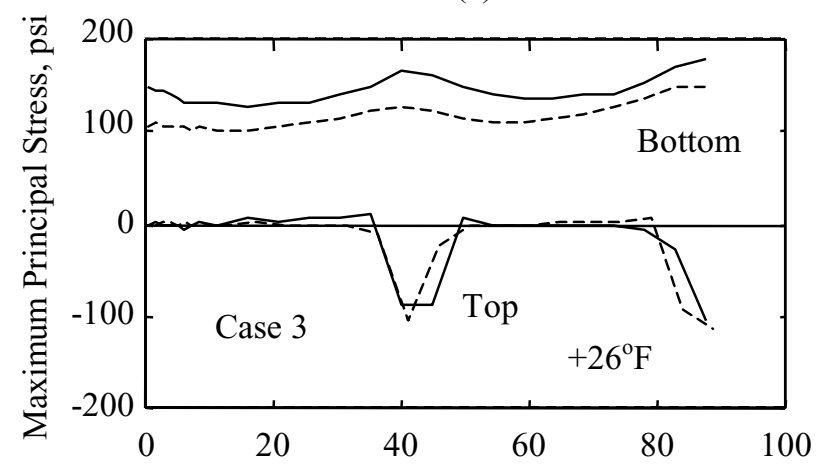

(e)

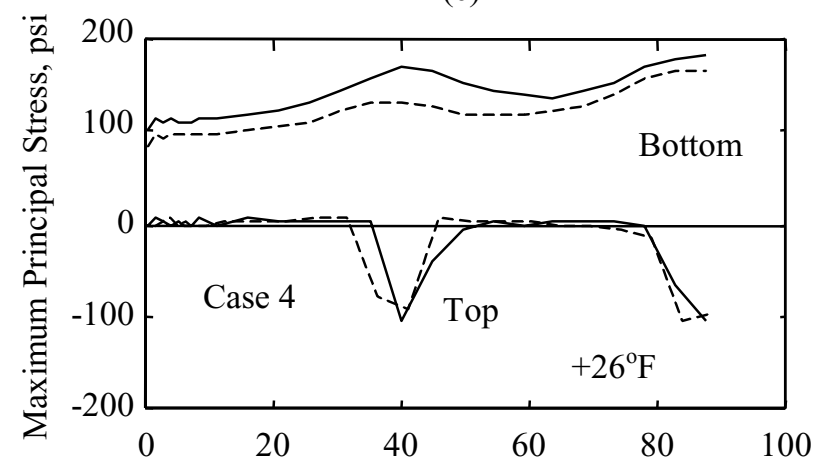

(g)

Distance from First Joint, in.

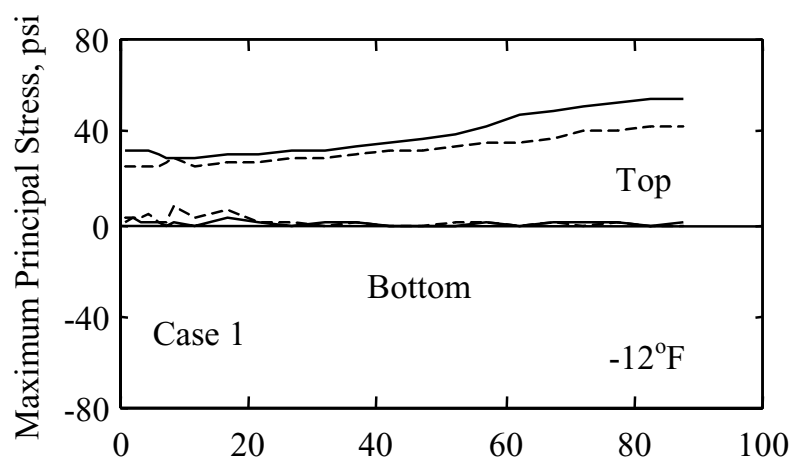

(b)

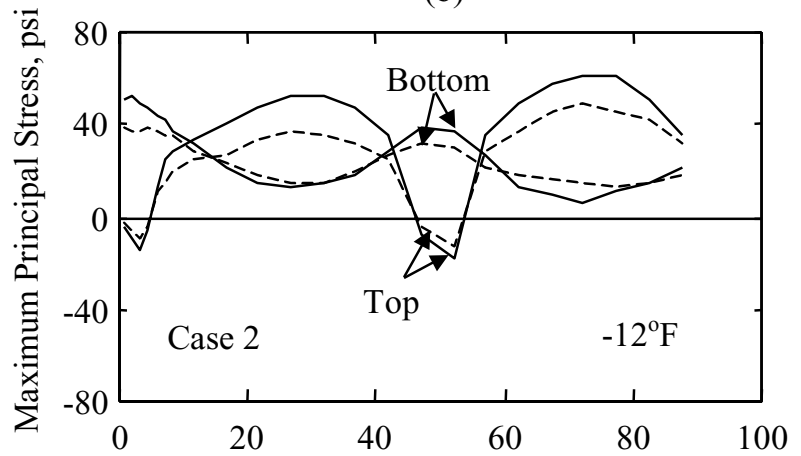

(d)

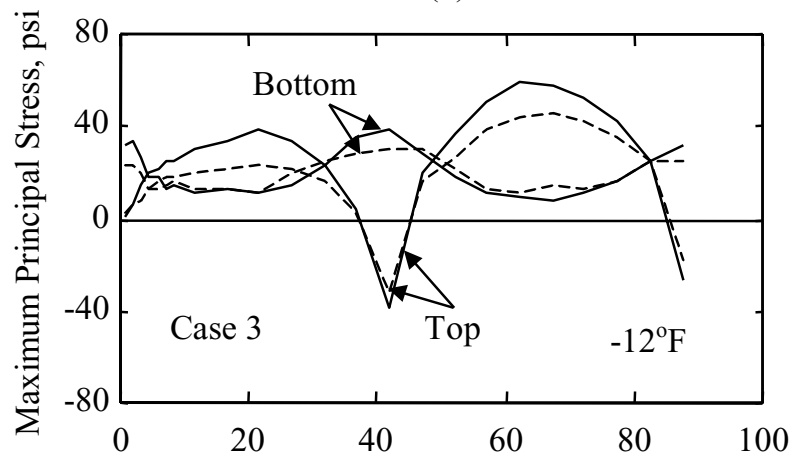

(f)

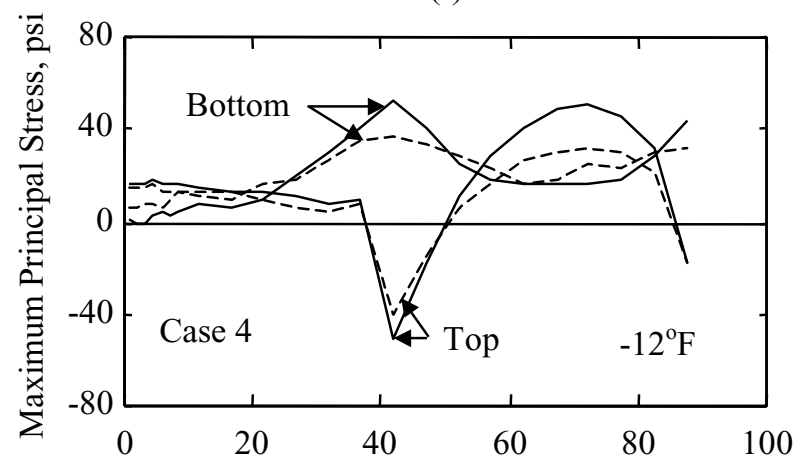

(h)

Distance from First Joint, in. 11 in. 9 in.

FIGURE 6.31 Effect of Slab Thickness on the MPS Profile along Wheel-Path (15 ft. Long Slab \& Tridem Axle 54,000 lb) 


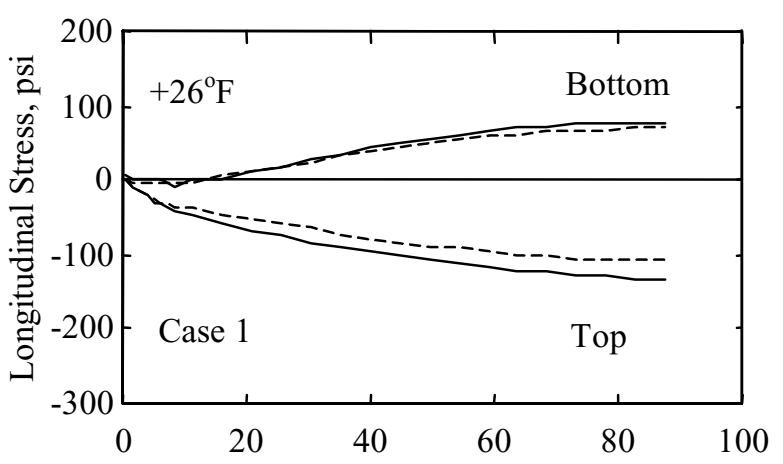

(a)

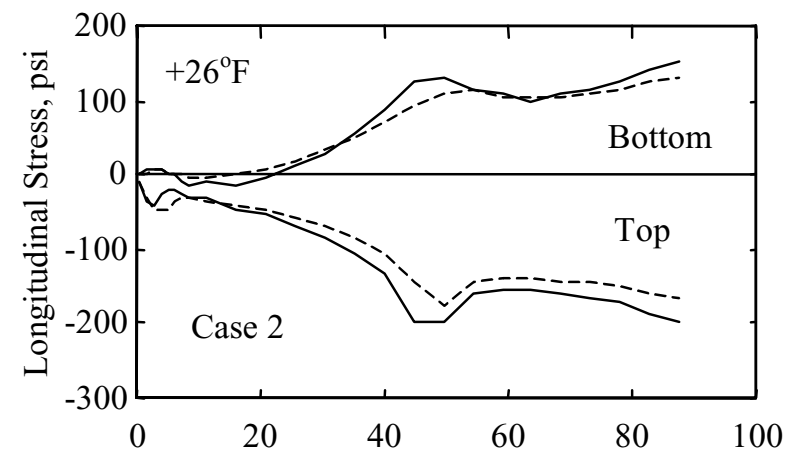

(c)

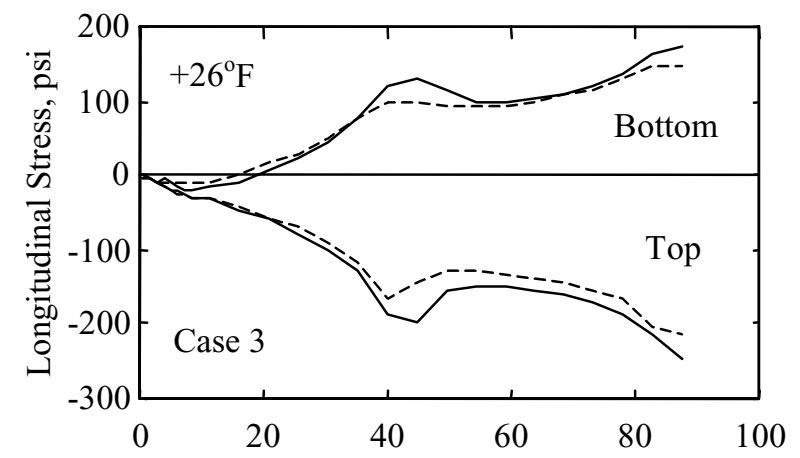

(e)

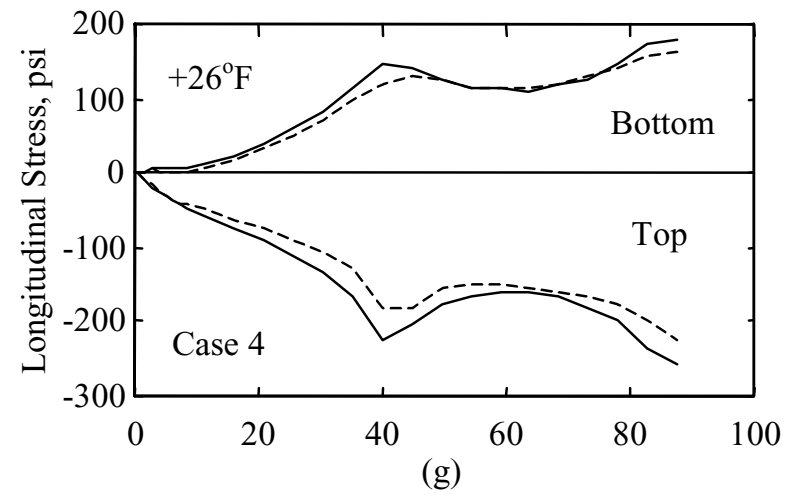

Distance from First Joint, in.

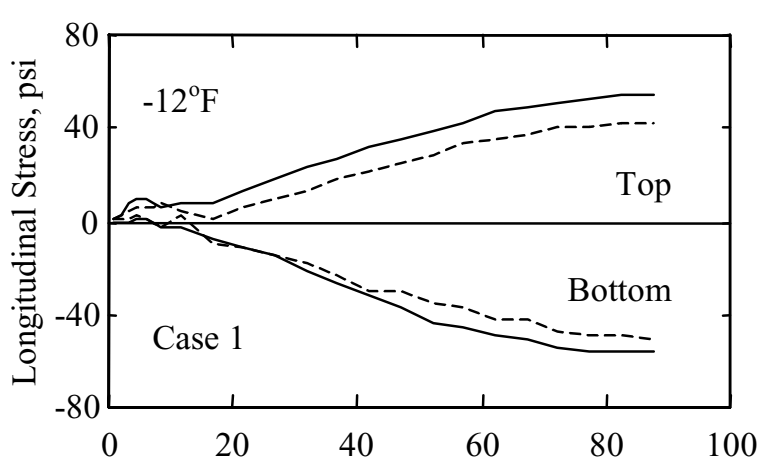

(b)

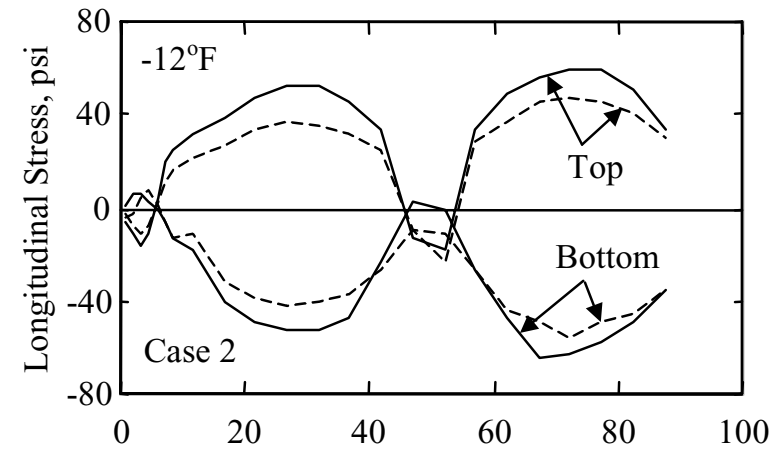

(d)

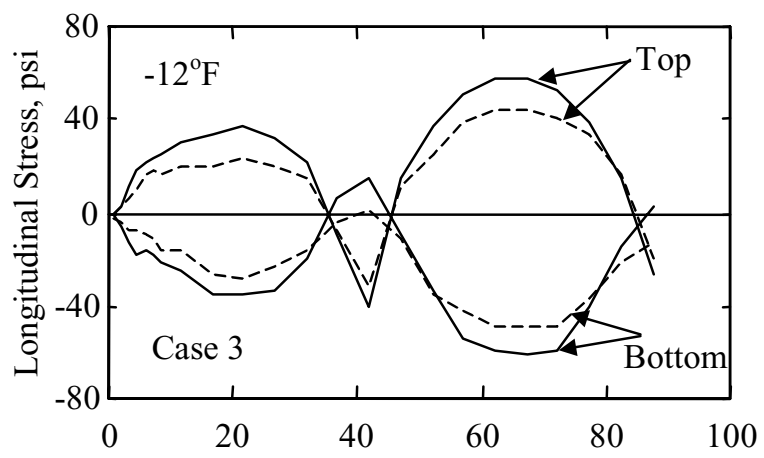

(f)

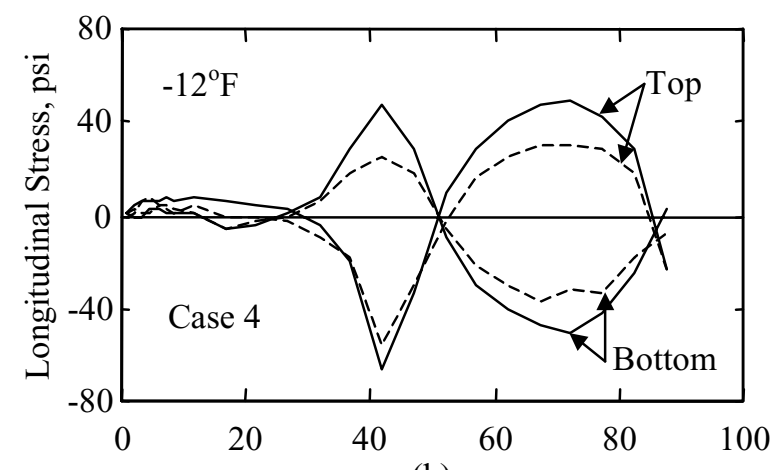

(h) 11 in. 9 in.

FIGURE 6.32 Effect of Slab Thickness on $\sigma_{\mathrm{x}}$ Profile along Wheel-Path (15 ft. Long Slab \& Tridem Axle 54,000 lb) 


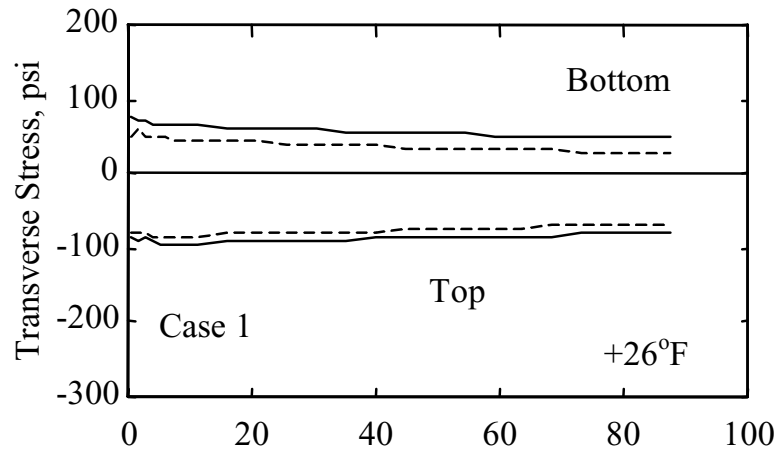

(a)

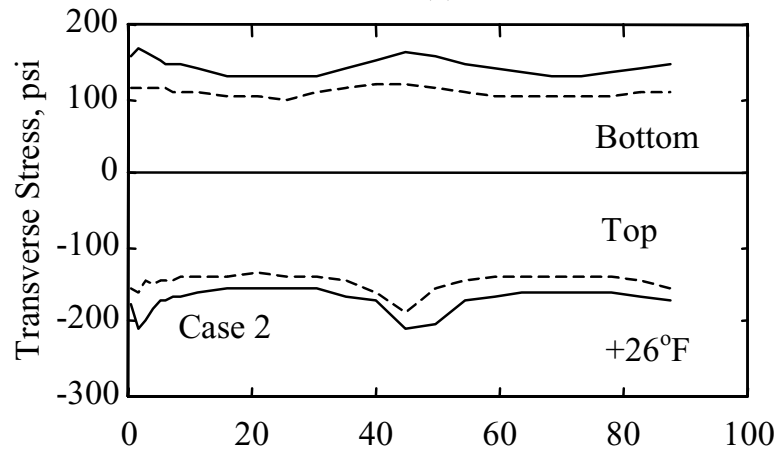

(c)

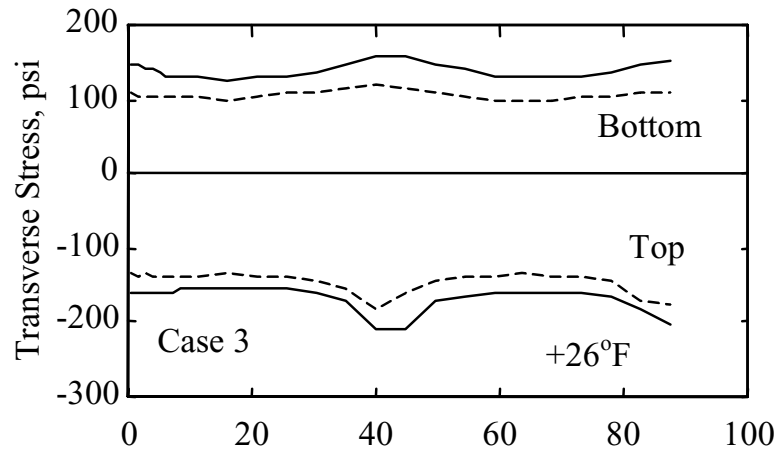

(e)

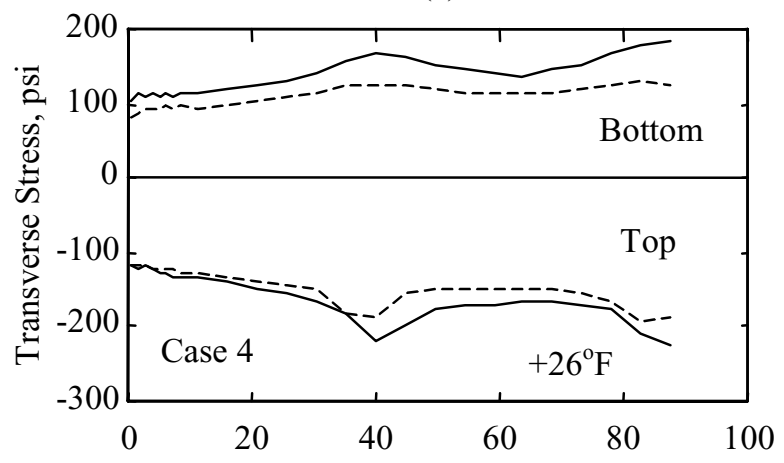

(g)

Distance from First Joint, in.

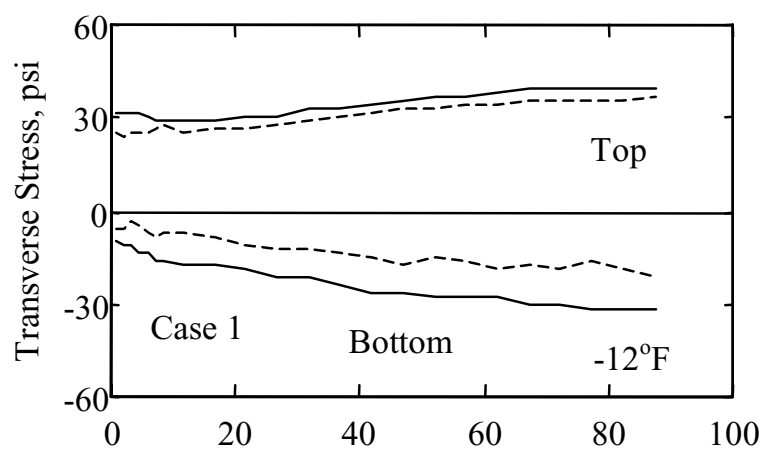

(b)

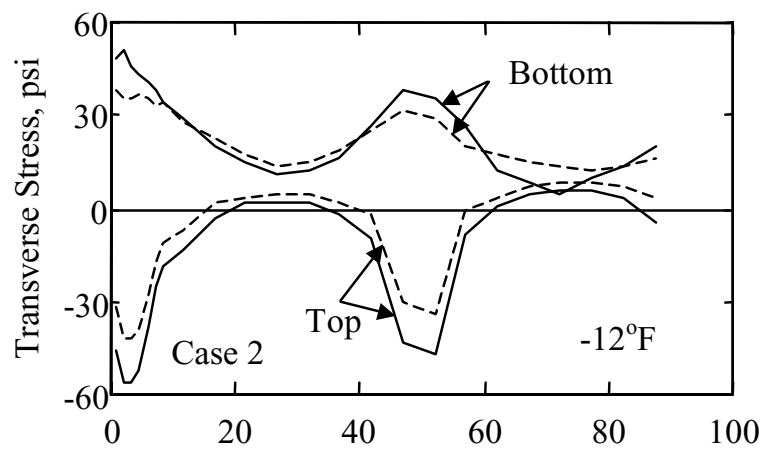

(d)
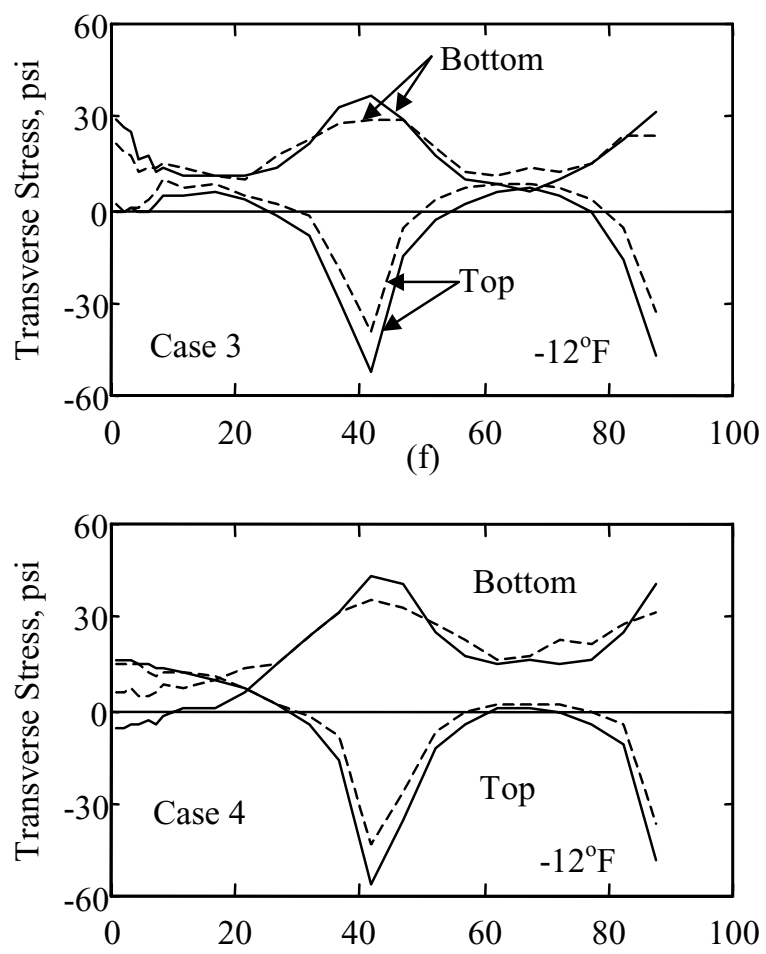

(h) 11 in. 9 in.

Distance from First Joint, in.

FIGURE 6.33 Effect of Slab Thickness on $\sigma_{\mathrm{y}}$ Profile along Wheel-Path (15 ft. Long Slab \& Tridem Axle 54,000 lb) 


\section{CHAPTER SEVEN}

\section{CONCLUSIONS AND FUTURE RESEARCH NEEDS}

\subsection{CONCLUSIONS}

The work presented in this study included the development of 3D-FE models that can be used to investigate the separate or combined effect of moving traffic loads and thermal gradient on the response of jointed plain concrete pavement structures. The verification presented illustrates that the theoretical model is capable of producing typically the same results obtained from field studies and, therefore, increases the confidence in its results. The sensitivity analysis presented illustrates some model results that demonstrate how powerful and useful that model is. Due to the flexibility of that model, it can be altered to investigate many other aspects that affect the response of rigid pavements under moving traffic loads applied separately or simultaneously with thermal gradient through the slab thickness.

The results obtained from the studies performed under the combined effect of moving axle loads and nonlinear thermal gradient through the slab thickness demonstrate that:

1) Pavement response is significantly changed when the axle loads are combined with nonlinear thermal gradients. The combined thermal and axle stresses obtained for different gradients show that ignoring the thermal stresses during design can underestimate the design stresses, especially when the pavement is subjected to positive thermal gradient.

2) Under the specific gradients and loading conditions examined in this study, the peak stresses developed in rigid pavement slabs result from combined positive thermal gradient and axle loads and are located at the middle of the slab. The peak stresses also increased as the thermal gradient is increased. 
3) The change in the thermal gradient from positive to negative or vice versa significantly changes the slab curvature. The results also show that slab curvature is affected by the passage of the traffic load.

4) Nighttime curling (negative gradient) increases the differential displacement between the highest and the lowest point along the slab length, especially when the axles load the thermally deformed slab. The high truck intensity during nighttime accompanied by the high differential displacement due to negative gradient may develop cracks along its length.

5) The change in the thermal gradient developed through the slab thickness from positive to negative between day and night subjects the slab to stress reversals. The higher the difference between daytime and nighttime thermal gradients, the higher the magnitude of these stress reversals. Results also show that the magnitude of this reversal is increased each time a truck loads the slab.

6) Examination of the combined thermal and axle stress and the thermal stress show that the longitudinal stress $\left(\sigma_{\mathrm{x}}\right)$ is the governing stress and is always higher than the transverse stress $\left(\sigma_{\mathrm{y}}\right)$, except at the transverse joint where $\sigma_{\mathrm{y}}$ is significantly higher than $\sigma_{\mathrm{x}}$. Therefore, to consider the effect of both $\sigma_{\mathrm{x}}$ and $\sigma_{\mathrm{y}}$, it is suggested to use the MPS as the design stress instead of the current design procedure which is based on $\sigma_{\mathrm{x}}$.

7) Based on the FEM results, shorter slab lengths reduce both the thermal stresses and the combined axle load and thermal gradient stresses. It is recommended to consider the thermal induced stresses when designing the slab length since the response of each slab length is greatly affected by the inclusion of thermal gradient.

8) The comparison between tandem and tridem axles demonstrates that the use of tridem axle when combined with a negative gradient reduces the high tensile stresses observed at mid-slab top.

9) Edge loading is the most damaging loading position. Results show that mid-slab loading is the critical loading position under edge loading. The results as well indicate that, when combined with negative gradient through the slab thickness, corner load increases the tensile stress observed at mid-slab top, which increases the chances of the initiation of top-down crack. 
10) Increasing the slab thickness reduces the stresses and the strains induced in the slab, especially at the joint. Results from this study show that transverse stresses developed under combined thermal gradient and axle loads along the wheel-path are significantly reduced by the thickness increase.

The results obtained from the studies performed under the effect of a moving tandem axle load (thermal gradient through the slab thickness is not considered) show that:

1) The axle speed has a small effect on the stresses and strains induced in the slab.

2) Increasing the concrete slab modulus of elasticity reduces the longitudinal strain developed in the slab along the wheel-path due to axle loads. However, the modulus increase does not affect the maximum principal stress induced in the slab.

3) Changing the base course moduli does not affect the response of rigid pavement slabs subjected to axles loads. The significant difference between the slab and the base course moduli makes the slab carry the major portion of the load and therefore will be hardly affected by the variation in base modulus.

4) Using dowel bars and aggregate interlock to transfer the load across transverse joints reduce the stress and displacement developed in the slab along the wheel-path. It also reduces the severe stress drop that takes place each time an axle crosses the joint.

5) The comparison between single, tandem, and tridem axles show that the largest stress and strain are produced by single axle and are located at the middle of the slab. Results also show that it is preferred to change the axle configuration rather than increasing their magnitudes, since the latter significantly increases the stresses induced in the slab.

6) The distribution of peak stresses developed in the slab along the wheel-path shows that the stress is constant along the slab length and changes significantly in the vicinity of the transverse joint.

7) The stress reduction from slab thickness increase is higher for longer slabs.

8) Edge loading significantly increases the stresses developed in the base course. 
The experience gained from the FE models developed in this study demonstrates the following:

1) Modeling the dowel bars using hexahedron solid brick elements has several advantages including modeling the embedded length of the dowel bar as well as the dowel/concrete interface. This method of modeling the dowels also permits locating the areas of high stresses in the concrete surrounding the bars.

2) Using an interface to model aggregate interlock along the transverse joint permits the simulation of load transfer, relative motion, and gap formulation between the slabs along the transverse joint under the combined effect of thermal gradient and axle loads.

3) Using a symmetry plan boundary condition along the traffic direction in case of wheelpath loading has a minor effect on the structural response of rigid pavement and results in great savings in model size, computer memory, and CPU time. However, a symmetry plan cannot be used for cases where there is no symmetry in loading or geometry such as the edge loading condition.

4) The selection of the element size in the FE mesh should compromise between the accuracy of the results and the solution time. Since the coarser the mesh the lower the accuracy of the results obtained and the finer the mesh the longer the solution time.

5) Using an unbonded interface with friction between the slab and the base course permits a better simulation of the pavement structure, especially under the effect of thermal gradient when gaps initiate between the slab and the supporting layers.

6) The magnitude of the friction coefficient applied along the unbonded interface between the slab and the base course has a small effect on the results obtained along the wheelpath under the effect of axle loads.

7) Results obtained along the wheel-path show that constraining the lateral sides of the slab at tie bars locations does not affect the slab response under axle loads. Therefore modeling the tie bars in this case is not essential.

8) Using a moving load allows studying the fatigue cycles the pavement can be subjected to under different axle configurations. This permits examining the stress reversal caused by alternating tension-compression traffic loading which may reduce the strength of the concrete and develop more fatigue damage than a static load imposed only in one direction, i.e. no stress reversal is involved. 


\subsection{FUTURE RESEARCH NEEDS}

1) The work presented in this study was mainly focused on studying the response of the slab under combined nonlinear thermal gradient and axle loads. However, additional work is needed to study the response of foundation layers, i.e. base course and subgrade, especially during slab curling and warping when the slab loses some of the contact with the base.

2) Westergaard analyses, as well as most of the existing FE models including the model developed in this study, assume that pavement materials are linear elastic. Research is needed to study how the rigid pavement response changes when nonlinear-plastic material properties are used, especially under combined moving axle loads and thermal gradient.

3) Under repeated cycles of loading and unloading, concrete slabs undergo cracks, i.e. fatigue damage. Additional work is required to investigate the effect of slab length and axle configuration on fatigue damage in rigid pavement slabs subjected to combined thermal gradient and axle loads.

4) Results from this study recommend using the MPS as the design stress instead of the current design procedure, which is based on the longitudinal stress. Research is needed to study the possibility of implementing the MPS as the design stress.

5) Research is needed to identify an exact value for the friction coefficient assumed at the sliding interface between the dowel bars and the concrete slab. 


\section{REFERENCES}

American Concrete Pavement Association, ACPA, Portland Cement Association, 1991. "Concrete Paving Technology: Design and Construction of Joints for Concrete Highways," Technical Bulletin-010.0 D, Skokie, Illinois.

American Association of State Highway and Transportation Officials, AASHTO, 1993. "AASHTO Guide for Design of Pavement Structures," AASHTO Committee on Design, Washington, D. C.

Bathe, K. J., 1982. Finite Element Procedures in Engineering Analysis, Prentice-Hall, Inc., Englewood Cliffs, New Jersey 07632.

Boresi, A. P., R. J. Schmidt, and O. M. Sidebottom, 1993. Advanced Mechanics of Materials, fifth edition, John Wiley and Sons, Inc.

Byung-Wan, Jo, 1988. A Finite Element Parametric Study for the Response of Concrete Highway Pavements with Skewed Joints, Ph.D. Dissertation, University of Florida.

Channakeshava, C., and F. Barzegar, 1993. "Nonlinear FE Analysis of Plain Concrete Pavements with Doweled Joints," Journal of Transportation Engineering, Vol. 119, No. 5, pp. 763 to 781.

Chatti, K., 1992. Dynamic Analysis of Jointed Concrete Pavements Subjected to Moving Transient Load, Ph.D. Dissertation, Institute of Transportation Studies, University of California at Berkeley.

Cheung, Y. K., and O. C. Zienkiewicz, 1965. "Plates and Tanks on Elastic Foundations - An Application of Finite Element Method," International Journal of Solids and Structures, Vol. 1, pp. 451-461. 
Chou, Y. T., 1981. "Structural Analysis Computer Programs for Rigid Multi-component Pavements with Discontinuities- WESLIQUID and WESLAYER," Technical Reports 1, 2 and 3, U.S. Army Engineer Waterways Station, Vicksburg, Mississippi.

Chou, Y. T., 1984. "Stress Analysis of Small Concrete Slabs on Grade," Journal of Transportation Engineering, American Society of Civil Engineers, Vol. 110, No. 5, pp. 481-491.

Choubane, B. and M. Tia, 1995. "Analysis and Verification of Thermal Gradient Effects on Concrete Pavement," Journal of Transportation Engineering, ASCE, Vol. 121, No. 1, pp. 75-81.

Darter, M. I., K. T. Hall, and C. M. Kuo, 1995. "Support Under Portland Cement Concrete Pavements," National Cooperative Highway Research Program, NCHRP Report 372, Transportation Research Board, National Research Council, Washington, D. C.

Darter, M.I., 1977. "Design of Zero-Maintenance Plain Concrete Pavement, Vol. 1 Development of Design Procedures," FHWA, D.O.T., Office of Research, Washington D.C., DOT-FH-11-8474.

Davids, W.G, 1998. Modeling of Rigid Pavements: Joint Shear Transfer Mechanisms and Finite Element Solution Strategies, Department of Civil and Environmental Engineering, Ph.D. Dissertation, University of Washington.

Faragi, V., C. Jofre, and C. Kraemer, 1987. "Combined Effect of Traffic Loads and Thermal Gradients on Concrete Pavement Design," Transportation Research Record 1136, TRB, National Research Council, Washington, D. C., pp. 108-118.

Federal Highway Administration, FHWA, 1990. "Concrete Pavement Joints," U. S. Department of Transportation, Federal Highway Administration, Technical Advisory: T 5040.30.

Federal Aviation Administration, 1996. "Airport Pavement Design and Evaluation," FAA Advisory Circular, 150/5320-6D, FAA, U.S. Department of Transportation. 
Federal Highway Administration, FHWA, 1986. Improved Rigid Pavement Joints, U.S. Department of Transportation, Publication No. FHWA/RD-86/040, McLean, Virginia.

Federal Highway Administration, 1997. "LTPP Data Analysis: Frequently Asked Questions About Joint Faulting with Answers from LTPP," U.S. Department of Transportation, Federal Highway Administration, Research and Development Turner-Fairbank Highway Research Center, Publication No. FHWA-RD-97-101.

Goldbeck, A. T., 1924. "Friction Tests of Concrete on Various Subbases," Public Roads, Vol.5 No .5.

Hallquist, J. O., 1996. “LS-DYNA3D Theoretical Manual: Version 936," Livermore Software Technology Corporation, Livermore, CA 94550.

Hallquist, J. O., 1998. "LS-DYNA Theoretical Manual," Livermore Software Technology Corporation, Livermore, CA 94550.

Hammons, M. I., 1997. Development of an Analysis System for Discontinuities in Rigid Airfield Pavements, Final Report No.GL-97-3, U.S. Army Corps of Engineers, Waterways Experiment Station, Vicksburgh, MS 39180-6199.

Harik, I. E., P. Jianping, H. Southgate, and D. Allen, 1994. "Temperature Effects on Rigid Pavements," Journal of Transportation Engineering, ASCE, Vol. 120, No. 1, pp. 127-143.

Huang, Y. H., and S. T. Wang, 1973. "Finite-Element Analysis of Concrete Slabs and its Implications for Rigid Pavement Design,” Highway Research Record No. 466, Washington, D.C., pp. 55-69.

Huang, Y. H., 1974. "Finite Element Analysis of Slabs on Elastic Solids," Journal of Transportation Engineering, ASCE, Vol. 100, No. 2, pp. 403-416. 
Huang, Y. H., 1985. "A Computer Package for Structural Analysis of Concrete Pavements," Proceedings, 3rd International Conference on Concrete Pavement Design and Rehabilitation, Purdue University, pp. 295-307.

Huang, Y. H., 1993. Pavement Analysis and Design, Prentice Hall, Englewood Cliffs, New Jersey 07632 .

Hughes, T. J. R., R. L. Taylor, J. L. Sackman, A. C. Curnier, and W. Kanoknukulchai, 1976. “A Finite Element Method for a Class of Contact-Impact Problems," Journal of Computer Methods in Applied Mechanics Engineering, Vol. 8, pp. 249-276.

Hutchinson, R. L., 1966. "Basis for Rigid Pavement Design for Military Airfields," Miscellaneous paper No. 5-7, Cincinnati, Ohio River Division Laboratories.

Ioannides, A. M., 1984. Analysis of Slabs-On-Grade for a Variety of Loading and Support Conditions, PhD. Dissertation. Urbana, Illinois: Department of Civil Engineering, University of Illinois.

Ioannides, A. M., J. P. Donelly, 1988. "Three-Dimensional Analysis of Slab on StressDependent Foundation," Transportation Research Record 1196, TRB, National Research Council, Washington, D.C., pp. 72-84.

Ioannides, A. M., 1988. "Interlayer and Subgrade Friction: A Brief Review of the State-of-theArt," Field Evaluation of Newly Developed Rigid Pavement Design Features, Phase IModification No. 3.

Ioannidies, A. M., and R. A. Salsilli-Murua, 1989. "Temperature Curling in Rigid Pavements: an Application of Dimensional Analysis," Transportation Research Record 1227, TRB, National Research Council, Washington, D. C., pp. 1-11. 
Ioannides, A. M., 1990. "Aggregate Interlock: A Pure-Shear Load Transfer Mechanism," Transportation Research Record 1286, TRB, National Research Council, Washington, D.C., pp. $14-24$.

Jiang, Y., M. I. Darter, and E. Owusu-Antwi, 1997. "Analysis of Current State Rigid Pavement Design Practices in the United States," Transportation Research Record No. 1525, National Research Council, Washington, D.C., pp. 72-82.

Kawmura, K., S. Nakagawa, T. Nishizawa, and A. Kasahara, 1993. "Evaluation Method for Joint Load Transfer Efficiency in Concrete Pavements," Proceedings of the 5th international conference on concrete pavement design and rehabilitation, Purdue University, pp. 13-21.

Kennedy, J. C., R. D. Everhart, T. P. Forte, and J. A. Hadden, 1994. Development of a Governing Primary Response Model (GPRM) for Airport Pavement Design and Analysis: Volume I, Battelle and Resource International Institute, Columbus, Ohio 43201-2693, Final Report, Contract No. VA 2043, DTRS-57-89-D-00006.

Kennedy, J. C., and R. D. Everhart, 1995. Dynamic Compliant Boundary, Battelle and Resource International Institute, Columbus, Ohio 43201-2693, Final Report, Contract No. DTFH61-93-C00055, Work Order Number BAT-94-019, Technical Work Request No. 1.

Kennedy, J. C, 1996. "Pavement Response to Vehicular Loads - A Mechanistic Approach Involving Nondestructive Evaluation Techniques," Proceedings of the International Society for Optical Engineering, Nondestructive Evaluation of Bridges and Highways, Vol. 2946, pp. 121138.

Kennedy, J. C., and R. D. Everhart, 1997. Comparison of Predicted Pavement Structural Response with Field Measured Data, Battelle Research Institute, Columbus, Ohio 43201-2693, Final Report, Contract No. DTFH61-93-C-00055, Work Order Number BAT-94-019, Technical Work Request No.3. 
Kelleher, K., and R. M. Larson, 1989. "The Design of Plain Doweled Jointed Concrete Pavement," Proceedings of the Fourth International Conference on Concrete Pavement Design and Rehabilitation, Purdue University, West Lafayette, Indiana, pp. 279-292.

Khazanovich, L. and A. M. Ioannides, 1993. "Finite Element Analysis of Slabs-On-Grade Using Higher Order Subgrade Models," Airport Pavements Innovations: Theory to Practice. New York: American Society of Civil Engineers.

Korovesis, G. T., 1990. Analysis of Slab-On-Grade Pavement Systems Subjected to Wheel and Temperature Loadings, PhD Dissertation. Urbana, Illinois: Department of Civil Engineering, University of Illinois.

Kuo, Chen-Ming, 1994. "Three-dimensional Finite Element Analysis of Concrete Pavement," Ph.D. Dissertation, Department of Civil Engineering, University of Illinois at UrbanaChampaign.

Kuo, C., 1997. "Analysis of Key Joints of Concrete Pavements," paper presented at Transportation Research Board 76th Annual Meeting January 12-16, Washington, D.C.

Lee, X., D. R. Brill, and E. H. Guo, 1998. "Advances in Finite Element Models for Airport Pavement Design," Proceedings of the First National Symposium on 3D Finite Element Modeling for Pavement Analysis and Design, Charleston, West Virginia, pp. 112-127.

Mallela, J., and K. P. George, 1994. "Three-dimensional Dynamic Response Model for Rigid Pavements," Transportation Research Record 1448, TRB, National Research Council, Washington, D.C., pp. 92-99.

Majidzadeh, K. and G.J. Ilves, 1983. "Evaluation of Rigid Pavement Overlay Design Procedure, Development of the OAR Procedure." DTFH11-9489. 
Masad, A., Taha, R., Muhunthan, B, 1996. "Finite Element Analysis of Temperature Effects on Plain Jointed Concrete Pavements," Journal of Transportation Engineering, Sept.-Oct., Vol. 122, No. 5, pp. 388-389.

McGhee, K. H., 1995. "Design, Construction, and Maintenance of PCC Pavement Joints," National Cooperative Highway Research Program, Synthesis of Highway Practice 211, Transportation Research Board, National Research Council, Washington, D.C.

Nasim, M. A., 1992. Effect of Heavy Vehicle Dynamic Loading on Rigid Pavements, Ph.D. Dissertation, Department of Civil Engineering, University of Michigan.

Nazarian, S., and K. M. Boddapti, 1995. "Pavement-Falling Weight Deflectometer Interaction Using Dynamic Finite Element Analysis," Transportation Research Record 1482, TRB, National Research Council, Washington, D. C., pp. 33-43.

Owusu-Antwi, E. B., A. H. Meyer, and W. R. Hudson, 1990. Assessing Load Transfer Across Joints and Cracks in Rigid Pavements Using the Falling Weight Deflectometer, Report No. 4602, Center for Transportation Research, the University of Texas at Austin.

Picket, G., and G. K. Ray, 1951. "Influence Charts for Concrete Pavements," Transactions of the American Society of Civil Engineers, Vol. 116, pp. 49-73.

Richardson, J. M., and J. M. Armaghani, 1988. "Stress Caused by Temperature Gradient in Portland Cement Concrete Pavements," Transportation Research Record 1121, Transportation Research Board, National Research Council, Washington, D. C., pp. 7-13.

Roesler, J. R., and L. Khazanovich, 1997. "Finite Element Analysis of PCC Pavements with Cracks," paper presented at Transportation Research Board 76th Annual Meeting January 12-16, Washington, D.C. 
Sargand, S. M. and D. I. Beegle, 1998. "Three-Dimensional Finite-Element Software Development and Verification Case Study," Proceedings of the First National Symposium on 3D Finite Element Modeling for Pavement Analysis and Design, Charleston, West Virginia.

Seaman, L., J. W. Simons, D. A. Shockey, R. F. Carmichael, and B. F. McCullough, 1991. "Unified Airport Pavement Design Procedure," Unified Airport Pavement Design and Analysis Concepts Workshops, Federal Aviation Administration, Washington, D. C., pp. 447-537.

Sebaaly, P., and N. Tabatabaee, 1989. "Effect of Tire Pressure and Type on Response of Flexible Pavement," Transportation Research Record 1227, TRB, National Research Council, Washington, D.C., pp. 115-127.

Shoukry, S. N., D. R. Martinelli, and O. I. Selezneva, 1996. "Dynamic Considerations in Pavement Layers Moduli Evaluation Using Falling Weight Deflectometer," Proceedings of the International Society for Optical Engineering, Nondestructive Evaluation of Bridges and Highways, Vol. 2946, pp. 109-120.

Shoukry, S. N., D. R. Martinelli, and O. I. Selezneva, 1997. "Dynamic Performance of Composite Pavements Under Impact," Transportation Research Record 1570, TRB, National Research Council, Washington, D. C., pp. 163-171.

Shoukry, S. N., D. R. Martinelli, G. William, and O. I. Selezneva, 1997. Evaluation of Backcalculation Algorithms Through Dynamic Modeling of FWD Test, West Virginia University, Final Report No. MAUTC-6.

Shoukry, S. N. and G.W. William, 1999. "Performance Evaluation of Backcalculation Algorithms Through 3D Finite Element Modeling of Pavement Structures," Transportation Research Record 1655, National Research Council, Washington, D. C, pp. 152-160. 
Shoukry, S. N., 2000. "Backcalculation of Thermally Deformed Concrete Pavements," paper presented at Transportation Research Record $79^{\text {th }}$ Annual Meeting, National Research Council, Washington, D. C.

Smith, K. D., D. G. Peshkin, M. I. Darter, A. L. Mueller, and S. H. Carpenter, 1990. Performance of the Jointed Concrete Pavements, Volume I, Evaluation of Concrete Pavement Performance and Design Features, Federal Highway Administration, Report No. FHWA-RD-89-136, Washington, D.C.

Tabatabaie, A. M., and E. J. Barenberg, 1978. "Finite Element Analysis of Jointed or Cracked Concrete Pavements," Transportation Research Record 671, TRB, National Research Council, Washington, D.C., pp. 11-19.

Taheri, M. R., M.M. Zaman, and V. Khanna, 1992. "Dynamic Response of Concrete Airport Pavements to Temperature Induced Warping," Proceedings 16th Southeastern Conference on Theoretical and Applied Mechanics, pp. II.10.17-II.10.26.

Tayabji, S. P., and B. E. Colley, 1984. Analysis of Jointed Concrete Pavements, Federal Highway Administration, Report No. FHWA/RD-86/041. McClean, VA.

Teller, L. W., and E. C. Southerland, 1943. "The Structural Design of Concrete Pavements," Public Roads, Vol. 16, Nos. 8, 9, and 10 (October, November, and December 1935); Vol. 17, Nos. 7 and 8 (September and October 1936); No. 8 (April-June 1943), pp. 167-211..

Thomas-Yu, H., L. Khazanovich, M. I. Darter, and A. Ardani, 1998. "Analysis of Concrete Pavement Response to Temperature and Wheel Loads Measured from Instrumented Slabs," paper presented at Transportation Research Board $77^{\text {th }}$ Annual Meeting, Washington, D.C.

Tia, M., J. M. Armaghani, C. L. Wu, S. Lei, and K. L. Toye, 1987. "FEACONS III Computer Program for Analysis of Jointed Concrete Pavements," Transportation Research Record 1136, TRB, National Research Council, Washington, D. C., pp. 12-22. 
Timms, A. G., 1964. "Evaluating Subgrade Friction-Reducing Mediums for Rigid Pavements," Highway Research Record No. 60, Highway Research Board, National Research Council, pp. 28 to 38 .

Treybig, H.J., B.F. McCullough, P. Smith and H.V. Quintus, 1977. "Overlay Design and Reflection Cracking Analysis for Rigid Pavements," Federal Highway Administration, FHWARD-77-76, Washington, D. C.

Uddin, W., T. Noppakunwijai, and T. Chung, 1997. "Performance Evaluation of Jointed Concrete Pavement Using Three Dimensional Finite Element Dynamic Analysis," Transportation Research Board, 76th Annual Meeting January 12-16, Washington, D.C.

United States General Accounting Office, 1997. “ Transportation Infrastructure: Highway Pavement Design Guide Is Outdated," Report No. GAO/RCED-98-9. Report to the Secretary of Transportation, Washington, D.C.

Vesic, A.S. and S.K. Saxena, 1969. "Analysis of Structural Behavior of Road Test Rigid Pavements," Highway Research Record, No. 291, pp. 156-158.

Westergaard, H. M., 1926. "Stresses in Concrete Pavements Computed by Theoretical Analysis," Public Roads, Vol. 7, No. 2, pp. 25-35.

Westergaard, H. M., 1927. "Analysis of Stresses in Concrete Pavements Caused Due to Variations of Temperature," Proceedings of the Sixth Annual Meeting of the Highway Research Record, Washington, D. C., pp. 201-215.

Zaghloul, S. M., T. D. White, and T. Kuczek, 1994. "Evaluation of Heavy Load Damage Effect on Concrete Pavements Using Three-Dimensional, Nonlinear Dynamic Analysis," Transportation Research Record 1449, TRB, National Research Council, Washington, D. C., pp. 123-133. 
Zaghloul, S. M., 1993. Nonlinear Dynamic Analysis of Flexible and Rigid Pavements, Ph.D. Dissertation, Department of Civil Engineering, Purdue University.

Zaman, M. M., M. R. Taheri, and V. Khanna, 1995. "Static and Dynamic Analysis of Concrete Pavements Including Thermal Warping Effects," The Arabian Journal for Science and Engineering, Volume 20, Number 3, pp. 433-466. 


\section{VITA}

Michel Ramsis Fahmy was born in Alexandria, Egypt on December 16, 1969. He graduated from pre-university school (College Saint Mark) in Alexandria in 1987 and then received his Bachelor in Civil Engineering (B.E) from College of Engineering, Alexandria University in 1992. During his military service he worked as a teaching assistant in the Air Defense College. Later, he worked for a French Company working in the construction of the second line of Cairo underground for 18 months. He joined West Virginia University in August 1995, where he started his graduate work for the Master of Science in Civil Engineering (M.S.C.E.) degree. He received his MSCE in May 1997. He worked as a graduate research assistant from August 1995 until August 2000. His research was concentrated in the area of pavement analysis and design. Currently he is a Civil Engineer in McClier Corporation in Chicago, Illinois. Extracurricular activities include reading, listening to music, biking, and swimming. 